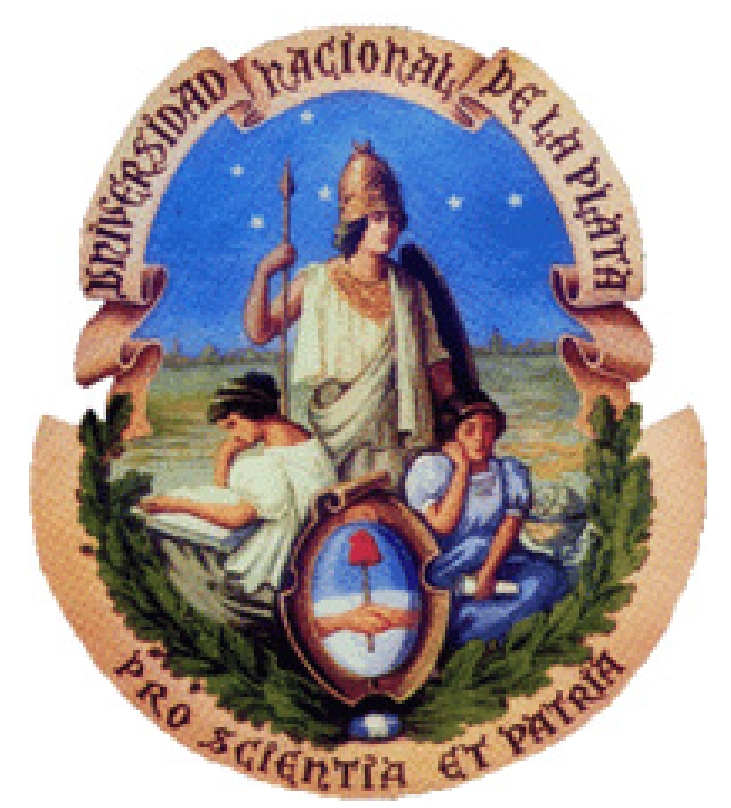

Universidad Nacional de La Plata

Facultad de Ciencias Astronómicas y Geofísicas

Tesis para obtener el grado académico de

Doctor en Astronomía

INTERACCIÓN ENTRE LOS RADIO-JETS Y EL MATERIAL INTERESTELAR EN RADIOGALAXIAS.

Lic. María Victoria Reynaldi

Director: Dr. Carlos Feinstein 



\section{Prefacio}

Esta Tesis es presentada como parte de los requisitos para obtener el grado académico de Doctor en Astronomía de la Universidad Nacional de La Plata. La misma contiene los resultados de los estudios desarrollados bajo la dirección del Dr. Carlos Feinstein en la Facultad de Ciencias Astronómicas y Geofísicas y el Instituto de Astrofísica de La Plata, entre los años 2010 y 2014.

Victoria Reynaldi. e-mail: vreynaldi@fcaglp.unlp.edu.ar La Plata, Octubre de 2014 



\section{Resumen}

En este trabajo se estudian los sistemas nebulares (gas ionizado) localizados en las regiones más externas de potentes radiogalaxias y conocidos como Regiones Extendidas con Emisión de Líneas (EELR). Fueron descubiertos en forma sistemática mediante observaciones con el Telescopio Espacial Hubble (HST). Las propiedades que las definen desde su propio nombre son las grandes distancias hasta las cuales es posible localizarlas, superando el alcance de la componente estelar en las mismas imágenes del HST, y el tipo de líneas de emisión que componen su espectro.

El estudio consta de la determinación del proceso de ionización dominante en la zona, mediante la comparación de los dos principales mecanismos posibles: la ionización de las nebulosas por parte del campo de radiación emitido por la fuente central, y la ionización por ondas de choque radiativas, desencadenadas por la interacción de la radiofuente, en particular, sus jets, con el medio que atraviesa (sólo en un objeto los procesos de choque estarían desencadenados por otro mecanismo). Los análisis requieren de la evaluación de las propiedades físicas del sistema gaseoso, ya sea la profundidad óptica, la distancia que las separa de la fuente puntual, el comportamiento espacial de la emisión o sus características cinemáticas, para poder estudiarlas bajo las hipótesis de cada modelo. El rol que desempeñe el núcleo activo nunca será despreciable, sin embargo, el interés por el estudio sistemático de la interacción entre los jets y el material interestelar radica en que este mecanismo podría explicar el estado de ionización de las EELR de la mano de su estado cinemático.

La técnica empleada fue la espectroscopía óptica de ranura larga (long-slit). Todos los espectros nebulares se tomaron especialmente para el desarrollo de esta Tesis con el instrumento GMOS del Telescopio Gemini Norte (TGN). La excelente calidad de los datos obtenidos permitió completar las tres líneas principales de la investigación: el análisis espectroscópico, el comportamiento espacial de la emisión y la cinemática de la región.

El objetivo principal fue obtener una explicación tan global como fuera posible sobre las características multibanda de la emisión, con especial énfasis en la relación espacial que pudiera haber entre la emisión y la cinemática en las distintas bandas del espectro, y en la relación de alineamiento entre las estructuras en óptico y en radio.

Los modelos se analizaron según sus predicciones sobre las estructuras de ionización y con la información contenida en los cocientes de líneas (diagramas de diagóstico). En general, la estructura de ionización no puede resolverse espacialmente en ninguno de los dos escenarios, pero la información contenida en el comportamiento espacial de las líneas de emisión fue determinante para evaluar el dominio de una región sobre otra y, consecuentemente, de un mecanismo de ionización sobre el otro.

Se encontraron fuentes donde se puede asegurar el dominio de un mecanismo concreto, y fuentes donde se necesita la contribución de ambos para poder explicar tanto las características espectrales, como la intensidad de la radiación observada. En la mayoría de los objetos analizados (cinco de siete) la EELR está alineada con los radio-jets. Sin embargo, los resultados son compatibles no con la dirección de alineación radio-óptico sino con la in- 
formación contenida en los campos de velocidades. En los casos donde se puede asegurar que la ionización ocurre predominantemente como consecuencia de procesos de choque, el campo de velocidades siempre muestra importantes indicios de movimientos de perturbación con velocidades altas. En los casos donde domina la fotoionización del campo central, las perturbaciones cinemáticas nunca son significativas. 


\section{Originalidad}

Las ideas, desarrollos, y resultados obtenidos son originales de la autora y del director de la Tesis, salvo explícita mención. Algunos resultados parciales fueron presentados en Congresos nacionales e internacionales y reuniones de la especialidad, y publicados en revistas internacionales. 

A To y nuestra Julia. 

Cada uno carga con su alma y con su cruz, para dar batalla en las tormentas.

Cada uno carga con sus sombras y la luz, tras de los espejos que se enfrentan.

$\mathrm{Y}$ en la brevedad de la eternidad cada hombre elige su destino,

justo en el umbral donde el bien y el mal echan a la suerte los caminos. 



\section{Agradecimientos}

Haber cumplido esta etapa significa uno de los mayores logros que haya alcanzado. Escribo esto con la satisfacción de haber llegado a una meta que me propuse cuando prácticamente no sabía lo que significaba el desafío que tenía por delante. Pasó mucho tiempo desde aquel momento, tenía trece años y una profesora, monja, Doctora en Matemáticas. La Astronomía ya formaba parte de mi mundo para ese entonces, pero ella plantó la semilla. La curiosidad hizo el resto. Alice no lo supo ni lo sabrá, pero vaya para ella mi agradecimiento.

A lo largo de estos años comprobé que ningún proyecto, por personal que sea, puede llevarse a cabo en soledad. No sería quien soy sin la gente que me rodea, ni hubiera llegado hasta este punto sin ustedes. Mis grandes amigos, los hermanos que me dio la sangre y los hermanos que me dio la vida, mis viejos, mis compañeros de trabajo y mis hermosos sobrinos llenos de vida. Tengo mucho para agradecerles, desde las charlas reflexivas hasta los recreos interminables donde nunca faltaron las carcajadas, pero por sobre todas las cosas, porque su amistad y compañía me hacen mejor persona. Gracias por haber estado, por estar siempre, y por haber compartido esta etapa conmigo.

Y por sobre todo, gracias a las dos personas más importantes de mi vida: Tomás y Julia. No es del todo justo agradecerles porque ustedes también son parte de esto. Con ustedes dos la vida no sólo es más linda, también es más fácil. Pero igual tengo que agradecerte, Julita, porque me ayudaste a escribir mientras crecías en la panza y porque más de una vez alguna de tus pataditas me empujaron a seguir. Adornaste esta Tesis con flores, moños y puntillas; tu sola presencia llenó de magia lo que en un principio eran solamente una carrera y una meta a alcanzar. Una sola sonrisa tuya vale cada segundo de mi vida, mi Julia hermosa. $\mathrm{Y}$ a vos, To, tengo que agradecerte porque caminaste conmigo en este camino y nunca me dejaste bajar los brazos. En estos años fuiste aliento y claridad de pensamiento, compañía y seguridad. Me diste la fuerza que necesitaba y muchas veces tu mejor sonrisa se transformó en la más simple y pura invitación a seguir adelante. Y como si todo eso fuera poco, hasta formamos una familia en el camino. No hay nada en este mundo más importante que ustedes. Lo esencial es invisible a los ojos. Gracias mi amor! 



\section{Índice general}

$\begin{array}{lll}\text { Prefacio III } & \text { III }\end{array}$

Resumen $\quad$ V

$\begin{array}{lll}\text { Originalidad } & \text { VII }\end{array}$

$\begin{array}{lll}\text { Agradecimientos } & \text { XIII }\end{array}$

$\begin{array}{ll}\text { 1. Sobre galaxias activas. } & 1\end{array}$

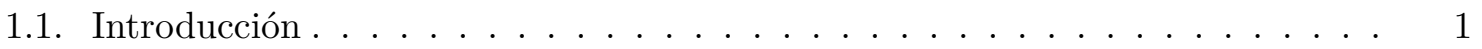

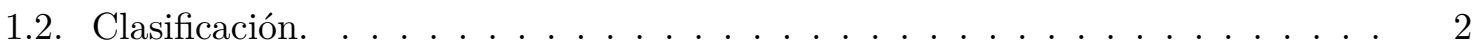

1.2.1. Galaxias Seyfert . . . . . . . . . . . . . . . . 2

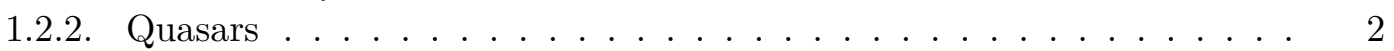

1.2.3. Radiogalaxias . . . . . . . . . . . . . . . . . 3

1.2.4. LINERs . . . . . . . . . . . . . . . . . . . 3

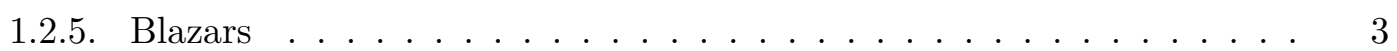

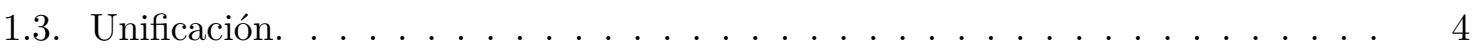

1.3.1. La fuente de energía . . . . . . . . . . . . . . . . . 4

1.3.2. Las líneas de emisión . . . . . . . . . . . . . . 5

1.3.3. Modelo de Unificación . . . . . . . . . . . . . . . . . . . 8

2. Sobre la Región Extendida con Emisión de Líneas y los Mecanismos de $\begin{array}{ll}\text { Ionización. } & 11\end{array}$

2.1. Introducción . . . . . . . . . . . . . . . . . . . . 11

2.2. Gas ionizado en escala de kiloparsecs: la EELR . . . . . . . . . . . . . . . 11

2.3. Parámetros físicos del gas: temperatura y densidad . . . . . . . . . . . . . . 13

2.3.1. Determinación de la densidad electrónica . . . . . . . . . . . . . . 13

2.3.2. Determinación de la temperatura electrónica . . . . . . . . . . . . 16

2.4. Mecanismos de ionización . . . . . . . . . . . . . . . . . 17

2.4.1. Fotoionización central . . . . . . . . . . . . . . . 18

2.4.2. Fotoionización central en un medio multifase . . . . . . . . . . . 20

2.4.3. Ionización por ondas de choque . . . . . . . . . . . . . . . . 26

3. Sobre los objetos. $\quad 33$

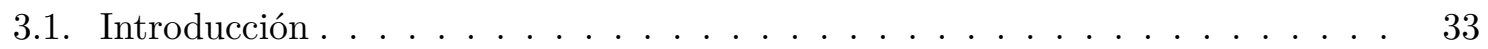

3.2. Telescopio Espacial Hubble: Las imágenes. . . . . . . . . . . . . . . . . . . . . 34

3.2.1. Selección de la muestra. I. . . . . . . . . . . . . . . . . . . . . . 35

3.3. Telescopio Gemini: Los espectros. . . . . . . . . . . . . . . . . . . . . 39

3.3.1. El instrumental. . . . . . . . . . . . . . . . . . . . . . 49

3.3.2. Proceso de observación. . . . . . . . . . . . . . . . . 50 
3.3.3. Selección de la muestra. II. . . . . . . . . . . . . . . . . . 56

4. Sobre el procesamiento y medición. $\quad \mathbf{5 7}$

4.1. Reducción. . . . . . . . . . . . . . . . . . . . 57

4.2. Proceso de medición de líneas de emisión. . . . . . . . . . . . . . 58

5. Resultados observacionales. $\quad \mathbf{6 5}$

5.1. Introducción . . . . . . . . . . . . . . . . . . . . 65

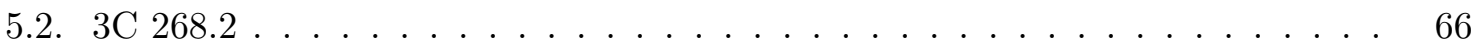

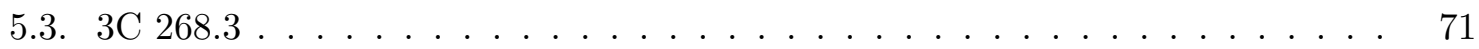

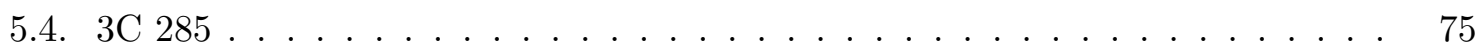

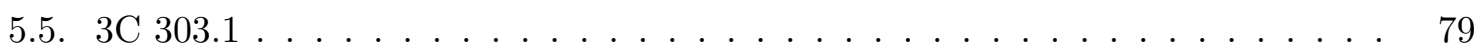

$5.6 .3 \mathrm{C} 305 \ldots \ldots \ldots \ldots \ldots \ldots \ldots \ldots$

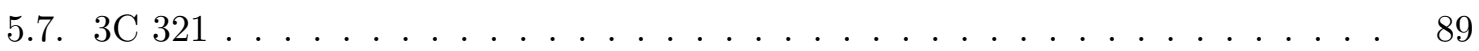

$5.8 .3 \mathrm{C} 381 \ldots \ldots \ldots \ldots \ldots \ldots \ldots \ldots \ldots$

5.9. Otras fuentes observadas . . . . . . . . . . . . . . . . . . . . . 99

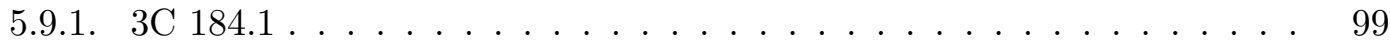

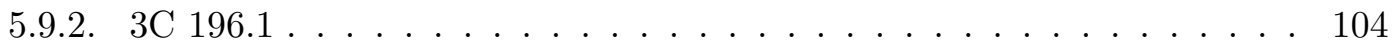

$5.9 .3 . \quad 3 \mathrm{C} 284 \ldots \ldots \ldots \ldots \ldots \ldots$

6. Fotoionización vs. Ionización por ondas de choque $\mathbf{1 1 5}$

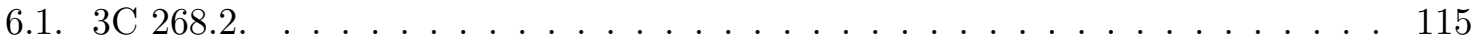

6.1.1. Mecanismo de ionización . . . . . . . . . . . . . . . . 118

6.1.2. Resumen ....................... . . 124

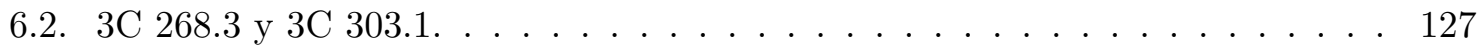

6.2.1. Mecanismo de ionización. . . . . . . . . . . . . . . . 128

6.2.2. Resumen . . . . . . . . . . . . . . . . 135

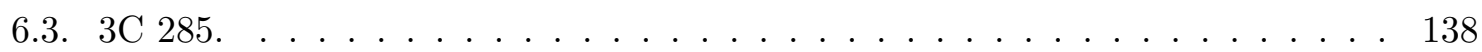

6.3.1. Mecanismo de ionización . . . . . . . . . . . . . . . . . . 139

6.3.2. Resumen . . . . . . . . . . . . . . . . . . . . 148

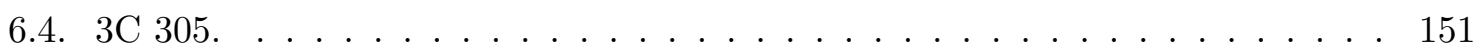

6.4.1. Mecanismo de ionización . . . . . . . . . . . . . . . . 152

6.4.2. Resumen . . . . . . . . . . . . . . . 158

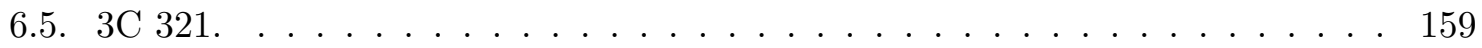

6.5.1. Mecanismo de ionización . . . . . . . . . . . . . . . 160

6.5.2. Resumen . . . . . . . . . . . . . . . . . 165

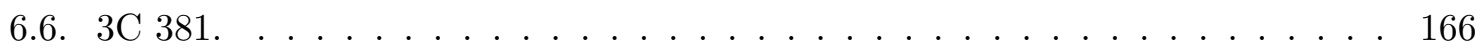

6.6.1. Mecanismo de ionización . . . . . . . . . . . . . . . . . 167

6.6.2. Resumen . . . . . . . . . . . . . . . . . . 173

7. Conclusiones $\quad \mathbf{1 7 5}$

7.1. Sobre la muestra definitiva de objetos analizados. . . . . . . . . . . . . . 175

7.2. Sobre los mecanismos de ionización estudiados. . . . . . . . . . . . . . 177

7.3. Sobre los resultados de la investigación. . . . . . . . . . . . . . . . . 178

7.3.1. Sobre los resultados secundarios de la investigación. . . . . . . . . . . 181

A. Mecanismos de formación de líneas de emisión. $\quad 183$

A.1. Recombinación . . . . . . . . . . . . . . . . . . . 183

A.2. Excitación colisional . . . . . . . . . . . . . . . . . . 183

A.2.1. Ionización colisional . . . . . . . . . . . . . . . . . . . . . 184 
A.3. Excitación radiativa . . . . . . . . . . . . . . . . . . 185

B. Algunas consideraciones sobre Magnetohidrodinámica. $\quad 187$

B.1. Sobre la aproximación MHD y el congelamiento del plasma . . . . . . . . . . 187

B.2. Sobre la compresión del gas en ondas de choque magnéticas y la definición del parámetro magnético . . . . . . . . . . . . . . . . . . . . . . 189

C. Proceso de reducción de datos Gemini/GMOS en modo long-slit. 191

D. Efecto de la extinción provocada por el material interestelar en los valores de los cocientes de líneas

E. Validación del método de medición. Diagramas complementarios de 3C 321.197 



\section{Índice de figuras}

1.1. Esquema de las componentes internas de un AGN. . . . . . . . . . . . . . 9

1.2. Modelo de Unificación de AGN. . . . . . . . . . . . . . . . . . . . . 10

2.1. Regiones de gas ionizado en un AGN. . . . . . . . . . . . . . . . . 12

2.2. Diagnóstico de la densidad electrónica con líneas del ion $\mathrm{S}^{+} \ldots \ldots \ldots$. . . . 15

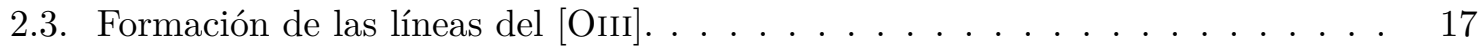

2.4. Geometría de la EELR en modelos de fotoionización multifase. . . . . . . . . 22

2.5. Campos de radiación incidente en el modelo de fotoionización multifase. . . . 24

2.6. Campos de radiación generados por ondas de choque. . . . . . . . . . . . 30

2.7. Estructura de ionización en ondas de choque. . . . . . . . . . . . . . . 32

3.1. Curva de transmisión del filtro F702W . . . . . . . . . . . . . . . 36

3.2. Esquema de la configuración de un filtro rampa. . . . . . . . . . . . . . 38

3.3. 3C 184.1. Imágenes de HST y VLA . . . . . . . . . . . . . . . . 40

3.4. 3C 196.1. Imágenes de HST . . . . . . . . . . . . . . . . . . . . 41

3.5. 3C 268.2. Imágenes de HST y VLA . . . . . . . . . . . . . . . . . . . 42

3.6. 3C 268.3. Imágenes de HST y MERLIN . . . . . . . . . . . . . . . . . . 43

3.7. 3C 284. Imágenes de HST y VLA . . . . . . . . . . . . . . . . . . . . . 44

3.8. 3C 285. Imágenes de HST y VLA . . . . . . . . . . . . . . . . . . . 45

3.9. 3C 303.1. Imágenes de HST . . . . . . . . . . . . . . . . . . . 45

3.10. 3C 305. Imágenes de HST y MERLIN/VLA . . . . . . . . . . . . . . . . 46

3.11. 3C 321. Imágenes de HST y VLA . . . . . . . . . . . . . . . . . . . 47

3.12. 3C 381. Imágenes de HST y VLA . . . . . . . . . . . . . . . . . . 48

3.13. Fotometría instrumental. . . . . . . . . . . . . . . . 51

3.14. Brillo de fondo del cielo en Mauna Kea . . . . . . . . . . . . . . . . 53

3.15. Refracción atmosférica diferencial en Mauna Kea . . . . . . . . . . . . . 55

4.1. GMOS: $3 \mathrm{C} 184.1 \ldots \ldots \ldots \ldots \ldots \ldots \ldots$

4.2. GMOS: 3C $196.1 \ldots \ldots \ldots \ldots \ldots \ldots \ldots$

4.3. GMOS: $3 \mathrm{C} 284 \ldots \ldots \ldots \ldots \ldots \ldots \ldots \ldots \ldots$

4.4. GMOS: $3 \mathrm{C} 285 \ldots \ldots \ldots \ldots \ldots \ldots \ldots \ldots \ldots$

4.5. GMOS: 3C $268.2 \ldots \ldots \ldots \ldots \ldots \ldots$

4.6. GMOS: $3 \mathrm{C} 268.3 \ldots \ldots \ldots \ldots \ldots \ldots \ldots \ldots$

4.7. GMOS: $3 \mathrm{C} 303.1 \ldots \ldots \ldots \ldots \ldots \ldots \ldots$

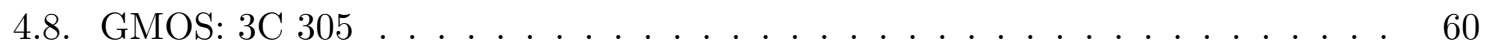

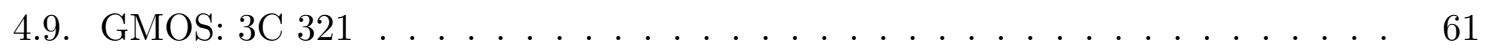

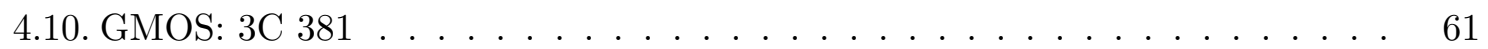

4.11. Mapas 2-D y 3-D del [Öri $] \lambda 5007$ en 3C 381. . . . . . . . . . . . . 63

5.1. Espectros de la EELR en $3 \mathrm{C} 268.2 \ldots \ldots \ldots \ldots$. . . . . . . . . . 69 
5.2. Descomposición Gaussiana y Campo de Velocidad en 3C 268.2. . . . . . . . . 70

5.3. Espectros de la EELR en 3C 268.3 . . . . . . . . . . . . . . . . . . 72

5.4. Descomposición Gaussiana y Campo de Velocidad en 3C 268.3 . . . . . . . . 73

5.5. Espectros de la EELR en 3C 285. . . . . . . . . . . . . . . . . 77

5.6. Descomposición Gaussiana y Campo de Velocidad en 3C 285 . . . . . . . . 78

5.7. Espectros de la EELR en 3C 303.1. . . . . . . . . . . . . . . . . 82

5.8. Descomposición Gaussiana y Campo de Velocidad en 3C 303.1. . . . . . . . 83

5.9. Espectros de la EELR en 3C 305 . . . . . . . . . . . . . . . . 86

5.10. Descomposición Gaussiana y Campo de Velocidad en 3C 305. . . . . . . . . 87

5.11. Espectros de la EELR en 3C 321. . . . . . . . . . . . . . . . . . . 92

5.12. Descomposición Gaussiana y Campo de Velocidad en 3C 321. . . . . . . . . 93

5.13. Espectros de la EELR en 3C 381. . . . . . . . . . . . . . . . . 97

5.14. Descomposición Gaussiana y Campo de Velocidad en 3C 381. . . . . . . . . 98

5.15. Espectros de la EELR en 3C 184.1 . . . . . . . . . . . . . . . . . . . . 102

5.16. Descomposición Gaussiana y Campo de Velocidad en 3C 184.1. . . . . . . . . 103

5.17. Espectros de la EELR en 3C 196.1 . . . . . . . . . . . . . . . . . 107

5.18. Descomposición Gaussiana y Campo de Velocidad en 3C 196.1. . . . . . . . . 108

5.19. Espectros de la EELR en 3C 284. . . . . . . . . . . . . . . . . . . 111

5.20. Descomposición Gaussiana y Campo de Velocidad en 3C 284. . . . . . . . . . 112

6.1. 3C 268.2. Componentes de velocidad y anchos característicos. . . . . . . . 116

6.2. 3C 268.2. Evaluación de mecanismos de ionización: FMF, IOC y shocks puros. 121

6.3. 3C 268.2. Evolución espacial del parámetro de ionización y las líneas de emisión. 125

6.4. 3C 268.3 y 3C 303.1. Evaluación de la densidad bajo modelos de IOC y FMF. 129

6.5. 3C 268.3 y 3C 303.1. Comportamiento del [Nev] bajo modelos de IOC y FMF. 130

6.6. 3C 268.3 y 3C 303.1. Parámetros de ionización y evolución espacial del [Nev]. 132

6.7. 3C 268.3 y 3C 303.1. Evolución espacial de los oxígenos. . . . . . . . . . . . . 134

6.8. 3C 268.3 y 3C 303.1. Evaluación de modelos de IOC y FMF. . . . . . . . . . 136

6.9. 3C 285. Mapa de emisión nebular - Identificación de las regiones en emisión. . 139

6.10. 3C 285. Diagramas de excitación. . . . . . . . . . . . . . . . . . . . . 142

6.11. 3C 285. Evaluación de mecanismos de ionización. I. . . . . . . . . . . . . . . . 145

6.12. 3C 285. Evaluación de mecanismos de ionización. II. . . . . . . . . . . . . . . 149

6.13. 3C 305. Modelos de IOC: $n_{e}=10^{2}-10^{3} \mathrm{~cm}^{-3}$; abundancia solar. . . . . . . . . 154

6.14. 3C 305. Comparación de modelos de IOC variando densidades y abundancias. 157

6.15. 3C 321. Identificación de las regiones en emisión. . . . . . . . . . . . . . . . 160

6.16. 3C 321. Evaluación de los mecanismos de ionización. . . . . . . . . . . . . 163

6.17. 3C 381. Parámetro de ionización . . . . . . . . . . . . . . 168

6.18. 3C 381. Modelos de fotoionización . . . . . . . . . . . . . . 170

6.19. 3C 381. Modelo de IOC: $n_{e}=10^{2} \mathrm{~cm}^{-3}$; abundancia solar. . . . . . . . . . . . 172

E.1. Validación del método de medición . . . . . . . . . . . . . . . . . . . 198

E.2. 3C 321. Diagramas complementarios. . . . . . . . . . . . . . . . . . . . . 199 


\section{Índice de Tablas}

1.1. Líneas prohibidas - Densidad crítica. . . . . . . . . . . 8

2.1. Modelos de fotoionización multifase: parámetros . . . . . . . . . 25

3.1. Objetos de estudio de este trabajo. . . . . . . . . . . . . . . . 34

3.2. WFPC2/HST: filtros. . . . . . . . . . . . . . . . . 35

3.3. WFPC2/HST: datos de archivo. . . . . . . . . . . . . . . 37

3.4. GMOS/Gemini: características instrumentales de las observaciones. . . . . . . 50

3.5. Ángulos de posición de las estructuras radio-óptico. . . . . . . . . . . . 56

5.1. Líneas de emisión en la EELR de 3C 268.2. . . . . . . . . . . . . . . . 67

5.2. Líneas de emisión en la EELR de 3C 268.3 . . . . . . . . . . . . . . . . . 74

5.3. Líneas de emisión en la EELR de 3C 285. . . . . . . . . . . . . . . . 76

5.4. Líneas de emisión en la EELR de 3C 303.1. . . . . . . . . . . . . . . . 80

5.5. Líneas de emisión en la EELR de 3C 305. . . . . . . . . . . . . . . 85

5.6. Líneas de emisión en la EELR de 3C 321. . . . . . . . . . . . . . . . . . 91

5.7. Líneas de emisión en la EELR de 3C 381. . . . . . . . . . . . . . . . . . . 95

5.8. Líneas de emisión en la EELR de 3C 184.1. . . . . . . . . . . . . . . . . . 100

5.9. Líneas de emisión en la EELR de 3C 196.1. . . . . . . . . . . . . . . . . 105

5.10. Líneas de emisión en la EELR de 3C 284. . . . . . . . . . . . . . . . . . 109

D.1. Efecto de la extinción en los cocientes de líneas. . . . . . . . . . . . . . . 196 



\section{Capítulo 1}

\section{Sobre galaxias activas.}

Este trabajo de Tesis se basa en el estudio de regiones de gas ionizado, pertenecientes a un cierto grupo de galaxias activas, llamadas radiogalaxias. Resulta necesario, entonces, comenzar explicando qué es una galaxia activa (Sección 1.1), qué diferencia a los distintos grupos existentes (Sección 1.2), y cuáles son las regiones que la componen (Sección 1.3).

\subsection{Introducción}

Se llaman galaxias activas a todas aquellas que albergan un núcleo activo. Esta sutileza del lenguaje implica que la actividad que caracteriza y distingue a las galaxias activas de las galaxias "normales" está concentrada en la región central. Por tal razón, también se las conoce como galaxias con núcleo activo, o AGN de su sigla en inglés Active Galactic Nuclei. Concretamente, la denominación se refiere a la existencia de fenómenos energéticos localizados en la región central/nuclear que no pueden atribuirse a las estrellas de la galaxia. Se desprende de este criterio que una galaxia se considera "normal" cuando su brillo se puede atribuir a la totalidad de las estrellas que la componen; o, desde el punto de vista espectral, el espectro de una galaxia "normal" se aprecia como la integración de los espectros estelares de sus estrellas, por lo cual tiene su misma apariencia. La energía por unidad de tiempo (luminosidad, $L$ ) que emite una galaxia activa en la región central es tanto mayor que la emitida por una galaxia normal que no puede explicarse mediante ningún proceso en ninguna etapa estelar.

La emisión proveniente de un AGN es apreciable a lo largo de todo el espectro electromagnético, y se pueden identificar las contribuciones de procesos térmicos y no térmicos. Los procesos no térmicos son particularmente importantes en las bandas de radio y rayos-X duros, mientras que la emisión en rayos-X blandos ${ }^{1}$, UV, óptico e IR se origina en procesos térmicos. Los procesos físicos que tienen lugar en un AGN, junto con la forma en que éstos se manifiestan en el espectro, revelando (o no) información sobre la estructura de los objetos o la cantidad de radiación emititda, hacen que el estudio de estos objetos sea tan fascinante como complejo. Gravedad extrema, acreción, viscosidad, agujeros negros super masivos, campos magnéticos, hidrodinámica, emisión, absorción y re-emisión de radiación, todo entra en juego.

La primera manifestación de actividad nuclear se encontró mediante la detección de líneas de emisión nebular en la zona nuclear de galaxias espirales cercanas (Fath 1909; Slipher 1917; Hubble 1926, NGC 1068, NGC 4051, NGC 4151;). Sin embargo no fue hasta la década del '40 en que se realizó el primer estudio sistemático de esta clase de objetos (Seyfert 1943). Por otra

\footnotetext{
${ }^{1}$ Los rayos-X duros (blandos) son los de más alta (baja) energía dentro de este rango espectral. Se suelen adoptar las siguientes bandas de energía: rayos-X blandos: $0.3-1 \mathrm{keV}$; rayos-X medios: 1-2 keV; rayos-X duros: $2-8 \mathrm{keV}$.
} 
parte, el desarrollo de la radio-astronomía (desde Jansky 1933, en adelante) tuvo un papel fundamental. La identificación de fuentes emisoras de ondas de radio, galácticas y extragalácticas, la controversia por los objetos cuasi-estelares (quasars), la posterior identificación de la contraparte óptica, el papel de la radiación sincrotrón, las luminosidades involucradas en las fuentes extragalácticas, entre otras características (ver el trabajo de revisión de Shields 1999, y sus referencias) abrieron una nueva puerta al estudio de galaxias activas.

En la medida en que las observaciones fueron permitiendo encontrar características comunes entre algunos objetos se fueron generando los primeros esquemas de clasificación. Las líneas de emisión nucleares y la actividad en ondas de radio siguen siendo parámetros importantes, a tal punto que dos de los grandes grupos de galaxias activas todavía se siguen llamando Galaxias Seyfert y Radiogalaxias. Dado que la clasificación nació desde el punto de vista observacional, que siempre depende de la capacidad de los instrumentos empleados, los límites de los grupos son cada vez más difusos.

\subsection{Clasificación.}

\subsubsection{Galaxias Seyfert}

Son los AGN menos luminosos $\left(M_{B}>-23\right)$. El espectro se caracteriza por la presencia de líneas de emisión intensas de metales altamente ionizados y líneas de recombinación del H. En general, a pesar de que el brillo superficial del núcleo es muy alto, también se puede identificar la estructura de la galaxia anfitriona ${ }^{2}$; en la mayoría de los casos, si no todos, se trata de una galaxia espiral. Sus características espectrales las divide en dos grandes grupos:

Seyfert 1: La emisión del continuo es intensa y se puede reproducir mediante una ley de potencias. Las líneas de emisión (prohibidas) de elementos ionizados tienen anchos que se corresponden con velocidades de algunos cientos de $\mathrm{km} \mathrm{s}^{-1}$; este es el conjunto de líneas angostas. Las líneas de recombinación del $\mathrm{H}$ tienen un ensanchamiento muy grande en la base, lo que permite identificar dos componentes: en el centro de la línea se observa la componente delgada, como antes, y con menor intensidad se distingue una segunda componente cuyo ancho característico puede alcanzar velocidades de $10^{4} \mathrm{~km} \mathrm{~s}^{-1}$ (Peterson 1997). Así, en el espectro de una Seyfert 1 conviven las líneas angostas (narrow lines) y anchas (broad lines). La intensidad relativa entre estos conjuntos de líneas en distintos espectros dio lugar a clasificaciones intermedias dentro de este mismo grupo (por ejemplo Seyfert 1.2, 1.5, 1.8).

Seyfert 2: La emisión del continuo es débil; las líneas de emisión son las estructuras que dominan el espectro. Sin embargo, ya no se observa la componente ancha en las líneas del H: todas las líneas del espectro son angostas. Existen estudios espectroscópicos que muestran que las componentes anchas son detectables en luz polarizada, lo cual indica que intrínsecamente están presentes, pero ocultas.

\subsubsection{Quasars}

Son los AGN más luminosos $\left(M_{B}<-23\right)$. Son objetos muy compactos, lo cual les da una apariencia estelar. Por otro lado, también fueron las primeras radiofuentes extragalácticas intensas (radio loud) en encontrarse. El hecho de tratarse de fuentes puntuales, ópticamente muy luminosos, y a su vez, fuertes emisores en ondas de radio, les valió el nombre (en inglés) de quasi stellar radio sources, que luego derivó en quasar.

\footnotetext{
${ }^{2}$ Dado que el fenómeno de actividad es independiente de la componente estelar, se suele utilizar la idea de que una galaxia activa es aquella que alberga un núcleo activo: de ahí el concepto de galaxia "anfitriona".
} 
Hoy se sabe que sólo entre el $5 \%$ y $10 \%$ del total de los quasars son fuertes emisores en radio (RLQ, radio-loud quasar ${ }^{3}$ ). La emisión sincrotrón proviene del núcleo (que coincide con la localización óptica del objeto) y de dos lóbulos en direcciones prácticamente opuestas, alimentados por jets que emanan de la fuente central, transportando partículas relativistas. La mayoría de los quasars, sin embargo, son emisores débiles en ondas de radio (RQQ, radioquiet quasar).

Sus espectros ópticos son muy similares a los de las galaxias Seyfert 1, con emisión intensa en el continuo y los dos grupos de líneas de emisión presentes; sus luminosidades, en cambio, son mucho mayores. La galaxia anfitriona es difícil de resolver, dado que se encuentran a grandes distancias; aún así parecen estar alojados en galaxias elípticas.

\subsubsection{Radiogalaxias}

Son radiofuentes muy intensas, cuyas galaxias anfitrionas son, en general, de tipo elíptica gigante, o bien muestran signos de interacción; son objetos distantes. La estructura en radio muestra un núcleo, como emisor puntual, jets y lóbulos a grandísimas distancias del núcleo. A las más intensas se las suele asociar con quasars, por lo que aquí se ve una muestra de que los límites de la clasificación son difusos.

Los dos conjuntos de líneas de emisión también se aprecian en los espectros ópticos. Las radiogalaxias cuyos espectros muestran líneas anchas y angostas se llaman Radiogalaxias de Líneas Anchas (BLRG, sigla en inglés de Broad-Line Radio Galaxy), mientras que las que sólo tienen líneas angostas se llaman Radiogalaxias de Líneas Angostas (NLRG, Narrow-Line Radio Galaxy). Se trata de un criterio equivalente al que separa a las Seyfert 1 de las Seyfert 2, respectivamente, pero se las llama de otro modo para enfatizar que en un grupo hay galaxias elípticas, gigantes, lejanas, con fuerte emisión en ondas de radio, y en el otro hay galaxias espirales y cercanas.

\subsubsection{LINERs}

El nombre viene de la sigla de Low-Inization Nuclear Emission-Line Region. Es decir, se trata de objetos cuyos espectros nucleares muestran líneas de emisión de baja ionización. A diferencia de todos los objetos descritos anteriormente, donde las líneas de emisión más intensas son las de más alta excitación, en los LINERs las líneas intensas son las de más bajo estado de ionización. Por otra parte, tienen luminosidades nucleares más bajas que otras galaxias activas.

\subsubsection{Blazars}

El nombre de este grupo deriva de la combinación entre quasar y el nombre del objetoprototipo BL Lacertae (BL Lac). Este objeto fue originalmente identificado como una estrella altamente variable, hasta que luego se encontró que se trataba de la contraparte óptica del RLQ VRO 42.22.01.

Los objetos tipo BL Lac son quasars con fortísima emisión en radio (RLQ) donde la dirección del jet relativista es prácticamente coincidente con la línea de la visual. Los espectros se caracterizan por la ausencia de, o extrema debilidad en, las líneas de emisión. Sin embargo, los objetos conocidos como [quasars] Variables Ópticamente Violentos (OVV, sigla en inglés de Optically Violent Variables) también pertenecen al grupo de blazars. Los blazares OVV

\footnotetext{
${ }^{3}$ Un AGN se considera como fuerte emisor en radio cuando el cociente entre el flujo medido en radio, a la frecuencia de $5 \mathrm{GHz}, F_{5}$, y el flujo medido en el óptico, en la banda fotométrica $\mathrm{B}, F_{B}$, es $F_{5} / F_{B}>10$ (Urry \& Padovani 1995).
} 
se distinguen por sus variaciones extremas de flujo en escalas de tiempo muy cortas y por tener un grado de polarización muy alto. Algunas características son compartidas por OVV y objetos tipo BL Lac: son fuentes puntuales intensas, particularmente en ondas de radio, variables en todas las frecuencias y escalas temporales y fuertemente polarizadas (Andruchow 2006).

La radiación proveniente de los blazars, dominada por la componente no térmica, sufre los efectos de amplificación relativista (relativistic beaming, Doppler boosting), como consecuencia de la anisotropía en la emisión y de su dirección de propagación.

\subsection{Unificación.}

\subsubsection{La fuente de energía}

Se puede decir que el problema tiene dos partes, por un lado entender el fenémeno físico, y por el otro unificar, si es posible, todas las clases de AGN existentes.

Las observaciones indican que la luminosidad típica de esos objetos ronda entre

$$
L= \begin{cases}10^{44} \mathrm{erg} \mathrm{seg}^{-1} & ; \text { galaxias Seyfert } \\ 10^{46} \mathrm{erg} \mathrm{seg}^{-1} & ; \text { quasars }\end{cases}
$$

Por otro lado, los estudios de variabilidad en quasars sirvieron para estimar el tamaño de la región emisora. La combinación de estos resultados mostró que la radiación que se recibe de un núcleo activo proviene de una región muy pequeña, menor a $1 \mathrm{pc}^{3}$. Esto es, una región de tamaño comparable al Sistema Solar emite más radiación que una galaxia entera (Peterson 1997).

Dejando de lado por un momento el proceso de generación de energía, y teniendo en cuenta el orden de magnitud de las luminosidades involucradas, se puede estimar qué masa debería tener un objeto esféricamente simétrico donde la gravedad y la presión de radiación mantengan el equilibrio. En otras palabras, un objeto que satisfaga esta condición de estabilidad no puede tener una luminosidad mayor que el valor límite de Eddington:

$$
L \leqslant L_{E}=\frac{4 \pi c G m_{p} M}{\sigma_{T}}
$$

donde $G$ es la constante de gravitación universal, $c$ es la velocidad de propagación de la luz en el vacío, $m_{p}$ es la masa del protón, $\sigma_{T}$ es la sección eficaz de Thomson, y $M$ es la masa del objeto central. Esta expresión puede reescribirse de la siguiente manera, adoptando unidades apropiadas:

$$
\frac{L}{L_{\odot}} \leqslant 3.22 \times 10^{4} \frac{M}{M_{\odot}}
$$

Si bien en este análisis se utilizan algunas simplificaciones, es útil para estimar las masas involucradas. Si se adopta el valor $L=10^{46} \mathrm{erg} \mathrm{seg}^{-1}$, se desprende que la fuente central de un AGN debe tener una masa:

$$
M \geqslant 3 \times 10^{7} M_{\odot}
$$

Se liberan enormes cantidades de energía desde volúmenes muy pequeños, pero que encierran también enormes concentraciones de masa. Las reacciones termonucleares (el mecanismo de generación de energía, hasta entonces, más eficiente) no pueden explicar este escenario, sin embargo la conversión de energía gravitatoria en radiación, sí (Osterbrock 1989). El modelo 
aceptado (modelo estándar) indica que, efectivamente, este proceso constituye la fuente de energía en un AGN. El sistema está constituido por un agujero negro super masivo (SMBH, sigla en inglés de Super-Massive Black Hole) y rotante, cuya masa es de $\sim 10^{6}-10^{10} M_{\odot}$. El SMBH acreta materia de la galaxia anfitriona formando un disco. La estructura de este disco depende de muchos parámetros, como la intensidad del campo magnético presente o la tasa de acreción; lo cierto es que, en el proceso de caída hacia el SMBH, la materia es calentada a altísimas temperaturas, y a su vez, su energía potencial gravitatoria se convierte en radiación mediantes procesos de disipación viscosos. El cálculo de la eficiencia $(\eta)$ del proceso de conversión de energía es complejo, dependiendo fuertemente de la forma en que se produce la acreción de materia. Sin embargo es posible obtener un valor aproximado del orden de magnitud, a través de hipótesis simples (ver Peterson 1997). La eficiencia del proceso de acreción es de $\eta \sim 0.1$, un orden de magnitud mayor que la correspondiente a la fusión del $\mathrm{H}$ $(\eta \sim 0.007)$.

El disco de acreción está envuelto por una corona formada mayoritariamente por electrones libres. La radiación en rayos-X proveniente de esta zona se observa gracias a la dispersión provocada por la población de electrones. El disco está, a su vez, rodeado de una estructura coplanar toroidal formada por gas y polvo, que absorbe la radiación proveniente de la región más interna. El hecho de que este material opaco no esté distribuido de forma esférica, implica que la posición relativa ente el objeto y el observador será crucial para detectar (o no) la radiación proveniente de la zona central/interna del AGN (Sección 1.3.3).

\subsubsection{Las líneas de emisión}

El ensanchamiento de una línea espectral manifiesta las condiciones físicas de las nubes de gas donde fue emitida la línea. Además del ancho natural, contribuyen factores locales como movimientos rotacionales, la presencia de campos magnéticos, o agitación térmica. Es de esperar, entonces, que en virtud de las grandes diferencias existentes en los anchos caraterísticos (Sección 1.2.1), estos conjuntos de líneas se formen en regiones distintas: se les dio el (autoconsistente) nombre de Región de Líneas Angostas (o NLR, de su sigla en inglés Narrow-Line Region) y Región de Líneas Anchas (o BLR, de su sigla en inglés Broad Line Region).

A continuación se describen someramente las características distintivas de las dos regiones.

\section{BLR}

El espectro de la BLR contiene casi únicamente líneas permitidas (líneas de recombinación del $\mathrm{H}$ ). La densidad electrónica es tan alta en esta zona que la desexcitación de los iones ocurre predominantemente por procesos colisionales, y por esta razón no se observan líneas prohibidas. Dado que los diagnósticos sobre densidad y temperatura en regiones nebulares se realizan en base a la información de ciertas líneas prohibidas, no es posible aplicar esta clase de análisis en la BLR.

Aún así, la ausencia de líneas prohibidas también permite establecer cotas sobre la densidad del medio. La línea [OIII] $\lambda 4363$, típicamente presente en los espectros de regiones de gas ionizado, tiene una densidad crítica de $n_{\text {crit }}^{[O I I I]}=3.3 \times 10^{7} \mathrm{~cm}^{-3}$, por lo tanto, su ausencia en el espectro de la BLR indica que la densidad allí debe ser mayor que este valor. Por otra parte, una de las pocas líneas no permitidas, intensa y ancha en el espectro UV de la BLR es la línea semi-prohibida (también llamada de intercombinación) Ciri] $\lambda 1909$. Su densidad crítica es $n_{\text {crit }}^{C I I]}=3 \times 10^{10} \mathrm{~cm}^{-3}$, lo cual implicaría que la densidad de la BLR no puede ser tan alta, de lo contrario esta línea tampoco estaría presente en el espectro. Este es un ejemplo muy simple del razonamiento seguido para derivar los rangos de densidad típicos. El 
valor aceptado ronda los $10^{11} \mathrm{~cm}^{-3}$; es el valor que toma la densidad en la zona de la BLR donde se aprecia una fuerte emisión de Ly $\alpha$ o Civ. La diferencia con el valor de $n_{c r i t}^{C I I I]}$ en el ejemplo se debe a que otros estudios (Reverberación) han demostrado que la emisión de CIII] $\lambda 1909$ se produce en una zona diferente de la que produce Ly $\alpha$ o CIV, al punto tal que, en la zona dominada por CIv, el CiII se desexcita colisionalmente (Peterson 1997). En síntesis, la densidad de la BLR es alta, pero no lo suficiente como para suprimir la emisión de líneas semi-prohibidas, y entre ellas, las del CIII] 11909 y OIII] $\lambda 1663$ son las más intensas. Las más intensas del espectro, por su parte, son Ly $\alpha$, Civ $\lambda 1549$ y Ovi $\lambda 1035$ (Netzer 2008).

La intensidad relativa entre las líneas del espectro resulta muy similar a la que puede encontrarse en otros sistemas de gas ionizado, como Regiones HII, o Nebulosas Planetarias. La temperatura típica del gas en estos sistemas es del orden de $10^{4} \mathrm{~K}$, por lo cual, podría concluirse que la temperatura en la BLR ronda este valor. Bajo la hipótesis de que el ensanchamiento de las líneas se debe sólo a movimientos térmicos, se puede calcular la dispersión de velocidades mediante la relación

$$
\Delta v \sim\left(\frac{k T}{m_{p}}\right)^{1 / 2}
$$

que para $T=10^{4} \mathrm{~K}$, implica $\Delta v \sim 10 \mathrm{~km} \mathrm{seg}^{-1}$. Los valores típicos para la dispersión de velocidades observada ronda $\Delta v \sim 5 \times 10^{3} \mathrm{~km} \mathrm{seg}^{-1}$, e incluso puede alcanzar valores cercanos a $10^{4} \mathrm{~km} \mathrm{seg}^{-1}$. Invirtiendo el razonamiento, se puede calcular la temperatura correspondiente a estas velocidades, que resulta $T \sim 10^{9} \mathrm{~K}$. Por supuesto, no es posible que el gas alcance temperaturas del orden de mil millones de grados, por lo tanto es evidente que existen otros mecanismos que producen el ensanchamiento de las líneas del espectro. Las velocidades relativas de las nubes de gas que componen la BLR, que en el espectro se traducen como desplazamientos en longitud de onda por efecto Doppler, constituyen el factor más importante (Peterson 1997).

Las BLR tienen tamaños típicos de $10^{-2}-10^{-1}$ pc en galaxias Seyfert, y de hasta algunos parsecs en quasars, es decir, se trata de regiones pequeñas. Estos resultados se derivaron de estudios de la variación de flujo en las líneas de emisión en respuesta a variaciones observadas en el continuo nuclear (conocido como Reverberación). Para poder detectar estas variaciones de flujo es necesario que la BLR se encuentre relativamente cerca de la fuente emisora. De hecho, dadas las diferencias existentes en los espectros, discutidas en la Sección 1.2, esta región tiene que ser lo suficientemente interna como para quedar oculta (no manifestarse en el espectro) en la dirección de la línea de la visual, cuando el objeto tiene una posición determinada con respecto esta última. La unificación geométrica de AGNs se discutirá en la Sección 1.3.3.

\section{NLR}

El espectro de la NLR está compuesto tanto por líneas permitidas como prohibidas. Las líneas prohibidas se producen por transiciones cuadrupolares eléctricas, o dipolares magnéticas, cuya probabilidad de ocurrencia es mucho menor que la de las transiciones dipolares eléctricas que producen las líneas permitidas. En un sistema gaseoso en equilibrio, donde ocurren transiciones radiativas y colisionales, no se observan líneas prohibidas porque, de producirse la excitación correspondiente, el desexcitamiento colisional ocurrirá antes que el radiativo, inhibiendo así la emisión discreta que origina la línea. Cada una de estas transiciones prohibidas tiene asociado un valor de densidad, llamado densidad crítica $\left(n_{\text {crit }}\right.$, que indica que si la densidad del medio es mayor que este valor, domina el desexcitamiento colisional y no se produce emisión. Cuando la densidad del medio es suficientemente baja, las 
colisiones dentro del gas disminuyen considerablemente, y con ellas, también disminuye su poder de desexcitación. Bajo estas circunstancias se produce la emisión de líneas prohibidas; aunque la probabilidad de desexcitación radiativa es muy baja, el hecho de que prácticamente no exista otro mecanismo de desexcitación da lugar a la ocurrencia de este proceso.

La principal diferencia entre la NLR y la BLR es que la densidad en la NLR debe ser mucho más baja, favoreciendo así la desexcitación radiativa de los iones. En el espectro pueden identificarse líneas con distintos estados de ionización, todas muy intensas.

Existen casos donde las transiciones que originan ciertas líneas prohibidas son fuertemente sensibles a la densidad y temperatura del medio. Dado que la característica distintiva del espectro de la NLR es la presencia de líneas prohibidas, se puede obtener información sobre las condiciones del gas a través de ellas (Sección 2.3). Para la determinación de la densidad se suelen emplear las líneas del oxígeno [OII] $\lambda \lambda 3726,3729$ y las del azufre [SII] $\lambda \lambda 6716,6731$. La densidad media en estas regiones es de $\sim 10^{4} \mathrm{~cm}^{-3}$ (Netzer 2008), pero se observan valores muy dispersos en el rango $10^{3}-10^{6} \mathrm{~cm}^{-3}$ (Peterson 1997). Para la determinación de la temperatura electrónica se utiliza el conjunto de líneas del oxígeno dos veces ionizado $[\mathrm{OIII}] \lambda \lambda 4363,4959,5007$. Se encuentra que la temperatura de la NLR es de $10^{4}-2.5 \times 10^{4} \mathrm{~K}$, pero la posible estratificación del medio puede introducir variaciones.

Cuando se analizan los espectros de objetos individuales se encuentra que las líneas de emisión tienen distintos anchos $\Delta v$ (aún cuando la apariencia de los perfiles es la misma en todas) y que existen correlaciones entre $\Delta v$ tanto con la densidad crítica $n_{\text {crit }}$ como con el potencial de ionización. Dado que $\Delta v$ parece tener un origen virial ${ }^{4}$, la correlación $\Delta v-n_{\text {crit }}$ implica la existencia una estratificación en la NLR, donde la densidad o el nivel de ionización, e incluso ambos, aumentan en la dirección al objeto central. Una consecuencia importante de este resultado recae sobre la determinación de la temperatura y densidad del gas: en un medio estratificado la zona donde domina la emisión del oxígeno $\left(\right.$ zona $\mathrm{O}^{++}$) podría no ser la misma zona desde donde proviene la emisión del azufre (zona $\mathrm{S}^{+}$). Incluso hasta sería posible que, dentro de la zona dominada por el oxígeno, la línea [OIII] $\lambda 4363$ se forme en una región más interna (y más densa) que las otras dos líneas involucradas (Peterson 1997). Esto puede verse a través de los valores de densidad crítica para cada una de las líneas mencionadas, listados en la Tabla 1.1. Por lo tanto, la temperatura de la zona donde se observa el indicador de densidad ([SiI] $\lambda \lambda 6716,6731)$ puede ser diferente de la que se mide con las líneas [OıII] $\lambda \lambda 4363,4959,5007$ (Peterson 1997).

Los tamaños de las NLR rondan entre $100-300$ pc. A distancias mayores $(d \geqslant 1 \mathrm{kpc})$ también es posible encontrar gas ionizado, extendiéndose hasta cientos de kiloparsecs en muchos casos. Esta región se conoce como Región Extendida de Líneas Angostas (ENLR, sigla en inglés de Extended Narrow-Line Region), cuando la galaxia anfitriona es de tipo Seyfert, o Región Extendida con Emisión de Líneas (EELR, Extended Emission-Line Region) cuando la galaxia anfitriona es una Radiogalaxia. La presencia de estas regiones fue descubriéndose en la medida en que mejoraron los intrumentos de observación, en particular la resolución espacial y angular. En un principio se encontraron asociadas a galaxias Seyfert y la similitud entre este nuevo espectro con el de la NLR, junto con su extensión espacial les valió su nombre (ENLR). Luego se fueron encontrando también en AGNs más lejanos, particularmente en Radiogalaxias; aunque las características espectrales son las mismas, se les llamó de otro modo (EELR).

El objeto de estudio de este trabajo de Tesis es, justamente, esta región de gas ionizado conocida como EELR, cuya descripción se aborda en el siguiente Capítulo.

\footnotetext{
${ }^{4} \mathrm{El}$ ancho de las líneas de la NLR parece reflejar el campo gravitatorio de las estrellas de la galaxia anfitriona, mientras que los anchos de las líneas de la BLR, también de origen virial, reflejan el campo gravitatorio del objeto central (Peterson 1997).
} 
Tabla 1.1. Líneas prohibidas - Densidad crítica.

\begin{tabular}{c|c}
\hline \hline $\begin{array}{c}\text { Línea } \\
{[\AA]}\end{array}$ & $\begin{array}{c}\mathrm{n}_{\text {crit }} \\
{\left[\mathrm{cm}^{-3}\right]}\end{array}$ \\
\hline$[\mathrm{OIII}] \lambda 4363$ & $3.3 \times 10^{7}$ \\
{$[\mathrm{OIII}] \lambda 4959$} & $7.0 \times 10^{5}$ \\
{$[\mathrm{OIII}] \lambda 5007$} & $7.0 \times 10^{5}$ \\
\hline$[\mathrm{S} \mathrm{II}] \lambda 6717$ & $1.5 \times 10^{3}$ \\
{$[\mathrm{~S} \mathrm{II}] \lambda 6731$} & $3.9 \times 10^{3}$ \\
\hline \hline
\end{tabular}

Densidad crítica de líneas indicadoras de temperatura ([OIII] $\lambda \lambda 4363,4959,5007)$ y densidad ([SII $] \lambda \lambda 6716,6731)$ del gas.

\subsubsection{Modelo de Unificación}

El modelo de unificación de AGNs (Antonucci 1993; Urry \& Padovani 1995) propone que prácticamente todas las clases de objetos, discutidas en la Sección 1.2, son manifestaciones del mismo fenómeno físico, en donde las diferencias se deben principalmente a la orientación del objeto respecto de la línea de la visual.

Como se describió en la Sección 1.3.1, un AGN está conformado por un disco de acreción en torno a un agujero negro supermasivo (SMBH, $M>10^{6} M_{\odot}$ ). Se cree que la emisión del continuo en el óptico-UV se genera principalmente en el disco de acreción. De este sistema emergen flujos bi-direccionales de partículas relativistas fuertemente colimados, los jets, en la dirección del eje del disco de acreción. Allí se producen procesos sincrotrón y Compton inverso, y la radiación sufre el efecto de amplificación Doppler (Doppler-boosted radiation) cuando el objeto se observa en la dirección (aproximada) de propagación del jet. Tanto el disco como la parte interna de los jets contribuyen a la emisión en la banda de rayos-X. Las líneas de emisión anchas se producen en un ambiente denso (la BLR), cuya distancia $d$ al SMBH es menor que $10^{-2} \mathrm{pc}$. El sistema hasta aquí descrito está contenido en una estructura opaca, formada de gas y polvo, de forma toroidal, cuyo tamaño es de algunos parsecs (Peterson \& Wilkes 2001). En la Figura 1.1 se muestran estas componentes en forma esquemática, y sin respetar las escalas espaciales.

El toroide absorbe prácticamente toda la radiación proveniente del interior del sistema y re-emite en el IR. Por otra parte, su disposición geométrica en combinación con la línea de la visual al objeto desempeñan un papel fundamental en el modelo.

Aproximadamente en la misma escala espacial del toroide, pero en la dirección de su eje (que puede tomarse como eje de simetría del sistema) se encuentra la NLR, compuesta por nubes de baja densidad. No siempre se detectan los dos conjuntos de líneas de emisión en un dado espectro. En algunos sólo se ven las líneas de la NLR, mientras que en otros también se identifican las líneas de la BLR. Este hecho constituyó el puntapié de la clasificación espectroscópica: se llamó objetos Tipo I a aquellos cuyos espectros ópticos tenían líneas angostas y anchas y Tipo II a los que sólo tenían líneas angostas, independientemente de su nivel de actividad en radio (por ejemplo, las galaxias Seyfert 2 y las NLRG son todos objetos Tipo II).

Sin embargo, con el avance de las investigaciones espectro-polarimétricas, se encontró que el espectro de la galaxia prototipo del grupo Seyfert 2, NGC 1068, era idéntico al de un objeto Tipo I cuando se observaba en luz polarizada (Antonucci \& Miller 1985). La 
Figura 1.1. Esquema de las componentes internas de un AGN.

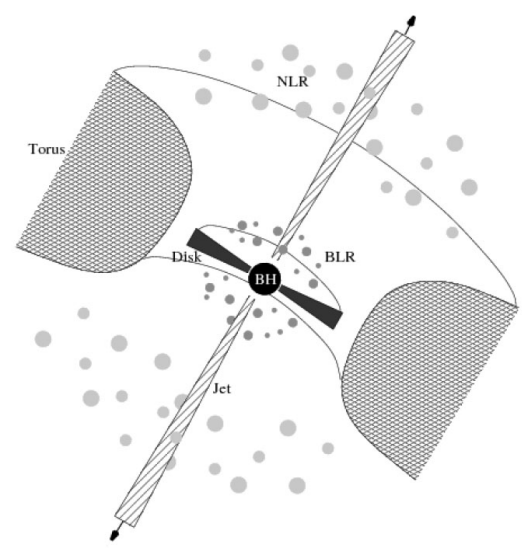

La estructura interna de un AGN está compuesta por el SMBH ( $B H$ en la figura), el disco de acreción (Disk), el toroide (Torus) de material opaco, y la región de líneas anchas $(B L R)$. También se señala la ubicación de las nubes de la NLR, en la zona más externa.

emisión proveniente del núcleo era tan intensa como en los objetos Tipo I, y presentaba un altísimo grado $(16 \%)$ de polarización, que además resultaba independiente de la longitud de onda; en cuanto a las líneas de emisión, en luz polarizada se revelaba la presencia de las líneas de recombinación anchas provenientes de la BLR. Este hallazgo constituyó un importante resultado, dado que revelaba que los objetos Tipo II tenían un núcleo con las mismas características que los Tipo I, y que la BLR efectivamente estaba presente en la estructura del objeto. El hecho de que la luz polarizada revelara la presencia de la BLR y del continuo nuclear con tal grado de polarización permitió concluir que la radiación emitida había sido reflejada y por lo tanto dispersada, pudiendo así detectada en la línea de la visual ${ }^{5}$. Por lo tanto (sólo bajos consideraciones espectroscópicas), los objetos Tipo II son intrínsecamente iguales a los Tipo I, con la salvedad de que en los Tipo II, la radiación del núcleo y de la BLR está bloqueada.

Sin incorporar a la discusión el nivel de actividad en radio (que, a su vez, está relacionado con la presencia o no de jets), la geometría propuesta permite unificar las distintas clases de AGN de acuerdo con la orientación que tenga el objeto respecto de la dirección al observador. Si el objeto se observa de modo tal que la línea de la visual es perpendicular al eje del toroide, entonces toda la radiación proveniente de la zona interna del sistema quedará bloqueada: el objeto se clasifica como Tipo II. Si la línea de la visual es paralela al eje del toroide, entonces la dirección de observación coincide con la dirección de propagación del jet (en el caso de objetos con fuerte emisión en radio), y la emisión del jet domina por completo el espectro: el objeto se clasifica como Blazar. Pero en el caso en que la línea de la visual forme un ángulo

\footnotetext{
${ }^{5}$ El hecho de que el grado de polarización fuese independiente de la longitud de onda en el espectro ópticoUV indicaba, también, que los elementos dispersores debían ser electrones y no granos de polvo: la dispersión provocada por el polvo es fuertemente dependiente de la longitud de onda de la radiación, mientras que la sección eficaz de [dispersión] Thomson no. La misma población de electrones que dispersa la radiación emitida en la banda de rayos-X es la responsable de la dispersión de la radiación proveniente de la BLR (Antonucci 1993, y referencias allí citadas).
} 
Figura 1.2. Modelo de Unificación de AGN.

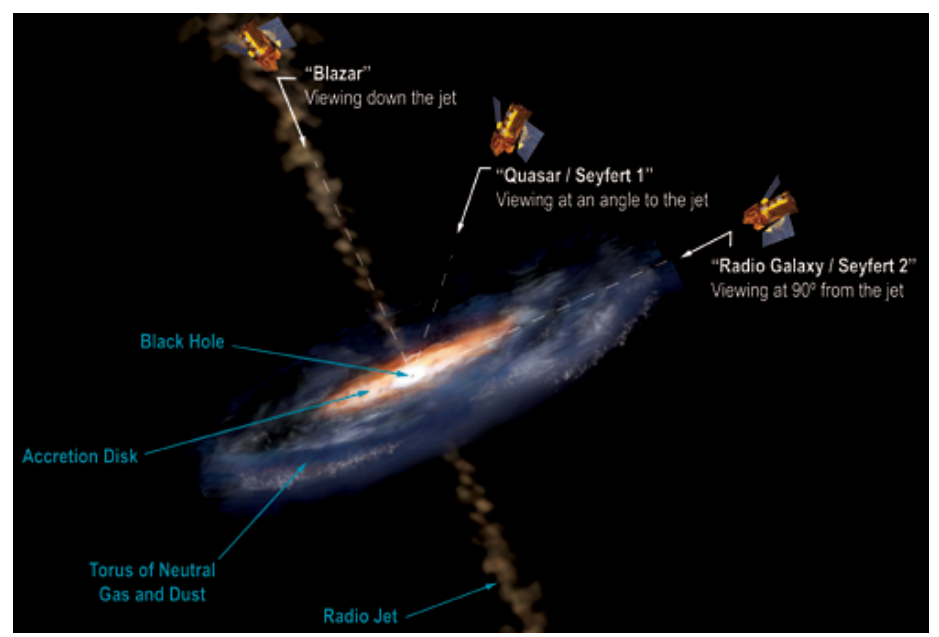

Esquema de un AGN. En la parte inferior izquierda de la figura se señalan las estructuras que componen la parte interna del sistema. En la parte superior derecha de la figura se indica qué tipo de clasificación recibe un objeto dependiendo de la orientación relativa entre la línea de la visual y el eje del toroide de material opaco.

intermedio con el eje del toroide, éste ya no es capaz de ocultar las regiones internas, y la emisión del disco de acreción, de la BLR, y el continuo nuclear quedan al descubierto: el objeto se clasifica como Tipo I. La Figura 1.2 indica la dependencia de la clasificación con la geometría del sistema.

La unificación en cuanto al nivel de actividad en radio sigue siendo una cuenta pendiente. Aún no es posible explicar la existencia de una minoría de objetos (RL, de radio loud) donde la actividad es tan intensa, en particular porque hay muy pocos objetos con luminosidades intermedias entre los $\mathrm{RL}$ y los emisores débiles en radio ( $\mathrm{RQ}$, de radio quiet), lo que hace suponer que efectivamente existen dos poblaciones distintas. La luminosidad de los objetos RL en ondas de radio supera a la de los RQ por 2-3 órdenes de magnitud, para una dado valor de luminosidad integrada entre el IR y rayos-X blandos; en rayos- $\mathrm{X}$ medios es tres veces mayor para los RL, y la pendiente de la distribución espectral de energía es más chata, implicando que existe mayor cantidad de fotones de alta energía. Es probable que el momento angular del SMBH sea un factor determinante al momento de explicar las diferencias entre objetos RL y RQ, ya que sería el momento angular quien determine si los efectos electromagnéticos son capaces de generar y colimar los jets (Peterson \& Wilkes 2001). Los esquemas mostrados en las Figuras 1.1-1.2 son también válidos (exceptuando la presencia de jets) en el caso de objetos RQ. 


\section{Capítulo 2}

\section{Sobre la Región Extendida con Emisión de Líneas y los Mecanismos de Ionización.}

\subsection{Introducción}

Este Capítulo se concentra en la descripción de las regiones de gas ionizado conocidas como EELR, y de los mecanismos de ionización que podrían explicar cómo debió ser el campo de radiación ionizante y bajo qué condiciones debió actuar para obtener como resultado el espectro observado de la región. El estudio y evaluación de estos modelos en función de los espectros ópticos de la EELR, obtenidos especialmente para el desarrollo de esta Tesis, se retoma en el Capítulo 6.

\subsection{Gas ionizado en escala de kiloparsecs: la EELR}

En el Capítulo anterior se discutieron someramente las regiones que componen el esquema general de una galaxia con núcleo activo (o simplemente AGN). Existen tres regiones cuya emisión puede detectarse en la banda óptica ${ }^{1}$ : la BLR, la NLR y la ENLR/EELR, y se diferencian tanto por su ubicación en este modelo como por las características de la emisión que proviene de ellas. En la Figura 2.1 se muestra esquemáticamente la posición de cada región, junto con la escala de distancias típicas para cada una (también se incluye una región de formación estelar, SB, localizada en zonas aledañas al toroide de material opaco; esta región estaría presente en galaxias jóvenes con alto contenido de polvo, que en general se agrupan en los AGN tipo Seyfert).

La región más alejada del núcleo es la ENLR/EELR. Esta región recibió originalmente el nombre de ENLR porque comparte las características espectrales de la NLR (Robinson 1989), en cuanto a la presencia de líneas permitidas y prohibidas con perfiles de emisión angostos (es decir, los anchos $\Delta v$ de las líneas indican velocidades $\Delta v<600 \mathrm{~km} \mathrm{~s}^{-1}$ ); y porque, vista desde el núcleo de la galaxia, se encuentra luego de la NLR, y se extiende a grandes distancias. Sin embargo, el aspecto distintivo de la ENLR es que se trata de la primer región de gas ionizado asociada a un AGN donde las nubes de material pueden, en términos generales, resolverse

\footnotetext{
${ }^{1}$ Cuando se estudian regiones de gas ionizado en otras bandas del espectro, muchas veces aparecen subregiones, o regiones nuevas. Tal es el caso, por ejemplo, de la región conocida como "absorbente tibio" (warm absorber) que se detecta en rayos-X; esta zona, potencialmente ubicada entre la BLR y la NLR (Netzer 2008), está compuesta por gas altamente ionizado, pero su característica distintiva es que se manifiesta tanto en absorción como en emisión en esta banda del espectro.
} 
Figura 2.1. Regiones de gas ionizado en un AGN.

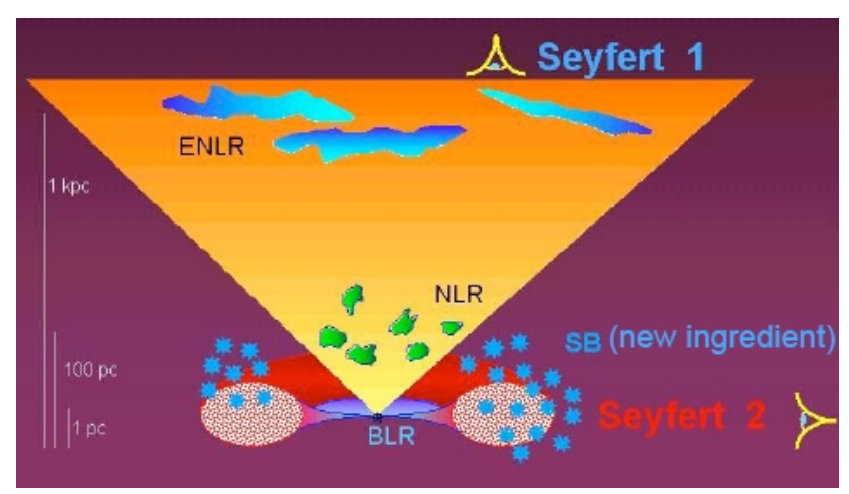

Esquema de las regiones en emisión que se observan en el espectro óptico. Se indican las escalas de distancias típicas para cada una de ellas. La región de formación estelar (SB) en las cercanías del toroide de material opaco puede estar presente AGNs tipo Seyfert.

espacialmente. A diferencia de la BLR o la NLR, cuya presencia se deducía originalmente a partir de espectros, en virtud de las líneas de emisión provenientes de la región central del AGN, la ENLR fue detectada a través de imágenes. La distribución espacial de este gas tibio ${ }^{2}$ ( $\left.\mathrm{T} \sim 10^{4} \mathrm{~K}\right)$ y extendido se pudo conocer una vez que fue posible obtener imágenes de línea (Fosbury 1989); es decir, una vez que se pudo aislar la emisión en una pequeña banda del espectro mediante la utilización de un filtro angosto (ver Sección 3.2.1).

Las imágenes revelan que el gas de la ENLR (y NLR en los objetos más cercanos, donde la distribución espacial puede resolverse parcialmente) no está dispuesto en forma esférica en torno al núcleo de la galaxia, por el contrario, tiene una distribución particular que podría asemejarse a un cono cuyo vértice coincide con el objeto central. Dado que el material de la BLR y la NLR está fotoionizado por el campo de radiación del núcleo activo, es decir que la radiación proveniente de estas regiones se produce a expensas de la absorción del campo de radiación central (Peterson 1997), y que los límites entre la NLR y la ENLR son difusos, de inmediato se propuso un modelo donde las tres regiones (BLR, NLR y ENLR) estarían ubicadas en la zona de influencia de este campo ionizante, que recibió el nombre de "cono de ionización", o "cono de iluminación" (así se ilustra en la Fig. 2.1). La similitud entre los espectros de la NLR y la ENLR permitió suponer que también la ENLR está fotoionizada por el AGN; la discusión sobre los posibles mecanismos de ionización y excitación actuantes en la región se aborda en la Sección 2.4.

Luego de que estas estructuras nebulares también se encontraran asociadas a radiogalaxias, el nombre/sigla ENLR quedó reservado para designar a las regiones extendidas de gas ionizado asociadas a galaxias Seyfert, mientras que para las mismas regiones, asociadas a radiogalaxias se comenzó a emplear la designación EELR (sigla en inglés de Extended Emission-Line Region, Regiones Extendidas con Emisión de Líneas). De todas las regiones nebulares con emisión extra-nuclear, las EELR son los sistemas más imponentes, en lo que se

\footnotetext{
${ }^{2}$ Se lo llama así para diferenciarlo del gas caliente, cuya temperatura característica es de $\mathrm{T} \sim 10^{6} \mathrm{~K}$, y del gas frío, con temperaturas $\mathrm{T} \sim 10^{2} \mathrm{~K}$. El gas caliente emite en la banda de rayos-X, el gas tibio emite en el óptico, y el gas frío, mayoritariamente compuesto por gas neutro, emite en longitudes de onda mayores.
} 
refiere al grado de ionización del material, la luminosidad total, o la propia extensión espacial del gas (Robinson 1989).

Tal vez una de las características que más interrogantes ha despertado sobre el material que las compone es su distribución espacial. La morfología de la región, según observaciones en el óptico y en UV, indica que el gas tiende a distribuirse aproximadamente en la misma dirección del radio eje. Se conoce como "efecto de alineamiento", y aunque tiene una tendencia mucho más notoria para objetos de alto redshift ( $\mathrm{z}>1$; McCarthy et al. 1987; Chambers et al. 1987), también está presente en objetos más cercanos (Baum \& Heckman 1989b; Best, Longair \& Rottgering 1996). Si bien existen algunos ejemplos de radiogalaxias donde se puede identificar el cono de ionización mediante la EELR, éstas son una minoría. En general, incluso para estos casos, el gas de la EELR no se concentra de la misma manera que en las ENLR. En consecuencia, no es posible identificar la estructura relativamente nítida del cono de ionización como sí sucede con galaxias Seyfert (Fosbury 1989). El alcance del efecto de alineamiento no se limita al aspecto morfológico, sino que ha influido en los estudios cinemáticos de la región, así como en el análisis del mecanismo de ionización actuante.

La cinemática de la región, estudiada principalmente mediante espectroscopía de ranura larga (long-slit), reveló desde un comienzo la existencia de movimientos de alta velocidad dentro de las nebulosas. Las líneas de emisión más intensas tienen perfiles formados por más de una componente, con anchos característicos (determinados por el ancho de la Gaussiana, medido en la mitad de su potencia máxima: FWHM) diferentes. A través del estudio de estas componentes se identifican movimientos relativos dentro de las nubes. Estos movimientos generalmente tienen lugar en la dirección de elongación de la EELR, que en virtud del alineamiento, también coincide con el radio-eje (la dirección del jet). La relación entre el efecto de alineamiento, la cinemática y los mecanismos de ionización se discute en detalle en la Sección 2.4 .

\subsection{Parámetros físicos del gas: temperatura y densidad}

El material que compone las EELR es un gas diluido, de baja densidad. En este tipo de nebulosas se producen líneas de emisión, que pueden clasificarse como permitidas, semiprohibidas o de intercombinación, y prohibidas, y líneas de recombinación. En el Apéndice A se discuten los mecanismos de formación de las líneas de emisión.

Como se mencionó someramente en la Sección 1.3.2, la presencia e intensidad de líneas de emisión prohibidas requiere que la densidad sea suficientemente baja. Como las transiciones que las originan son excitadas colisionalmente, y las colisiones dentro del gas están gobernadas por la temperatura y densidad del medio, algunas de estas líneas son importantes elementos de diagnóstico sobre la temperatura $(T)$ y densidad electrónica $(n)$ de la región. Los iones más importantes para estos propósitos son $\mathrm{O}^{+}, \mathrm{O}^{++}, \mathrm{N}^{+}, \mathrm{S}^{+}$porque, a pesar de ser poco abundantes, sus niveles de energía más bajos tienen potenciales de excitación del orden de $k T$ (Osterbrock 1989).

A continuación se describen los mecanismos para determinar estos parámetros en función de la física involucrada en la formación de las líneas prohibidas.

\subsubsection{Determinación de la densidad electrónica}

\section{[Adaptación de Peterson 1997]}

La densidad media de una determinada región de la nebulosa se puede determinar a partir de la observación de los efectos de la desexcitación colisional. Para ello se utilizan 
dos líneas de un dado ion, emitidas desde niveles de energía diferentes, pero cuyas energías de excitación difieren levemente. Si las líneas tienen probabilidades de transición radiativa distinta, o si las tasas de desexcitación colisional son distintas, la población relativa entre estos dos niveles dependerá de la densidad; consecuentemente, el cociente entre las líneas de emisión que resulten de la excitación de estos niveles, también dependerá de la densidad (Osterbrock 1989). Las líneas del doblete del [OII] $\lambda \lambda 3726,3729$ y del $[\mathrm{Sir}] \lambda \lambda 6716,6731$, son ejemplos de esta clase de transiciones $\left({ }^{4} S_{3 / 2}-{ }^{2} D_{5 / 2}\right.$ y $\left.{ }^{4} S_{3 / 2}-{ }^{2} D_{3 / 2}\right)$, que se producen en las configuraciones electrónicas $2 p^{3}$ y $3 p^{3}$, respectivamente. Las líneas del OiI son tan cercanas que sólo pueden resolverse con espectros de alta resolución; en los espectros de baja resolución el ensanchamieto Doppler no permite identificar las dos líneas por separado. Luego, el cálculo de densidad, tanto en la NLR como en la región extendida, suele realizarse con las líneas del azufre (Peterson 1997).

Para simplificar la discusión, se puede considerar que las líneas se producen en un ion con una configuración simple de dos niveles de energía (1 y 2, siendo $2 \rightarrow 1$ la transición correspondiente según el caso). Sean $n_{2}$ la densidad volumétrica de iones en el estado $2, A_{(2 \rightarrow 1)}$ el coeficiente de Einstein (probabilidad de transición espontánea por unidad de tiempo) desde el nivel 2 al nivel 1, y $h \nu_{2 \rightarrow 1}$ la energía del fotón emitido en la transición; la emisividad $j_{(2 \rightarrow 1)}$ (en $\mathrm{erg} \mathrm{s}^{-1} \mathrm{~cm}^{-3}$ ster $^{-1}$ ) en la línea será:

$$
j_{(2 \rightarrow 1)}=n_{2} A_{(2 \rightarrow 1)} \frac{h \nu_{21}}{4 \pi}
$$

En equilibrio estadístico la tasa de excitación colisional, es decir el ritmo con el que se está poblando el nivel 2, debe estar balanceada por la tasa de despoblación; los mecanismos por los cuales este nivel se despuebla son desexcitaciones colisionales, y transiciones radiativas espontáneas hacia el nivel 1. Esto puede escribirse de la siguiente forma:

$$
\left\langle\sigma_{(1 \rightarrow 2)} v\right\rangle n_{e} n_{1}=n_{2} A_{(2 \rightarrow 1)}+\left\langle\sigma_{(2 \rightarrow 1)} v\right\rangle n_{e} n_{2}
$$

El estado excitado (nivel 2) se puebla a una tasa dada por el producto $\left\langle\sigma_{(1 \rightarrow 2)} v\right\rangle$, donde $\sigma_{(1 \rightarrow 2)}$ es la sección eficaz de colisiones que lleva al ion del estado base (nivel 1) al estado excitado (nivel 2). La tasa de despoblación colisional es $\left\langle\sigma_{(2 \rightarrow 1)} v\right\rangle$, siendo $\sigma_{(2 \rightarrow 1)}$ la sección eficaz de despoblación colisional. Las secciones eficaces dependen de la velocidad $v$ de los proyectiles, es decir, de los electrones libres de medio, cuya distribución de velocidades es Maxwelliana (el valor medio se toma sobre esta distribución de velocidades). Por esta misma razón, los términos colisionales involucran la densidad electrónica $n_{e}$. Combinando las dos expresiones se puede obtener una nueva forma para la emisividad $j_{(2 \rightarrow 1)}$, que no depende explícitamente de la densidad en el nivel excitado $\left(n_{2}\right)$ :

$$
j_{(2 \rightarrow 1)}=n_{e} n_{1}\left\langle\sigma_{(1 \rightarrow 2)} v\right\rangle \frac{A_{(2 \rightarrow 1)}}{A_{(2 \rightarrow 1)}+n_{e}\left\langle\sigma_{(2 \rightarrow 1)} v\right\rangle} \frac{h \nu_{21}}{4 \pi}
$$

Si $g_{1}$ y $g_{2}$ son los pesos estadísticos ${ }^{3}$ de cada nivel, $\chi$ es el potencial de excitación, y $T_{e}$ es la temperatura electrónica, entonces la relación entre las tasas de población y despoblación colisional es

$$
\left\langle\sigma_{(1 \rightarrow 2)} v\right\rangle=\left\langle\sigma_{(2 \rightarrow 1)} v\right\rangle \frac{g_{2}}{g_{1}} e^{-\chi / k T_{e}}
$$

\footnotetext{
${ }^{3}$ El peso estadístico $g$ se relaciona con el número cuántico $J$, asociado al momento angular total, como $g=2 J+1$.
} 
Figura 2.2. Diagnóstico de la densidad electrónica con líneas del ion $\mathrm{S}^{+}$.

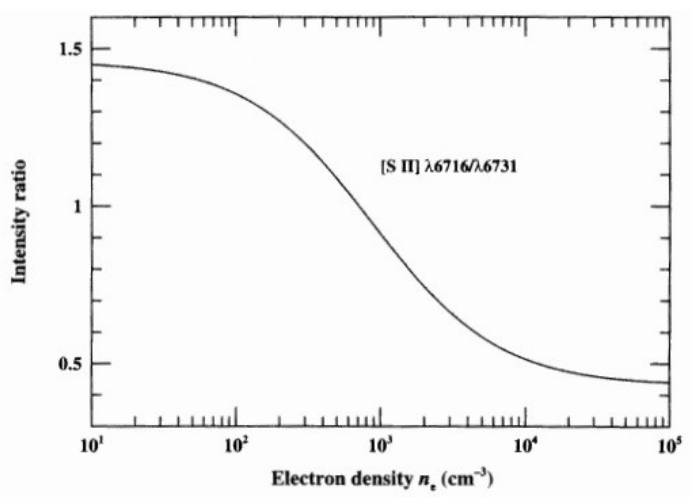

Relación entre el cociente de intensidades de las líneas $\mathrm{SII}] \lambda \lambda 6716,6731$ y la densidad ambiental. Figura extraída de Peterson (1997).

donde el factor exponencial pone de manifiesto que existe un valor mínimo para la energía de los electrones $(\chi)$ por encima del cual éstos son capaces de excitar colisionalmente el nivel 2.

Ahora bien, dado que la presencia e intensidad de las líneas prohibidas dependen esencialmente de la densidad electrónica del medio (Sección 1.3.2), se puede esperar que la emisividad $j_{(2 \rightarrow 1)}$ tenga distintos comportamientos en el límite donde la densidad es muy baja, o es muy alta. Estas diferencias estarán gobernadas por la competencia entre los términos de desexcitación radiativa $\left(A_{(2 \rightarrow 1)}\right)$ y colisional $\left(n_{e}\left\langle\sigma_{(2 \rightarrow 1)} v\right\rangle\right)$ del nivel 2, y son las que permiten determinar la densidad electrónica en el medio:

- Límite de densidad baja.

La emisividad puede expresarse como

$$
j_{(2 \rightarrow 1)}=n_{e} n_{1}\left\langle\sigma_{(1 \rightarrow 2)} v\right\rangle \frac{h \nu_{21}}{4 \pi}
$$

porque, al tratarse de casos de densidad extremadamente baja, las desexcitaciones colisionales pueden despreciarse frente a las radiativas $\left(n_{e}\left\langle\sigma_{(2 \rightarrow 1)} v\right\rangle \ll A_{(2 \rightarrow 1)}\right)$. La situación se puede describir bajo la hipótesis de que cada excitación colisional provocará una desexcitación radiativa, y por lo tanto la dependencia de la emisividad con la densidad es de tipo:

$$
j_{(2 \rightarrow 1)} \propto n^{2}
$$

- Límite de densidad alta. La emisividad puede expresarse como

$$
j_{(2 \rightarrow 1)}=n_{1} A_{(2 \rightarrow 1)} \frac{h \nu_{21}}{4 \pi} \frac{g_{2}}{g_{1}} e^{-\chi / k T_{e}}
$$

porque en este límite la densidad del medio es mucho mayor que la densidad crítica para la transición (ver Sección 1.3.2), y como consecuencia, las desexcitaciones colisionales dominan por completo la despoblación del nivel $2\left(n_{e}\left\langle\sigma_{(2 \rightarrow 1)} v\right\rangle \gg A_{(2 \rightarrow 1)}\right)$. En este caso, sólo una fracción minoritaria de las excitaciones colisionales decaerán radiativamente, y por tanto, la relación entre la emisividad y la densidad es de tipo:

$$
j_{(2 \rightarrow 1)} \propto n
$$


Las líneas del $\mathrm{S}^{+}$que se utilizan para determinación de densidades son [SII] $\lambda 6716$, correspondiente a la transición ${ }^{2} D_{5 / 2} \rightarrow{ }^{4} S_{3 / 2}$, y [SII] $\lambda 6731$, correspondiente a la transición ${ }^{2} D_{3 / 2} \rightarrow{ }^{4} S_{3 / 2}$. Como las densidades críticas de estas líneas son diferentes (ver Tabla 1.1), es posible encontrar un rango de densidad donde una de ellas se encuentre en el límite de densidad baja y la otra en el límite opuesto, de manera tal que el cociente entre los flujos medidos en cada una depende de la densidad como:

$$
\frac{j_{\lambda 6716}}{j_{\lambda 6731}} \propto n^{-1}
$$

En la Figura 2.2 se muestra la curva que indica cómo se comporta el cociente de intensidades de las dos líneas involucradas con la densidad; este cociente puede usarse como diagnóstico de la densidad del gas en el rango $10^{2}<n_{e}<10^{4} \mathrm{~cm}^{-3}$.

\subsubsection{Determinación de la temperatura electrónica}

La temperatura del gas se puede obtener con líneas cuyos potenciales de excitación son notoriamente diferentes. Como la excitación colisional de los estados de energía involucrados depende de la energía cinética de los electrones libres del medio, y ésta queda determinada por la temperatura, la población de estos niveles y la consecuente emisión de fotones de línea serán fuertemente dependientes de la temperatura electrónica del gas $\left(T_{e}\right)$. Las líneas del oxígeno [OIII] $\lambda \lambda 4363,4959,5007$ y del nitrógeno [NII] $\lambda \lambda 5755,6548,6583$ son ejemplos de estas transiciones. En el caso de AGNs es más frecuente el uso de las líneas del $\mathrm{O}^{++}$porque [NII] $\lambda 5755$ suele ser muy tenue (Peterson 1997).

Las líneas del oxígeno se producen en la configuración electrónica $2 p^{2}$ (Figura 2.3); la transición ${ }^{1} S_{0} \rightarrow{ }^{1} D_{2}$ corresponde al [OIII] $\lambda 4363$; la transición ${ }^{1} D_{2} \rightarrow{ }^{3} P_{1}$, al [OIII] $\lambda 4959$; y la ${ }^{1} D_{2} \rightarrow{ }^{3} P_{2}$, al [OIII] $\lambda 5007$. La temperatura del gas determinará la población relativa de los niveles ${ }^{1} S$ y ${ }^{1} D$ y, en consecuencia, determinará la intensidad relativa de las líneas que de allí emergen. Cada excitación al nivel ${ }^{1} D$ provocará la emisión de un fotón $\lambda 4959$ o $\lambda 5007^{4}$. Por otro lado, cada excitación al nivel ${ }^{1} S$ provocará la emisión de un fotón $\lambda 4363$, pero como esta transición puebla el nivel ${ }^{1} D$, también se emitirán fotones $\lambda 4959$ o $\lambda 5007$ en este caso (Osterbrock 1989).

Mediante un análisis similar al de la Sección anterior (ver Capítulo 3 de Osterbrock 1989), se encuentra que la relación entre las intensidades de las tres líneas y la temperatura electrónica está dada por la siguiente expresión (Peterson 1997):

$$
\frac{F(\lambda 4959+\lambda 5007)}{F(\lambda 4363)} \sim \frac{7.33 e^{\left(3.29 \times 10^{4} / T_{e}\right)}}{1+4.5 \times 10^{-4} n_{e} T_{e}^{-1 / 2}}
$$

donde puede verse que también existe una dependencia menor con la densidad $\left(n_{e}\right)$. La explicación de esta dependencia se ve en los efectos que el aumento o disminución de la densidad tiene en la formación de líneas excitadas colisionalmente. Las densidad crítica de la línea $[\mathrm{OIII}] \lambda 4363$ es aproximadamente dos órdenes de magnitud mayor que para las otras dos (ver Tabla 1.1); cuando la densidad aumenta, sus efectos no sólo son importantes, sino que además no afectan de la misma manera a las tres líneas. Por un lado, el nivel ${ }^{1} D$ se ve afectado

\footnotetext{
${ }^{4}$ También es posible obtener la emisión de un fotón $\lambda 4931$, correspondiente a la transición ${ }^{1} D_{2} \rightarrow{ }^{3} P_{0}$, pero la línea resultaría extremadamente débil y por tanto, indistinguible. Mientras que la probabilidad de obtener un fotón $\lambda 5007$ respecto de otro $\lambda 4959$ es de 3 a 1, la probabilidad de obtener un fotón $\lambda 5007$ respecto de un fotón $\lambda 4931$ es de 2800 a 1; y la de obtener uno $\lambda 4959$ respecto de otro $\lambda 4931$ es de 520 a 1 , aproximadamente (de acuerdo con sus probabilidades de transición; Stasińska 2009).
} 
Figura 2.3. Formación de las líneas del [OIII].

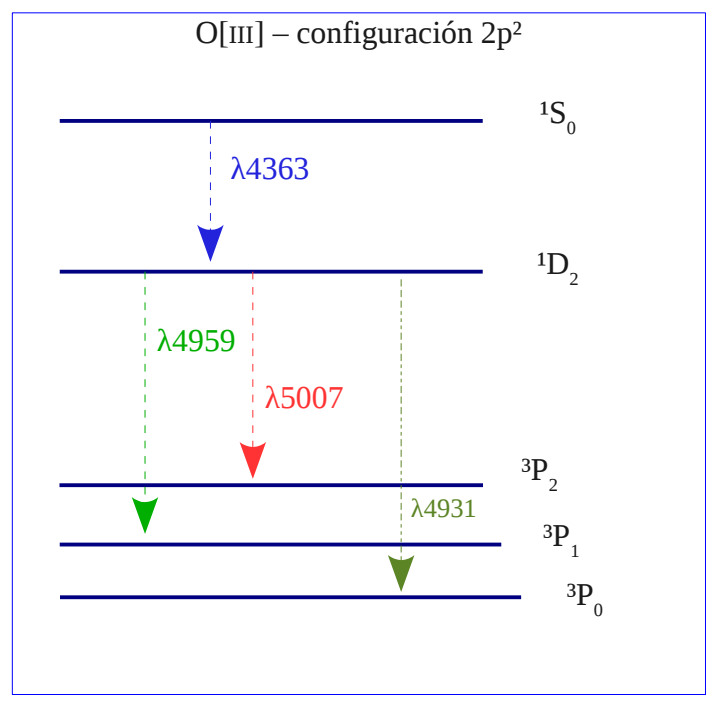

Transiciones que originan las líneas más importantes del [OIII] en la configuración $2 p^{2}$. Estas líneas se utilizan como indicadores de la temperatura electrónica (adaptación de Osterbrock 1989).

por desexcitación colisional, con lo cual disminuye la intensidad del doblete [OrII] $\lambda \lambda 44959,5007$, y por el otro, en el nivel ${ }^{1} S$ se ve favorecida la población colisional proveniente del nivel ${ }^{1} D$, que conlleva el aumento de intensidad de la línea [OIII] $\lambda 4363$ (Osterbrock 1989).

\subsection{Mecanismos de ionización}

Desde su temprana detección, el mecanismo de ionización dominante en la EELR ha sido un tema de constante discusión. En principio, la similitud entre el espectro de la región extendida y la NLR hizo suponer que, si la NLR está fotoionizada por el campo de radiación del AGN, entonces la EELR también. Sin embargo, no se abandonaron otras hipótesis tales como que el origen del campo de radiación fuera estelar (como en Regiones HiI), o que existiera una relación entre el radio-plasma y el gas óptico que no se limitara únicamente al aspecto morfológico (Ferland \& Netzer 1983; Robinson et al. 1987; Robinson 1989; Tadhunter et al. 1989).

Desde el trabajo pionero de Baldwin, Phillips \& Terlevich (1981) no han cesado los esfuerzos por distinguir la principal fuente de ionización en distintos sistemas de gas ionizado a partir de la información contenida en las líneas de emisión. En primera instancia, y según esta clase de análisis, quedó descartada la posibilidad de que un conjunto de estrellas jóvenes y masivas pudieran generar el campo ionizante necesario para explicar el estado de las EELR. Esta conclusión se obtuvo a partir de las particularidades en la formación de la línea [OI] $\lambda 6300$, y en virtud de que la línea adquiere intensidades diferentes en Regiones His respecto de nebulosas asociadas a AGNs (Veilleux \& Osterbrock 1987). Tiempo después también se descartó que pudieran existir brotes de formación estelar (starbursts) en la zona (Viegas \& de Gouveia dal Pino 1992). 
Los dos principales mecanismos que hoy siguen en debate son la ionización por parte del campo de radiación no térmico emitido por el AGN (fotoionicación), y la ionización por ondas de choque (shocks), surgidas como consecuencia de la inyección de energía mecánica en el sistema. Ambos escenarios se discuten en detalle a continuación.

\subsubsection{Fotoionización central}

El modelo de fotoionización (y su consecuente cono de ionización) deriva directamente de los esquemas de unificación, que proponen que radiogalaxias y quasars son intrínsecamente el mismo objeto visto desde direcciones diferentes. En las radiogalaxias, la visión directa del núcleo está bloqueada porque el toroide de material opaco está en la línea de la visual. Si este esquema de unificación es correcto, entonces todas las galaxias activas con fuerte emisión en radio deberían tener una fuente de fotones ionizantes extremadamente potente que sea capaz de iluminar el medio y explicar el espectro observado hasta las distancias observadas (Tadhunter 2002, y sus referencias).

Los procesos altamente energéticos que tienen lugar en las cercanías del agujero negro central de una galaxia activa producen emisión en el continuo a lo largo de todo el espectro electromagético. La forma que toma esta distribución espectral de energía, SED (del inglés, Spectral Energy Distribution), puede variar en distintas bandas. En el óptico-UV se describe aproximadamente bien mediante una ley de potencias (espectro no térmico). Los procesos involucrados están relacionados con las componentes del AGN discutidas en la Sección 1.3.1 e incluyen la emisión térmica proveniente de la disipación viscosa que tiene lugar dentro del disco de acreción, y emisión sincrotrón con su consecuente Comptonización. Es decir, se produce un exceso de energía en la banda de rayos-X blandos por efecto Compton inverso: los electrones relativistas responsables de la emisión sincrotrón entregan energía a los fotones térmicos y poco energéticos generados en el disco (Allen et al. 1998; O'Brien et al. 2001; de La Calle Pérez et al. 2010).

Los modelos de fotoionización consideran que el campo de radiación del AGN incide sobre el gas y, como consecuencia de su absorción, éste produce el espectro de emisión observado. El gas de la región absorbe los fotones del continuo, y dependiendo de la energía absorbida, los átomos se ionizan y/o excitan. La temperatura de la región (caracterizada por la distribución Maxwelliana de velocidades que adquieren los electrones libres) aumenta. Los electrones adquieren energía suficiente para excitar colisionalmente los átomos e iones presentes, aumentando el grado de excitación del sistema. Como etapa final del reprocesamiento de la energía recibida, la nebulosa emite radiación pero de energía menor a la incidente. Tanto las recombinaciones como desexcitaciones radiativas que tienen lugar dentro de la región generan fotones que, pudiendo escapar del sistema, contribuyen al espectro finalmente observado (Allen et al. 1998).

Para predecir el espectro de una nebulosa fotoionizada se necesita conocer la forma del campo de radiación emitido por la fuente central (la SED), el flujo de fotones que recibe la cara iluminada de la nube de gas, y la densidad y composición química (metalicidad) del material que la compone. El flujo de fotones que impacta en la nube y la densidad del gas se suelen combinar originando así un único parámetro que sirve como indicador del estado de excitación/ionización de la nube (Ferland 2003, y sus referencias). Se llama parámetro de ionización y hay distintas maneras de expresarlo. Aquí se adopta la forma adimensional, conocida como $U$ :

$$
U=\frac{1}{c n_{e}} \int_{\nu_{0}}^{\infty} \phi_{\nu} \frac{1}{h \nu} d \nu=\frac{\Phi_{H}}{c n_{e}}=\frac{Q}{4 \pi r^{2} c n_{e}}
$$

donde: 
$c$ es la velocidad de propagación de la luz en el vacío;

$n_{e}$ es la densidad electrónica del medio;

$\nu_{0}=3.29 \times 10^{9} \mathrm{MHz}$, es la frecuencia que corresponde a la mínima energía necesaria para ionizar el átomo de $\mathrm{H}$, es decir, $E_{0}=13.6 \mathrm{eV}$;

$\phi_{\nu}$ es el flujo de energía ionizante (es decir, $E>E_{0}$ ) monocromático $\left(\mathrm{erg} \mathrm{s}^{-1} \mathrm{~cm}^{-2} \mathrm{~Hz}^{-1}\right.$ )

$\Phi_{H}$ es el flujo de fotones ionizantes $\left(E>E_{0}\right)$ integrado (fotones $\mathrm{s}^{-1} \mathrm{~cm}^{-2}$ );

$r$ es la distancia entre la fuente de radiación y un cierto punto dentro de la nebulosa; y

$Q$ es la cantidad de fotones ionizantes emitidos por el núcleo activo por unidad de tiempo (fotones s ${ }^{-1}$ ) (Binette et al. 1996).

Para obtener $U$ se suponen condiciones de equilibrio entre los procesos de ionización, gobernados por la fuente central, y de recombinación, dentro de la nebulosa. Sin embargo, también es posible obtener fotones ionizantes mediante procesos de recombinación que afectan el balance de ionización y deben ser tenidos en cuenta, particularmente en lo que respecta a la radiación que escapa (o no) de la nube. Por ejemplo, cuando un ion $\mathrm{H}^{+}$captura un electrón y se recombina directamente al nivel fundamental emite un fotón de energía $E_{0}=13.6 \mathrm{eV}$. Por lo tanto, ese fotón, que no proviene de la SED del objeto central, también es capaz de ionizar otro átomo de H. Existen dos situaciones límite que determinan qué radiación escapa del sistema y cuál queda atrapada hasta que su energía se degrade lo suficiente; se conocen como Caso A y Caso B (Baker \& Menzel 1938; Osterbrock 1989). En el Caso A se supone que todas las líneas son ópticamente delgadas, y por lo tanto, cada transición radiativa genera un fotón que puede escapar libremente de la nebulosa. En el Caso B se supone que todas las líneas de la serie de Lyman son ópticamente gruesas; por lo tanto estos fotones no escapan del sistema sino que son reabsorbidos por el plasma. Tras sucesivas emisiones y absorciones, la energía de todos los fotones Lyman se va degradando; es decir, se va convirtiendo en fotones menos energéticos pertenecientes a otras series, y pueden finalmente escapar de la nebulosa. Eventualmente también los fotones Ly $\alpha$ (los menos energéticos de la serie de Lyman) pueden escapar del sistema (Peterson 1997). Para obtener la expresión de $U$ se considera que la nebulosa responde al Caso B (Ferland 2003).

El parámetro de ionización guarda la información de cómo se diluye el campo de radiación ionizante a medida que la distancia al núcleo aumenta.

El nivel de ionización dentro de la nebulosa depende del cociente entre ionizaciones $(I)$ y recombinaciones $(R)$ para un dado ion $(X)$ a una cierta distancia de la fuente. Este cociente es proporcional a la razón entre la densidad de fotones ionizantes y la densidad de partículas del gas, que, a su vez, es proporcional a $U$ :

$$
\frac{I_{X}}{R_{X}} \propto \frac{Q}{n_{e}} \propto U
$$

Por lo tanto, $U$ es un indicador del nivel de ionización. Los sistemas gaseosos donde se observan líneas de emisión intensas se caracterizan por parámetros de ionización en el rango $10^{-2} \lesssim U \lesssim 10^{-1}$. Si $U \ll 10^{-2}$ el estado de ionización es muy bajo, y podría tratarse de un gas casi neutro. En cambio, $U \gg 10^{-1}$ indica que el medio está altamente ionizado, y todavía muy caliente como para que la emisión de líneas (que funciona como mecanismo de enfriamiento de la nebulosa) sea apreciable (Netzer 2008). El rango de valores de $U$ medido para galaxias de bajo redshift es $10^{-3}<U<10^{-1}$ ( $\mathrm{z}<0.7$; Tadhunter et al. 1998, y sus referencias).

Penston et al. (1990) encontraron una manera empírica de relacionar el parámetro de ionización con la intensidad del cociente [OII] $\lambda 3727 /[\mathrm{OIII}] \lambda 5007$, que ya había sido usado por Baldwin et al. (1981) como parámetro (eje) de excitación en distintos sistemas de gas ionizado. Se derivaron los valores que tomaría $U$ para distintos modelos de fotoionización diferenciados únicamente por la SED empleada. Se utilizaron modelos de cuerpo negro (CN), 
con temperaturas en el rango $10^{5}<T_{C N}<2 \times 10^{7} \mathrm{~K}$, para evaluar qué comportamiento tendría $U$ bajo un continuo térmico; y modelos de ley de potencias $\left(f_{\nu} \propto \nu^{\alpha}\right)$, con índices espectrales $(\alpha)$ en el rango $-2<\alpha<-1$, para evaluar el comportamiento bajo un continuo no térmico. En todos los modelos se consideró: abundancia solar, densidad constante e igual a $n_{e}=100 \mathrm{~cm}^{-3}$, y que la nube de gas es ópticamente gruesa, de manera que absorbe todo el campo de radiación incidente. Obtuvieron dos resultados importantes; por un lado, que $U$ es relativamente insensible a la forma de la SED, y por el otro, que la relación con el cociente $[\mathrm{OII}] \lambda 3727 /[\mathrm{OIII}] \lambda 5007$ cubre cuatro órdenes de magnitud en $\log (U)$ y responde a la forma:

$$
\log (U)=-2.74-1.0 \log \left(\frac{[\mathrm{OII}] \lambda 3727}{[\mathrm{OIII}] \lambda 5007}\right)
$$

A partir de las Ecs. 2.1 y 2.2 se establece la conexión entre la teoría y la observación. Las líneas $[\mathrm{OII}] \lambda 3727$ y [OIII] $\lambda 5007$ suelen ser muy intensas en los espectros de la EELR, con lo cual se puede obtener el valor $U_{o b s}$ para una cierta distancia al núcleo. Luego, bajo ciertas suposiciones sobre la densidad del gas, se puede obtener una estimación del flujo ionizante emitidos por el AGN $(Q)$ y determinar si ese valor es coherente para el escenario propuesto.

El modelo más aceptado para el campo de radiación del objeto central indica que la SED está dominada por un espectro no térmico, cuyo índice espectral entre las bandas de rayos-X y óptico es $\alpha \sim-1.4$ (Ferland \& Osterbrock 1986; Korista et al. 1997).

\subsubsection{Fotoionización central en un medio multifase}

El modelo de fotoionización, tal como fue descrito hasta aquí, enfrenta algunas dificultades que pueden agruparse en dos tipos. Por un lado algunas líneas son muy intensas y los modelos, aunque pueden predecir su presencia, no pueden reproducir las intensidades observadas. En general se trata de la incapacidad de reproducir la intensidad de líneas de alta excitación, como HeII o [Nev] $\lambda 3424$, respecto de la intensidad de $\mathrm{H} \beta$. Incluso tampoco se puede explicar la intensidad del $[\mathrm{OIII}] \lambda 4363$, que conduce a temperaturas electrónicas demasiado altas (Viegas \& de Gouveia dal Pino 1992; Viegas \& Prieto 1992; Binette et al. 1996). Por ejemplo, mientras los modelos (SED no térmica, $\alpha=-1.5$ ) predicen valores que rondan $\mathrm{HeII} / \mathrm{H} \beta \sim 0.2$, las observaciones pueden alcanzar valores que triplican estas estimaciones (Viegas \& Prieto 1992). Por otro lado, el medio no es homogéneo (Sección 1.3.2), por lo cual la hipótesis de que un único valor de densidad (y por ende, de $U$ ) pueda caracterizar a toda la EELR no parece ser la más adecuada (Viegas \& de Gouveia dal Pino 1992; Binette, Wilson \& Storchi-Bergmann 1996).

El origen de ambos problemas radica en la suposición de que el medio absorbe el campo ionizante por completo, o dicho de otro modo, que el medio es ópticamente grueso respecto de la radiación incidente. Una estructura de ionización de este tipo se conoce como limitada por ionización o radiación (IB, de inglés ionization bounded). Viegas \& Prieto (1992) y Binette et al. (1996) mostraron que para poder reproducir simultáneamente la intensidad de líneas de alta y baja excitación es necesario considerar también una población de nubes ópticamente delgadas respecto de la radiación incidente. En este caso, el material absorbe una cierta fracción del campo de fotones, mientras que la fracción restante escapa. Se trata de una estructura de ionización diferente a las IB, y se conoce como limitada por densidad o materia (MB, del inglés matter bounded). Los modelos de fotoionización que contemplan este tipo de inhomogeneidades en el medio, basadas principalmente en la profundidad óptica del gas, reciben el nombre de modelos multifase, o de mezcla. Si bien existe un notable contraste de densidades entre ambas regiones, no es la densidad el parámetro que determina la intensidad relativa de las líneas, sino la profundidad óptica (Viegas \& Prieto 1992). 
En los modelos de fotoionización simple (Sección 2.4.1) se supone que el medio es de tipo IB. Y, en general, la densidad o bien es constante, o bien depende de la distancia $r$ como $n_{e} \propto r^{-2}$.

La incorporación de nubes ópticamente delgadas (OD) introduce modificaciones en la estructura de ionización, y consecuentemente, en la intensidad de algunas líneas. En este tipo de material, el volumen de la zona de baja ionización (donde domina el ion $\mathrm{H}^{+}$) se reduce respecto del caso ópticamente grueso (OG), pero el volumen de la zona dominada por iones $\mathrm{He}^{++}$no; por tal motivo el cociente HeII/H $\beta$ puede tomar valores mayores (Viegas \& Prieto 1992). Sin embargo, otras líneas de baja ionización e intensas en el espectro pueden verse afectadas, como el $[\mathrm{OII}] \lambda 3727$. Esta línea se produce en la zona de ionización parcial ${ }^{5}$, por lo tanto, si esta zona reduce su tamaño conforme la profundidad óptica disminuye, entonces la emisión del [OII] también disminuye (Tadhunter et al. 1998). Algo similar sucede con las líneas de oxígeno neutro. El [OI] $\lambda 6300$ se produce en una zona más interna aún, donde sólo llegan los fotones más energéticos que hayan sido capaces de atravesar la zona $\mathrm{H}^{+}$sin ser absorbidos (Robinson 1989). Como consecuencia, la reducción de la profundidad óptica también afecta severamente la emisión del [OI]. En cambio, la emisión de las líneas de alta excitación, como [OIII] $\lambda 5007$ o HeII, no se ve afectada. Se deduce, entonces, que para poder reproducir la intensidad de toda clase de líneas se necesita contemplar la presencia de nubes OG (IB) y OD (MB) simultáneamente (Stasińska 1984; Viegas \& Prieto 1992).

Viegas \& Prieto (1992) mostraron que para cada línea de emisión existe una relación estrecha y compleja entre la profundidad óptica $(\tau)$, el parámetro de ionización $(U)$, y el tamaño de la región donde se genera la línea. Pero el problema es más complejo, dado que las variaciones en $\tau$ también se pueden interpretar como las variaciones que sufre $U$ en un modelo OG. Por esta razón es necesario analizar el comportamiento de líneas clave como [OI] 76300 o HeII, que son muy sensibles a estos parámetros. La detección de líneas de alta y baja ionización dentro de la misma subregión en un dado objeto (en este trabajo se estudiaron Cen A y 3C 227), indicaba que había que combinar de alguna manera los dos tipos de nubes para poder reproducir la intensidad de todas las líneas presentes. Propusieron un escenario ${ }^{6}$ donde la relación entre los parámetros de ionización fuera $U_{M B} / U_{I B}=16$. Como, según la Ec. 2.1, $U \propto\left(n r^{2}\right)^{-1}$ hay dos maneras de interpretar la variación de $U$ :

1. las nubes tiene la misma densidad, pero las OD están más cerca de la fuente central que las OG;

2. los dos conjuntos de nubes están a la misma distancia de la fuente central, y sus densidades son diferentes (el contraste de densidades está dado por $n_{I B} / n_{M B}=16$ )

Los dos escenarios se representan de modo esquemático en los paneles superior e inferior, respectivamente, de la Figura 2.4. El problema con la configuración 1 surge de la dependencia geométrica de los modelos de unificación (Sección 1.3.3). Si hay nubes muy cercanas a la fuente central, el espectro combinado sólo sería posible de observar para situaciones geométricas especiales. Según los autores, es más probable que la distribución de material en la EELR sea del tipo propuesto en la configuración 2, donde las nubes densas (OG) están inmersas en un gas más diluido (OD). En cualquiera de los casos, las nubes MB absorben una parte del campo de radiación central, y la fracción restante es absorbida por el material de las

\footnotetext{
${ }^{5} \mathrm{El}$ potencial de ionización del oxígeno neutro es igual al del hidrógeno, $13.6 \mathrm{eV}$.

${ }^{6} \mathrm{La}$ configuración propuesta se comporta como un caso extremo entre las posibles maneras de combinar los dos tipos de nubes. Surge como consecuencia de un trabajo anterior (Morganti et al. 1991) donde se propuso una distribución continua de densidades para poder explicar los espectros de la EELR. En el trabajo de Viegas \& Prieto (1992) se hace hincapié en que tal distribución no es necesaria, particularmente porque el rango de densidades observadas en la EELR es muy reducido.
} 
Figura 2.4. Geometría de la EELR en modelos de fotoionización multifase.

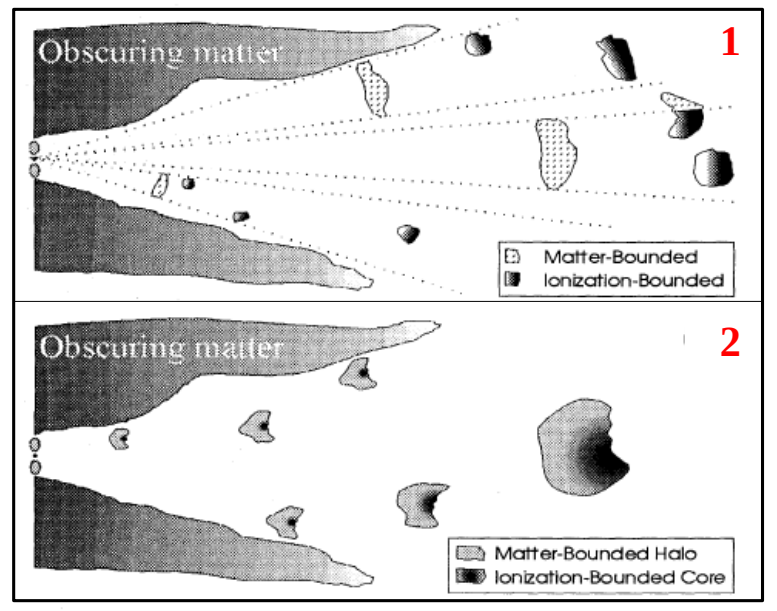

Posibles configuraciones geométricas de nubes MB (ópticamente delgadas) e IB (ópticamente gruesas) en modelos de mezcla. Figura extraída de Binette, Wilson \& Storchi-Bergmann (1996).

IB. Los resultados del modelo fueron, en general, satisfactorios; sin embargo la temperatura electrónica de la región (dada por el cociente de los oxígenos) sigue siendo demasiado alta para poder reproducirla de este modo.

El modelo de mezcla más complejo disponible en la literatura es el que desarrollaron Binette et al. (1996, de aquí en adelante, BWS96), donde se utilizan muchos de los aciertos del trabajo anterior (Viegas \& Prieto 1992). El modelo se desarrolló puntualmente para ser capaz de reproducir las intensidades observadas en el cociente HeII/H $\beta$ y su rango de variabilidad, pero también ataca otras dificultades de los modelos de fotoionización simple. Dada la dependencia del cociente HeII/H $\beta$ con el tamaño de la región de emisión, y de ésta con $\tau$, se propone un nuevo parámetro de excitación en reemplazo de $U$. Así como $U$ es una medida de la excitación del gas dada por el cociente [OII] $\lambda 3727 /[\mathrm{OIII}] \lambda 5007$ (Ec 2.2), este nuevo parámetro será otra medida de la excitación del gas que seguirá el comportamiento del cociente $\mathrm{HeII} / \mathrm{H} \beta$.

Las líneas de mayor nivel de ionización se forman en las nubes $\mathrm{MB}$, que absorben el campo de radiación emitido por el objeto central (la SED es una ley de potencias de índice $\alpha=-1.3)$. Para poder reproducir la intensidad de esas líneas y a la vez contribuir de manera significativa a la temperatura electrónica de la región, se imponen condiciones sobre el parámetro de ionización $\left(U_{M B}\right)$ y sobre la profundidad óptica. La dependencia de $U_{M B}$ con la temperatura se da porque la mayor parte del calentamiento de la región $\mathrm{MB}$ se produce por la fotoionización del ion $\mathrm{He}^{+}$; esto ocurre para $U_{M B} \gtrsim 0.04$. La profundidad óptica, por su parte, queda determinada una vez que se establece qué fracción del campo ionizante $(F)$ será absorbida por el sistema de nubes. Para las nubes MB esa fracción es del $40 \%$, es decir $F_{M B}=0.4$; cuando se llega a este punto prácticamente ya no hay más fotones con energía en el rango 54-200 eV, que son los responsables de la ionización del $\mathrm{He}^{+}$. Con estas condiciones es posible reproducir las temperaturas electrónicas en la muestra de EELR/ENLR adoptada 
por los autores. La densidad de las nubes MB se fijó ${ }^{7}$ en $n_{M B}=50 \mathrm{~cm}^{-3}$, dentro del límite de baja densidad (Sección 2.3.1).

Las líneas de menor nivel de ionización se forman predominantemente en las nubes IB, ópticamente gruesas. Estas nubes absorben el campo de radiación que escapa del sistema MB; se trata del campo del objeto central pero filtrado en el conjunto de frecuencias absorbidas por el material de las nubes MB. En la Figura 2.5 (extraída del trabajo original de BWS96) se muestra la distribución de energía que llega a las nubes MB (línea continua), y la que escapa de ellas, transformándose en el campo incidente para las nubes IB (línea a trazos). El sistema MB puede caracterizarse por un único parámetro de ionización, pero no ocurre lo mismo con el conjunto IB. Esto se debe principalmente a que la SED que éste recibe ha sido modificada respecto de su forma original, y a que su estado de excitación no es tan parejo como en el caso de las nubes MB. Aún así es posible definir un valor de $U_{I B}$, pero por las características del modelo $U_{I B}$ ya no guarda relación con la Ec. 2.1. La relación entre los dos conjuntos de nubes se da a través de la presión. Cada región constituye un sistema isobárico independiente, donde $P_{I B} \sim 20 P_{M B}$; el parámetro de ionización en las nubes IB que se desprende de esta condición es $U_{I B}=5.2 \times 10^{-4}$. Esto marca una diferencia importante entre los dos conjuntos. La presión en las nubes MB se deduce de los valores adoptados para $U_{M B}$ y $n_{M B}$, pero la presión en las nubes IB se determina según cuál va a ser la contribución de estas nubes a la emisión total. Concretamente, $P_{I B}$ se elige de manera tal que la emisión de [OIII] $\lambda 5007$ proveniente de las nubes IB sea menor que la contribución de las MB. Y esto garantiza que la intensidad total $(\mathrm{MB}+\mathrm{IB})$ del cociente $[\mathrm{OIII}] \lambda 5007 / \mathrm{H} \beta$ sea compatible con los valores observados la muestra de objetos seleccionada. Como las nubes IB son ópticamente gruesas respecto de la radiación incidente, en principio, absorben todo el campo de radiación. Sin embargo, para evitar que las líneas de baja excitación que se forman en esta zona tengan flujos muy altos, se estableció que el porcentaje de absorción sea del $97 \%\left(F_{I B}=0.97\right)$.

La geometría del sistema puede interpretarse de dos formas equivalentes, tal como habían señalado Viegas \& Prieto (1992) en su trabajo. O bien las nubes IB son más densas que las MB (configuración 2, Fig. 2.4), o bien el campo filtrado que reciben las nubes IB sufre mayor dilución geométrica (configuración $\mathbf{1}$ en la misma Fig.). Aunque las consideraciones sobre la discontinuidad en la presión favorecen un escenario del tipo propuesto en la configuración $\mathbf{2}$, los autores hacen uso de esta ambigüedad para definir un nuevo parámetro de excitación de características puramente geométricas cuyo sustento se basa en la configuración $\mathbf{1}$.

El nuevo parámetro de excitación $A_{M / I}$ se define como el cociente entre los ángulos sólidos subtendidos por el conjunto MB respecto del IB desde la fuente central (configuración 1, Fig. 2.4). De aquí se desprende que $A_{M / I}$ sólo podría adoptar valores en el rango $A_{M / I}>1$ porque las nubes MB se sitúan entre el núcleo y las IB. Sin embargo, los efectos geométricos son determinantes. En el caso de objetos tipo Seyfert 2 o NLRG no se espera que un observador pueda detectar una fracción importante de nubes MB, porque éstas son más internas, y la zona interna del AGN está bloqueada a la visión (Sección 1.3.3). Por lo tanto, y dado que en la definición de $A_{M / I}$ sólo intervienen las nubes visibles, estos objetos deberían caracterizarse por valores $A_{M / I}<1$. Cuanto mayor sea la influencia de la componente MB respecto de la IB en un dado espectro, mayor será el nivel de excitación observado. Bajo estas circunstancias, se esperan valores de $A_{M / I}$ cada vez mayores. Es, justamente, esta característica la que determina que $A_{M / I}$ se adopte como nuevo parámetro de excitación del gas.

El modelo se implementa a través de diagramas de diagnóstico ${ }^{8}$, es decir, a través de

\footnotetext{
${ }^{7}$ En rigor, la densidad no es constante. El modelo es isobárico en cada sistema de nubes. Por lo tanto el comportamiento de la densidad en función de la distancia dentro de la nube está modulado por el comportamiento de la temperatura y la fracción de ionización del gas.

${ }^{8}$ Los diagramas de diagóstico se empezaron a utilizar de manera sistemática luego del trabajo de Baldwin et al. (1981, también conocido como BPT). Los diagramas se construyen con cocientes entre distintas líneas de
} 
Figura 2.5. Campos de radiación incidente en el modelo de fotoionización multifase.

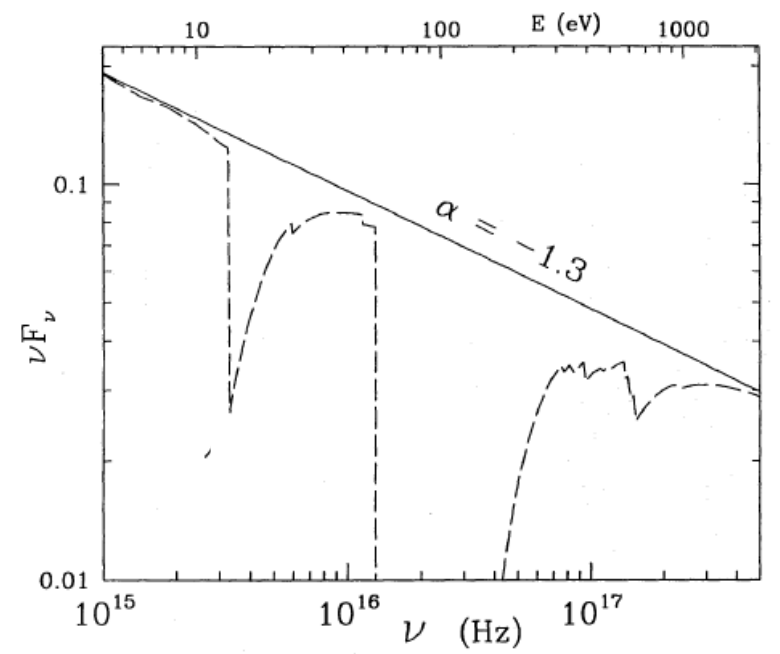

Línea continua: SED del objeto central. Línea a trazos: SED incidente sobre las nubes IB. Figura extraída de Binette, Wilson \& Storchi-Bergmann (1996).

diagramas bidimensionales formados por cocientes entre las líneas de emisión. Para ello, el parámetro $A_{M / I}$ define una secuencia de excitación que estará gobernada por la intensidad relativa de las líneas en cuestión. Como existen dos conjuntos de nubes, cada una contribuye de manera particular a la emisión de cada línea. Por lo tanto, en el espectro resultante la intensidad de cada una de ellas estará determinada por una combinación particular de las contribuciones provenientes de las nubes MB y las IB. Sea $i$ una línea de emisión cualquiera del espectro. La intensidad resultante de la línea $i$ respecto de $\mathrm{H} \beta$, y como función del parámetro de excitación $A_{M / I}\left(R_{r e s}^{i}\left(A_{M / I}\right)\right)$ será:

$$
R_{r e s}^{i}\left(A_{M / I}\right)=\frac{R_{I B}^{i}+C \cdot A_{M / I} \cdot R_{M B}^{i}}{1+C \cdot A_{M / I}}
$$

donde $R_{M B}^{i}$ y $R_{I B}^{i}$ son las intensidades de la línea en las nubes MB e IB, respectivamente, y $C$ es el factor de peso, determinado por el cociente de luminosidades de $\mathrm{H} \beta$ en las regiones MB e IB. Como se ve en la Ec. 2.3, el único parámetro libre del modelo es $A_{M / I}$.

Los autores desarrollaron cuatro modelos diferentes (BWS96; Binette et al. 1997), todos ellos constituidos por las nubes MB e IB, pero distintas entre sí. En la Tabla 2.1 se encuentran

emisión; el análisis mostró que los distintos mecanismos de excitación posibles (fotoionización por un espectro no térmico, por un campo estelar, excitación por ondas de choque) ocupan diferentes zonas de los diagramas. El diagrama más ampliamente usado es $[\mathrm{OIII}] \lambda 5007 / \mathrm{H} \beta$ vs $[\mathrm{N}$ II] $\lambda 6584 / \mathrm{H} \alpha$, que muchas veces recibe el nombre de el diagrama BPT. En él se diferencian claramente dos zonas: la que ocupan los objetos con formación estelar y la que ocupan las galaxias tipo Seyfert 2. La física subyacente indica que los fotones que emite un AGN son mucho más energéticos que los que pueden emitir el conjunto de estrellas masivas que generan las regiones HII. Por lo tanto, al ser más energéticos, el gas es más caliente, las partículas son más veloces y como resultado, las líneas colisionalmente excitadas son más intensas que las de recombinación (respecto del caso en que la nebulosa es excitada por estrellas; Stasińska 2009). La utilización generalizada de los diagramas de diagóstico busca repetir esta clase de comportamiento, es decir, que distintos procesos ocupen distintas zonas de manera tal de poder identificar cuál es el proceso que actúa en un dado objeto. 
Tabla 2.1. Modelos de fotoionización multifase: parámetros

\begin{tabular}{ccccc}
\hline \hline Denominación & & $U$ & $n_{e}\left[\mathrm{~cm}^{-3}\right]$ & $\tau$ \\
\hline $\mathrm{T}$ & $\mathrm{MB}$ & 0.04 & 50 & $F_{M B}^{T}=0.4$ \\
$\left(C_{T}=0.571^{a}\right)$ & $\mathrm{IB}$ & $5.2 \times 10^{-4}$ & $2.3 \times 10^{3}$ & $F_{I B}^{T}=0.97$ \\
\hline $\mathrm{H}$ & $\mathrm{MB}$ & 0.5 & $1 \times 10^{3}$ & $F_{M B}^{H}=0.35$ \\
$\left(C_{H}=0.461\right)$ & $\mathrm{IB}$ & $6.5 \times 10^{-4}$ & $\gtrsim 1.2 \times 10^{4}$ & $F_{I B}^{H}=0.97$ \\
\hline $\mathrm{M}$ & $\mathrm{MB}$ & 0.05 & $1 \times 10^{3}$ & $F_{M B}^{M}=0.35$ \\
$\left(C_{M}=0.368\right)$ & $\mathrm{IB}$ & $6.5 \times 10^{-4}$ & $\gtrsim 1.2 \times 10^{4}$ & $F_{I B}^{M}=0.97$ \\
\hline $\mathrm{L}$ & $\mathrm{MB}$ & 0.02 & $1 \times 10^{3}$ & $F_{M B}^{L}=0.35$ \\
$\left(C_{L}=0.354\right)$ & $\mathrm{IB}$ & $6.5 \times 10^{-4}$ & $\gtrsim 1.2 \times 10^{4}$ & $F_{I B}^{L}=0.97$ \\
\hline \hline
\end{tabular}

Notas: ${ }^{a} \mathrm{El}$ factor de peso $C$ representa la relación entre las luminosidades de $\mathrm{H} \beta$ en la región $\mathrm{MB}$ respecto de la IB. El cociente de luminosidades de $\mathrm{H} \beta$ en el modelo $\mathrm{T}$ es $C_{T}=0.571$. Aunque las luminosidades están expresamente indicadas en el trabajo original (BWS96), los autores usaron un valor diferente $\left(C^{*}=0.568\right)$. Como no hay ninguna referencia a $C^{*}$ en el trabajo, aquí se optó por usar el $C_{T}$.

todos los parámetros característicos. Las nubes $\mathrm{MB}$ en los modelos denominados $\mathrm{H}, \mathrm{M}$ y L (Binette et al. 1997) enfrentan un campo de radiación nuclear más energético que el de la Fig 2.5 (modelo T; BWS96). Se debe a que esos modelos fueron desarrollados con el propósito de reproducir la intensidad de líneas coronales, y para eso se requería que la SED tuviera mayor contribución en el rango de rayos-X; también el parámetro de ionización $U$ es considerablemente mayor respecto de los otros casos. Los valores de $U$ y $n_{e}$ corresponden a la superficie de la nube (ya sea MB o IB) que enfrenta al campo de radiación incidente. La medida de la profundidad óptica $(\tau)$ está dada por la fracción absorbida del campo ionizante $(F)$.

Los modelos se desarrollaron con el propósito de reproducir los valores del cociente HeII/H $\beta$. Por tal motivo, no sorprende que el parámetro $A_{M / I}$ muestre una muy buena correlación con este cociente, entendiendo por correlación a una relación biunívoca en el rango de valores adoptado para $A_{M / I}\left(0.04<A_{M / I}<16\right.$, BWS96), donde $A_{M / I}$ crece conforme la intensidad del cociente aumenta. De aquí se desprende que el eje de excitación adoptado para evaluar estos modelos sea el cociente $\mathrm{HeII} / \mathrm{H} \beta$.

La principal ventaja de los modelos multifase radica en que definen una secuencia de excitación diferente a la secuencia tradicional dada por $U$. Este comportamiento se hace evidente en los diagramas construidos por los cocientes [OII] $\lambda 3727 /[\mathrm{OIII}] \lambda 5007$ vs $\mathrm{HeII} / \mathrm{H} \beta$, o $[\mathrm{OII}] \lambda 3727 /[\mathrm{Nev}] \lambda 3424$ vs HeII/H $\beta$ (ver figs. 7 y 8 de BWS96), donde las secuencias son prácticamente perpendiculares. Esto constituye una herramienta de gran utilidad para evaluar la competencia del mecanismo de fotoionización bajo dos situaciones definidas por el papel que pueda desempeñar el MIG:

- medio pasivo: el espectro de la región estará determinado por las características del campo ionizante. El papel del MIG queda relegado únicamente a absorber ese campo, sin importar qué tan extendido esté el gas (en los modelos de fotoionización simple, las condiciones del medio son siempre de tipo IB)

- medio activo: el espectro de la región está determinado tanto por el campo ionizante del objeto central como por la capacidad del medio para absorber y reprocesar la energía que recibe.

Como punto débil debe señalarse que todos los parámetros involucrados en el desarrollo de 
los modelos fueron cuidadosamente elegidos para obtener espectros de emisión combinados que fueran capaces de reproducir las observaciones empleadas en cada trabajo. Aún así, es el modelo de fotoionización más complejo y realista disponible, porque es el único que contempla que el campo de fotones emitido por el núcleo activo no puede llegar inalterado hasta las regiones extendidas (ENLR o EELR).

\subsubsection{Ionización por ondas de choque}

Como alternativa al mecanismo de fotoionización central (en todas sus variantes), y sin poner en tela de juicio la capacidad ionizante de ese campo de radiación (Tadhunter 2002; Evans et al. 2008), existe otro mecanismo de excitación e ionización que puede explicar el estado de la EELR. Este mecanismo se basa en la interacción entre los radio-jets y el MIE/MIG. Debido a las velocidades involucradas, tal interacción desencadena ondas de choque en el medio, cambiando por completo el estado del mismo ${ }^{9}$. Cuando una onda de choque (shock, de modo abreviado) se propaga por el MIG, las condiciones magnetohidrodinámicas (MHD) del gas cambian de manera irreversible. Bajo ciertas circunstancias que serán discutidas a continuación, junto con el frente de choque puede aparecer un frente de ionización; es decir, es posible que una onda de choque genere un campo ionizante local. Mientras el frente de choque cambia el estado MHD del gas, el frente de ionización también cambia el estado de excitación e ionización.

No se trata de una competencia mutuamente excluyente entre los dos modelos en cuestión (aunque muchas veces en la jerga la problemática se identifique como fotoionización vs. ionización por ondas de choque) sino de establecer dónde es posible que uno domine sobre el otro (Tadhunter 2002). Incluso, en el desarrollo de los modelos de fotoionización multifase se hace hincapié en que ciertas características espectrales requieren la presencia de shocks. Viegas \& de Gouveia dal Pino (1992) resaltan que para poder reproducir ciertos cocientes de líneas en la NLR hacen falta modelos híbridos, que tengan en cuenta el efecto acoplado de la fotoionización por el continuo nuclear y las colisiones térmicas por shocks. También Viegas \& Prieto (1992) y BWS96 encontraron que la intensidad de los cocientes que involucran líneas de alta y baja excitación requieren tanto de modelos de mezcla (nubes MB e IB) como de la presencia de shocks. Es probable que el modelo de iluminación central sea más importante en las zonas internas donde los efectos de la dilución geométrica de fotones todavía no son tan importantes. En cambio, de las observaciones se deduce que los jets pueden recorrer un camino extremadamente largo antes de "desintegrarse", por lo cual los efectos de su interacción con el medio podrían observarse incluso en escala de kiloparsecs (Tadhunter 2002), es decir en la EELR.

En este sentido, el efecto de alineamiento (Sección 2.2) ha desempeñado un papel importante. Este aspecto de la relación radio-óptico sugiere que existen interacciones importantes entre la radiofuente y el medio (McCarthy et al. 1987), a la vez que debilita la hipótesis que sostiene que la morfología de la región extendida revela la zona de influencia del campo de radiación del núcleo activo (Baum \& Heckman 1989a,b; Tadhunter 2002).

A su vez, el paso del jet por el medio inyecta energía mecánica en el sistema y sus huellas podrían encontrarse en la cinemática de la región. Parte de esta energía se puede invertir en

\footnotetext{
${ }^{9}$ Las ondas de choque se desarrolan en medios compresibles cuando los gradientes de presión son suficientemente grandes. La velocidad de propagación de una onda de choque es mayor que la velocidad del sonido en el medio, y por este motivo el medio no puede responder a tan brusco cambio en sus condiciones físicas: los cambios que el shock produce son irreversibles. Es la diferencia fundamental con las ondas sonoras, u ondas de presión, donde la velocidad de perturbación es suficientemente pequeña (menor que la velocidad del sonido en el medio) como para que el gas pueda acomodarse rápidamente a los cambios provocados por el paso de la onda, y luego volver a sus condiciones de equilibrio (McKee \& Hollenbach 1980).
} 
procesos de excitación e ionización colisional del gas que serán detectados espectroscópicamente a través de la intensidad de ciertas líneas de emisión. Pero otra fracción de esa energía mecánica queda almacenada como energía cinética del gas. Los disturbios provocados dentro del sistema gaseoso, materializados en la aceleración de las nubes de gas, no son despreciables y deberían poder detectarse. Estos efectos se manifiestan en la separación de componentes de una misma línea espectral; la detección o no, en este caso, depende fuertemente de las características instrumentales empleadas en la observación.

Sin embargo, ni la cinemática de la región ni la verificación de alineamiento en la emisión radio-óptico son determinantes al momento de definir el mecanismo de ionización dominante. $\mathrm{E}$ incluso hay ejemplos contradictorios, donde se puede ver que no siempre ambos efectos están presentes. La emisión de [OII] $\lambda 3727$ en la radiogalaxia 3C 433 presenta múltiples componentes, cuyas velocidades relativas alcanzan alrededor de $1500 \mathrm{~km} \mathrm{~s}^{-1}$; sin embargo, la emisión óptica no se distribuye a lo largo del radio-eje. Por otro lado, en la radiogalaxia 3C 277.3 (Coma A) se ha comprobado que el jet está interactuando con la región en emisión ubicada hacia el sur del núcleo de la galaxia, pero la cinemática del gas no muestra ningún signo de alteración (Tadhunter 2002, y sus referencias). De la misma manera, se han encontrado signos de interacción jet-nube aún en radiogalaxias donde la radiofuente es mucho más extendida que la EELR (3C 34 y 3C 330; Solórzano-Iñarrea et al. 2001). En estos casos no hay coincidencia espacial, aunque sí puede haber algún tipo de alineamiento.

El aspecto más importante a analizar es si este mecanismo es capaz de producir un espectro de emisión como el observado. Los movimientos de alta velocidad que ocurren en muchos sistemas astrofísicos pueden tener consecuencias sobre el espectro emergente. Cuando se desarrollan ondas de choque, se generan grandes cantidades de gas muy caliente. Parte del espectro observado se debe al enfriamiento de este material, pero dependiendo de la velocidad de la onda, se puede generar un campo de fotones UV y rayos-X suficientemente intenso como para ionizar el gas que aún no ha sido afectado por el paso de la onda (Cox 1972). Esta región se conoce como zona precursora ${ }^{10} \mathrm{y}$, en términos de su estructura de ionización, puede describirse como una Región HiI (Dopita \& Sutherland 1995, 1996). Stasińska (2009) resumió los efectos que pueden producir las ondas de choque sobre un espectro de emisión de la siguiente manera:

- la onda de choque comprime el gas, con lo cual se obtienen densidades altas.

- la compresión reduce localmente el parámetro de ionización (por la relación entre $U$ y $\left.n_{e}\right)$, y por ello aumenta la emisión en líneas con estado de ionización bajo: [OII], [NII], [SII] y $[\mathrm{OI}]$.

- cuando el gas se comprime, también se calienta, pudiendo alcanzar temperaturas de $\gtrsim 10^{6} \mathrm{~K}$. Bajo estas condiciones es posible que los átomos o iones del medio sean ionizados colisionalmente (ver Apéndice A); mediante este proceso se pueden obtener especies tales como $\mathrm{O}^{+3} \mathrm{o} \mathrm{He}^{++}$.

- el gas caliente emite en las bandas de rayos-X y UV; los fotones altamente energéticos que se generan de este modo contribuyen a la ionización del gas por delante y por detrás del frente de choque.

- entre la zona de gas caliente y la de baja excitación existe una región con un pronunciado gradiente de temperatura donde se ve favorecida la emisión de líneas del UV excitadas colisionalmente y de líneas aurorales; en esta zona, el cociente [OІІІ] $\lambda 4363 /[\mathrm{OIII}] \lambda 5007$ puede crecer significativamente.

En este trabajo se aplicarán los modelos MHD (ver Apéndice B) más recientes de ioniza-

\footnotetext{
${ }^{10}$ Existen experimentos en laboratorio que confirman que las ondas de choque radiativas son capaces de generar una región precursora aún en un sistema hidrodinámico puro (campo magnético ausente; Keiter et al. 2002).
} 
ción por ondas de choque, desarrollados por Allen et al. (2008, de aquí en adelante, A08) y basados en los resultados previos de Dopita \& Sutherland (1995, 1996, en adelante, DS95 y DS96, respectivamente). Sus características, resultados e implementación se explican a continuación. Lo que aquí se llama el modelo es en realidad un conjunto de modelos definidos por la densidad del medio antes de ser perturbado, $n$, la velocidad del shock, $v_{s}$, el valor del campo magnético transversal (paralelo al plano de choque) en el medio sin perturbar, $B, \mathrm{y}$ el conjunto de abundancias.

El modelo predice el espectro de emisión generado por choques puros o autoionizantes, unidimensionales y de flujo estacionario, que tienen lugar dentro de un plasma magnetizado. La hidrodinámica del fluido se obtiene de las condiciones de salto de Rankine-Hugoniot que incluyen el término magnético. Las ecuaciones representan la conservación de masa, de movimiento, la condición de congelamiento de las líneas de campo magnético con el plasma (Apéndice B), y la conservación de la energía:

$$
\begin{gathered}
\rho v=\rho_{0} v_{0} \\
\rho v^{2}+P+\frac{B^{2}}{8 \pi}=\rho_{0} v_{0}^{2}+P_{0}+\frac{B_{0}^{2}}{8 \pi} \\
\frac{B}{\rho}=\frac{B_{0}}{\rho_{0}} \\
\frac{v^{2}}{2}+\frac{P}{\rho(1-\gamma)}+\frac{P}{\rho}+\frac{B^{2}}{4 \pi}+\bar{\Lambda}\left(t-t_{0}\right)=\frac{v_{0}^{2}}{2}+\frac{P_{0}}{\rho_{0}(1-\gamma)}+\frac{P_{0}}{\rho_{0}}+\frac{B_{0}^{2}}{4 \pi}
\end{gathered}
$$

Las ecuaciones conectan cualesquiera dos puntos del fluido, caracterizados por ciertos valores de densidad $\rho$, presión $P$, velocidad $v$, campo magnético $B$ y energía interna, en los tiempo $t$ y $t_{0}$. La magnitud $U=P /[\rho(1-\gamma)]$ es la energía interna del elemento de plasma; y $\bar{\Lambda}\left(t-t_{0}\right)$ representa la tasa media de enfriamiento en el intervalo $\left(t-t_{0}\right)$.

Los modelos consideran choques rápidos. En estas situaciones la radiación ionizante generada por el enfriamiento del gas chocado (postshock) se convierte en un potente campo de fotones energéticos (UV y rayos-X blandos-medios) que provocan la fotoionización del gas sin perturbar (preshock), por delante del frente de choque (A08). El frente de ionización se propaga en el gas preshock con velocidad $V_{F I}$, mientras que el frente de choque se propaga con velocidad $v_{s}$. La relación entre ambas está dada por (DS95):

$$
\frac{V_{F I}}{100 \mathrm{~km} \mathrm{~s}^{-1}}=0.4548\left(\frac{v_{s}}{100 \mathrm{~km} \mathrm{~s}^{-1}}\right)^{2.371}
$$

De aquí se deduce que si $v_{s} \gtrsim 170 \mathrm{~km} \mathrm{~s}^{-1}$, entonces $V_{F I}>v_{s}$, con lo cual el frente de ionización se desprende del frente de choque, adelantándose. Como consecuencia, el estado de excitación e ionización del gas preshock se modifica antes que su estado dinámico, pues la onda de choque llega luego de que el gas haya sido fotoionizado por el propio campo que ella ha generado (A08). Si la onda de choque, en cambio, tiene una velocidad $v_{s} \lesssim 100 \mathrm{~km} \mathrm{~s}^{-1}$ ya no es capaz de pre-ionizar el gas pero aún en este caso puede provocar un aumento de la emisión en la parte azul del espectro. En particular, en este tipo de situaciones aumentan los procesos de excitación colisional del Hi; cuando el átomo decae, emite dos fotones azules en el continuo ${ }^{11}$ (DS96).

\footnotetext{
${ }^{11}$ La emisión de dos fotones (two-photon continuum) se produce por la transición desde el nivel metaestable $2{ }^{2} S_{1 / 2}$ al nivel fundamental. La transición desde el nivel $2 p$ al fundamental da origen a la línea de recombinación Ly $\alpha$, la línea menos energética de la serie de Lyman. Pero como las transiciones $2 s \rightarrow 1 s$ son prohibidas mientras se emita un único fotón, el decaimiento puede producirse emitiendo dos fotones. Las energías individ-
} 
El frente de ionización no sólo viaja en la dirección de avance de la onda, sino también en dirección contraria, hacia el gas chocado. Los cambios que produce son diferentes. En la dirección propagación de la onda, el frente de ionización se encuentra con el gas preshock, sin perturbar, mientras que en la otra dirección se encuentra con el gas chocado, caliente y comprimido por el shock. Aunque el efecto sobre el gas postshock consiste en aumentar la emisión de este gas caliente, el frente de ionización no puede avanzar de la misma manera que en el gas sin perturbar debido a la compresión que ha sufrido el material (A08). Si bien el gas está fuertemente comprimido, cabe destacar que la presencia del campo magnético provoca que la compresión sea menor que la que sufriría si el campo $B$ estuviera ausente (ver Apéndice B). Esto trae como consecuencia que, si existiera un campo de radiación, como el que genera el propio shock, o como el del AGN, su influencia sobre el gas será mayor en este caso (Shapiro, Clocchiatti \& Kang 1992, A08).

La emisión proveniente del precursor fotoionizado dependerá de las características del campo ionizante generado en el shock. Cuanto mayor sea la velocidad del shock, mayor será la influencia de su campo de radiación sobre el precursor. Este campo es complejo, y está compuesto por emisión Bremsstrahlung y líneas resonantes provenientes de una amplia variedad de elementos y estados iónicos. La emisión de líneas de iones tipo H (conocidos como hidrogenoides; son los que han perdido todos excepto uno de sus electrones) y tipo He (iones que conservan dos electrones en órbita) es particularmente importante en el rango de rayos-X (Dopita \& Sutherland 1996). En la Figura 2.6 se muestran los campos de radiación generados por ondas de choque de distinta velocidad. Los modelos contemplan velocidades en el rango $10^{2}<v_{s}<10^{3} \mathrm{~km} \mathrm{~s}^{-1}$.

La presencia del campo magnético influye de forma directa en la emisión proveniente de la zona de recombinación, por el hecho de limitar la compresión del gas. DS95 y DS96 definieron el parámetro magnético como $B / n^{1 / 2}$ para contemplar el efecto conjunto del campo $B$ y la densidad $n$ sobre la compresión del gas postshock (ver Apéndice B). El rango de valores considerado es $10^{-4}<B / n^{1 / 2}<10^{2} \mu \mathrm{G} \mathrm{cm}{ }^{3 / 2}$.

La zona radiativa de una onda de choque (región postshock) está compuesta por regiones de diferentes características; se describen a continuación. La Figura 2.7 (tomada del trabajo original de A08) muestra cada una de estas regiones en la estructura de ionización del hidrógeno; el ejemplo corresponde a un shock de $500 \mathrm{~km} \mathrm{~s}^{-1}$, propagándose por un medio con abundancia solar, densidad $n=1 \mathrm{~cm}^{-3}$, y parámetro magnético $B / n^{1 / 2}=3.23$. La estructura se presenta de modo tal que el frente de choque está en el tiempo $t=0$. La región del gas chocado se indica en el rango $t>0$, y la zona precursora (donde todavía la onda no ha perturbado el gas), en el rango $t<0$. El eje de ordenadas representa la fracción de ionización $X_{\text {ion }}(\leq 1)$, la densidad del H y la temperatura $(\mathrm{K})$.

En general, estas regiones no pueden resolverse individualmente en un dado objeto y/o espectro, e incluso pueden no estar todas presentes, dependiendo de las condiciones del modelo particular (A08). Sin embargo la siguiente descripción (DS96, A08) es útil porque ayuda a

uales no pueden ser cuantificadas, pero la suma de sus energías coincide con la del fotón Ly $\alpha$. Por tal motivo, la emisión contribuye al continuo, y en la zona azul del espectro.

$\mathrm{El}$ átomo de $\mathrm{H}$, recién formado, puede alcanzar el estado $2 s$ mediante dos caminos. Por un lado, la captura del electrón puede producirse directamente al nivel $2 s$, o bien el electrón puede alcanzar este nivel como consecuencia de la cascada radiativa que se produce cuando es capturado en niveles superiores, y decae hacia el fundamental. Por otro lado, el átomo, en su estado fundamental, puede ser excitado radiativamente al nivel $2 p$ y luego ser desexcitado colisionalmente al nivel $2 s$. Si bien la probabilidad de que ocurra esta desexcitación colisional es muy baja, queda compensada por la gran cantidad de veces que el cuanto de radiación Ly $\alpha$ es dispersado dentro de la nebulosa hasta poder escapar de ella.

El proceso de emisión de dos fotones es un mecanismo secundario, pero cobra relevancia cuando en el MIE existen procesos de choque que contribuyen a la excitación colisional del gas (Spitzer \& Greenstein 1951; Brown \& Mathews 1970). 
Figura 2.6. Campos de radiación generados por ondas de choque.

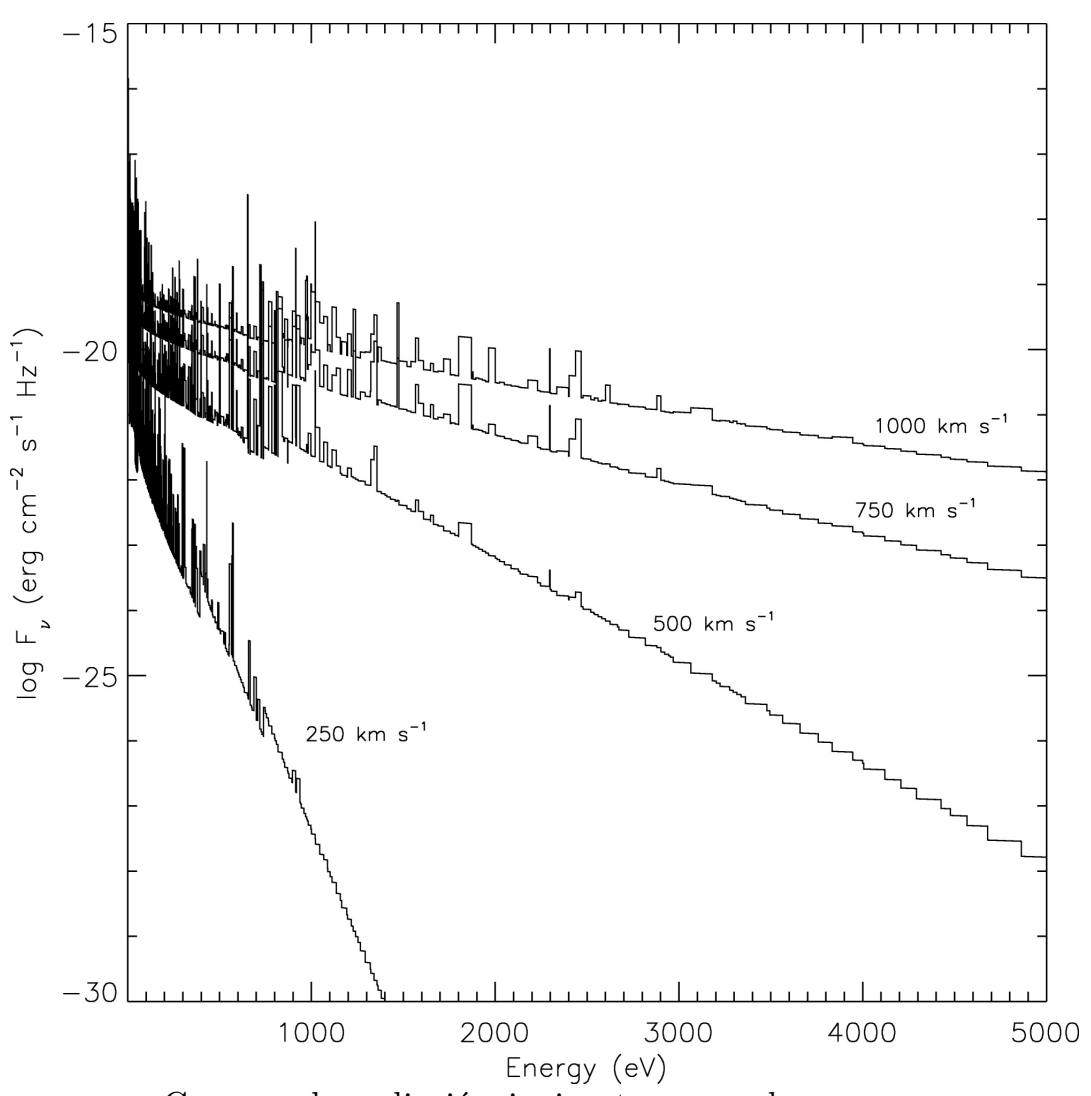

Campos de radiación ionizante generados en ondas de choque de distinta velocidad $(250,500,750$ y $1000 \mathrm{~km} \mathrm{~s}^{-1}$ ) propagándose por un medio con abundancia solar y densidad $n=1 \mathrm{~cm}^{-3}$. Figura tomada de Allen, Groves, Dopita, Sutherland \& Kewley (2008). 
comprender de dónde provienen las distintas contribuciones al espectro resultante.

1. Región de ionización. La temperatura del gas es muy alta; el estado de ionización es bajo, y la emisión de líneas es intensa.

2. Zona radiativa con temperatura alta. En esta zona se emite la mayor parte del flujo en las bandas de rayos-X blandos y UV extremo. La temperatura de la región es muy alta y por ende, la tasa de enfriamiento es baja. Aún así la mayor contribución al campo de radiación del shock se produce en esta zona.

3. Zona de enfriamiento fuera del equilibrio. La región tiene un estado de ionización más alto que el que correspondería a su temperatura. Se debe a que una vez que la temperatura baja de $10^{6} \mathrm{~K}$, la tasa de enfriamiento se vuelve muy alta y las escalas de tiempo de recombinación de un gran número de iones resultan más largas que la escala de tiempo de enfriamiento local. El gas es ópticamente delgado respecto del campo de radiación difuso creado en la zona previa.

4. Región super-enfriada. En esta región el plasma se torna ópticamente grueso respecto del campo ionizante creado por el shock. Es decir, en esta zona el gas es fotoionizado por ese campo. Sin embargo, inicialmente el estado de ionización es tan alto que la absorción de estos fotones no es eficiente (condición de continuidad respecto de la región anterior) y el gas continúa enfriándose hasta alcanzar temperaturas incluso por debajo de $10^{4} \mathrm{~K}$.

5. Región de fotoabsorción. Esta zona puede interpretarse como una región HiI muy delgada, en equilibrio, con estructura tipo plano-paralela, iluminada por el campo de fotones UV extremo creado en el frente de choque. También existe una zona de ionización parcial donde la temperatura es apenas mayor que $10^{3} \mathrm{~K}$; hasta aquí pueden penetrar los fotones más energéticos (rayos-X duros), desencadenando procesos de emisión secundarios.

En los modelos de fotoionización (Secciones 2.4.1 y 2.4.2), los parámetros más influyentes son el índice espectral $(\alpha)$, que se asocia con la dureza del campo de radiación incidente y el parámetro de ionización $(U)$. En los modelos MHD de shocks autoionizantes (fotoionizantes), los parámetros que controlan la apariencia del espectro emergente son la velocidad del shock $\left(v_{s}\right)$ y el parámetro magnético $\left(B / n^{1 / 2}\right)$. La velocidad $v_{s}$ determina la cantidad de fotones UV-X creados localmente por el shock (en otras palabras, la dureza del campo ionizante local; ver Fig. 2.6.), y el parámetro magnético controla el parámetro de ionización efectivo en la zona de recombinación (A08).

Los modelos ${ }^{12}$ están desarrollados de manera tal que es posible estudiar la emisión proveniente únicamente de la zona de recombinación (las cinco zonas descriptas anteriormente), o de la suma de los efectos producidos por la zona de recombinación y el precursor. Para diferenciar un escenario del otro, se suele llamar shocks al primero de ellos, y shocks autoionizantes al segundo. La librería que reúne al conjunto de modelos está organizada en dos bloques:

- un grupo de modelos con densidad $n=1 \mathrm{~cm}^{-3}$ que difieren en el conjunto de abundancias adoptado: 1) ab. solar reducida y 2) ab. solar doble, ambas tomadas según DS96; 3) ab. solar (DS95, y sus referencias); 4) ab. de la Nube Mayor de Magallanes (LMC) y 5) ab. de la

\footnotetext{
${ }^{12} \mathrm{La}$ librería completa de modelos de shocks (emisión proveniente de la zona de recombinación) y shocks autoionizantes (la emisión proviene tanto de la zona de recombinación como del precursor) está disponible en los sitios web http://www.ifa.hawaii.edu/ kewley/Mappings/ y http://cdsweb.u-strasbg.fr/ allen/mappings_page1.html
} 
Figura 2.7. Estructura de ionización en ondas de choque.

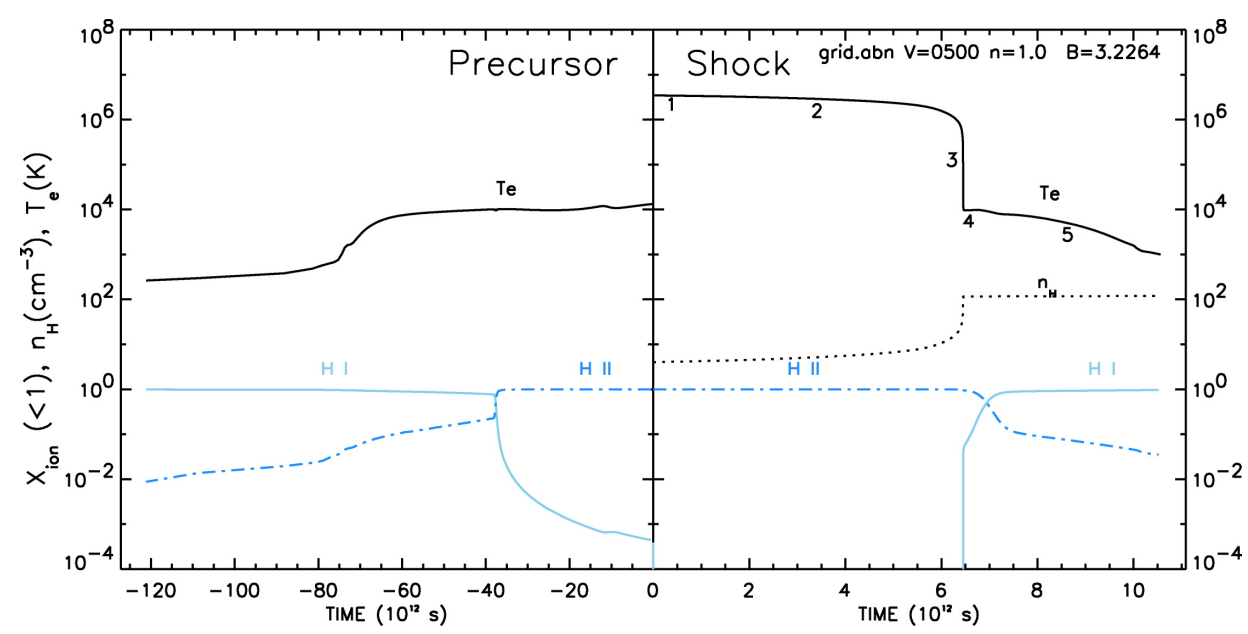

Estructura de ionización del $\mathrm{H}$ para una onda de choque de $500 \mathrm{~km} \mathrm{~s}^{-1}$, propagándose por un medio con abundancia solar, densidad $n=1 \mathrm{~cm}^{-3}$, y parámetro magnético $B / n^{1 / 2}=3.23$. Absisas: $t>0$ indica el gas chocado (las etiquetas numeradas identifican cada una de las regiones que componen la estructura del shock; ver texto), y $t<0$ la región precursora; el sistema de referencia así planteado es solidario al frente de choque, que se encuentra en $t=0$. Figura tomada de Allen, Groves, Dopita, Sutherland \& Kewley (2008).

Nube Menor de Magallanes (SMC), ambas tomadas según Russell \& Dopita (1992).

- un grupo de modelos con abundancia solar (DS96), que diferencian por la densidad adoptada en el gas preshock: 1) $n=10^{-2} \mathrm{~cm}^{-3}$;2) $n=10^{-1} \mathrm{~cm}^{-3}$; 3) $n=1 \mathrm{~cm}^{-3}$, este es el único modelo que se encuentra en ambos bloques; 4) $n=10 \mathrm{~cm}^{-3}$; 5) $n=100 \mathrm{~cm}^{-3}$; y 6 ) $n=1000 \mathrm{~cm}^{-3}$.

El rango de velocidades y del parámetro magnético es igual para todos.

La implementación también se realiza a través de diagramas de diagnóstico, lo que equivale a decir que, para un dado diagrama, las zonas que ocupan los distintos modelos dependen de los parámetros físicos involucrados. Uno de los resultados destacables de los trabajos de DS95 y A08 fue mostrar que los shocks y los shocks autoionizantes ocupan regiones diferentes en ciertos diagramas. Por lo tanto es posible inferir si la emisión proveniente de un determinado objeto (región en emisión) es producto únicamente del proceso de choque, o si ese proceso ha sido lo suficientemente violento (velocidad alta) como para que el proceso de choque haya adquirido, también, poder de ionización.

En el desarrollo de este trabajo (Capítulo 6) se utilizará el bloque de modelos con abundancia solar, a menos que para algún objeto existan antecedentes en la literatura que permitan utilizar otro conjunto de abundancias. Dado que los modelos de fotoionización multifase también se implementan mediante la misma clase de diagramas, la comparación entre modelos a través de ellos resulta ciertamente práctica. Sin embargo, se harán comparaciones directas siempre que el conjunto de parámetros involucrados lo permita, particularmente en lo que concierne a la densidad del medio. 


\section{Capítulo 3}

\section{Sobre los objetos.}

\subsection{Introducción}

Los objetos astronómicos que se estudian en esta Tesis son galaxias activas cuya emisión en la banda de radio es muy intensa (radio-loud). La recopilación más completa de esta clase de objetos se encuentra en el Tercer Catálogo de Cambridge, 3C, (Edge et al. 1959) y sus revisiones: 3CR (Bennett 1962a,b) y 3CRR (Laing et al. 1983).

El catálogo $3 \mathrm{C}$ es el resultado de un relevamiento realizado con el interferómetro de Cambridge (Reino Unido de Gran Bretaña) en la frecuencia de $159 \mathrm{MHz}$, cuyos resultados se publicaron en 1959 (Edge et al. 1959). Consta de 471 radiofuentes con densidad de flujo mayor que $8 \mathrm{Jy}^{1}$ localizadas en el rango de declinación $-22^{\circ}<\delta<71^{\circ}$. Los objetos se denominan como 3C nnn, donde la correlación del número nnn está dada por la ascención recta del objeto. La primer revisión del catálogo 3C, realizada en 1962 (Bennett 1962b), lleva el nombre de 3CR. Las radiofuentes de este catálogo tienen densidades de flujo mayores que 9 Jy observadas en la frecuencia de $178 \mathrm{MHz}$, y sus declinaciones son $\delta>-5^{\circ}$. Con la aparición de este catálogo algunas fuentes $3 \mathrm{C}$ fueron eliminadas (por ejemplo, los remanentes de supernova) y otras incorporadas. Muchas incorporaciones se debieron al mejoramiento de la capacidad de resolución, con lo cual se detectaron más de un objeto asociados al mismo número de catálogo. Las denominaciones decimales (3C nnn.d) reflejan estas incorporaciones. Una última revisión del catálogo de realizó en 1983 (Laing et al. 1983), y se llamó 3CRR. El catálogo está compuesto de 173 radiofuentes extragalácticas, con densidad de flujo mayor a 10.9 Jy en $178 \mathrm{MHz}$. La declinación fue nuevamente restringida; los objetos tienen declinaciones $\delta>10^{\circ}$, pero para evitar la emisión de la Vía Láctea también se restringió la latitud galáctica $(\lambda)$, quedando sólo aquellos objetos para los cuales $|\lambda|>10^{\circ}$. En esta etapa también se realizó la identificación de la contraparte óptica de cada fuente.

Las radiofuentes extragalácticas extendidas (radiogalaxias) admiten una clasificación estructural bimodal basada en su morfología, que muestra una muy buena correlación con la potencia emitida en radiofrecuencias. El trabajo original de Fanaroff \& Riley (1974) establece una división entre galaxias tipo I y tipo II (a partir de entonces se las llamó FRI y FRII, con las iniciales de los autores del trabajo). Los objetos FRI son aquellos cuya máxima intensidad se observa en la parte interna de los lóbulos, es decir, la emisión se concentra en los alrededores de la radiofuente puntual (el core central) cuya ubicación coincide con la identificación óptica de la galaxia anfitriona. En los objetos FRII, en cambio, la máxima intensidad de la emisión se observa en los extremos externos de los lóbulos, siendo (en general, pero no siempre) la parte más alejada del core central. Los sitios donde la radiación sincrotrón alcanza su máximo

\footnotetext{
${ }^{1}$ Jy es la abreviatura de Jansky. Las medidas de flujo monocromático en la banda de radio se expresan en esta unidad. En el Sistema Internacional (SI) equivale a $10^{-26} \mathrm{~W} \mathrm{~m}^{-2} \mathrm{~Hz}^{-1}=10^{-26} \mathrm{Joules} \mathrm{s}^{-1} \mathrm{~m}^{-2} \mathrm{~Hz}^{-1}$.
} 
Tabla 3.1. Objetos de estudio de este trabajo.

\begin{tabular}{lccccccc}
\hline \hline Nombre & $\alpha_{J 2000.0}$ & $\delta_{J 2000.0}$ & $\mathrm{z}$ & $\mathrm{M}_{V}$ & $\mathrm{~S}_{178}$ & $\mathrm{D}(\mathrm{Mpc})$ & Escala (kpc/") \\
\hline 3C 184.1 & 7h 43m 1.4s & $80^{\circ} 26^{\prime} 26^{\prime \prime}$ & 0.1182 & 17 & 14.2 & 529 & 2.35 \\
3C 196.1 & 8h 15m 27.8s & $-3^{\circ} 8^{\prime} 27^{\prime \prime}$ & $0.198^{*}$ & 16.94 & 18.6 & 938 & 3.94 \\
3C 268.2 & 12h 00m 59.1s & $31^{\circ} 33^{\prime} 28^{\prime \prime}$ & $0.362^{*}$ & $19(\mathrm{~B})$ & 9.7 & 1873 & 7.23 \\
3C 268.3 & 12h 06m 24.7s & $64^{\circ} 13^{\prime} 37^{\prime \prime}$ & 0.3717 & 20.79 & 10.7 & 1928 & 7.4 \\
3C 284 & 13h 11m 4.7s & $27^{\circ} 28^{\prime} 7^{\prime \prime}$ & 0.2398 & 18 & 12.3 & 1160 & 4.8 \\
3C 285 & 13h 21m 17.9s & $42^{\circ} 35^{\prime} 15^{\prime \prime}$ & 0.0794 & 16.23 & 11.3 & 349 & 1.61 \\
3C 303.1 & 14h 43m 14.5s & $77^{\circ} 77^{\prime} 28^{\prime \prime}$ & $0.2704^{*}$ & $19(\mathrm{~B})$ & 8.1 & 1329 & 5.39 \\
3C 305 & 14h 49m 21.6s & $63^{\circ} 16^{\prime} 14^{\prime \prime}$ & 0.0416 & 16.39 & 15.7 & 177 & 0.851 \\
3C 321 & 15h 31m 43.5s & $24^{\circ} 44^{\prime} 19^{\prime \prime}$ & 0.0961 & $16(\mathrm{~B})$ & 14.7 & 426 & 1.95 \\
3C 381 & 18h 33m 46.3s & $47^{\circ} 27^{\prime} 3 "$ & 0.1605 & 17.24 & 18.1 & 737 & 3.2 \\
\hline \hline
\end{tabular}

Notas: Se indica la magnitud $M_{B}$ en los casos en donde no estaba disponible $M_{V}$. La densidad de flujo $S_{178}$ está medida a la frecuencia de $178 \mathrm{MHz}$. La distancia $D$ se expresa en Mpc. Todos los corrimientos al rojo listados corresponden a los resultados de NED; algunos de ellos están marcados con $*$ para indicar que son diferentes de los valores obtenidos con nuestros espectros (ver Capítulo 5).

brillo superficial se denominan hot spots. En la mayoría de los casos el contraste de los hot spots con el resto de la estructura facilita la clasificación, pero en casos menos evidentes el criterio original (Fanaroff \& Riley 1974) resulta mucho más útil: si la separación entre los hot spots es menor que la mitad del máximo tamaño de la fuente, ésta se clasifica como FRI; en cambio, si tal separación es mayor que la mitad del máximo tamaño de la fuente, ésta se clasifica como FRII. Existe otra diferencia en cuanto a los jets (la radiación sincrotrón que emerge de la fuente puntual en forma colimada y en direcciones opuestas): en las galaxias FRI los jets son visibles, mientras que en las FRII no. El punto interesante de esta clasificación radica en que la separación, enteramente morfológica, también divide a los objetos de acuerdo a la potencia de la radiación sincrotrón emitida. La mayoría de los objetos cuya emisión está por debajo de $P_{\text {lim }} \simeq 10^{25} \mathrm{~W} \mathrm{~Hz}^{-1} \mathrm{sr}^{-1}$ son FRI, mientas que la mayoría de los objetos cuya emisión está por encima de $P_{\text {lim }}$ son FRII.

Las radiogalaxias que estudiaremos en este trabajo son radiofuentes de tipo FRII, que pertenecen al catálogo 3C y/o sus revisiones 3CR y 3CRR.

\subsection{Telescopio Espacial Hubble: Las imágenes.}

Los objetos seleccionados para este trabajo se encuentras listados en la Tabla 3.1. El criterio de selección se explicará en la Sección 3.2.1. La Tabla reune las coordenadas ecuatoriales J2000.0, corrimiento al rojo (z), magnitud visual ( $M_{V}$; se indica la magnitud $B$ entre paréntesis cuando $V$ no está disponible), densidad de flujo (Laing et al. 1983; Spinrad et al. 1985; Hardcastle et al. 1997) medida a la frecuencia de $178 \mathrm{MHz}\left(S_{178}\right.$, en Jy), distancia ( $D$, en Mpc) y escala (en kpc/") ${ }^{2}$. Estos últimos parámetros fueron obtenidos de las bases de datos NED (NASA-IPAC Extragalactic Database) y SIMBAD (Set of Identifications, Measurements, and Bibliography for Astronomical Data).

Las observaciones realizadas con el Telescopio Espacial Hubble (HST) (de Koff et al. 1996; McCarthy et al. 1997) evidenciaron la presencia de regiones de gas ionizado en las cercanías de estas radio galaxias. En la literatura, se las conoce con el nombre de Regiones Extendidas

\footnotetext{
${ }^{2} \mathrm{H}_{0}=73 \mathrm{~km} \mathrm{~s}^{-1} \mathrm{Mpc}^{-1} ; \Omega_{\text {mat }}=0.27 ; \Omega_{\Lambda}=0.73$
} 
Tabla 3.2. WFPC2/HST: filtros.

\begin{tabular}{lcc}
\hline \hline Filtro & $\lambda_{0}$ & $\Delta \lambda$ \\
\hline FR533N & 5400 & 55 \\
FR680N & 6800 & 70 \\
F702W & 6895 & 1389 \\
F555W & 5407 & 1236 \\
\hline \hline
\end{tabular}

Notas: Parámtros característicos de los filtros usados en la WFPC2 (longitud de onda central y ancho de banda, en $\AA$ ). Se listan sólo aquellos filtros utilizados en los programas de observación citados en el texto, que revisten interés para nuestro trabajo.

con Emisión de Líneas (EELR, su sigla en inglés), que hace referencia tanto a su localización, a grandes distancias del núcleo, como a su huella espectral característica, la emisión nebular. La extensión de las EELR en las imágenes del HST suele ser mucho mayor que la de la componente estelar.

\subsubsection{Selección de la muestra. I.}

Las galaxias del Catálogo $3 \mathrm{C}^{3}$ fueron observadas con el Telescopio Espacial Hubble (HST) en distintas oportunidades; algunas formaron parte de diferentes programas, y se observaron con todas las cámaras disponibles en el telescopio, sin embargo la observación sistemática de las galaxias 3C se realizó sólo con la cámara WFPC2 (Wide Field and Planetary Camera 2). Estos datos, pertenecientes al archivo del HST y a los programas de observación que se mencionan a continuación, son los que se utilizaron para seleccionar los objetos que componen el presente estudio:

- Continuum Snapshot of the 3CR Radio Galaxies. ID: 5476, IP ${ }^{4}$ : W. Sparks, Ciclo 4.

- Snapshot of the 3CR Radio Galaxies. ID: 5957, IP: W. Sparks, Ciclo 5.

- Blue Continuum Snapshot of 3CR Radio-Continued Galaxies. ID: 6967, IP: W. Sparks, Ciclo 6.

- Optical Emission in Double Radio Galaxy Lobes. ID: 5156, IP: P. Crane, Ciclo 4.

Las imágenes se tomaron con dos tipos de filtro: un filtro de banda ancha y un filtro rampa de banda angosta. Los filtros se caracterizan por la longitud de onda central $\left(\lambda_{0}\right)$, como indicador de la región del espectro donde su eficacia es máxima, y el ancho de banda $(\Delta \lambda)$ de la transmisión. La Tabla 3.2 muestra los parámetros de los filtros que se emplearon para obtener las imágenes que se presentarán a continuación.

Con los filtros de banda ancha se obtiene una imagen de la estructura de la galaxia, dominada por su componente estelar. Sin embargo, como el ancho de banda es muy grande

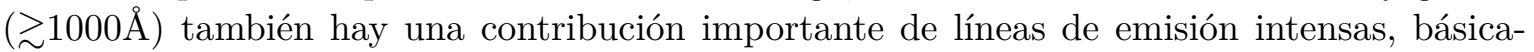
mente $\mathrm{H} \alpha, \mathrm{H} \beta$ y [OIII] $\lambda 5007$. En la Figura 3.1 se muestra la curva de transmisión del filtro F702W, junto con la posible contribución de emisión de líneas dentro de un rango de corrimientos al rojo $(z)$ de $0.1<z<0.5$.

\footnotetext{
${ }^{3}$ En adelante, nos referiremos al Catálogo 3C en forma general, sin especificar la etapa de revisión

${ }^{4}$ Investigador Principal del programa de observación
} 
Figura 3.1. Curva de transmisión del filtro F702W.

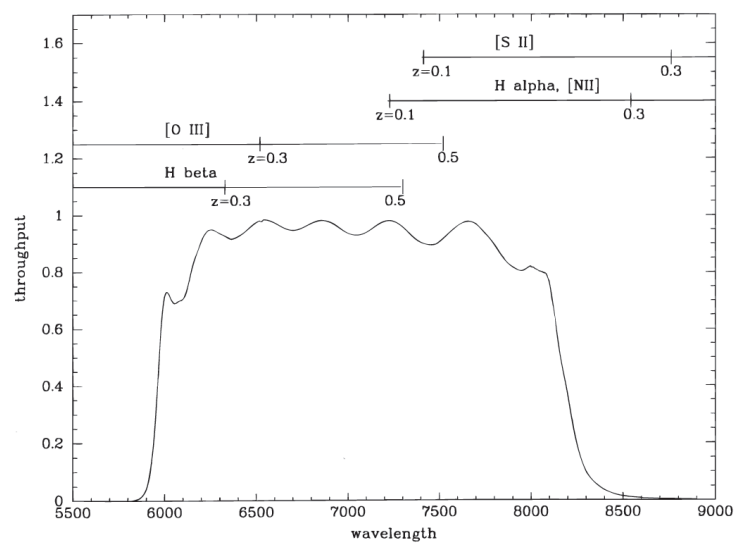

La presencia de las líneas de emisión dependen del corrimiento al rojo $z$. Este esquema es válido en el rango $0.1<z<0.5$ (de Koff et al. 1996).

El filtro rampa, en cambio, está diseñado para ser eficiente en un rango muy acotado de longitud de onda, permitiendo obtener la emisión ${ }^{5}$ aislada de una pequeña región del espectro. En todos los casos que estudiaremos aquí esta herramienta se utilizó para obtener un mapa de la componente nebular mediante la emisión del [OIII] $\lambda 5007$; en otros casos, que dependen exclusivamente del corrimiento al rojo del objeto, el filtro rampa se adecuó a la longitud de onda del [OII] $\lambda 3727$ o de $\mathrm{H} \alpha$. Los filtros rampa están divididos en cuatro bandas paralelas, donde $\lambda_{0}$ varía aproximadamente un $6 \%$ en cada una de ellas. Luego, dada la disposición de los CCD del detector en la WFPC2, es posible que para obtener una imagen en una $\lambda_{0}$ determinada (acotada dentro de los límites establecidos por $\Delta \lambda$ ) sea necesaria una rotación del filtro. Este hecho se ilustra en la Figura 3.2, con los valores correspondientes al filtro FR533N. En el panel superior se muestra el "mapa" del filtro en su posición nominal (inclinación nula), superpuesto al esquema del detector de la cámara. Se ve que la región superior derecha del filtro, donde se espera obtener la emisión comprendida entre $\sim 5500 \mathrm{y}$ $\sim 5900 \AA$, se encuentra en una posición que el detector no puede cubrir. Por tal motivo, el filtro puede rotarse de forma tal de hacer coincidir la región de interés del filtro con la zona de detección. En el panel inferior se muestra el mismo esquema cuando el filtro se encuentra rotado en $33^{\circ}$. Un filtro rampa se trata de una herramienta sintonizable, donde la imagen resultante se obtiene mediante una combinación entre la región de eficacia del filtro $\left(\lambda_{0}-\Delta \lambda\right)$, el redshift del objeto que se observa (que determina el desplazamiento que sufre la radiación que se pretende detectar), y el diseño del detector de la WFPC2, que puede implicar una rotación del filtro para detectar, efectivamente, el objeto.

En la Tabla 3.3 se indican la fecha de observación, filtros y tiempos de exposición $\left(\mathrm{T}_{\text {exp }}\right)$ empleados en las observaciones de las galaxias seleccionadas; también se indica el número de identificación del programa de observación (ID). Si el filtro rampa fue rotado, el ángulo de rotación se agrega al final del nombre del filtro (es decir, FR680N18 es el filtro FR680N, rotado en $\left.18^{\circ}\right)$.

\footnotetext{
${ }^{5}$ El filtro también puede ser empleado para obtener información sobre la absorción de una fuente. Aquí nos concentraremos sólo en lo que a emisión se refiera.
} 
Tabla 3.3. WFPC2/HST: datos de archivo.

\begin{tabular}{l|cccc}
\hline \hline Objeto & Fecha obs. & $\mathrm{T}_{\exp }$ & Filtro & ID \\
\hline 3C 184.1 & Ago 1995 & $300(2)$ & FR533N18 & 5957 \\
& Sep 1994 & $140(2)$ & F702W & 5476 \\
\hline 3C 196.1 & Feb 1996 & $300(2)$ & FR533N & 5957 \\
& Feb 1994 & $140(2)$ & F702W & 5476 \\
\hline 3C 268.2 & Jun 1996 & $300(2)$ & FR680N18 & 5957 \\
& May 1996 & 300 & F702W & 5476 \\
\hline 3C 268.3 & Ago 1995 & $300(2)$ & FR680N18 & 5957 \\
& Oct 1994 & 300 & F702W & 5476 \\
& May 1995 & 300 & F702W & 5476 \\
\hline 3C 284 & Dic 1995 & $300(2)$ & FR680N & 5957 \\
& Ago 1994 & $140(2)$ & F702W & 5476 \\
\hline 3C 285* & Feb 1994 & $600(2)$ & F702W & 5156 \\
& Jun 1996 & $300(2)$ & F555W & 6967 \\
\hline 3C 303.1 & Ago 1995 & $300(2)$ & FR680N & 5957 \\
& Mar 1994 & 300 & F702W & 5476 \\
\hline 3C 305 & Oct 1995 & $300(2)$ & FR533N & 5957 \\
& Sep 1994 & $140(4)$ & F702W & 5476 \\
\hline 3C 321 & Ago 1995 & $300(2)$ & FR 533N18 & 5957 \\
& Abr 1995 & $140(2)$ & F702W & 5476 \\
\hline 3C 381 & Ago 1995 & $300(2)$ & FR533N33 & 5957 \\
& Feb 1995 & $140(2)$ & F702W & 5476 \\
\hline \hline
\end{tabular}

Notas: La cantidad de exposiciones, cuando hubo más de una, se indican entre paréntesis en la columna $\mathrm{T}_{\text {exp. }}\left(^{*}\right) 3 \mathrm{C} 285$ es la única galaxia en nuestra muestra para la cual no se tomaron imágenes nebulares con la cámara WFPC2 (ver texto). 
Figura 3.2. Esquema de la configuración de un filtro rampa.

FR533N

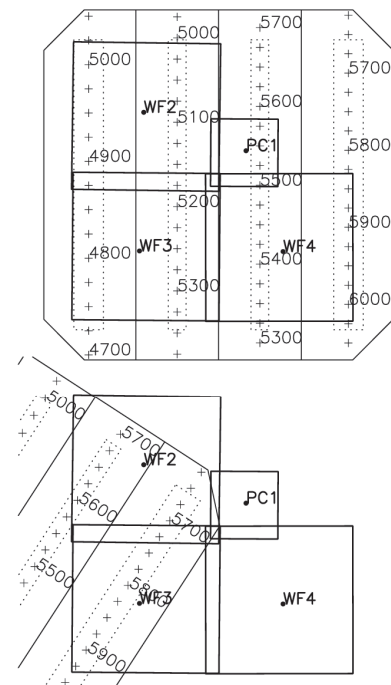

Imagen tomada del Wide Field and Planetary Camera 2 Instrument Handbook.

Los datos fueron procesados con el paquete de tareas STSDAS (Space Telescope Science Data Analysis) dentro IRAF (NOAO Image Reduction and Analysis Facility) siguiendo el procedimiento estándar para la cámara WFPC2, cuya discución completa se encuentra en Martel et al. (1999). Las galaxias de la Tabla 3.1 fueron seleccionadas en base a los mapas de emisión nebular pura, esto es, las imágenes del filtro rampa, corregidas por la contribución del continuo. La estimación de la contribución del continuo en cada objeto se realiza a través de la imagen de banda ancha (F702W en la mayoría de los casos). El continuo se normaliza de acuerdo a la longitud de onda del filtro rampa ([OIII $] \lambda 5007$ en todos los objetos de nuestra muestra) suponiendo la emisión de un cuerpo negro a $3000 \mathrm{~K}$ (Biretta et al. 2002), y luego se le resta a la imagen del filtro rampa. El resultado de este procedimiento puede verse en las imágenes de la WFPC2 publicadas por Biretta et al. (2002) y Privon et al. (2008), incluso un mecanismo similar se empleó para corregir otras imágenes de galaxias $3 \mathrm{C}$ tomadas con la cámara ACS (Tremblay et al. 2009).

De todas las galaxias 3C observadas con HST, se seleccionaron aquellas cuya emisión nebular fuera significativa, ya sea por su brillo superficial o por la distribución espacial del gas. Asimismo, se estableció un compromiso entre la extensión de la EELR y su brillo superficial, dado que el objetivo principal estaba enfocado en obtener el espectro de la región con información espacial valiosa (Sección 3.3). La calidad de las imágenes HST garantizaba una relación señal-ruido $(\mathrm{S} / \mathrm{N})$ alta en los espectros que se tomarían con el Telescopio Gemini, por lo cual el factor determinante fue la extensión de la EELR. Como regla general, se tomaron espectros de aquellas galaxias cuya EELR tuviera una extensión mayor que $\sim 2$ " en su respectiva imagen nebular pura.

Las galaxias 3C 196.1 y 3C 285 merecen un párrafo aparte. La región de emisión asociada a 3C 196.1 en las imágenes WFPC2 es muy pequeña y morfológicamente no presenta ninguna singularidad, como sí revelan las imágenes WFPC2 de los demás objetos. En el caso de 
3C 285 directamente no se tomaron imágenes nebulares (con ningún filtro) con esta cámara. Sin embargo, ambas radiogalaxias fueron obervadas con la cámara ACS (Advanced Camera for Surveys) con tres filtros rampa, uno para observar la emisión del continuo y otros dos para detectar emisión en [OIII] $\lambda 5007$ y H $\alpha$. El relevamiento completo fue presentado en Tremblay et al. (2009). A partir de esas imágenes fue posible encontrar regiones de gas ionizado muy extensas y morfológicamente peculiares, asociadas a estos dos objetos. Por lo tanto ambos se incorporaron a la muestra no como consecuencia de nuestro análisis sobre los datos de la WFPC2 sino a raíz del relevamiento de Tremblay et al.

Según este criterio la muestra está compuesta por diez objetos, pero no todos ellos evidencian algún tipo de relación entre las EELR y las estructuras observadas en radio. En muchos casos las EELR están en la misma dirección del jet, en otros casos se ve una relación más notoria con los lóbulos, y en otros no es posible establecer una relación directa. Para ilustrar este aspecto, en las Figuras 3.12 a 3.8 se reunen las imágenes ópticas del HST y las de radio, tomadas de datos de archivo de MERLIN (Multi-Element Radio Linked Interferometer Network) o VLA (Very Large Array). Las coordenadas están expresadas en el sistema J2000.0; la frecuencia a la que corresponde cada imagen en radio se indica en el respectivo epígrafe. Las Figuras están organizadas de la siguiente manera (con la excepción de aquellos objetos para los cuales alguno de los datos no se encuentran disponibles):

- en el panel superior izquierdo se muestra la imagen tomada con el filtro F702W. En esta imagen puede verse la estructura de la galaxia, dada por la distribución y extensión de su componente estelar.

- en el panel superior derecho se muestra la imagen nebular pura (EELR) en [OIII] $\lambda 5007$. El filtro utilizado depende del redshift del objeto; están especificados en la Tabla 3.3. Se han superpuesto las isofotas para enfatizar la estructura de la región. La dirección del jet, que se indica en el ángulo inferior derecho en cada caso, se obtuvo de de Koff et al. (1996).

- el panel inferior izquierdo muestra la radiofuente completa, la frecuencia y escala son diferentes en cada caso (ver efígrafes). La región amarilla señala la zona ampliada en el siguiente panel.

- el panel inferior derecho se muestra sólo la región donde se superpone la emisión en ambas bandas del espectro. La imagen en ondas de radio corresponde a la sección delimitada en el panel inferior izquierdo. Se usó la misma imagen de la EELR que en el panel superior derecho.

\subsection{Telescopio Gemini: Los espectros.}

La observación de las EELR desde Tierra está limitada a los telescopios de mayor porte. Por esta razón, los espectros de estas regiones se tomaron con el Telescopio Gemini de $8.1 \mathrm{~m}$ de diámetro, y debido a su declinación, todos se observaron con el Telescopio Gemini Norte (TGN). Este telescopio está ubicado a $4200 \mathrm{~m}$ sobre el nivel del mar, en la cima de Mauna Kea ${ }^{6}$ el volcán más importante de la isla de Hawaii, tanto por su tamaño y como por su carga cultural.

Las observaciones pertenecen al programa denominado Searching for evidence of jet-cloud interaction in radiogalaxies. El programa se completó en los siguientes turnos de observación:

\footnotetext{
${ }^{6}$ En la mitología hawaiiana, las islas que forman el archipiélago donde se encuentra Hawaii son los hijos de Wakea, el Padre-Cielo, y Papahanaumoku, la Madre-Tierra. Hawaii es el mayor de sus hijos, y Mauna Kea representa su ombligo. La montaña también se conoce como Mauna a Wakea, que significa "la montaña de Wakea", y a su vez, en la genealogía de la tribu hawaiiana, Mauna Kea es un ancestro. Por tales motivos, se trata de un lugar sagrado al cual sólo los jefes tribales tenían acceso. El asentamiento de los actualmente trece telescopios en el sitio ha sido siempre un motivo de conflicto cultural. (www.mauna-a-wakea.info;www.piccom.org)
} 
Figura 3.3. 3C 184.1. Imágenes de HST y VLA
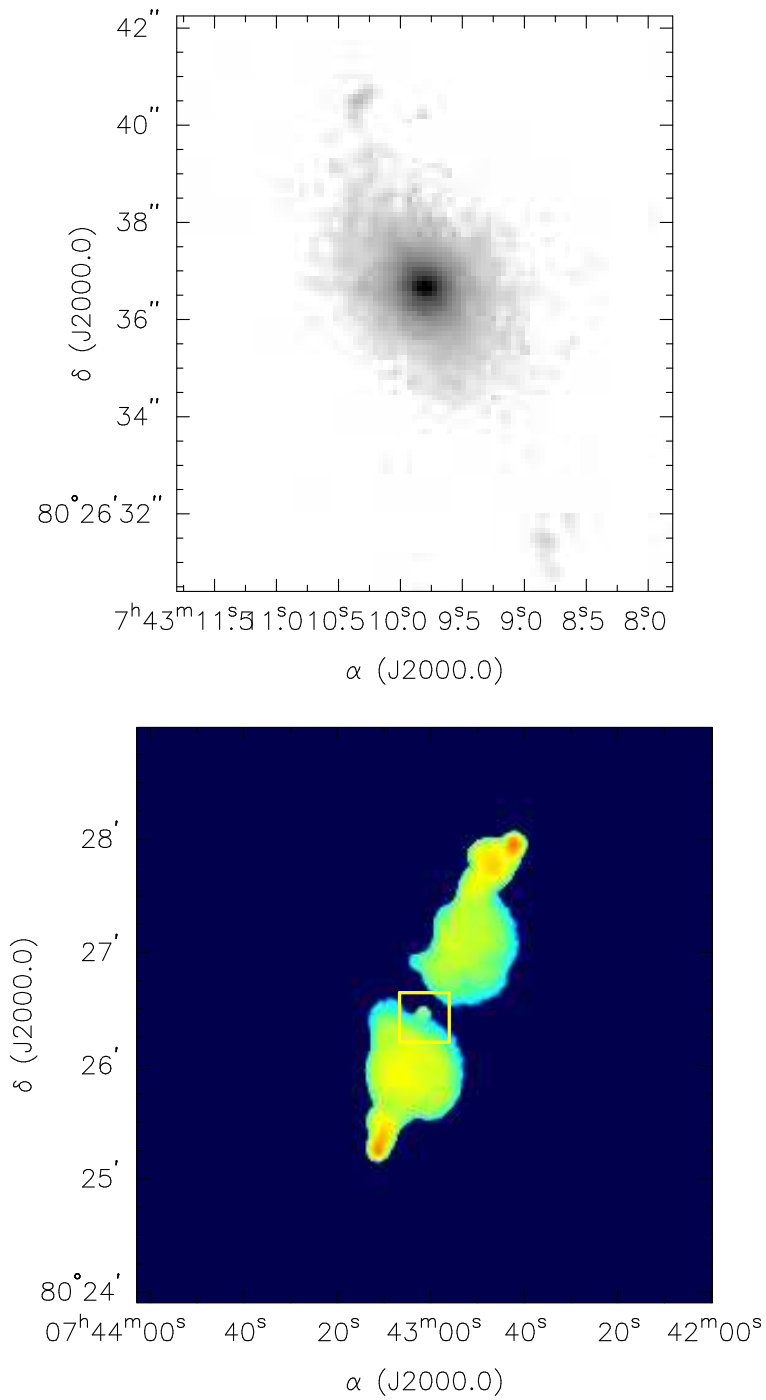

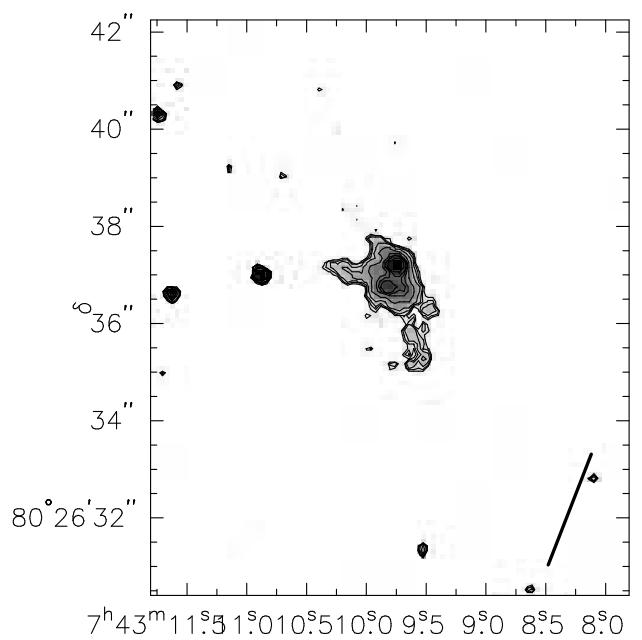

$\alpha$

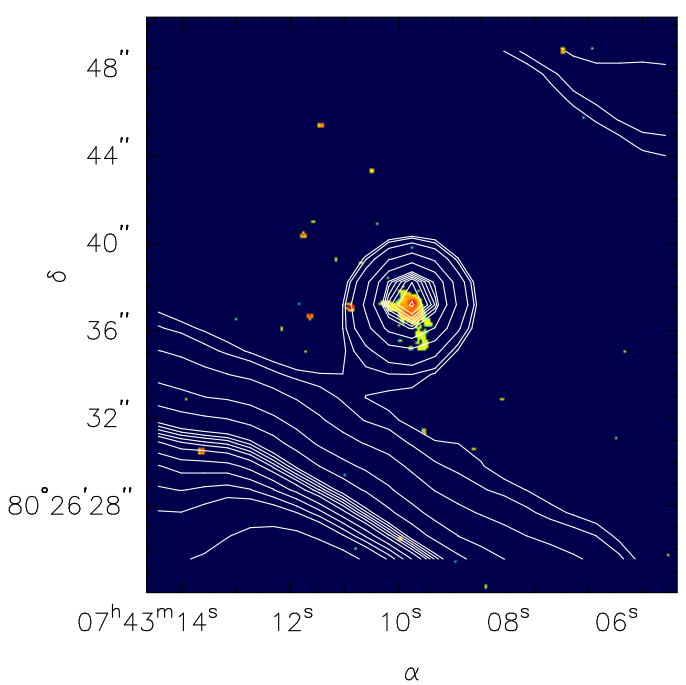

Izquierda: Componente estelar. Derecha: EELR. Los contornos representan el 3, 4, 5, 6, 11, 17, 22, 26 y $39 \%$ del máximo de intensidad en la región central. Se indica la dirección del jet. Abajo izquierda: Imagen de archivo VLA, en $1477 \mathrm{MHz}, 307.2 " \times 307.2 "$ (Leahy \& Perley 1991). Abajo derecha: superposición radio-óptico. La imagen corresponde a la sección marcada en panel anterior. 
Figura 3.4. 3C 196.1. Imágenes de HST
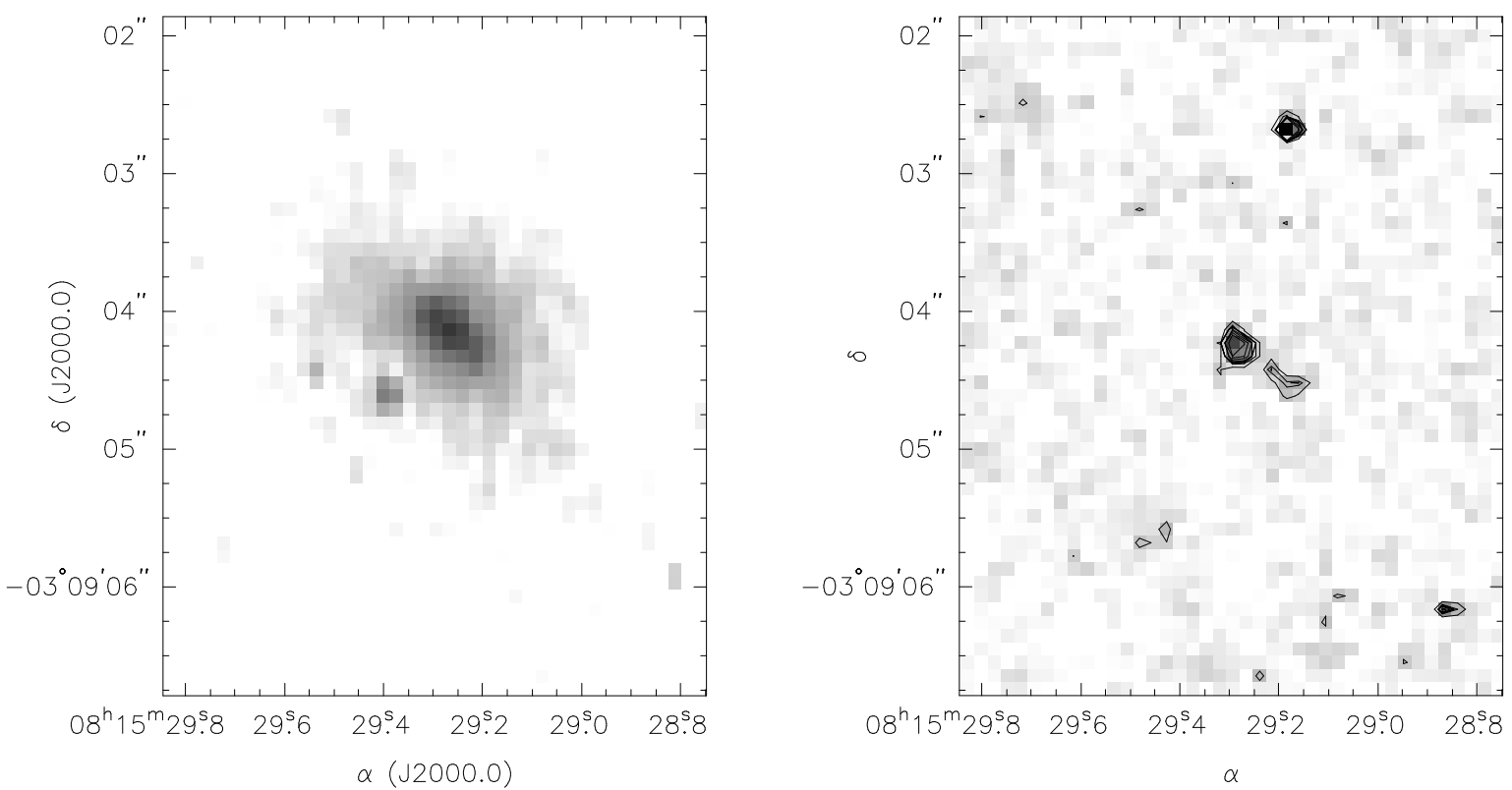

Izquierda: Componente estelar. Derecha: EELR. Los contornos representan el 5, 7, 10, 18, y $22 \%$ del máximo de intensidad en la región central. Comparar esta imagen con las imágenes nebulares en H $\alpha$ y [OIII] $\lambda 5007$ tomadas con la cámara ACS en Tremblay et al. (2009). Hay contradicciones en la literarura en cuanto a la presencia de jets. Según de Koff et al. (1996) el ángulo de posición es de $43^{\circ}$. Las imágenes disponibles en radio pueden consultarse en Neff et al. (1995); Massaro et al. (2012) (ver Capítulo 5). 
Figura 3.5. 3C 268.2. Imágenes de HST y VLA
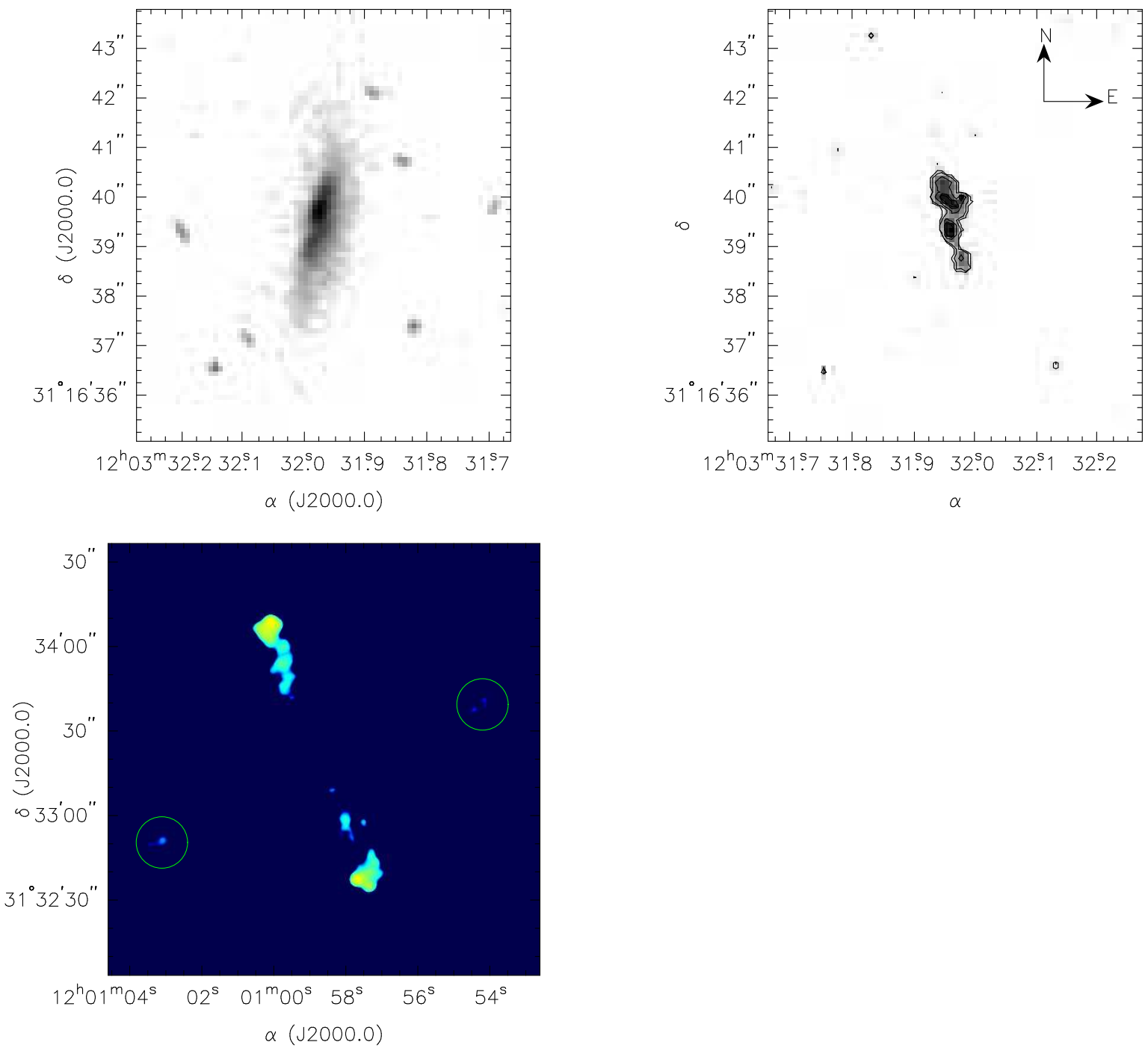

Arriba izquierda: Componente estelar. Arriba derecha: EELR. Los contornos representan el 16, 22, 43, 65 y $76 \%$ del máximo de intensidad en la región central. Los puntos cardinales E-O están alternados debido a un error en el archivo original. Abajo: Imagen de archivo VLA, en $1527 \mathrm{MHz}, 156$ " $\times 156$ " (Neff, Roberts \& Hutchings 1995). Los círculos verdes a cada lado de la imagen señalan regiones que no pertenecen a la radiofuente. La superposición óptico-radio no fue posible por la diferencia en los puntos cardinales. 
Figura 3.6. 3C 268.3. Imágenes de HST y MER-

LIN
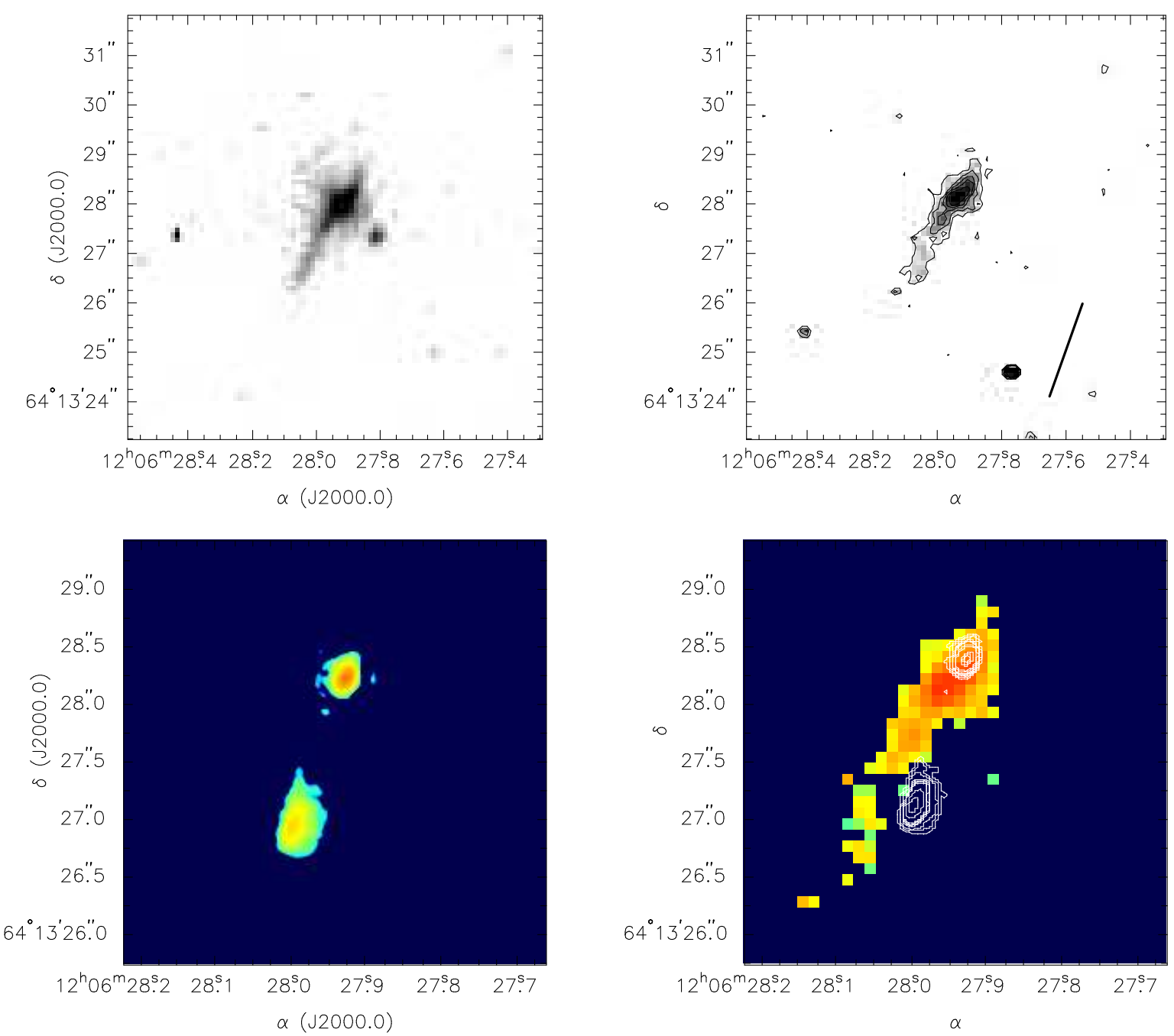

Arriba izquierda: Componente estelar. Arriba derecha: EELR. Los contornos representan el 11, 22, 33, 44 y $67 \%$ del máximo de intensidad en la región central. Se indica la dirección del jet. Abajo izquierda: Imagen de archivo MERLIN, en $4995 \mathrm{MHz}, 3.8$ "×3.8" (Lüdke et al. 1998). Abajo derecha: superposición radio-óptico. 
Figura 3.7. 3C 284. Imágenes de HST y VLA
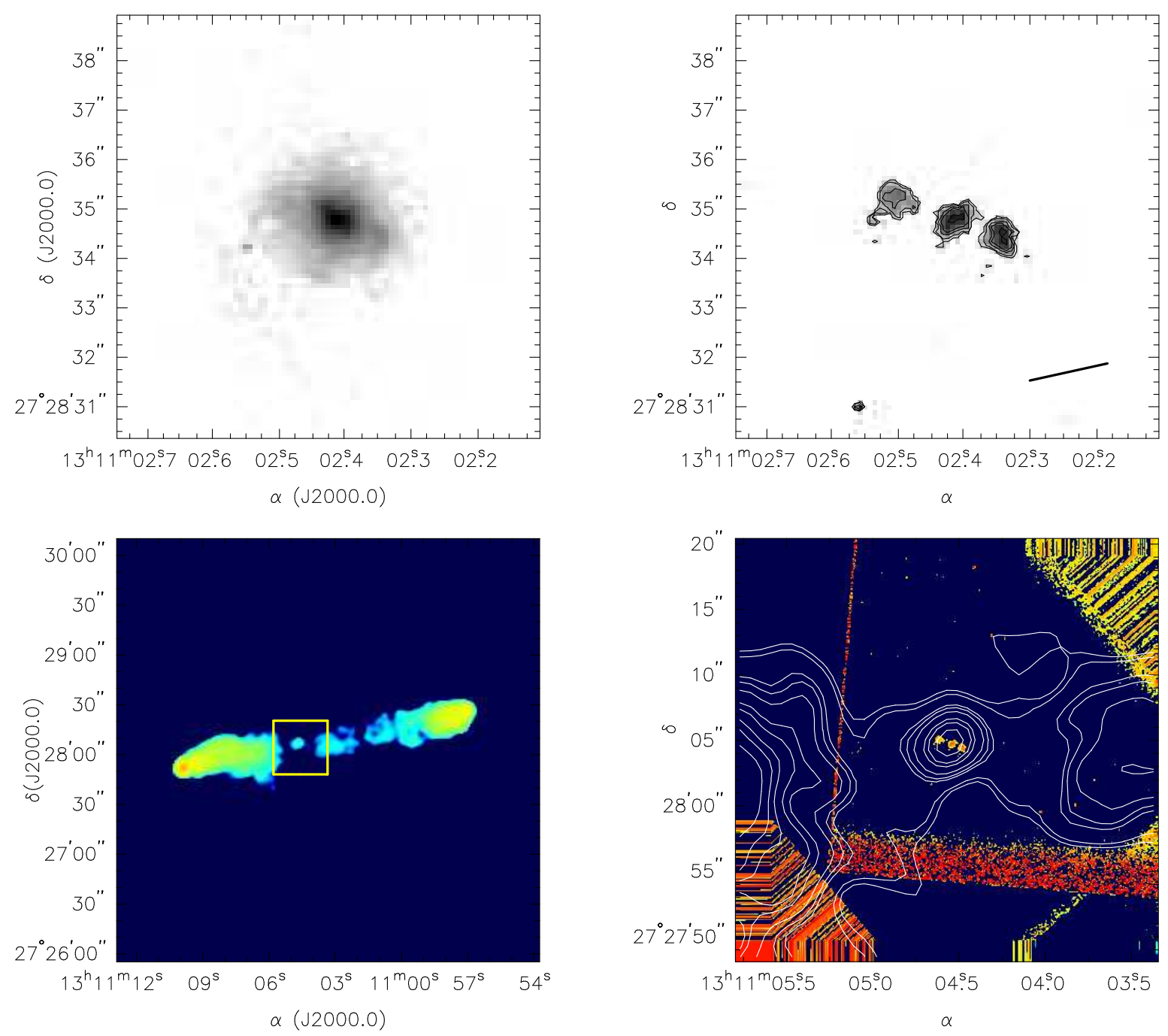

Arriba izquierda: Componente estelar. Arriba derecha: EELR. Los contornos representan el 19, 25, 38, 50 y $88 \%$ del máximo de intensidad en la región central. Se indica la dirección del jet. Abajo izquierda: Imagen de archivo VLA, en $1527 \mathrm{MHz}, 256 " \times 256 "$ ". Abajo derecha: superposición radioóptico. La imagen corresponde a la sección marcada en panel anterior. 
Figura 3.8. 3C 285. Imágenes de HST y VLA
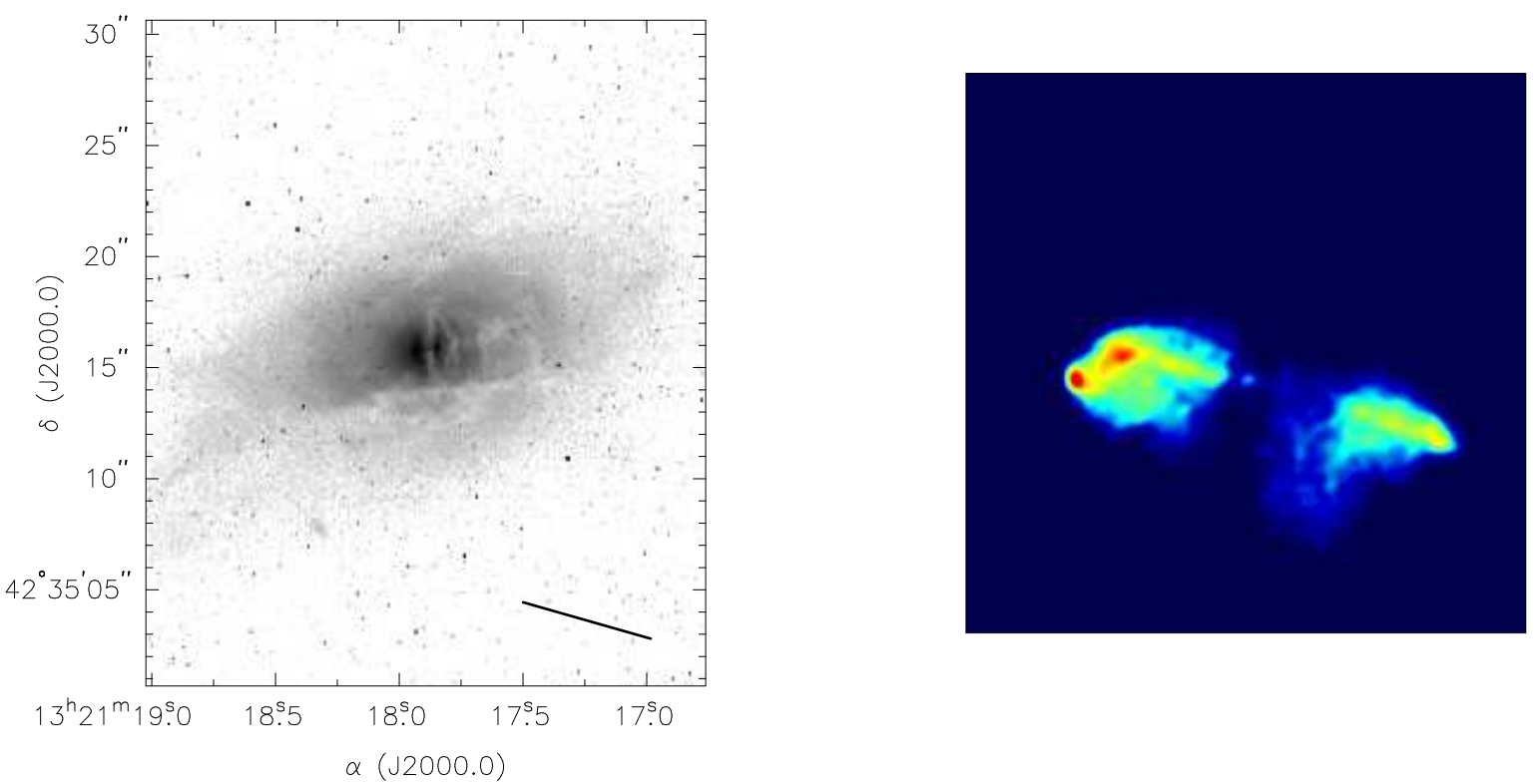

Izquierda: Componente estelar. Se indica la dirección del jet en esta imagen dado que no hay imagen nebular tomada con la cámara WFPC2. La imagen nebular de esta galaxia tomada con la cámara ACS figura en el trabajo de Tremblay et al. (2009). Derecha: Imagen de archivo VLA, en $1530 \mathrm{MHz}$, $256 " \times 256$ " (www.jb.man.ac.uk/atlas). Por un problema en el archivo original no se pudieron recuperar las coordenadas de la imagen.

Figura 3.9. 3C 303.1. Imágenes de HST
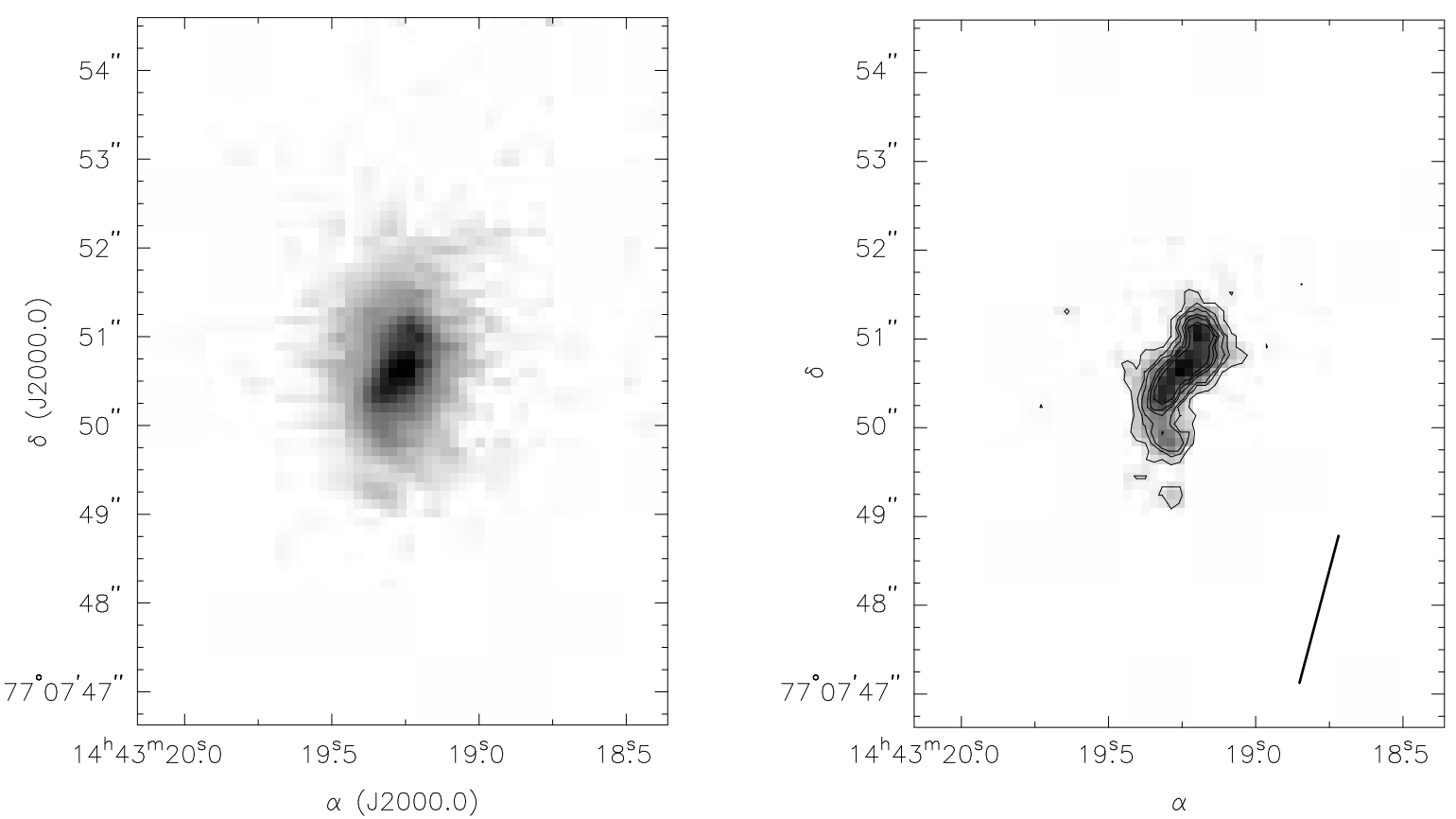

Izquierda: Componente estelar. Derecha: EELR. Los contornos representan el 5, 10, 13, 22, 28, y 38 \% del máximo de intensidad en la región central. Se indica la dirección del jet. 
Figura 3.10. 3C 305. Imágenes de HST y MER-

LIN/VLA
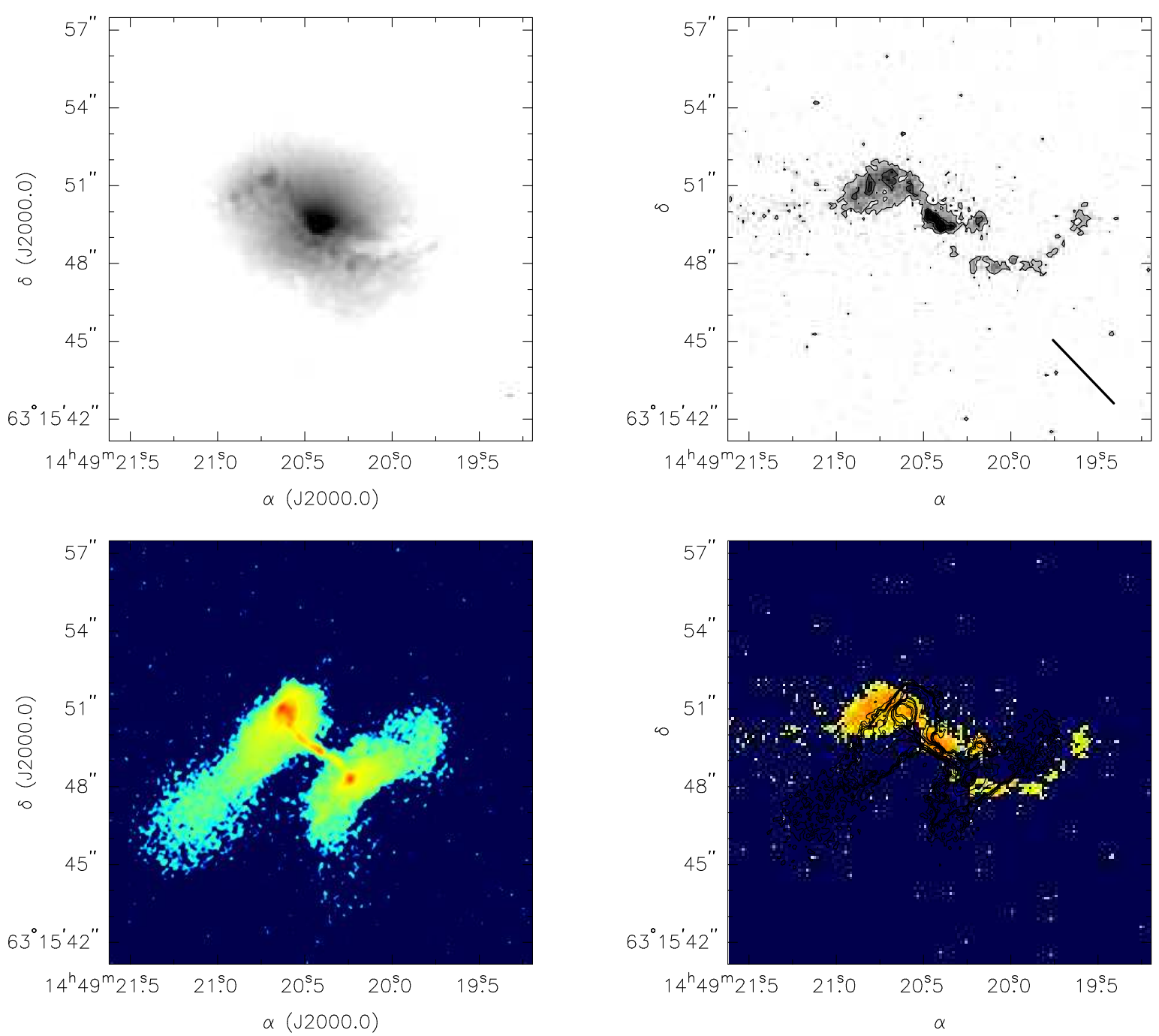

Arriba izquierda: Componente estelar. Arriba derecha: EELR. Los contornos representan el 4, 7, 12, 18, 23, 28 y $41 \%$ del máximo de intensidad en la región central. Se indica la dirección del jet. Abajo izquierda: Imagen de archivo MERLIN/VLA, en $1534 \mathrm{MHz}, 16.2$ "×16.2"(www.jb.man.ac.uk/atlas). Abajo derecha: superposición radio-óptico. 
Figura 3.11. 3C 321. Imágenes de HST y VLA
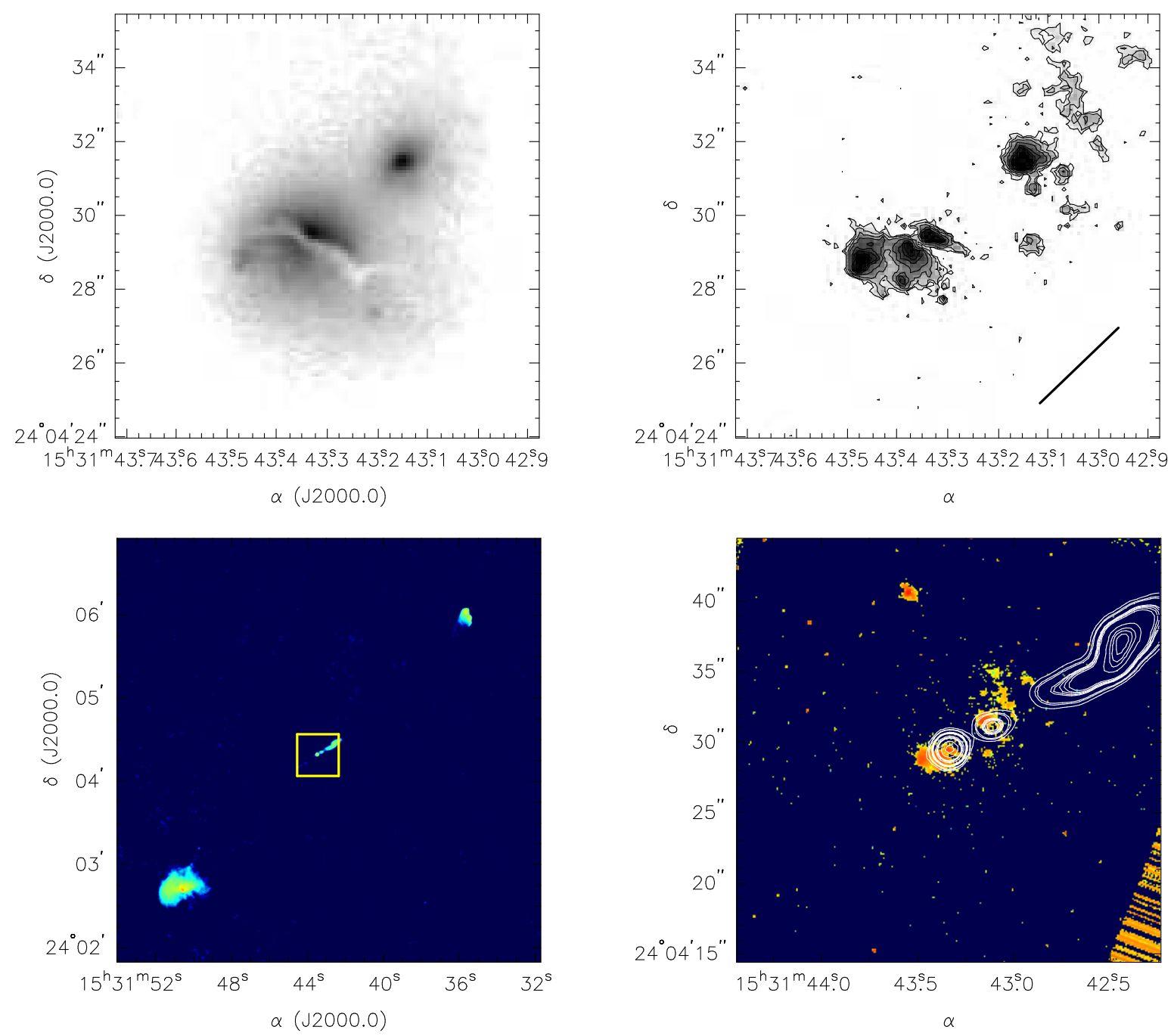

Arriba izquierda: Componente estelar. Arriba derecha: EELR. Los contornos representan el 4, 5, 9, 15, 23, 29, 35 y $53 \%$ del máximo de intensidad en la región central. Se indica la dirección del jet. Abajo izquierda: Imagen de archivo VLA, en $1507 \mathrm{MHz}, 235.2 " \times 235.2 "$ (Baum et al. 1988). Abajo derecha: superposición radio-óptico. La imagen corresponde a la sección marcada en panel anterior. 
Figura 3.12. 3C 381. Imágenes de HST y VLA
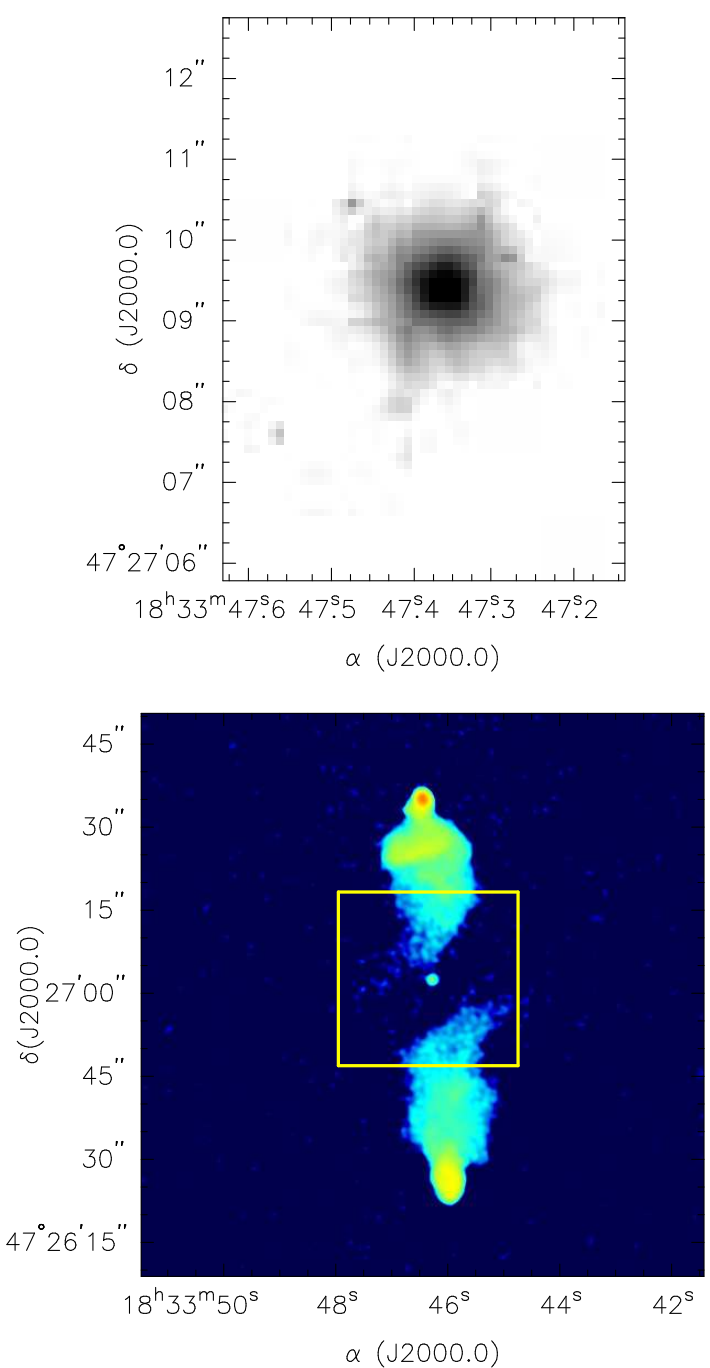
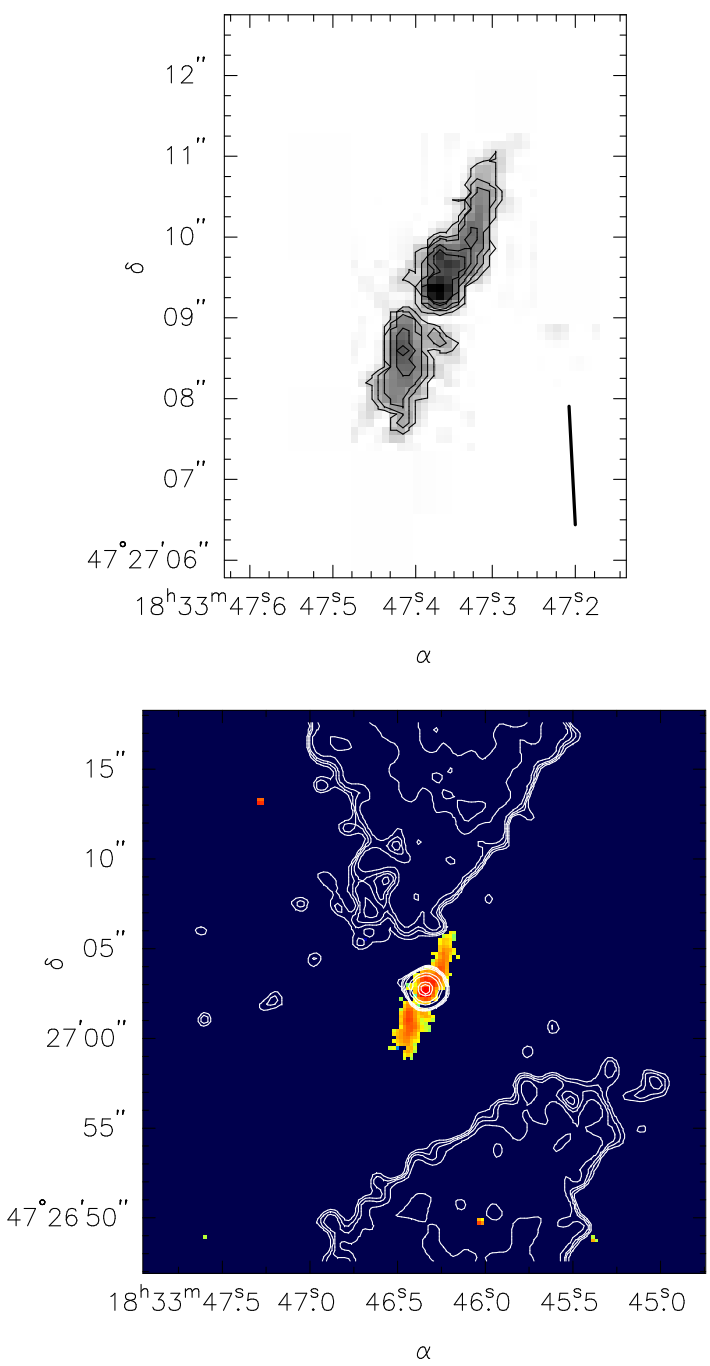

Arriba izquierda: Componente estelar. Arriba derecha: EELR. Los contornos representan el 5, 7, 10, 18 y $22 \%$ del máximo de intensidad en la región central. Se indica la dirección del jet. Abajo izquierda: Imagen de archivo VLA, en $1477 \mathrm{MHz}, 80$ "×80" (Leahy \& Perley 1991). Abajo derecha: superposición radio-óptico. La imagen corresponde a la sección marcada en panel anterior. Todas coordenadas están en el sistema J2000.0; pueden existir peqeñas diferencias debido a los errores asociados a cada telescopio. 
- GN-2005A-Q-37; PI: C. Feinstein.

- GN-2011A-Q-66; PI: C. Feinstein.

- GN-2012A-Q-18; PI: V. Reynaldi.

\subsubsection{El instrumental.}

Los espectros se tomaron con el instrumento GMOS (Gemini Multi-Object Spectrograph),

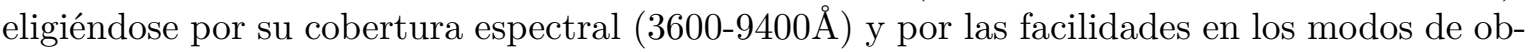
servación. El instrumento se puede utilizar en diferentes modos: observación con cámara directa (modo imagen), espectroscopía multi-objeto (se toman los espectros de tantos objetos como sea posible, simultáneamente, en un campo del cielo de 5.5 minutos de arco), espectroscopía de campo integrado (también se conoce como espectroscopía 3-D, se obtiene información espectroscópica sobre un área de 35 segundos de arco cuadrados, es decir sobre una imagen) y espectroscopía de ranura larga (long-slit). La ventaja del modo long-slit es que, al ser utilizado sobre objetos extendidos, permite obtener información espacial en la dirección dada por la posición de la ranura. Dado que las EELR son fuentes extendidas, donde a su vez existe una dirección preferencial de elongación, nuestras observaciones se realizaron en el modo de ranura larga.

En la Tabla 3.4 se detallan los parámetros de cada observación. Las ranuras utilizadas tienen anchos de 0.5 ", 0.75 ", 1" y 1.5", y su longitud es de 330"; todas ellas están disponibles de manera permanente en el instrumento. Los anchos se variaron de acuerdo a las dimensiones del objeto en cuestión, según se aprecia en las imágenes HST. En la Tabla también se indican los ángulos de posición (PA) de la ranura con los cuales se obtuvieron los datos. Los ángulos están medidos desde el Norte hacia el Este, es decir en sentido antihorario. La posición de la ranura se determinó en base a la dirección de la elongación de las EELR tal como se observa en las imágenes del HST (Figs. 3.3 a 3.12, panel superior derecho).

Se empleó la red de difracción B600 en todas las observaciones con el objetivo de tener la misma cobertura espectral. Para esto fue necesario variar la longitud de onda central $\left(\lambda_{c}\right)$ de acuerdo al redshift del objeto, lo que, a su vez, implica un análisis sobre la localización de los dos espacios vacíos (gaps) que existen entre los tres CCD (Charge Coupled Device) del detector de GMOS, para evitar la pérdida de información valiosa en la líneas de emisión (Sección 3.3.2). La red B600 original (B600-G5303) se dañó en Diciembre del año 2008 (las observaciones de 3C 284 y 3C 381 fueron tomadas con esta red), y en Mayo de 2009 fue reemplazada por la red actual B600-5307. En la mayor parte del rango espectral $(2760 \AA)$, que coincide con el de la red anterior, su sensibilidad es mayor (20-30\%). El poder resolvente es $\mathrm{R} \sim 1700$, medido (en laboratorio) a la longitud de onda efectiva, que corresponde a $4610 \AA$.

Para optimizar la calidad de la información, los datos se obtuvieron con un reagrupamiento espacial y espectral de los pixels del detector (binning). Éste consistió en duplicar el tamaño de los pixels (0.0728") en ambas direcciones (binning $2 \times 2$ ), con lo cual tanto la resolución espacial como espectral originales se redujeron a la mitad. En consecuencia, la resolución de nuestros datos en la dirección espacial es de $0.1454 " \mathrm{px}^{-1}$, mientras que la resolución espectral es de $0.9 \AA \mathrm{px}^{-1}$ (el factor de dispersión original de la red B600 es de $0.45 \AA \mathrm{px}^{-1}$ ). La última columna de la Tabla muestra la escala espacial resultante de la combinación de la escala del detector $\left(0.1454 " \mathrm{px}^{-1}\right)$ y el corrimiento al rojo de cada objeto particular. Esta escala indica la distancia lineal ( en $\mathrm{pc} \mathrm{px}^{-1}$; sin correcciones por efectos de proyección) cubierta por cada pixel del detector.

El tiempo de exposición neto ronda los cuarenta (40) minutos en todos los casos, y en la mayoría de ellos se tomó una única exposición (Sección 3.3.2). La Tabla también incluye los 
Tabla 3.4. GMOS/Gemini: características instrumentales de las observaciones.

\begin{tabular}{|c|c|c|c|c|c|c|c|c|}
\hline Objeto & Fecha obs. & Ranura & $\overline{\mathrm{PA}}$ & $\overline{\lambda_{c}[\mathrm{~nm}]}$ & $\overline{T_{e x p}}$ & seeing & $\overline{\mathrm{AM}}$ & Escala \\
\hline 3C 184.1 & Mar 2012 & $1 "$ & $18^{\circ}$ & 450 & $760^{s}(3)$ & $1.1 "$ & 2.0 & 342 \\
\hline 3C 196.1 & Mar 2012 & $0.5 "$ & $50^{\circ}$ & 525 & $1280^{s}(2)$ & $0.83 "$ & 1.1 & 573 \\
\hline $3 \mathrm{C} 268.2$ & Feb 2011 & $0.5 "$ & $165^{\circ}$ & 565 & $2576^{s}$ & $0.65 "$ & 1.2 & 1050 \\
\hline $3 \mathrm{C} 268.3$ & Abr 2011 & $0.5 "$ & $146^{\circ}$ & 570 & $2580^{s}$ & $0.76 "$ & 1.4 & 1080 \\
\hline $3 \mathrm{C} 284$ & Abr 2005 & $0.5 "$ & $70^{\circ}$ & 500 & $2400^{s}$ & $0.82 "$ & 1.8 & 698 \\
\hline $3 \mathrm{C} 285$ & Feb 2012 & $1.5 "$ & $80^{\circ}$ & 430 & $780^{s}(3)$ & $0.95 "$ & 1.2 & 234 \\
\hline 3C 303.1 & Feb 2012 & $1 "$ & $145^{\circ}$ & 560 & $1280^{s}(2)$ & $0.95 "$ & 1.8 & 784 \\
\hline $3 \mathrm{C} 305$ & Abr 2011 & $0.75 "$ & $45^{\circ}$ & 445 & $720^{s}(3)$ & $1 "$ & 1.4 & 124 \\
\hline $3 \mathrm{C} 321$ & Abr 2011 & $0.75 "$ & $127^{\circ}$ & 445 & $2400^{s}$ & $0.42 "$ & 1.0 & 284 \\
\hline 3C 381 & Abr 2005 & $0.5 "$ & $155^{\circ}$ & 450 & $2251^{s}$ & $0.8 "$ & 1.1 & 465 \\
\hline
\end{tabular}

Notas: Para todas las observaciones se empleó la red B600. La cantidad de exposiciones, cuando hubo más de una, se indican entre paréntesis en la columna $\mathrm{T}_{\text {exp }}$. La última columna corresponde a la escala lineal ( $\mathrm{pc} \mathrm{px}^{-1}$; sin considerar efectos de proyección), resultante de la combinación de la escala del detector y el redshift del objeto.

valores del seeing y masa de aire (AM, por su nombre en inglés airmass) como indicadores de las condiciones climáticas al momento de la observación. El seeing se midió como el ancho a la mitad de la intensidad (FWHM, según su sigla en inglés: full width at half maximum) del perfil gaussiano que representa a un objeto estelar en el campo donde se encuentra la galaxia, y en el mismo momento de su observación.

\subsubsection{Proceso de observación.}

El diseño de la observación requiere establecer un compromiso entre el flujo emitido por el objeto en la banda del espectro donde se observa y el tiempo de exposición, con el fin de optimizar los recursos instrumentales en pos de la calidad de los datos que se quieren conseguir. Esta evaluación, que se explica a continuación, se realizó con la Calculadora de Tiempo de Integración $^{7}$ (ITC, de su sigla en inglés Integration Time Calculator) de GMOS en la cual están recreadas todas las características del instrumento para poder predecir el resultado de la observación de un objeto dado bajo las condiciones climáticas que se requieran. Para llegar a esta instancia es imprescindible conocer el flujo emitido por cada EELR a estudiar. Se utilizaron las imágenes del filtro rampa de la WFPC2 (emisión pura, ver Sección 3.2.1) con el fin de medir el flujo en [OIII] con un criterio homogéneo para todas las galaxias (excepto 3C 285) de la muestra. A continuación se describen los pasos seguidos en el proceso de observación.

\section{Fotometría instrumental - HST}

El proceso de fotometría instrumental consiste en obtener el flujo de una región (la EELR) como la suma de los flujos emitidos por todas las sub-regiones que la componen. Como resultado, se obtiene es una medida instrumental, que no estará expresada en unidades de flujo reales, sino que estará dada por las unidades analógicas/digitales (ADUs) características de las observaciones CCD. De esta forma, el flujo obtenido será una medida de la cantidad de electrones (la relación entre ADUs y electrones está dada por la ganancia) capturados en el área

${ }^{7}$ www.gemini.edu/sciops/instruments/gmos/itc-sensitivity-and-overheads?q=node/10478 
Figura 3.13. Fotometría instrumental.

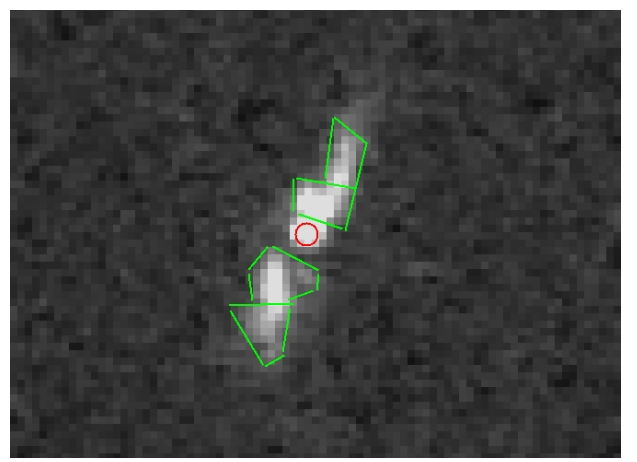

Esquema ilustrativo de la definición de los polígonos para la tarea polyphot en el caso de la radiogalaxia 3C 381.

de la EELR. El análisis se realizó con la tarea polyphot del paquete NOAO.DIGIPHOT.APPHOT de IRAF (Image Reduction and Analysis Facility), que permite definir áreas con formas poligonales arbitrarias. El área de la EELR se define con tantos polígonos como sean necesarios. A modo de ejemplo, en la Figura 3.13 se muestra el conjunto de polígonos (trazos en verde) que definen la EELR en la radiogalaxia 3C 381; la región central (círculo rojo) está excluida. La tarea polyphot sólo requiere de los vértices de cada polígono, junto con una estimación de su centroide. De todos los resultados que arroja, sólo nos interesan los denominados sum, area y flux para cada polígono definido. Sum es la cantidad neta de ADUs dentro del polígono, incluyendo la contribución del cielo; area es el área del polígono, medida por la cantidad de pixels que ocupa ${ }^{8}$; y flux, el flujo instrumental, se define como la cantidad total de ADUs que quedan dentro del área poligonal una vez realizada la siguiente corrección por la contribución del cielo (msky):

$$
\text { flux }=\text { sum }- \text { area } * \text { msky }
$$

La determinación de la contribución del cielo se obtuvo como el promedio de la emisión en zonas aledañas a cada galaxia, mediante la tarea imexamine del paquete IMAGES.TV. El valor resultante se especifica dentro del archivo de parámetros @fitskypars antes de ejecutar la tarea polyphot, y se mantiene constante.

De esta manera se obtiene una medida de la emisión nebular de cada galaxia, cuya mayor contribución proviene del $[\mathrm{O} I I I] \lambda 5007$. La conversión de estas unidades instrumentales en unidades físicas reales se realizó con la Calculadora de Tiempo de Exposición ${ }^{9}$ (ETC, de su sigla en inglés Exposure Time Calculator) para fuentes extendidas de la cámara WFPC2 del HST.

\footnotetext{
${ }^{8}$ La medida del área en este caso suele expresarse como $\mathrm{px}^{2}$. Esta denominación suele dar lugar a confusión porque un pixel es intrínsecamente un elemento de área, en el sentido de unidad colectora del detector. El problema surge porque se suele usar el pixel como medida de longitud, sobre todo empleándose para indicar la resolución angular/lineal de un dado instrumento $\left(X " \mathrm{px}^{-1} ; Y \mathrm{pc} \mathrm{px}^{-1}\right)$. En adelante, en el texto, cuando se haga referencia $1 \mathrm{px}^{2}$, deberá entenderse como la medida de un área cuadrada cuyo lado tiene una longitud igual al tamaño lineal de pixel del detector en cuestión. Así, por ejemplo, si un objeto extendido tiene un área de $\mathrm{A} \mathrm{px}^{2}$ medida en una imagen de la WFPC2, se entiende que tal objeto ocupa una cantidad A de pixels sobre el detector de la WFPC2, y el valor de esta información radica en la resolución angular, es decir cuántos segundos de arco cubre cada pixel (en el ejemplo, la resolución angular dependerá de si la observación se realizó en modo $\mathrm{PC}$ o WF).

${ }^{9}$ www.stsci.edu/hst/wfpc2/software/wfpc2-etc-extended-source-v40.html
} 
En este caso se sigue el procedimiento contrario al que se realizará con la ITC de GMOS. Con esta última se busca evaluar qué $\mathrm{S} / \mathrm{N}$ se va a conseguir con el espectro, conociendo el flujo emitido (en unidades reales), y variando el tiempo de exposición. Con la ETC del HST, en cambio, se conocen el tiempo de exposición, el filtro usado, la ganancia empleada, y lo que se busca es calibrar el flujo instrumental obtenido antes (ADUs $\mathrm{px}^{-2}$ ) en una magnitud de real ( $\mathrm{erg} \mathrm{s}^{-1} \mathrm{~cm}^{-2} \operatorname{arcsec}^{-2}$ ), a partir de un valor de referencia arbitrario. En otras palabras, se establece una relación de escala, donde el valor obtenido en este proceso será el que se utilice en la calculadora de GMOS. En promedio, la emisión proveniente de las EELRs ronda los $7 \times 10^{-16} \mathrm{erg} \mathrm{s}^{-1} \mathrm{~cm}^{-2} \operatorname{arcsec}^{-2}$.

\section{Diseño de las observaciones con GMOS.}

La medida del flujo obtenida en el paso anterior está ampliamente dominada por la emisión del [OIII]. Ese valor se utiliza como referencia en la ITC de GMOS para evaluar la respuesta espectroscópica del detector.

La calculadora puede simular distintos tipos de distribuciones espectrales de energía (SED, de su sigla en inglés: spectral energy distribution), desde una simple línea de emisión, hasta la SED de un quásar (QSO, de su sigla en inglés: quasi stellar object), una galaxia espiral o una galaxia elíptica. Dentro de los modelos de SED disponibles se elige una línea de emisión en $5007 \AA$, desplazada según el corrimiento al rojo de la galaxia en cuestión. En primera instancia se evalúan la relación $\mathrm{S} / \mathrm{N}$ y la cantidad de electrones capturados cuando toda la energía se concentra en la línea. Se evalúa la cantidad de electrones que recibiría el detector para asegurar que no se llegará al límite de saturación (65000 electrones). Las exposiciones de algunos objetos fueron fragmentadas de acuerdo a estos resultados y a la magnitud visual del objeto.

El valor de la relación $\mathrm{S} / \mathrm{N}$ que alcanza la línea es la referencia con la que se establece la relación de escala a todo el espectro. Para ello es necesario cambiar la SED. La opción más parecida al tipo de espectro esperado es el modelo de QSO. En este espectro modelo se encuentran las líneas de emisión que esperamos detectar en las EELR. Las líneas de emisión de un QSO y las de la EELR tienen diferencias morfológicas muy importantes (el FWHM en las líneas de recombinación del Hidrógeno) que están asociadas a las condiciones físicas del gas responsable de la emisión. Pero para la evaluación que se realiza en esta etapa, esas diferencias pueden ignorarse. Al cambiar la distribución espectral, el flujo de energía asociado al [OIII] se adopta como el flujo emitido por toda la fuente extendida en el filtro $\mathrm{V}(0.55 \mu \mathrm{m})$. Al utilizar esta SED modelo, podemos evaluar la caída de la relación $\mathrm{S} / \mathrm{N}$ para las líneas más débiles. Por tal motivo, buscamos $\mathrm{S} / \mathrm{N} \sim 40$ para el [OIII] $\lambda 5007$, para poder conseguir un valor cercano a $\mathrm{S} / \mathrm{N} \sim 10$ para líneas mucho más tenues como el $[\mathrm{Nev}] \lambda 3424$. Estos valores garantizan que las diferencias en intensidad entre las líneas presentes no se trasladen a diferencias en la calidad de los datos obtenidos; este aspecto es de especial importancia en el proceso de medición (ajuste Gaussiano). El tiempo de integración neto para el cual se consigue la relación $\mathrm{S} / \mathrm{N}$ esperada es de cuarenta (40) minutos. Pueden existir pequeñas diferencias en los tiempos de exposición reales (ver Tabla 3.4) debido a la forma en que deben repartirse los tiempos técnicos ${ }^{10}$, conocidos como overheads, durante el proceso de observación.

La calidad de los datos, cuantificada por el valor de $\mathrm{S} / \mathrm{N}$, es fuertemente dependiente de las condiciones atmosféricas bajo las cuales se realiza la observación. Nuestros datos fueron obtenidos bajo las siguientes condiciones, que se explican a continuación:

\footnotetext{
${ }^{10}$ Es el tiempo invertido en cambiar la configuración del instrumento entre observaciones sucesivas, lo que incluye desde el apuntamiento del telescopio hacia un nuevo objeto, hasta el cambio de ranuras, redes de difracción, etc.
} 
Figura 3.14. Brillo de fondo del cielo en Mauna Kea

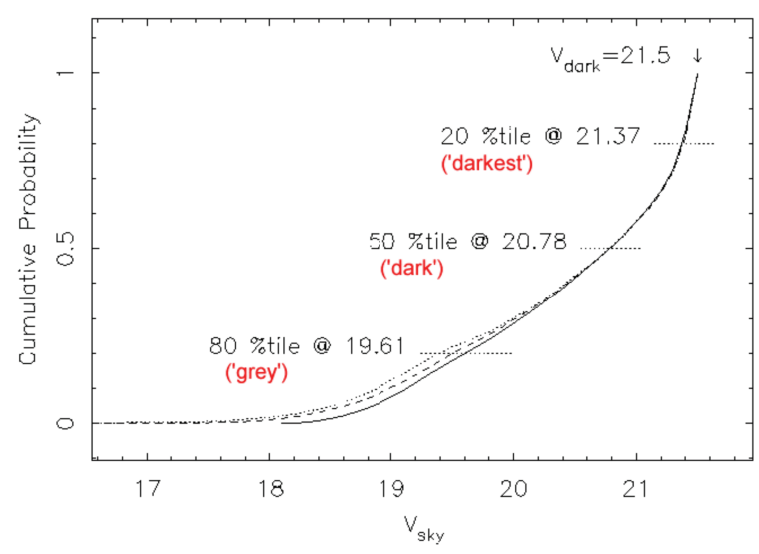

Definición de los percentiles que caracterizan el brillo de fondo del cielo, en la cima de Mauna Kea. $\mathrm{V}_{s k y}$ es la magnitud visual del cielo por unidad de segundo de arco cuadrado.

- Calidad de imagen: percentil 70

- Cobertura de nubes: percentil 70

- Vapor de agua: sin condiciones

- Brillo de fondo del cielo: percentil 50

Los percentiles representan la frecuencia con que ocurre una determinada condición. La calidad de la imagen (CI) se define como el FWHM del perfil radial de una fuente puntual, cuando es observada en la dirección del cenit con un dado instrumento y en una cierta longitud de onda. El valor adoptado para nuestras observaciones $(\mathrm{CI}=70)$ indica que durante el $70 \%$ del tiempo útil del semestre de observación se espera obtener FWHM $<0.8$ " en el visual (filtro V). Es importante destacar que estos valores son resultados teóricos de complejas simulaciones donde se tienen en cuenta múltiples factores: propiedades atmosféricas, velocidad y dirección del viento, el brillo de la estrella guía y su distancia relativa al objeto de estudio, y la longitud de onda de la observación. CI no es el seeing, aunque lo contempla. El valor del seeing en la Tabla 3.4 es un valor obtenido en base a observaciones reales, con un criterio determinado. CI está asociado a una referencia teórica necesaria para el diseño de la observación, mientras que el seeing es un valor derivado de ésta.

La cobertura de nubes $(\mathrm{CN})$ y el vapor de agua (VA) son las dos formas de caracterizar la transparencia del cielo, pero en el rango óptico el factor relevante es $\mathrm{CN}$, motivo por el cual no se impusieron restricciones sobre VA. En cuanto a la presencia de nubes, el valor $\mathrm{CN}=70$ implica una merma en la transmisión que se cuantifica en 0.3 mag. Es decir, la observación puede realizarse aceptando la presencia de pequeñas nubes transparentes o cirrus extendidos.

El brillo de fondo del cielo (BC) en el rango óptico está dominado por la fase lunar y por la separación angular entre el objeto y la Luna, pero en mucho menor medida también influyen la latitud ecliptical, las fases del ciclo solar y la distancia cenital. La Figura 3.14 muestra cómo se definen los rangos de percentiles en función de la magnitud $\mathrm{V}$ del cielo por unidad de segundo de arco cuadrado $\left(\mathrm{V}_{s k y}\right)$. La condición $\mathrm{BC}=50$ quiere decir que $\mathrm{V}_{s k y}<20.7$ durante el $50 \%$ del tiempo útil del semestre. Esto implica que la observación debe realizarse en el 
período comprendido entre \pm 7 noches desde la noche de Luna Nueva.

Como última etapa, se estudia la longitud de onda central $\left(\lambda_{c}\right.$, ver Tabla 3.4) del espectro para la red de difracción elegida. Este análisis está estrechamente relacionado con el diseño del detector de GMOS. Con el objetivo de obtener la misma cobertura espectral para todos los objetos, $\lambda_{c}$ fue elegida, en primera instancia, de manera tal que se pudieran detectar (potencialmente) todas las líneas de emisión comprendidas entre $\sim 3300 \AA$ y $\sim 5400 \AA$. El diseño del detector influye por la separación entre los tres CCDs, que deja dos espacios vacíos (gaps). Cada gap tiene un tamaño que equivale a 37 pixels. La cobertura espectral está afectada por la presencia de estos espacios vacíos. La cuantificación de la pérdida de información que esto implica depende del factor de dispersión de la red de difracción utilizada y de si se realiza o no un reagrupamiento de pixels (binning). En todos los espectros que presentaremos aquí, la presencia de los gaps implica la pérdida de $\sim 33 \AA$ en la posición de cada uno de ellos.

Existen técnicas para evitar esta pérdida de información ${ }^{11}$, sin embargo, por la naturaleza de las EELR, aplicar tales técnicas implicaba una potencial pérdida de información en la estructura de las líneas de emisión que se pretendían detectar. Por este motivo, se optó por estudiar cuidadosamente cuál debía ser $\lambda_{c}$ para conseguir el rango espectral señalado antes, y simultáneamente asegurar que los gaps estuvieran ubicados en posiciones donde no afectaran la detección de las líneas de emisión.

\section{Ejecución de las observaciones}

Las observaciones con el Telescopio Gemini pueden realizarse en dos modos, clásico y en cola (del inglés, queue). En el modo clásico cada observador toma sus propios datos, con absoluto manejo del telescopio. En el modo queue la secuencia de observaciones de una dada noche se diseña de acuerdo a las condiciones atmosféricas esperadas para esa noche, y de acuerdo al orden de prioridades establecido por el Comité Internacional en la evaluación de las propuestas de observación. En el armado de esa secuencia no se busca completar un dado programa en una determinada noche, sino optimizar el tiempo útil de observación. En este modo, las observaciones están a cargo del personal del Telescopio.

Todas las observaciones de nuestra muestra fueron ejecutadas en modo queue. Los tres (3) turnos de observación de los cuales provienen los datos consumieron cuatro (4) horas cada uno, aproximadamente, del tiempo que le corresponde a la República Argentina, como integrante del consorcio Gemini. La cantidad de tiempo argentino disponible en el Telescopio Gemini Norte, en los tres (3) semestres involucrados, fue de 24 hs. en $2005 \mathrm{~A}^{12}$, y de 31 hs. en 2011A y 2012A.

Los detalles finos de la observación se realizan en la etapa denominada Fase II, una vez que el proyecto fue evaluado y posteriormente aceptado. En esta etapa se definen, por ejemplo, las estrellas que servirán de guía o la orientación que debe tener la ranura.

El papel que desempeña la posición de la ranura en este trabajo es particularmente importante por dos motivos: por un lado porque la principal ventaja de la espectroscopía long-slit es que permite obtener información espacial en la dirección de la ranura, y por el otro porque la forma en que se distribuye el gas de las EELR determina la existencia de una dirección preferencial. En otras palabras, la orientación de la ranura en esta clase de objetos extendidos no es, en absoluto, trivial. En todos los casos la ranura se orientó en la dirección de la distibución de gas ionizado que compone la EELR, pasando por el núcleo del objeto (PA, Tabla 3.4). A lo largo de las Figs. 3.3 a 3.12 se puede apreciar que la distribución del material

\footnotetext{
${ }^{11}$ Cuando se requiere una cobertura espectral continua se recomienda fragmentar el tiempo de integración para permitir un ligero desplazamiento en $\lambda_{c}$ en cada exposición, de manera tal que cuando se combinan las observaciones, desaparecen los gaps.

${ }^{12}$ La letra A indica que la observación se realizó en el primer semestre del año.
} 
Figura 3.15. Refracción atmosférica diferencial en Mauna Kea

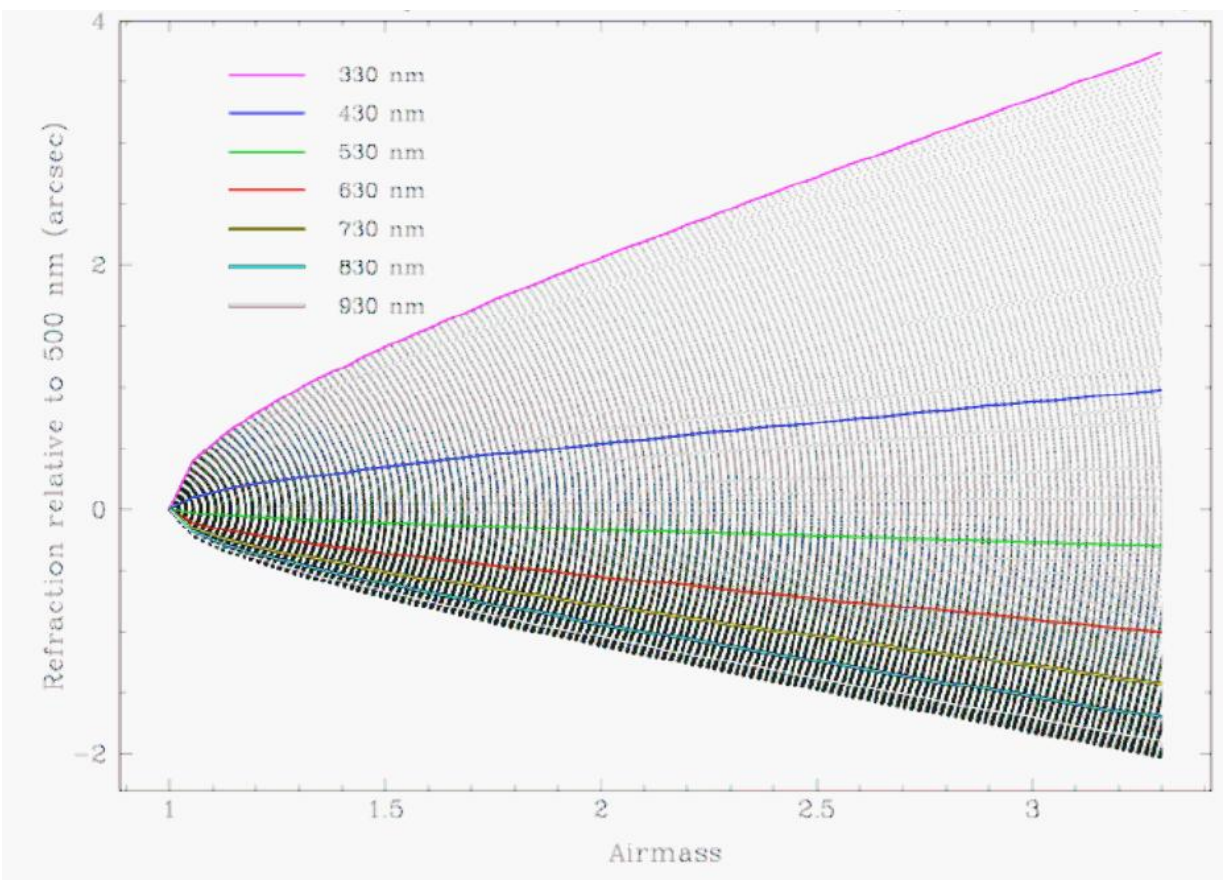

La refracción se expresa en segundos de arco, cada curva representa el comportamiento de la emisión en una dada longitud de onda respecto de la longitud de onda de referencia (5000Å), en función de la masa de aire (airmass).

de la EELR está siempre relacionado con las estructuras observadas en ondas de radio, ya sea el jet o los lóbulos. Se buscó que el espectro contenga la región nuclear para poder utilizarla como origen de coordenadas en el cálculo de distancias relativas, y como punto de referencia para el campo de velocidades del gas (Capítulo 5).

La elección de un ángulo de posición diferente del ángulo paraláctico compromete la observación espectroscópica por el posible efecto que pudiera tener la refracción atmosférica diferencial. Sin embargo, para el propósito de la investigación, el ángulo de posición con el cual debían tomarse los espectros no podía ser otro que el que acompañara la dirección preferencial de elongación de las nebulosas. El efecto de la refracción atmosférica puede evaluarse a través de la Figura 3.15, donde se observa cómo se ve afectada la emisión en distintas longitudes de onda (respecto de la longitud de onda de referencia, $5000 \AA ̊$ ) en función de la masa de aire en la cima de Mauna Kea. Esta Figura debe analizarse junto con la información contenida en la Tabla 3.4: ancho de la ranura, seeing y masa de aire (AM) para cada objeto, individualmente. Como las líneas de emisión más distantes en los espectros son [OII] $\lambda 3727$ y [OIII] $\lambda 5007$, en todos los casos se comprueba que el desplazamiento que sufre la emisión cercana a $3300 \AA ̊$ respecto de la emisión en $5000 \AA$ queda contenida dentro del ancho de la ranura en todos los objetos observados, por lo cual no hay pérdidas por refracción atmosférica. Es justo mencionar que este resultado fue corroborado luego de haber obtenido las observaciones. 
Tabla 3.5. Ángulos de posición de las estructuras radio-óptico.

\begin{tabular}{l|c|c|c}
\hline \hline Objeto & PA $_{j e t}$ & PA $_{\mathrm{GMOS}}$ & $\Delta \mathrm{PA}$ \\
\hline 3C 184.1 & $157^{\circ}$ & $18^{\circ}$ & $139^{\circ}$ \\
3C 196.1 & incierto* $^{\circ}$ & $50^{\circ}$ & - \\
3C 268.2 & $21^{\circ}$ & $165^{\circ}$ & $144^{\circ}$ \\
3C 268.3 & $161^{\circ}$ & $146^{\circ}$ & $15^{\circ}$ \\
3C 284 & $101^{\circ}$ & $70^{\circ}$ & $31^{\circ}$ \\
3C 285 & $\sim 80^{\circ}$ & $80^{\circ}$ & $\sim 0^{\circ}$ \\
3C 303.1 & $\sim 131^{\circ}$ & $145^{\circ}$ & $\sim 14^{\circ}$ \\
3C 305 & $42^{\circ}$ & $45^{\circ}$ & $3^{\circ}$ \\
3C 321 & 136 & $127^{\circ}$ & $9^{\circ}$ \\
3C 381 & $4^{\circ}$ & $155^{\circ}$ & $29^{\circ}$ \\
\hline \hline
\end{tabular}

Las características de las radiofuentes se presentan en el Capítulo 5.

* ver Sección 5.9.2.

\subsubsection{Selección de la muestra. II.}

La extensión de los sistemas nebulares externos (EELR) de cada galaxia, según las imágenes del HST, se utilizó como primer criterio de selección (Sección 3.2.1) para determinar qué objetos serían observados con el TGN con el fin de obtener su espectro. Sin embargo, el propósito de la presente investigación es el de dilucidar si los jets pueden desencadenar (y de ser así, bajo qué circunstancias) la emisión en estos sistemas nebulares mediante procesos de choque (Sección 2.4.3), o bien determinar el nivel de competencia entre este mecanismo y la acción del campo de radiación del núcleo activo (Secciones 2.4.1 y 2.4.2). Por lo tanto, la muestra de objetos a analizar efectivamente en este trabajo requiere de un segundo criterio de selección, que ponga en evidencia que los dos mecanismos son, en principio, válidos para ser analizados. Sobre el efecto fotoionizante del núcleo activo no hay nada que agregar. Pero con respecto al mecanismo de ionización por ondas de choque, el hecho de que sean (potencialmente) desencadenadas por el paso de los jets requiere de la existencia de alún tipo de alineamiento entre éstos y las EELR.

En la Tabla 3.5 se muestran los ángulos de posición del radio-eje en cada fuente (la descripción completa de los diez objetos, que incluye las características y disposición de su emisión en radiofrecuencias, se desarrolla en el Capítulo 5; por consistencia con la nomenclatura que empleará allí, este ángulo de posición se denomina $\mathrm{PA}_{j e t}$ ), junto con los ángulos de posición con los que se tomaron los espectos GMOS/Gemini (prácticamente coinciden con la dirección preferencial de elongación de las EELR), y la diferencia (en valor absoluto) entre ambos. Las fuentes donde se considerará que existe "alineamiento global", siguiendo el criterio definido por de Vries et al. (1999), son aquellas para las cuales $\Delta \mathrm{PA} \lesssim 15^{\circ}$, y constituyen la muestra de objetos a analizar. La muestra definitiva la componen 3C 268.2, 3C 268.3, 3C 285, 3C 303.1, 3C 305, 3C 321 y 3C 381. Los objetos 3C 381 y 3C 268.2 no satisfacen este criterio, pero fueron incorporados al análisis por características particulares que se explicarán en el desarrollo de los Capítulos 5 y 6. 


\section{Capítulo 4}

\section{Sobre el procesamiento y medición.}

\subsection{Reducción.}

Cada paquete de datos está compuesto por el espectro de la fuente junto con las imágenes de adquisición con cámara directa, una imagen de campo plano (flat-field), el espectro de la lámpara de comparación, tomado con la misma $\lambda_{c}$ que el espectro de la radiogalaxia, y el espectro de una estrella estándar de flujo. Para todos los casos se usó una lámpara de CobreArgón. Tanto los flats como las lámparas se tomaron en el mismo momento de la observación de la fuente, para minimizar los efectos que pudiera provocar la flexión del telescopio. Las imágenes bias no son datos exclusivos de un programa de observación, sino que forman parte del paquete de calibraciones estándar que el telescopio provee para todos los usuarios. Para la reducción de cada espectro se utilizaron todos los bias tomados durante el mismo mes de observación que el espectro en cuestión, bajo las mismas condiciones instrumentales, en particular el binning.

En el proceso de reducción se emplearon los paquetes GEMINI-GMOS (versión 1.11 y 1.12beta) dentro de IRAF (versión 2.14.1). Las tareas de este paquete son las tareas usuales asociadas al procedimiento estándar que fueron adaptadas específicamente para el instrumento GMOS, conteplando todas las características instrumentales necesarias. Los bloques principales de la secuencia de reducción son (el procedimiento completo de reducción se detalla en el Apéndice C): resta de bias, corrección de campo plano (flat-field), calibración en longitud de onda, resta del cielo, eliminación de rayos cósmicos (RC), y calibración en flujo. Para el proceso de eliminación de RC se evaluaron los funcionamientos y/o rendimientos de dos tareas: gscrrej perteneciente al paquete GMOs y la tarea independiente lacos (Laplacian Cosmic Ray Identification; van Dokkum 2001). En términos generales, el rendimiento de lacos es notablemente mejor. Sin embargo, en algunos casos, cuando la remoción de RC actúa sobre una línea se observan fallas importantes que podrían asemejarse a "agujeros" en el perfil de emisión. La eliminación de RC sobre el cielo no arrojó esta clase de errores, pero sí fue particularmente notable sobre algunas líneas, motivo por el cual en la mayoría de los espectros no se realizó esta corrección. Este hecho no se tradujo en un problema al momento de la medición, dado que tanto la forma del perfil como la intensidad de los RC son significativamente diferentes del perfil e intensidad de cualquier línea de emisión en el espectro. Como se explicará en la Sección 4.2, los RC pueden ser eliminados de forma mucho más eficiente si el proceso se realiza sobre el perfil de emisión uni-dimensional. El espectro de la estrella estándar se utilizó para aplicar la calibración en flujo. Este espectro se redujo con un procedimiento idéntico al de los objetos. El flujo de energía en los espectros uni-dimensionales resultantes estará expresado en unidades de $10^{-15} \mathrm{erg} \mathrm{s}^{-1} \mathrm{~cm}^{-2} \AA^{-1}$.

En las Figuras 4.10 a 4.4 se muestran las secciones del espectro 2D de cada objeto que 
Figura 4.1. GMOS: 3C 184.1

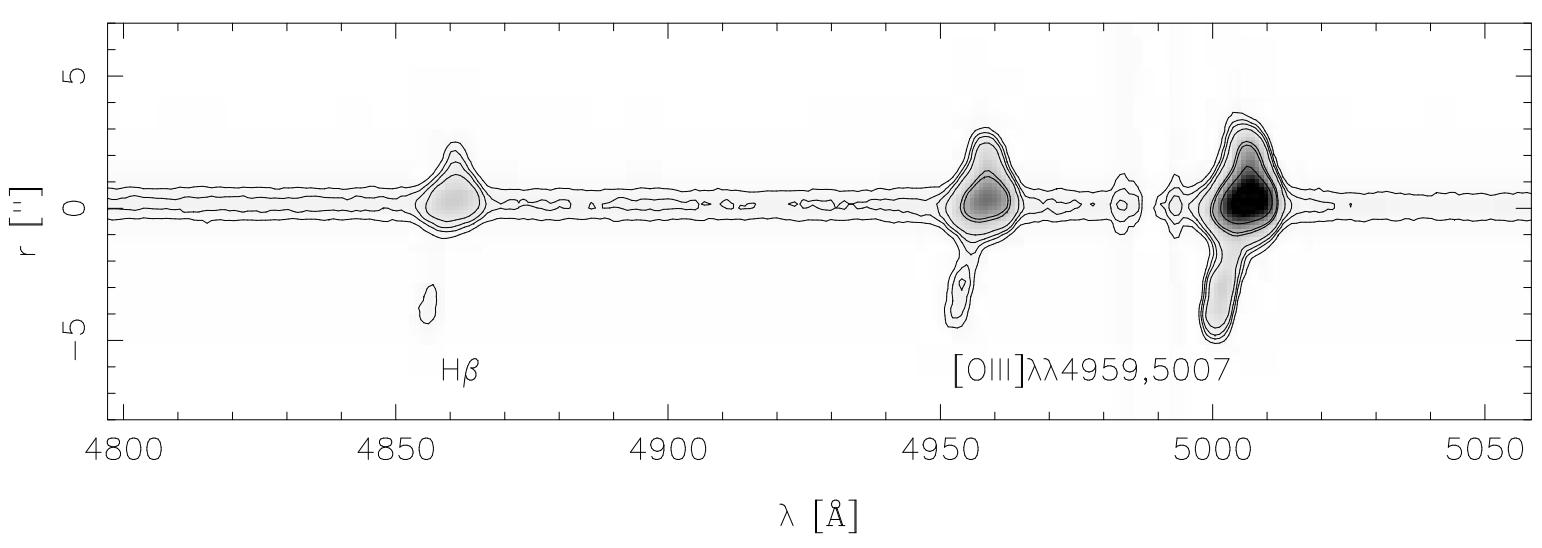

Figura 4.2. GMOS: 3C 196.1

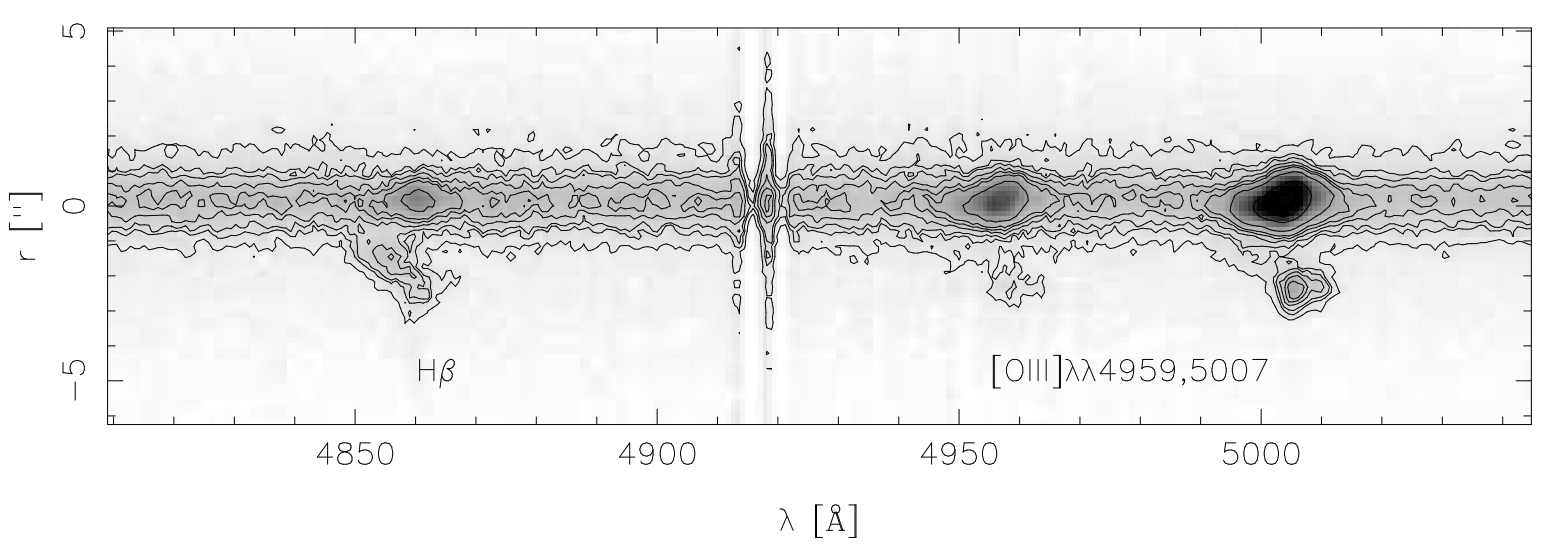

abarcan las líneas de emisión (generalmente) más intensas: H $\beta$ y [OIII] $\lambda \lambda 4959,5007$. La estructura de las líneas varía significativamente de objeto a objeto, los contornos se graficaron con la intención de resaltar esas estructuras sobre la escala de grises.

\subsection{Proceso de medición de líneas de emisión.}

En todos los espectros 2-D se observa una estructura compleja en las líneas de emisión, tanto en la dirección espacial como espectral. Con el objetivo de no perder información espacial, se extrajo un espectro por cada pixel espacial. La calidad de cada uno de los espectros resultantes está garantizada por el análisis de la relación $\mathrm{S} / \mathrm{N}$ realizado con anterioridad a la observación. En cuanto a la información en la dirección espectral, las extracciones revelan que los perfiles de las líneas están formados por varias componentes.

La descomposición Gaussiana de los perfiles de emisión se realizó con las tareas ngaussfit del paquete STSDAS-ANALYSIS-FITTING (versión 3.12), y splot del paquete NOAO-TWODSPECLONGSLIT de IRAF. La tarea ngaussfit ajusta funciones Gaussianas en una dimensión, en un proceso iterativo que comienza con condiciones iniciales impuestas por el usuario. Los parámetros libres son $I_{0}, \Lambda_{c}$ y $f w h m$, donde $I_{0}$ es la amplitud por encima de la línea recta $R$ que definirá al continuo local, $\Lambda_{c}$ es la longitud de onda central (el máximo de la función), y 
Figura 4.3. GMOS: 3C 284

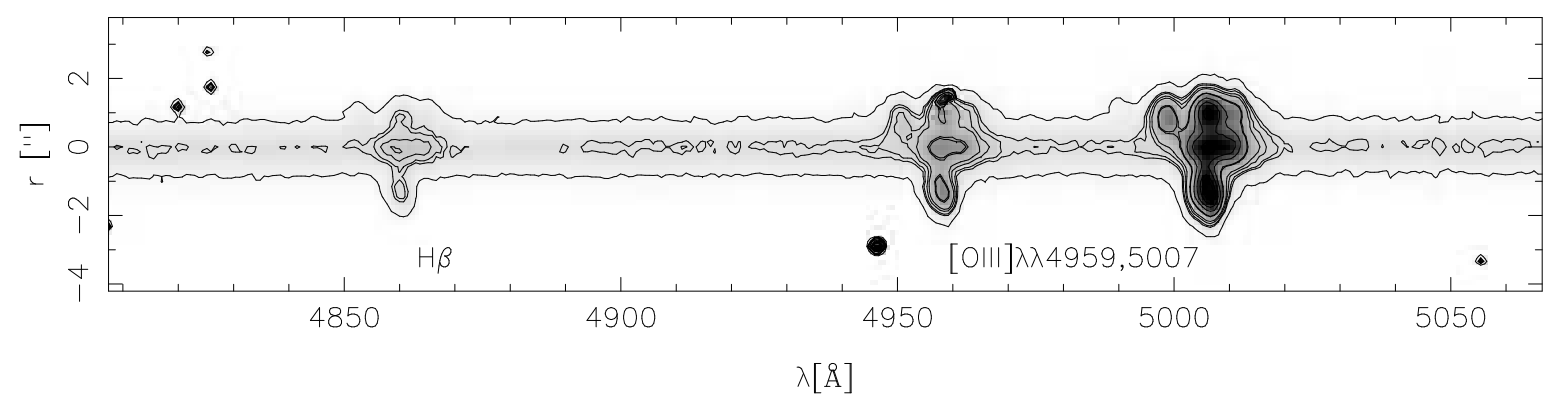

Figura 4.4. GMOS: 3C 285

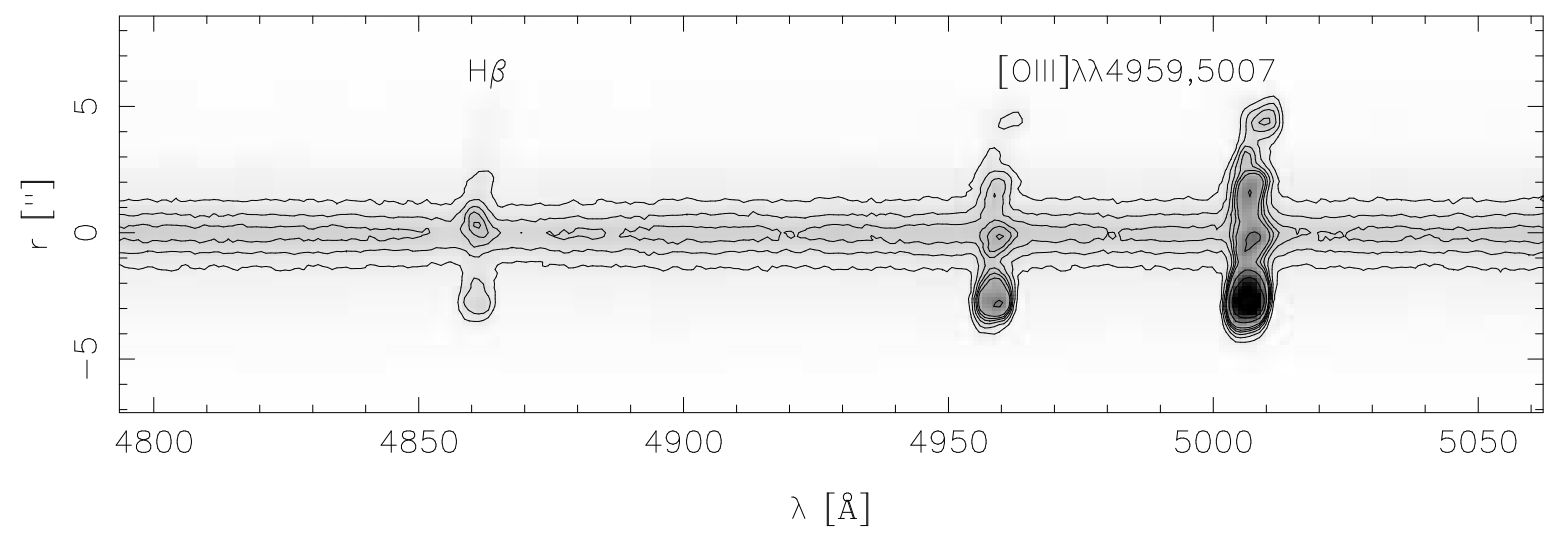

Figura 4.5. GMOS: 3C 268.2

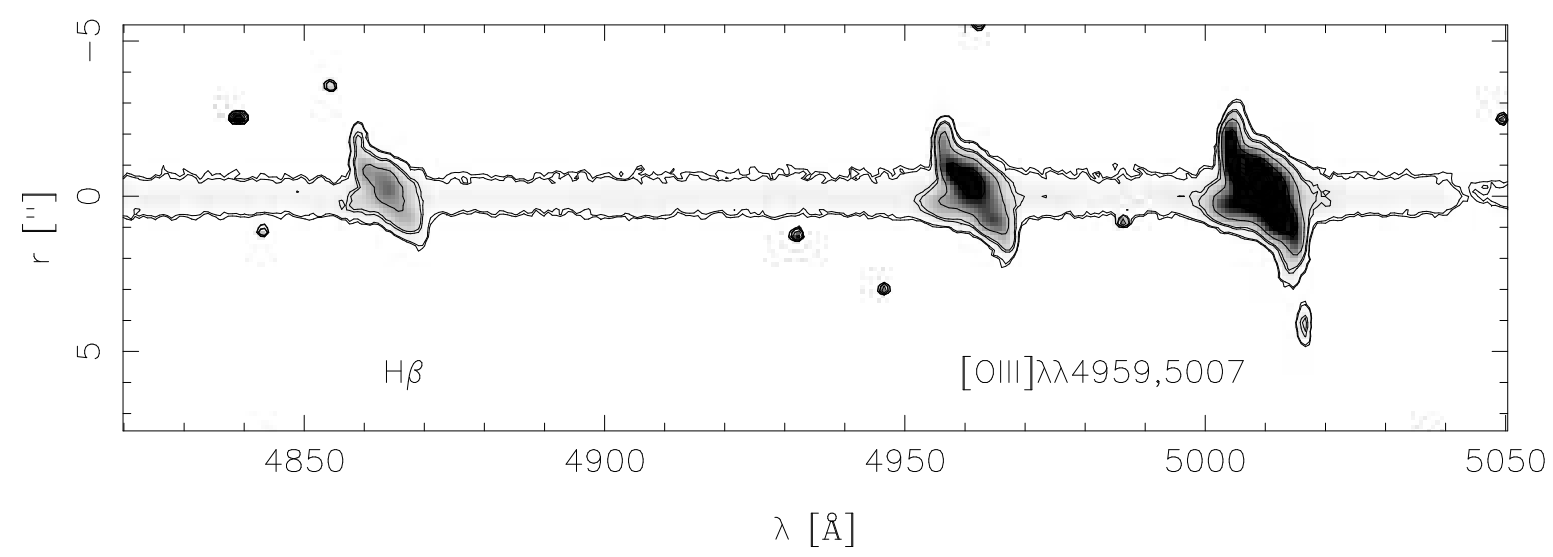


Figura 4.6. GMOS: 3C 268.3

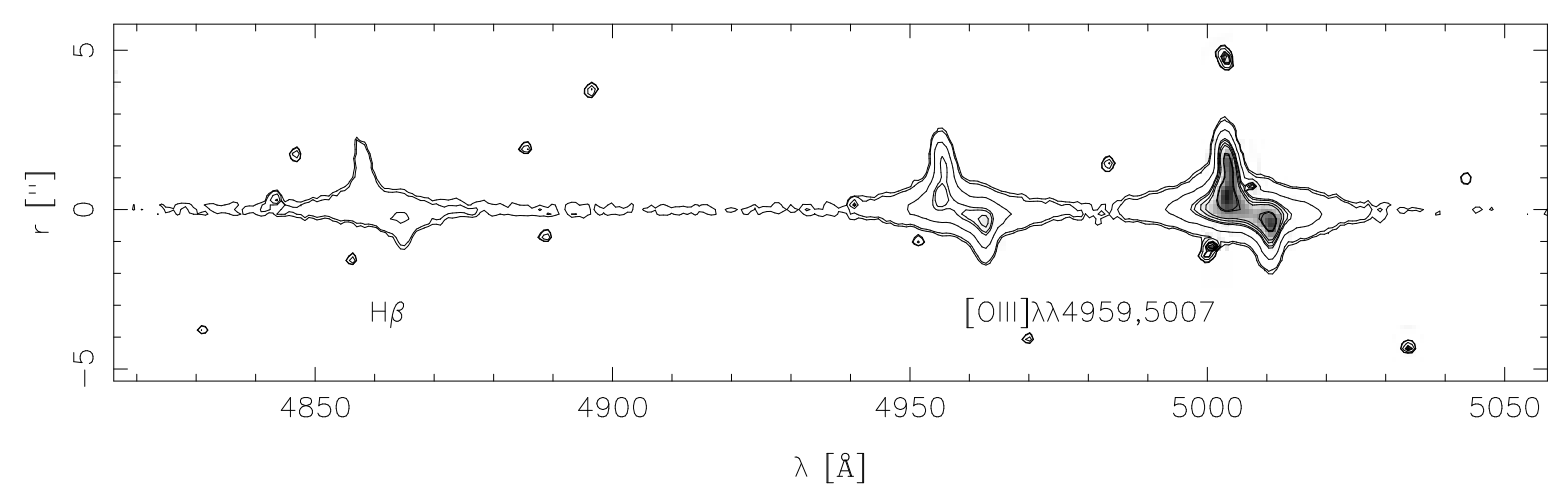

Figura 4.7. GMOS: 3C 303.1

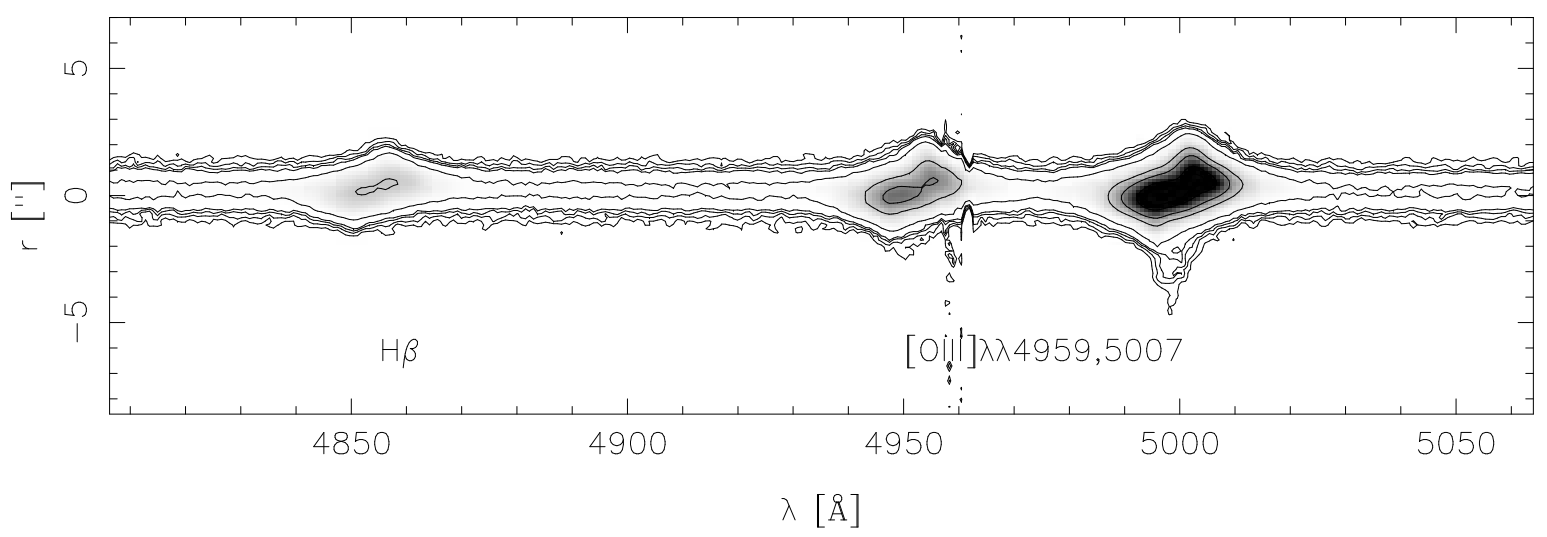

Figura 4.8. GMOS: 3C 305

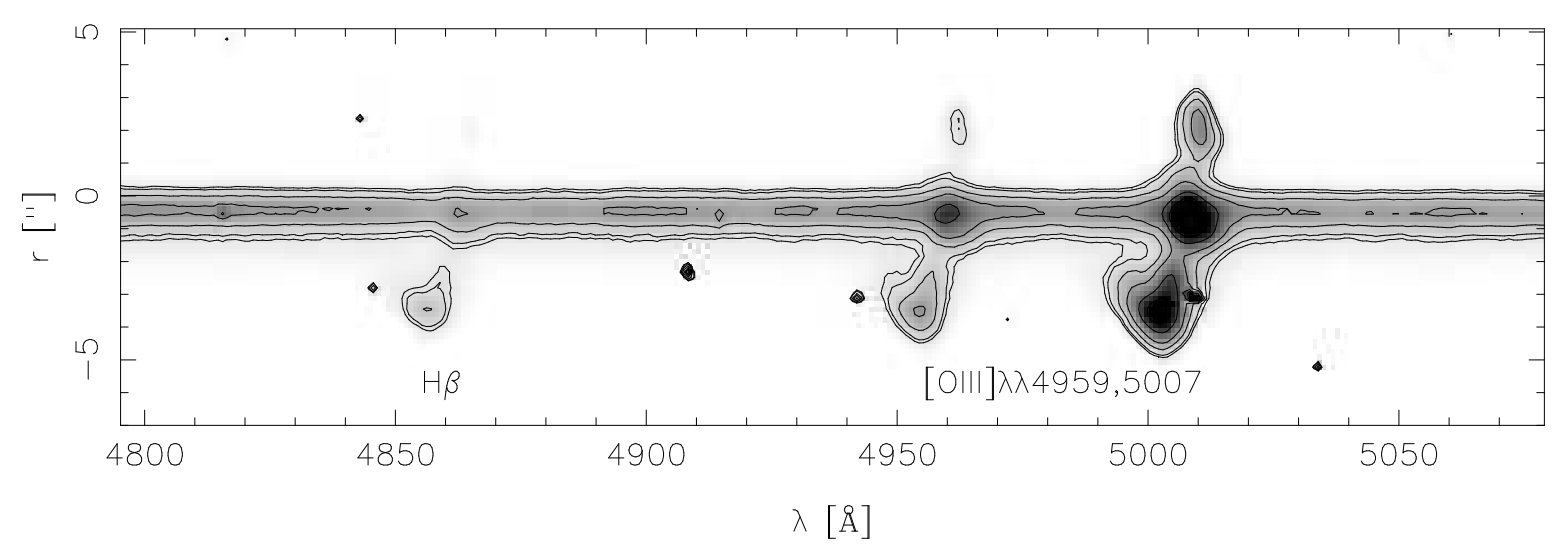


Figura 4.9. GMOS: 3C 321

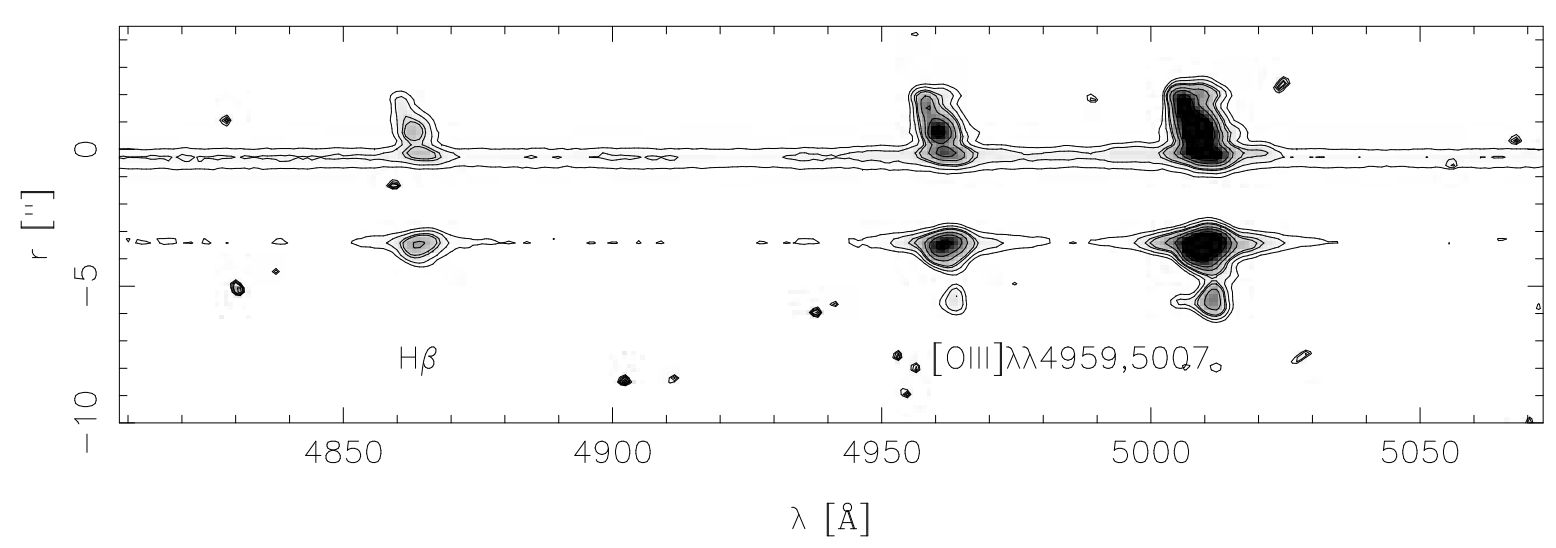

Figura 4.10. GMOS: 3C 381

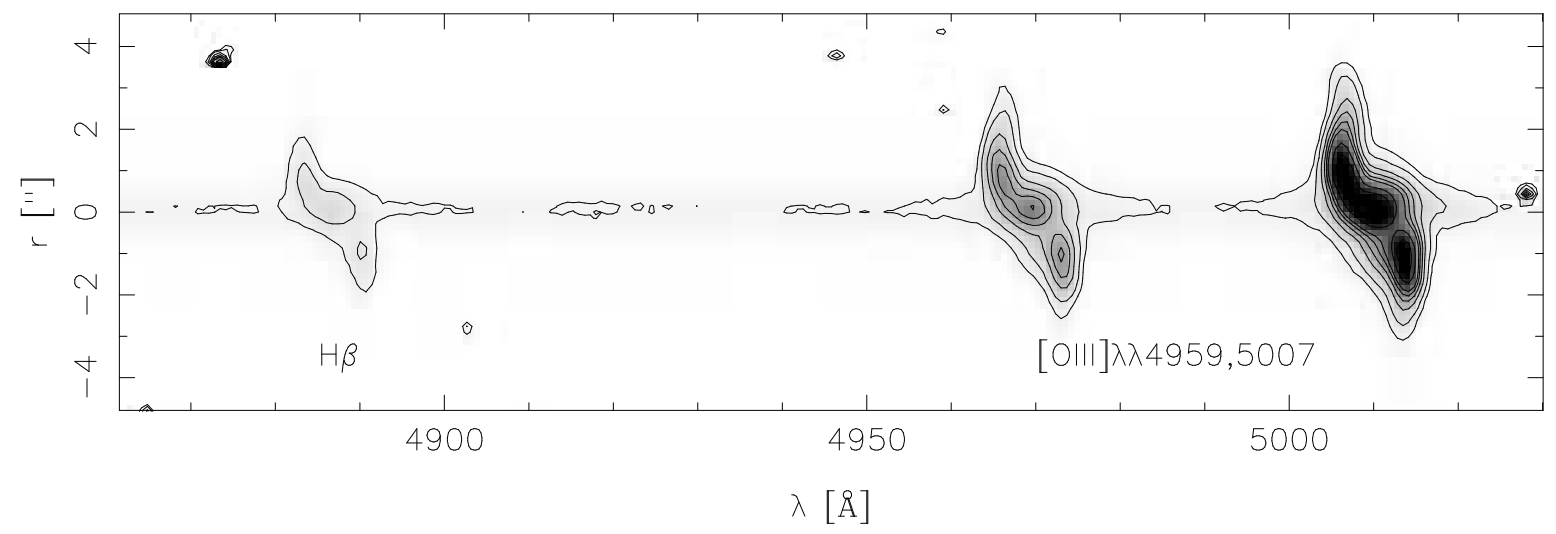


fwhm es, obviamente, el FWHM. Este último se relaciona con la dispersión $\sigma$ de la Gaussiana mediante $\mathrm{FWHM}=2.35 \cdot \sigma$. La pendiente $(m)$ y ordenada al origen $(b)$ de la recta que define el continuo se mantienen constantes durante cada ajuste. La forma de cada línea está dada, entonces, por:

$$
\begin{gathered}
f(\lambda)=R(\lambda)+\left[I_{0} \cdot e^{-\frac{\left(\lambda-\Lambda_{c}\right)^{2}}{2\left(\frac{f w h m}{2.35}\right)^{2}}}\right] \\
R(\lambda)=m \cdot \lambda+b
\end{gathered}
$$

Como resultado, se obtienen los valores de los tres parámetros antes mencionados $\left(I_{0}, \Lambda_{c}\right.$ y fwhm), junto con sus errores $\left(\Delta I_{0}, \Delta \Lambda_{c}\right.$ y $\left.\Delta f w h m\right)$. A partir de ellos se calcula el flujo de energía en cada componente $\left(F_{i}\right)$, junto con el error que se propaga de las mediciones $\left(\Delta F_{i}\right)$ :

$$
\begin{gathered}
F_{i}=\int f_{i}(\lambda) d \lambda ; i=1,2,3, \ldots \\
F_{i}=I_{0}^{i} \cdot \sqrt{2 \pi} \cdot \frac{f w h m^{i}}{2.35} ; \Delta^{2} F_{i}=\frac{2 \pi\left(\Lambda_{c}^{i} \cdot \Delta I_{0}^{i}\right)^{2}+\left(I_{0}^{i} \cdot \Delta f w h m^{i}\right)^{2}}{2.35^{2}}
\end{gathered}
$$

y el flujo total $(\mathcal{F})$ en la línea, también con su error $(\Delta \mathcal{F})$ :

$$
\mathcal{F}=\sum F_{i} ; \Delta \mathcal{F}=\sqrt{\sum \Delta^{2} F_{i}}
$$

La tarea splot realiza el mismo tipo de descomposición gaussiana. A diferencia de la tarea anterior, tiene la ventaja de permitir efectuar una resta entre el perfil real de la línea y el perfil calculado (suma de las componentes individuales identificadas), pudiendo así evaluar el ajuste en conjunto, mediante el comportamiento del residuo. Como desventaja debe mencionarse que, entre los resultados de la tarea, no se encuentran los errores asociados a cada parámetro calculado.

El procedimiento de descomposición Gaussiana y medición del flujo de energía en cada línea se realizó con ngaussfit como herramienta principal, y luego con splot como herramienta de control. Los resultados arrojados por ngaussfit se utilizaron luego como datos de entrada para splot de manera tal de poder evaluar la resta entre el perfil real y el calculado. Si estos residuos resultaban indistinguibles del continuo de fondo, los resultados de ngaussfit se consideraban aceptados, de lo contrario se realizaba un nuevo ajuste. Es decir, la tarea splot se utilizó como herramienta de control sobre los resultados de ngaussfit.

La descomposición gaussiana presenta dos problemas importantes desde el punto de vista matemático. Por un lado, el hecho de que el conjunto de funciones Gaussianas no formen un Conjunto Ortogonal Completo implica que tal descomposición no es única. Y por otro lado, la reproducción del perfil es mejor cuanto mayor sea el número de componentes. Desde el punto de vista físico, trabajamos bajo la hipótesis de que cada componente Gaussiana es la forma en que se manifiesta una determinada región en emisión; luego, las diferencias en $\Lambda_{c}$ y $f w h m$ están directamente asociadas a diferencias en las propiedades físicas intrínsecas de las nubes de gas, como su movimiento relativo, o la turbulencia interna. Por este motivo, sumar componentes Gaussianas de manera arbitraria para mejorar la reproducción de un perfil puede no tener sustento físico. Como regla general, se buscó mantener la cantidad de componentes en el mínimo estrictamente necesario y físicamente aceptable.

En algunos casos, la forma del perfil pone en evidencia la cantidad de componentes que lo conforman, pero en otros casos se observan perfiles muy deformados, lo que hace mucho más 
Figura 4.11. Mapas 2-D y 3-D del [OIII] $\lambda 5007$ en $3 \mathrm{C} 381$.
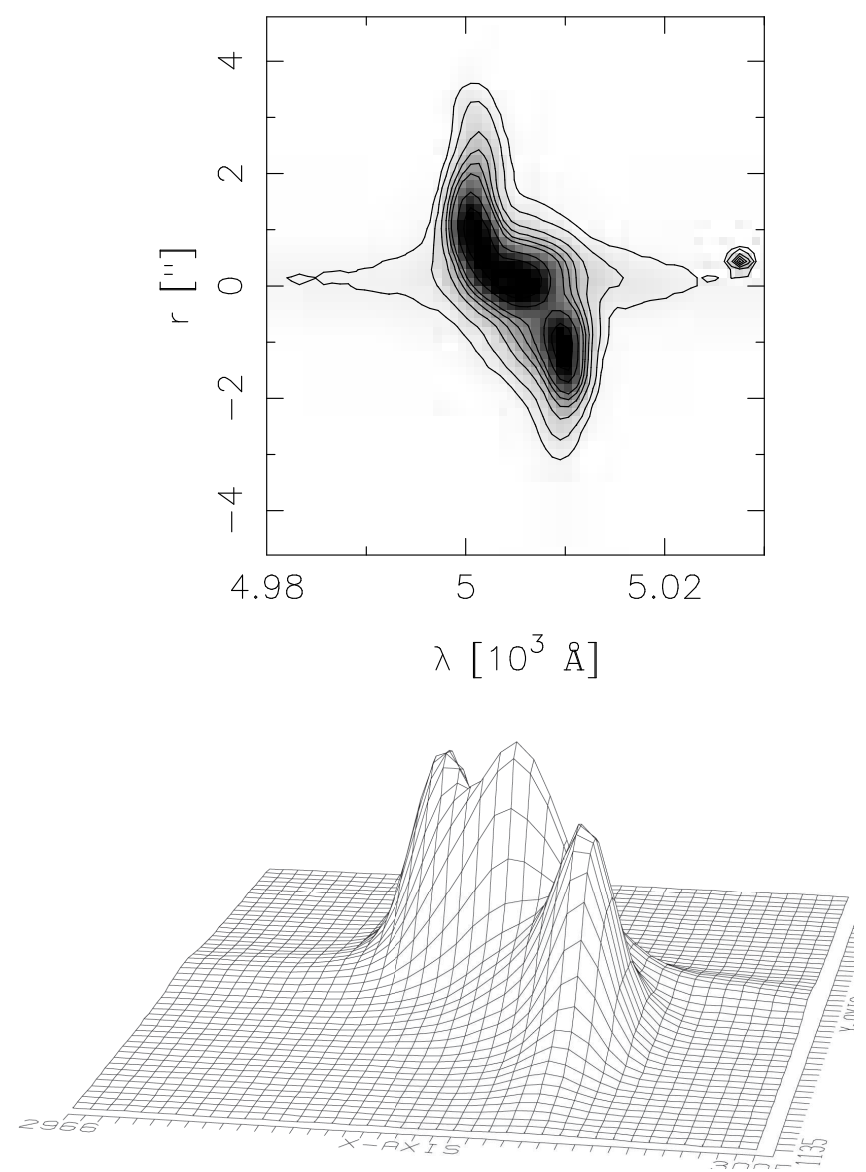
difícil determinar su composición. En el proceso de medición, la cantidad de componentes se determinó en base al análisis morfológico del mapa de intensidad de la línea en cuestión sobre el espectro 2-D y el perfil 3-D (Figura 4.11), y en última instancia de acuerdo al comportamiento de los residuos dado por splot. De acuerdo con este análisis, se establecieron condiciones iniciales para $I_{0}$ y $\Lambda_{c}$. La convergencia de estos parámetros es muy sensible a las condiciones iniciales impuestas, a diferencia de lo que sucede con fwhm.

Los resultados inherentes al flujo emitido en cada línea se desarrollarán en forma individual en los capítulos siguientes. 


\section{Capítulo 5}

\section{Resultados observacionales.}

\subsection{Introducción}

En este Capítulo se realiza la presentación completa de las radiogalaxias que comprenden el trabajo, y de los resultados generales derivados de sus espectros. También se describen los resultados espectrales y características generales de las galaxias que, aunque no pertenecen a la muestra definitiva de estudio, fueron observadas dentro del mismo conjunto (Sección 5.9). Se reúne toda la información multifrecuencia disponible para cada objeto que pueda guardar algún tipo de relación con la emisión de las EELR, particularmente en la banda de radio. Concretamente sobre los espectros, se analizan las líneas de emisión presentes en cada uno, las características particulares de cada EELR, la extensión hasta la cual es posible detectarla, y puntualmente, los resultados inmediatos de la descomposición de los perfiles de emisión.

El resultado que se desprende directamente de la descomposición Gaussiana (la hipótesis subyecente en la descomposición sostiene que existen tantas nubes de gas como componentes Gaussianas compongan el perfil a lo largo de la línea de la visual; Sección 4.2) es el que concierne al análisis de los centroides $\left(\Lambda_{c}\right)$ de las componentes de un dado perfil conforme aumenta la distancia al origen adoptado (el centro galáctico). Al respecto, cabe señalar que la longitud de la ranura es mucho mayor que la extensión de las EELR, por lo cual el límite de detección está impuesto únicamente por la intensidad de la EELR en cuestión. El comportamiento de $\Lambda_{c}$ en función de la distancia al centro galáctico da origen al campo de velocidades del gas, medido en la dirección de la ranura (PA, Tabla 3.4). El estudio se concentra sobre la línea del [OIII] $\lambda 5007$ por tratarse, en la muestra completa, de la línea de emisión más intensa (relación S/N más alta) y más extendida. Se observa que en la posición del centro galáctico existe al menos una componente Gaussiana cuyo centroide $\Lambda_{c}$ está desplazado respecto de la longitud de onda en reposo en la magnitud dada por el corrimiento al rojo $z$ del objeto (es decir, $\left.\Lambda_{c}=5007 \cdot(1+z)\right)$. En otras palabras, en la posición del centro galáctico (CG) existe una componente cuya velocidad coincide con la velocidad sistémica del objeto. Por tal motivo, esta posición se adoptó como origen de velocidades, en el sentido de que lo que se medirá a continuación son apartamientos de la velocidad sistémica de cada galaxia, o bien movimientos respecto del CG. Conforme aumenta la distancia al origen se observan desplazamientos de $\Lambda_{c}$ tanto al azul como hacia el rojo, hacia ambos sentidos de la ranura respectivamente. Pero también, y debido a la descomposición Gaussiana, se observa que para una dada posición existen componentes con velocidades notoriamente distintas. Esto evidencia que dentro de la EELR existen movimientos relativos de las nubes de gas, y que, en muchos casos son turbulentos, desordenados y de muy alta velocidad.

De aquí en adelante, las distancias angulares $(r$, afectadas de los posibles efectos de la inclinación de cada fuente respecto de la línea de la visual) se miden en la dirección de 
la ranura, y respecto al centro galáctico $\left(r_{C G}=0\right)$, que se identifica como la región de máxima emisión dentro del continuo. En general en los espectros 2D (Figs. 4.1 a 4.10) se pueden identificar dos grandes regiones en emisión hacia uno y otro lado del continuo, que se diferenciarán mediante distancias positivas y negativas, y por su localización cardinal respecto de la galaxia anfitriona. Son las mismas regiones que muestran las imágenes HST en [OIII] (Figs. 3.3 a 3.12). A continuación cada vez que se haga mención al espectro de un dado objeto, se da por entendido que se trata del espectro de la región nebular (es decir, no nuclear).

\section{2. $\quad 3 \mathrm{C} 268.2$}

3C 268.2 es una radiofuente bi-lobular, de tipo FRII, cuya densidad de flujo a la frecuencia de $178 \mathrm{MHz}$ es de 9.7 Jy (Spinrad et al. 1985; Massaro et al. 2013). La detección de la fuente puntual central es dudosa. Un estudio reciente de Massaro et al. (2013) indica que los mapas de la emisión a $1.4 \mathrm{GHz}(21 \mathrm{~cm})$ no permiten identificar la fuente puntual; y existen trabajos anteriores que coinciden en este sentido (Neff et al. 1995; Privon et al. 2008). Sin embargo, Strom et al. (1990) habían señalado que en los mapas de emisión en 6 cm (5 GHz; ver fig. 7 de ese trabajo) existe un pequeño aumento de la intensidad en las cercanías de la posición óptica del objeto (tomada de Wyndham 1966) que podría tratarse del núcleo. Existe una diferencia de 0.9 " en ascención recta y de 2.8 " en declinación respecto de las coordenadas en radio y en óptico (Strom et al. 1990). No se conocen los errores de las mediciones en radio, pero se sabe que el error de las medidas del óptico es de 7" (Harvanek \& Hardcastle 1998), por lo cual la posición del núcleo en radio estaría dentro de los márgenes de error de su contraparte óptica.

Es una radiofuente muy extendida, cuyas estelas de emisión en ambos lóbulos ya habían sido notadas por Fanaroff \& Riley (1974) en su trabajo pionero; su máximo tamaño angular es de aproximadamente 113.2" (818 kpc; Harvanek \& Stocke 2002). Aceptando que la localización de la fuente puntual en radiofrecuencias es la establecida por Strom et al. (1990), este núcleo se sitúa aproximadamente en la mitad de la estructura. La extensión de los lóbulos es prácticamente la misma, y se encuentran en dirección noreste y sudoeste, respectivamente (Fig. 3.5, panel inferior). El radio-eje (el ángulo de posición del radio-eje se denominará, por simplicidad, $\mathrm{PA}_{j e t}$ ), definido mediante los hot spots, está ubicado en la dirección de $\mathrm{PA}_{j e t}=21^{\circ}$ (de Koff et al. 1996), sin embargo en la zona cercana al núcleo los lóbulos se curvan, apartándose se la dirección establecida por PA jet (Harvanek \& Hardcastle 1998).

Los estudios en la banda óptica resaltan la presencia de una región de emisión de líneas muy extendida (la EELR) y muy intensa, y de una galaxia anfitriona cuya forma parece estar distorsionada por la presencia de la EELR (de Koff et al. 1996). Según los datos obtenidos con el Observatorio Chandra ${ }^{1}$ en órbita, la emisión en rayos-X comparte estas mismas características: un núcleo deformado, posiblemente influenciado por la EELR del óptico, y emisión de rayos-X extendida en las cercaías de la región central. También se encontró que existe emisión proveniente del extremo del lóbulo sur, focalizada en la misma posición del hot spot (Massaro et al. 2013).

La imagen de emisión nebular del HST (Fig. 3.5, panel superior derecho; notar que, debido a un problema con el sistema de coordenadas en la imagen original, la dirección del Este es hacia la derecha, y no hacia la izquierda como es usual) muestra que la dirección en que se extiende la EELR no coincide con el radio-eje. La emisión se extiende hacia el NO (nornoroeste) y SE (sur-sudeste), con un ángulo de posición de aproximadamente $165^{\circ}$, por lo

\footnotetext{
${ }^{1}$ El Observatorio de Rayos-X Chandra (Chandra X-ray Observatory) es el telescopio de rayos-X operado por la Agencia Nacional de Administración Aeroespacial de Estados Unidos (NASA, National Aeronautics and Space Administration). Fue puesto en órbita en Julio de 1999, y continúa en operaciones.
} 
Tabla 5.1. Líneas de emisión en la EELR de 3C 268.2.

\begin{tabular}{lccc|ccc}
\hline \hline & \multicolumn{5}{c}{ Flujo $^{a}$} \\
Línea $(\AA)$ & \multicolumn{3}{c}{ Noroeste } & \multicolumn{3}{c}{ Sudeste } \\
& $-2.5 "$ & $-1.6 "$ & $-0.9 "$ & $0.9 ”$ & $1.6 "$ & $4.5 "$ \\
\hline$[\mathrm{Ne}$ V] $] 3424$ & - & 1.02 & 0.86 & 0.9 & 2.43 & - \\
{$[\mathrm{O}$ II $] \lambda 3727$} & 2.04 & 1.85 & 1.13 & 1.88 & 4.09 & 2.5 \\
{$[\mathrm{Ne}$ III $] \lambda 3869$} & - & 1.03 & 0.68 & 0.6 & 1.08 & - \\
$\mathrm{H} \delta(4101)$ & - & - & 0.22 & 0.12 & - & - \\
$\mathrm{H} \gamma(4340)$ & - & 0.47 & 0.44 & 0.45 & - & - \\
{$[\mathrm{O}$ III $] \lambda 4363$} & - & 0.18 & 0.09 & - & - & - \\
$\mathrm{He}$ II $(4686)$ & - & 0.51 & 0.43 & 0.31 & - & - \\
$\mathrm{H} \beta(4861)$ & 1 & 1 & 1 & 1 & 1 & 1 \\
{$[\mathrm{O}$ III $] \lambda 4959$} & 3.97 & 4.03 & 3.08 & 2.69 & 3.27 & 1.25 \\
{$[\mathrm{O}$ III $] \lambda 5007$} & 11.09 & 12.09 & 9.33 & 8.27 & 9.37 & 2.01 \\
\hline \hline
\end{tabular}

Notas: ${ }^{a}$ Flujo relativo a $\mathrm{H} \beta$ para cada posición. Las distancias (NO negativas, SE positivas) se expresan respecto al centro galáctico.

cual no hay ningún tipo de alineamiento con las estructuras observadas en la banda de radio ${ }^{2}$. En adelante, la región NO se expresará mediante distancias negativas $\left(r_{N O}<0\right)$ y la región SE con distancias positivas $\left(r_{S E}>0\right)$. En estas imágenes, la EELR es más extensa y más intensa también en la dirección NO, donde se puede apreciar un aumento local de la emisión a una distancia de $0.5 "-0.8$ " hacia el norte.

El espectro de la región se tomó en la dirección dada por las imágenes nebulares, con $\mathrm{PA}=165^{\circ}$. La emisión se concentra en esta dirección, siendo prácticamente despreciable la contribución en dirección perpendicular. En el espectro 2D (Fig. 4.5, se muestra la zona comprendida entre $\mathrm{H} \beta$ y [OIII] $\lambda \lambda 4959,5007)$ se puede apreciar cómo aumenta la intensidad de la emisión en dirección NO, tal como indican las imágenes del HST. En cambio hacia el SE, además de la pequeña región que puede verse en las imágenes nebulares, el espectro permite detectar una zona de emisión más distante y de menor brillo superficial. Se trata de un aumento local de la emisión, se produce a una distancia aproximada de 4 " ( $\sim 29 \mathrm{kpc}$ ) y sólo puede detectarse en las líneas más intensas del espectro, [OII] $\lambda 3727, \mathrm{H} \beta$, y [OІІІ] $\lambda \lambda 4959,5007$ (por el contraste de la imagen, en la Fig. 4.5 puede apreciarse únicamente en el [OIII] $\lambda 5007)$. La EELR tiene una extensión, entonces, de 3.6" ( $\sim 26 \mathrm{kpc})$ en dirección NO, y de 5" ( $\sim 36 \mathrm{kpc})$ hacia el SE.

El conjunto de las líneas presentes en el espectro se reúnen en la Tabla 5.1; el flujo de cada una se expresa respecto del de $\mathrm{H} \beta$ en cada posición. La contribución del continuo nuclear es extremadamente débil, y por lo tanto puede despreciarse. Las líneas no alcanzan el máximo de emisión en la región central, sino en la EELR-NO, a una distancia de 0.6" ( $\sim 4.3 \mathrm{kpc})$. En la región central se produce otro aumento de intensidad, que decae hacia el SE para luego volver a aumentar ligeramente a la distancia de 4". La emisión decae por completo a 5" al $\mathrm{SE}$, siendo indistinguible del ruido de fondo a partir de esta distancia.

En la Figura 5.1 se presentan dos espectros de la región nebular, el panel superior corresponde a la EELR-NO y el inferior a la EELR-SE, la distancia al centro es la misma en

\footnotetext{
${ }^{2}$ Privon et al. (2008) señalaron que la EELR está alineada con la emisión en radio, sin embargo, y dado que utilizaron las mismas imágenes del HST que se emplean en este trabajo, es probable que hayan arribado a esa conclusión debido al error en las coordenadas de los archivos originales.
} 
ambos casos (1.2", $\sim 8.7 \mathrm{kpc})$. Se mantuvo la escala de ordenadas para apreciar la variación de intensidad en las líneas respecto de una y otra región. Los perfiles del [OIII] $\lambda 5007$ de estos espectros se ampliaron en la Figura 5.2 para mostrar tanto la descomposición Gaussiana (paneles superiores) como su consecuencia inmediata: el campo de velocidades del gas (panel inferior). La forma de los perfiles (en negro) varía significativamente entre una y otra región, pero en general, a igual distancia desde el núcleo, se necesita la misma cantidad de componentes Gaussianas (en color) para reproducirlos.

De la inspección de los centroides de todas las líneas, en particular aquellas que tienen perfiles de emisión simples, se advierte que los desplazamientos en longitud de onda de los centroides $\Lambda_{c}$ no se corresponden con el valor conocido y aceptado de corrimiento al rojo, $z=0.362$ (Spinrad et al. 1985). Es decir:

$$
\Lambda_{c} \neq \lambda_{0} \cdot(1+z)
$$

donde $\lambda_{0}$ corresponde a la longitud de onda en reposo de la línea en cuestión.

El comportamiento sistemático descarta la posibilidad de que se trate de errores en las mediciones, o que sea inherente a una especie atómica/iónica en particular. También quedan descartados posibles errores en la reducción de los datos crudos (en particular en lo que respecta a la calibración en longitud de onda), dado que el procedimiento de reducción de 3C 268.2 se realizó de manera idéntica y simultánea para las cuatro galaxias que se observaron en el mismo turno (las otras tres son 3C 268.3, 3C 305 y 3C 321) y sólo en este caso se detectaron diferencias en $\Lambda_{c}$ inconsistentes con $z$.

El corrimiento al rojo se recalculó, entonces, con las mediciones de $\Lambda_{c}$ de todas las líneas en el espectro de la región nuclear. Para ello se extrajo el espectro central con una apertura de 3 px (el diámetro de la apertura corresponde a 0.3") centrada en la posición del núcleo, la misma técnica empleada por Holt, Tadhunter \& Morganti $(2003,2008)$ ante una situación idéntica. En un primer paso se utilizaron sólo las líneas que presentaran perfiles de emisión simples (aquellos que pueden reproducirse con una única componente Gaussiana) y se obtuvo un valor corregido de corrimiento al rojo $z^{\prime}$. Luego se inspeccionaron las componentes que forman los perfiles de [OIII] $\lambda 4959$ y [OIII] $\lambda 5007$ (los únicos perfiles múltiples), para poder incorporar las componentes adecuadas en el cálculo de $z^{\prime}$. El redshift resultante para 3C 238.2, junto con su error es de

$$
z^{\prime}=0.36280 \pm 3 \times 10^{-5}
$$

El campo de velocidades (Fig. 5.2, panel inferior) se obtuvo a partir de este nuevo valor $z^{\prime}$.

Allí se puede identificar un patrón de velocidades ordenado, que se estabiliza en torno a velocidades altas, de 400-500 $\mathrm{km} \mathrm{s}^{-1}$, a partir de $1 "(\sim 7.2 \mathrm{kpc})$. Podría decirse que esta estructura en velocidad tiene el aspecto de una curva de rotación, pero su velocidad de estabilización es demasiado alta para ser compatible con el movimiento dentro del potencial galáctico (Tadhunter et al. 1989). Sobre esta estructura se superponen movimientos desordenados, particularmente en la zona comprendida entre $\pm 2 "(\sim \pm 14.4 \mathrm{kpc})$. Esta es la única zona del espectro donde el perfil de emisión del [OIII] $\lambda 5007$ está formado por tres componentes, y es también la zona donde se aprecian notables apartamientos de la curva de rotación, con velocidades igualmente altas, entre $500-600 \mathrm{~km} \mathrm{~s}^{-1}$. Dos de las tres componentes en la región NO se pueden apreciar hasta el límite de detección de la línea, a una distancia aproximada de $3.5 "$ ( $\sim 25 \mathrm{kpc})$. La segunda componente tiene un comportamiento relativamente ordenado, que puede asemejarse incluso con otra curva de rotación, cuya estabilidad se alcanza a una velocidad distinta de la primera, en torno a los $200 \mathrm{~km} \mathrm{~s}^{-1}$ (el orden de magnitud en este caso sí es compatible con el movimiento Kepleriano en el pozo de potencial; Tadhunter et al. 
Figura 5.1. Espectros de la EELR en 3C 268.2.
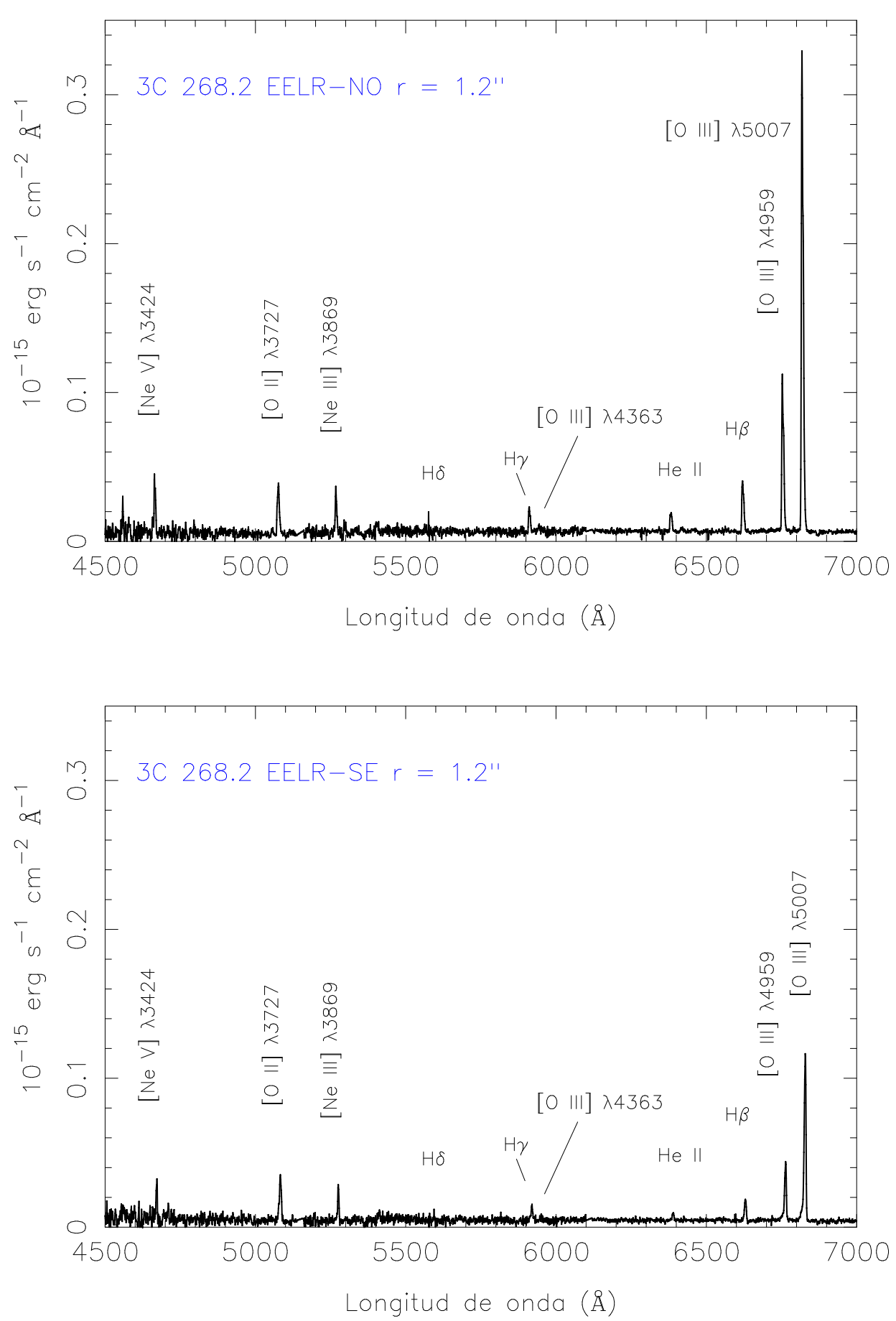

Arriba: Espectro de la EELR noroeste, a 1.2" del centro galáctico. Abajo: Espectro de la EELR sudeste, a la misma distancia. Se puede apreciar la variación de intensidades en todas las líneas respecto de una y otra región. 
Figura 5.2. Descomposición Gaussiana y Campo de Velocidad en 3C 268.2.
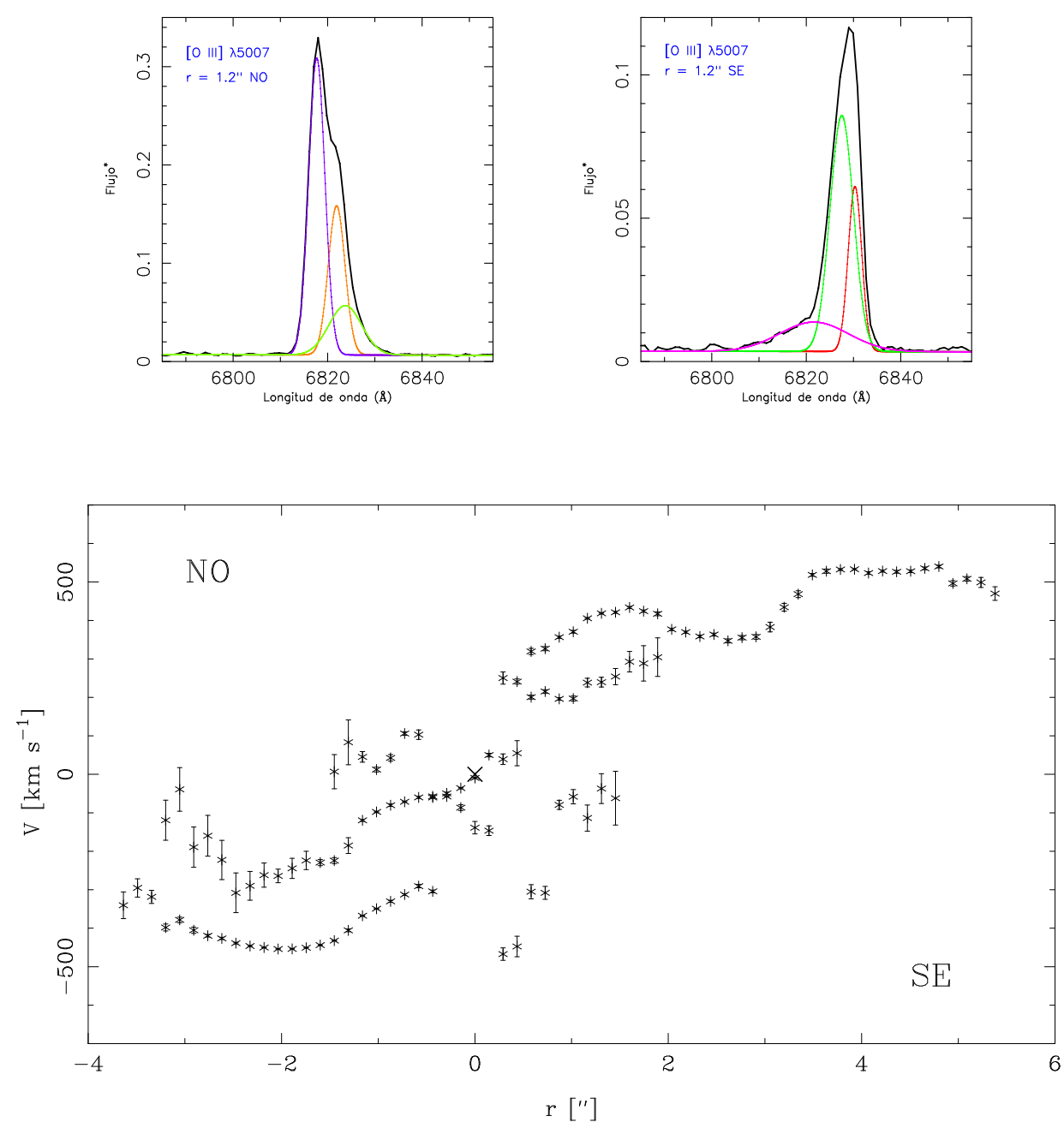

Arriba: Descomposición Gaussiana (en color) de los perfiles de [OIII] $\lambda 5007$ (en negro) para los espectros de la Fig. $5.1\left[^{(*)}\right.$ El flujo está expresado en las mismas unidades]. Abajo: Campo de velocidad del gas en la EELR, en la dirección de la ranura $\left(\mathrm{PA}=165^{\circ}\right)$. La cruz indica el centro galáctico. Se utilizan distancias negativas para la región NO, y positivas para la SE. 
1989). Su contraparte en la región SE (aceptando que este patrón puede considerarse como una segunda curva de rotación), sin embargo, no puede distinguirse a distancias mayores que $2 "$

\section{3. $\quad 3 \mathrm{C} 268.3$}

3C 268.3 es una radiofuente compacta $^{3}$, la más pequeña de la muestra, cuyo máximo tamaño angular ${ }^{4}$ es de 1.85" ( $\left.13.7 \mathrm{kpc}\right)$. Su densidad de flujo a la frecuencia de $178 \mathrm{MHz}$ es de 10.7 Jy (Spinrad et al. 1985), se trata de una galaxia FRII, bi-lobular, pero notablemente asimétrica. El lóbulo noroeste es tanto más pequeño como más intenso, mientras que el lóbulo sudeste, más tenue, se extiende a distancias mayores. La radiofuente puntual se detectó apenas marginalmente en las imágenes de MERLIN en $5 \mathrm{GHz}$ (Lüdke et al. 1998) como la pequeña concentración de brillo ubicada a 0.3 " hacia el sur del hot spot en el lóbulo noroeste (ver Fig. 3.6, panel inferior izquierdo). El radio-eje se encuentra en la posición $\mathrm{PA}_{j e t}=161^{\circ}$ (de Koff et al. 1996).

Los primeros estudios en el óptico, realizados por McCarthy et al. (1995) con datos del HST, resaltan la presencia de una región con emisión nebular, cuyo tamaño sería de 4", más extensa que la estructura en radio pero alineada con ella. Al igual que sucede en radiofrecuencias, la EELR es asimétrica, extendiéndose mucho más hacia el SE que hacia el NO (ver Fig. 3.6, panel superior derecho). La dirección preferencial de alineación está dada por $\mathrm{PA}=146^{\circ}$, ligeramente diferente de $\mathrm{PA}_{j e t}$. El lóbulo NO está completamente contenido dentro de la EELR-NO, mientras que el lóbulo SE se encuentra desplazado hacia el oeste de la EELR-SE.

El espectro 2D de la región, que se tomó con la ranura alineada según PA, se muestra en la Fig. 4.6 (la zona comprendida por $\mathrm{H} \beta$ y [OIII] $\lambda \lambda 4959,5007$ ). La emisión del continuo es completamente despreciable, constrastando con la intensidad de las líneas. La región SE está expresada mediante distancias positivas $\left(r_{S E}>0\right)$, y la región NO con distancias negativas $\left(r_{N O}<0\right)$. Aquí también se ve claramente que la región SE es más extensa que la NO, incluso el espectro es capaz de detectar regiones de muy bajo brillo superficial que no son visibles con HST. La EELR tiene una extensión de 5.3" ( $\sim 39.3 \mathrm{kpc}): 3.3$ " hacia el SE ( 24.7 kpc) y 2" hacia el NO ( $\sim 11 \mathrm{kpc})$. Ya desde la forma de las líneas se puede apreciar cómo la emisión se desplaza hacia el rojo y el azul en cada región. La emisión proveniente de las bandas óptica y de radio puede considerarse alineada y superpuesta, a pesar de la pequeña diferencia en los ángulos de posición (PA y $\mathrm{PA}_{j e t}$ ) y en el ligero desalineamiento hacia el SE.

El conjunto de líneas de emisión del espectro se reunen en la Tabla 5.2, junto con el flujo

\footnotetext{
${ }^{3}$ Este tipo de fuentes reciben el nombre de CSS (Compact Steep Spectrum). Se trata de radiofuentes compactas: los tamaños lineales proyectados varían entre 1-20 kpc; muy potentes: la potencia emitida en la frecuencia de $178 \mathrm{MHz}$ es $P_{178}>10^{26.5} \mathrm{~W} \mathrm{~Hz}^{-1}$ (de Vries et al. 1997); y sus SED en la banda de radio se caracterizan por presentar un máximo en la zona de $100 \mathrm{MHz}$ (O'Dea et al. 2002) y tener pendientes pronunciadas: si la densidad de flujo se expresa como $S_{\nu} \propto \nu^{-\alpha}$, entonces los índices espectrales típicos pertenecen al rango $\alpha \gtrsim 0.5$ (de Vries et al. 1997, y sus referencias). Otro grupo de fuentes compactas, distinto de las CSS, recibe el nombre de GPS (Gigahertz Peaked Spectrum). Son más pequeñas, sus tamaños son menores que 1 kpc, y la SED tiene un máximo en la zona de frecuencias del orden del GHz (Holt et al. 2008).

Existen dos versiones sobre el posible origen de las fuentes CSS. Una sugiere que son las versiones jóvenes de las típicas fuentes bi-lobulares de gran escala, de manera que evolucionarán hasta convertirse en fuentes FRII, o tal vez en FRi si la disminución en luminosidad conforme la fuente envejece es suficientemente grande. La otra teoría indica que el tamaño de estas fuentes se debe a que están inmersas en un MIG suficientemente denso; de esta forma no se espera que la evolución del objeto cambie su apariencia, en particular, no se espera que evolucionen convirtiéndose en radiofuentes de gran escala (de Vries et al. 1997, 1999; Axon et al. 2000; Holt et al. 2009).

${ }^{4}$ http://www.jb.man.ac.uk/atlas/object/3C268P3.html
} 
Figura 5.3. Espectros de la EELR en 3C 268.3.
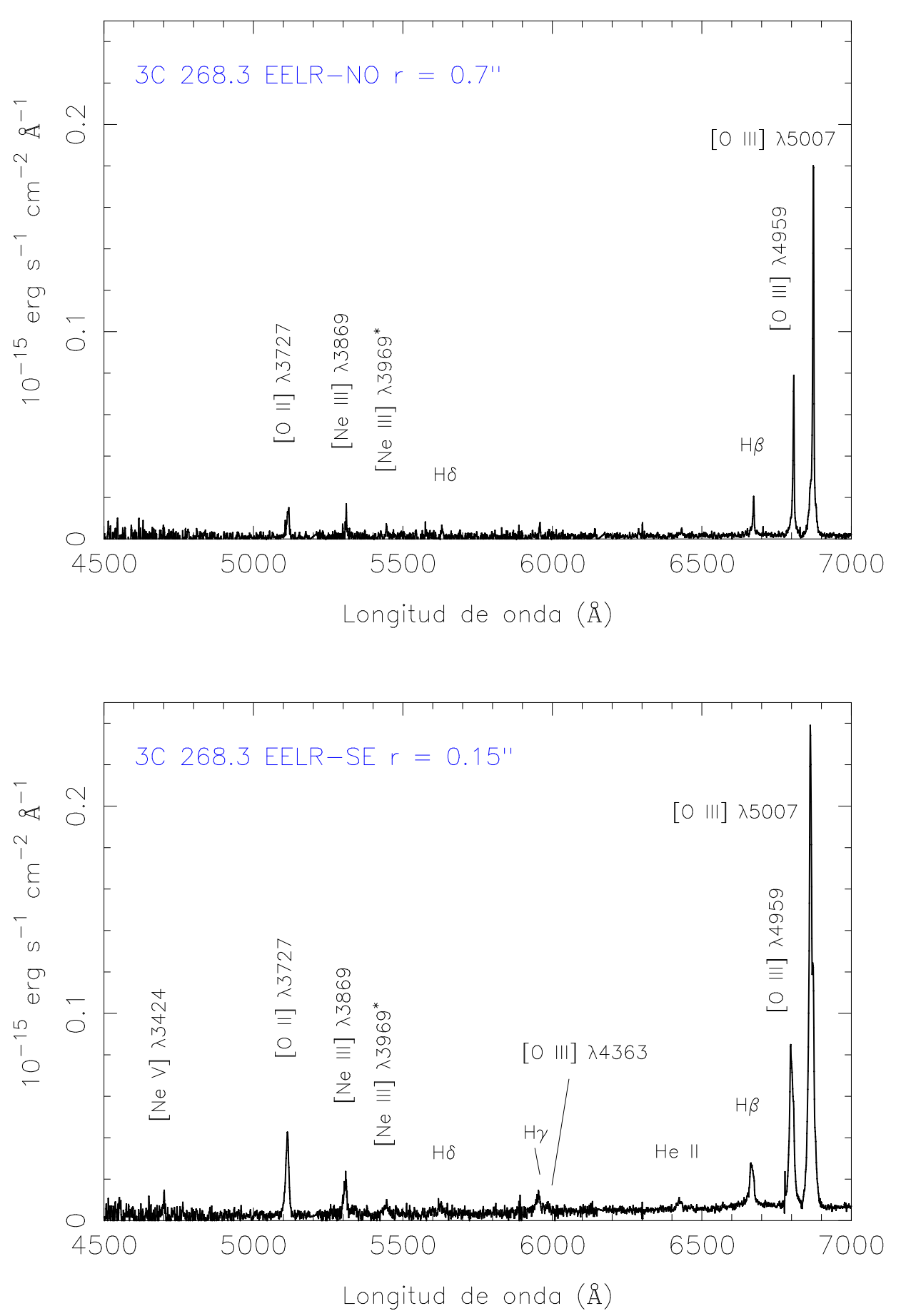

Arriba: Espectro de la EELR noroeste, a 0.7" del centro galáctico. Abajo: Espectro de la EELR sudoeste, a 0.15" (* ver comentario en la Tabla 5.2). En el espectro NO muchas de las líneas, que se manifiestan con más intensidad en la zona central (como en el espectro SE), ya no están presente. 
Figura 5.4. Descomposición Gaussiana y Campo de Velocidad en 3C 268.3.
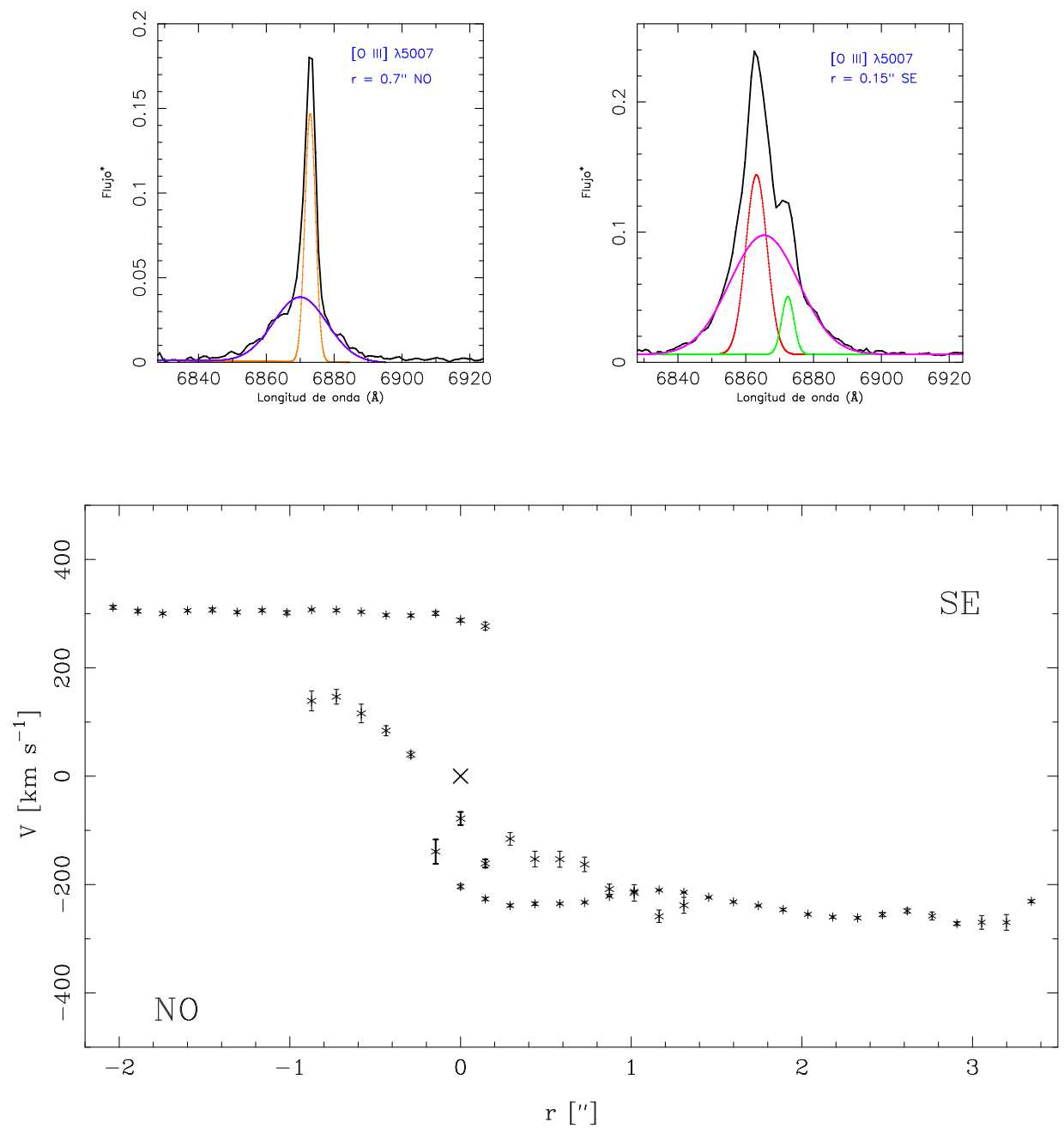

Arriba: Descomposición Gaussiana (en color) de los perfiles de [OIII] $\lambda 5007$ (en negro) para los espectros de la Fig. $5.3\left[{ }^{(*)}\right.$ El flujo está expresado en las mismas unidades]. Abajo: Campo de velocidad del gas en la EELR, en la dirección de la ranura $\left(\mathrm{PA}=146^{\circ}\right)$. La cruz indica el centro galáctico, que se mueve con la velocidad sistémica. Se utilizan distancias negativas para la región NO, y positivas para la SE. 
Tabla 5.2. Líneas de emisión en la EELR de 3C 268.3.

\begin{tabular}{lccc|ccc}
\hline \hline & \multicolumn{5}{c}{ Flujo $^{a}$} \\
Línea $(\AA)$ & $-1.6 "$ & $-0.7 "$ & $-0.3 "$ & $0.6 ”$ & $1.00 "$ & $2.04 "$ \\
\hline$[\mathrm{Ne}$ v $] \lambda 3424$ & - & - & - & 0.32 & 0.75 & 1.55 \\
{$[\mathrm{O}$ II $] \lambda 3727$} & 0.8 & 1.16 & 0.94 & 2.05 & 2.7 & 1.96 \\
{$[\mathrm{Ne}$ III $] \lambda 3869$} & - & 0.28 & 0.22 & 0.68 & 0.75 & 1.07 \\
{$[\mathrm{Ne}$ III $] \lambda 3968^{b}$} & - & 0.29 & 0.08 & 0.21 & 0.17 & 0.49 \\
$\mathrm{H} \delta(4101)$ & - & 0.18 & 0.06 & 0.03 & 0.09 & 0.32 \\
$\mathrm{H} \gamma(4340)$ & - & 0.18 & 0.14 & 0.22 & 0.23 & 0.41 \\
{$[\mathrm{O}$ III $] \lambda 4363$} & - & 0.09 & - & 0.15 & - & - \\
$\mathrm{He}$ II $(4686)$ & - & 0.14 & 0.17 & 0.14 & 0.25 & 0.32 \\
$\mathrm{H} \beta(4861)$ & 1 & 1 & 1 & 1 & 1 & 1 \\
{$[\mathrm{O}$ III $] \lambda 4959$} & 2.28 & 5.06 & 3.53 & 3.24 & 3.69 & 2.88 \\
{$[\mathrm{O}$ III $] \lambda 5007$} & 4.0 & 11.93 & 8.71 & 9.55 & 11.61 & 8.46 \\
\hline \hline
\end{tabular}

Notas: ${ }^{a}$ Flujo relativo a $\mathrm{H} \beta$ para cada posición. Las distancias (NO negativas, SE positivas) se expresan respecto al centro galáctico.

${ }^{b}$ En esta longitud de onda coinciden tres líneas de emisión: [NeIII] 33967.4 , [CaII] $\lambda 3968.44$ y HeII (3968.43), en orden de intensidad.

relativo al de $\mathrm{H} \beta$ en cada posición. La intensidad de todas ellas decae desde el centro hacia las afueras de la región, generalmente de manera abrupta, con las excepciones de la misma $\mathrm{H} \beta$ y las líneas de oxígeno. Los espectros de la EELR se muestran en la Fig. 5.3, en el panel superior, el de la región NO, a 0.7", y en el panel inferior, el de la región SE, a 0.15" del núcleo. Aunque las regiones se extienden a grandes distancias, se eligieron espectros cercanos a la región central porque es la zona donde todas las líneas son más intensas. A su vez, también se puede notar que la contribución del continuo es despreciable. Los perfiles del [OIII] $\lambda 5007$ son complejos, particularmente en la zona interna de la región SE.

En la Figura 5.4 se muestran los perfiles de $[\mathrm{OIII}] \lambda 5007$ correspondientes a los dos espectros anteriores (panel superior), y el campo de velocidades obtenido a partir de esta línea (panel inferior). La región más turbulenta de la EELR comprende la zona interna, particularmente en la EELR-SE. Esto puede verse también a través de los perfiles del panel superior, donde se ponen de manifiesto las diferencias respecto de las componentes cinemáticas en cada región. En el campo de velocidades se puede apreciar la curva de rotación, estabilizándose torno a velocidades de $\pm 300 \mathrm{~km} \mathrm{~s}^{-1}$. En la EELR-NO la componente cinemática dominante es la que traza la curva de rotación, sin embargo se detecta una componente secundaria, menos intensa y más ancha. Esta componente no es tan extendida como la primera, pudiéndose detectar hasta la mitad del alcance de aquella ( 1"; $\sim 7.4 \mathrm{kpc})$. La velociad relativa entre ambas es $\gtrsim 200 \mathrm{~km} \mathrm{~s}^{-1}$. La situación es similar hacia el SE, aunque la intensidad de la emisión es mayor (característica compartida por todas las líneas del espectro). En la zona nuclear $(|\mathrm{r}| \lesssim 0.15 ”)$ se manifiesta una tercer componente cinemática. Aunque la intensidad es mucho menor que la de las otras dos, su presencia es evidente en la descomposición del perfil, como puede verse en el ejemplo de la Fig. 5.4. Se observa turbulencia en la zona comprendida por $|\mathrm{r}| \lesssim 1$ " (corresponde a una extensión total de $\sim 15 \mathrm{kpc}$ ), pero las velocidades relativas de estas componentes se mantienen relativamente bajas $\left(\gtrsim 200 \mathrm{~km} \mathrm{~s}^{-1}\right)$. 


\section{4. $\quad 3 \mathrm{C} 285$}

La radiofuente 3C 285 es un objeto clase FRII cuya densidad de flujo en la frecuencia de $178 \mathrm{MHz}$ es de 11.3 Jy (Laing et al. 1983; Allen et al. 2002). Se trata de un objeto bi-lobular de grandes dimensiones, su máximo tamaño angular es de 183.7". La presencia de los jets se distingue con mayor claridad hacia el este, donde pueden verse las concentraciones de emisión (knots) que deja a su paso (ver fig. 5 de van Breugel \& Dey 1993). El último de estos knots determina el punto donde se produce una interrupción en el camino del jet, y éste se curva hacia el sur para finalmente originar el hot spot. El ángulo de posición de la estructura en radio es de $\mathrm{PA}_{j e t}^{a}=78^{\circ}$, si se toma como referencia la dirección de los jets, y de $\mathrm{PA}_{j e t}^{b}=81^{\circ}$ (Baum \& Heckman 1989a) si se toma la posición del hot spot "desalineado" (ver Figura 3.8, panel derecho). Ninguno de los hot spots es tan intenso como en otras típicas fuentes FRII 5 .

La galaxia anfitriona se observó en el óptico con los instrumentos STIS (Allen et al. 2002) y ACS (Tremblay et al. 2009) del HST, previamente había sido observada desde Tierra, con el telescopio Mayall/NOAO en Kitt Peak (Baum et al. 1988, 1990). En las imágenes del continuo (panel izquierdo de la Fig. 3.8) se distinguen múltiples estructuras de polvo (Allen et al. 2002). En los datos de Baum et al. (1988) existe una envoltura elongada en dirección norte que podría ser un indicador de interacción entre 3C 285 y una galaxia ubicada a 40". Las dos principales estructuras de polvo se disponen en posición relativamente perpendicular (los ángulos de posición son $5^{\circ}$ y $150^{\circ}$ ), la más pequeña de ellas se ubica justo por delante del núcleo óptico (Allen et al. 2002).

Las imágenes de línea se tomaron en $\mathrm{H} \alpha+$ [NII] y [OIII]. Baum et al. (1988) distinguen dos sistemas gas ionizado, una región compacta con brillo superficial alto en dirección este-oeste, alineada con la emisión en radio, y un filamento cuya dirección (nor-noroeste - sur-sudeste) coincide con la dirección de elongación de la envoltura. En las imágenes de la cámara ACS del HST (ver fig. 8 de Tremblay et al. 2009) se puede inferir la presencia de una región importante de gas ionzado, dominada por la emisión extendida en $\mathrm{H} \alpha+$ [NII] en la región central, y por el [OIII] hacia el oeste. Las estructuras que se manifiestan en ambas imágenes son radicalmente diferentes. La emisión del [OIII] adopta una forma semejante a una "W" incompleta. En la región central no es posible distinguir el núcleo porque la emisión está "repartida" en un filamento que lo cubre; hacia el oeste se encuentran las estructuras de más alto brillo superficial, siendo la más alejada del núcleo, la estructura más intensa.

Dado que no hay datos de la cámara WFPC2 disponibles sobre este objeto, el espectro GMOS se tomó de acuerdo a la información provista por Tremblay et al. (2009). Se utilizó una ranura ancha, de 1.5" para cubrir la mayor parte posible de la región en emisión, teniendo en cuenta que la estructura es compleja. El ángulo de posición adoptado fue $\mathrm{PA}=80^{\circ}$, de manera que la ranura se encuentra en la dirección del radio eje $\left(\mathrm{PA}_{j e t}^{b}\right)$. El espectro es rico en líneas de emisión, el conjunto completo se lista en la Tabla 5.3, con los flujos expresados respecto del de $\mathrm{H} \beta$ en cada posición. Si bien no es posible inferir la presencia de una región significativa con emisión de líneas (es decir, una región de gas ionizado) hacia el este a partir de las imágenes, en el espectro se encuentra que tal región existe, aunque la intensidad de su emisión es, claramente, menor (ver la sección del espectro 2 D que comprende la zona entre $\mathrm{H} \beta$ у $[\mathrm{OIII}] \lambda \lambda 4959,5007$, en la Fig. 4.4). Se emplearon coordenadas negativas para expresar las distancias al centro de la galaxia en la región $\mathrm{O}[\mathrm{SO}]$ (oeste-sudoeste; $r_{O S O}["]<$ 0 ), y coordenadas positivas para expresar las distancias en dirección E[NE] (este-noreste; $\left.r_{E N E}["]>0\right)$. La región $\mathrm{O}[\mathrm{SO}]$ se extiende por 5.2" (8.4 kpc, aproximadamente) y la región $\mathrm{E}[\mathrm{NE}]$, por $6.3 "(\sim 10 \mathrm{kpc})$, medido según la máxima distancia a la cual puede medirse la línea $[\mathrm{OIII}] \lambda 5007$.

\footnotetext{
${ }^{5}$ http://www.jb.man.ac.uk/atlas/object/3C285.html
} 
Tabla 5.3. Líneas de emisión en la EELR de 3C 285.

\begin{tabular}{lccc|ccc}
\hline \hline & \multicolumn{6}{c}{ Flujo $^{a}$} \\
Línea $(\AA)$ & \multicolumn{3}{c}{ Oeste-sudoeste } & \multicolumn{3}{c}{ Este-noreste } \\
& $-4.1 "$ & $-2.6 "$ & $-1.6 "$ & $1.6 "$ & $2.6 "$ & $5.0 "$ \\
\hline$[\mathrm{O}$ II $] \lambda 3727$ & 5.92 & 4.46 & 5.47 & 5.0 & 3.21 & 10.1 \\
{$[\mathrm{Ne}$ III $] \lambda 3869$} & - & 1.24 & 1.98 & 1.06 & - & - \\
{$[\mathrm{Ne}$ III $] \lambda 3968^{b}$} & - & 0.28 & - & - & - & - \\
$\mathrm{H} \delta(4101)$ & - & 0.18 & - & - & - & - \\
$\mathrm{H} \gamma(4340)$ & - & 0.56 & - & - & - & - \\
{$[\mathrm{O}$ III $] \lambda 4363$} & - & 0.37 & - & - & - & - \\
$\mathrm{He}$ II $(4686)$ & - & 0.33 & - & 0.33 & - & - \\
$\mathrm{H} \beta(4861)$ & 1 & 1 & 1 & 1 & 1 & 1 \\
{$[\mathrm{O}$ III $] \lambda 4959$} & 4.11 & 4.03 & 3.85 & 3.77 & 3.23 & 2.27 \\
{$[\mathrm{O}$ III $] \lambda 5007$} & 12.01 & 11.84 & 11.55 & 11.23 & 8.77 & 6.5 \\
\hline \hline
\end{tabular}

Notas: ${ }^{a}$ Flujo relativo a $\mathrm{H} \beta$ para cada posición. Las distancias (O[SO] negativas, E[NE] positivas) se expresan respecto al centro galáctico.

${ }^{b}$ En esta longitud de onda coinciden tres líneas de emisión: [NeIII] $\lambda 3967.4$, [CaII] $\lambda 3968.44$ y HeII (3968.43), en orden de intensidad.

El comportamiento de la emisión es notoriamente irregular. La única especie que puede medirse en forma continua a lo largo de los 11.5" que se extiende la emisión es el [OIn] $\lambda 5007$. En la región central, las únicas líneas presentes son [OІІ] $\lambda 3727$ y [OIII] $\lambda \lambda 4959,5007$. En dirección $\mathrm{O}[\mathrm{SO}]$, la emisión (en general) emerge a partir de 1.6" aproximadamente $(\sim 2.6 \mathrm{kpc})$ y se desvanece en torno a $3.4 "(\sim 5.5 \mathrm{kpc})$, con la excepción de los oxígenos (por ejemplo, el [OII] $\lambda 3727$ se detecta hasta 4", o $6.4 \mathrm{kpc}$, del núcleo). Sólo en esta zona es posible encontrar la emisión de $\mathrm{H} \delta$, [OIII] $\lambda 4363$ y en la longitud de onda (en reposo) 3968Å, cuya contribución dominante podría deberse al [Ne III] $\lambda 3968$. En esta zona se produce la máxima intensidad del espectro en conjunto, en concordancia con lo esperado según la imagen de [OIII] de Tremblay et al. (2009).

En dirección $\mathrm{E}[\mathrm{NE}]$ la emisión también emerge por regiones, pero aquí se detectan menos cantidad de especies y con mucha menor intensidad. Mientras que el [OII] $\lambda 3727$ se puede detectar con continuidad desde el extremo de la región $\mathrm{O}[\mathrm{SO}]$ hasta 2.6" en dirección E[NE], es posible encontrar emisión en $\mathrm{H} \gamma$ entre $0.6 "-0.9$ " aproximadamente $(\sim 1-1.4 \mathrm{kpc})$ cuando no hay otra línea detectable que no sea la de los oxígenos. A la distancia de 1.5" ( $2.4 \mathrm{kpc})$ emergen [NeIII] $\lambda 3869$, HeII y H $\beta$; las dos primeras se desvanecen en torno a 2.3 " ( $\sim 3.7 \mathrm{kpc})$, y $\mathrm{H} \beta$ permanece detectable hasta los $5.4 "(\sim 8.7 \mathrm{kpc})$. El [OII] $\lambda 3727$ emerge en la zona 4"-5.7" (6.4-9.2 kpc, aproximadamente) y compite en intensidad con el [OIII] $\lambda 5007$.

En la Figura 5.5 se presentan espectros unidimensionales de las dos regiones. El espectro de la región $\mathrm{O}[\mathrm{SO}]$ (panel superior) corresponde a una distancia de 2.9" ( $\sim 4.7 \mathrm{kpc}$ ) del núcleo, mientras que el de la región E[NE] corresponde a 1.7" ( $\sim 2.7 \mathrm{kpc})$. La escala de ordenadas se mantiene en ambos espectros para apreciar la diferencia de intensidades en todas las líneas de emisión, se puede ver cómo la intensidad es notoriamente mayor en el espectro de la región $\mathrm{O}[\mathrm{SO}]$ respecto del de la región $\mathrm{E}[\mathrm{NE}]$, aún cuando la distancia al centro es mayor.

En la Figura 5.6 se ampliaron los perfiles del [OIII] correspondientes a estos dos espectros (en negro) junto con su descomposición Gaussiana (en color). En la nebulosa E[NE] el perfil es simple hasta una distancia de 2.3" aproximadamente, pero luego se necesitan dos componentes 
Figura 5.5. Espectros de la EELR en 3C 285.
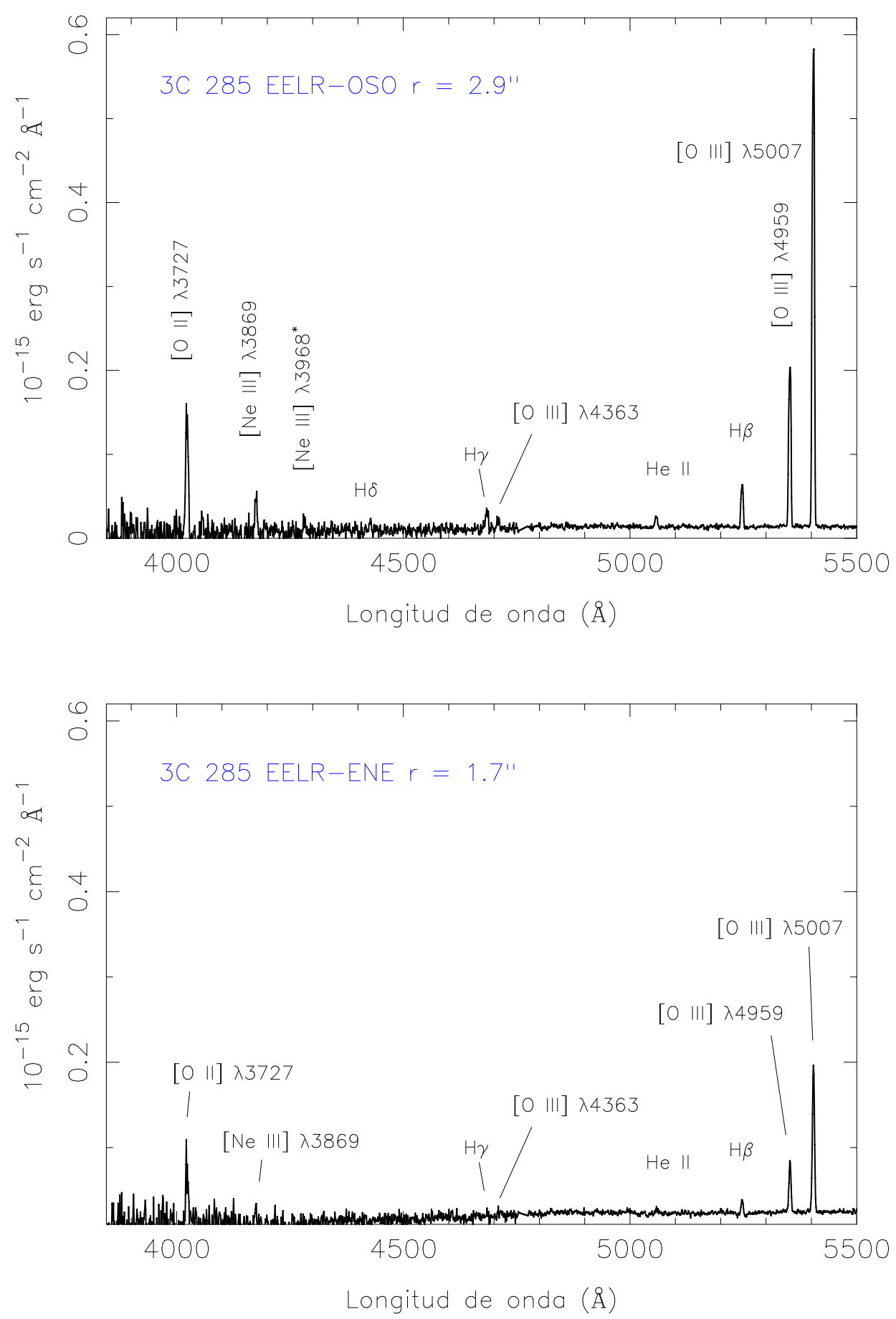

Arriba: Espectro de la EELR oeste-sudoeste, a 2.9" del centro galáctico (* ver comentario en la Tabla 5.3). Abajo: Espectro de la EELR este-noreste 1.7". 
Figura 5.6. Descomposición Gaussiana y Campo de Velocidad en 3C 285.
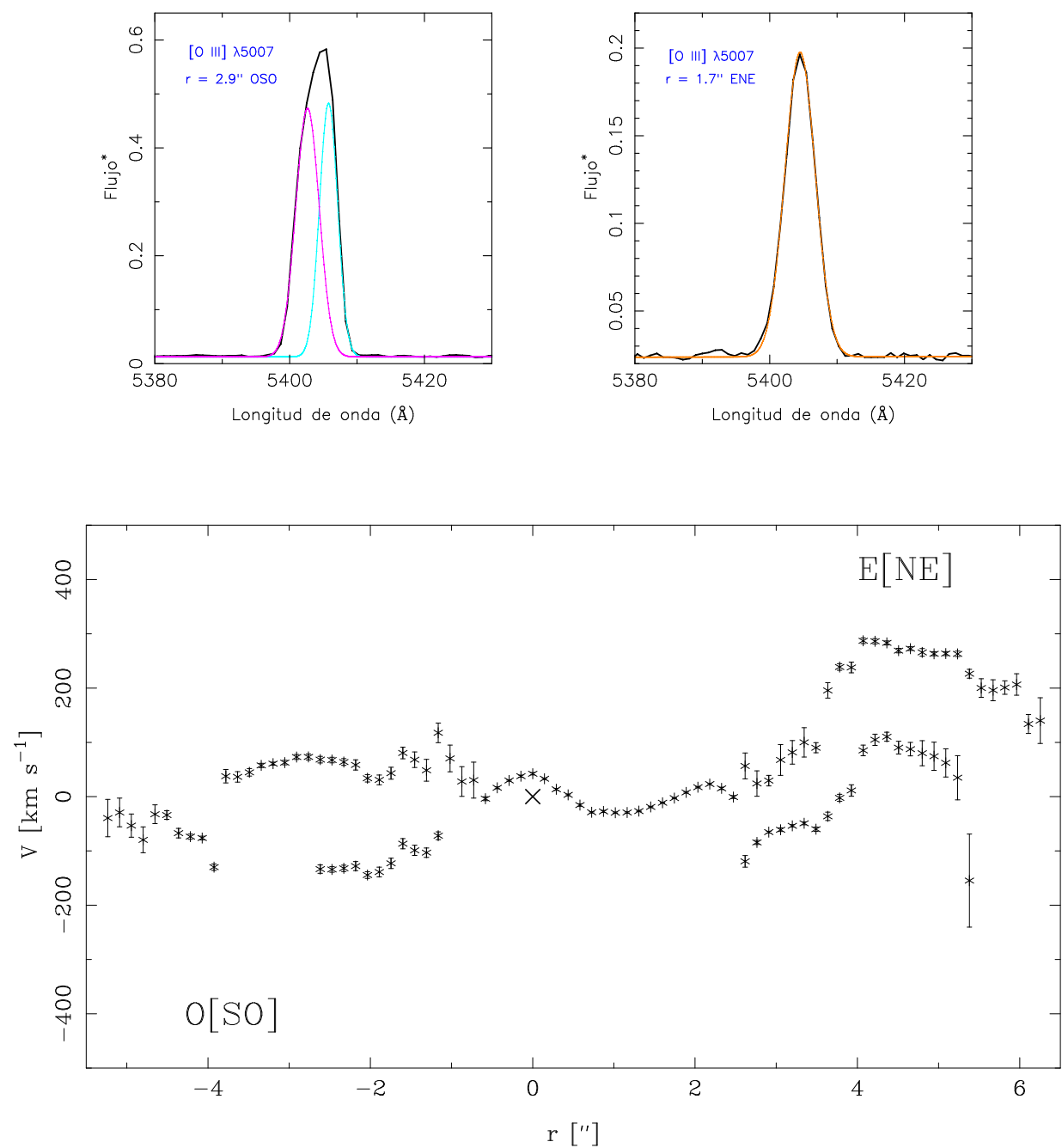

Arriba: Descomposición Gaussiana (en color) de los perfiles de [OIII] $\lambda 5007$ (en negro) para los espectros de la Fig. $5.5\left[^{(*)}\right.$ El flujo está expresado en las mismas unidades]. Abajo: Campo de velocidad del gas en la EELR, en la dirección de la ranura $\left(\mathrm{PA}=80^{\circ}\right)$. La cruz indica la posición del centro galáctico. 
para poder reproducirlo; estas componentes presentan una velocidad relativa algo menor a $200 \mathrm{~km} \mathrm{~s}^{-1}$ que permanece aproximadamente constante mientras la velocidad de ambas componentes varía, como puede apreciarse en el campo de velocidades (panel inferior de la misma figura). En él, el centro galáctico se marca con una cruz y las velocidades se expresan respecto a la velocidad sistémica del objeto $\left(v_{\text {sis }}=23804 \mathrm{~km} \mathrm{~s}^{-1}[\mathrm{NED}] ; V=0\right.$ en el diagrama). En general, puede decirse que existe una componente a lo largo de toda la región en emisión que se mueve con la velocidad sistémica de la galaxia. Aunque es posible notar un ligero desplazamiento de las velocidades hacia el rojo en la región $\mathrm{O}[\mathrm{SO}]$ y hacia el azul en la región $\mathrm{E}[\mathrm{NE}]$, no es posible distinguir con claridad la presencia de una curva de rotación. En dirección $\mathrm{O}[\mathrm{SO}]$ aparece una segunda componente localizada en la región -3 " $<r<-1$ ", que coincide con la región de máxima emisión, como se explicó antes. Esta componente, desplazada hacia el azul del espectro, se mueve respecto de la primera con velocidades $\lesssim 300 \mathrm{~km} \mathrm{~s}^{-1}$.

En el trabajo de Baum et al. (1990) se obtuvieron los campos de velocidades del gas a partir de la línea $\mathrm{H} \alpha$, mediante espectros long-slit cuyas ranuras se ubicaron en $\mathrm{PA}=95^{\circ} \mathrm{y}$ $\mathrm{PA}=140^{\circ}$. En ambos casos los autores encuentran una curva de rotación asimétrica, es decir, las velocidades de estabilización son diferentes a cada lado (este-oeste, en forma general) del núcleo. Además encuentran que cambia su sentido de rotación en la parte interna de la galaxia $^{6}$.

El campo de velocidades obtenido aquí según la línea [OIII] es más complejo. La característica sobresaliente no es la posible presencia de una curva de rotación (que, por otra parte no es obvia), sino la presencia de una componente muy extendida, relativamente estable y de velocidad baja $\left(<100 \mathrm{~km} \mathrm{~s}^{-1}\right)$. En cambio, los resultados sí coinciden en cuanto a que la región Este (cualquier sea el ángulo de posición adoptado) parece ser la zona más perturbada del sistema nebular. También se obtienen resultados coherentes respecto de la amplitud de velocidades observada en toda la extensión de las nebulosas (este-oeste).

\section{5. $\quad 3 \mathrm{C} 303.1$}

3C 303.1 es una radiofuente compacta de tipo CSS, al igual que 3C 268.3 (de Vries et al. 1997; Labiano et al. 2005; O'Dea et al. 2002; Holt et al. 2008), aunque también ha sido clasificada como fuente FRII (ver nota al pie $\mathrm{N}^{r o} 3$; de Koff et al. 1996, y sus referencias). Su máximo tamaño angular medido es de 1.9" (10.3 kpc, aproximadamente; Lüdke et al. 1998). Se trata de una fuente bi-lobular asimétrica (Akujor \& Garrington 1995; Axon et al. 2000), cuya densidad de flujo en la frecuencia de $178 \mathrm{MHz}$ es de 8.1 Jy (Laing et al. 1983). La estructura está dispuesta según el ángulo de posición $\mathrm{PA}_{j e t}=130-133^{\circ}$ (de Koff et al. 1996; Axon et al. 2000; Privon et al. 2008). El lóbulo NO es más pequeño que el que se ubica hacia el SE, y existe una diferencia de un factor 10 entre los flujos emitidos (en radio) por cada uno de ellos, siendo el lóbulo SE el más intenso (Lüdke et al. 1998). La información acerca de la identificación de la radiofuente puntual es ambigua; aunque Laing et al. (1983) señalan que existe una fuente central compacta, según Lüdke et al. (1998) no hay evidencia de ella en los mapas de emisión en la frecuencia de $5 \mathrm{GHz}$.

La galaxia fue observada en el óptico-UV con las cámaras STIS (Labiano et al. 2005) y WFPC2 (de Koff et al. 1996; de Vries et al. 1997; Privon et al. 2008) del HST, revelando la presencia de gas extendido. La estructura interna en 3C 303.1 es compleja, y hacia el SE del núcleo existe una zona de brillo superficial alto que podría indicar que se trata de un sistema perturbado (posiblemente durante un proceso de interacción con otro objeto;

\footnotetext{
${ }^{6}$ En este trabajo se tomaron espectros con dos ángulos de posición: $95^{\circ}$ y $140^{\circ}$; los autores advierten el cambio en el sentido de rotación de la curva en el espectro tomado según $\mathrm{PA}=95^{\circ}$ e indican que esa es la dirección del jet. Como se mencionó al comienzo de esta sección, $\mathrm{PA}_{j e t}$ no es mayor que $81^{\circ}$.
} 
Tabla 5.4. Líneas de emisión en la EELR de 3C 303.1.

\begin{tabular}{|c|c|c|c|c|c|c|}
\hline \multirow{3}{*}{ Línea $(\AA)$} & \multicolumn{6}{|c|}{ Flujo $^{a}$} \\
\hline & \multicolumn{3}{|c|}{ Noroeste } & \multicolumn{3}{|c|}{ Sudeste } \\
\hline & $-1.6 "$ & $-1.02 "$ & $-0.6 ”$ & $0.6 "$ & $1.2 "$ & $1.7 "$ \\
\hline$[\mathrm{Ne} \mathrm{V}] \lambda 3424$ & - & - & - & 0.12 & 0.4 & - \\
\hline$[\mathrm{O}$ Іा $] \lambda 3727$ & 6.19 & 5.37 & 4.01 & 3.6 & 3.11 & 4.31 \\
\hline$[\mathrm{Ne}$ III $] \lambda 3869$ & 1.36 & 1.01 & 0.77 & 0.58 & 0.61 & 0.83 \\
\hline $\mathrm{H} \mathrm{I}+\mathrm{He}$ I $(3890)$ & - & - & 0.23 & 0.15 & 0.22 & - \\
\hline$[\mathrm{Ne}$ III $] \lambda 3968^{b}$ & - & 0.48 & 0.39 & 0.28 & 0.19 & - \\
\hline$[\mathrm{S}$ II $] \lambda 4068$ & - & - & - & 0.23 & - & - \\
\hline $\mathrm{H} \delta(4101)$ & - & - & 0.19 & 0.21 & - & - \\
\hline $\mathrm{H} \gamma(4340)$ & - & 0.61 & 0.52 & 0.37 & 0.33 & 0.37 \\
\hline$[\mathrm{O}$ III $] \lambda 4363$ & - & - & 0.18 & 0.14 & 0.13 & - \\
\hline He II (4686) & - & 0.31 & 0.19 & 0.12 & 0.13 & - \\
\hline $\mathrm{H} \beta$ (4861) & 1 & 1 & 1 & 1 & 1 & 1 \\
\hline$[\mathrm{O}$ III $] \lambda 4959$ & 3.29 & 3.61 & 3.01 & 2.06 & 2.39 & 3.62 \\
\hline$[\mathrm{O}$ III $] \lambda 5007$ & 10.14 & 11.27 & 9.68 & 6.11 & 7.11 & 10.52 \\
\hline
\end{tabular}

Notas: ${ }^{a}$ Flujo relativo a $\mathrm{H} \beta$ para cada posición. Las distancias (NO negativas, SE positivas) se expresan respecto al centro galáctico.

${ }^{b}$ En esta longitud de onda coinciden tres líneas de emisión: [NeIII] $\lambda 3967.4,[\mathrm{CaII}] \lambda 3968.44$ y HeII (3968.43), en orden de intensidad.

merger, en la literatura; de Vries et al. 1997). En las imágenes de emisión nebular, dadas por el $[\mathrm{OIII}] \lambda 5007$, se puede distinguir que la disposición del gas es ligeramente diferente en la zona interna respecto de las regiones más extendidas. En la zona interna, la dirección de elongación se caracteriza por un ángulo de posición $\mathrm{PA}_{i n t}=140^{\circ}$, pero luego la nebulosa se curva en dirección norte-sur (ver Figura 3.9, panel derecho), alcanzando un tamaño de aproximadamente 3" (Axon et al. 2000).

Se puede decir que la nebulosa está alineada con la emisión observada en ondas de ra$\operatorname{dio}^{7}$ (de Vries et al. 1997; Axon et al. 2000; Holt et al. 2008), al menos en la parte más interna de ambas estructuras, cercana al núcleo óptico. En las regiones externas, la elongación de los lóbulos se produce en dirección NO y SE $\left(\mathrm{PA}_{j e t}\right)$, pero no existe acuerdo entre las mediciones respecto del ángulo de posición de la nebulosa óptica: $\mathrm{PA}_{e x t}=169^{\circ}$ según de Koff et al. (1996) y $\mathrm{PA}_{e x t}=151^{\circ}$ según Labiano et al. (2005).

El espectro GMOS se tomó con un ángulo de posición de $\mathrm{PA}=145^{\circ}$, de manera tal que el ancho de la ranura (1") cubriera la mayor parte de la EELR. El espectro resultante es muy rico en cuanto a las líneas de emisión, cuya presencia se concentra en la zona interna $( \pm 1$ ”). El conjunto de líneas presentes se lista en la Tabla 5.4 junto con el flujo de cada una respecto del de $\mathrm{H} \beta$ para cada posición elegida. La nebulosa en dirección NO se expresa con coordenadas negativas $\left(r_{N O}["]<0\right)$ y la nebulosa al SE con coordenadas positivas $\left(r_{S E}["]>0\right)$, todas las distancias están referidas al núcleo óptico $(r=0)$. La EELR-NO es más extensa, pero la emisión es más intensa en la EELR-SE. Esto puede verse en la sección del espectro bi-dimensional mostrada en la Fig. 4.7 que comprende la zona de $\mathrm{H} \beta$ y el doblete $[\mathrm{O} I I I] \lambda \lambda 4959,5007$; allí se aprecia una estela de emisión en el [OIII] 25007 extendiéndose hacia

\footnotetext{
${ }^{7}$ En la figura 41 de Privon et al. (2008) se puede ver una imagen de la superposición entre la emisión en radio $(8.4 \mathrm{GHz})$ con el [OIII] $\lambda 5007$.
} 
el NO. El tamaño de ambas regiones, medido según el alcance de esta línea y en el ángulo de posición $\mathrm{PA}=145^{\circ}$, es de 5.7" ( $\left.\sim 31 \mathrm{kpc}\right)$ al NO, y de 3.2" ( 17 kpc) al SE. Luego, la extensión de la estructura completa es de $8.9 "(\sim 48 \mathrm{kpc})$ lo cual revela que con el espectro es posible distinguir regiones de muy bajo brillo superficial. La intensidad de las líneas decrece desde el núcleo hacia los extremos de ambas regiones, pero la caída es más pronunciada hacia el NO; incluso líneas como [Ne v] $\lambda 3424$ o [S II] $\lambda 4068$ sólo se manifiestan hacia el SE. A pesar de la extensión que muestra el [OIII] hacia el NO, su intensidad se comporta de la misma manera que el conjunto de líneas del espectro, siendo más intensa hacia el SE. Por ejemplo, a la distancia de \pm 2 " $( \pm 10.1 \mathrm{kpc})$, la intensidad del $[\mathrm{OIII}] \lambda 5007$ es un $60 \%$ mayor en el SE que en el NO.

En la Figura 5.7 se muestran los espectos unidimensionales de las regiones NO (panel superior) y SE (panel inferior). El primero corresponde a una distancia de 0.7" ( $3.8 \mathrm{kpc})$ respecto del núcleo, y el segundo a $0.9 "(\sim 4.9 \mathrm{kpc})$. Allí se puede apreciar claramente la variación de intensidades de todas las líneas presentes respecto de una y otra región, incluso cuando el espectro de la EELR-SE corresponde a una mayor distancia al núcleo. En este sentido, cabe mencionar particularmente la relación de intensidades entre los oxígenos [OII] $\lambda 3727$ y [OIII] $\lambda 5007$ : mientras que en el espectro del NO la relación es del $42 \%$, en el SE es del $52 \%$, y el cambio se debe fundamentalmente al aumento de la intensidad del [OII] $\lambda 3727$ en esta zona.

El perfil de emisión del [OIII] revela la presencia de diferentes componentes. En la Figura 5.8 (paneles superiores) se muestran los perfiles del [OIII] $\lambda 5007$ (color negro) correspondientes a los espectros de la Fig. 5.7, y su descomposición Gaussiana (en color). Como puede apreciarse, la deformación del perfil es mucho mayor hacia el SE que hacia el NO principalmente debido a la presencia de una tercer componente. Sin embargo, esta componente está presente en la región NO, aunque se detecta sólo en la región más cercana al centro de la galaxia, en la zona dada por $|r|<0.6 "(\lesssim 3 \mathrm{kpc})$; hacia el SE, en cambio, esta tercer componente del perfil puede encontrarse hasta distancias mayores, resultando indistinguible a partir de $r>1.5 "(\gtrsim 8 \mathrm{kpc}$ ). En el panel inferior de esta Figura se muestra el campo de velocidades derivado según tal descomposición Gaussiana.

Durante el proceso de ajuste y medición de todas las líneas del espectro se encontró que el desplazamiento de los centroides no es compatible con el valor de corrimiento al rojo conocido en la literatura de $z=0.2704$ (Holt et al. 2008). Luego de realizar el mismo análisis descripto para el caso de 3C 268.2, se obtuvo el nuevo redshift con su error:

$$
z^{\prime}=0.26862 \pm 3 \times 10^{-5}
$$

En el cálculo no se utilizó la línea de emisión denominada como Hi + HeI (3890) en la Tabla 5.4, para evitar la incerteza que provoca el hecho de no poder distinguir cuál de las dos líneas es el mayor contribuyente a la emisión detectada ${ }^{8}$. Este $z^{\prime}$ es el redshift empleado en el cómputo del campo de velocidad.

El campo de velocidad es relativamente complejo, en el sentido de que, aunque se observan movimientos estables en cada región, no es posible identificar una curva de rotación. O'Dea et al. (2002) obtuvieron un resultado similar mediante sus observaciones con STIS/HST, aunque el ángulo de posición de la ranura era ligeramente diferente $\left(\mathrm{PA}_{S T I S}=151^{\circ}\right)$. La velocidad sistémica del objeto, derivada según $z^{\prime}$ es $v_{\text {sis }}=80530 \mathrm{~km} \mathrm{~s}^{-1}$ y se adopta como origen de velocidades para el campo ( $V=0$ en el diagrama). En la región central $(|r|<1$ ") se observan los movimientos de mayor perturbación, tal como se indicara anteriormente en cuanto a la composición de los perfiles. Allí se observan movimientos de alta velocidad, de $400 \mathrm{~km} \mathrm{~s}^{-1}$ aproximadamente, tanto de alejamiento como acercamiento. Los corrimientos al

\footnotetext{
${ }^{8}$ Las longitudes de onda en reposo de cada una de las líneas involucradas son HeI(3888.6) y $\operatorname{HI}(3889.05)$.
} 
Figura 5.7. Espectros de la EELR en 3C 303.1.
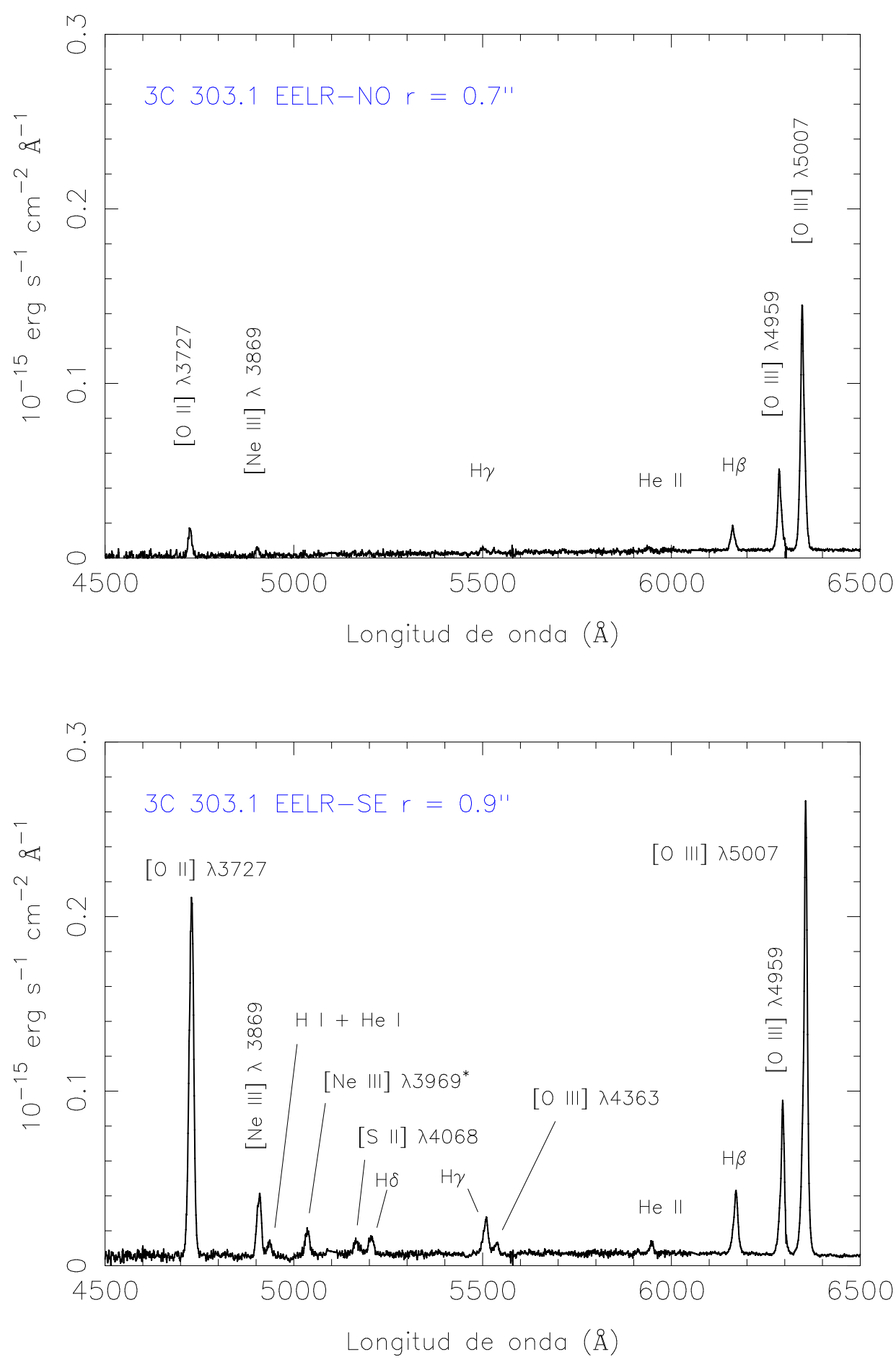

Arriba: Espectro de la EELR noroeste, a 0.7" del centro galáctico. Abajo: Espectro de la EELR sudeste, a $0.9 "$ (* ver comentario en la Tabla 5.4). La intensidad de las líneas varía notoriamente de una región a otra. 
Figura 5.8. Descomposición Gaussiana y Campo de Velocidad en 3C 303.1.
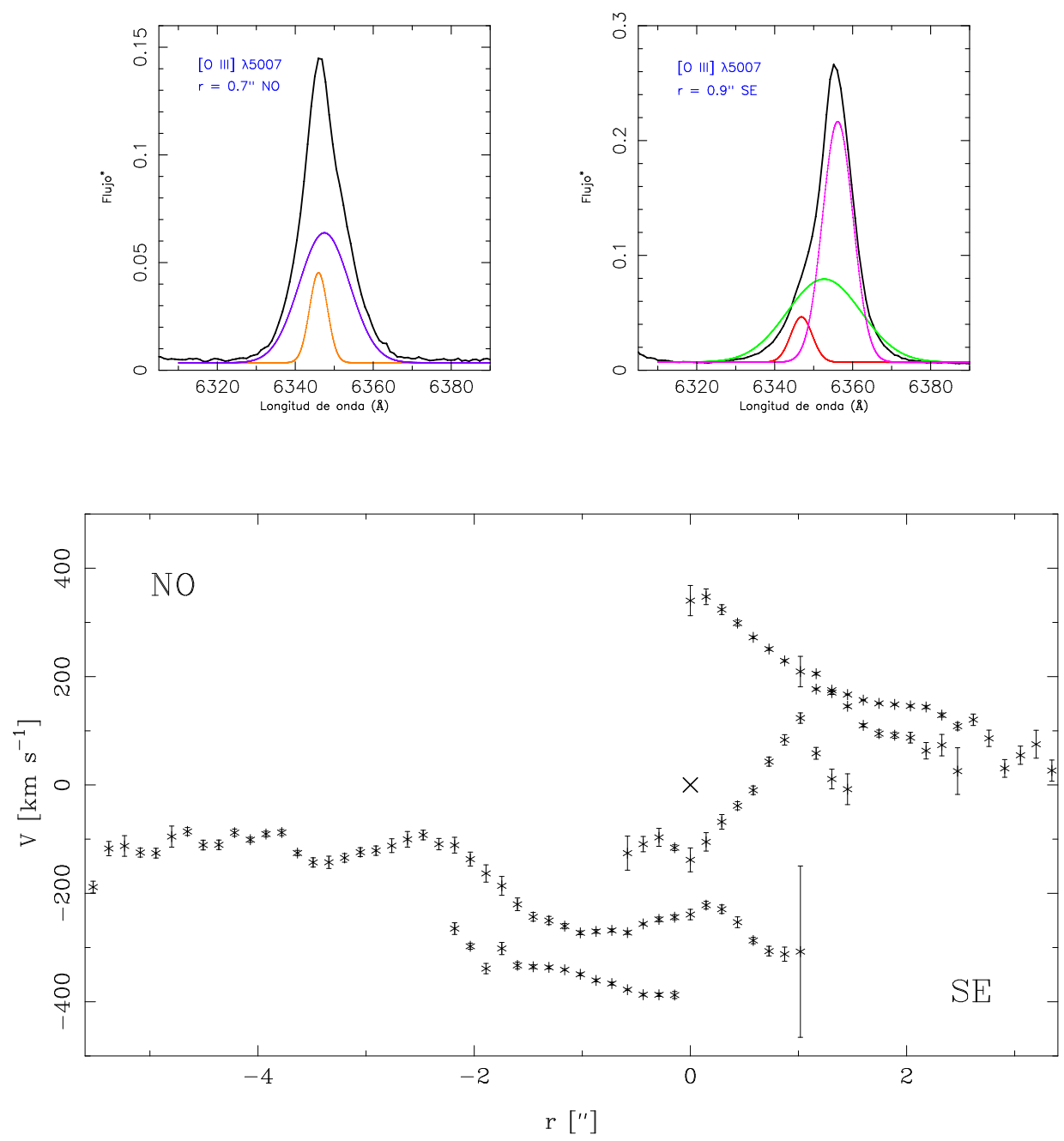

Arriba: Descomposición Gaussiana (en color) de los perfiles de [OIII] $\lambda 5007$ (en negro) para los espectros de la Fig. $5.7\left[{ }^{(*)}\right.$ El flujo está expresado en las mismas unidades]. Abajo: Campo de velocidad del gas en la EELR, en la dirección de la ranura $\left(\mathrm{PA}=145^{\circ}\right)$. La cruz indica la posición del centro galáctico. No existe ninguna componente cuya velocidad coincida con la velocidad sistémica del objeto. 
rojo (alejamiento) corresponden a la nebulosa del SE, mientras que los corrimientos al azul (acercamiento) se manifiestan en la región NO. En la región SE sólo se observan movimientos de alta velocidad en la región central; para distancias $r>1$ " la velocidad de la componente dominante decrece hasta prácticamente coincidir con la velocidad de la segunda componente del perfil para distancias $r \sim 1.5-2.5$ ". La segunda componente muestra el comportamiento opuesto en la zona interna: se desplaza cada vez más hacia el rojo adquiriendo velocidades de alejamiento cada vez mayores, hasta coincidir con la velocidad de la primera componente. Esto ocurre aproximadamente para $v \lesssim 200 \mathrm{~km}^{-1}$. Existe una tercer componente en la región SE que se manifiesta como la continuidad del movimiento observado en la región NO. La velocidad de esta componente ronda los $300 \mathrm{~km} \mathrm{~s}^{-1}$ en esta zona, pero su movimiento es de acercamiento (corrimiento al azul). En la región NO también se observan movimientos de velocidad (de acercamiento) relativamente alta $300 \lesssim|v| \lesssim 400 \mathrm{~km} \mathrm{~s}^{-1}$ pero están presentes a lo largo de una zona más extensa (2", $10.1 \mathrm{kpc}$ aproximadamente) que el mismo tipo de movimiento en la región SE. La componente principal del perfil (aquella que determina la extensión se la región) sufre variaciones continuas en su velocidad en el rango $100 \lesssim|v| \lesssim 300 \mathrm{~km} \mathrm{~s}^{-1}$. Los resultados referentes a la ausencia de una curva de velocidad, la notoria amplitud de velocidades entre las componentes del perfil, o los movimientos de alta velocidad en la zona interna de la región SE coinciden con los obtenidos por (O'Dea et al. 2002). Tal como se señala allí, no es posible compatibilizar los movimientos de alta velocidad dentro del gas, y con las amplitudes observadas, con el movimiento gravitatorio esperado dentro del potencial galáctico (Tadhunter et al. 1989).

\section{6. $3 \mathrm{C} 305$}

3C 305 es una radiofuente morfológicamente atípica. Posee dos lóbulos de emisión sincrotrón pero no tiene el aspecto característico de otra fuentes bi-lobulares (ver Fig. 3.10); el tamaño de éstos en dirección perpendicular al radio-eje $\left(\mathrm{PA}_{j e t}=42^{\circ}\right.$; Morganti et al. 2005) es mucho mayor que la distancia entre la fuente puntual central y los hot spots (Hardcastle et al. 2012). Su densidad de flujo a la frecuencia de $178 \mathrm{MHz}$ es de 17.11 Jy (Laing \& Peacock 1980), siendo notoriamente intensa la emisión proveniente de los jets y hot spots. El lóbulo noreste (NE) es muy extenso en dirección sudeste pero con bajo brillo superficial; la emisión en el lóbulo sudoeste (SO), en cambio, presenta una distribución más simétrica, donde el hot spot se localiza aproximadamente en la mitad de la estructura. El tamaño angular ${ }^{9}$ de la radiofuente completa es de 13.6", por lo cual resulta un objeto mucho más pequeño que las típicas radiofuentes bi-lobulares, pero comparable a estas últimas en cuanto a su luminosidad (Heckman et al. 1982). Desde la perspectiva estrictamente morfológica, ha sido clasificada como una galaxia FRI por el tipo de estructura deformada que presenta en mapas de baja resolución (Laing et al. 1983; Donzelli et al. 2007). Sin embargo, los mapas de alta resolución obtenidos en trabajos recientes (Jackson et al. 2003; Hardcastle et al. 2012) muestran que tanto los jets como los hot spots tienen características típicas de los objetos FRII. Esta controversia no se limita al aspecto morfológico, dado que su luminosidad también la sitúa en el límite entre ambas clases (Hardcastle et al. 2012).

En rayos-X, según los datos de Chandra (Massaro et al. 2009), la galaxia también tiene una morfología peculiar, que se caracteriza por la emisión extendida en la banda $0.2-2.0 \mathrm{keV}$. La emisión predomina en esta $s u b$-banda (rayos-X blandos), cuyo flujo es de $F_{0.5-2 k e V}=$ $3.49 \times 10^{-14} \mathrm{erg} \mathrm{s}^{-1} \mathrm{~cm}^{-2}$, y está concentrada en un radio de 15 " centrado en el núcleo. La forma en que se distribuye la emisión no coincide con lo que se observa en radio. La emisión está más extendida, en particular hacia el NE, y además los picos de máxima intensidad no

\footnotetext{
${ }^{9}$ www.jb.man.ac.uk/atlas/object/3C305.html
} 
Tabla 5.5. Líneas de emisión en la EELR de $3 \mathrm{C} 305$.

\begin{tabular}{lccc|ccc}
\hline \hline & \multicolumn{5}{c}{ Flujo $^{a}$} \\
Línea $(\AA)$ & \multicolumn{3}{c}{ Noreste } & \multicolumn{3}{c}{ Sudoeste } \\
& $-3.8 "$ & $-2.6 "$ & $-1.5 "$ & $1.5 "$ & $2.6 "$ & $3.3 "$ \\
\hline$[\mathrm{O}$ II $] \lambda 3727$ & 4.1 & 4.39 & 8.34 & 4.08 & 3.96 & 15.66 \\
{$[\mathrm{Ne}$ II $] \lambda 3869$} & 0.79 & 0.53 & 0.8 & 0.63 & 0.73 & - \\
He II $(4686)$ & - & 0.12 & - & 0.43 & - & - \\
$\mathrm{H} \beta(4861)$ & 1 & 1 & 1 & 1 & 1 & 1 \\
{$[\mathrm{O}$ III $] \lambda 4959$} & 2.08 & 1.52 & 2.91 & 2.74 & 2.53 & 6.78 \\
{$[\mathrm{O}$ III $] \lambda 5007$} & 6.2 & 4.67 & 8.24 & 8.44 & 7.57 & 20.1 \\
{$[\mathrm{~N}$ I $] \lambda 5200$} & 0.19 & 0.26 & 0.36 & 0.51 & 0.26 & - \\
\hline \hline
\end{tabular}

Notas: ${ }^{a}$ Flujo relativo a $\mathrm{H} \beta$ para cada posición. Las distancias (NE negativas, SO positivas) se expresan respecto al centro galáctico.

se producen en el mismo lugar que los hot spots de radio (Massaro et al. 2009). En cambio, se puede apreciar una asociación directa en la superposición con las imágenes ópticas de gas ionizado (EELR) dominadas por el [OIII] $\lambda 5007$. La coincidencia es tanto espacial como morfológica, predominantemente en la región NE (ver fig. 1 de Massaro et al. 2009 y fig. 4 de Hardcastle et al. 2012, la imagen óptica que se usa en ambos ejemplos es la misma de la Fig. 3.10). En este caso se ve claramente que las zonas de máxima intensidad en los mapas de [OIII] coincide con los focos de emisión en rayos-X, tanto al NE como al SO. En el trabajo de Hardcastle et al. (2012), también con datos de Chandra, se reveló la existencia de una estructura de bajo brillo superficial ${ }^{10}$, extendida en dirección aproximadamente perpendicular al radio-eje (es decir, SE-NO). Estas estructuras, que los autores llaman "alas", no tienen una contraparte óptica en las imágenes de [OIII], como sí sucede con el resto de la emisión en rayos$\mathrm{X}$, aunque es posible que exista una correspondencia con la emisión en $\mathrm{H} \alpha+[\mathrm{NII}]$ (Heckman et al. 1982; Hardcastle et al. 2012).

En el óptico, 3C 305 fue observada primero con la cámara FOC (Faint Object Camera ${ }^{11}$ ) del HST y luego con la WFPC2. Con la FOC se obtuvieron mapas de la emisión nebular tanto en [OII] como en [OIII] (Jackson et al. 1995), pero los datos de la WFPC2 en [OIII] (Privon et al. 2008, y Fig. 3.10), menos contaminados por la emisión del continuo, revelan los detalles de la estructura nebular. La galaxia parece mostrar signos de interacción (Heckman et al. 1982); si bien la disposición de la componente estelar sugiere una estructura elíptica, también se identifican patrones que se asocian con brazos espirales y con alto contenido de polvo (Donzelli et al. 2007).

En la imagen nebular pura de la Fig. 3.10 (panel superior derecho) se observa que la distribución del gas en la región interna coincide, aproximadamente, con la posición del radioeje. En las zonas más alejadas, en cambio, la emisión de línea y en radio están superpuestas, aunque no parece haber una relación intrínseca, como sí sucede con la emisión en rayos-X. Este aspecto se discutirá en el próximo Capítulo. En vista del alineamiento interno entre

\footnotetext{
${ }^{10}$ Tanto Hardcastle et al. (2012) como Massaro et al. (2009) utilizaron datos de Chandra. En el trabajo de Hardcastle et al. (2012) se combinaron todos los datos disponibles, para mejorar la relación S/N. De esta manera, el tiempo de exposición de la combinación de datos fue de ocho (8) veces el tiempo de exposición de la observación de Massaro et al. (2009), lo que explica el aumento en la sensibilidad de los datos.

${ }^{11} \mathrm{La}$ FOC era uno de los cinco instrumentos originales con los que contaba el HST cuando fue puesto en órbita en 1990. Fue retirada del telescopio en el año 2002 para colocar la ACS en su lugar.
} 
Figura 5.9. Espectros de la EELR en 3C 305.
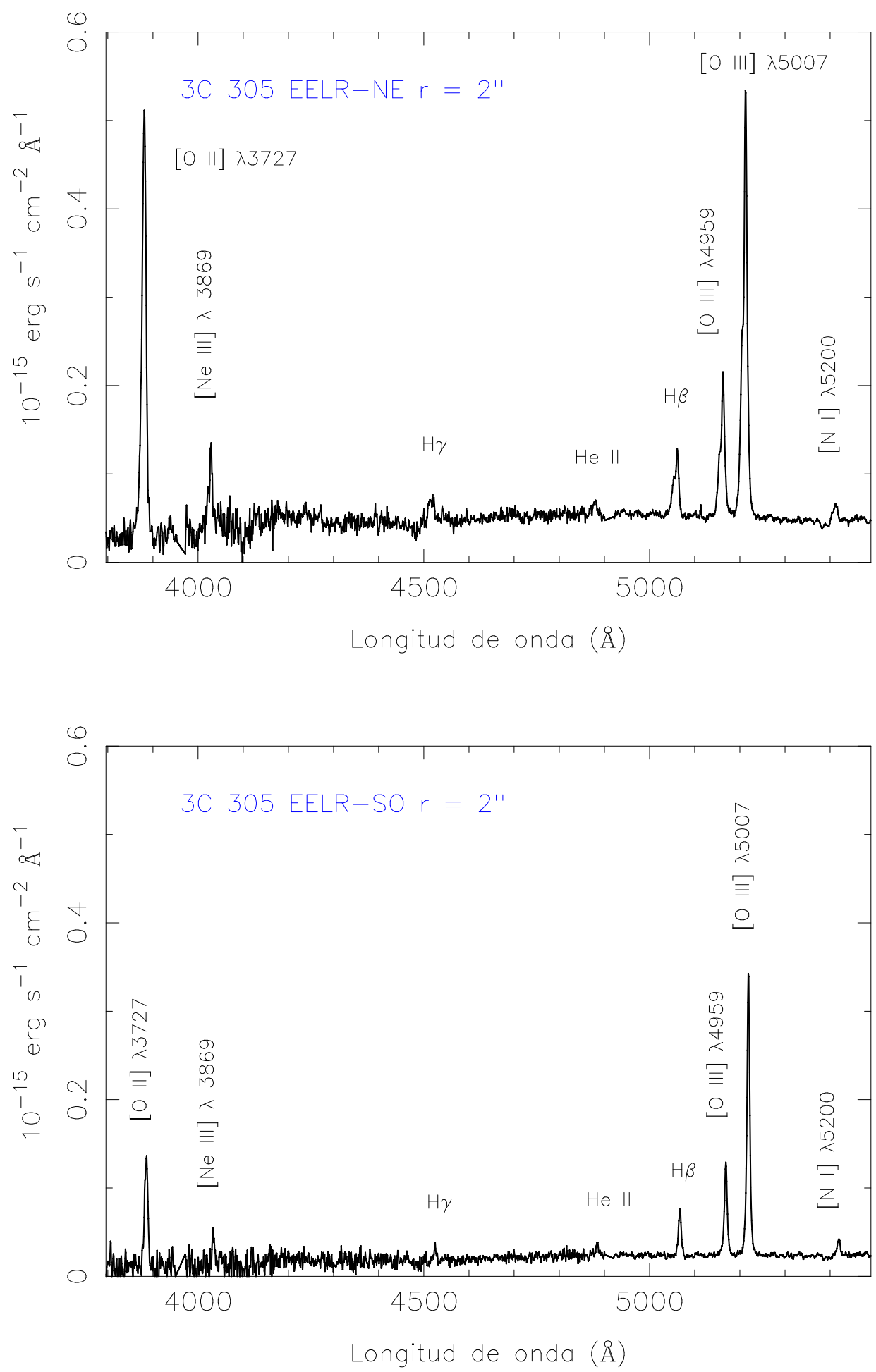

Arriba: Espectro de la EELR noreste, a 2" del centro galáctico. Abajo: Espectro de la EELR sudoeste, a la misma distancia. Se puede apreciar la variación de intensidades en todas las líneas respecto de una y otra región. 
Figura 5.10. Descomposición Gaussiana y Campo de Velocidad en 3C 305.
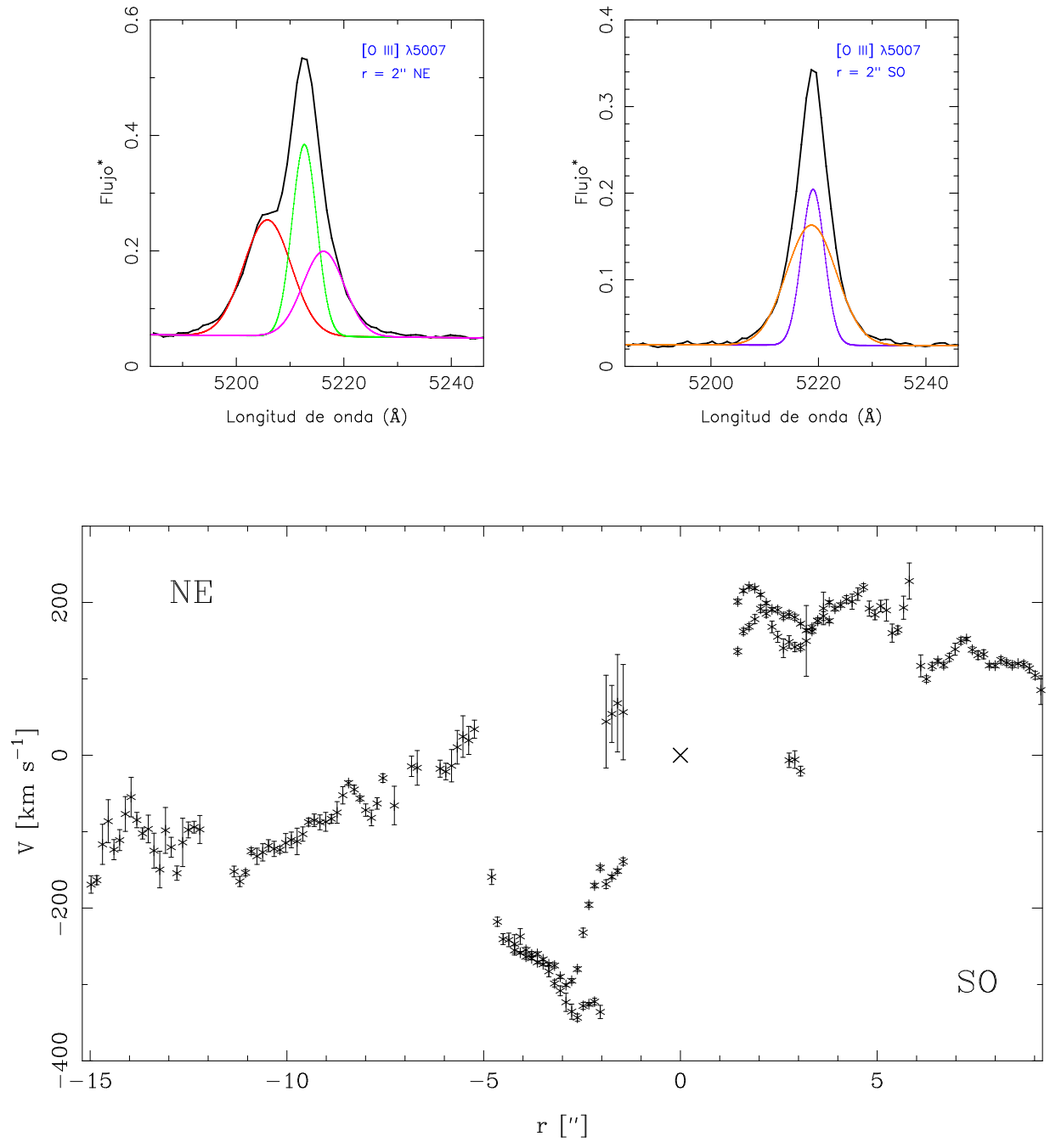

Arriba: Descomposición Gaussiana (en color) de los perfiles de [OIII] $\lambda 5007$ (en negro) para los espectros de la Fig. $5.9\left[^{(*)}\right.$ El flujo está expresado en las mismas unidades]. Abajo: Campo de velocidad del gas en la EELR, en la dirección de la ranura $\left(\mathrm{PA}=45^{\circ}\right)$. La cruz indica el centro galáctico, que se mueve con la velocidad sistémica. Se utilizan distancias negativas para la región NE, y positivas para la SO. La región central está excluida del análisis. 
los jets y la emisión de [OIII], se obtuvo el espectro long slit de la EELR con la ranura en esta misma dirección aproximada $\left(\mathrm{PA}=45^{\circ}\right)$. Existe una diferencia de $3^{\circ}$ entre la posición del radio-eje y la ranura, esta diferencia obedece a la conveniencia de desplazar ligeramente la ranura respecto de $\mathrm{PA}_{j e t}$ para alcanzar regiones de alto brillo superficial que no están perfectamente alineadas con el jet.

El espectro de la EELR está dominado por las líneas del oxígeno [OII] $\lambda 3727$ y el doblete [OIII $] \lambda \lambda 4959,5007$. En la Tabla 5.5 se reune el conjunto de líneas presentes, junto con el flujo relativo a $\mathrm{H} \beta$ para cada posición elegida. La EELR-NE (Fig. 3.10, panel superior derecho) se expresa mediante distancias negativas $\left(r_{N E}["]<0\right)$ y la EELR-SO, con distancias positivas $\left(r_{S O}["]>0\right)$. La emisión del continuo puede considerarse despreciable a partir de $\sim 1$ " tanto en dirección NE como SO; a esta distancia, el continuo es indistinguible del ruido de fondo en el espectro GMOS. Se definió como "región central" del espectro a la zona comprendida por los 3" internos $( \pm 1.5$ "; $\sim 2.6 \mathrm{kpc})$. Dentro de la región central existen zonas donde la intensidad del continuo es importante, o donde pueden distinguirse algunas estructuras en absorción, por lo tanto, para evitar la posible contribución de la componente estelar en las mediciones, esta región fue excluida del análisis.

La emisión nebular (gas ionizado) se concentra en los 8 " internos $( \pm 4 " ; \sim 6.8 \mathrm{kpc}$ ), pero la extensión total, dada por la máxima distancia hasta la cual puede medirse el [OIII] $\lambda 5007$, es de 24.2" ( $\sim 20.6 \mathrm{kpc})$ en la dirección de la ranura. La extensión de la EELR-SO es de 9.2" $(\sim 7.8 \mathrm{kpc})$, mientras que la EELR-NE es un $63 \%$ más extensa (15"; $\sim 12.8 \mathrm{kpc})$. Los máximos de emisión en las líneas no se encuentran en la región central, tal como encontrara Heckman et al. (1982); el máximo se encuentra en dirección NE a 2-3" ( 1.7-2.6 kpc), y existe un máximo secundario ${ }^{12}$ a la misma distancia, aproximadamente, en dirección SO. Esto mismo puede verse en la Fig. 4.8, donde se mostró una sección del espectro 2D, comprendida por las líneas $\mathrm{H} \beta$, y [OIII] $\lambda \lambda 4959,5007$. El máximo de emisión al NE coincide con una estructura intensa en rayos-X, y se encuentra en una posición muy cercana al hot spot ${ }^{13}$.

En la Figura 5.9 se presentan dos espectros (uni-dimensionales) de la EELR, el panel superior corresponde a la región NE y el inferior a la SO. En ambos casos la distancia al centro galáctico es de $2 "(\sim 1.7 \mathrm{kpc})$, se eligieron los espectros de las zonas donde la emisión es máxima en cada EELR. El impacto del rayo cósmico que se puede apreciar sobre el perfil del [OIII] $\lambda 5007$ en el espectro 2D de la Fig. 4.8 a esta distancia fue eliminado ${ }^{14}$, tanto con fines cualitativos (gráficos) como cuantitativos (en las mediciones de intensidad). Existe una notoria variación de intensidades, siendo la del $[\mathrm{OH}] \lambda 3727$ la más importante.

La complejidad que muestran los perfiles de todas las líneas de emisión, es decir su forma, se traduce en la igualmente compleja cinemática de la región, tal como se conocía de resultados previos (Heckman et al. 1982; Morganti et al. 2005). La extracción de espectros individuales a partir del espectro long-slit se realizó, como en todos los objetos de la muestra, pixel por pixel para evitar la pérdida de información espacial. De acuerdo con el proceso de medición, discutido en la Sección 4.2, se necesitaron hasta tres componentes Gaussianas para ajustar el perfil del [OIII] $\lambda 5007$ en la EELR-NE. Aunque la región SO no muestra el mismo nivel de complejidad, el perfil del [OIII] 55007 también necesita más de una componente para poder reproducirse. En la Figura 5.10 (panel superior) se muestran dos ejemplos de la descomposición Gaussiana en las EELR. Los perfiles de [OIII] 55007 (en negro) corresponden a

\footnotetext{
${ }^{12}$ Con la exclusión de la región central, el máximo de intensidad al SO es el máximo secundario. Si se considerara la región central, entonces el segundo máximo ocurriría allí y el pico de emisión del SO sería el tercer máximo del espectro completo.

${ }^{13}$ La superposición de imágenes radio-rayos-X y rayos-X-[OIII] pueden verse en las figs. 3-4 de Hardcastle et al. (2012).

${ }^{14}$ Como se explicó en el Capítulo 4, referente al procesamiento y reducción de los datos, es más simple y más eficiente eliminar los impactos de rayos cósmicos de los perfiles uni-dimensionales que de los espectros 2D.
} 
los dos espectros de la Fig. 5.9 (2" NE y SO, respectivamente); las componentes Gaussianas se muestran en color.

La descomposición Gaussiana de la línea del [OIII] $\lambda 5007$ a lo largo de toda la extensión de la EELR se utilizó para construir el campo de velocidad del gas, en la dirección de la ranura. El resultado se muestra en el panel inferior de la misma Fig. 5.10. Debe tenerse en cuenta que este campo de velocidades está afectado por la inclinación (desconocida) del objeto respecto de la línea de la visual. La exclusión de la región central explica la falta de datos en la zona interna $( \pm 1.5 ")$; la cruz indica la posición del centro galáctico, punto de referencia respecto al cual se calcularon las velocidades $\left(v_{s i s}=12483 \mathrm{~km} \mathrm{~s}^{-1}\right.$ (NED); $V=0$ en el campo de velocidad.). Se puede identificar un patrón de movimiento ordenado, una "curva de rotación", que se estabiliza en torno a velocidades de $\pm 200 \mathrm{~km} \mathrm{~s}^{-1}$ aproximadamente. La cinemática es mucho más compleja en la EELR-NE, donde pueden observarse claros apartamientos del movimiento colectivo que alcanzan velocidades de $\sim 400 \mathrm{~km} \mathrm{~s}^{-1}$. Estos comportamientos ya habían sido notados por Morganti et al. (2005), estudiando la cinemática del gas ionizado a través de los perfiles de $\mathrm{H} \alpha$; sin embargo, las componentes de alta velocidad en [OIII], que se encuentran a una distancia de 2-5" (NE), están ligeramente más alejadas que las nubes de alta velocidad en $\mathrm{H} \alpha$. Cabe señalar, no obstante, que nuestro espectro y el de estos autores se tomaron con ángulos de posición que difieren en $3^{\circ}$. El campo de velocidad también fue estudiado mediante observaciones de Hi en absorción (Morganti et al. 2005). El estudio mostró que existen componentes que alcanzan velocidades de hasta $500 \mathrm{~km} \mathrm{~s}^{-1}$, a distancias de $1.6 \mathrm{kpc}$, dentro del lóbulo NE. Las características del movimiento coinciden con los resultados derivados del espectro GMOS tanto en la posición aproximada de las nubes de alta velocidad (1.6 kpc equivaldría a $\sim 2 ")$, como en la dirección del movimiento, dado que tanto el [OIII] como $\mathrm{H} \alpha$ y el $\mathrm{HI}$ indican que toda la región $\mathrm{NE}$ tiene velocidades de aproximación (corrimientos al azul).

\section{7. $3 \mathrm{C} 321$}

La radiogalaxia 3C 321 es una fuente verdaderamente interesante. Es un objeto de tipo FRII, pero cuando se lo examina a escala reducida (la escala dada por la emisión óptica) presenta características morfológicas típicas de objetos FRI (Evans et al. 2008). Su densidad de flujo en la frecuencia de $178 \mathrm{MHz}$ es de $14.7 \mathrm{Jy}^{15}$. Si bien se trata de una fuente bi-lobular, los lóbulos son relativamente pequeños, aunque poseen intensos hot spots. Éstos se localizan a grandísimas distancias hacia el noroeste (NO) y sudeste (SE) del objeto central; el tamaño angular de la radiofuente medido de este modo es de 307" ( $\sim 597 \mathrm{kpc})$. En una escala de distancias mucho menor, de 20" aproximadamente, se identifica claramente la presencia de un jet de características tipo FRI en dirección NO. Sin embargo, su contraparte SE sólo puede detectarse marginalmente (Baum et al. 1988). El radio-eje, dado por el ángulo de posición de la estructura de gran escala, es de $\mathrm{PA}_{j e t}=136^{\circ}$ (Baum \& Heckman 1989a) pero existe un desalineamiento respecto de la estructura interna (el jet interno) de aproximadamente $11^{\circ}$ (Baum et al. 1988), lo que indica que el jet sufre un cambio de dirección (ver Fig. 3.11, panel inferior izquierdo).

La estructura óptica es igualmente compleja, posiblemente debido a un proceso de interacción (merger) reciente (Heckman et al. 1986). Como puede verse en la Fig. 3.11, se trata de un objeto con doble núcleo, separados por 3-4", y con envoltura estelar y gaseosa conjunta (Heckman et al. 1986; Baum et al. 1988; McCarthy et al. 1995; Robinson et al. 2000, 2002). En el reciente trabajo de Evans et al. (2008) no se habla de doble núcleo sino de dos galaxias interactuantes, y se resalta el hecho de que ambas albergan un núcleo activo. El núcleo sur

\footnotetext{
${ }^{15}$ http://www.jb.man.ac.uk/atlas/object/3C321.html
} 
(NS) constituye la contraparte óptica de la radiofuente puntual (Baum et al. 1988), mientras que no se detecta emisión en radio proveniente del núcleo norte (NN). Como los espectros nucleares de ambas galaxias tienen las mismas características en lo que respecta a las líneas de emisión (Filippenko 1987), este objeto se clasifica como Seyfert 2 (Evans et al. 2008). Por lo tanto la fuente óptica asociada con 3C 321 es un sistema interactuante de dos AGNs, compuesto por una NLRG y una Seyfert 2.

La galaxia también fue observada en rayos-X (Chandra), UV (HST/STIS $\left.{ }^{16}\right)$ e IR $\left(\right.$ Spitzer $\left.^{17}\right)$. La emisión en estas bandas se superpone en distintas regiones. Hacia el sur del NS y hacia el noroeste del NN se observa emisión en rayos-X blandos, en el óptico, dada por las imágenes de línea en [OIII], y en el UV cercano. También existe emisión IR superpuesta con rayosX hacia el sudoeste del NS (Evans et al. 2008). En su estudio del UV, Allen et al. (2002) notaron que la emisión cubre la zona que abarcan las dos galaxias, pero éstas no pueden resolverse individualmente, como sucede en el óptico. Por su parte, hay superposición entre la emisión en radio y rayos-X en los extremos de la radiofuente, es decir, en los hot spots, con evidencia de aceleración de partículas hacia energías altas (rayos-X; Evans et al. 2008). Esta característica, típica de fuentes FRII no se observa en la estructura interna que, en cambio, está dominada por la presencia de un jet cuya morfología coincide con la de fuentes FRI (ver Capítulo 3).

La emisión óptica extendida, la EELR, constituye un gran complejo (McCarthy et al. 1995) que mantiene la estructura doble dada por los núcleos interactuantes, y se encuentra alineado con el radio-eje (Hurt et al. 1999). En la imagen de línea (HST/WFPC2) de la Fig. 3.11 (panel superior derecho) se puede apreciar la distribución del gas. Existe emisión localizada en ambos núcleos pero también existen concentraciones locales desplazadas hacia el SE del núcleo sur, y hacia el NO del núcleo norte. Esta última estructura tiene una distribución mucho más extendida (en dirección NE-SO) que la EELR cercana al núcleo sur. En el panel inferior derecho de la misma figura se aprecia la superposición de la imagen nebular con la radiofuente interna. Como se mencionó antes, la radiofuente puntual coincide con el núcleo óptico sur, mientra que el núcleo norte no emite en radiofrecuencias. En ese panel también se puede identificar una contribución en ondas de radio proveniente de las zonas aledañas al núcleo norte, sin embargo esta emisión no proviene del núcleo sino que está asociada al MIE/MIG que circunda al sistema; e incluso es posible que el comportamiento del jet esté directamente asociado a (y afectado por) la presencia de gas en esta zona (Evans et al. 2008, la discusión sobre este punto se retoma en el próximo Capítulo).

$\mathrm{El}$ espectro de la EELR se tomó con una ranura de 0.75 " en dirección PA=127\%. Se eligió combinar una ranura relativamente ancha, con un PA ligeramente diferente del ángulo de posición característico de la EELR (130 ; Robinson et al. 2000) para que el espectro abarcara todas las zonas que componen la EELR. El resultado puede verse en la Figura 4.9, donde se aprecian las dos fuentes de continuo que corresponden a ambos núcleos. El núcleo sur corresponde al continuo localizado en la posición $r=0$; el núcleo norte, más débil, se encuentra a una distancia de 3.3" del núcleo sur en dirección NO. Se adoptan distancias negativas para indicar las regiones ubicadas al NO del núcleo sur $\left(r_{N O}["]<0\right)$, y distancias positivas para indicar las regiones al SE de este último $\left(r_{S E}["]>0\right)$. La EELR-SE se extiende por $3.2 "(\sim 6.2 \mathrm{kpc})$ y luego su intensidad decae súbitamente. El máximo de emisión en esta zona (que coincide con el máximo de emisión en todo el espectro) se alcanza a 0.7" ( 1.4 kpc);

\footnotetext{
${ }^{16} \mathrm{El}$ instrumento STIS (Space Telescope Imaging Spectrograph) se encuentra a bordo del Telescopio Espacial Hubble (HST). Es un espectrógrafo, pero también puede usarse en el modo de cámara directa. Está optimizado para la banda UV, pero su rango espectral cubre hasta el IR cercano. El instrumento se acopló al telescopio en 1997 y, aunque ha estado temporariamente fuera de operaciones, aún se encuentra funcionando.

${ }^{17} \mathrm{El}$ Telescopio Espacial Spitzer (Spitzer Space Telescope) es un observatorio en órbita diseñado para observar en IR, en el rango 3-180 $\mu \mathrm{m}$. Fue lanzado en el año 2003.
} 
Tabla 5.6. Líneas de emisión en la EELR de $3 \mathrm{C} 321$.

\begin{tabular}{|c|c|c|c|c|c|c|}
\hline \multirow{3}{*}{ Línea $(\AA)$} & \multicolumn{6}{|c|}{ Flujo $^{a}$} \\
\hline & \multicolumn{4}{|c|}{ Noroeste } & \multicolumn{2}{|c|}{ Sudeste } \\
\hline & $-7.6 "$ & $-4.5 ”$ & $-3.8 ”$ & $-2.9 ”$ & $0.9 "$ & $1.9 "$ \\
\hline$[\mathrm{Ne} \mathrm{v}] \lambda 3424$ & - & 1.97 & 1.56 & 0.46 & 1.16 & 2.0 \\
\hline$[\mathrm{O} \quad \mathrm{II}] \lambda 3727$ & 4.46 & 3.07 & 1.92 & 1.48 & 1.45 & 1.75 \\
\hline$[\mathrm{Ne}$ III $] \lambda 3869$ & - & - & 1.03 & 0.74 & 0.78 & 1.13 \\
\hline$[\mathrm{Ne}$ III $] \lambda 3968^{b}$ & - & - & 0.35 & 0.15 & 0.29 & 0.37 \\
\hline $\mathrm{H} \delta(4101)$ & - & - & 0.28 & - & 0.15 & 0.18 \\
\hline $\mathrm{H} \gamma(4340)$ & - & - & 0.49 & 0.5 & 0.41 & 0.55 \\
\hline$[\mathrm{O}$ III $] \lambda 4363$ & - & - & 0.14 & 0.15 & 0.16 & 0.11 \\
\hline He II (4686) & - & 0.51 & 0.56 & 0.44 & 0.49 & 0.54 \\
\hline $\mathrm{H} \beta(4861)$ & 1 & 1 & 1 & 1 & 1 & 1 \\
\hline$[\mathrm{O}$ III] $] \lambda 4959$ & 3.2 & 2.9 & 3.01 & 3.65 & 3.94 & 3.55 \\
\hline$[\mathrm{O}$ III $] \lambda 5007$ & 8.82 & 9.19 & 9.07 & 10.67 & 11.85 & 10.6 \\
\hline
\end{tabular}

Notas: ${ }^{a}$ Flujo relativo a $\mathrm{H} \beta$ para cada posición. Dado que $3 \mathrm{C} 321$ es una galaxia con doble núcleo, se adoptó el núcleo Sur como origen de distancias $\left(r_{N S}=0\right)$. De esta manera, la nebulosa localizada al NO, que está superpuesta con la emisión en radio se expresa mediante distancias negativas $(r<0)$, quedando el núcleo Norte en la posición $r_{N N}=-3.2$ ". La (pequeña) nebulosa al SE se expresa con distancias positivas.

${ }^{b}$ En esta longitud de onda coinciden tres líneas de emisión: [NeIII] $\lambda 3967.4$, [CaII] $\lambda 3968.44$ y HeII (3968.43), en orden de intensidad.

la emisión del [OIII] es $\sim 16 \%$ mayor allí que en el núcleo sur. Hacia el NO la EELR es mucho más extensa, siendo posible medir su emisión (en [OIII] 55007$)$ hasta 9" ( $17.5 \mathrm{kpc}$ ). En esta región se distinguen dos zonas de emisión bien localizadas. Los máximos de emisión en cada una de ellas se producen a $5.2 "(\sim 10.1 \mathrm{kpc})$ y a $7.6 "(\sim 14.8 \mathrm{kpc})$ del núcleo sur (que corresponden a aproximadamente 2", o $3.9 \mathrm{kpc}$; y a 4.4 ", o $8.6 \mathrm{kpc}$, del núcleo norte). De aquí en adelante, cuando se haga mención a "el núcleo", se entenderá que se trata del núcleo sur.

En la Tabla 5.6 se listan el conjunto de líneas presentes en el espectro de la EELR, con su intensidad expresada en función de $\mathrm{H} \beta$ para cada posición. Las distancias responden a la convención anteriormente adoptada. En la Figura 5.11 se extrajeron los espectros unidimensionales de las dos regiones; en el panel superior se muestra el espectro de la EELR-NO, a 5.5" del núcleo, y en el panel inferior, el espectro de la zona interna de la región SE, a 0.3 ". Este espectro no corresponde estrictamente a la EELR (por la escala de distancias); se muestra para apreciar que la contribución del continuo es despreciable, aún para posiciones cercanas al núcleo.

En los paneles superiores de la Figura 5.12 se ampliaron los perfiles de emisión del [OIII $] \lambda 5007$ correspondientes a los dos espectros de la figura anterior (Fig. 5.11). Allí se manifiesta claramente la complejidad de los perfiles en cualesquiera de las zonas de emisión. En el panel inferior se muestra el campo de velocidades obtenido a partir de esta descomposición Gaussiana. Las velocidades se computan respecto de la velocidad sistémica del objeto que, a su vez, corresponde a la velocidad del núcleo sur $\left(v_{\text {sis }}=28810 \mathrm{~km} \mathrm{~s}^{-1}(\mathrm{NED}) ; V=0\right.$ en el campo de velocidades). La posición y velocidad de ambos núcleos se indican con cruces. El perfil del [OIII] $\lambda 5007$ en el espectro del núcleo norte también es un perfil compuesto; se 
Figura 5.11. Espectros de la EELR en 3C 321.
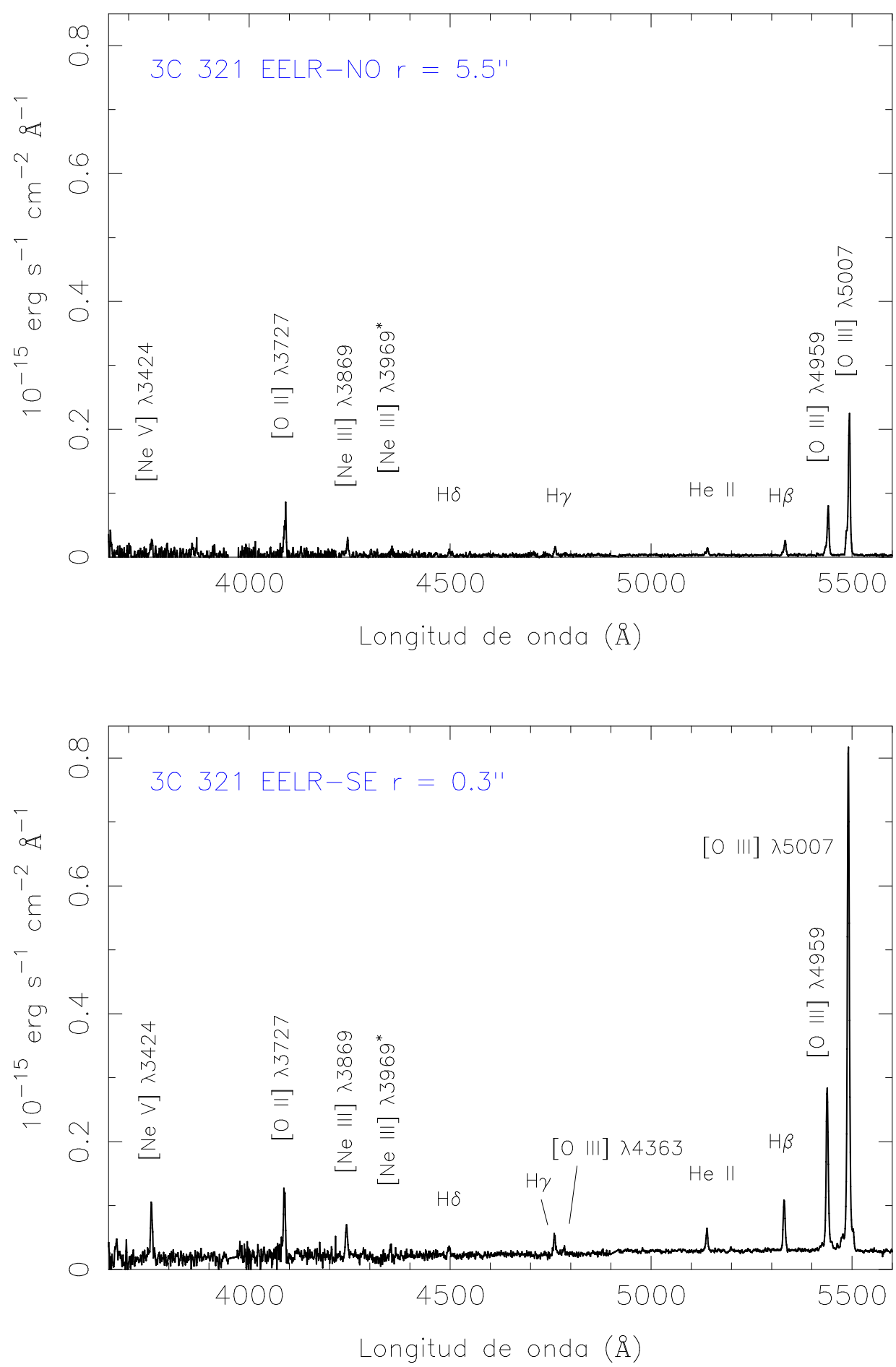

Arriba: Espectro de la EELR noroeste, a 5.5" del núcleo sur. Abajo: Espectro de la EELR sudeste, a 0.3 " del núcleo sur (* ver comentario en la Tabla 5.6). La intensidad de las líneas varía notoriamente de una región a otra; la ausencia de algunas líneas en la región NO se debe a que este espectro está tomado a una distancia mucho mayor del núcleo (las distancias siempre se refieren al núcleo sur) que la distancia a la que corresponde el espectro de la región SE. 
Figura 5.12. Descomposición Gaussiana y Campo de Velocidad en 3C 321.
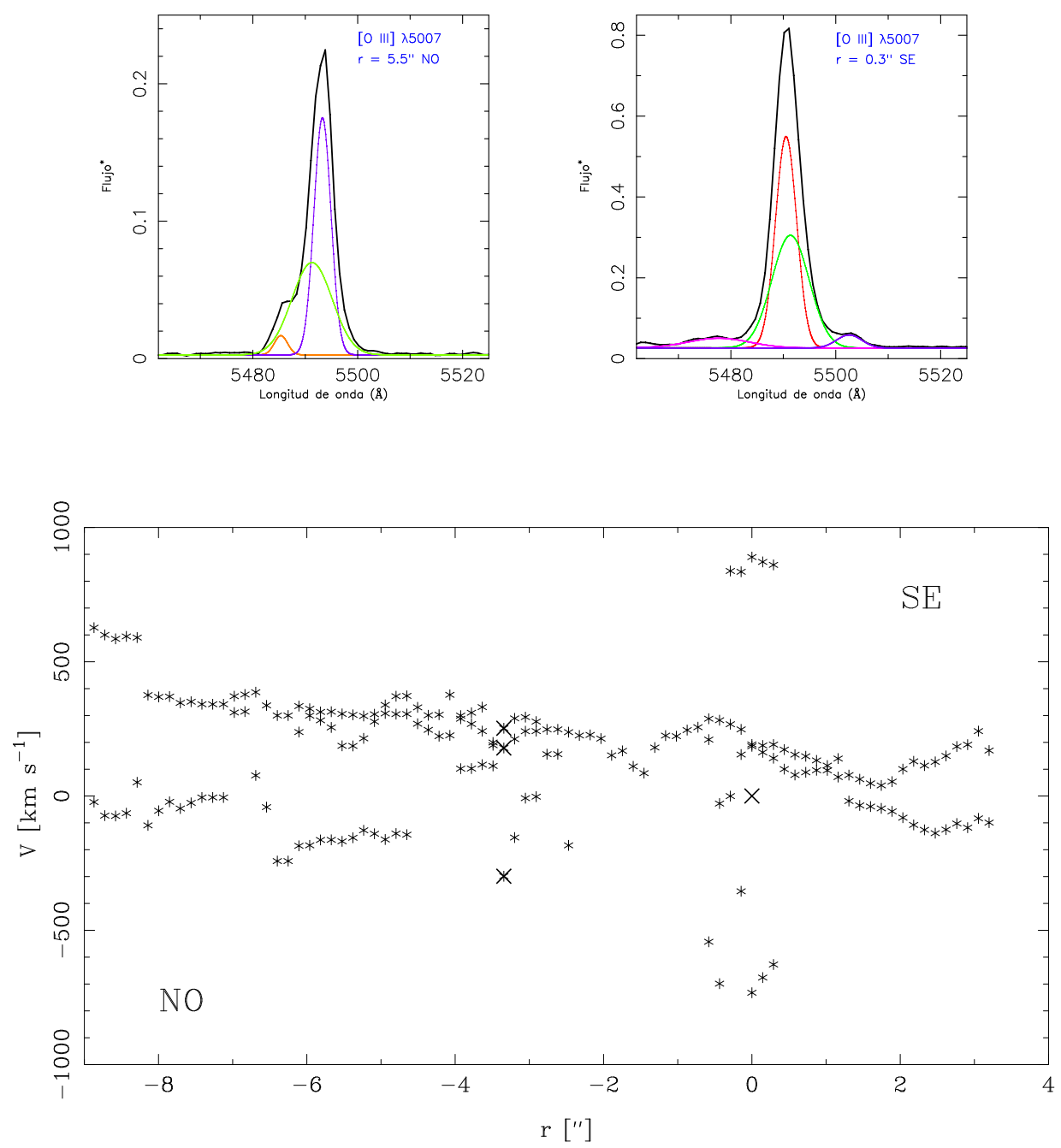

Arriba: Descomposición Gaussiana (en color) de los perfiles de [OIII] 25007 (en negro) para los espectros de la Fig. $5.11\left[^{(*)}\right.$ El flujo está expresado en las mismas unidades]. Abajo: Campo de velocidad del gas en la EELR, en la dirección de la ranura $\left(\mathrm{PA}=127^{\circ}\right)$. Las cruces marcan los núcleos sur $(r=0)$ y norte $(r=-3.2)$. El núcleo sur es el que coincide con la radiofuente puntual, y al que se le asigna la velocidad sistémica del objeto compuesto. La región NO, junto con el núcleo norte, están superpuestos a la emisión extendida interna en ondas de radio (ver Fig. 3.11). 
necesitaron tres (3) componentes para poder reproducirlo. Las velocidades de estas componentes (respecto del núcleo sur) son $v_{1} \approx 180 \mathrm{~km} \mathrm{~s}^{-1}, v_{2} \approx 250 \mathrm{~km} \mathrm{~s}^{-1}$ y $v_{3} \approx-300 \mathrm{~km} \mathrm{~s}^{-1}$; es decir, dos componentes tienen velocidades de alejamiento (corrimientos al rojo) y una componente tiene velocidad de acercamiento (corrimiento al azul). Si se adopta como velocidad del núcleo norte $\left(v_{N N}\right)$ a aquella correspondiente a la componente Gaussiana más intensa, entonces su velocidad es $V_{N N} \approx 180 \mathrm{~km} \mathrm{~s}^{-1}$. El resultado concuerda con el valor adoptado en la literatura, de $v_{N N}^{\prime}=200 \mathrm{~km} \mathrm{~s}^{-1}$ (Robinson et al. 2000).

La zona cinemáticamente más compleja se ubica en las cercanías del núcleo (sur). Allí se necesitaron cuatro (4) componentes para poder reproducir el perfil del [OIII] $\lambda 5007$, en la zona comprendida por $|r|<0.4$ ". Esto puede verse tanto en la descomposición del perfil para $r=0.3$ " al SE, como en el campo de velocidades (panel superior derecho y panel inferior de la Fig. 5.12, respectivamente). En esta zona se aprecian movimiento de muy alta velocidad, tanto de acercamiento $\left(|v| \sim 500-800 \mathrm{~km} \mathrm{~s}^{-1}\right)$ como de alejamiento $\left(v \sim 800-1000 \mathrm{~km} \mathrm{~s}^{-1}\right)$.

En la mayor parte de la EELR-NO el perfil está compuesto por tres (3) componentes Gaussianas. Una de esas componentes mantiene una velocidad relativamente estable en el rango $300-400 \mathrm{~km} \mathrm{~s}^{-1}$ a lo largo de $8 "(\sim 15.6 \mathrm{kpc})$. La segunda componente, cuya velocidad fluctúa entre 100-400 $\mathrm{km} \mathrm{s}^{-1}$, se puede distinguir con mayor claridad en la región comprendida entre $r=3-7 "(\sim 5.8-13.6 \mathrm{kpc})$. La tercer componente es la única que presenta movimientos de acercamiento, con velocidades $|v| \lesssim 300 \mathrm{~km} \mathrm{~s}^{-1}$. Estos movimientos se manifiestan en la zona más externa de la EELR-NO, a partir de $5 "(\sim 9.7 \mathrm{kpc})$ y hasta el límite de detección en el espectro (9", o $\sim 17.5 \mathrm{kpc}$ ). En la zona más externa de la región, comprendida entre 8-9" sólo se distinguen dos componentes de velocidad. Una de ellas es la componente con corrimiento al azul, recientemente descripta. La otra componente, con velocidad de alejamiento, no puede asociarse directamente a las dos componentes anteriores porque su velocidad característica es apreciablemente mayor, entre $600-700 \mathrm{~km} \mathrm{~s}^{-1}$.

En la EELR-SE el perfil se puede reproducir con sólo dos componentes, exceptuando la zona interna. Una de estas componentes tiene velocidades desplazadas hacia el azul, ligeramente apartadas de la velocidad sistémica del objeto $\left(|v| \lesssim 200 \mathrm{~km} \mathrm{~s}^{-1}\right)$. La otra componente, desplazada hacia el rojo, presenta velocidades ligeramente mayores $\left(v \lesssim 300 \mathrm{~km} \mathrm{~s}^{-1}\right)$. Ambas pueden detectarse hasta el límite de la región, a 3.2" ( $\sim 6.2 \mathrm{kpc})$ del núcleo sur.

En términos generales, la cinemática de toda la región es muy compleja. Se observan movimientos de altísima velocidad relativa en regiones muy alejadas del núcleo hacia el NO, donde estudios recientes sugieren que el radio jet está interactuando con el medio (Evans et al. 2008).

\section{8. $\quad 3 \mathrm{C} 381$}

La galaxia 3C 381 es una radiofuente bi-lobular, clase FRII, cuya densidad de flujo a $178 \mathrm{MHz}$ es de $18.1 \mathrm{Jy}$ (Hardcastle et al. 1997). Los jets no son visibles, pero su presencia se infiere según la localización de los hot spots, que, junto con la fuente puntual central, definen el radio-eje. La dirección de la estructura está dada por $\mathrm{PA}_{j e t}=4^{\circ}$, norte-sur aproximadamente (de Koff et al. 1996). En la dirección de este eje se mide la extensión de la estructura completa, que resulta de $74 "$ ( $\sim 237 \mathrm{kpc})$. El lóbulo sur es más grande que el lóbulo norte (40.5" y 33.4", respectivamente Leahy \& Perley 1991) y en la región interna, se aprecia una mayor separación respecto de la fuente puntual.

Los primeros estudios en la banda óptica fueron realizados por McCarthy, Spinrad \& van Breugel (1995), quienes dieron cuenta de la emisión extendida en [OIII] 25007 , y caracterizaron a 3C 381 como uno de los objetos con mayor extensión de gas altamente ionizado dentro del grupo de radiogalaxias a bajo redshift. En las imágenes HST (Fig. 3.12, panel superior 
Tabla 5.7. Líneas de emisión en la EELR de $3 \mathrm{C} 381$.

\begin{tabular}{lccc|ccc}
\hline \hline & \multicolumn{5}{c}{ Flujo $^{a}$} \\
Línea $(\AA)$ & $-3.2 "$ & $-2.2 "$ & $-1.1 "$ & $1.1 "$ & $2.2 "$ & $3.2 "$ \\
\hline$[\mathrm{Ne}$ III $] \lambda 3345$ & - & - & - & 0.26 & - & - \\
{$[\mathrm{Ne}$ v $] \lambda 3424$} & - & - & 1.04 & 0.7 & - & - \\
{$[\mathrm{O}$ II $] \lambda 3727$} & 11.36 & 7.17 & 3.32 & 2.12 & 3.37 & 4.52 \\
{$[\mathrm{Ne}$ III $] \lambda 3869$} & - & 2.0 & 1.24 & 0.95 & 1.17 & - \\
{$[\mathrm{Ne}$ III $] \lambda 3968^{b}$} & - & - & 0.49 & 0.39 & - & - \\
$\mathrm{H} \delta(4101)$ & - & - & 0.21 & 0.15 & 0.19 & - \\
$\mathrm{H} \gamma(4340)$ & - & 0.45 & 0.46 & 0.44 & 0.49 & - \\
{$[\mathrm{O}$ III $] \lambda 4363$} & - & 0.28 & 0.24 & 0.24 & 0.25 & - \\
$\mathrm{He}$ II $(4686)$ & - & 0.31 & 0.31 & 0.39 & 0.19 & - \\
{$[\mathrm{Ar}$ IV $] \lambda 4711^{c}$} & - & - & 0.07 & 0.06 & - & - \\
{$[\mathrm{Ar}$ IV $] \lambda 4740$} & - & - & 0.05 & 0.06 & - & - \\
$\mathrm{H} \beta(4861)$ & 1 & 1 & 1 & 1 & 1 & 1 \\
{$[\mathrm{O}$ III $] \lambda 4959$} & 3.95 & 4.0 & 4.35 & 4.56 & 4.25 & 3.75 \\
{$[\mathrm{O}$ III $] \lambda 5007$} & 13.43 & 11.83 & 12.97 & 13.74 & 12.8 & 10.9 \\
\hline \hline
\end{tabular}

Notas: ${ }^{a}$ Flujo relativo a $\mathrm{H} \beta$ para cada posición. Las distancias (SE negativas, NO positivas) se expresan respecto al centro galáctico.

${ }^{b}$ En esta longitud de onda coinciden tres líneas de emisión: [NeIII] $\lambda 3967.4$, [CaII] $\lambda 3968.44$ y HeII (3968.43), en orden de intensidad.

${ }^{c}$ Posible contaminación de $[\mathrm{Ne}$ IV] $\lambda 4718$. 
derecho) la extensión de la región nebular completa es de 4.5" ( $14.4 \mathrm{kpc})$. La región NO concentra la emisión en la parte más interna, cercana al objeto central, extendiéndose luego hacia las afueras hasta alcanzar el extremo sur del lóbulo norte. La emisión proveniente de la región SE, en cambio, está claramente separada de la galaxia anfitriona, mostrando un comportamiento similar al del lóbulo sur. El máximo de emisión se produce a una distancia de $1.1 "(\sim 3.5 \mathrm{kpc})$.

En las cercanías de la fuente puntual, los lóbulos están desplazados ("desalineados") respecto del radio-eje en la misma dirección que la emisión extendida del [OIII] (ver Fig. 3.12). Las imágenes WFPC2/HST no permiten detectar superposición radio-óptico, exceptuando el extremo norte de la EELR-NO. Sin embargo, con las observaciones realizadas con el telescopio de $3 \mathrm{~m}$ del Observatorio Lick, McCarthy et al. (1995) mostraron que existe un filamento de [OIII] $\lambda 5007$ a 25" ( 80 kpc) en dirección norte. Este filamento está completamente contenido en el lóbulo norte, $\mathrm{y}$ se halla en la misma direción del radio-eje.

Espectroscópicamente, 3C 381 fue clasificada como una galaxia de alta excitación, en base a las características del espectro nuclear y la intensidad de la emisión en [OIII] $\lambda 5007$ (Buttiglione et al. 2009, 2010). El espectro de la EELR, en general, es muy rico en cuanto a la cantidad de línea presentes, aunque muchas de ellas son relativamente débiles y sólo se distinguen con claridad en la zona más interna, cercana al núcleo activo. Una de ellas es [NeIII] $\lambda 3345$, la más azul del espectro, y que sólo fue detectada en este objeto. En la Tabla 5.7 se listan las líneas detectadas, y los flujos en distintas posiciones de ambas EELR, relativos al de $\mathrm{H} \beta$ en cada posición. En la Fig. 4.10 se muestra el extremo rojo del espectro long-slit de 3C 381, donde se encuentran las líneas más intensas H $\beta$, y [OIII] $\lambda \lambda 4959$, 5007. La EELR-NO (Fig. 3.12, panel superior derecho) se expresa mediante distancias positivas $\left(r_{N O}["]>0\right)$ y la EELR-SE, mediante distancias negativas $\left(r_{S E}["]<0\right)$. Según el procedimiento explicado en el Capítulo anterior, se extrajeron los espectros $1 \mathrm{D}$ de toda la región nebular, siendo aquellos de la Figura 5.13 ejemplos de cada una de las regiones. En el panel superior se encuentra un espectro de la EELR-SE, a 0.9", y en el panel inferior, uno de la EELR-NO a 1.2".

La región donde co-existen líneas de baja y alta excitación se extiende por 3.2" ( 10 kpc) en ambos sentidos en la dirección de la ranura $\left(\mathrm{PA}=155^{\circ}\right.$; Tabla 3.4). Sin embargo, por tratarse de la línea más intensa (mayor relación $\mathrm{S} / \mathrm{N}$ ) del espectro, el [OIII] $\lambda 5007$ se extiende hasta $4.8 "(\sim 15.4 \mathrm{kpc})$ hacia el NO y 7.3" ( 23.4 kpc) hacia el SE. De aquí resulta que la extensión de la EELR (en la dirección de la ranura) es de 12" ( $38.4 \mathrm{kpc})$, alrededor del triple de la extensión derivada de las imágenes de la WFPC2, lo cual indica la presencia de estructuras de muy bajo brillo superficial hacia las afueras de la EELR.

La forma de las líneas en el espectro 2D muestra una notable concentración de emisión en la región central, con alas donde la emisión se desplaza hacia el azul, en la EELR-NO y rojo, en la EELR-SE (Fig. 4.10). Luego de la extracción individual de espectros 1D, se aprecian estructuras complejas en los perfiles, que, en general, no pueden reproducirse con sólo una componente Gaussiana, como se discute a continuación. La intensidad de las líneas en la EELR-NO decrece monótonamente desde el núcleo hacia las afueras de la región. En la región SE, en cambio, se observa un súbito incremento en la emisión de todas las líneas del espectro a una distancia de 1" ( $\sim 3.2 \mathrm{kpc})$ aproximadamente. Las imágenes WFPC2/HST evidenciaban este comportamiento para la emisión proveniente del [OIII], como se mencionó antes. A través del espectro se comprueba que este hecho es un fenómeno tan global, en tanto el aumento es apreciable en todas las líneas, como local, dado que no manifiesta conexión alguna con la emisión proveniente de la región central.

En los paneles superiores de la Figura 5.14 se ampliaron los perfiles de [OIII] $\lambda 5007$ de los espectros de la Fig. 5.13. El perfil real se muestra en negro, y su descomposición en componentes Gaussianas en color. Se pueden distinguir cambios muy importantes en la forma del 
Figura 5.13. Espectros de la EELR en $3 \mathrm{C} 381$.
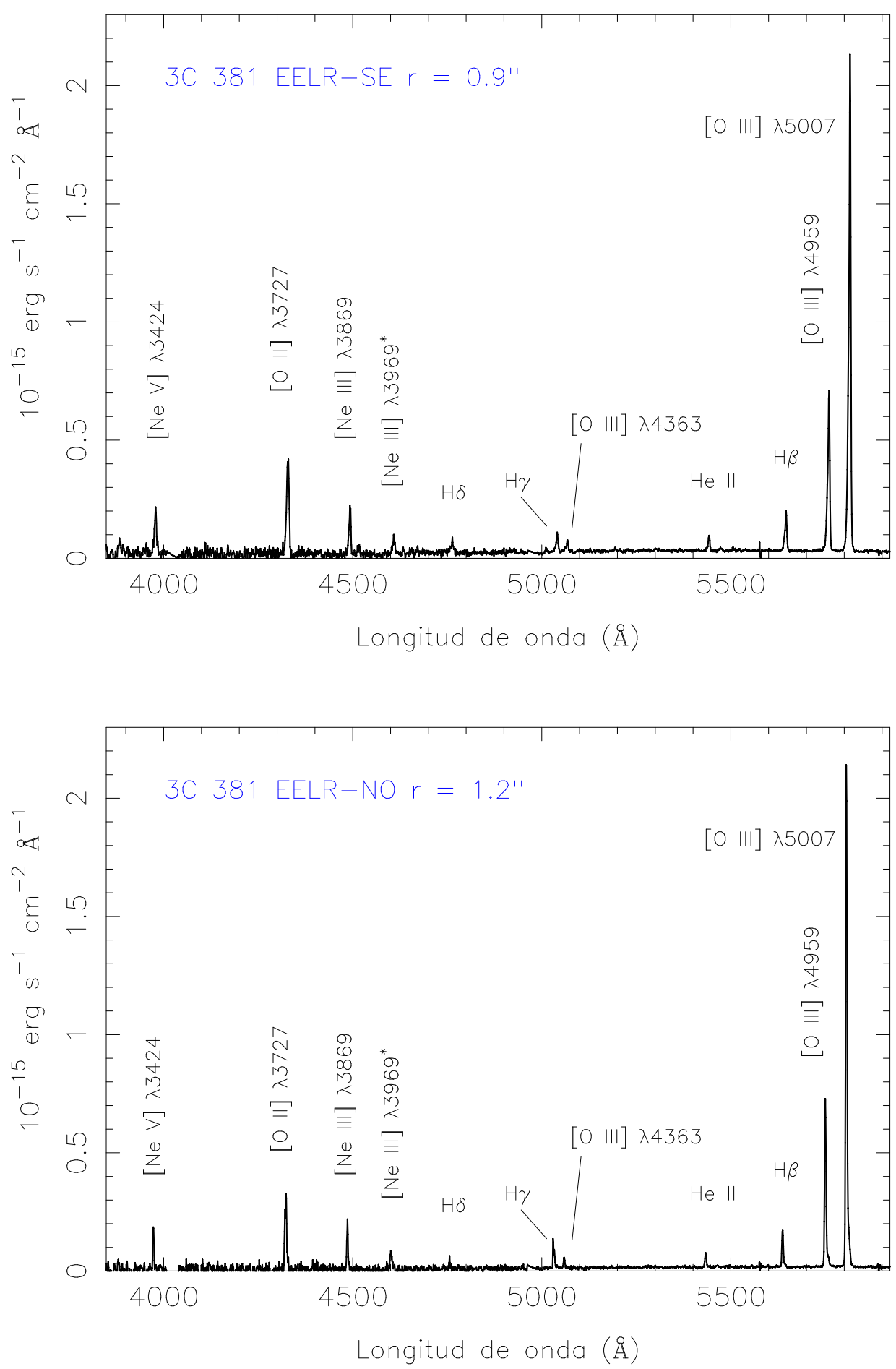

Arriba: Espectro de la EELR sudeste, a 0.9" del centro galáctico. En esta zona se produce el máximo de emisión en la región SE (ver texto). Abajo: Espectro de la EELR a 1.2" en dirección NO. 
Figura 5.14. Descomposición Gaussiana y Campo de Velocidad en 3C 381.
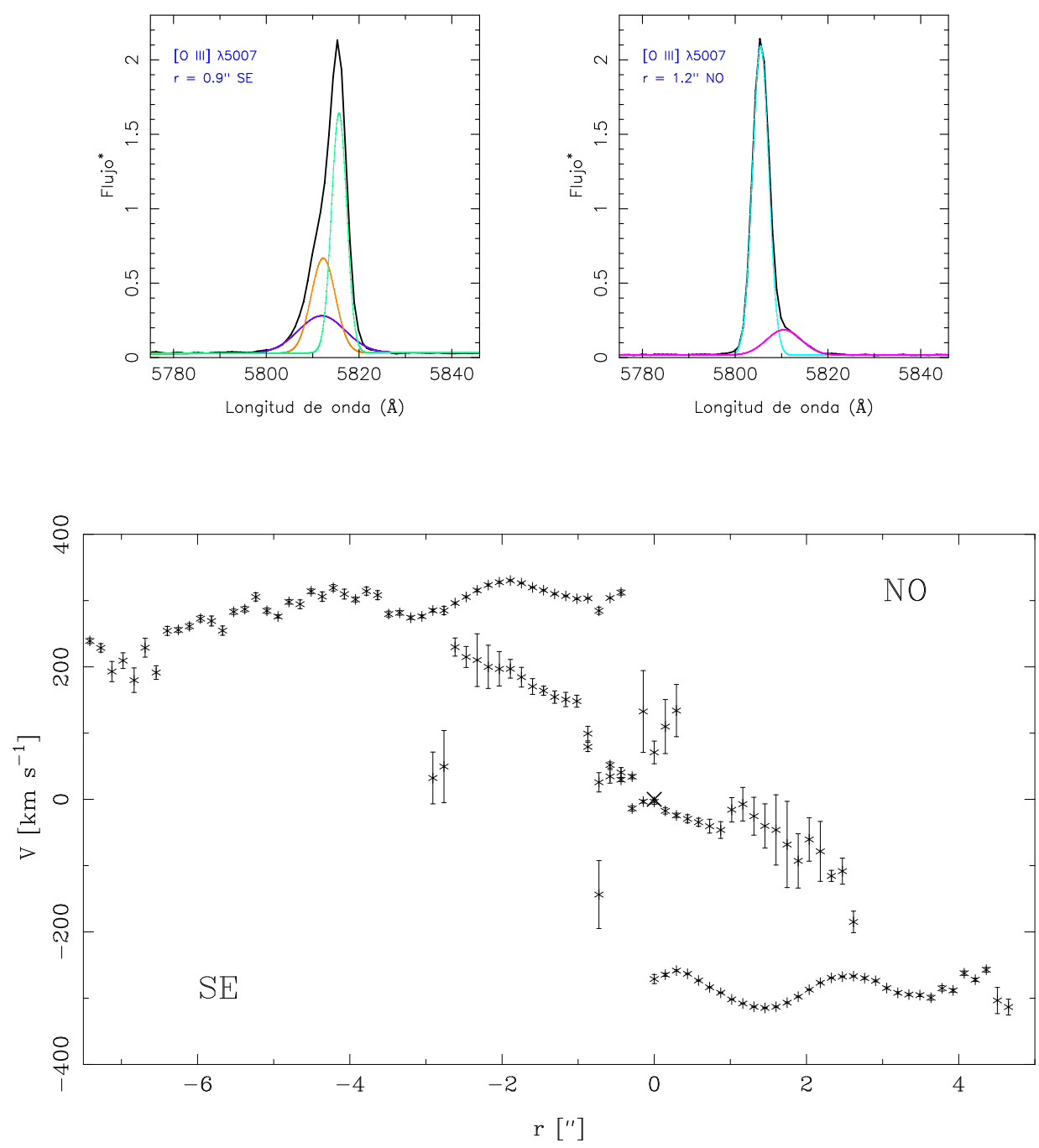

Arriba: Descomposición Gaussiana (en color) de los perfiles de [OIII] $\lambda 5007$ (en negro) para los espectros de la Fig. $5.13\left[^{(*)}\right.$ El flujo está expresado en las mismas unidades]. Abajo: Campo de velocidad del gas en la EELR, en la dirección de la ranura $\left(\mathrm{PA}=70^{\circ}\right)$. La cruz indica el centro galáctico, que se mueve con la velocidad sistémica. Se utilizan distancias negativas para la región SE, y positivas para la NO. 
perfil respecto de una y otra región, que se traduce en la cantidad de componentes necesarias (siempre manteniendo el mínimo indispensable, como se explicó en el Capítulo 4, Sección 4.2) para poder reproducirlo. Estos ejemplos son ilustrativos, también, del desplazamiento en longitud de onda que va sufriendo la emisión conforme varía la distancia al centro. Tanto la descomposición Gaussiana como este evidente desplazamiento se utilizaron para obtener el campo de velocidades del gas, que se muestra en el panel inferior de la misma Figura 5.14. En la zona central ( $r=0$, existen componentes cuya velocidad coincide con la velocidad sistémica del objeto $\left(v_{\text {sis }}=48117 \mathrm{~km} \mathrm{~s}^{-1}\right.$ [NED]; $V=0$ en el campo de velocidad.). Hacia una y otra región se observan componentes aproximadamente estabilizadas en torno a $\pm 300 \mathrm{~km} \mathrm{~s}^{-1}$ a una distancia de $\mp 1.5 "$ ( $\mp 5 \mathrm{kpc} ; \mathrm{SE} / \mathrm{NO}$, respectivamente). Este comportamiento colectivo y ordenado del gas, la curva de rotación, es consistente con el movimiento gravitatorio esperado dentro del potencial galáctico (Tadhunter, Fosbury \& Quinn 1989). Sin embargo, pueden identificarse claramente otras componentes de alta velocidad, superpuestas a la curva de rotación. Este tipo de movimiento, desordenado y de características puramente locales, no puede ser explicado bajo la misma hipótesis gravitacional. Los movimientos de más alta velocidad están concentrados en los 6 " internos $( \pm 3 " ; \sim \pm 10 \mathrm{kpc})$, y su velocidad relativa a la curva de rotación es de aproximadamente $\pm 300 \mathrm{~km} \mathrm{~s}^{-1}$. Estas nubes de alta velocidad también pueden identificarse claramente en las líneas de recombinación del hidrógeno, en particular $\mathrm{H} \beta$ por tratarse de la línea más intensa en este subconjunto.

3C 381 ha sido considerada durante mucho tiempo como una BLRG, sobre la base de la existencia de una componente ancha, aunque débil, en el perfil de emisión de $\mathrm{H} \alpha$ (Grandi \& Osterbrock 1978). Sin embargo, los espectros que condujeron a esa clasificación nunca fueron publicados. Recientemente se han obtenido espectros nucleares tanto en rayos-X, con Chandra (Hardcastle et al. 2009, y las referencias allí citadas), como en el óptico, con el Telescopio Nacional Galileo (TNG; Buttiglione et al. 2009) que indican que no existe ningún indicio de tal componente. En consecuencia, y aún cuando $\mathrm{H} \alpha$ no está en el rango cubierto por nuestros espectros, este conjunto de resultados nos permite afirmar que 3C 381 no es una BLRG, sino que tiene, indudablemente, un espectro de Tipo II.

\subsection{Otras fuentes observadas}

En esta Sección se reúnen los características de los espectros GMOS/Gemini y la información multifrecuencia disponible de tres (3) objetos que, aunque fueron observados junto con los anteriores, no forman parte de esta investigación. Estas tres radiogalaxias se observaron porque las estructuras nebulares externas de cada una de ellas son suficientemente extensas e intensas, según se aprecia en las imágenes del HST. Sin embargo quedan separadas de la muestra principal porque no respetan el criterio de alineamiento óptico-radio adoptado para el análisis, en el marco de los modelos propuestos en el Capítulo 2.

\subsection{1. $\quad 3 \mathrm{C} 184.1$}

La radiofuente 3C 184.1 es un objeto bi-lobular de tipo FRII, cuya densidad de flujo en la frecuencia de $178 \mathrm{MHz}$ es de $14.2 \mathrm{Jy}^{18}$. Los lóbulos se disponen en dirección noroeste y sudeste, respectivamente; la radiofuente puntual se ubica en el extremo norte del lóbulo sur (ver Fig 3.3, panel inferior izquierdo). Ambos lóbulos presentan hot spots en sus extremos, aunque, como señalan Leahy \& Perley (1991), estrictamente, éstos se encuentran fuera de los límites de los lóbulos. Es decir, se produce una estructura de tipo "cuello de botella", donde los hot spots parecen haber avanzado más allá de los extremos externos de los lóbulos

\footnotetext{
${ }^{18}$ http://www.jb.man.ac.uk/atlas/object/3C184P1.html
} 
Tabla 5.8. Líneas de emisión en la EELR de 3C 184.1.

\begin{tabular}{|c|c|c|c|c|c|c|}
\hline \multirow{3}{*}{ Línea $(\AA)$} & \multicolumn{6}{|c|}{ Flujo $^{a}$} \\
\hline & \multicolumn{3}{|c|}{ Noreste } & \multicolumn{3}{|c|}{ Sudoeste } \\
\hline & $-2.8 ”$ & $-1.7 ”$ & $-0.7 ”$ & $0.7 "$ & $1.7 ”$ & $2.8 ”$ \\
\hline$[\mathrm{Ne} \mathrm{V}] \lambda 3424$ & - & - & 0.54 & 0.73 & 0.7 & - \\
\hline$[\mathrm{O} \quad \mathrm{II}] \lambda 3727$ & 1.67 & 3.09 & 2.58 & 1.59 & 2.01 & 2.0 \\
\hline$[\mathrm{Ne}$ III $] \lambda 3869$ & - & - & 0.77 & 0.81 & 0.86 & - \\
\hline H I + He I (3890) & - & - & - & 0.11 & - & - \\
\hline$[\mathrm{Ne}$ III $] \lambda 3968^{b}$ & - & - & 0.23 & 0.36 & 0.36 & - \\
\hline $\mathrm{H} \delta(4101)$ & - & - & 0.26 & 0.23 & 0.2 & - \\
\hline $\mathrm{H} \gamma(4340)$ & 0.31 & 6.41 & 0.44 & 0.49 & 0.5 & 0.49 \\
\hline$[\mathrm{O}$ III $] \lambda 4363$ & - & 0.29 & 0.3 & 0.3 & 0.36 & - \\
\hline He II (4686) & 0.18 & 0.17 & 0.23 & 0.36 & 0.43 & 0.32 \\
\hline $\mathrm{H} \beta(4861)$ & 1 & 1 & 1 & 1 & 1 & 1 \\
\hline$\left[\begin{array}{ll}\text { O III }] \lambda 4959\end{array}\right.$ & 2.6 & 3.06 & 2.69 & 4.01 & 3.7 & 3.78 \\
\hline$[\mathrm{O}$ III $] \lambda 5007$ & 7.62 & 9.28 & 8.29 & 11.66 & 10.86 & 10.58 \\
\hline
\end{tabular}

Notas: ${ }^{a}$ Flujo relativo a $\mathrm{H} \beta$ para cada posición. Las distancias (NE negativas, SO positivas) se expresan respecto al centro galáctico.

${ }^{b}$ En esta longitud de onda coinciden tres líneas de emisión: [NeIII] $\lambda 3967.4$, [CaII] $\lambda 3968.44$ y HeII (3968.43), en orden de intensidad.

posiblemente debido a una caída brusca en la densidad ambiental. Una estructura similar se observa en la radiofuente 3C 381 (Sección 5.8; Fig. 3.12, panel inferior izquierdo). La dirección de alineación de la estructura completa está dada por $\mathrm{PA}_{j e t}=157^{\circ}$ (Privon et al. 2008), y su máximo tamaño angular es de 182" (428 kpc aproximadamente; Leahy \& Perley 1991).

El objeto también emite en las bandas de rayos-X y óptico (Massaro et al. 2010; de Koff et al. 1996) aunque las escalas características de la emisión son completamente diferentes a las de radio. Los datos tomados con Chandra confirman que la radiofuente puntual es un fuerte emisor en rayos-X, y que la emisión se concentra en su entorno, dado por un radio menor a 8" (ver fig. 22 de Massaro et al. 2010, los mapas de radio usados en este trabajo corresponden a la frecuencia de $8 \mathrm{GHz}$; en esta frecuencia la emisión de la fuente puntual no se ve afectada por la del lóbulo, como sí sucede en los mapas presentados en la Fig. 3.3 donde se usaron los datos en $1477 \mathrm{MHz}$.). La luminosidad en la frecuencia de $178 \mathrm{MHz}$ es sólo el $1 \%$ de la luminosidad integrada en el rango $2-10 \mathrm{keV}^{19}$ (Wu et al. 2013).

La galaxia 3C 184.1 es conocida por tener líneas de emisión muy intensas, y por la particular disposición de sus regiones de gas ionizado respecto de la distribución observada en radio (de Koff et al. 1996). En cuanto a las líneas presentes, cabe una mención acerca de la clasificación espectral de la galaxia, dado que ha sido catalogada tanto BLRG como tipo Seyfert 2. Según Véron-Cetty \& Véron (2006), se trata de una Seyfert 2 donde ha sido posible detectar una componente ancha en la línea $\mathrm{Pa} \beta^{20}$; lo cual sería un indicador de enrojecimiento en la BLR. Como consecuencia de esta característica, en el $\mathbf{1 2}^{\text {vo }}$ Catálogo de Quasars y Núcleos Activos de Véron-Cetty \& Véron (2006) se introdujo una nueva denominación:

\footnotetext{
${ }^{19} L_{2-10}=8.1 \times 10^{43} \mathrm{erg} \mathrm{s}^{-1}$ y $L_{178}=8.9 \times 10^{41} \mathrm{erg} \mathrm{s}^{-1}$ (Wu et al. 2013)

${ }^{20} \mathrm{~Pa} \beta$ es la línea (de emisión, en este caso) de la serie de Paschen que se produce cuando el electrón decae desde el nivel cuántico $n=5$ al nivel $n=3$. Su longitud de onda en reposo corresponde a $12818 \AA$, por lo tanto se detecta en el IR cercano. La serie de Paschen es el conjunto de todas las líneas que decaen al nivel n=3.
} 
los objetos que, como 3C 184.1, presentan espectros tipo Seyfert 2 y una componente ancha en $\mathrm{Pa} \beta$ se clasifican como Seyfert 1i. Por su parte, Massaro et al. (2010) si bien parten de la hipótesis de que 3C 184.1 es una BLRG (Donzelli et al. 2007; Buttiglione et al. 2009), encuentran que sus mediciones de densidad columnar ${ }^{21}$ arroja un valor (demasiado alto) que no es representativo para el tipo de objeto propuesto.

En lo que a alineamiento se refiere, la distribución espacial del gas óptico no guarda ningún tipo de relación con lo que se observa en radio. Más aún, el material de la EELR parece estar dispuesto en dirección prácticamente perpendicular a los lóbulos (Leahy \& Perley 1991; de Koff et al. 1996). En el panel superior derecho de la Figura 3.3 se puede ver que el gas se extiende en direcciones diferentes. Una región se elonga preferentemente hacia el este del núcleo de la galaxia; otra región, más pequeña según las imágenes del HST, se extiende en dirección noreste; y una tercer región, la más extendida, se encuentra hacia el sur. Como se aprecia en la superposición de las imágenes del HST y VLA (panel inferior derecho de la misma Figura), toda la región óptica está contenida dentro de lo que, en radio y en rayos$\mathrm{X}$, se asocia a la posición de la radiofuente puntual; no existe evidencia en la literatura de conexión alguna con la emisión de los lóbulos.

Dado que resulta imposible observar las tres regiones en emisión dentro de un mismo espectro long-slit, se optó por buscar la mejor combinación entre el ancho de la ranura y el ángulo de posición para cubrir la mayor parte de la región junto con el núcleo de la galaxia. Con la ranura de 1", ubicada según $\mathrm{PA}=18^{\circ}$, fue posible obtener el espectro de la región más extensa junto con el de la región aparentemente más pequeña hacia el noreste. El espectro resultante es muy rico en líneas de emisión (Tabla 5.8); en la Figura 4.1 se muestra la zona comprendida por las líneas $\mathrm{H} \beta$ y [OIII] $\lambda \lambda 4959,5007$. La nebulosa NE se expresa mediante coordenadas negativas $\left(r_{N E}["]<0\right)$ y la región SO con coordenadas positivas $\left(r_{S O}["]>0\right)$, todas las distancias se expresan respecto del centro galáctico. Contrariamente a lo que sugiere la imagen del HST (panel superior derecho de la Fig. 3.3), la nebulosa de la región NE es tan extensa como la del SO. El tamaño de ambas regiones, según el alcance de la línea [OıII] $\lambda 5007$, es muy similar: 6" ( $\sim 14 \mathrm{kpc})$ hacia el NE, y 5.8" ( 13.7 kpc) hacia el SO.

La intensidad de las líneas en toda la región tiene dos comportamientos bien definidos. Dentro de la zona comprendida por $|r|<2$ " la intensidad cae más rápidamente hacia el NE que hacia el SO, es decir, son más intensas hacia el SO. Un ejemplo de ello puede verse en la Figura 5.15, donde se muestran los espectros unidimensionales de ambas regiones para la misma distancia al centro de la galaxia (1"). A partir de $|r|>2$ " se observa un comportamiento diferente en cada zona. En la región NE, las líneas más intensas ([OII] $] \lambda 3727, \mathrm{H} \gamma, \mathrm{H} \beta$ y [OIII $] \lambda \lambda 4959,5007)$ se pueden detectar, aunque débiles, hasta el extremo de la región. Hacia el SO, en cambio, estas mismas líneas van perdiendo gradualmente su intensidad: [OII] $\lambda 3727$ y $\mathrm{H} \gamma$ ya no pueden detectarse a partir de 3 ", $\mathrm{H} \beta$ a partir de los 4", y finalmente [OIII] $\lambda 5007$, quien marca la extensión total de la región, se desvanece en 5.8".

El perfil de emisión del [OIII] es relativamente simple. En la región interna de la galaxia $(|r|<0.7$ ") se pueden identificar dos componentes, una desplazada hacia el rojo y otra hacia el azul, pero moviéndose a la misma velocidad relativa $\left(150 \mathrm{~km} \mathrm{~s}^{-1}\right.$ aproximadamente) respecto de la velocidad sistémica del objeto $\left(v_{\text {sis }}=35435 \mathrm{~km} \mathrm{~s}^{-1}, V=0\right.$ en el campo de velocidad). A partir de esta distancia, ninguna de las componentes del [OIII] que se medirán hacia el SO o NE volverán a manifestar velocidades de alejamiento (centroides desplazados hacia el rojo). En los paneles superiores de la Figura 5.16 se muestran los perfiles ampliados del [OIII] (en negro) correspondientes a los espectros de la figura anterior (Fig. 5.15) y su descomposición Gaussiana (en color). En el panel inferior, el campo de velocidades; la cruz indica la posición del centro de la galaxia. Para distancias mayores a \pm 0.7 ", en la región $\mathrm{SO}$ sólo se puede

\footnotetext{
${ }^{21} N_{H}=4-5 \times 10^{22} \mathrm{~cm}^{-2}$ (Massaro et al. 2010).
} 
Figura 5.15. Espectros de la EELR en 3C 184.1.
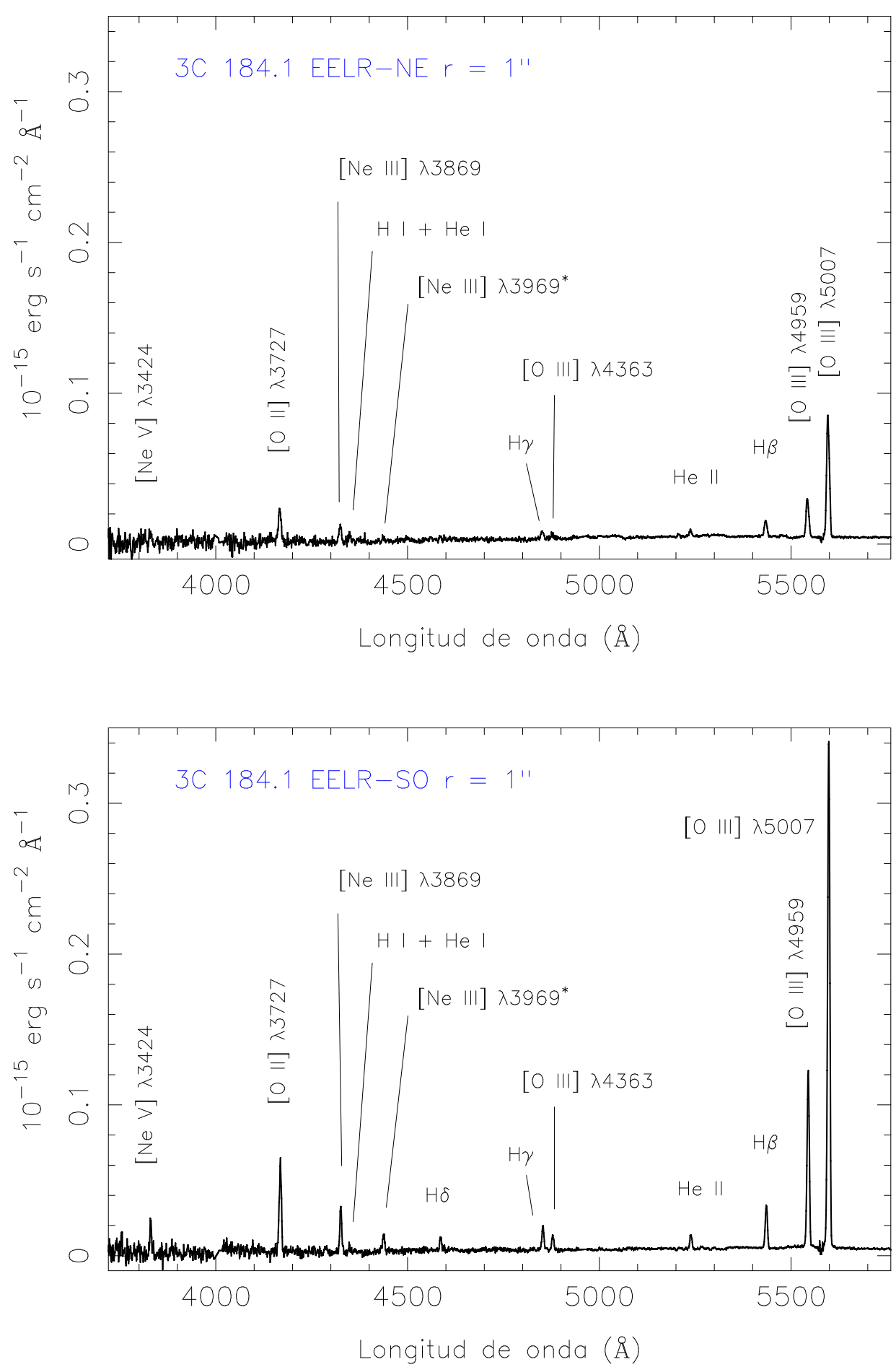

Arriba: Espectro de la EELR noreste, a 1" del centro galáctico. Abajo: Espectro de la EELR sudoeste a la misma distancia. La intensidad de las líneas varía notoriamente de una región a otra, siendo indistinguibles algunas de ellas en la región menos intensa (* ver comentario en la Tabla 5.8). 
Figura 5.16. Descomposición Gaussiana y Campo de Velocidad en 3C 184.1.
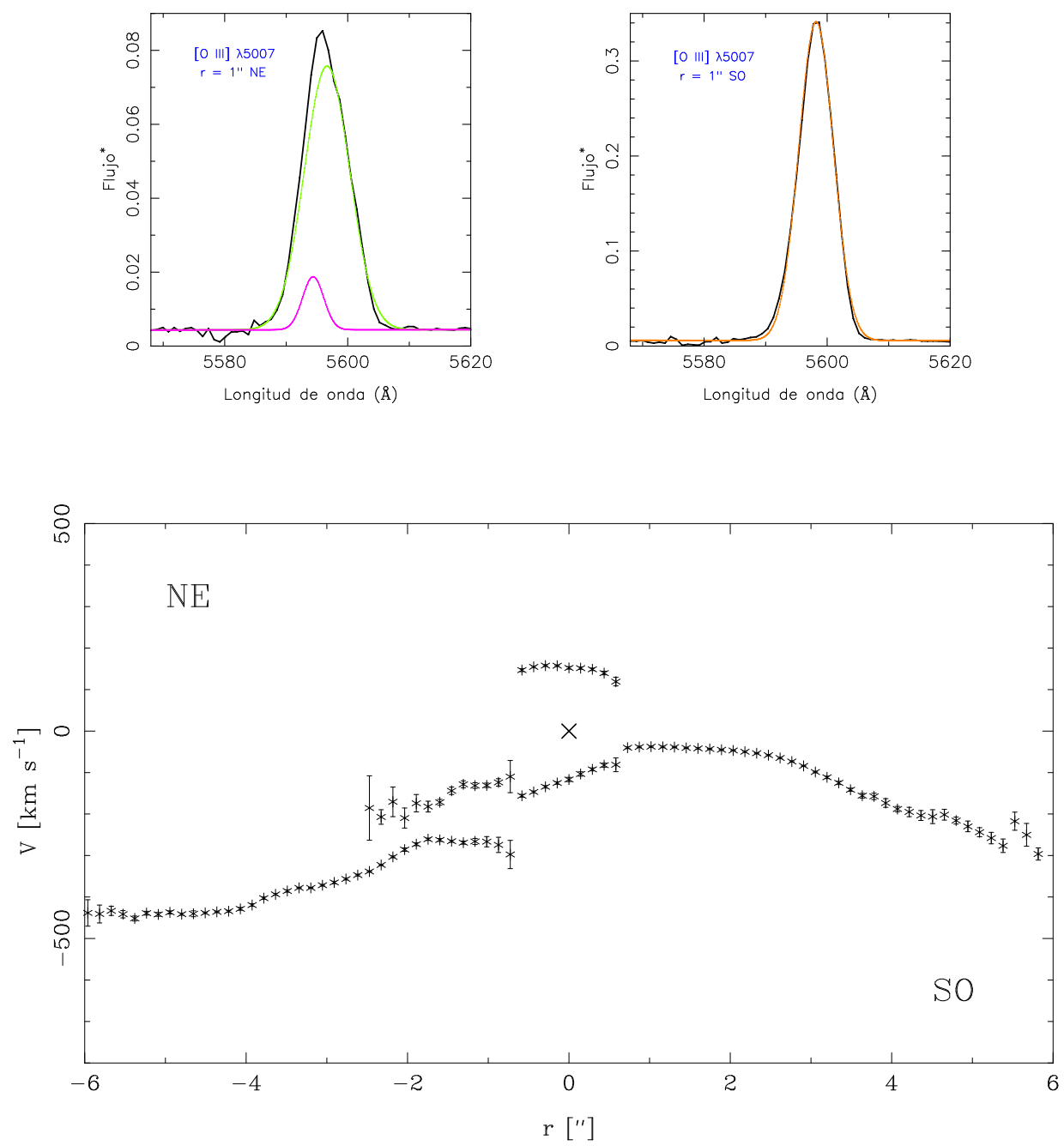

Arriba: Descomposición Gaussiana (en color) de los perfiles de [OIII] $\lambda 5007$ (en negro) para los espectros de la Fig. $5.15\left[{ }^{(*)}\right.$ El flujo está expresado en las mismas unidades]. Abajo: Campo de velocidad del gas en la EELR, en la dirección de la ranura $\left(\mathrm{PA}=18^{\circ}\right)$. La cruz indica la posición del centro galáctico. No existe ninguna componente cuya velocidad coincida con la velocidad sistémica del objeto. 
identificar una única componente cuya velocidad (la componente de la velocidad en la línea de la visual) aumenta desde 100 hasta $300 \mathrm{~km} \mathrm{~s}^{-1}$ cuando la distancia al centro crece. En la región NE se distinguen dos componentes hasta una distancia de 2.5" y luego sólo una hasta el límite de detección de la línea. La componente que se manifiesta en la zona -2.5 " $<r<0.7$ " presenta velocidad estable entre 100-200 $\mathrm{km} \mathrm{s}^{-1}$; la componente que se hace presente hasta el extremo de la región también muestra un aumento en la velocidad relativa al centro conforme aumenta la distancia, como sucede en la región SO; en este caso se alcanzan velocidades cercanas a los $500 \mathrm{~km} \mathrm{~s}^{-1}$. En términos generales, prácticamente toda la emisión parece estar experimentando movimientos de acercamiento en la línea de la visual, por lo cual es imposible identificar una curva de rotación mediante el campo de velocidades. Esto no constituye una prueba en contra del valor de corrimiento al rojo adoptado para el objeto (o al menos no es posible afirmarlo con nuestros datos), dado que en la región central el valor que se desprende de las dos componentes observadas es compatible con $z=0.1182$, el valor aceptado en la literatura (Spinrad et al. 1985, NED).

\subsection{2. $\quad 3 \mathrm{C} 196.1$}

3C 196.1 es una radiofuente peculiar. Si bien ha sido clasificada como FRII (de Koff et al. 1996; Donzelli et al. 2007; Buttiglione et al. 2010), prácticamente no hay indicios en la morfología como para incluir a este objeto en el mismo grupo de las típicas fuentes bilobulares. Otros autores han optado por no asignarle clasificación en este esquema (Harvanek \& Stocke 2002), otros la han agrupado dentro de las CSS (Privon et al. 2008), e incluso otros la clasifican como HYMORS: Radiofuente de morfología híbrida (HYbrid MOrphology Radio Source; Massaro et al. 2012; Gopal-Krishna \& Wiita 2000). Los mapas de radio disponibles en la literatura muestran que el objeto presenta características muy diferentes en distintas frecuencias. Por ejemplo, en los mapas de Neff et al. (1995) se observa una fuente puntual algo deformada en dirección noreste en $20 \mathrm{~cm}$, mientras que en $6 \mathrm{~cm}$ se distingue una estructura doble, alineada en dirección noreste-sudoeste. Esta estructura indica que podría tratarse de un objeto con núcleo doble; propuesta que, incluso, ya había sido sugerida por Baum et al. (1988). Más recientemente, Massaro et al. (2012) presentaron mapas en $8.4 \mathrm{GHz}(3.6 \mathrm{~cm})$, muy similares a los de $6 \mathrm{~cm}$, pero su interpretación es muy diferente. Allí se considera que la región SO tiene la estructura típica de un jet FRI, pero que la región NE podría considerarse como un clásico lóbulo FRII (al ser más intenso en su borde externo se puede considerar que tal aumento de intensidad es un hot spot); de aquí que estos autores propongan que se trata de un objeto híbrido. Sin embargo, tanto por la potencia emitida en radio (su densidad de flujo en la frecuencia de $178 \mathrm{MHz}$ es de $18.6 \mathrm{Jy}$; Spinrad et al. 1985) como por su magnitud óptica $^{22}$ el objeto bien puede considerarse como perteneciente al grupo de las FRII (Massaro et al. 2012). El ángulo de posición de la estructura, en este caso, es de $\mathrm{PA}_{j e t}=43^{\circ}$ (de Koff et al. 1996).

Tanto en el óptico (Baum et al. 1988; de Koff et al. 1996, y Figura 3.4) como en IR (Madrid et al. 2006) la galaxia se observa elongada como en radio, es decir, en dirección NE-SO. El gas ionizado asociado al conjunto, y que en principio Baum et al. (1988) definió como "envoltura", tiene distintas características según se observe en $\mathrm{H} \alpha+[\mathrm{NII}$ ] o en [OIII] (ver fig. 7 de Tremblay et al. 2009, estos datos fueron tomados con la cámara ACS del HST). La emisión en $\mathrm{H} \alpha+[\mathrm{NII}]$ se detecta en tres zonas: en el núcleo, donde se observa el mismo tipo de elongación que en otras bandas; hacia el NE, en una estructura extensa y de muy alto brillo

\footnotetext{
${ }^{22}$ Estudios recientes indican que la luminosidad nuclear en el óptico también podría usarse como discriminante para fuentes FRI/II, dado que las galaxias con mayor luminosidad óptica son la que albergan mayoritariamente a las radiofuentes FRI (en radio, la fuente puntual en los objetos FRI es más luminosa que en objetos FRII; Harvanek \& Stocke 2002, y sus referencias).
} 
Tabla 5.9. Líneas de emisión en la EELR de 3C 196.1.

\begin{tabular}{|c|c|c|c|c|c|c|}
\hline \multirow{3}{*}{ Línea $(\AA)$} & \multicolumn{6}{|c|}{ Flujo $^{a}$} \\
\hline & \multicolumn{4}{|c|}{ Noreste } & \multicolumn{2}{|c|}{ Sudoeste } \\
\hline & $-3.3 ”$ & $-2.5 ”$ & $-1.3 ”$ & $-0.6 "$ & $0.4 "$ & $0.9 ”$ \\
\hline$[\mathrm{O}$ II $] \lambda 3727$ & 11.83 & 7.52 & 5.55 & 25.79 & 6.03 & 6.01 \\
\hline$[\mathrm{Ne}$ III $] \lambda 3869$ & - & - & - & 3.58 & - & - \\
\hline $\mathrm{H} \beta(4861)$ & 1 & 1 & 1 & 1 & 1 & 1 \\
\hline$\left[\begin{array}{lll}\mathrm{O} & \mathrm{III}\end{array}\right] \lambda 4959$ & 0.36 & 0.83 & 0.37 & 4.32 & 2.75 & 3.59 \\
\hline$\left[\begin{array}{ll}\mathrm{O} & \mathrm{III}\end{array}\right] \lambda 5007$ & 0.7 & 2.09 & 0.83 & 11.28 & 8.1 & 9.15 \\
\hline$[\mathrm{N}$ I $] \lambda 5200$ & - & 0.4 & 0.25 & - & 0.42 & 0.65 \\
\hline
\end{tabular}

Notas: ${ }^{a}$ Flujo relativo a $\mathrm{H} \beta$ para cada posición. Las distancias (NE negativas, SO positivas) se expresan respecto al centro galáctico.

superficial; y una tercer zona cuya dirección de elongación es prácticamente perpendicular a la anterior, es decir noroeste-sudeste. En [OIII] no se observan las mismas características. Aún cuando sí puede afirmarse que sigue existiendo una dirección preferencial de elongación en dirección NE-SO, el brillo superficial de la estructura es mucho menor. En cambio, no existe una contraparte de la región que se observa en dirección perpendicular. En la región nuclear hay dos concentraciones de emisión (también llamados knots) en [OIII] que coinciden con lo que, en $\mathrm{H} \alpha+[\mathrm{NII}]$, se identifica como núcleo elongado (Tremblay et al. 2009). En los datos de gas ionizado de la WFPC2 (panel derecho de la Fig. 3.4) se puede identificar el núcleo de la galaxia y una muy pequeña región en emisión en dirección SO. Dado que esta pequeña región no tiene características de fuente puntual, como sí se puede apreciar en la otra estructura, podemos concluir que 3C 196.1 no es un objeto con núcleo doble.

El espectro GMOS se tomó de acuerdo con la información provista por las dos cámaras del HST (ACS y WFPC2). Para ello se utilizó la ranura de 0.5" ubicada en un ángulo de posición de $\mathrm{PA}=50^{\circ}$. El espectro del conjunto es relativamente pobre en líneas de emisión. En la Tabla 5.9 se listan las líneas presentes, junto con el flujo relativo a $\mathrm{H} \beta$ para cada posición. Las líneas son muy intensas en la zona nuclear, como se conocía de resultados previos (Hewitt \& Burbidge 1991), pero ocurre un aumento local de intensidad en la región NE, a una distancia de 2.3" ( $\sim 9 \mathrm{kpc})$ aproximadamente, como puede verse en la sección del espectro $2 \mathrm{D}$ de la Fig. 4.2 que comprende la zona de $\mathrm{H} \beta$ y [OIII] $\lambda \lambda 4959,5007$.

En todos los objetos, el tamaño de las regiones nebulares se midió según el alcance de la línea [OIII] $\lambda 5007$. En el caso de 3C 196.1, esta línea se utilizó para medir el tamaño de la región $\mathrm{SO}$, y $\mathrm{H} \beta$ para medir el tamaño de la región NE. Esto se debe a que, en esta región, es $\mathrm{H} \beta$ la línea más profunda del espectro. El tamaño de las regiones es de 4.8" ( $18.9 \mathrm{kpc})$ hacia el NE, donde las distancias se expresan con coordenadas negativas $\left(r_{N E}["]<0\right)$, y de $1.45 "(\sim 5.7 \mathrm{kpc})$ hacia el SO, donde las distancias se expresan con coordenadas positivas $\left(r_{S O}["]>0\right)$. Otro aspecto distintivo del espectro concierne a la intensidad de la línea [OII] $\lambda 3727$ que, como puede verse en los ejemplos de la Tabla 5.9, es más intensa que [OIII] $\lambda 5007$ a lo largo de prácticamente toda la nebulosa NE.

La Figura 5.17 muestra los espectros unidimensionales de las dos regiones: en el panel superior se encuentra el espectro de la zona donde se produce el aumento local de intensidad de las líneas, situada a 2" del núcleo en dirección NE, y en el panel inferior, el espectro correspondiente a una distancia de 0.3" en dirección SO. En la EELR-NE es notorio cómo se invierte la relación de intensidades entre los oxígenos respecto de todos los otros objetos 
de la muestra, al punto que es el [OII] $\lambda 3727$ quien domina el espectro. Sin emabrgo, también puede apreciarse que $\mathrm{H} \beta$ es mucho más intensa en relación al [OIII] $\lambda 5007$. En general, para todos los otros casos, [OIII] $\lambda 5007$ es alrededor de 10 veces más intensa que $\mathrm{H} \beta$, pero en este caso (3C 196.1; EELR-NE, 2") es sólo un $21 \%$ mayor. En el espectro de la EELR-SO las líneas son más intensas (el espectro corresponde a una zona más cercana a la región nuclear, por eso también la intensidad del continuo es mayor), pero el espectro está dominado por el [OIII] $\lambda 5007$.

En los paneles superiores de la Figura 5.18 se ampliaron los perfiles del [OIII] 55007 correspondientes a los espectros anteriores. La descomposición Gaussiana revela que los perfiles más complejos están compuestos por sólo dos componentes, pero las amplitudes de velocidad (desplazamientos entre centroides) son muy grandes en distintas zonas.

Tal como sucedió en los casos de las galaxias 3C 268.2 y 3C 303.1, durante el proceso de medición de líneas se encontraron diferencias importantes entre los desplazamientos de los centroides medidos y los esperados según el corrimiento al rojo aceptado en la literatura, que corresponde al valor $z=0.198$ (Smith \& Spinrad 1980; Hewitt \& Burbidge 1991, NED). Se siguió el mismo procedimiento descripto en los casos anteriores, y se encontró que los desplazamientos medidos se corresponden con un redshift de

$$
z^{\prime}=0.19753 \pm 2 \times 10^{-5}
$$

Este es el valor empleado en el cómputo del campo de velocidad. La velocidad sistémica del objeto, según $z^{\prime}$, es $v_{\text {sis }}=59218 \mathrm{~km} \mathrm{~s}^{-1}$.

En el panel inferior de la Fig. 5.18 se encuentran dos campos de velocidades, los asteriscos (*) negros representan el campo derivado de la descomposición del perfil del [OIII] $\lambda 5007$, como en todos los casos anteriores, y los puntos $(\bullet)$ rojos, el campo derivado de la descomposición del [OII] $\lambda 3727$. La posición del núcleo se marca con una cruz. En el caso de esta galaxia se muestran los dos conjuntos de resultados porque es el único objeto donde se observan diferencias tan importantes. Se pueden identificar movimientos de muy alta velocidad en ambas líneas que alcanzan alrededor de $1000 \mathrm{~km} \mathrm{~s}^{-1}$, pero tal vez el dato más curioso es que en el caso del [OII] $\lambda 3727$ estos movimientos se observan desplazados hacia el rojo (movimientos de alejamiento) mientras que para el [OIII] $\lambda 5007$ (con velocidades relativamente menores) se observan desplazados hacia el azul (movimientos de acercamiento). Todos los movimientos de alta velocidad se observan únicamente en la región NE. No es posible identificar una curva de rotación con ninguno de los dos conjuntos de datos, aunque sí se pueden encontrar zonas, en ambas regiones, donde existen movimientos estables con velocidades en el rango $\pm 200-400 \mathrm{~km} \mathrm{~s}^{-1}$.

\subsection{3. $\quad 3 \mathrm{C} 284$}

La radiofuente 3C 284 es un objeto de grandes dimensiones. Con un tamaño angular ${ }^{23}$ de 178.5", su extensión lineal es de aproximadamente $860 \mathrm{kpc}$. Está compuesta por una fuente puntual y dos lóbulos, que terminan en intensos hot spots. El radio-eje determinado por estas estructuras se encuentra en un ángulo de posición de $101^{\circ}$ (Leahy \& Williams 1984). La fuente es asimétrica, el lóbulo localizado hacia el Oeste-Noroeste $(\mathrm{O}[\mathrm{NO}])$ es más extenso que el que se encuentra en dirección Este-Sudeste (E[SE]). Tiene una densidad de flujo de 12.3 Jy a la frecuencia de $178 \mathrm{MHz}$ (Hardcastle et al. 1997), mientras que su luminosidad en radio, $L_{178 \mathrm{MHz}}=3.7 \times 10^{42} \mathrm{erg} \mathrm{s}^{-1}$ (Wu et al. 2013), es comparable a la de 3C 273 (Croston et al. 2004), el quasar radio-intenso más potente a bajo redshift (Robinson et al. 2000). Pertenece al grupo de galaxias FRII.

\footnotetext{
${ }^{23}$ www.jb.man.ac.uk/atlas/object/3C284.html
} 
Figura 5.17. Espectros de la EELR en 3C 196.1.
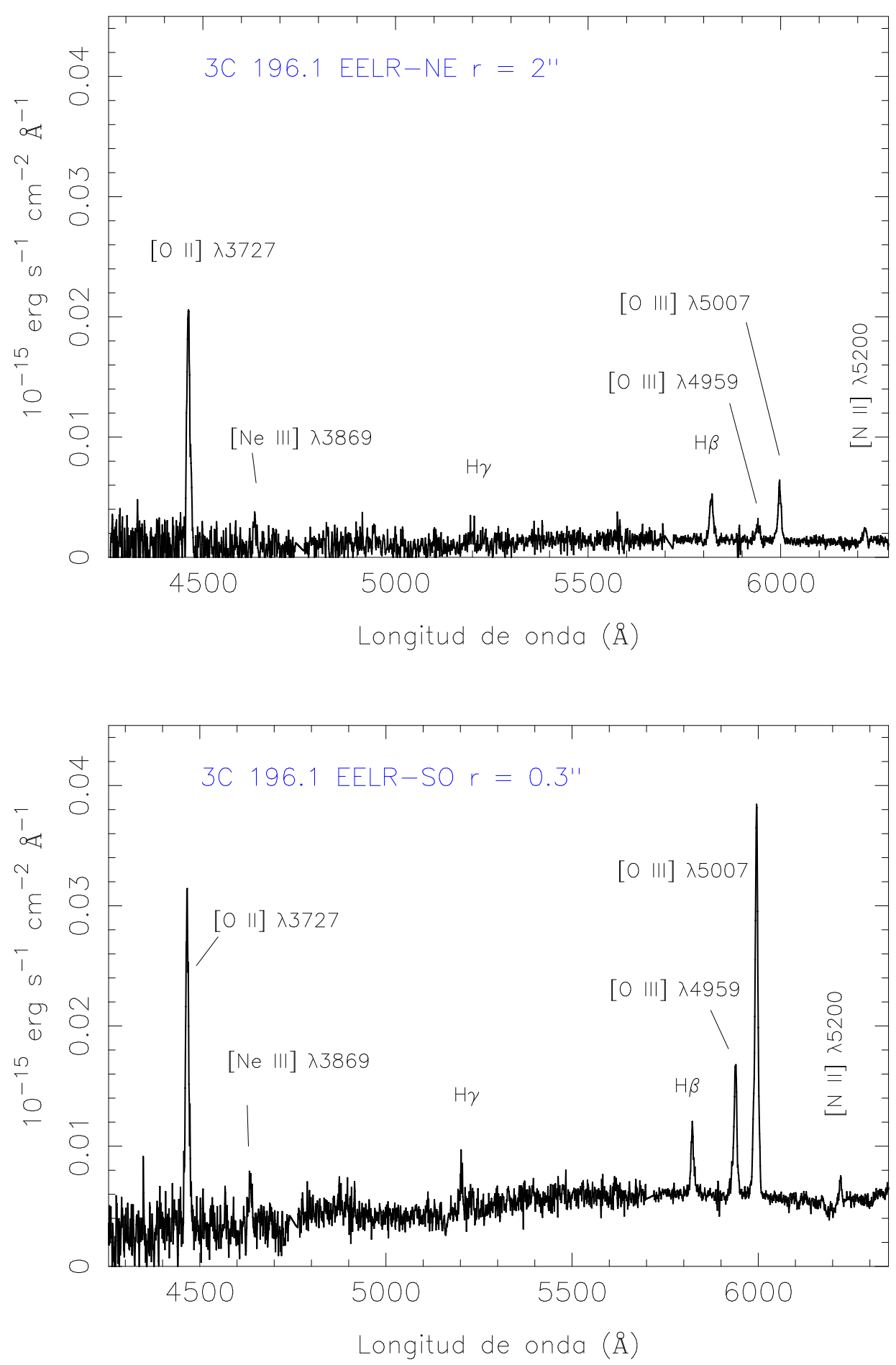

Arriba: Espectro de la EELR noreste, a 2" del centro galáctico. Abajo: Espectro de la EELR sudoeste 0.3". La región NE, que es mucho más extensa que la SO, no fue detectada con la cámara WFPC2 sino con ACS (Tremblay et al. 2009). La intensidad de las líneas varía notoriamente de una región a otra, en particular se aprecia el cambio en la relación de intensidades entre [OII] $\lambda 3727$ y [OIII] $\lambda \lambda 4959,5007$. 
Figura 5.18. Descomposición Gaussiana y Campo de Velocidad en 3C 196.1.
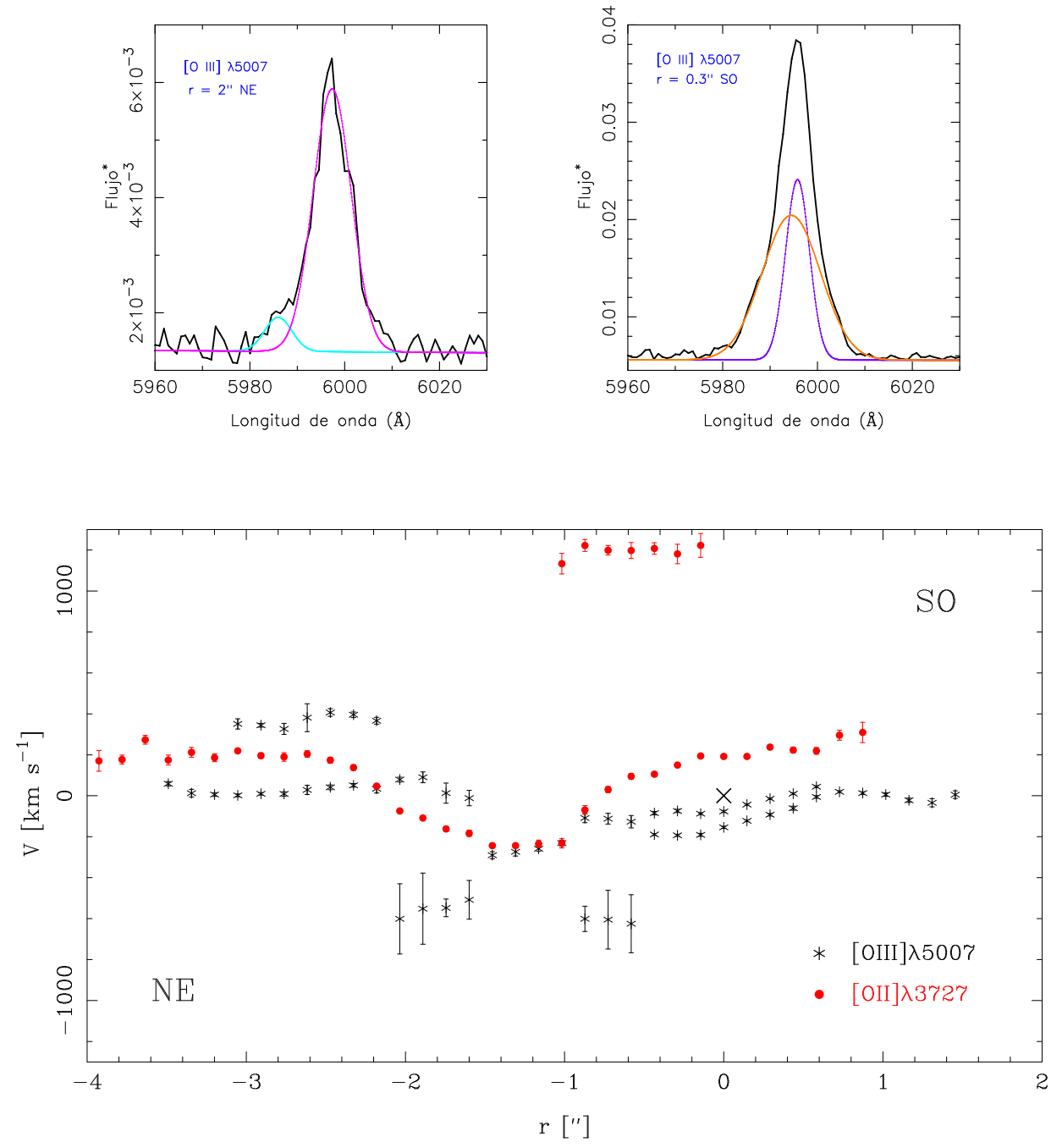

Arriba: Descomposición Gaussiana (en color) de los perfiles de [OIII] $\lambda 5007$ (en negro) para los espectros de la Fig. $5.17\left[^{(*)}\right.$ El flujo está expresado en las mismas unidades]. Abajo: Campo de velocidad del gas en la EELR, en la dirección de la ranura $\left(\mathrm{PA}=50^{\circ}\right)$. La cruz indica la posición del centro galáctico. No existe ninguna componente cuya velocidad coincida con la velocidad sistémica del objeto. 
Tabla 5.10. Líneas de emisión en la EELR de $3 \mathrm{C} 284$.

\begin{tabular}{|c|c|c|c|c|c|c|}
\hline \multirow{3}{*}{ Línea $(\AA)$} & \multicolumn{6}{|c|}{ Flujo $^{a}$} \\
\hline & \multicolumn{3}{|c|}{ Noreste } & \multicolumn{3}{|c|}{ Sudoeste } \\
\hline & $-2.2 "$ & $-1.7 ”$ & $-0.9 "$ & $0.6 "$ & $1.2 "$ & $1.6 "$ \\
\hline$[\mathrm{Ne} \mathrm{v}] \lambda 3424$ & - & 0.99 & 1.21 & 1.03 & 0.97 & 1.03 \\
\hline$[\mathrm{O}$ II $] \lambda 3727$ & - & 0.48 & 1.32 & 0.79 & 1.05 & 2.15 \\
\hline$[\mathrm{Ne}$ III $] \lambda 3869$ & 0.63 & 0.52 & 0.67 & 0.17 & 0.44 & - \\
\hline $\mathrm{H} \delta(4101)$ & - & 0.23 & 0.28 & - & 0.12 & - \\
\hline $\mathrm{H} \gamma(4340)$ & - & 0.36 & _ & 0.37 & 0.29 & - \\
\hline He II (4686) & 0.15 & 0.31 & 0.5 & 0.32 & 0.6 & 0.58 \\
\hline $\mathrm{H} \beta(4861)$ & 1 & 1 & 1 & 1 & 1 & 1 \\
\hline [O III] $] \lambda 4959$ & 2.39 & 2.84 & 3.54 & 2.73 & 3.48 & - \\
\hline$[\mathrm{O}$ III $] \lambda 5007$ & 7.36 & 8.57 & 11.7 & 7.97 & 10.16 & 11.92 \\
\hline
\end{tabular}

Notas: ${ }^{a}$ Flujo relativo a $\mathrm{H} \beta$ para cada posición. Las distancias (NE negativas, SO positivas) se expresan respecto al centro galáctico.

La galaxia fue observada en la banda de rayos-X con el telescopio $X M M-N e w t o n^{24}$ en órbita. La emisión en X parece estar asociada a la emisión en radio, superponiéndose tanto en la fuente puntual, como en los lóbulos (Croston et al. 2004). En el espectro de la región nuclear se identifican dos contribuciones de tipo no térmico, una ley de potencia proveniente de la fuente puntual y fuertemente absorbida por el material circundante, y otra ley de potencia que proviene muy probablemente de la base de los jets. La primera se manifiesta predominantemente en banda de rayos- $\mathrm{X}$ duros, mientras que la segunda domina en rayos$\mathrm{X}$ blandos y muestra una importante correlación con el flujo en radio (Hardcastle \& Worrall 1999; Croston et al. 2004; Hardcastle et al. 2006). En los lóbulos, en cambio, la emisión X se produce por efecto Compton inverso, donde los electrones relativistas presentes en el medio (y responsables de la emisión sincrotrón en radio) entregan energía a los fotones del fondo cósmico de microondas ${ }^{25}$ (Croston et al. 2004).

Los primeros resultados de 3C 284 en la banda óptica se obtuvieron con el telescopio de Kitt Peak (Kitt Peak National Observatory, KPNO) de 2.1 m, y mostraron la existencia de regiones de gas ionizado (McCarthy et al. 1995). En las imágenes de [OIII] $\lambda 5007$ (McCarthy et al. 1995, fig. 10) se pueden identificar tres regiones diferentes. Una de ellas se encuentra en la misma posición que el núcleo de la galaxia, de tamaño pequeño y con alto brillo superficial. Las otras dos regiones, una en dirección SE y otra en dirección NO, se encuentran a una distancia de 40" ( 192 kpc) del núcleo, notoriamente alejadas de la galaxia. Las tres regiones están alineadas en una dirección $\left(\mathrm{PA} \simeq 115^{\circ}\right)$ similar a la de las estructuras observadas en radio $\left(\mathrm{PA}_{j e t}=101^{\circ}\right)$, y dadas las distancias involucradas, estarían ubicadas completamente dentro de los lóbulos (ver Fig. 3.7, panel inferior izquierdo).

\footnotetext{
${ }^{24}$ XMM-Newton (X-ray Multi Mirror) es una misión científica de la Agencia Espacial Europea (ESA) diseñada para realizar observaciones en la banda de rayos-X, equipada con tres telescopios de rayos-X y un monitor óptico. Fue lanzada en Diciembre de 1999, y continúa en operaciones.

${ }^{25} \mathrm{El}$ fondo cósmico de microondas (CMB, sigla en inglés de Cosmic Microwave Background), es la radiación que constituye las reminiscencias del Big Bang, mostrando que el Universo continúa enfriándose, luego de aquella Gran Explosión. La radiación del CMB puede considerarse isótropa, y es de tipo térmico, es decir, puede describirse como la radiación de un cuerpo negro, con una temperatura característica de $2.7 \mathrm{~K}$. De acuerdo con la Ley de Wien, el máximo de la curva de Planck se produce a la frecuencia de $\sim 160 \mathrm{GHz}$, que en el espectro electromagético corresponde a la banda de microondas; de aquí su nombre.
} 
3C 284 también fue observada con HST; la resolución de estos datos es mucho mayor que la de los de Kitt Peak, pero la cobertura espacial es mucho más pequeña, por lo tanto las zonas de gas ionizado a 40" no se detectaron. Sin embargo, las imágenes nebulares del [OIII] $\lambda 5007$ (Privon et al. 2008, y Fig. 3.7, panel superior derecho) también revelan la presencia de regiones ionizadas alejadas de la galaxia anfitriona, pero a menor escala. En adelante, cuando se haga referencia a la EELR en 3C 284 se entenderá que se trata de las regiones detectadas por HST. Curiosamente, la EELR está separada en tres componentes, tal como habían encontrado McCarthy et al. (1995) a otra escala y en otra dirección. Una de las componentes se encuentra en la misma posición que el núcleo de la galaxia, pero las otras dos regiones donde se concentra la emisión se ubican al NE y SO del núcleo, respectivamente. La distancia que las separa del centro de la galaxia es de aproximadamente 1", aunque la región NE está ligeramente más alejada que la SO. Las tres estructuras están alineadas en un ángulo de posición $\mathrm{PA}=70^{\circ}$, formando un ángulo de alrededor de $45^{\circ}$ con las regiones ionizadas encontradas por McCarthy et al. (1995).

Mientras las estructuras en radio a gran escala permiten definir $\mathrm{PA}_{\text {jet }}$ como el radio-eje del sistema, a menor escala, en las cercanías de la fuente puntual, es posible definir también una dirección preferencial de la emisión en radio dada por la dirección de deformación de los lóbulos $\left(\mathrm{PA}_{i n t}\right.$, por simplicidad), que difiere significativamente de $\mathrm{PA}_{j e t}$. Tal como indicaron Privon et al. (2008), la EELR está alineada con la emisión interna en radio, según $\mathrm{PA}_{\text {int }}$ (ver Fig. 3.7, panel inferior derecho).

El espectro de la EELR se tomó con la ranura orientada en la misma dirección que indican los datos HST (Tabla 3.4). Es un espectro rico en líneas de emisión, pero la característica sobresaliente es la diferencia en la forma de las líneas respecto de una y otra región, como puede verse en la Fig. 4.3 para la zona comprendida por $\mathrm{H} \beta$ y los oxígenos [OIII] $\lambda \lambda 4959,5007$. La EELR-NE se expresa mediante distancias negativas $\left(r_{N E}<0\right)$ y la EELR-SO, mediante distancias positivas $\left(r_{S O}>0\right)$. En la Tabla 5.10 figuran las líneas detectadas en ambas regiones; las intensidades se expresan respecto de la intensidad de $\mathrm{H} \beta$ en cada posición. La EELR tiene una extensión total de 6" ( $\sim 29 \mathrm{kpc})$, medido según el [OIII] $\lambda 5007 ; 3.5 "(\sim 17 \mathrm{kpc})$ hacia el NE y de $2.5 "(\sim 12 \mathrm{kpc})$ hacia el SO.

En la región central la emisión del continuo es completamente despreciable, pero la emisión de líneas es relativamente intensa allí. En general, todas las líneas son muy intensas; en un pequeño entorno de la región central la intensidad decae desde el centro en ambos sentidos de la ranura (NE y SO, respectivamente) para luego volver a aumentar, aunque con distinta intensidad. La máxima emisión no se alcanza en el centro de la galaxia $(r=0)$, sino en la región SO, entre 0.7"-0.9" ( $\sim \mathrm{kpc})$. En la EELE-NE también se produce un aumento de la emisión, pero no alcanza la intensidad de la zona central. Cualitativamente, esto también puede apreciarse en las imágenes del HST, a través de los contornos de nivel en la imagen nebular (Fig. 3.7, panel superior derecho). En la Fig 5.19 se presentan los espectros unidimensionales de la región NE (arriba) y SO (abajo). En los dos casos se tomaron los espectros de las zonas donde se produce el aumento local de intensidad en las líneas, a 1.5" en la EELRNE y a 0.7" en la EELR-SO. Si bien este último espectro corresponde a la zona de mayor emisión en toda la EELR, no es posible apreciarlo mediante la escala de ordenadas. Esto de debe a que los perfiles presentan múltiples componentes; mientras en la escala de intensidades de la Fig. 5.19 predomina la componente de mayor intensidad, el flujo en una dada línea será la suma de los flujos de sus componentes.

La región SO es a la vez la zona más intensa del espectro y la de mayor complejidad en cuanto a la cantidad de componentes que conforman el perfil de emisión, característica compartida por todas las líneas del espectro. Como puede apreciarse claramente a través del espectro 2D (Fig 4.3), existe una diferencia sustancial en este sentido respecto de la región 
Figura 5.19. Espectros de la EELR en 3C 284.
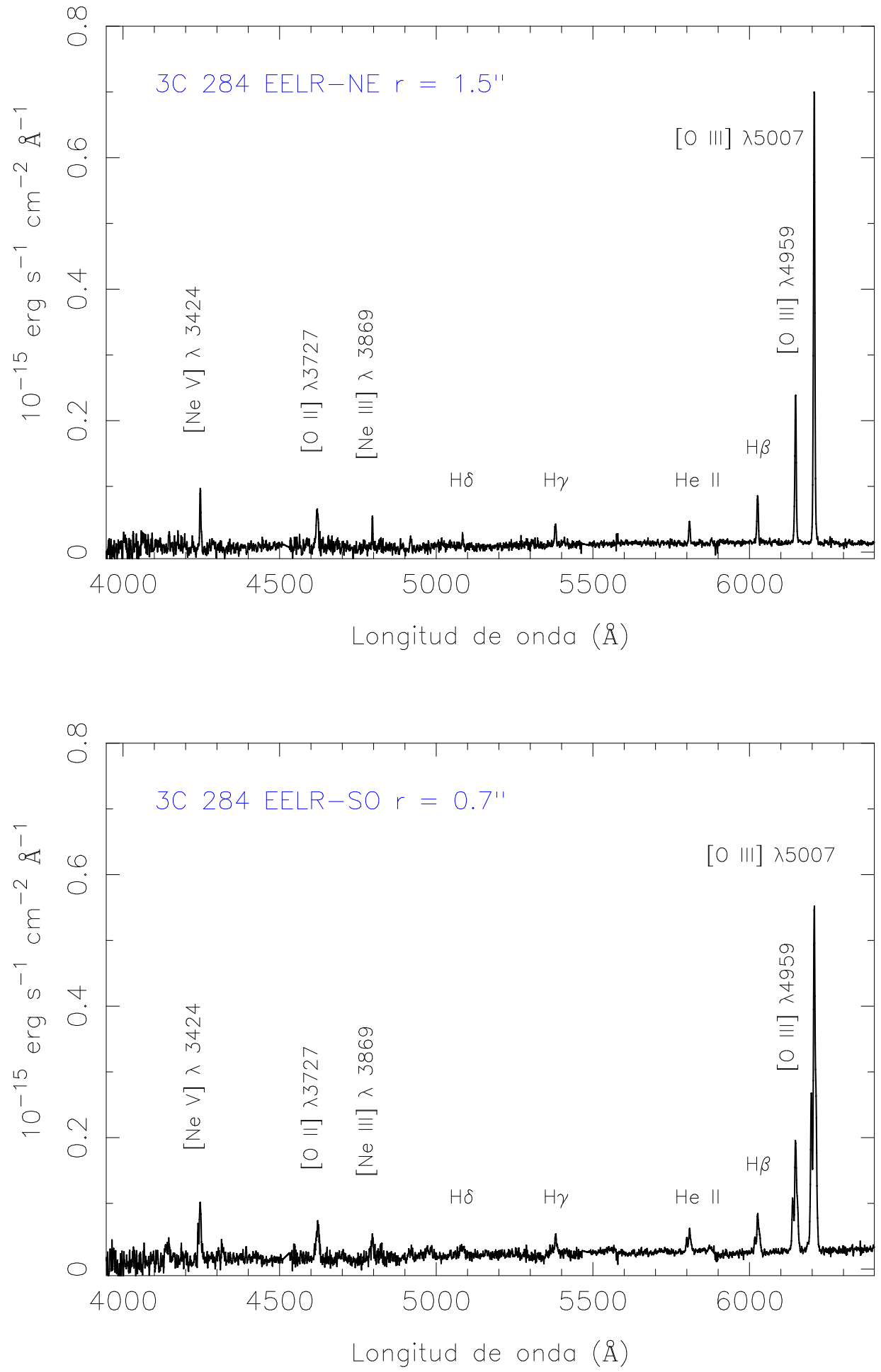

Arriba: Espectro de la EELR noreste, a 1.5" del centro galáctico. Abajo: Espectro de la EELR a 0.7" en dirección SO. Se eligieron los espectros donde la intensidad de las líneas aumenta localmente. El espectro de la región SO corresponde a la zona de mayor emisión de toda la EELR, pero no es posible apreciarlo a través de la escala de ordenadas debido a la multiplicidad en la composición (Gaussiana) de los perfiles (ver texto). 
Figura 5.20. Descomposición Gaussiana y Campo de Velocidad en 3C 284.
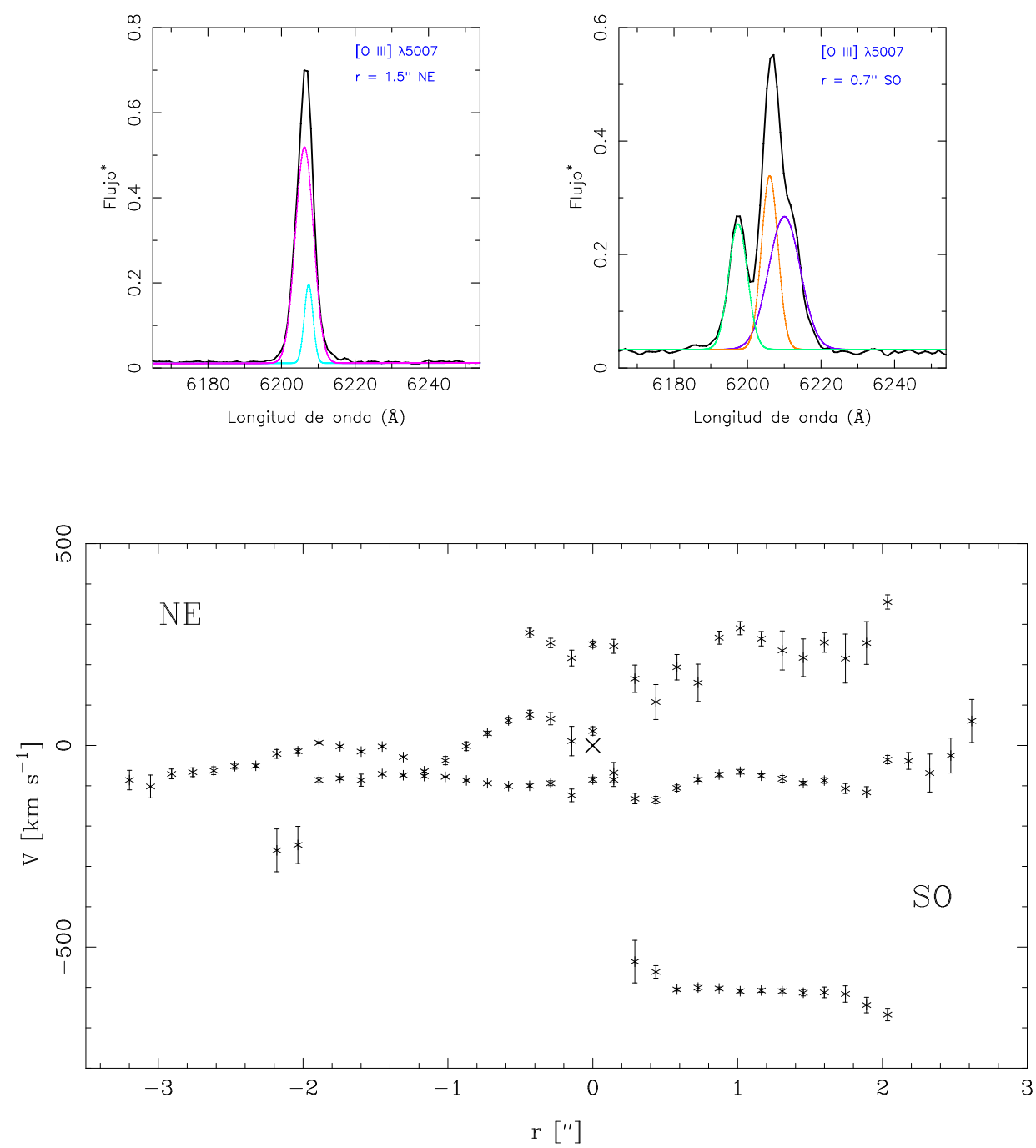

Arriba: Descomposición Gaussiana (en color) de los perfiles de [OIII] $\lambda 5007$ (en negro) para los espectros de la Fig. $5.19\left[^{(*)}\right.$ El flujo está expresado en las mismas unidades]. Abajo: Campo de velocidad del gas en la EELR, en la dirección de la ranura $\left(\mathrm{PA}=70^{\circ}\right)$. La cruz indica el centro galáctico, que se mueve con la velocidad sistémica. Se utilizan distancias negativas para la región NE, y positivas para la SO. 
NE. En los paneles superiores de la Figura 5.20 se ampliaron los perfiles del [Orit] $\lambda 5007$ correspondientes a los mismos espectros de la Fig. 5.19. El perfil real se muestra en negro, y la descomposición Gaussiana en colores. Aún cuando el perfil de la región NE (panel izquierdo) parece simple, no es posible reproducirlo con una única componente Gaussiana; en la región $\mathrm{SO}$, en cambio, los perfiles del [OIII] (panel derecho) ponen en evidencia la presencia de tres componentes. Como en todos los objetos de la muestra, se construyó el campo de velocidades del gas a partir de los resultados de la descomposición del perfil del [OIII] $\lambda 5007$, que se muestra en el panel inferior de la Fig. 5.20. La forma de los perfiles se mantiene aproximadamente invariable a lo largo de cada la EELR, cada una con sus características propias. Esto se manifiesta claramente en el campo de velocidades, donde puede apreciarse que las velocidades relativas de las componentes Gaussianas respecto al centro galáctico, que se mueve con la velocidad sistémica de la galaxia $\left(v_{s i s}=71876 \mathrm{~km} \mathrm{~s}^{-1}[\mathrm{NED}] ; V=0\right.$ en el campo de velocidad) se mantienen aproximadamente constante. No hay una curva de rotación fácilmente distinguible, pero sí existen movimientos de muy alta velocidad, especialmente en la región $\mathrm{SO}$, donde se observan simultáneamente desplazamientos hacia el azul y el rojo. Estos movimientos alcanzan velocidades de aproximación de alrededor de $600 \mathrm{~km} \mathrm{~s}^{-1}$, y de recesión, de alrededor de $250 \mathrm{~km} \mathrm{~s}^{-1}$, siendo claramente identificables en una extensión de $\sim 2$ " $(\lesssim 10 \mathrm{kpc})$. En la EELR-NE el comportamiento es muy diferente, si bien se mantiene la estabilidad en las velocidades de las componentes, estas velocidades no superan los $200 \mathrm{~km} \mathrm{~s}^{-1}$, salvo excepciones. En las cercanías del centro de la galaxia también se observan movimientos de acercamiento y recesión para una dada posición, pero en este caso y a diferencia de lo que ocurre a distancias mayores hacia el SO, los movimientos de mayor velocidad son los de recesión. 



\section{Capítulo 6}

\section{Fotoionización vs. Ionización por ondas de choque}

En este Capítulo se evalúan los posibles mecanismos de ionización que pueden tener lugar dentro de las EELR, con el objetivo de identificar el mecanismo dominante. Se analizan las nebulosas de las siete (7) radiogalaxias que conforman la muestra definitiva de objetos, ordenadas según su numeración: 3C 268.2, 3C 268.3 y 3C 303.1 juntas, 3C 285, 3C 305, 3C 321 y 3 c 381 .

\section{1. $3 \mathrm{C} 268.2$.}

Las propiedades de la emisión óptica asociada a la radiofuente 3C 268.2 no han sido estudiadas, pero desde del momento de su detección (de Koff et al. 1996) se supo que tanto la región nebular como la propia galaxia son notablemente elongadas en dirección NO-SE. Los estudios en la banda de radio indican que la disposición espacial de la radiofuente no guarda relación con la dirección preferencial de elongación de las nebulosas ópticas ${ }^{1}\left(\Delta \mathrm{PA}=144^{\circ}\right.$; ver Fig. 3.5).

La EELR de 3C 268.2 es una región con intensa emisión de líneas en el óptico, pero es débil en otras bandas del espectro, como por ejemplo en rayos-X, donde su presencia sólo fue detectada de manera indirecta (Massaro et al. 2013). De ese análisis se pudo concluir que existe emisión y que está extendida con dirección preferencial NO-SE, del mismo modo que la emisión óptica y la emisión proveniente de la fuente puntual x (núcleo). Según los mismos autores, la emisión del núcleo posiblemente le deba su deformación ${ }^{2}$ a la influencia de la EELR.

Por otra parte, el campo de velocidades del gas ionizado (Fig. 5.2) muestra claros signos de complejidad. Sus caracteríticas globales se desarrollaron en el Capítulo 5; aquí se continúa el análisis con una interpretación del mismo, que se presenta en forma gráfica en la Figura 6.1.

La descomposición del perfil del [OIII] $\lambda 5007$ permite identificar una componente dominante (cuadrados color azul), que es la que determina la extensión de la EELR. Esta componente muestra un comportamiento de tipo rotacional, se obervan desplazamientos al azul en la región NO y al rojo en la región SE; la velocidad de estabilización de esta curva de rotación es de $450 \mathrm{~km} \mathrm{~s}^{-1}$ aproximadamente, sin embargo, no es compatible con movimientos dentro del potencial galáctico (Tadhunter et al. 1989). Los anchos (FWHM) que caracterizan

\footnotetext{
${ }^{1}$ Como se señaló en la Sección 5.2, según Privon et al. (2008) las nebulosas ópticas están alineadas con $\mathrm{PA}_{j e t}$, esto es un error y su origen muy posiblemente esté relacionado con un problema en las coordenadas del archivo original de la cámara WFPC2.

${ }^{2}$ Estrictamente se trata de un "estiramiento" en dirección este-oeste (Massaro et al. 2013).
} 
Figura 6.1. 3C 268.2. Componentes de velocidad y anchos característicos.
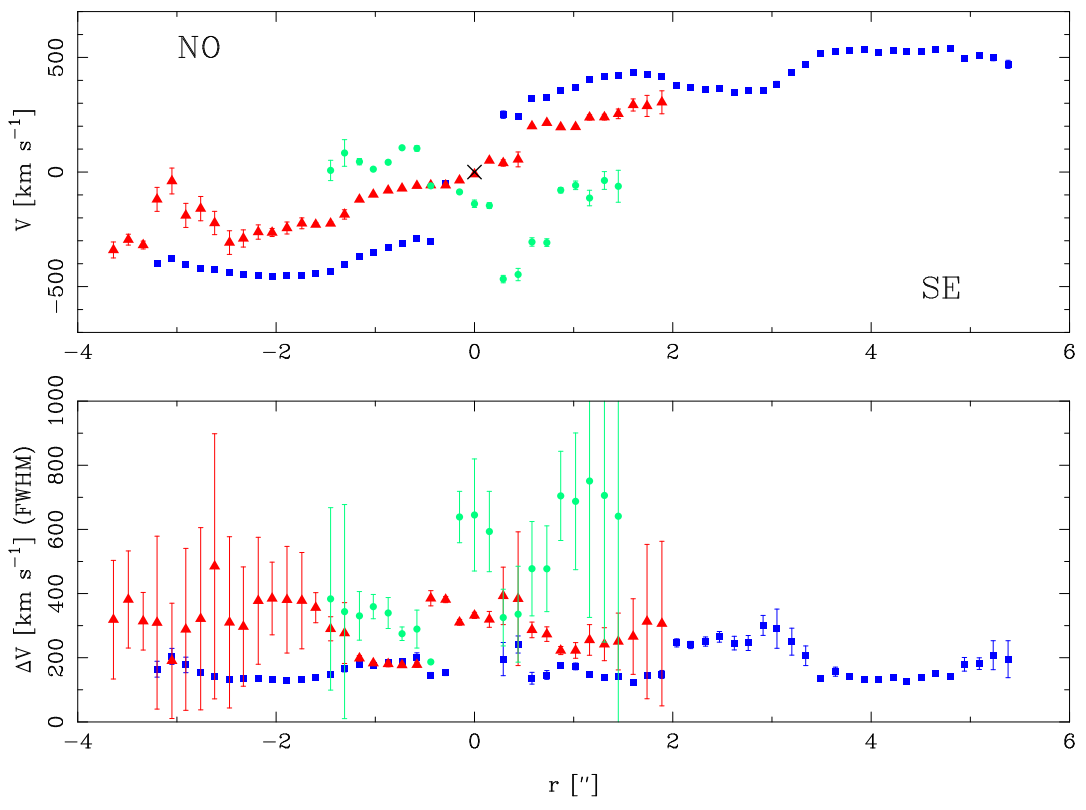

Panel superior: Campo de velocidades del gas (Fig. 5.2), obtenido a partir de la descomposición Gaussiana del perfil del [OIII]. En este caso se indica una posible interpretación del movimiento del gas a partir de las características del campo. Se distinguen tres (3) patrones de movimiento diferentes, que se indican con símbolos y colores diferentes. Panel inferior: Anchos característicos de cada componente de velocidad, medido según el ancho a mitad de potencia (FWHM, full width half maximum). Los símbolos y colores establecen la correspondencia con cada componente del campo de velocidad del panel superior.

a la componente dominante rondan los $200 \mathrm{~km} \mathrm{~s}^{-1}$, siendo las componentes más delgadas del perfil.

La segunda componente también se puede identificar en grandes rangos de distancia (triángulos color rojo), particularmente hacia el NO. En la región SE, en cambio, se detecta hasta 2". Esta distancia (equivalente a $14 \mathrm{kpc}$ aproximadamente) corresponde al límite de emisión del espectro en conjunto, mientras que para distancias mayores sólo se detectan las líneas del [OIII] y en menor medida [OII] y H $\beta$ (ver Fig. 4.5 y Sección 5.2). La segunda componente del campo evidencia un patrón rotacional similar al de la componente dominante, pero las velocidades (la curva de rotación se estabiliza en torno a $250 \mathrm{~km} \mathrm{~s}^{-1}$ ) sí son compatibles con el movimiento gravitatorio en el pozo de potencial (Tadhunter et al. 1989). Los anchos característicos son mayores: rondan los $350 \mathrm{~km} \mathrm{~s}^{-1}$; los errores de medición son mayores en la región $\mathrm{NO}$, pero el valor medio del FWHM es aproximadamente constante.

La tercer componente de velocidad (círculos color verde) se manifiesta únicamente en el rango $|r|<2$ ", y a simple vista es la que presenta los movimientos menos organizados del campo. Aún así se pueden distinguir dos comportamientos: en la zona más interna de la región SE $(|r|<1$ ") se observan algunos (pocos) movimientos de alta velocidad que alcanzan hasta (-)500 $\mathrm{km} \mathrm{s}^{-1}$ respecto de la velocidad sistémica de la galaxia; pero la mayor parte de los datos de la tercer componente se comporta como una nueva curva de rotación. Este tercer patrón rotacional estaría indicando el movimiento del gas más interno del sistema nebular, aunque cabe resaltar que por las escalas involucradas, el gas más interno corresponde a las escalas características de lo que podría considerarse como zona de transición entre la NLR y la EELR 
$(|r|<1$ " equivale a distancias menores que $7 \mathrm{kpc})$. Sin embargo el aspecto más importante no radica en las escalas sino en que este nuevo sistema rota en sentido contrario al de las otras dos componentes de velocidad: la región NO presenta corrimientos al rojo, y la región SE al azul. Su velocidad se estabiliza en torno a $150 \mathrm{~km} \mathrm{~s}^{-1}$, por lo cual la hipótesis de movimiento gravitatorio también sería aceptable. Los anchos característicos, por su parte, son diferentes en cada región. El valor medio del FWHM en el NO es de $350 \mathrm{~km} \mathrm{~s}^{-1}$, comparable con los FWHM de la segunda componente de velocidad. En el SE la amplitud de valores es mayor $\left(350<\mathrm{FWHM}<750 \mathrm{~km} \mathrm{~s}^{-1}\right)$, pero la mayoría de las componentes tienen anchos característicos en torno a $700 \mathrm{~km} \mathrm{~s}^{-1}$. En esta zona se encuentran las componentes más anchas, aunque debe señalarse que también en esta zona se encuentran los errores de medición más altos, como se puede ver en el panel inferior de la Fig. 6.1.

De todas las características señaladas sobre el campo de velocidad, hay dos que merecen especial atención. Por un lado, las altas velocidades que presenta la componente dominante (cuadrados azules) permitirían explicar el único aspecto ampliamente conocido, e igualmente enigmático, sobre 3C 268.2: su morfología elongada. Los análisis con datos del óptico (de Koff et al. 1996) y de rayos-X (Massaro et al. 2013) remarcan enfáticamente el aspecto morfológico y su falta de conexión con la dirección preferencial de la radiofuente, a la vez que señalan a la EELR como posible causa de tal disposición espacial. Los resultados derivados del campo de velocidades constituyen una base importante para esta hipótesis, que cobra mayor relevancia por el hecho de que las nebulosas de la EELR manifiestan una única y muy bien definida dirección de elongaciópn (si se extendieran también en otras direcciones, entonces cabría realizar un análisis del campo de velocidades en esas otras direcciones).

Por otro lado, si bien no deja de ser una rareza la posible existencia de tres patrones rotacionales, más aún lo es el hecho de que uno de ellos manifieste una dirección de rotación diferente de la de los otros dos. Y a esto deben sumarse los movimientos de mayor perturbación observados en la región interna, que podrían indicar la presencia de eyecciones de material a altas velocidades (conocidos como outflows en la literatura). En este punto hay que resaltar que el campo de velocidades se obtuvo para una dirección que difiere del radio-eje en $144^{\circ}$, por lo cual el origen de los outflows no puede asignarse al paso de los jets por el MIG. El escenario es poco usual pero no imposible. Recientemente Riffel et al. (2014) estudiaron la región interna $\left(<300\right.$ pc) de NGC $5929^{3}$ y encontraron outflows en dirección perpendicular al radio-eje cuyo campo de velocidad indica rotación en sentido contrario al de la curva de rotación estelar. Riffel et al. (2014) concluyeron que existió un proceso de interacción entre el gas de la zona interna de la galaxia con un "outflow ecuatorial"4 (distinto del encontrado por ellos). Este outflow ecuatorial podría provenir del disco de acreción, o bien podría ser el producto de la interacción del sistema gaseoso interno con vientos asociados al toroiode. En cualquier caso, el resultado de esa interacción se combinó con la presencia e influencia de la galaxia compañera de NGC 5929 de manera tal de provocar la rotación en sentido contrario.

Ciertamente en el caso de 3C 268.2 se necesitan estudios más detallados del campo de velocidades interno y del medio intergaláctico (MIG) al que pertenece la galaxia como para poder explicar los diferentes sentidos de rotación observados, así como la velocidad de estabilización de la componente dominante. Pero la importancia del trabajo de Riffel et al. (como antecedente observacional) y sus referencias (como marco teórico) en este contexto

\footnotetext{
${ }^{3}$ NGC 5929 es una galaxia espiral que alberga un núcleo activo de tipo Seyfert 2 y presenta emisión en radiofrecuencias. La dirección del radio-eje es $\mathrm{PA}_{j e t} \simeq 60^{\circ}$. La dirección del outflow encontrado por Riffel et al. (ver texto) es $\mathrm{PA}=-30^{\circ}$.

${ }^{4} \mathrm{Li}$ et al. (2013) propusieron la existencia de outflows "ecuatoriales" provenientes del disco de acreción, el proceso también es compatible con un escenario donde el toroide que rodea al AGN es, en realidad, un viento de polvo (dusty wind) que emana de las regiones externas del disco de acreción (ver referencias en Riffel et al. 2014).
} 
radica en que permiten explicar la existencia y generación de outflows desconectados de la radio-estructura. En conclusión, entonces, es posible que en la región central de 3C 268.2 haya ocurrido algún tipo de proceso donde el gas circundante haya sido eyectado hacia las afueras de la galaxia en dirección SE.

\subsubsection{Mecanismo de ionización}

A continuación se analizarán los posibles mecanismos de ionización actuantes en las dos regiones de gas ionizado que componen el sistema nebular de 3C 268.2. Las características que presenta el campo de velocidades abren la posibilidad de estudiar el escenario propuesto por los procesos de choque, pero en el caso de este objeto (dadas las diferentes alineaciones discutidas anteriormente) tales procesos, si existen, debieron ser desencadenados por los outflows observados en la dirección de la EELR y no por el paso de los radio-jets.

En la Figura 6.2 se reúnen los diagramas de diagnóstico con los cuatro modelos de fotoionización multifase (en adelante FMF, modelos T, H, M y L definidos en la Tabla 2.1) e ionización por ondas de choque (en adelante IOC; Sección 2.4.3). Estos últimos se evalúan según la densidad ambiental estándar de $100 \mathrm{~cm}^{-3}$, dado que no hay información en la literatura respecto de este parámetro. En los modelos de FMF la densidad varía: en el modelo $\mathrm{T}$ (azul) se considera que la densidad (inicial) de las nubes $\mathrm{MB}$ es de $50 \mathrm{~cm}^{-3}$, mientras que para los modelos $\mathrm{H}$ (verde), M (rojo) y L (naranja), la densidad de estas nubes es de $10^{3} \mathrm{~cm}^{-3}$. En algunos diagramas $(\mathbf{B}, \mathbf{E}$ y $\mathbf{F})$ se graficaron los modelos de choque autoionizantes (es decir aquellos donde la emisión proviene tanto de la zona de recombinación como del precursor radiativo) con líneas punteadas, color negro, y los modelos de choques puros (no contemplan la formación del precursor fotoionizado por la propia onda de choque) con líneas de puntos y trazos cortos, color violeta. Los motivos de esta incorporación se desarrollan en la discusión de cada diagrama. Las curvas en color verde (líneas continuas) son curvas de iso-velocidad, y se indican sólo en los modelos autoionizantes. Las EELR se representan de manera independiente: la región NO con círculos magenta y la SE con cuadrados. La emisión de todas las líneas del espectro en la región SE se concentra en $r<2$ " (Sección 5.2); los datos de esta zona, que corresponden a la mayor parte de la muestra, se graficaron con cuadrados amarillos (en adelante, cuando se haga referencia a la EELR-SE se entenderá que se trata de esta zona). La muestra de cuadrados celeste (presentes en el diagrama $\mathbf{B}$ únicamente) corresponde a la estela de emisión detectada en torno a 4", donde sólo se observa emisión en $[\mathrm{O}$ III $] \lambda \lambda 4959,5007$, [OII] $\lambda 3727$ y H $\beta$ (en adelante, esta región se denominará como estela de la EELR-SE). El triángulo color negro indica la intensidad de los cocientes de líneas en el centro de la galaxia.

En el diagrama A (relación entre los ejes de excitación sensibles a cada grupo de modelos) se puede distinguir una clara separación entre las dos regiones respecto de los valores que adopta el cociente HeII/H $\beta$. Bajo las hipótesis de los modelos de fotoionización, este comportamiento se puede interpretar como una diferencia en el nivel de excitación: en la EELR-NO es mayor que en la EELR-SE. Las observaciones son compatibles tanto con la FMF como con la IOC, aunque la disposición de la muestra podría indicar una tendencia en favor de la FMF en ambas regiones.

Por las características espectrales ya mencionadas, el diagrama $\mathbf{B}$ es el único donde puede volcarse la información disponible de la estela de emisión en la EELR-SE (cuadrados celeste). El comportamiento observado amerita un análisis en función de los modelos y un análisis en función de la información contenida en los cocientes involucrados. Analizados según los modelos, los datos de la estela de emisión se ubican en la zona del diagrama dominada por shocks autoionizantes de "baja" velocidad $\left(v_{s} \lesssim 400 \mathrm{~km} \mathrm{~s}^{-1}\right)$, o bien en el extremo de menor excitación de los modelos de FMF, aunque el ajuste presenta mayor dispersión 
(es menos significativo) en este caso. Cualquiera de los dos escenarios es coherente con las observaciones, en el sentido de que tratándose de una región ubicada a una distancia promedio de 4" (alrededor de $30 \mathrm{kpc}$ ) de la región central es esperable que:

- en el contexto de la FMF, ésta sea la región donde el campo de radiación llega más debilitado y por lo tanto su nivel de excitación será considerablemente menor que en las cercanías de la fuente central. Como contraparte, en este análisis no se tiene en cuenta que la densidad ambiental puede estar desempeñando un papel mucho más importante, ya sea por su distribución a gran escala (MIG) como por el peso que pueda tener en el efecto de selección para que sólo se puedan detectar (con la sensibiliad empleada) las líneas más intensas del espectro.

- en el contexto de la IOC, el campo de velocidades del gas no muestra grandes signos de perturbación en esta zona. La velocidad radial de las componentes del oxígeno son considerablemente altas allí ( $500 \mathrm{~km} \mathrm{~s}^{-1}$ ), pero el comportamiento es estable. Luego, si el gas está experimentando procesos de choque, éstos no pueden ser tan violentos como en otros casos donde la perturbación cinemática refleja tales procesos; y consecuentemente, el campo de radiación que generarían esos shocks sería considerablemente más débil (ver Sección 2.4.3). Del mismo modo, podría ocurrir que este campo local fuera insignificante. En otras palabras, podrían estar ocurriendo procesos de shock puros (noautoionizantes), razón por la cual se incorporaron los modelos en el diagrama. Si este fuera el caso en la estela de la EELR-SE, la emisión se produciría únicamente en la zona de recombinación del shock. Sin embargo, las observaciones indican que estas predicciones no son suficientes para explicar la emisión en la zona, por lo tanto se requiere la presencia de un campo ionizante.

Las EELR-SE y NO, por su parte, se ubican en las zonas de mayor excitación, pero la EELRNO muestra una tendencia mucho más marcada hacia los modelos de FMF y la EELR-SE hacia los modelos de IOC. Dentro de la EELR-SE se identifican dos zonas, cuyos niveles de excitación se diferencian por las velocidades características del shock. La zona más interna, en torno a $700<v_{s}<1000 \mathrm{~km} \mathrm{~s}^{-1}$, y la zona externa en torno a $400<v_{s}<500 \mathrm{~km} \mathrm{~s}^{-1}$. Dado que el campo de velocidades no muestra indicios de movimientos con velocidades en el rango ${ }^{5} 700-1000 \mathrm{~km} \mathrm{~s}^{-1}$ el ajuste en esta zona puede entenderse en términos de una mayor influencia del campo de radiación central sobre las regiones más internas. El ajuste en la región externa sí es compatible con los resultados del campo de velocidades. También es aceptable en términos de la FMF, en el sentido de que recibe un campo de radiación diezmado.

Si el comportamiento de la muestra en conjunto se analiza según la información contenida en los cocientes involucrados en el diagrama, se observa lo siguiente. El cociente [OII]/[OIII], que mapea al parámetro de ionización (Ec. 2.2), permite identificar cuatro zonas con niveles de excitación diferentes: la de menor excitación corresponde a la estela en la EELR-SE, la de mayor excitación a la EELR-NO (acuedo interno entre [OII]/[OIII] y HeII/H $\beta$, diagrama A); y dentro de la EELR-SE se ubican las dos zonas de excitación intermedia, que a su vez guardan relación con la distancia a la fuente central. La Figura 6.3 muestra el comportamiento espacial de $U$ (asteriscos color rojo, panel superior) a través del cociente de oxígenos, junto con el de

\footnotetext{
${ }^{5}$ La velocidades relativas entre las componentes cinemáticas sí alcanzan amplitudes cercanas a $1000 \mathrm{~km} \mathrm{~s}^{-1}$, pero no hay indicios de que las nubes se muevan a esas velocidades. Incluso, aúnque sí es posible que la velocidad espacial alcance estos valores, tal escenario es imposible en virtud de la dirección del movimiento: no hay argumentos para sostener que la velocidad radial pueda invertir su sentido (ver Fig 6.1: corrimientos al azul en la región interna, corrimientos al rojo en la región externa). El comportamiento del campo de velocidades en esta zona se explica con la presencia de outflows.
} 
todas las líneas intensas del espectro (intensidad respecto de $\mathrm{H} \beta$ ). Las cuatro regiones de excitación recién descriptas se pueden identificar espacialmente.

En la EELR-NO el parámetro de ionización crece y alcanza el máximo; en esta zona las líneas de baja excitación ([OII], $\mathrm{H} \beta$ ) disminuyen su intensidad, pero aumenta la de las líneas de excitación media-alta ([Nev], [NeIII], HeII, [OIII]). La línea [OIII] $\lambda 4363$ está presente sólo en esta zona.

En la estela de la EELR-SE la emisión de [OII] y [OIII] es comparable, pero mientras la emisión de [OIII] es significativamente menor que en el resto de la nebulosas, la emisión de [OII] es similar e incluso mayor que en otras zonas. Es un aspecto interesante porque debilita la hipótesis de que allí sólo se observan [OII], $\mathrm{H} \beta$ y [OIII] por un efecto de selección ${ }^{6}$. La disminución del parámetro $U$ en la zona se produce porque el [OIII] no puede contrarrestar el aumento de emisión del [OII]. En el escenario propuesto por los modelos de IOC, esto es lo que sucede en la zona de recombinación como consecuencia de la compresión del material. Sin embargo, dadas las características cinemáticas, la influencia del shock debe ser necesariamente menor que en la EELR-SE.

En las zonas de excitación intermedia de la EELR-SE $(r<1$ ", y 1 " $<r<2$ ", respectivamente) las líneas de alta y baja excitación tienen comportamientos diferentes. En la zona más interna $(r<1$ ") se produce un leve aumento local en $U$, pero dentro de un patrón de decrecimiento. La intensidad de todas las líneas se mantiene aproximadamente constante. En la zona externa $(1 "<r<2$ ") $U$ continúa decreciendo, pero la intensidad del [OII] (excitación baja), [NeIII] (excitación media) y [Nev] (excitación alta) aumenta ${ }^{7}$. Curiosamente también se observa que la emisión de $[\mathrm{Nev}]$ es más extendida que la de HeII, la otra línea de excitación alta presente en el espectro. Las mismas características espectrales se encontraron en los sistemas nebulares de las radiofuentes 3C 268.3 y 3C 303.1 (Sección 6.2). Luego, teniendo en cuenta que en estos rangos de distancias se identifican perturbaciones en el campo de velocidad, el escenario se puede explicar en términos de los procesos que ocurren en la región de recombinación del shock con la contribución de los dos campos de radiación existentes: el campo externo proveniente de la fuente central, y el campo local creado por los shocks. Respecto de este último, los fotones ionizantes que alteran el estado de ionización no son los que viajan en la dirección de propagación de la onda generando el precursor radiativo, sino los que viajan en dirección contraria, hacia el gas chocado.

Cabe, sin embargo, un último comentario sobre el cociente de oxígenos que también será válido para el análisis del diagrama C. El cociente $[\mathrm{OII}] \lambda 3727 /[\mathrm{OIII}] \lambda 5007$ es el único donde se utilizan líneas suficientemente distantes como para sospechar que pueda estar afectado por la extinción provocada por el medio. No sucede lo mismo con las abscisas utilizadas en los dos diagramas, esto es, $[\mathrm{OIII}] \lambda 5007 / \mathrm{H} \beta$ en B y HeII/H $\beta$ en C. En el Apéndice D se discuten las posibles componentes de la extinción interestelar, y puede verse allí también que el efecto de la extinción sobre los cocientes de líneas (Tabla D.1; en escala logarítmica, para facilitar el análisis sobre los diagramas de diagnóstico) es considerablemente mayor sobre el [OII]/[OIII] que sobre cualquier otro cociente empleado, debido a la separación entre las líneas. Como no se conocen ni las propiedades físicas del medio interestelar en 3C 268.2 (ni en ningún otro objeto de la muestra estudiada), los coeficientes de extinción de la Tabla D.1 se obtuvieron considerando de que la absorción en el visual $\left(A_{V}\right)$ entre una y otra región de la galaxia observada equivale a una (1) magnitud ${ }^{8}$. Es una suposición arbitraria, pero

\footnotetext{
${ }^{6} \mathrm{Si}$ así fuera, entonces [OıII] debería ser más intensa que [OіI].

${ }^{7} \mathrm{El}$ [OIII], de excitación media según esta división, también aumenta pero su comportamiento es más errático.

${ }^{8}$ Es decir, los coeficientes de extinción listados en la Tabla D.1 del Apéndice D representan, en la forma más general posible, los valores relativos entre las nebulosas ubicadas a ambos lados de la galaxia, bajo la hipótesis de que las características del MIE en cada galaxia con comparables a las del MIE en la Vía Láctea.
} 
Figura 6.2. 3C 268.2. Evaluación de mecanismos de ionización: FMF, IOC y shocks puros.
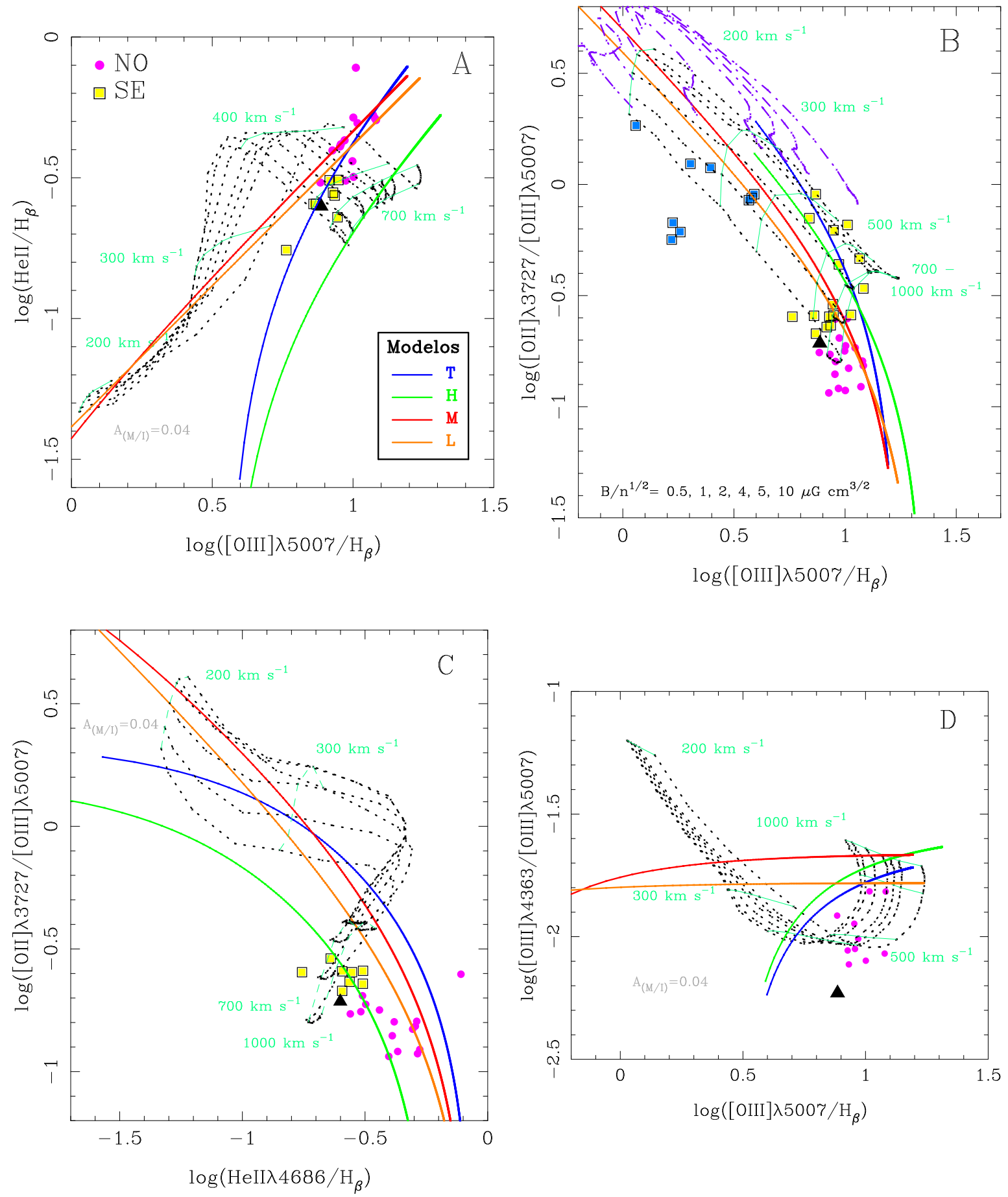
Fig. 6.2: continuación
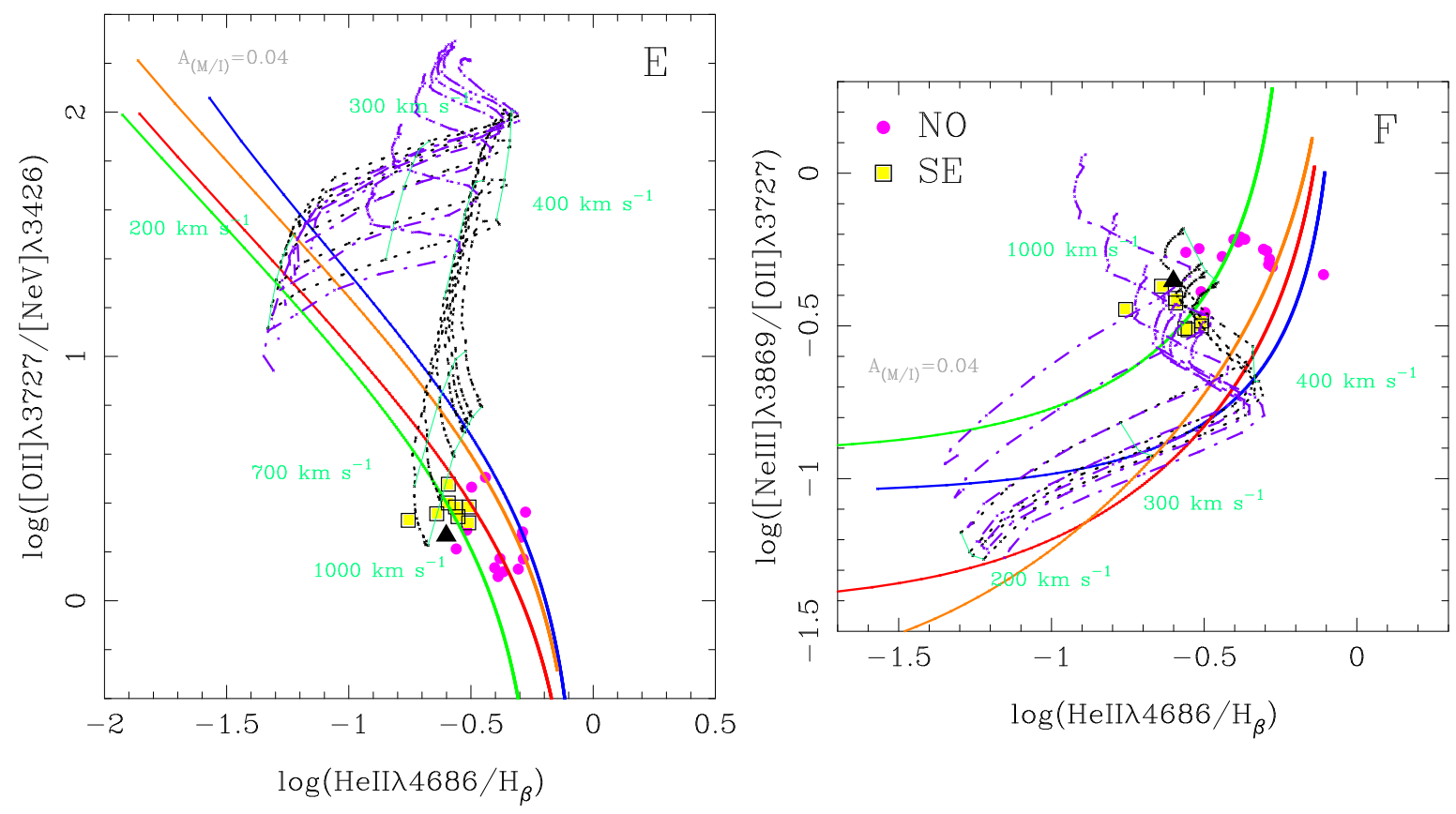

Se evalúan los mecanismos de FMF (modelos T, H, M y L, graficados en líneas continuas), junto con los modelos de IOC (choques autoionizantes, líneas punteadas, en color negro) y los modelos de shocks que no contemplan la contribución de la región precursora (shocks puros o no-autoionizantes, graficados con líneas de puntos y trazos cortos, en color violeta). Estos últimos se evalúan sólo en los diagramas donde cobran relevancia (ver texto). Las regiones en emisión de 3C 268.2 se grafican como: NO con círculos, color magenta, y SE con cuadrados, color amarillo; el triángulo negro indica la intensidad de las líneas en el centro de la galaxia. La muestra graficada con cuadrados en color celeste corresponde al extremo de la región SE, zona en la que sólo fue posible medir las tres líneas que intervienen en el diagrama B: [OII], $\mathrm{H} \beta$ y [OIII]. Éste es el único diagrama donde puede evaluarse el comportamiento del extremo de la región. 
es útil para estudiar cómo se verían afectados (en principio todos) los cocientes. Y, en el caso concreto de los diagramas $\mathbf{B}$ y $\mathbf{C}$, se observa que una corrección equivalente a $A_{V}=1$ desplazaría (en dirección vertical) la muestra de la región NO (puntos magenta) hacia la zona donde se ubica la zona interna de la región SE (cuadrados amarillos). Puesto que los desplazamientos en dirección horizontal no se pueden explicar en términos de un posible efecto de extinción, se sostiene la hipótesis de que las regiones tienen grados de excitación diferentes, particularmente en lo que respecta a $\mathrm{HeII} / \mathrm{H} \beta$.

Retomando, entonces, el análisis de los diagramas de diagnóstico, el diagrama $\mathbf{C}$ muestra la tercer proyección del diagrama 3D que conforma junto con A y B. La muestra de la EELR$\mathrm{SE}$ se reduce respecto de lo que se observa en el diagrama $\mathbf{B}$ porque la línea HeII se observa hasta distancias menores que los oxígenos, o $\mathrm{H} \beta$ (ver panel inferior de la Fig. 6.3; tanto en $\mathbf{A}$ como en $\mathbf{C}$ la muestra corresponde a la zona que en el párrafo anterior se denominó "interna"). En este diagrama se refuerza la tendencia de la EELR-NO hacia los modelos de FMF. La región SE, por su parte, mantiene el comportamiento límite observado en $\mathbf{B}$ en lo que podría denominarse como "zona de transición" entre los modelos, en virtud de la falta de argumentos cinemáticos para justificar el ajuste sobre el rango más alto de velocidad de los modelos de IOC. Sin embargo debe destacarse que los cocientes involucrados en este diagrama no son independientes: $[\mathrm{OII}] /[\mathrm{OIII}]$ es el parámetro de ionización $U$, y HeII/H $\beta$ es el parámetro geomético/ionizante $A_{M / I}$, en cuya constitución participa $U$.

En el diagrama $\mathbf{D}$ se utiliza el cociente de oxígenos [ÖII] $\lambda 4363 /[\mathrm{OIII}] \lambda 5007$. El [OIII] $\lambda 4363$ está presente sólo en la EELR-NO (panel inferior de la Fig. 6.3), la zona de mayor excitación y muy posiblemente dominada por la fotoionización, según el análisis anterior. Pero su comportamiento en el diagrama es ambiguo, pues la tendencia indica un ajuste más favorable hacia los modelos de IOC. Sin embargo, si se analiza de la mano del diagrama $\mathbf{A}^{9}$, se observa que tal ajuste es sólo un efecto de proyección.

En los diagramas $\mathbf{E}$ y $\mathbf{F}$ de la Fig. 6.2 se utilizaron las líneas del neón $[\mathrm{NeV}] \lambda 3424$ y [NeIII] $\lambda 3869$. Son dos líneas de excitación alta y media, respectivamente, combinadas con el [OII], de excitación baja; su comportamiento se evalúa con el eje de excitación correspondiente a la FMF $(\mathrm{HeII} / \mathrm{H} \beta)$. En ellos se hace uso nuevamente de los modelos de shocks puros para analizar la influencia del campo de ionización actuante, ya sea el que crea el propio shock o el que proviene de la fuente central. En primer lugar, del diagrama $\mathbf{E}$ se observa que las líneas de mayor excitación [Nev] y HeII respetan la tendencia marcada anteriormente: la EELR-NO hacia FMF y la EELR-SE hacia la zona mixta FMF-IOC. Se evidencia, también, que los shocks puros quedan descartados. En el diagrama $\mathbf{F}$ se observa un comportamiento similar respecto de los datos; y aunque el apartamiento en favor de la FMF en todos los casos está gobernado por el HeII, si el eje de excitación se cambia por [OIII] $\lambda 5007 / \mathrm{H} \beta$ (tal diagrama no se muestra en la Figura) la tendencia, aunque menos marcada, se mantiene.

Las claras diferencias existentes entre los modelos de shocks puros y autoionizantes respecto del cociente $[\mathrm{OII}] /[\mathrm{NeV}]$ (diagrama $\mathbf{E}$ ), junto con las [prácticamente] insignificantes diferencias en el cociente $[\mathrm{NeIII}] /[\mathrm{OII}]$ (diagrama $\mathbf{F}$ ) son un elocuente indicio de la influencia que un campo de radiación externo (cualquiera, en principio) ejerce sobre algunas líneas de emisión. De $\mathbf{E}$ se deduce que cuando el shock se propaga con velocidades mayores que $400 \mathrm{~km} \mathrm{~s}^{-1}$ aproximadamente, el efecto del campo de fotones creado localmente es el de reducir la intensidad del cociente $[\mathrm{OII}] /[\mathrm{Nev}]$, y esa reducción será mayor cuanto más duro sea ese campo ionizante (como el comportamiento de los modelos se parametriza con la velocidad de la onda de choque, esta situación equivale a shocks cada vez más rápidos y por ende, más violentos). Supóngase ahora que este campo de radiación se reemplaza por otro campo más potente. Siguiendo el mismo razonamiento, el efecto de ese campo sería el de disminuir

\footnotetext{
${ }^{9}$ Análisis del diagrama 3D formado por $[\mathrm{OIII}] \lambda 5007 / \mathrm{H} \beta$ vs. HeII/H $\beta$ vs $[\mathrm{OIII}] \lambda 4363 /[\mathrm{OIII}] \lambda 5007$.
} 
aún más la intensidad de [OII]/[Nev]. Bajo las consideraciones de la FMF, la disminución en $[\mathrm{OII}] /[\mathrm{Nev}]$ es una consecuencia del dominio de la componente MB respecto de la IB (traducido en valores crecientes de $A_{M / I}$ ) que, a su vez, implica de forma implícita la disminución de la distancia a la fuente central. Ahora bien, si se calcula el valor del parámetro de ionización $U$ en cada una de las zonas (EELR-NO, EELR-SE interna ${ }^{10}$ ) se puede analizar la validez de este escenario según los valores de referencia de $U$ para cada sistema nebular (MB o IB). Se obtiene: $U_{\text {máx }}^{N O}=1.5 \times 10^{-2}$ : compatible con el parámetro de ionización del sistema $\mathrm{MB}$ propuesto en el modelo L, y $\left\langle U_{i n t}^{S E}=7.3 \times 10^{-3}\right\rangle$, demasiado bajo para poder representar cualquier sistema nebular de tipo MB y por ende, demasiado bajo para explicar la presencia, extensión e intensidad de las líneas [Nev] y HeII.

Luego, el estado de ionización de las regiones nebulares de 3C 268.2 se puede explicar, de la mano de la información cinemática, del siguiente modo:

- en la EELR-NO domina la FMF: ni la cinemática ni los modelos permiten identificar una contribución significativa de la IOC, mientras que sus parámetros y características son compatibles con las del sistema nebular MB en los modelos de FMF;

- en la EELR-SE "interna" $(r<1$ ") se observan efectos de la IOC con la contribución no despreciable de un campo ionizante. Ese campo debe ser necesariamente más potente que el campo creado localmente por shocks de velocidades compatibles con las que manifiesta el campo de velocidad del gas;

- en la EELR-SE externa ( 1 " $<r<2$ ") los signos de perturbación en el campo de velocidades están presentes pero disminuyen, así como también disminuye el estado de excitación respecto de la región interna. Sin embargo las características espectrales (Fig. 6.3) muestran indicios de continuidad con el escenario planteado para la región interna, con un campo externo más debilitado y shocks menos violentos. En el diagrama B se observa que la tendencia hacia los modelos de IOC se produce en la zona de velocidades compatibles con el campo de velocidad.

En cuanto a la estela de emisión en la EELR-SE $(r \sim 4$ ") es posible que se necesiten observaciones más sensibles que permitan determinar fehacientemente la presencia de más especies en emisión, o confirmar las existentes. Mientras tanto, la única información disponible proviene de las líneas [OIr] $\lambda 3727, \mathrm{H} \beta$ y [OIII] $\lambda \lambda 4949,5007$, con lo cual los mecanismos de ionización (a través de los diagramas de diagnóstico) se pueden evaluar únicamente con la combinación del diagrama B. Aunque las conclusiones que de éste se deriven sean, entonces, preliminares, las características de la emisión pueden entenderse como la continuidad del escenario planteado en la región $\mathrm{SE}$, con el debilitamiento esperado según las distancias involucradas.

\subsubsection{Resumen}

El análisis del espectro long-slit de 3C 268.2 permitió, en primer lugar, determinar un nuevo valor del corrimiento al rojo $\left(z^{\prime}\right)$ de la galaxia a partir de las inconsistencias observadas con el valor actualmente conocido $z=0.362$ (Spinrad et al. 1985, y NED). El nuevo redshift es

$$
z^{\prime}=0.36280 \pm 3 \times 10^{-5}
$$

Los resultados del campo de velocidad indican que, en la dirección de elongación de 3C $268.2\left(\mathrm{PA}=165^{\circ}\right)$ existen tres componentes de velocidad que pueden interpretarse como

\footnotetext{
${ }^{10}$ La EELR-SE externa queda fuera del diagrama, pero el parámetro de ionización $U$ se puede obtener y analizar del mismo modo que para las dos regiones que sí forman parte del diagrama. En esta zona se obtiene $\left\langle U_{\text {ext }}^{S E}=4.5 \times 10^{-3}\right\rangle$, que al igual que en la EELR-SE interna, es un valor demasiado bajo, incompatible con el sistema MB. Es decir, que con este/os valor/es de $U$ no se podrían formar las líneas de mayor excitación ni con la intensidad ni con la extensión observadas en el espectro de 3C 268.2.
} 
Figura 6.3. $3 \mathrm{C}$ 268.2. Evolución espacial del parámetro de ionización y las líneas de emisión.
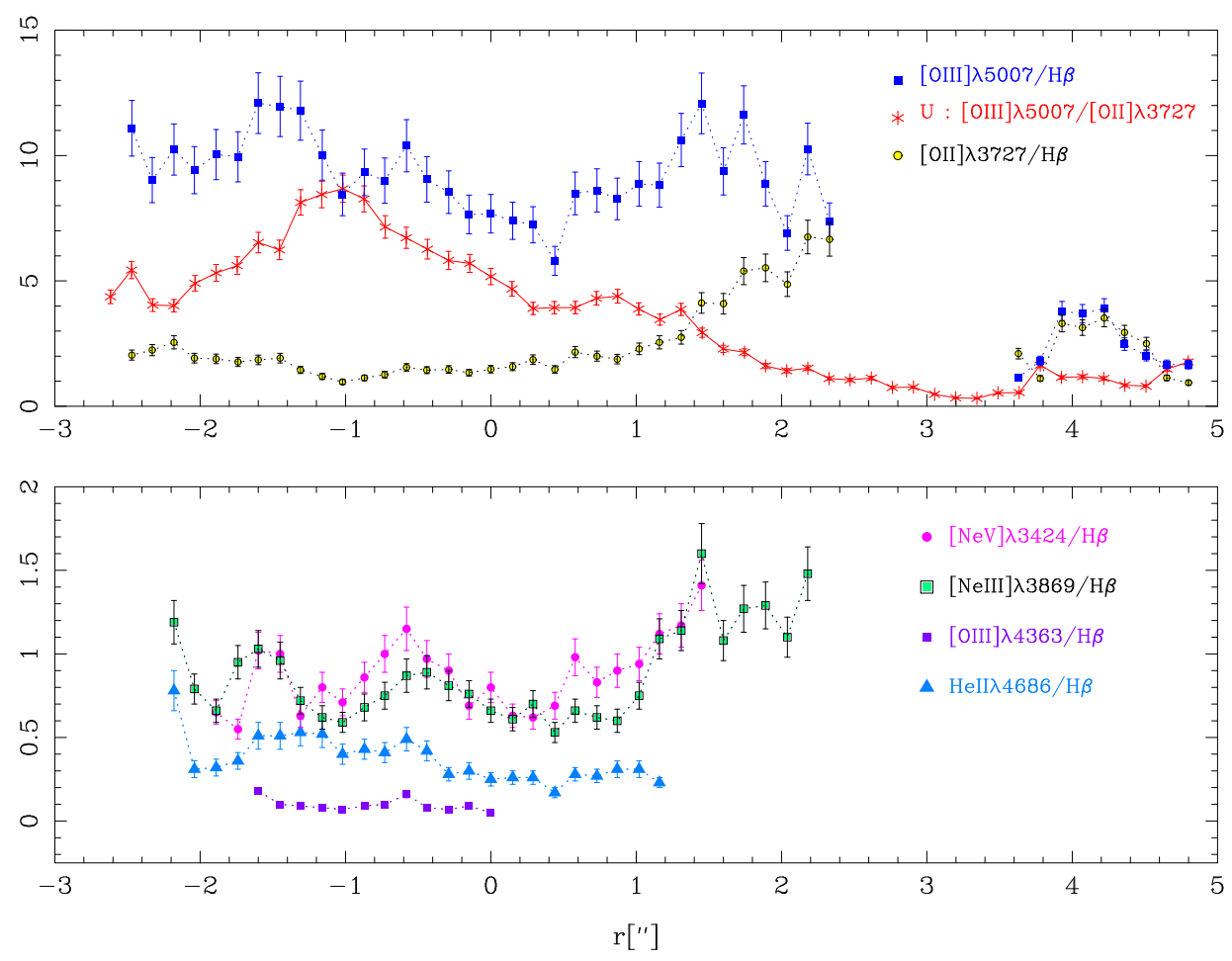

Panel superior: Comportamiento del parámetro de ionización (asteriscos, color rojo) en función de la distancia al centro de la galaxia $(r=0)$. También se muestra el mismo comportamiento en los cocientes $[\mathrm{OIII}] \lambda 5007 / \mathrm{H} \beta$ (cuadrados, color azul) y $[\mathrm{OII}] \lambda 3727 / \mathrm{H} \beta$ (círculos, color amarillo). En la zona comprendida por $2.5 "<r<3.5$ " no hay información sobre estos cocientes porque no se puede detectar emisión en la línea $\mathrm{H} \beta$. Panel inferior: El mismo comportamiento espacial en las demás líneas intensas del espectro respecto de $\mathrm{H} \beta$; [Nev] $\lambda 3424$ (círculos, color magenta), [NeIII] $\lambda 3869$ (cuadrados, color verde), [OIII] $\lambda 4363$ (cuadrados, color violeta) y HeII (triángulos, color celeste). La escala de ordenadas fue ajustada de acuerdo a la intensidad de los cocientes, pero la escala de abscisas se mantuvo en ambos paneles para facilitar la comparación sobre el alcance de la emisión de cada especie y/o estado de ionización. 
tres patrones rotacionales. Uno de ellos, descripto por la componente dominante del perfil, presenta velocidades de estabilización que rondan los $450 \mathrm{~km} \mathrm{~s}^{-1}$ y que, por ende, no pueden asociarse con movimientos dentro del pozo de potencial galáctico (Tadhunter et al. 1989). La segunda componente del perfil conforma la segunda curva de rotación, se extiende a lo largo de toda la EELR-NO (3.6") pero en la región SE sólo puede detectarse hasta 2". La tercer componente constituye la tercer y más interna $(|r| \lesssim 1.8$ ") curva de rotación. Este movimiento se produce en sentido contrario al que indican las otras dos curvas. En la zona más interna se observan perturbaciones al movimiento colectivo claramente asociables a un outflow; estos movimientos se producen en dirección al observador (corrimientos al azul) con amplitudes de velocidad que alcanzan los $500 \mathrm{~km} \mathrm{~s}^{-1}$ aproximadamente.

El outflow se detecta en una dirección que forma un ángulo de $144^{\circ}$ con la dirección del radio-eje, por lo cual su generación no puede estar ligada al paso del jet a través del medio. Recientemente Riffel et al. (2014) encontraron un escenario de similares características en la galaxia cercana NGC 5929. En estos casos los outflows son generados por procesos asociados a la acreción y eyección de material ${ }^{11}$, y en la literatura se conocen según su nombre en inglés como feeding \& feedback (Di Matteo et al. 2005; Hopkins et al. 2005). La acreción de material "alimenta" al agujero negro central (feeding) y los vientos asociados a las regiones más internas del núcleo activo provocan la eyección del gas (o outflows) hacia las afueras de la galaxia (feedback; Lena et al. 2014; Riffel et al. 2014; Schnorr-Müller et al. 2014a,b, por citar los más recientes).

La galaxia, su región nuclear y su región nebular completa están elongadas en la dirección dada por la EELR $\left(\mathrm{PA}=165^{\circ}\right.$ ), cuya extensión total alcanza los 5.6" (equivalen a $60 \mathrm{kpc}$ aproximadamente, medida según el alcance del $[\mathrm{O} I I]] \lambda 5007)$. No se observa la presencia de gas en otra dirección, por lo tanto el estado de ionización de la región deberá estar relacionado con los procesos que ocurren en esa dirección. Además de la siempre presente influencia del campo de radiación del núcleo activo, la presencia del outflow puede generar la contribución ionizante de ondas de choque radiativas.

Se analizaron los mecanismos de FMF e IOC. También se estudió el accionar de ondas de choque puras, es decir, procesos de choque donde la emisión del gas proviene únicamente de la zona de recombinación (gas chocado). Con respecto a este último escenario, se concluyó que tales procesos no pueden explicar la intensidad observada en las líneas (cocientes). Aún cuando existen indicios de la contribución proveniente de la zona de recombinación, el efecto fotoionizante del campo de ionización central o del campo local creado por los shocks son estrictamente necesarios para reproducir las observaciones.

La zona de mayor excitación se observa en la EELR-NO, que además no presenta indicios de perturbación cinemática, más allá de la "rareza" de los tres patrones rotacionales simultáneos. En la EELR-SE se distinguen tres zonas, cuyos niveles de excitación decrecen hacia las afueras de la galaxia. Las zonas se denominaron interna, correspondiente al rango de distancias dado por $r<1$ ", externa en el rango 1" $<r<2$ ", y la estela de emisión que corresponde al aumento aislado (pero igualmente alineado) de emisión en un grupo reducido de líneas que tiene lugar en torno a $r \sim 4$ ". En las zonas interna y externa el campo de velocidades evidencia la presencia del outflow; en la estela sólo se distingue la componente cinemática dominante.

El escenario observado en 3C 268.2 puede resumirse de la siguiente manera:

1) la EELR-NO está dominada por el mecanismo de FMF; no hay indicios de que exista ningún tipo de influencia que no se deba al núcleo activo. El valor máximo del parámetro de ionización $U$ es compatible con (aunque ligeramente menor que) el valor correspondiente al

\footnotetext{
${ }^{11}$ Estos procesos, a su vez, están íntimamente relacionados con la formación y evolución de galaxias y de los agujeros negros supermasivos (SMBH) que albergan en sus núcleos, del desencadenamiento de la actividad nuclear y la forma en que esa actividad contribuye a la evolución (ver Storchi-Bergmann 2014, y sus referencias).
} 
modelo L de FMF.

2) la EELR-SE está claramente perturbada por la presencia del outflow.

3) el outflow desencadena los procesos de choque.

4) en la zona interna de la EELR-SE se observa el efecto conjunto del campo de radiación del núcleo activo y los shocks autoionizantes.

5) en la zona externa de la EELR-SE disminuye el efecto del campo central y también el del campo local creado por el shock, con lo cual disminuye el nivel de excitación. Sin embargo, el comportamiento de líneas como $[\mathrm{Nev}]$ indican que el estado de la región sigue influenciado por estos campos. El parámetro de ionización $U$ tanto en la región interna como en la externa acusa valores bajos. Tanto por estos valores como por la presencia de las líneas de alta excitación, es muy improbable que la FMF domine el estado de la región, pero en términos de la IOC pueden comprenderse por la acción conjunta de los (ya más debilitados) campos de radiación y la compresión del material en la zona de recombinación.

6) en la estela de la EELR-SE la influencia del núcleo activo, si existe, es mínima. Y dado que el outflow no tiene injerencia en esta zona (ver Nota al pie $\mathrm{N}^{r o}$ 5), el campo de radiación local creado por shocks que pierden velocidad también es menos potente. En esta zona, sin embargo, son necesarias observaciones más profundas de modo tal de poder descartar cualquier posible efecto de selección en las líneas presentes, y/o re-evaluar los mecanismos actuantes (y el escenario propuesto) con la información de todas las líneas que, en tal caso, se detectaran.

\section{2. $\quad 3 \mathrm{C} 268.3$ y $3 \mathrm{C} 303.1$.}

Las radiogalaxias 3C 268.3 y 3C 303.1 son las dos fuentes CSS de la muestra, y por este motivo se estudian juntas. Como se describió en el Capítulo anterior, las radio-estructuras están alineadas con la emisión óptica. Según la terminología propuesta por de Vries et al. (1999), en ambos casos se trata de un "alineamiento global" (y no una correspondencia detallada de las características observadas en cada banda del espectro), que se explica en términos de la interacción entre el radio-plasma y el MIE a través de procesos de choque.

Si bien el citado trabajo se trató básicamente de un análisis morfológico, sirvió como antecedente para analizar si la interacción de estas estructuras podía extenderse a otros aspectos, como la cinemática o la ionización del gas. Entre los primeros se destaca el trabajo de Holt et al. (2008), quienes hicieron especial hincapié en que el hecho de que se tratara de fuentes compactas, convertía a estos objetos en interesantes candidatos para la detección de outflows en las regiones circumnucleares. En cuanto a los efectos de la interacción sobre el estado de ionización del gas, se encuentran, además del ya citado de Vries et al. (1999), los artículos de Labiano et al. (2005) y Holt et al. (2009), éste último muy relacionado con su trabajo anterior (Holt et al. 2008), como se describe a continuación.

En estos estudios se comparan las predicciones de los modelos de fotoionización simple, multifase e ionización por ondas de choque con las observaciones del gas circumnuclear $(|r|<1$ "), dado que es en esa región donde se buscaron los movimientos bruscos de MIE. A partir de la descomposición de los perfiles de emisión se comprobó que efectivamente existen outflows circumnucleares (Holt et al. 2008), pero ninguno de los tres trabajos que estudiaron los mecanismos de ionización en la región (de Vries et al. 1999; Labiano et al. 2005; Holt et al. 2009) ${ }^{12}$ permitieron obtener resultados concluyentes en ese sentido.

\footnotetext{
${ }^{12} \mathrm{El}$ análisis de Labiano et al. (2005) incluye parte del gas de la región extendida que se estudia aquí. Es de particular importancia resaltar que los modelos de ionización por ondas de choque que utilizaron, y que se citan como Kewley et al. (2003, en preparación) no son los que finalmente se publicaron como parte de la librería MAPPINGS III. Los resultados finales de MAPPINGS III para los modelos de IOC se presentaron en el artículo Allen, Groves, Dopita, Sutherland \& Kewley (2008).
} 
En el presente trabajo se realiza un análisis similar (dado que, en términos generales, se emplean los mismos modelos) sobre el gas extendido. Algunos resultados parciales de los trabajos anteriores se utilizan como punto de partida para el estudio de los mecanismos de ionización actuantes en la EELR.

\subsubsection{Mecanismo de ionización.}

Las características encontradas en los campos de velocidades (Sección 5.3 y Fig. 5.4; y Sección 5.5 y Fig. 5.8) coinciden con los resultados previos ${ }^{13}$ sobre ambas fuentes, en tanto existen movimientos de notable perturbación en las zonas aledañas al centro de la galaxia. Incluso en el caso de 3C 268.3 se señaló (ver Sección 5.3) que la descomposición Gaussiana del perfil del [OIII] $\lambda 5007$ manifiesta la existencia de una componente secundaria en la región interna (es decir, $|r|<1$ "), más ancha que la componente dominante y cuyo movimiento no está ligado a la curva de rotación, resultado que coincide con los de Holt et al. (2008).

En contraposición con los estudios anteriores, esta parte del análisis se focalizará en las regiones (de ambas radiogalaxias) cuyas distancias al núcleo estén dadas por $|r|>1$ ”. En estas zonas, el campo de velocidad de 3C 268.3 no muestra ningún signo de perturbación y/o turbulencia sino marcada estabilidad. De hecho, la componente que aquí se denomina "dominante" es la componente angosta que Holt et al. (2008) asocian al medio ambiente estacionario perteneciente al halo galáctico. En el caso de 3C 303.1, en cambio, se observa que los movimientos turbulentos presentes en la región interna se mantienen hasta una distancia apenas mayor que 2" ( $\gtrsim 10 \mathrm{kpc}$ ) tanto hacia el NO, como el SE.

Holt et al. (2009) obtuvieron estimaciones (no muy precisas) de la densidad a partir de las líneas del $[\mathrm{SiI}] \lambda \lambda 6716,6731$, según la descomposición Gaussiana derivada por Holt et al. (2008). En principio, la densidad de la región varía entre $1-100 \mathrm{~cm}^{-3}$, pero incluso podría alcanzar valores un orden de magnitud mayor.

A continuación se aplicarán los modelos de IOC y FMF. Debido a la indeterminación de densidades, en primer lugar se analiza el comportamiento de las observaciones frente a modelos de distinta densidad ambiental. En todos los casos se adopta el conjunto de abundancias solares. En la Figura 6.4 se presenta el diagrama [NeIII] $\lambda 3869 /[\mathrm{OII}] \lambda 3727$ versus $[\mathrm{OIII}] \lambda 5007 / \mathrm{H} \beta$, especialmente sensible a la densidad preshock en los modelos de IOC. El diagrama está duplicado en ambos paneles; en el panel del lado izquierdo se busca evaluar el comportamiento de los modelos de IOC para las densidades $n_{e}=1 \mathrm{~cm}^{-3}$ (líneas continuas, verde), $10^{2} \mathrm{~cm}^{-3}$ (líneas punteadas, negro) y $10^{3} \mathrm{~cm}^{-3}$ (líneas de trazos cortos, rojo). En el panel de la derecha se muestran el comportamiento de los modelos de FMF, cuyas densidades se encuentran en un rango similar (Tabla 2.1). Las observaciones (que en ambos casos corresponden a distancias $|r|>1$ ") se indican de la siguiente manera: 3C 268.3 con puntos (magenta) y 3C 303.1 con cuadrados (celeste). En ambos se utiliza un símbolo de mayor tamaño para indicar la intensidad de los cocientes en la posición del centro galáctico.

En el caso de IOC la intensidad del cociente [NeIII] $\lambda 3869 /[\mathrm{OII}] \lambda 3727$ marca una tendencia hacia densidades bajas; para la FMF, en cambio, la degeneración es completa. Sin embargo, excepto el modelo de IOC de mayor densidad, cuyo análisis se abandona en adelante, todos son capaces de reproducir las observaciones. La densidad ambiental en los modelos $\mathrm{H}, \mathrm{M}$ y L (FMF) también es (demasiado) alta, pero, en principio, por la forma y el propósito con los que estos modelos fueron desarrollados, la influencia de la densidad sobre el especto emergente puede no ser tan determinante como en el caso de IOC. En la FMF el parámetro crucial es $U$, el parámetro de ionización (y su relación con $A_{M / I}$ ), esto es: la combinación

\footnotetext{
${ }^{13}$ Los espectros de Holt et al. (2008) se tomaron con ángulos de posición de $155^{\circ}$, en el caso de 3C 268.3, y de $130^{\circ}$, en el caso de 3C 303.1. Las diferencias con los espectros GMOS utilizados en este análisis son de $11^{\circ}$ y $15^{\circ}$, respectivamente.
} 
Figura 6.4. 3C 268.3 y 3C 303.1. Evaluación de la densidad bajo modelos de IOC y FMF.
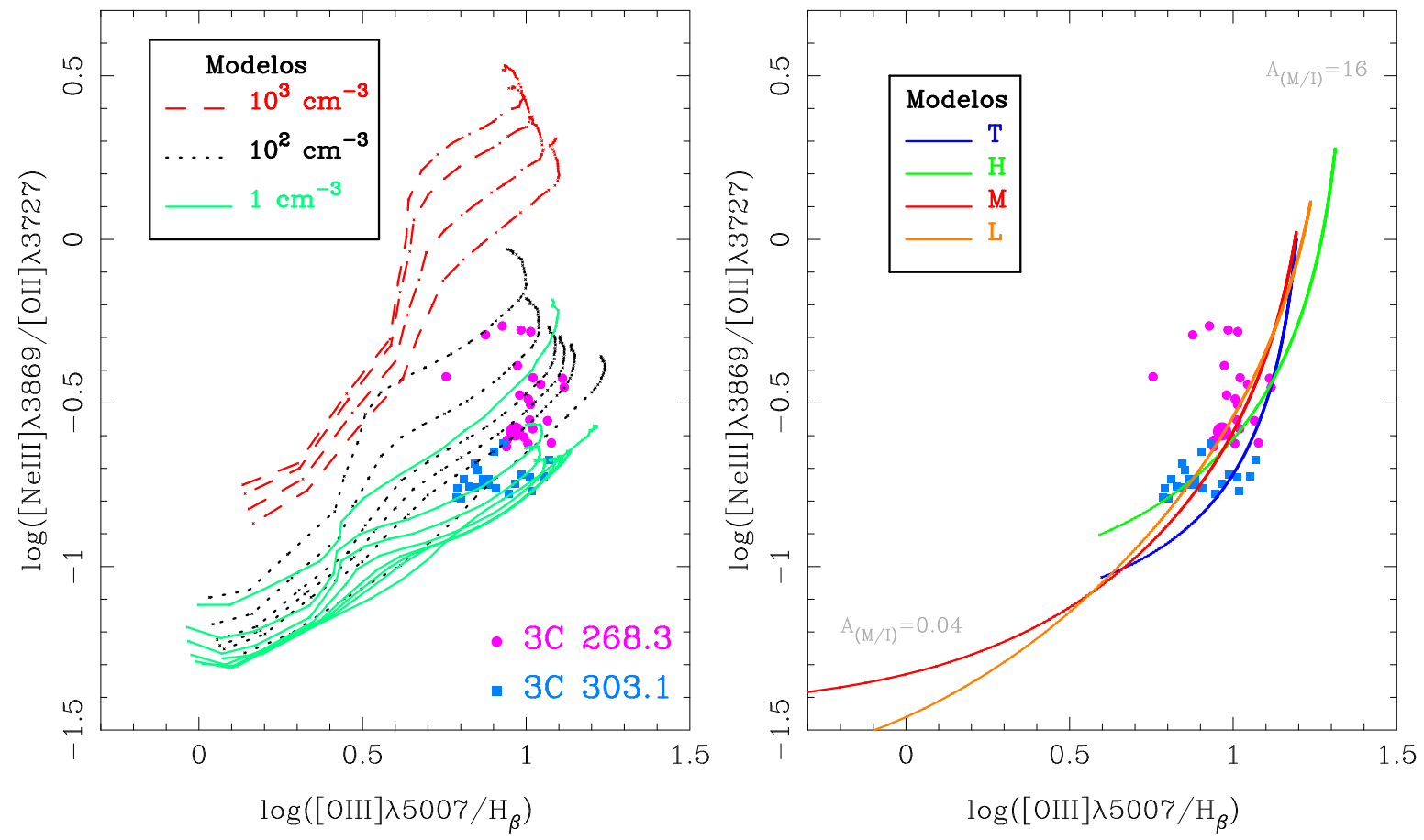

Izquierda: comportamiento de los modelos de IOC para las densidades $n_{e}=1 \mathrm{~cm}^{-3}$ (líneas continuas, verde), $10^{2} \mathrm{~cm}^{-3}$ (líneas punteadas, negro) y $10^{3} \mathrm{~cm}^{-3}$ (líneas de trazos cortos, rojo). Derecha: modelos de FMF; la densidad inicial de las nubes MB en cada uno de ellos es $50 \mathrm{~cm}-3$ en el modelo T (azul), y de $10^{3} \mathrm{~cm}^{-3}$ en los modelos H (verde), M (rojo) y L (naranja). Las observaciones de 3C 268.3 y 3C 303.1 se indican puntos (magenta) y cuadrados (celeste) respectivamente. Sólo se grafican los datos correspondientes a $|r|>1$ ". Los símbolos de mayor tamaño señalizan, como referencia, la posición del centro galáctico en el diagrama, de acuerdo a la intensidad de las líneas allí. 
Figura 6.5. 3C 268.3 y 3C 303.1. Comportamiento del $[\mathrm{Nev}]$ bajo modelos de IOC y FMF.
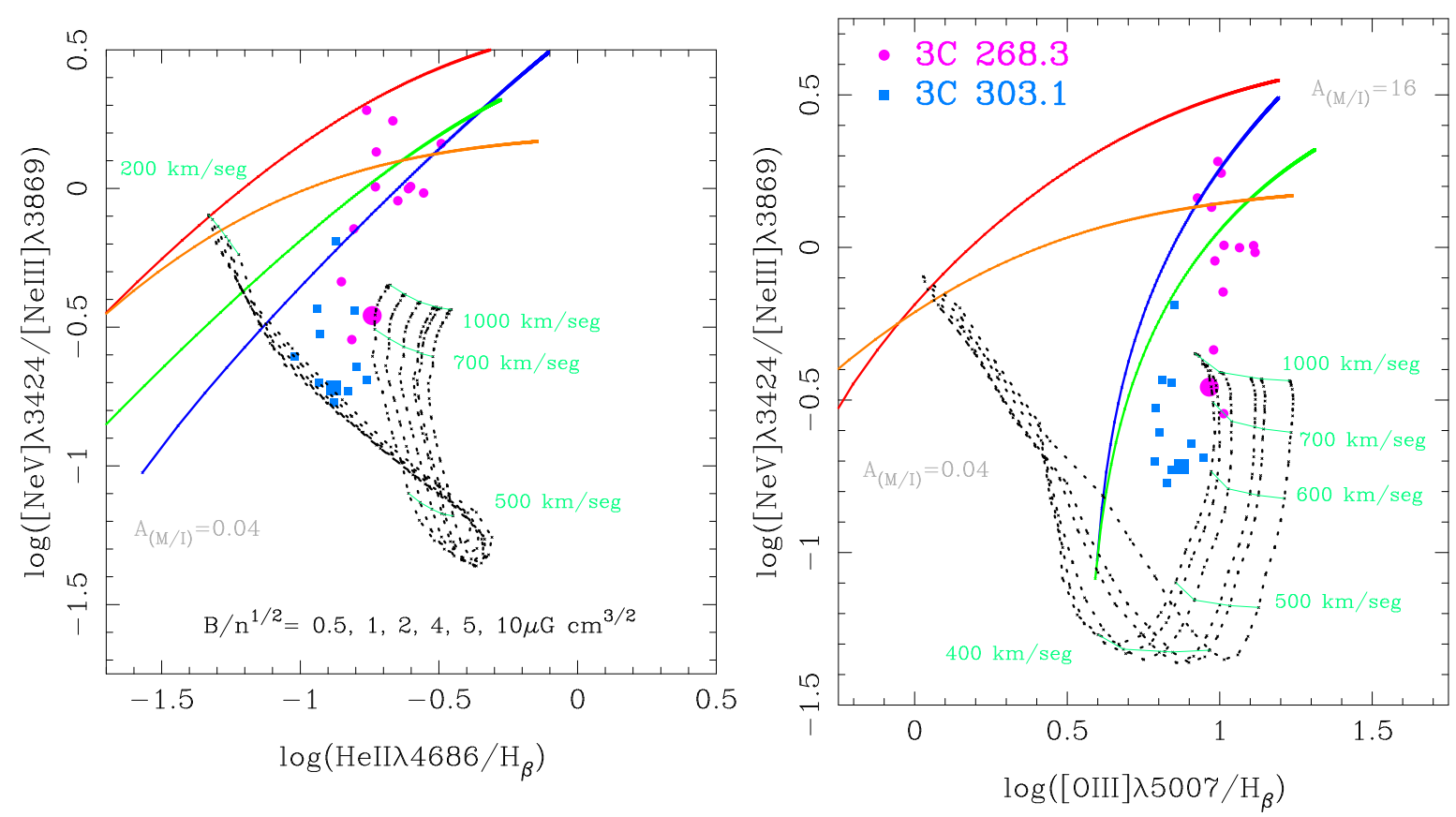

Evaluación del cociente $[\mathrm{Nev}] \lambda 3424 /[\mathrm{NeII}] \lambda 3869$ según el eje de excitación HeII/H $\beta$ (panel izquierdo) propuesto por BWS96, y según el eje tradicional [OIII] $\lambda 5007 / \mathrm{H} \beta$ (panel derecho). Modelos y observaciones se representan del mismo modo que en la Fig. 6.4.

entre la densidad y la distancia a la fuente de radiación. El análisis de la IOC continúa con los modelos de densidad intermedia $\left(10^{2} \mathrm{~cm}^{-3}\right)$.

En este punto del análisis cabe mencionar que los trabajos anteriormente citados concluyeron, aunque de manera no definitiva, que el mecanismo de ionización dominante en las regiones circumnucleares de 3C 268.3 y 3C 303.1 podría ser la FMF (Labiano et al. 2005; Holt et al. 2009). Asimismo, tanto en estos trabajos como en el presente análisis se comprueba la presencia de outflows en la misma zona (Holt et al. 2008). Naturalmente, suponiendo la validez del modelo de FMF, no es posible explicar la cinemática observada como parte del mismo fenómeno. A continuación se exploran algunos aspectos particulares de estos modelos en virtud del comportamiento de las observaciones en el gas extendido.

\section{El comportamiento del $[\mathrm{Nev}]$}

La fortaleza de los modelos de FMF radica en su capacidad para reproducir la intensidad de líneas de excitación y/o ionización alta. Los modelos $\mathrm{H}, \mathrm{M}$ y L, en particular, fueron concebidos con la intención de reproducir líneas coronales, como el [Fevir] $\lambda 6086$ (Binette et al. 1997). Para poder reproducir estas líneas junto con otras de baja excitación es necesario considerar que el medio está compuesto por zonas con distintos valores de $U$ (BWS96; Komossa \& Schulz 1997); las zonas caracterizadas por los parámetros de ionización más altos serán las que originen la emisión de líneas tales como el [Fevir] 66086 o el [Nev] $\lambda 3424$ (Stasińska 1984). El hecho de que la línea de mayor excitación en los espectros de 3C 268.3 y 3C 303.1 sea el $[\mathrm{Nev}] \lambda 3424$ permite analizar el comportamiento de los modelos H, M y L bajo esta perspectiva; como se sabe que estos modelos lograron reproducir la intensidad del [FevII] y 
éste se origina en las mismas condiciones que el [Nev], entonces es de esperar que los modelos puedan ajustar a las observaciones que involucran a esta última.

En la Figura 6.5 se muestran los diagramas formados con el cociente de líneas del neón $[\mathrm{Nev}] \lambda 3424 /[\mathrm{NeIII}] \lambda 3869$ y los dos ejes de excitación: HeII/H $\beta$ (BWS96, panel izquierdo) y [OIII $] \lambda 5007 / \mathrm{H} \beta$ (panel derecho). Se emplean los cuatro modelos de FMF disponibles y el modelo de IOC correspondiente a la densidad de $10^{2} \mathrm{~cm}^{-3}$. El cociente $[\mathrm{NeV}] \lambda 3424 /[\mathrm{NeIII}] \lambda 3869$ es completamente insensible a variaciones en la densidad en el rango $1-10^{2} \mathrm{~cm}^{-3}$. Esto equivale a decir que la degeneración es tal que el diagrama con ambos modelos sería ilegible, por este motivo no se graficó el modelo de IOC de menor densidad. Inmediatamente puede comprobarse que la FMF es capaz de reproducir la intensidad observada en el cociente de neones, mientras que éste aún representa una dificultad para la IOC con la posible y notable excepción del núcleo. Este resultado es esperable, en virtud de las características de los modelos. El ajuste se produce en la zona de valores más altos de $A_{M / I}$, esto es, en la zona dominada por las nubes MB que, a su vez, están caracterizadas por los mayores valores de $U$. En el panel derecho se observa una leve tendencia en favor de los modelos T y H: los modelos cuya fase MB es la de mayor parámetro de ionización (explícitamente predeterminado; ver Tabla 2.1).

Estos resultados requieren consistencia con el comportamiento del parámetro de ionización $U$, en cada objeto. En otras palabras, es necesario comprobar que $U$ adopta valores y/o tendencias de crecimiento o decrecimiento adecuados para justificar la formación de estas líneas en las zonas donde se observan. Aquí debe señalarse que el análisis de $U$ es viable porque los resultados discutidos en el párrafo anterior indican que, como la emisión está fuertemente dominada por la componente MB, entonces el modelo multifase tiende (en este límite) a un modelo de fotoionización simple compuesto por un sistema gaseoso ópticamente delgado. En la Figura 6.6 se ilustra el comportamiento de $U$ dado por el cociente de oxígenos (Ec. 2.2) en función de la distancia a la fuente central, para los dos objetos en cuestión (paneles superiores; se respeta la convención de símbolos y colores). En este caso, para analizar la evolución del parámetro, se incorporaron los datos correspondientes a la región $|r|<1$ ”. En ambos gráficos se identificó la zona donde se detecta la emisión de la línea [Nev] $\lambda 3424$ (recuadro gris). En el panel inferior se muestra su comportamiento espacial (respecto de $\mathrm{H} \beta$ ) en las zonas indicadas. Para los dos objetos, las coordenadas positivas indican la región SE y las negativas, la NO.

Hay varios aspectos para remarcar. En primer lugar, el comportamiento de $U$ no muestra ningún signo de fotoionización central: no alcanza su máximo valor en la región nuclear, ni muestra indicios de dilución geométrica. Por el contrario, se observan leves aumentos locales como parte de un patrón de decrecimiento, en 3C 268.3, o de oscilación en 3C 303.1. Los crecimientos locales del parámetro $U$ se producen: en $3 \mathrm{C} 268.3$, hacia el NO, y otro menos pronunciado en la zona 1-2" hacia el SE; en 3C 303.1 en la zona interna $(r<1$ ") de la región NO, y en la región 1-2" hacia el SE. En cuanto al comportamiento del [Nev] $\lambda 3424$ se observa que: 1) en 3C 268.3 la emisión es extremadamente extendida, siendo detectada hasta la distancia de 2.5 " ( $\sim 18.5 \mathrm{kpc})$ hacia el SE, lo que representa el $75 \%$ de la extensión del [OIII] $\lambda 5007$ en la misma región. En 3C 303.1 la extensión es menor, 1.2" ( $6.5 \mathrm{kpc})$ hacia el SE, pero aún en este caso representa un porcentaje importante $(30 \%)$ de la extensión del [OıII $\lambda 5007$. Y 2), que para los dos objetos la intensidad relativa entre $[\mathrm{Nev}] \lambda 3424$ y $\mathrm{H} \beta$, lejos de disminuir con la distancia, aumenta. Más aún (y en contra de las hipótesis de cualquier modelo de fotoionización), la intensidad del [Nev] $\lambda 3424$ aumenta en la zona donde $U$ disminuye.

Para una evaluación más profunda del comportamiento del $[\mathrm{Nev}]$, se pueden obtener los valores del parámetro de ionización en las zonas donde se produce la emisión. Estos valores representan un indicador de las condiciones de ionización allí, y resultan (en promedio): 
Figura 6.6. 3C 268.3 y 3C 303.1. Parámetros de ionización y evolución espacial del [Nev].

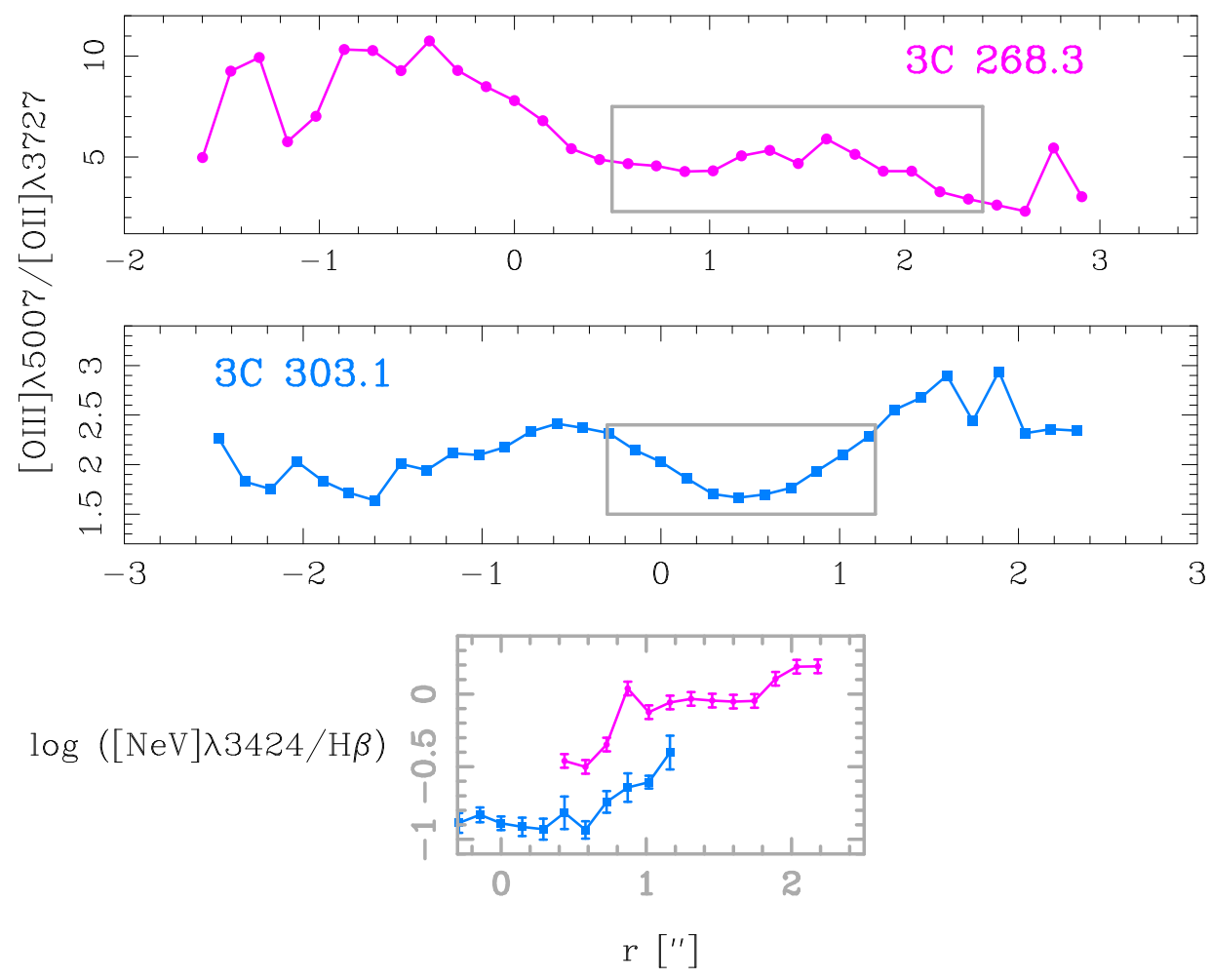

Paneles superiores: Comportamiento espacial del parámetro de ionización $U$, dado por el cociente de oxígenos (Ec. 2.2). Los recuadros (en gris) indican la región de emisión de la línea $[\mathrm{Nev}] \lambda 3424$, que se muestra en el panel inferior. Allí se indica cómo evoluciona el cociente $[\mathrm{NeV}] \lambda 3424 / \mathrm{H} \beta$, también en función de la distancia a la fuente de radiación. Por completitud, en los tres gráficos se incorporaron los datos correspondientes a $|r|<1$ " para ambos objetos. Tanto para 3C 268.3 como para 3C 303.1 las coordenadas negativas representan la región NO y las positivas, la SE. 
$\left\langle U_{3 C 268.3}\right\rangle=7 \times 10^{-3}$ y $\left\langle U_{3 C 303.1}\right\rangle=4.2 \times 10^{-3}$. Los parámetros de ionización necesarios para reproducir el $[\mathrm{Nev}]$ en los modelos $\mathrm{T}$ y $\mathrm{H}$ son entre uno y dos órdenes de magnitud mayores que estos promedios; y, aunque los modelos no incluyan explícitamente la distancia a la fuente central, esos valores de $U$ corresponden a las regiones más internas de la nebulosa (ver Sección 2.4.2 y Fig. 2.4; BWS96, Binette et al. 1997). Luego, el problema tiene dos partes. Por un lado, se observan valores de $U$ demasiado bajos; y por el otro, en virtud de que los modelos requieren que $U$ disminuya conforme aumenta la distancia ${ }^{14}$, tampoco es posible explicar por qué la emisión de [Nev] se extiende hasta las distancias observadas.

El tema de la extensión de la emisión se aborda en el trabajo de Komossa \& Schulz (1997), donde también se estudiaron modelos multifase. Allí se estudian detalladamente las condiciones de ionización bajo las cuales se producen las líneas de alta excitación, y las conclusiones son cualitativamente idénticas a las de BWS96 y Binette et al. (1997). Sin embargo, los resultados del análisis explícito sobre las distancias hasta las cuales es posible encontrar la emisión de ciertas líneas (junto con las intensidades esperadas en función, también, de la densidad) indica que no es posible encontrar emisión de [Nev] $\lambda 3424$ para distancias mayores a $\sim 330$ pc. Como se indicó en párrafos anteriores, y según las escalas expresadas en la Tabla 3.4, la emisión del $[\mathrm{Nev}]$ se observa hasta $6.5 \times 10^{3}$ pc en $3 \mathrm{C} 303.1$ y $1.9 \times 10^{4}$ pc en 3C 268.3.

\section{El rol de las ondas de choque}

Luego del análisis de la región circumnuclear en ambas fuentes, Holt et al. (2009) determinaron que no se pueden obtener resultados concluyentes acerca de si existe o no interacción jet-nube cuyos efectos repercutan en el estado de ionización del gas. Tanto en ese trabajo como en de Vries et al. (1999) y Labiano et al. (2005) también se sugiere que el mecanismo por el cual se produce la emisión de líneas podría ser una combinación de procesos de choque y de fotoionización del AGN. En esta Sección se explora qué influencia pueden tener los procesos de choque y cómo se relacionarían, si fuera el caso, con la FMF.

El comportamiento de los parámetros de ionización deja abierto el interrogante de cómo es posible obtener líneas de tan alta excitación con valores de $U$ tan bajos y en regiones tan distantes de la fuente de radiación. Y una posible respuesta puede hallarse en términos de la compresión que sufre el gas cuando es atravesado por una onda de choque. Cuando el gas se comprime, y a su vez alcanza temperaturas muy altas, el parámetro $U$ se reduce. Y como consecuencia de esta reducción, que tiene lugar en la zona de recombinación, aumenta la emisión proveniente de líneas de baja excitación, como por ejemplo el [OII] $\lambda 3727$ (Stasińska 2009). En la Figura 6.7 se muestran los comportamientos espaciales de los oxígenos [OII] $\lambda 3727$ y [OIII] $\lambda 5007$ (respecto de $\mathrm{H} \beta$ ) en la misma zona donde se evaluó el [Nev] (Fig. 6.6; por consistencia en las referencias, se mantuvo el recuadro gris). Tanto en 3C 268.3 como en 3C 303.1, aunque en este caso de forma menos pronunciada, se verifica el aumento de emisión en [OII] en la zona donde $U$ disminuye.

Este resultado, por importante que sea, no define el origen desencadenante de la emisión por sí solo. Y hasta podría decirse que abre más preguntas todavía, a saber: 1) aún cuando se pueda dar una explicación satisfactoria al decrecimiento de $U$ conforme aumenta la emisión del [OII], esto no explica por qué el [Nev] (que no es una línea de baja excitación) es tan intenso en esa misma región; 2) si lo que ocurre en la región es producto del paso de una onda de choque, eso no implica que ésta sea autoionizante, como se viene sugiriendo a lo largo de este análisis (y el de los trabajos ya citados); es más, la zona donde el gas se comprime,

\footnotetext{
${ }^{14}$ Este requisito es necesario para poder reproducir simultáneamente las líneas de alta y baja excitación (BWS96, Binette et al. 1997; Komossa \& Schulz 1997).
} 
Figura 6.7. 3C 268.3 y 3C 303.1. Evolución espacial de los oxígenos.
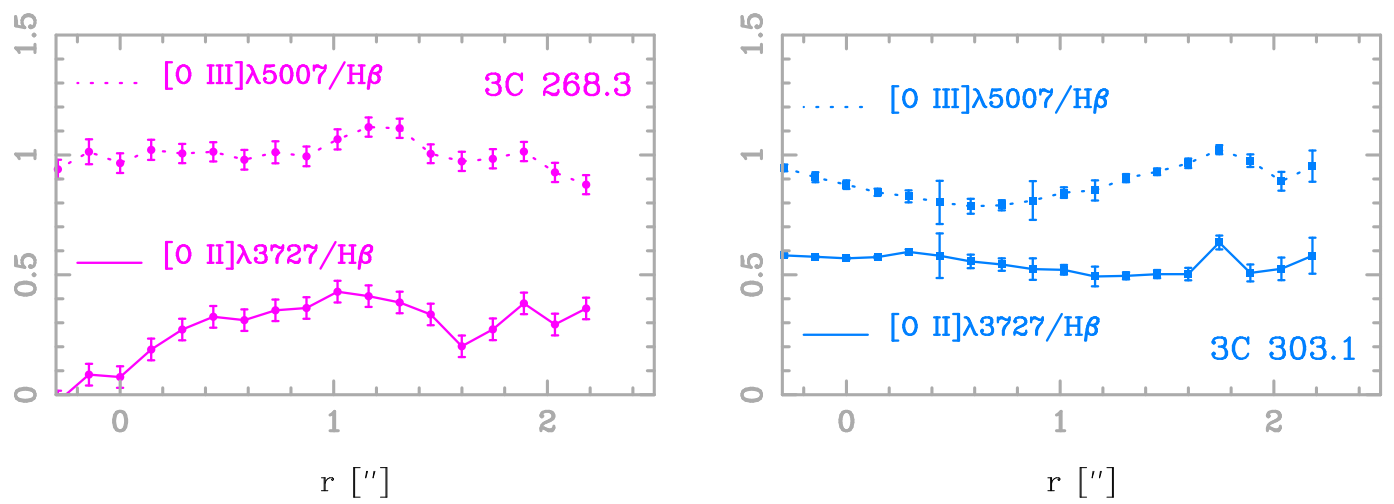

[OІІІ] $\lambda 5007 / \mathrm{H} \beta$ у $[\mathrm{OII}] \lambda 3727 / \mathrm{H} \beta$ versus $r$, la distancia a la fuente de radiación central. Se utiliza el mismo rango de distancias empleado en la evaluación del $[\mathrm{NeV}]$, y por consistencia en las referencias, se mantuvo el recuadro gris de la Fig. 6.6.

$U$ disminuye y [OII] aumenta pertenece a la región de recombinación, por lo tanto esto ocurrirá ya sea que la onda genere o no un campo ionizante local.

Pues bien, la intensidad de todos los cocientes estudiados indica que si, efectivamente, existen procesos de choque con influencia sobre el estado de ionización de la región, esos shocks deben ser autoionizantes. Los shocks puros producirían intensidades fuera del rango de las observaciones, por lo tanto la contribución del precursor radiativo a la emisión global no es despreciable. Los fotones altamente energéticos del campo ionizante local viajan tanto en la dirección de avance de la onda (generando el precursor) como en dirección contraria, es decir, hacia la zona de recombinación (DS95, DS96, A08). Los efectos sobre el gas chocado son muy importantes: por ejemplo, favorecen la formación de líneas de alta excitación en el UV (A08, Stasińska 2009), lo cual explicaría (aunque fuera en parte) el aumento de emisión detectado en el $[\mathrm{Nev}]$. E incluso, por el mismo efecto también aumenta la intensidad del cociente $[\mathrm{OIII}] \lambda 4363 /[\mathrm{OIII}] \lambda 5007$ (Stasińska 2009). La contribución más importante a la emisión de la línea $[\mathrm{OIII}] \lambda 4363$ proviene de la región de recombinación, y la contribución más importante en $[\mathrm{OIII}] \lambda 5007$ proviene del precursor. Por esta razón a medida que el precursor pasa a dominar el espectro emergente el efecto neto es el de disminuir la intensidad del cociente $[\mathrm{OIII}] \lambda 4363 /[\mathrm{OIII}] \lambda 5007$. Los valores más altos se obtienen para los modelos de IOC no-autoionizantes o para aquellos modelos autoionizantes donde la velocidad de propagación de la onda es baja. Este resultado marca una diferencia muy importante entre los modelos de fotoionización y de IOC: la fotoionización prevee que la temperatura electrónica disminuye conforme disminuye la intensidad del [OIII] $\lambda 5007$; los modelos de IOC muestran que se pueden medir temperaturas muy altas aún en estas circunstancias, porque en este escenario el [OıII $] \lambda 4363$ es quien desempeña el rol más importante (DS95; DS96; A08; Binette et al. 2012).

Es claro, a partir de la información provista en los diagramas anteriores, que este escenario no puede explicar completamente la emisión del [Nev] (la IOC predice valores menores a los observados). Sin embargo debe resaltarse que las condiciones en las que se encuentra el gas en la zona de recombinación favorece la acción de campos de radiación externos, sean o no generados por el shock, en cuanto a su poder fotoionizante (Shapiro et al. 1992; Robinson et al. 2002). Y si, además, en la zona existe un campo magnético no despreciable, los efectos de ese o esos campos será aún mayor (Shapiro et al. 1992; A08). 
En la Figura 6.8 se evalúan nuevamente los modelos de IOC para otros cocientes de importancia, [ÖII] $\lambda 4363 /[\mathrm{OIII}] \lambda 5007, \mathrm{HeII} / \mathrm{H} \beta$, [ÖII $] \lambda 5007 / \mathrm{H} \beta$ y [ÖI $] \lambda 3727 /[\mathrm{OIII}] \lambda 5007$. También se estudia la FMF. A estos diagramas se les debe agregar la información contenida en la Fig. 6.5 y en el panel izquierdo de la Fig. 6.4, que describen el comportamiento de los neones. Los diagramas A y $\mathbf{B}$ cobran importancia (aún con los reparos necesarios porque intrínsecamente se relacionan con una problemática más compleja) en tanto arrojan resultados consistentes con el escenario planteado en el párrafo anterior, donde se sugiere que la emisión en ambos objetos se produce predominantemente en la región de recombinación. Curiosamente, la región nuclear en 3C 268.3 queda apartada de todo tipo de predicciones (sea IOC o FMF), algo que no sucede en ningún otro diagrama, es decir, para ningún otro cociente de líneas.

El comportamiento de los neones ([NeIII $] \lambda 3869$ y $[\mathrm{NeV}] \lambda 3424)$ según la FMF ya fue discutido; en cuanto a la IOC, se observa que los modelos $\left(n_{e}=10^{2} \mathrm{~cm}^{-3}\right.$, líneas punteadas en negro en todos los diagramas) pueden reproducir las observaciones que involucran al [NeIII] $\lambda 3869$ (panel izquierdo de la Fig. 6.4) pero no las que involucran al [Nev] $\lambda 3424$ (Fig. 6.5). Como se mencionó anteriormente, esto puede explicarse en función de que el parámetro de ionización en la zona de formación de esta última línea debe ser alto (como el que se propone en condiciones de FMF, modelos T y H). En cambio, el [NeIII] $\lambda 3869$ se forma en condiciones similares al [OIII] o HeII ${ }^{15}$. En la Fig. 6.4 (diagrama izquierdo), que combina líneas de baja y mediana excitación, se observa un buen ajuste de los modelos de IOC $\left(n_{e}=10^{2} \mathrm{~cm}^{-3}\right)$.

En los paneles $\mathbf{C}$ y $\mathbf{D}$ se combinan nuevamente líneas de moderada a alta excitación, como el HeII, con líneas de baja excitación, como el [OII] $\lambda 3727$ y H $\beta$. El diagrama $\mathbf{C}$ confirma que las líneas de mayor excitación, que requieren de un parámetro de ionización alto para su formación (HeII, y antes el $[\mathrm{Nev}]$ ) indican la presencia (y/o remarcan el efecto) de un campo ionizante intenso, y que ese campo no puede estar conformado únicamente por los fotones creados por el shock. El modelo $\mathrm{H}$ de FMF reproduce las observaciones tanto como las ondas de choque autoionizantes más violentas $\left(500<v_{s}<1000 \mathrm{~km} \mathrm{~s}^{-1}\right)$. En el diagrama D se produce una completa degeneración no sólo entre los modelos de FMF (que también se produce en el diagrama [NeIII] $\lambda 3869 /[\mathrm{OII}] \lambda 3727$ versus $[\mathrm{OIII}] \lambda 5007 / \mathrm{H} \beta$ ) sino también con la IOC. De este gráfico sólo puede reafirmarse que los shocks puros no pueden reproducir las observaciones ${ }^{16}$. En el caso de 3C 268.3, las predicciones de todos los modelos (IOC y FMF) son mayores que las observaciones en los que respecta al cociente [OII] $\lambda 3727 /[\mathrm{OIII}] \lambda 5007$. Sin embargo debe señalarse que este cociente de algún modo es el parámetro de ionización $U$ (Penston et al. 1990), cuyo comportamiento y sus posibles razones ya fueron discutidos. En términos generales, el diagrama $\mathbf{D}$ indica que tanto la FMF como la IOC pueden reproducir la intensidad de las líneas de mediana ${ }^{17}$-baja excitación.

\subsubsection{Resumen}

Se estudiaron las condiciones cinemáticas y el estado de ionización del gas extendido $(|r|>1$ ") en las radiofuentes compactas tipo CSS, 3C 268.3 y 3C 303.1. Este estudio se complementa con un análisis similar del gas circumnuclear $(|r| \lesssim 1 ")$ realizado por de Vries et al. (1999); Labiano et al. (2005) y Holt et al. (2008, 2009).

El primer resultado directo del análisis espectral consiste en una corrección del corrimiento

\footnotetext{
${ }^{15} \mathrm{El}$ potencial de ionización (PI) del [NeIII] $\lambda 3869$ es $40 \mathrm{eV}$ aproximadamente, mientras que los PI del [OIII] y HeII son $35.5 \mathrm{eV}$ y $54 \mathrm{eV}$, respectivamente (Peterson 1997).

${ }^{16}$ Ver diagrama A de la Fig. 6.19.

${ }^{17}$ La línea [OIII] $\lambda 5007$ es una línea de excitación alta, igual que el HeII (DS95, DS96, BWS96, A08); pero como en este caso la línea de mayor excitación es el $[\mathrm{NeV}] \lambda 3424$ se las llama de excitación media para marcar la diferencia.
} 
Figura 6.8. 3C 268.3 y 3C 303.1. Evaluación de modelos de IOC y FMF.
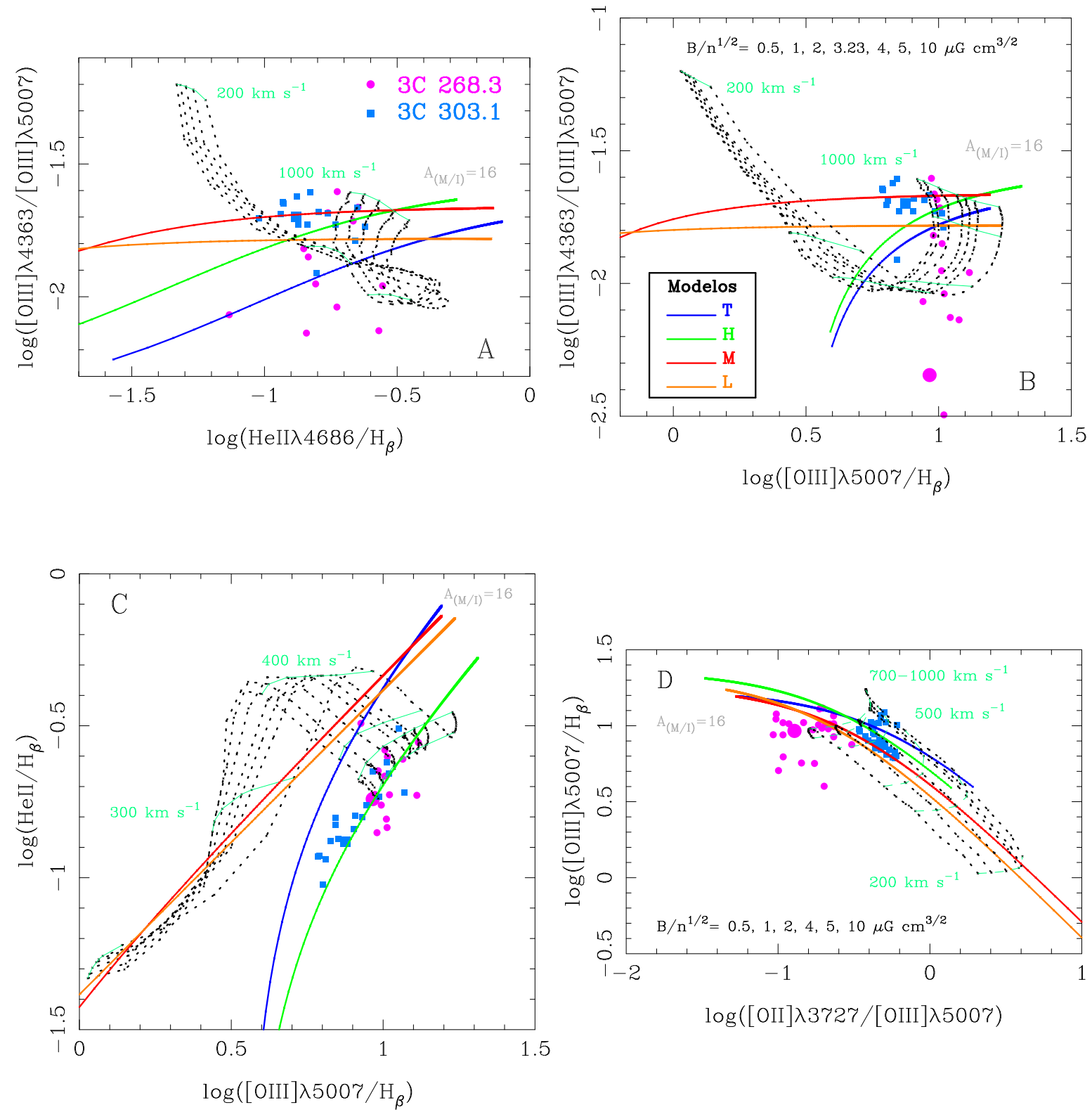

Modelos de IOC correspondientes a la densidad ambiental preshock de $n_{e}=10^{2} \mathrm{~cm}^{-3}$ (líneas punteadas, negro). En todos los casos el rango de velocidades adoptado es $200-1000 \mathrm{~km} \mathrm{~s}^{-1}$, pero en la mayoría de los casos sólo se muestran los valores extremos para salvaguardar la claridad de los gráficos. Paneles A y B muestran las predicciones sobre el cociente de oxígenos [OIII] $\lambda 4363 /[\mathrm{O}$ III $] \lambda 5007$ en función de los dos ejes de excitación propuestos HeII/H $\beta$ (BWS96) y [OIII] $\lambda 5007 / \mathrm{H} \beta$. En los diagramas C y D se evalúan los propios ejes de excitación, junto con [OII] $\lambda 3727 /[$ OIII $] \lambda 5007$. 
al rojo de la galaxia 3C 303.1. El valor actualmente aceptado $z=0.2704$ (Holt et al. 2008, y NED) no se corresponde con el redshift observado. El nuevo valor $z^{\prime}$ y su error se obtuvieron del modo descripto en la Sección 5.5, resultando:

$$
z^{\prime}=0.26862 \pm 3 \times 10^{-5}
$$

La cinemática de las regiones se estudió mediante la descomposición Gaussiana de los perfiles de emisión del [OIII] $\lambda 5007$. Se encuentran movimientos de perturbación en las zonas internas de ambos objetos, que indican la presencia de eyecciones de material a velocidades altas (outflows); los resultados concuerdan con la información disponible en la literatura. El comportamiento del gas extendido es diferente en cada objeto: en 3C 268.3 se observan movimientos estables para $|r|>1$ ", pero en 3C 303.1 subsisten movimientos turbulentos hasta $|r| \lesssim 2$ " aunque el campo de velocidades también muestra componentes de velocidad estable.

El análisis del estado de ionización indica, en primera instancia, que las observaciones de la línea de mayor excitación del espectro ([Nev] $\lambda 3424)$ muestran una tendencia en favor del mecanismo de FMF en la zona dominada por las nubes MB. La zona "MB-dominante" se caracteriza por los valores altos de $U$, necesarios para predecir valores altos en la intensidad de líneas de excitación alta (comportamiento teórico). Sin embargo, la evaluación del parámetro de ionización a partir del cociente de líneas [OII] $\lambda 3727 /[\mathrm{OIII}] \lambda 5007$ indica que $U$ toma valores demasiado bajos (comportamiento observacional). Según los modelos de fotoionización, estos valores son incompatibles con la intensidad observada del [Nev]. La evolución espacial del parámetro $U$ tampoco muestra indicios claros de fotoionización central; en términos generales se observa que $U$ decrece en la zona de mayor emisión de los espectros (región $\mathrm{SE}$, en ambos), o muestra comportamientos oscilantes, con leves aumentos locales.

Tanto por el comportamiento no convencional del parámetro $U$, como por las sugerencias y/o interrogantes planteados en los trabajos previos sobre estas fuentes, se evaluaron los modelos de IOC. En un escenario donde el gas experimenta procesos violentos de choque, este mecanismo es capaz de explicar la disminución de $U$ en términos de la compresión que sufre el gas en la zona de recombinación y el consecuente aumento de emisión en las líneas de baja excitación, como el [OII] $\lambda 3727$. Consecuentemente, se estudió el comportamiento espacial de esta línea (junto con el [OIII] $\lambda 5007$ a modo de comparación) y se comprobó que efectivamente aumenta la emisión del [OII] en la zona donde $U$ decrece.

Este resultado implica que existe una contribución muy importante de la zona de recombinación a la emisión global. Bajo esta hipótesis, y teniendo en cuenta que el shock genera un campo ionizante local, se espera que esos fotones contribuyan a la emisión de líneas de excitación alta, como el $[\mathrm{Nev}]$. Aún en estas circunstancias el mecanismo de IOC no logra reproducir las observaciones que involucran esta línea. Sin embargo, las condiciones en que queda el gas una vez que es atravesado por ondas de choque favorecen notablemente el efecto fotoionizante que pudiera ejercer cualquier campo de radiación, en particular el campo central, más aún si existe un campo magnético en el medio.

Se evaluó el comportamiento de la IOC en otros cocientes, como [ÖII] $\lambda 4363 /[\mathrm{OIII}] \lambda 5007$ y HeII/H $\beta$. Los modelos predicen que la emisión de [ÖII] $\lambda 4363 /[\mathrm{OIII}] \lambda 5007$ aumenta en la zona de recombinación, resultado que se comprueba a través de los diagramas de diagnóstico con los dos ejes de excitación propuestos. El cociente $\mathrm{HeII} / \mathrm{H} \beta$ muestra una notable tendencia hacia los modelos de FMF de mayor parámetro de ionización (del mismo modo que el [Nev]) y también hacia los modelos de IOC en la zona de choques de mayor velocidad $(700<$ $v_{s}<1000 \mathrm{~km} \mathrm{~s}^{-1}$ ). HeII y $[\mathrm{Nev}]$ son dos líneas que requieren que la zona donde se forman estén caracterizadas por valores de $U$ altos, por lo tanto no es sorprendente que las dos muestren una tendencia en favor de los modelos de FMF (modelo $\mathrm{H}$, en particular). Sin 
embargo, dado que $U$ definitivamente no adopta valores suficientemente altos, ni se observan movimientos de tan alta velocidad en los campos de velocidades, hay una única manera de explicar simultáneamente resultados aparentemente tan dispares.

Se concluye que las regiones de gas extendido en 3C 268.3 y 3C 303.1 han sufrido o están sufriendo procesos violentos producto de la interacción entre los jets y el MIE, cuyos outflows se pueden identificar en las regiones más internas de ambos objetos. Estos procesos generan ondas de choque que, de acuerdo a las observaciones, deben ser autoionizantes. Los efectos producidos se observan en el espectro de emisión del gas extendido $(|r|>1$ "), que presenta una contribución importante proveniente de la zona de recombinación (detrás del frente de choque). La compresión del material y la presencia del campo magnético en la región generan condiciones favorables para que el efecto fotoionizante del campo de radiación central se vea notablemente favorecido; de esta manera se pueden explicar las intensidades observadas en (y las distancias hasta las cuales es posible encontrar) líneas de alta excitación como HeII y [Nev]. 3C 268.3 y 3C 303.1 son dos objetos donde se puede comprobar que el estado de ionización del gas responde al efecto conjunto del campo central y de la interacción entre la radiofuente y el medio circundante.

\section{3. $3 \mathrm{C} 285$.}

3C 285 está compuesta por un sistema nebular complejo, alineado con la estructura observada en radiofrecuencias. En las imágenes de línea, $\mathrm{H} \alpha+[\mathrm{NII}]$ y [OIII], obtenidas con la cámara ACS/HST (Baldi \& Capetti 2008; Tremblay et al. 2009) se observa que el gas adquiere distintas distribuciones: la imagen de $\mathrm{H} \alpha$ muestra mayor concentración en la región nuclear, mientras que según el [OIII] el gas se extiende predominantemente en dirección oeste-sudoeste $(\mathrm{O}[\mathrm{SO}])$. Incluso la discrepancia es tal que la estructura de mayor brillo superficial en [OIII] no se encuentra en la zona central, como indicaría la distribución del material en $\mathrm{H} \alpha$, sino a la distancia promedio de $\langle r\rangle=-2.8$ " (según la convención adoptada en la Sección 5.4, la región $\mathrm{O}[\mathrm{SO}]$ se expresa con coordenadas negativas). El espectro GMOS/Gemini permitió identificar otra nebulosa en dirección este-noreste $(\mathrm{E}[\mathrm{NE}])$ de menor brillo superficial, cuya extensión alcanza hasta 6.3 " en la dirección de la ranura $\left(\mathrm{PA}=80^{\circ}\right)$, prácticamente desapercibida en las imágenes de línea (como se explicará luego, la parte externa de esta nebulosa está fuera del rango de distancia cubierto en las imágenes).

En un estudio del medio de gran escala que rodea a 3C 285, Tyson, Crane \& Saslaw (1977) encontraron emisión del continuo óptico-azul, localizada en zonas cercanas al hot spot y/o en el camino del jet. La más importante de esas regiones fue denominada como 3C 285/09.6 y se encuentra aproximadamene a 40" del centro de la galaxia. Baum et al. (1988) identificaron emisión de líneas proveniente de este objeto y comprobaron que no se trata de un objeto de campo (como supusieron en un principio Tyson et al. 1977) sino una región en emisión perteneciente a 3C 285. Años más tarde, van Breugel \& Dey (1993) estudiaron la emisión continua de 3C 285/09.6 y concluyeron que se trata de una región de formación estelar activada por el paso del jet.

El objeto 3C 285/09.6 (Tyson et al. 1977) pertenece a una escala de distancia mucho mayor que las nebulosas detectadas por el espectro GMOS, pero su presencia y características son una muestra de la complejidad del sistema, particularmente hacia el este. Por su parte, el espectro long-slit permite identificar tres zonas de emisión focalizada, ninguna de las cuales coincide con la región nuclear. Estas zonas se indican esquemáticamente en la Figura 6.9, a partir de la imagen nebular del [OIII] perteneciente a Tremblay et al. (2009, la flecha en el margen superior derecho indica la dirección del radio-eje). Se superpusieron un esquema de la ranura utilizada (1.5" de ancho, $\mathrm{PA}=80^{\circ}$, color amarillo), y la posición del centro de la 
Figura 6.9. 3C 285. Mapa de emisión nebular -

Identificación de las regiones en emisión.

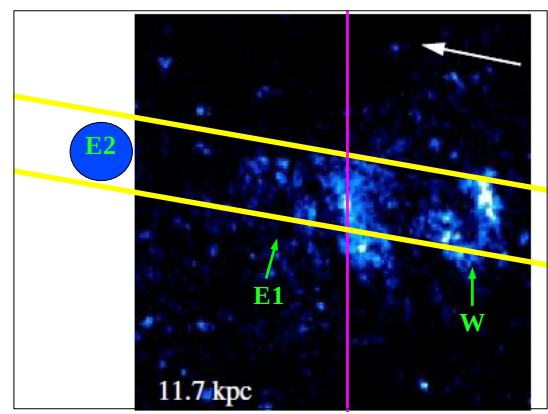

Mapa de la emisión de [OIII] en 3C 285 tomado de Tremblay et al. (2009). La flecha indica la dirección de los jets. Se indican la posición y ancho de la ranura con que se tomó el espectro GMOS (amarillo) y las tres (3) regiones de emisión focalizada. La región $\mathrm{O}[\mathrm{SO}]$ se designó como W y las dos regiones al E[NE], como E1 (región interna) y E2 (la región más alejada). La línea magenta (norte-sur) cruza la posición del centro de la galaxia.

galaxia (línea vertical, color magenta), estimada según las imágenes escaleadas de Tremblay et al. (2009) y Baldi \& Capetti (2008). Las regiones se denominarán como:

- W: es la nebulosa ubicada en dirección $\mathrm{O}[\mathrm{SO}]$; se encuentra a una distancia media de $\left\langle r_{W}\right\rangle=-2.8$ ". En la imagen se aprecian dos zonas diferentes (a partir de esa distribución Tremblay et al. asemejaron la distribución del gas con una "W" incompleta) pero en el espectro no se puede individualizar la emisión de cada una.

- E1: zona de bajo brillo superficial en la región E[NE] localizada a la distancia media de $\left\langle r_{E 1}\right\rangle=2$ ". La intensidad de la emisión es menor que en W, pero aún así se observan varias especies en emisión.

- E2: es la zona más alejada dentro de la región E[NE] (dentro del alcance de la ranura), se encuentra a la distancia media de $\left\langle r_{E 2}\right\rangle=4.8$ ". Su posición, respecto al centro de la galaxia y en la dirección de la ranura o $\mathrm{PA}_{j e t}$, se indica de modo esquemático en la Fig. 6.9, justo por fuera del rango de distancia cubierto en la imagen. En esta zona sólo se detectan las líneas [OІі] $\lambda 3727, \mathrm{H} \beta$ у [OІІІ $] \lambda \lambda 4959,5007$.

Las regiones E1 y E2 se aprecian con mayor claridad en el espectro bi-dimensional de la Fig. 4.4, allí también se manifiestan las distintas intensidades a través de la escala de grises y los contornos.

\subsubsection{Mecanismo de ionización}

La información de 3C 285 proveniente de rayos-X, óptico y UV es compleja para analizar en conjunto. Hasta cierto punto es, incluso, confusa respecto de la influencia del núcleo activo o de los jets, y de ambos frente a un escenario de formación estelar. Si bien el objeto fue considerado como una galaxia de excitación alta en base a su espectro óptico nuclear (Buttiglione et al. 2009, 2010), cuando se reúnen los análisis disponibles en las tres bandas se advierte que los procesos de formación estelar podrían ser suficientemente importantes como para dominar el estado de las nebulosas.

A continuación se discutirá brevemente la información proveniente de estas tres bandas del espectro para evaluar, en primera instancia, cuál es el nivel de influencia que podrían tener los procesos de formación estelar; luego se estudian los posibles mecanismos de ionización en las regiones nebulares. 


\section{El mecanismo de excitación.}

3C 285 presenta emisión extendida en el UV (Allen et al. 2002) y en el óptico (Tremblay et al. 2009), pero en rayos-X blandos no es posible resolverla ${ }^{18}$ (Balmaverde et al. 2012). En UV y el óptico las nebulosas tienen grandes semejanzas con las de 3C 305 y 3C 321, ya sea por la disposición desordenada del gas como por la forma en que éste se alinea con el/los jets.

La emisión UV, básicamente el continuo, indica que se trata de un medio grumoso (clumpy) y extendido, incluso la escala de la emisión es comparable con la extensión del complejo nebular de 3C 321 (Allen et al. 2002; Baldi \& Capetti 2008). Según el análisis de Baldi \& Capetti (2008), la emisión UV de gran escala no está relacionada con ningún proceso asociado al núcleo activo, sino que muy probablemente proviene de una población estelar joven. El brote de formación estelar (starburst) se habría originado como consecuencia de una importante colisión (merger) que, a su vez, también explicaría las peculiaridades de la morfología de las estructuras óptico-UV.

En cuanto a la emisión extendida en rayos-X blandos, el escenario es más complejo. En 3C 285 no es posible resolver la emisión x extendida, pero la galaxia comparte prácticamente todas las otras características de las demás fuentes 3CR donde sí es posible detectar y resolver, total o parcialmente, este tipo de emisión ${ }^{19}$ (Balmaverde et al. 2012), a tal punto que el objeto se considera perteneciente a ese grupo. Los autores señalan que sin embargo, quien mejor predice las propiedades de la emisión x blanda es el gas óptico (ionizado) a través de su morfología, y de la intensidad de las líneas del espectro.. Las conclusiones para el grupo, entonces, indican que el campo de radiación del núcleo activo controla el estado de las regiones extendidas en rayos-X blandos y el gas óptico a través del proceso de fotoionización (Balmaverde et al. 2012).

Sobre la emisión extendida en el óptico se deben diferenciar la emisión de gran escala (la escala de la radio fuente), concentrada en la zona de influencia del hot spot en el lóbulo Este; y la emisión de la EELR propiamente dicha. La región que rodea al hot spot ha sido estudiada en detalle, concentrándose en la emisión del continuo (van Breugel \& Dey 1993, y sus referencias). En la zona de interés dentro de esa región (3C 285/09.6) se observaron indicios de formación estelar. Sin embargo en este caso, el desencadenante del starburst habría sido el paso del jet. La emisión de la EELR, por su parte, se analizó únicamente según las líneas de baja ionización [OI] $\lambda 6300, \mathrm{H} \alpha$, [NII] $\lambda 5583$ y [Sir] $\lambda \lambda 6717,6730$ (Baum et al. 1990, 1992). Estos estudios indican que el gas muy probablemente esté fotoionizado por el campo de radiación nuclear, pero no se descartan contribuciones menores de procesos locales asociados con ondas de choque (Baum et al. 1992).

Evidentemente el panorama multifrecuencia presenta situaciones contradictorias. Los datos del UV indican que esa emisión proviene una zona muy extendida que contiene a la EELR (ver fig. 6 de Baldi \& Capetti 2008), y que se debe a brotes de formación estelar. Si los procesos de formación estelar dominaran el estado de excitación de la EELR, correspondería realizar un análisis que escapa de los lineamientos propuestos para este trabajo de Tesis. Luego, dada la importancia que podrían tener estos procesos, se hace necesario verificar si la fuente de energía dominante en la EELR proviene o no de starbursts.

\footnotetext{
${ }^{18}$ Desde la perspectiva adoptada en el trabajo de Balmaverde et al. (2012), que no sea posible resolver la emisión en rayos-X blandos no significa que no exista. Allí se diferencian claramente las fuentes donde no hay emisión extendida de aquellas donde no es posible resolverla.

${ }^{19}$ Esas características incluyen: la ausencia de un núcleo muy brillante, la presencia de una región extendida de gas ionizado (en el óptico) y que la galaxia se clasificó como un objeto de excitación alta en función de su espectro nuclear (HEG, High Excitation Galaxy; Buttiglione et al. 2009). La única característica que no cumple está relacionada con el tiempo de exposición de la imagen obtenida con Chandra: en la gran mayoría de los objetos observados durante más de $10^{4}$ segundos fue posible resolver, total o parcialmente, la emisión extendida en rayos-X blandos. 3C 285 fue observada durante $4 \times 10^{4}$ segundos (Balmaverde et al. 2012).
} 
Los diagramas de diagóstico propuestos por Baldwin et al. (1981) constituyen una de las herramientas más potentes y útiles para tal fin. Estos diagramas combinan cocientes de líneas de distinto grado de excitación e ionización del espectro óptico. Y en particular el diagrama formado por [NII] $\lambda 6583 / \mathrm{H} \alpha$ vs. [OIII] $\lambda 5007 / \mathrm{H} \beta$ se convirtió en el diagrama de excitación que permite distinguir si la fuente de energía dominante en un dado sistema gaseoso se corresponde con brotes de formación estelar o con el núcleo activo. Luego de muchos avances en la investigación de sistemas nebulares, Kewley et al. (2006) propusieron que la distinción entre los dos escenarios debe hacerse con tres diagramas simultáneamente: el ya citado [NII] $/ \mathrm{H} \alpha$ vs $[\mathrm{OIII}] / \mathrm{H} \beta$, junto con $[\mathrm{SII}] \lambda \lambda 6717,6730 / \mathrm{H} \alpha$ vs $[\mathrm{OIII}] / \mathrm{H} \beta$ y $[\mathrm{OI}] \lambda 6300 / \mathrm{H} \alpha$ vs $[\mathrm{OIII}] / \mathrm{H} \beta$. La Figura 6.10 muestra la relación entre los cocientes mencionados y los mecanismos de excitación. Las tres nebulosas se representan en forma independiente: W con círculos azules, E1 con cuadrados magenta, y E2 con triángulos verdes. En la región E1 no se detectaron las líneas del doblete del [Sir], por lo tanto no hay puntos representativos de esta zona en el diagrama del panel medio. En los tres diagramas (Figura 6.10) existen zonas bien delimitadas donde dominan uno u otro mecanismo. Las líneas en color celeste representan el límite inferior hasta el cual es posible que la combinación de líneas involucrada manifieste que la energía ionizante proviene del núcleo activo (Kewley et al. 2001). A su vez, representa el límite superior hasta el cual es posible que la fuente de energía sean los procesos de formación estelar en los diagramas $[\mathrm{SII}] / \mathrm{H} \alpha$ vs $[\mathrm{OIII}] / \mathrm{H} \beta$ (panel medio) y $[\mathrm{OI}] / \mathrm{H} \alpha$ vs $[\mathrm{OIII}] / \mathrm{H} \beta$ (panel derecho). En el caso del diagrama $[\mathrm{NII}] / \mathrm{H} \alpha$ vs. $[\mathrm{OIII}] / \mathrm{H} \beta$ (panel derecho) ese límite está impuesto por la línea violeta (Kauffmann et al. 2003), por lo cual allí existe una región de transición, donde la energía proviene (indistinguiblemente) de la combinación de los dos procesos. Las relaciones observadas en los tres diagramas exceden ampliamente las relaciones esperadas en el marco de procesos de formación estelar dominante.

Lamentablemente, no hay espectros disponibles de 3C 285 cuyo rango espectral cubra desde $\mathrm{H} \beta$ hasta [SII]. Sin embargo, la información de las líneas de baja ionización [OI], H $\alpha$, [NII] y [SII] está disponible como parte del estudio de Baum et al. (1990); y el espectro GMOS de 3 C 285, tomado especialmente para este trabajo, incluye la información de [OIII] y $\mathrm{H} \beta$. La combinación de la información no es trivial, dado que existe una diferencia de $15^{\circ}$ en los ángulos de posición con los que fueron tomados los dos espectos. Pero si se considera que:

- en ambos espectros la ranura atraviesa el núcleo de la galaxia, que se adopta como origen de distancias;

- los dos espectros long-slit cubren distancias radiales similares (Tabla 3.4 y Baum et al. 1990);

- la emisión en $\mathrm{H} \alpha$ tiene aproximadamente la misma escala que la emisión en [OIII] (Baldi \& Capetti 2008; Tremblay et al. 2009); y

- tanto con $\mathrm{PA}=95^{\circ}$ (Baum et al. 1990) como con $\mathrm{PA}=80^{\circ}$ (este trabajo) se cubren las mismas regiones nebulares,

entonces se puede trabajar bajo la hipótesis de que toda la información espectral disponible proviene de los mismos sistemas gaseosos, a uno y otro lado del núcleo de la galaxia. Con estas consideraciones, las distancias sobre la ranura se transforman en distancias radiales para poder combinar los datos en los tres diagramas en cuestión.

Por los reparos ya mencionados en lo que respecta a la combinación de la información, es posible realizar un análisis (de primer orden) de abscisas y ordenadas en forma "independiente". El aporte clave en favor del AGN como fuente de energía dominante proviene de la intensidad en ordenadas: sería necesario que el cociente [OIII]/H $\beta$ fuera aproximadamente un orden de magnitud menor para que el estado de las nebulosas pudiera estar dominado por brotes de formación estelar (o al menos para aceptar que su contribución pudiera no ser despreciable). 
Figura 6.10. 3C 285. Diagramas de excitación.
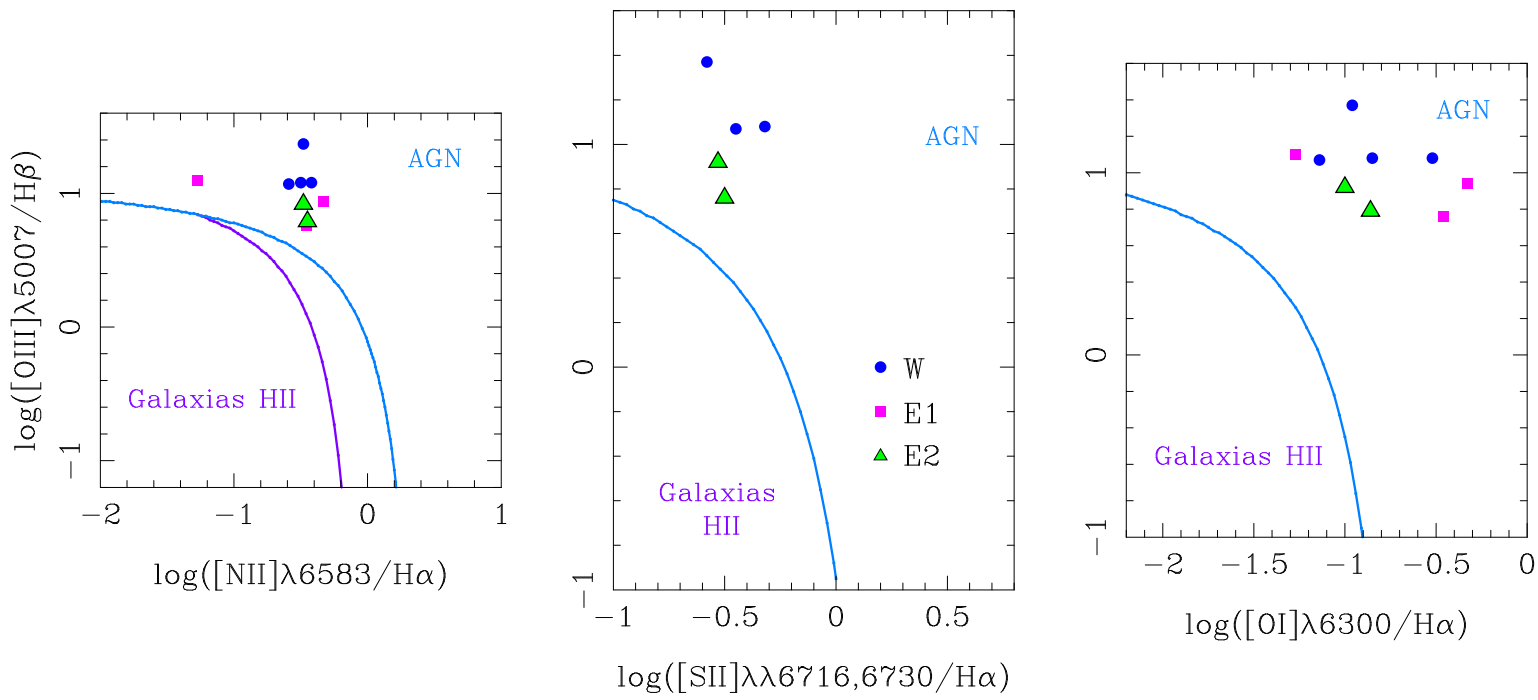

Evaluación de la fuente de energía dominante en la EELR de 3C 285 mediante los diagramas de excitación [NII] $\lambda 6583 / \mathrm{H} \alpha$ vs. [OIII] $\lambda 5007 / \mathrm{H} \beta$ (panel izquierdo), $[\mathrm{SII}] \lambda \lambda 6717,6730 / \mathrm{H} \alpha$ vs $[\mathrm{OIII}] / \mathrm{H} \beta$ (panel medio; según los datos de Baum et al. 1990, no se detecta emisión de [SII] a la distancia correspondiente a la región E1) y [OI] $\lambda 6300 / \mathrm{H} \alpha$ vs $[\mathrm{OIII}] / \mathrm{H} \beta$ (panel derecho). En los tres diagramas existen zonas bien delimitadas donde dominan uno u otro mecanismo, y en el primero de ellos (panel izquierdo), también se puede encontrar una zona de transición donde el estado del sistema gaseoso resulta de la combinación de ambos (Kewley et al. 2001; Kauffmann et al. 2003). Las tres regiones nebulares se grafican individualmente: W con círculos azules, E1 con cuadrados magenta, y E2 con triángulos verdes, con los datos combinados del espectro GMOS y de uno de los espectros de Baum et al. (1990, ver texto). 
El análisis de los valores observados en abscisas conduce directamente a las propiedades de las nebulosas y su estructura de ionización. Sin embargo, una rápida inspección sobre la ubicación de los datos en los diagramas muestra que aún si el cociente [OIII]/H $\beta$ fuera lo suficientemente bajo (un orden de magnitud, como se sugirió antes), la intensidad en [NII]/H $\alpha$ y $[\mathrm{OI}] / \mathrm{H} \alpha$ también es demasiado alta como para ser explicada en término de las predicciones de los modelos de formación estelar en la zona.

Desde la perspectiva de la estructura de ionización, se sabe que [NII], [SII] y [OI] se forman en regiones diferentes: [NII] en la zona de ionización total (convive con el hidrógeno ionizado), [OI] en la parte más interna de la zona de ionización parcial, y [SII] en la zona de transición (el "límite" entre la zona de ionización total y parcial), y que la relación entre las intensidades observadas puede tomarse como un indicador de la extensión de cada zona (Baum et al. 1992). De este modo, es posible sugerir que las zonas de ionización total y parcial son mucho más extensas que la zona de transición, lo cual también podría explicar la ausencia del [Sir] en la nebulosa E1.

\section{FMF vs. IOC}

La región nebular cuyos espectros se presentan en este trabajo de Tesis sólo ha sido estudiada a través de su emisión de baja ionización (Baum et al. 1990, 1992), pero aún así no existe información sobre los parámetros físicos del gas. En lo que respecta particularmente a la densidad ambiental, se adopta el valor estándar de $100 \mathrm{~cm}^{-3}$. Éste se utiliza para la evaluación de los modelos de IOC, con lo cual también es posible realizar una comparación consistente con los modelos de FMF.

La Figura 6.11 reúne todos los diagramas de diagóstico que es posible construir con las líneas presentes en el espectro GMOS de 3C 285. Para la identificación de las tres regiones nebulares se sigue el mismo criterio que en la discusión anterior. Como en la región central este espectro sólo permite detectar la emisión de [OII] y [OIII], no es posible posicionar el centro de la galaxia a lo largo de los diagramas (como se hizo para los demás objetos). La ausencia de alguna/s región/ones en determinado diagrama indica que alguna de las líneas involucradas no está presente allí. En el diagrama A se evalúan los dos ejes de excitación, en B se muestra el comportamiento del cociente $[\mathrm{OIII}] \lambda 4363 /[\mathrm{OIII}] \lambda 5007$ respecto de $\mathrm{HeII} / \mathrm{H} \beta$, y en los pares de diagramas C-D y E-F se analizan los cocientes [OII] $\lambda 3727 /[\mathrm{OIII}] \lambda 5007$ y [NeIII] $\lambda 3869 /[\mathrm{OII}] \lambda 3727$ respecto de los dos ejes de excitación.

En todos los casos (posibles) se observa que los cocientes de líneas tienen un comportamiento uniforme en las regiones $\mathrm{W}$ y E1, a pesar de las diferencias en las intensidades individuales de cada línea de emisión. En el diagrama A se ve que los datos de cada región son prácticamente indistinguibles unos de otros, cualquiera sea el cociente adoptado. Como cada cociente representa un eje de excitación, se puede decir que las dos regiones tienen el mismo estado de excitación. Sin embargo el diagrama B indica que alguna diferencia debe existir porque en la región E1 no se detecta emisión proveniente de la línea [OIII] $\lambda 4363$; tal diferencia podría estar relacionada con las temperaturas (distintas) de las nebulosas W y E1.

El par de diagramas C-D muestra el comportamiento del cociente [OII]/[OIII] respecto de cada eje. Como ya se ha señalado en Secciones anteriores, este cociente (su recíproco) representa al parámetro de ionización $U$ bajo las consideraciones descriptas en el Capítulo 2; y para muchos de los objetos analizados aquí se ha utilizado para evaluar el comportamiento y/o evolución espacial de $U$ a lo largo de toda la extensión de cada EELR. Una de las hipótesis sobre las que se basa la relación entre $U$ y el cociente de oxígenos es la homogeneidad (a primer orden, claro está) de la distribución de densidad del gas (Penston et al. 1990). En el caso de 3C 285 la disposición espacial de las nebulosas indica que el comportamiento de la densidad en el conjunto puede ser complejo, o en otras palabras, que no puede adoptarse la hipótesis de 
homogeneidad para la región completa. Por el contrario, cuando se requiera una evaluación de $U$ a través de $[\mathrm{OIII}] /[\mathrm{OII}]$ se hará de manera independiente para cada región (W, E1 o E2).

Los resultados de los diagramas C-D son coherentes con el comportamiento observado en $\mathbf{A}$, en tanto las dos regiones ( $\mathrm{W}$ y E1) son indistinguibles respecto del valor que adopta $[\mathrm{OII}] /[\mathrm{OIII}]$, reforzando la idea de que no existen diferencias importantes en el estado de excitación. El estado de la región E2, la región más alejada de la galaxia en dirección E[NE], sólo puede estudiarse a través del diagrama $\mathbf{D}$, que involucra las únicas líneas que se detectan allí. En esta región se observan las diferencias más importantes en la intensidad individual de las dos líneas del oxígeno, cuya intensidad es comparable sólo allí (ver Sección 5.4). La muestra correspondiente a E2 se desplaza hacia valores mayores de [OII]/[OIII] por la importancia que cobra [OII] frente al [OIII], con lo cual el estado de excitación en E2 es menor que en W y E1.

En los diagramas E-F se utiliza la línea [NeIII] $\lambda 3869$ que, junto con HeII son las dos líneas de mayor excitación del espectro. Si bien la muestra es mayor en la zona W porque la línea se observa más extendida que en E1, los dos diagramas muestran el mismo tipo de uniformidad observado con otras combinaciones de líneas. También se observa que los datos están más concentrados (en torno al valor medio que adopta el cociente) que en otras radiofuentes donde también se observa emisión de neón.

Desde la perspectiva de la ubicación de la muestra a lo largo de los diagramas, la evaluación del mecanismo de ionización dominante resulta ambigua. No hay una tendencia marcada en favor de uno u otro mecanismo, o equivalentemente, el ajuste es igualmente viable en ambos escenarios. Respecto de la IOC, el ajuste se beneficia por la concentración (poca dispersión) de la muestra, pero tiende a producirse en la zona de shocks de mayor velocidad: $500<v_{s}<1000 \mathrm{~km} \mathrm{~s}^{-1}$. El campo de velocidades, sin embargo, no presenta indicios de movimientos de tan alta velocidad. Y en este sentido debe remarcarse que esta clase de movimientos tampoco se han encontrado en las otras dos direcciones en que se ha evaluado la cinemática del gas: $\mathrm{PA}=95^{\circ}$ y $140^{\circ}$ (Baum et al. 1990). Por otra parte, si se pudieran dejar de lado las consideraciones sobre esta discrepancia cinemática y se considerara que el ajuste es válido, entonces habría que señalar que la contribución del precursor radiativo a la emisión global de cada nebulosa es sumamente importante. Los modelos de shocks puros (o no-autoionizantes, que no se muestran en los diagramas) no son capaces de reproducir las intensidades observadas, lo cual pone de manifiesto que se requiere de la presencia de un campo ionizante intenso. Los modelos de FMF también pueden reproducir las intensidades observadas en todos los cocientes, con la posible excepción de [OIII] $\lambda 4363 /[$ OIII] $\lambda 5007$ (diagrama B). Sin embargo, según las hipótesis del mecanismo de FMF sería esperable que los datos de las nebulosas se distribuyeran a lo largo de la secuencia de ionización dada por $A_{M / I}$. Como ya se ha mencionado, la muestra es notoriamente homogénea en lo que respecta a los valores de los cocientes de líneas.

Todos los indicadores del estado de excitación de las regiones (diagramas de diagóstico de la Fig. 6.10; diagramas C-D de la Fig. 6.11; valores aproximadamente constantes en todos los cocientes de líneas evaluados) muestran que no existen diferencias importantes entre ellas. Para ahondar en este aspecto se calcularon los valores medios del parámetro de ionización $U$ en cada una de las regiones W, E1 y E2, obteniéndose:

$$
\left\langle U_{W}\right\rangle=4.4 \times 10^{-3} ;\left\langle U_{E 1}\right\rangle=4.1 \times 10^{-3} ;\left\langle U_{E 2}\right\rangle=2.2 \times 10^{-3}
$$

Estos valores reflejan que, tal como se deduce de los diagramas, el estado de excitación es muy parejo entre W y E1 a pesar de las diferentes intensidades individuales (o brillo superficial en la imagen nebular) y que E2 tiene un estado de excitación menor. El orden de magnitud de $U$ en todos los casos indica que, en general, el estado de excitación es relativamente bajo; característica que permitiría explicar, por ejemplo, la ausencia del $[\mathrm{NeV}] \lambda 3424$ en el espectro. 
Figura 6.11. 3C 285. Evaluación de mecanismos de ionización. I.
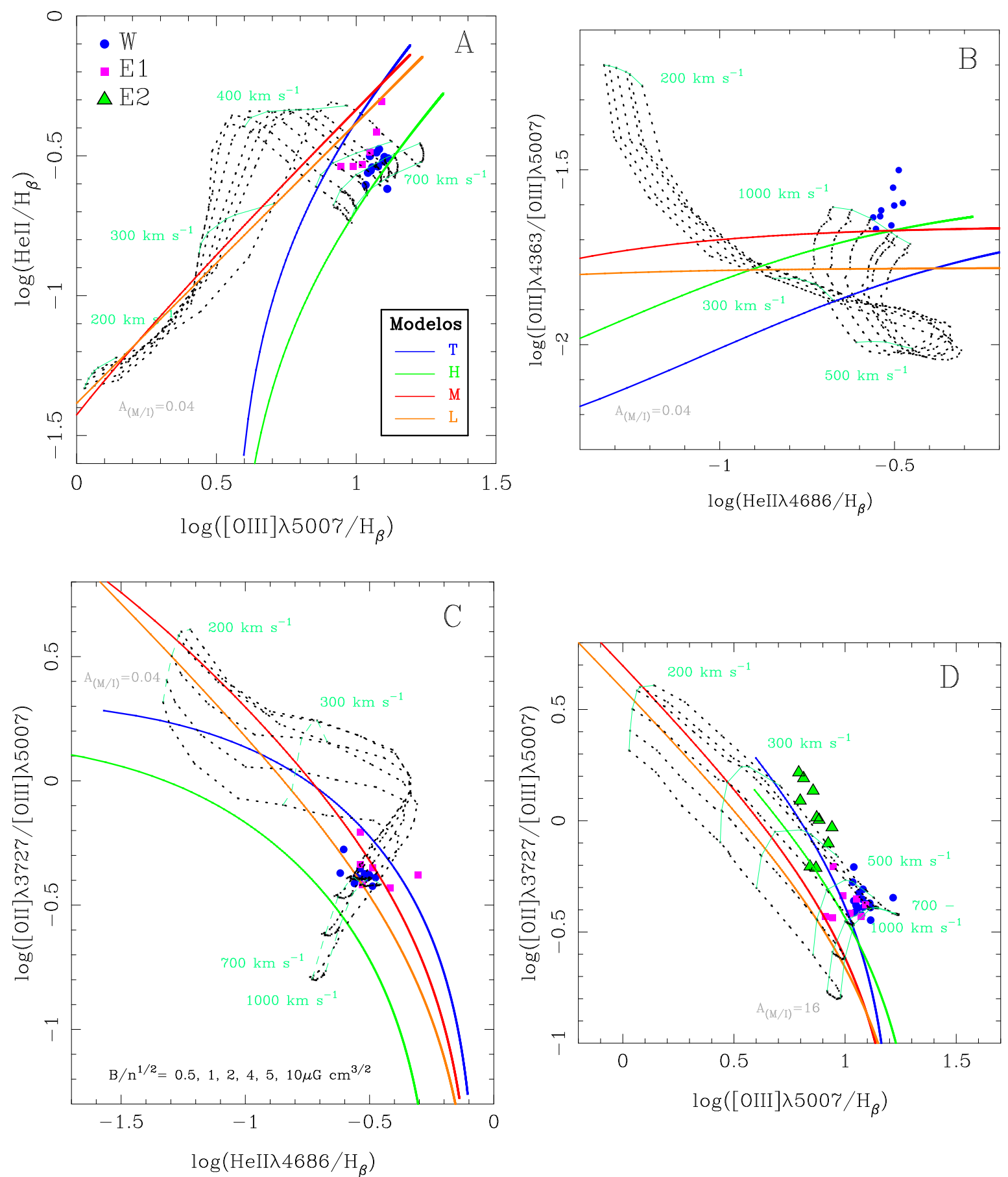
Fig. 6.11: continuación
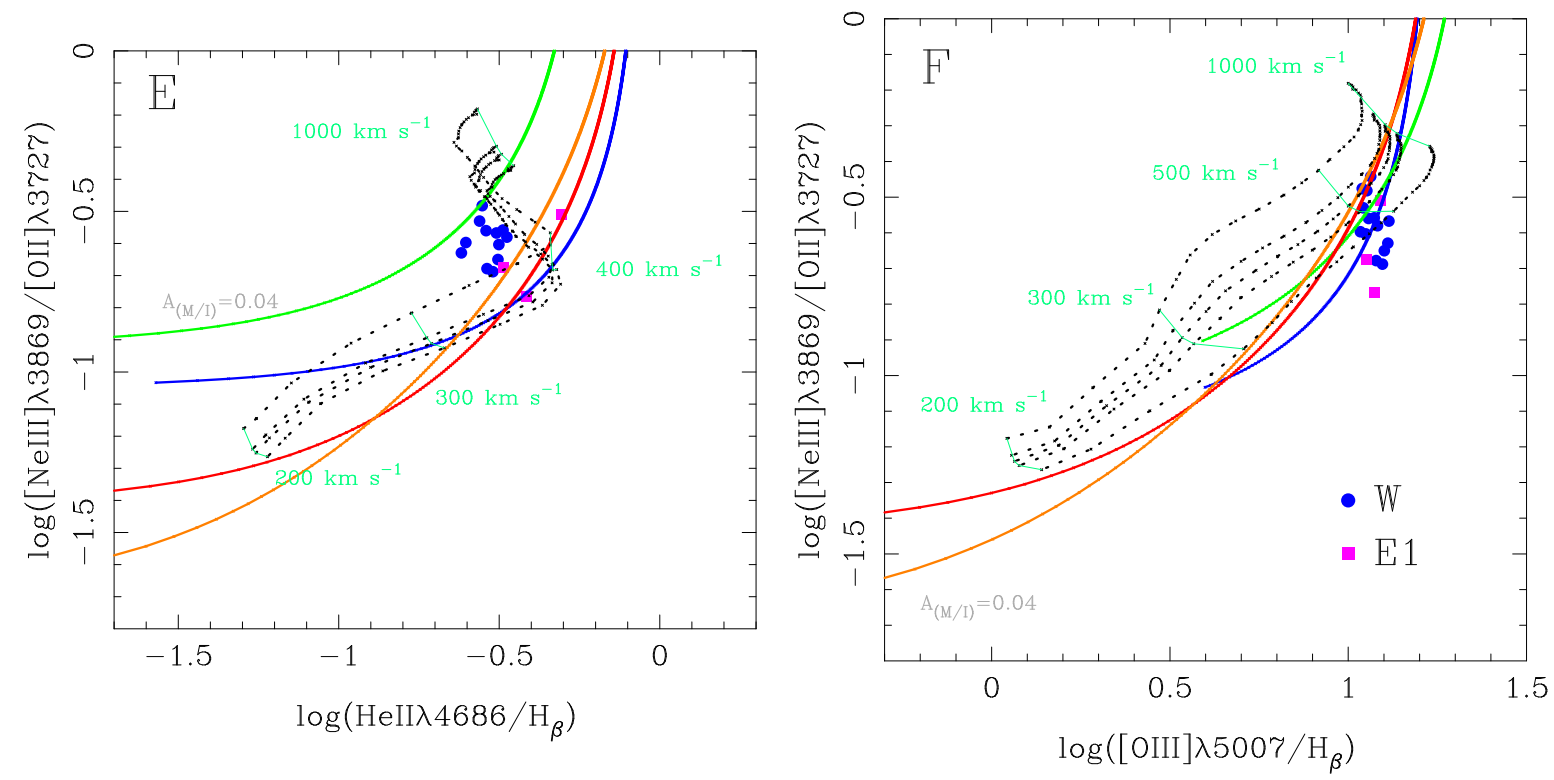

El modelo de IOC corresponde a la densidad ambiental pre-shock estándar de $100 \mathrm{~cm}^{-3}$. Las regiones en emisión (identificadas en la Fig. 6.9) se graficaron individualmente: W con círculos (azul), E1 con cuadrados (magenta) y E2 con triángulos (verde). La región central no puede posicionarse en ningún diagrama porque allí no puede detectarse prácticamente ninguna línea de emisión (ver texto). No todas las líneas están presentes en las tres regiones (W, E1 y E2).

Tales valores para el parámetro de ionización admiten una explicación en el marco de los dos escenarios de ionización propuestos: $U$ puede tomar valores bajos porque la nebulosa está compuesta por una mezcla de material ópticamente delgado y ópticamente grueso (o, en la terminología del modelo de FMF, por una mezcla nubes MB+IB), pero a su vez, dominada por la componente ópticamente gruesa (ver Tabla 2.1); o, en procesos de choque, $U$ puede verse reducido considerablemente por la compresión que sufre el gas detrás del frente de onda (Sección 2.4.3).

En cualquiera de los dos casos, el espectro de emisión global debería estar acompañado de otras características; por ejemplo, las líneas de baja ionización, como el [OI] o [SII] deberían ser intensas. En el marco de un proceso de fotoionización, estas líneas pueden ser intensas sólo cuando las propiedades ópticas de las nebulosas permite clasificarlas como [predominantemente] IB. Esto se debe a que las condiciones de formación de las líneas en cuestión requieren la existencia de una zona de ionización parcial extensa, tal como ocurre en este tipo de sistemas nebulares (en nubes ópticamente delgadas, o de tipo MB, la zona de ionización parcial es muy pequeña, o inexistente; Baum et al. 1992). Si, en cambio, la emisión proviene de un sistema gaseoso chocado, entonces el aumento de intensidad en las líneas de baja ionización se produce gracias al desequilibrio térmico que ocurre en una parte de la zona post-shock (ver Sección 2.4.3 y Fig. 2.7): el aumento de temperatura es tan brusco que el gas no puede responder al cambio de forma inmediata, y por lo tanto existe una región en estado de sub-ionización, esto es, un estado de ionización menor al que le correspondería de acuerdo a las temperaturas alcanzadas luego del paso de la onda (DS95; DS96; A08). Desde el punto de vista de la emisión, esta zona se comporta del mismo modo que la zona de ionización parcial en nebulosas fotoionizadas (Baum et al. 1992).

La información espectral que provee el espectro GMOS no es suficiente para discriminar 
cuál es el mecanismo de ionización dominante, así como tampoco lo es la información contenida únicamente en las líneas de baja ionización (Baum et al. 1992). Dada la importancia que podrían tener estas últimas, analizadas junto con las líneas del espectro GMOS (ejes de excitación y diagramas de diagnóstico) para los dos escenarios planteados, a continuación se combinará la información disponible, del mismo modo y bajo las mismas consideraciones que en la discusión sobre la fuente de energía.

En la Figura 6.12 se utilizan los diagramas de diagnóstico construidos con los cocientes $[\mathrm{NII}] \lambda 6583 / \mathrm{H} \alpha,[\mathrm{SiI}] \lambda \lambda 6717,6730 / \mathrm{H} \alpha$ y $[\mathrm{OI}] \lambda 6300 / \mathrm{H} \alpha$ en abscisas y los ejes de excitación $[\mathrm{OIII}] \lambda 5007 / \mathrm{H} \beta$ (paneles superiores) y HeII $/ \mathrm{H} \beta$ (paneles inferiores) en ordenadas. Los diagramas de los paneles superiores son los mismos diagramas de excitación de la Fig. 6.10; por completitud en la información, se mantuvieron las líneas que limitan la zona donde domina el núcleo activo como fuente de energía de las nebulosas. En estos diagramas se evalúan los mismos modelos (IOC y FMF) que en la Figura 6.11, y se utiliza la misma convención para la designación de las regiones W, E1 y E2.

La dispersión de los datos en estos nuevos diagramas es mayor respecto de lo que se observa en la Fig. 6.11, pero el dato más importante proviene del comportamiento de los modelos. A lo largo de todos los diagramas de la Fig. 6.11 se obtuvo un ajuste igualmente válido (desde el punto de vista de la ubicación de la muestra) para los dos conjuntos de modelos porque en todos ellos la zona de mayor excitación del mecanismo de FMF (valores altos del parámetro $A_{M / I}$ ) coincide con la zona de mayor excitación del mecanismo de IOC debido a la importante contribución del precursor radiativo (shocks de mayor velocidad). En todos ellos se observó que los dos procesos pueden reproducir satisfactoriamente la intensidad observada en los dos cocientes que actúan como ejes de excitación: [OIII] $\lambda 5007 / \mathrm{H} \beta$ y HeII/H $\beta$. Sin embargo, cuando ambos escenarios se evalúan de la mano del comportamiento de las líneas de ionización baja se obtienen predicciones diametralmente opuestas respecto de la variación conjunta de tales ejes con los cocientes de baja ionización. Esto es, cuanto mayor sea la intensidad de $[\mathrm{OIII}] \lambda 5007 / \mathrm{H} \beta$ o de $\mathrm{HeII} / \mathrm{H} \beta$, los modelos de FMF predicen que la intensidad de los cocientes $[\mathrm{SII}] \lambda \lambda 6717,6730 / \mathrm{H} \alpha$ y [OI] $\lambda 6300 / \mathrm{H} \alpha$ debe disminuir, mientras que los modelos de IOC predicen que la intensidad de esos mismos cocientes debe aumentar (la magnitud del campo magnético tiene un efecto de segundo orden que no afecta las conclusiones porque no modifica la tendencia observada). La relación con el cociente [NII] $\lambda 6583 / \mathrm{H} \alpha$ es diferente, pero de todos modos los comportamientos de los modelos también difieren significativamente en el rango de valores observados en los dos ejes de excitación (ejes de ordenadas en la Fig. 6.12). La disposición de los datos de 3C 285 se corresponde, sin excepciones, con las predicciones de los modelos de FMF.

El conjunto de información reunida permite, entonces, descartar el mecanismo de IOC como principal responsable del estado de ionización. A la falta de sustento cinemático para el aparente ajuste que se manifiesta en los diagramas de la Fig. 6.11 en la zona donde el precursor radiativo tiene su máxima influencia, debe sumarse: 1) que el modelo predice un comportamiento absolutamente contrario al observado en las líneas de ionización baja; y 2) que según los modelos de FMF, esas líneas se forman mayoritariamente en regiones caracterizadas por valores bajos de $U$, compatibles con las mediciones obtenidas para 3C 285 .

Las evidencias en favor de la FMF como principal mecanismo de ionización en las regiones W, E1 y E2 son las siguientes:

- el ajuste en los diagramas de la Fig. 6.11 se produce en zonas intermedias de la secuencia dada por $A_{M / I}$. En esa zona, la influencia de las nubes MB se reduce en favor de la componente IB, cuyo estado de ionización es (por hipótesis) menor;

- los parámetros de ionización en las tres regiones nebulares W, E1 y E2 son bajos y, a su vez, compatibles con sistemas gaseosos dominados por la componente IB. Estos dos puntos 
refuerzan la conclusión alcanzada por Baum et al. (1992), que señalaron que la ubicación de una dada fuente (o región de una fuente) en los diagramas de diagnóstico depende principalmente del parámetro de ionización que la caracterice;

- en los sistemas nebulares tipo IB (ópticamente gruesos) se espera que las líneas de ionización baja, formadas en la zona de ionización parcial, sea intensa; esto es lo que sucede con las líneas [OI] $\lambda 6300$ y [SII] $\lambda \lambda 6717,6730$ (Baum et al. 1990, 1992) en 3C 285;

- los modelos de FMF predicen que el rango de valores observados en [OIII] $\lambda 5007 / \mathrm{H} \beta$ y HeII/H $\beta$ se pueden alcanzar siempre que la intensidad de los cocientes de líneas de ionización baja ([SII] $\lambda \lambda 6717,6730 / \mathrm{H} \alpha$ y $[\mathrm{OI}] \lambda 6300 / \mathrm{H} \alpha$, y en menor medida $[\mathrm{NII}] \lambda 6583 / \mathrm{H} \alpha$ ) disminuya. Los diagramas de la Fig. 6.12 indican que, efectivamente, los datos de 3C 285 se comportan de este modo.

\subsubsection{Resumen}

3C 285 es una fuente que presenta emisión extendida (y comprobada) en el óptico, UV y radio. La escala de distancias asociadas a la emisión en cada banda es diferente, así como también lo son los procesos de emisión involucrados.

En el óptico se detectó emisión extendida (continuo) en la escala de la radiofuente, y se comprobó que la emisión fue desencadenada por la interacción de esta última con el gas del MIG (Tyson et al. 1977; Baum et al. 1988; van Breugel \& Dey 1993). En el orden de magnitud de la extensión le sigue la emisión UV (continuo), aparentemente asociada a procesos de formación estelar desencadenados por la colisión de la galaxia anfitriona (elíptica) con otra galaxia rica en polvo (Allen et al. 2002; Baldi \& Capetti 2008). La emisión extendida de menor escala corresponde a la emisión óptica (líneas) proveniente de la EELR. En este trabajo se analizaron las condiciones físicas del gas para dilucidar cuál fue el mecanismo que desencadenó la emisión.

Como las estructuras de la EELR están contenidas dento de la emisión extendida UV, y ésta se asocia a brotes de formación estelar, en primer lugar se evaluó la posibilidad de que la fuente de energía dominante en el gas óptico proviniera también de estos procesos. El espectro GMOS permitió identificar tres (3) regiones en emisión: la región W, en dirección $\mathrm{O}[\mathrm{SO}]$ y las regiones E1 y E2, en dirección E[SE].

Para realizar el análisis sobre el mecanismo de excitación fue necesario complementar la información del espectro GMOS $\left(\mathrm{PA}=80^{\circ}\right.$; cuyo rango espectral cubre las líneas de emisión desde $[\mathrm{OII}] \lambda 3727$ hasta $[\mathrm{OIII}] \lambda 5007)$ con la información contenida en la parte "roja" del espectro óptico (la información en las líneas de emisión de baja ionización [OI] $] 6300, \mathrm{H} \alpha$, [NII] 66583 y [SII] $\lambda \lambda 6717,6730)$. Este último conjunto de líneas está disponible en la literatura como parte del trabajo de Baum et al. (1990), quienes analizaron esta zona del espectro óptico con dos posiciones diferentes de la ranura: $\mathrm{PA}=95^{\circ}-140^{\circ}$. Tomando como base las imágenes a escala de la emisión nebular en $\mathrm{H} \alpha$, [OIII], y UV (Baldi \& Capetti 2008; Tremblay et al. 2009) y teniendo en cuenta que los tres espectros long-slit disponibles atraviesan el centro de la galaxia y cubren rangos de distancias (sobre las ranuras) similares, fue posible combinar la infomación de los espectros con $\mathrm{PA}=80^{\circ}$ (GMOS) y $\mathrm{PA}=95^{\circ}$ (Baum et al. 1990).

Se utilizaron los diagramas de excitación (Baldwin et al. 1981; Kewley et al. 2001; Kauffmann et al. 2003; Kewley et al. 2006) para analizar si la fuente de energía que alimenta la emisión en la EELR proviene del núcleo activo o de brotes de formación estelar. Las observaciones indican que para que estos últimos tengan una influencia no despreciable en el espectro óptico sería necesario que el cociente $[\mathrm{OIII}] \lambda 5007 / \mathrm{H} \beta$ (que representa el eje de excitación) fuera como mínimo un orden de magnitud menor a lo largo de cada una de las tres regiones en emisión identificadas.

Sabiendo que el núcleo activo provee la energía necesaria para generar la emisión observada 
Figura 6.12. 3C 285. Evaluación de mecanismos de ionización. II.
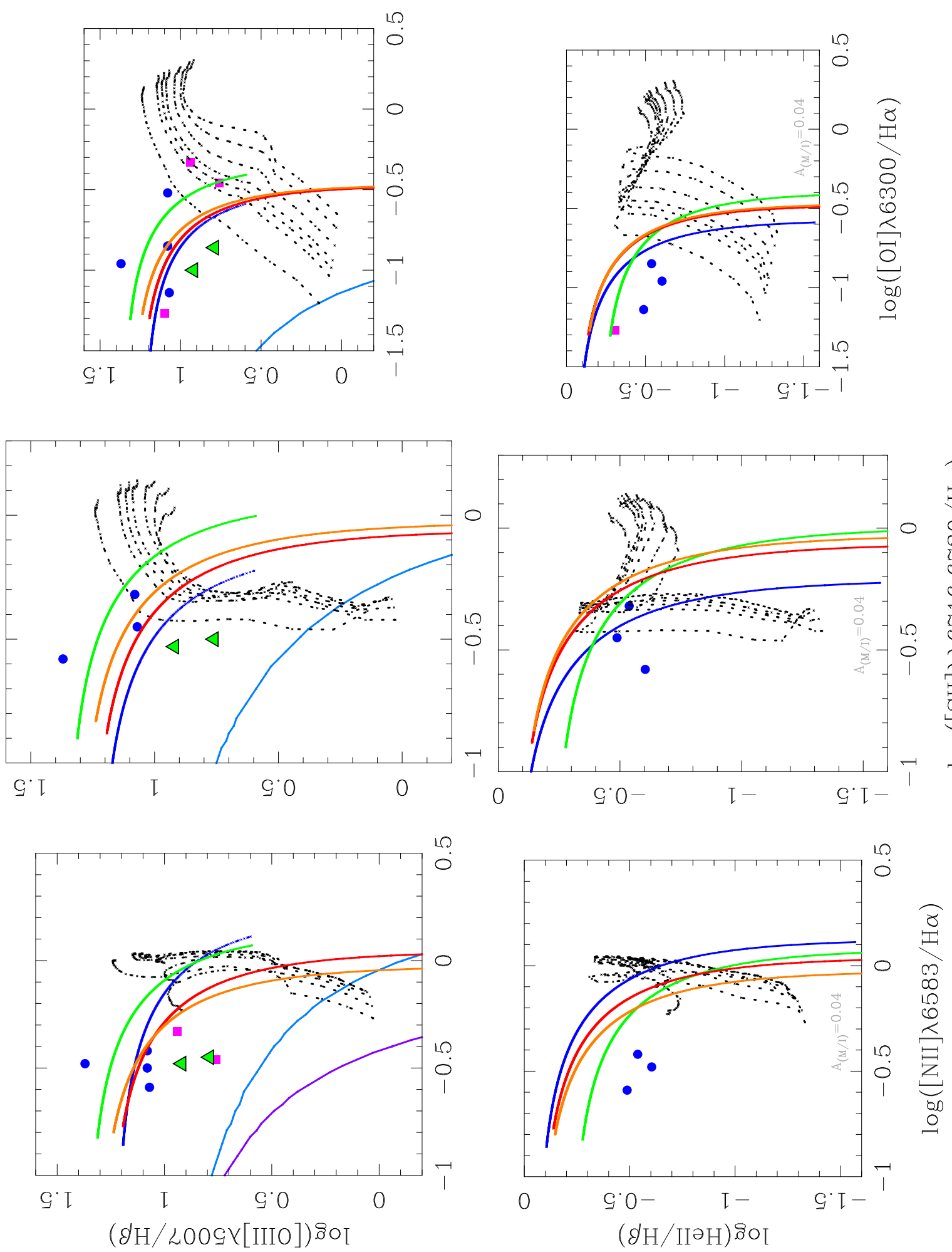

Evaluación de los mismos modelos de la Fig. 6.11 para las líneas de baja ionización [OI] $\lambda 6300, H \alpha$, $[\mathrm{NII}] \lambda 6583$ y [Sir] $\lambda \lambda 6717,6730$ del espectro long-slit de 3C 285 tomado con PA=95ㅇ (Baum et al. 1990, ver texto). En los diagramas del panel superior ([OIII] $\lambda 5007 / \mathrm{H} \beta$ en ordenadas) se mantuvieron las delimitaciones correspondientes a la Fig. 6.10 como referencia. 
en la EELR, el estudio continuó con el análisis del modo en que esa energía es estregada al medio: a través del campo de radiación central, mediante el mecanismo de FMF, o a través de la interacción de los jets con el medio que atraviesa en su paso, desencadenando ondas de choque.

En primera instancia, estos comportamientos se analizaron según los diagramas de diagnóstico construidos únicamente con las líneas de emisión del espectro GMOS (Fig. 6.11). Todos los casos demuestran que, de acuerdo a la localización de la muestra, los dos mecanismos pueden predecir y reproducir las intensidades observadas en todos los cocientes de líneas estudiados. El ajuste con los modelos de FMF se produce en la zona intermedia de la secuencia dada por $A_{M / I}$; desde el punto de vista teórico, esto indica que el sistema gaseoso en cuestión está formado por una mezcla de nubes MB-IB y que, en principio, la componente MB (la de mayor excitación) no domina el estado del sistema. El ajuste con los modelos de IOC se produce en la zona correspondiente a los choques más violentos $\left(500<v_{s}<1000 \mathrm{~km} \mathrm{~s}^{-1}\right)$, donde también se espera la mayor contribución del precursor radiativo. Sin embargo, no hay indicios de movimientos de perturbación tales ni en el campo de velocidades obtenido según $\mathrm{PA}=80^{\circ}$, ni en los campos de velocidad obtenidos por Baum et al. (1990) según $\mathrm{PA}=95^{\circ}-140^{\circ}$.

A través del cociente $[\mathrm{OII}] /[\mathrm{OIII}]$ en los diagramas $\mathbf{C}-\mathbf{D}$, se deduce que no existen diferencias significativas en el estado de excitación de las regiones W y E1, mientras que E2 claramente tiene un estado de excitación menor. Si bien los demás cocientes estudiados no son indicadores directos del estado de excitación como lo es [OII]/[OIII], en todos ellos se observan comportamientos uniformes, es decir, poca dispersión en torno del valor medio, que también dan cuenta de la homogeneidad en el estado de las regiones. Los parámetros de ionización $U$ en cada región tienen valores medios del orden de $U \sim 10^{-3}$.

En el marco de la FMF, se esperan valores de este orden en sistemas nebulares mezclados, pero dominados por la componente de baja ionización (IB). En el marco de la IOC, los valores bajos de $U$ provienen del gas chocado, cuya densidad aumenta considerablemente por el paso de la onda. En ambos casos el espectro manifiesta una u otra situación mediante el aumento de intensidad en las líneas de baja ionización, como [OI] y [Sir]. En el escenario planteado por la FMF, estas líneas se forman en la extensa zona de ionización parcial que se genera únicamente en nubes [predominantemente] IB. En el escenario de ondas de choque radiativas, se generan en la zona de gas chocado fuera del equilibrio térmico.

Se analizaron, entonces, los comportamientos de las líneas de ionización baja del espectro "ampliado" con los datos Baum et al. $\left(1990, \mathrm{PA}=95^{\circ}\right)$, bajo los mismos modelos. Con este análisis se manifestaron las diferencias más significativas entre los dos conjuntos de modelos (Fig. 6.12) en el rango de valores observados para los cocientes de mayor excitación, adoptados como ejes de excitación ([OIII] $\lambda 5007 / \mathrm{H} \beta$ y HeII/H $\beta$ ). El rango de valores observados en estos cocientes coincide con los máximos valores que ambos modelos pueden reproducir, y en todas las combinaciones de la Fig. 6.11 (que siempre involucran dos líneas de excitación media-alta; una en abscisas y otra en ordenadas) esas zonas coinciden. En otras palabras, en estos diagramas la zona de mayor excitación/ionización del modelo de FMF coincide con la zona de mayor excitación/ionización del modelo de IOC. En cambio, en los diagramas donde se estudian las líneas de ionización baja, las predicciones de los modelos son diametralmente opuestas. La FMF predice que el aumento de intensidad de los ejes de excitación $[\mathrm{OIII}] \lambda 5007 / \mathrm{H} \beta$ y HeII $/ \mathrm{H} \beta$ debe ir acompañado de la disminución de la intensidad en los cocientes $[\mathrm{OI}] \lambda 6300 / \mathrm{H} \alpha$ y $[\mathrm{SII}] \lambda \lambda 6717,6730 / \mathrm{H} \alpha$, mientras que según la IOC, el aumento de intensidad debería manifestarse en forma simultánea para los dos cocientes involucrados por diagrama. Respecto del cociente $[\mathrm{NII}] \lambda 6583 / \mathrm{H} \alpha$ no se observa una discrepancia tan tajante, posiblemente debido a que la línea de emisión [NII] 76583 es la de mayor excitación de este subconjunto, y no se forma en la zona de ionización parcial (Baum et al. 1992). Las obser- 
vaciones de $3 \mathrm{C} 285$ se comportan según la tendencia señalada por los modelos de FMF, sin excepciones.

Luego, del análisis de:

1. los parámetros de ionización característicos en W, E1 y E2;

2. la zona de formación de las líneas de baja ionización y su conexión con $U$;

3. el comportamiento de los modelos según los diagramas de diagnóstico con líneas de excitación media-alta (espectro GMOS; Fig 6.11);

4. el comportamiento de los modelos según los diagramas de diagnóstico con líneas de ionización baja ("espectro ampliado"; Fig 6.12);

5. el hecho de que el aparente ajuste con los modelos de IOC se produce en la zona dominada por el precursor, mientras que el estudio de la excitación a través de $U$ indica que la emisión debería generarse predominantemente en la zona de gas chocado;

6. la inexistencia de sustentos cinemáticos en los tres campos de velocidades disponibles para sostener la validez de un ajuste que señala la presencia de movimientos de perturbación importantes;

7. la compatibilidad de los resultados en favor de la FMF (la ubicación de la muestra en los diagramas es coherente con los parámetros de ionización teóricos y con los observados; esos valores de $U$, a su vez, con característicos de la zona de formación de las líneas de emisión para las cuales el comportamiento de los dos conjuntos de modelos es diametralmente opuesto, y los datos de 3C 285 se comportan indudablemente según la tendencia marcada por la FMF)

se concluye que el campo de radiación del núcleo activo es el responsable del estado de excitación/ionización en las tres regiones nebulares que componen la EELR de 3C 285, y que los tres sistemas gaseosos, por su parte, están compuestos mayoritariamente por material ópticamente grueso.

\section{4. $3 \mathrm{C} 305$.}

La mayor parte del contenido de esta Sección fue publicado en Reynaldi \& Feinstein (2013b).

En 3C 305 ha sido posible confirmar que la interacción entre los jets y el material interestelar, mediante la generación de ondas de choque radiativas, provoca la emisión en rayosX (Hardcastle et al. 2012), IR (Jackson et al. 2003) y el óptico (Heckman et al. 1982; Reynaldi \& Feinstein 2013b).

Este objeto fue estudiado en numerosas oportunidades en distintas bandas del espectro electromagético (EM); la mayoría de esos estudios centraron primeramente su atención en la cinemática de la EELR. En uno de los primeros análisis (Heckman et al. 1982) se observó que la separación entre las líneas en el óptico era un indicador de que el gas de la región estaba experimentando procesos violentos, traducidos en movimientos de alta velocidad. De este mismo trabajo provino la información de que la emisión (sincrotrón) en la banda de radio está superpuesta a la emisión en el óptico (ver Fig. 3.10), y que las zonas cinemáticamente complejas y desordenadas, que se aprecian mediante la deformación de los perfiles de las líneas de emisión, coinciden espacialmente con las estructuras más intensas en radio. 
Estudios recientes del Hi-21 cm (en absorción; Morganti et al. 2005) indican que esta fase del MIE también ha sufrido los efectos de la interacción, y permiten arribar a tres importantes conclusiones: 1) las nubes de la EELR no se destruyen por el paso del jet, 2) las nubes de alta velocidad, tanto en el gas neutro como en el gas ionizado, fueron expulsadas por el mismo proceso, y 3) el gas tiene la capacidad de enfriarse de un modo muy eficiente luego del calentamiento producido por los choques a los que es sometido. La presencia de la línea del [FeII] $\lambda 1.644 \mu \mathrm{m}$ en el espectro IR (Jackson et al. 2003) suma argumentos para sostener que han existido procesos de choque dentro del gas; en ese trabajo se muestra que la emisión del $[\mathrm{FeII}] \lambda 1.644 \mu \mathrm{m}$ se produce en el mismo lugar donde se detecta la emisión de la línea más intensa del espectro óptico: [OIII] $\lambda 5007$. Hacia el otro extremo del espectro EM, se ha mostrado que la distribución espacial del [OIII] está fuertemente relacionada con la emisión en rayos-X (Hardcastle et al. 2012). Existe una relación morfológica notable (superposición espacial), pero además es posible que tengan un origen común: la emisión en rayos-X proviene mayoritariamente de energías menores que $\sim 2 \mathrm{keV}$ (rayos-X blandos/medios) que es el rango donde se produce la excitación colisional de muchas de las líneas de emisión presentes (Bianchi et al. 2006; Massaro et al. 2009; Hardcastle et al. 2012).

Todos estos resultados, en conjunto, revelan que la información proveniente de la banda de radio (no térmico), $\mathrm{HI}-21 \mathrm{~cm}, \mathrm{IR}$, óptico y rayos-X está intrínsecamente relacionada, y no sólo por la superposición espacial.

\subsubsection{Mecanismo de ionización}

Los estudios multifrecuencia de 3C 305, que incluyen desde el análisis de la superposición de la emisión hasta la cinemática (en donde ha sido posible medirla) indican que los jets interactúan con el medio de un modo violento. En el óptico en particular, estas conclusiones se han obtenido casi exclusivamente a través de la información cinemática. El propósito de esta Sección es mostrar que la energía cinética que los jets transfieren al MIE provocan ondas de choque que son capaces de desencadenar la ionización del medio.

La detección de la línea [FeII] $\lambda 1.64 \mu \mathrm{m}$ en el espectro IR (Jackson et al. 2003) constituye el primer antecedente espectral sobre la presencia de ondas de choque en la EELR. Esta línea se produce por excitación colisional. La asociación con procesos de choque proviene de que fue primeramente descubierta en remanentes de supernova. La explosión de supernova desencadena ondas de choque en el medio que rodea a la estrella progenitora, y una de las características distintivas en muchos remanentes es la emisión sincrotrón proveniente de la zona de recombinación. La misma población de electrones responsable de la emisión sincrotrón es la que excita los iones de hierro (Kawara et al. 1988; Moorwood \& Oliva 1988; Greenhouse et al. 1991). En estos casos, luego, la emisión IR está superpuesta a la emisión no térmica en radio.

En el caso de 3C 305, la presencia de ondas de choque se evidencia en el extremo NE del jet donde la emisión del [FeII] $\lambda 1.64 \mu \mathrm{m}$ alcanza el máximo. La emisión de [OIII] $\lambda 5007$, por su parte, también coincide espacialmente con los datos IR y de radio, en particular en la dirección del radio-eje, aunque está más extendida que la emisión del [FeII] (Jackson et al. 2003). Como el espectro GMOS fue tomado, aproximadamente, en la misma dirección del jet, ofrece la posibilidad de explorar si existen signos de interacción a lo largo de toda su cobertura espacial, que además, incluye la región estudiada por Jackson et al. (2003) en el extremo terminal del jet.

Los resultados en los modelos de ionización por ondas de choque (IOC) varían de acuerdo a la densidad ambiental. Existen estimaciones de la densidad del gas en la EELR en este objeto, obtenidas bajo las condiciones de fotoionización dadas por el Caso B (ver Sección 2.4.1). Mediante las líneas [Sir] $\lambda \lambda 6717,6731$, Morganti et al. (2005) obtuvieron valores en el rango 
$n_{e}<500 \mathrm{~cm}^{-3}$, mientras que Heckman et al. (1982) habían derivado valores cercanos a $n_{e}=10^{3} \mathrm{~cm}^{-3}$, aunque es posible, según los propios autores del trabajo, que estos resultados hayan sido afectados por ciertas incertezas. Dado que ésta es la única información que proviene de datos del óptico, en primera instancia se emplean los modelos desarrollados para densidades ambientales de $10^{2}$ y $10^{3} \mathrm{~cm}^{-3}$, como casos extremos. Es necesario destacar, sin embargo, que los valores de densidad podrían ser significativamente diferentes bajo condiciones de IOC.

Por otro lado, como esta clase de modelos son de tipo magnetohidrodinámicos (MHD), el papel que desempeñe el campo magnético $(B)$ no es despreciable (ver Apéndice B). En un trabajo reciente, basado en medidas de la depolarización en radio, Hardcastle et al. (2012) establecieron que el valor de $B$ en la EELR se encuentra en el rango $16<B<100 \mu \mathrm{G}$. Luego, en el siguiente análisis sólo se utilizan los modelos cuyos valores asociados de campo magnético se encuentren dentro de este rango.

En la Figura 6.13 se presentan los diagramas de diagnóstico con los modelos de shocks autoionizantes en un medio con abundancia solar; los dos conjuntos de curvas corresponden a los modelos en los cuales la densidad del medio sin perturbar es de $n_{e}=10^{2} \mathrm{~cm}^{-3}$ (en líneas punteadas, color negro) y $n_{e}=10^{3} \mathrm{~cm}^{-3}$ (en líneas de trazos cortos, color magenta). Se tiene una curva por cada valor de parámetro magnético $B / n^{1 / 2}$. Las líneas continuas (color verde) indican la velocidad de la onda de choque; se indican las mismas velocidades en cada conjunto. Por claridad, cada EELR está representada por símbolos diferentes: la región NE se grafica con puntos rojos y la $\mathrm{SO}$ con triángulos color violeta.

Las líneas [OII] $\lambda 3727$ y H $\beta$ son particularmente intensas en el espectro de 3C 305, así como los cocientes $[\mathrm{OII}] \lambda 3727 /[\mathrm{OIII}] \lambda 5007$ y $[\mathrm{OIII}] \lambda 5007 / \mathrm{H} \beta$, que se combinan juntos en el diagrama A de la Fig. 6.13. Según la estructura de emisión de una onda de choque, la mayor contribución en las líneas mencionadas proviene de la zona de recombinación, detrás del frente de choque. Sin embargo, si sólo se considera la emisión de la zona de recombinación no es posible explicar los niveles de intensidad observados. Esto equivale a decir que las curvas correspondientes a los modelos de ionización por ondas de choque no-autoionizantes se localizan fuera del rango de las observaciones; por tal motivo no fueron graficadas.

Para poder reproducir las intensidades observadas en 3C 305, al menos en el orden de magnitud, es necesario considerar la contribución de la región precursora. Los diagramas combinan líneas de alta y baja excitación, y en todos los casos se observa que las intensidades de los cocientes se pueden reproducir cuando las velocidades del shock se encuentran en el rango $300<v_{s}<500 \mathrm{~km} \mathrm{~s}^{-1}$, cualquiera sea la combinación de las líneas. Es importante señalar en este punto que los resultados obtenidos del análisis del campo de velocidades del gas (Sección 5.6) coinciden con los modelos IOC, en tanto las velocidades para las cuales se puede obtener la emisión observada son aquellas que el gas manifiesta en sus movimientos de mayor perturbación.

No es posible esbozar conclusiones respecto de la densidad del gas dado que el comportamiento de las observaciones en este sentido depende notablemente de la combinación de las líneas involucradas. Así, por ejemplo, mientras los diagramas [OIII] $]$ 5007/H $\beta$ vs. $[\mathrm{OII}] \lambda 3727 /[\mathrm{OIII}] \lambda 5007$ (diagrama A) y $[\mathrm{NeIII}] \lambda 3869 /[\mathrm{OII}] \lambda 3727$ vs. $[\mathrm{OIII}] \lambda 5007 / \mathrm{H} \beta$ (diagrama D) parecen mostrar una tendencia en favor de densidades bajas, los otros dos (B y $\mathbf{C}$ ) presentan resultados ambiguos, con cierta tendencia hacia densidades altas. La falta de consistencia en este caso no se puede atribuir a la naturaleza de las líneas de emisión, en el sentido de que la variación en los resultados no depende de si se utilizan líneas de baja o alta excitación.

Las regiones NE y SO quedan claramente separadas de acuerdo al comportamiento del cociente $[\mathrm{OII}] \lambda 3727 /[\mathrm{OIII}] \lambda 5007$. Cada región se caracteriza por un valor promedio determinado, pero aún más importante es el hecho de que este cociente permanece prácticamente 
Figura 6.13. $3 \mathrm{C}$ 305. Modelos de IOC: $n_{e}=10^{2}$ $10^{3} \mathrm{~cm}^{-3}$; abundancia solar.
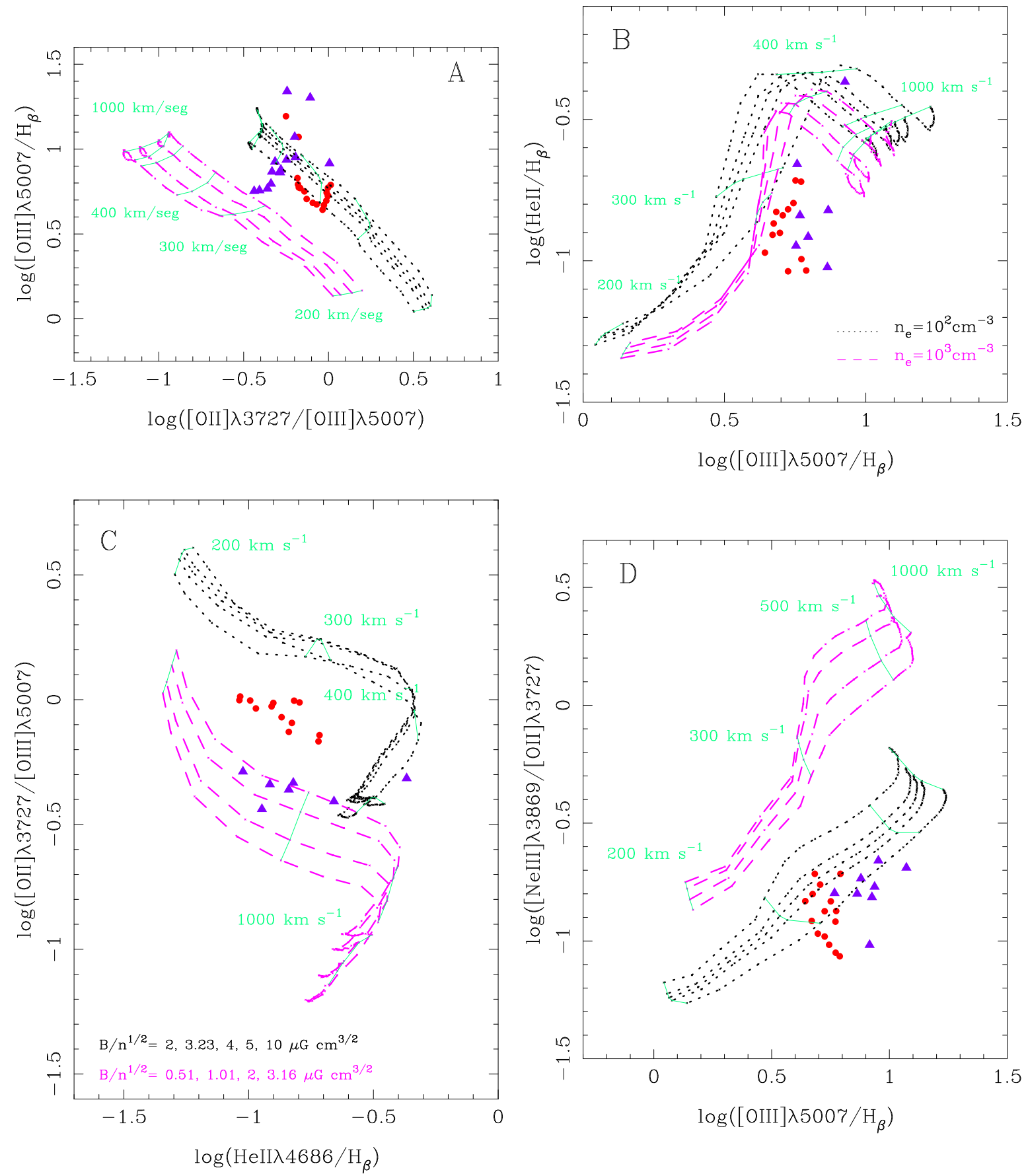

Modelos de ionización por ondas de choque en un medio con abundancia solar: las curvas de líneas punteadas (color negro) corresponden al modelo cuya densidad ambiental es de $n_{e}=10^{2} \mathrm{~cm}^{-3}$, y las de líneas de trazos cortos (color magenta) al de $n_{e}=10^{3} \mathrm{~cm}^{-3}$. Cada curva se corresponde con un valor dado del parámetro magnético; el rango de valores se indica en los diagramas A y C. Las líneas continuas (color verde) indican la velocidad de propagación de la onda de choque. Las regiones en emisión de 3C 305 se representan con símbolos diferentes: puntos (rojos) para la región NE y triángulos (violeta) para la región SO. 
constante a lo largo de cada sistema gaseoso. Estos resultados se pueden apreciar de forma muy clara en el diagrama [OII] $\lambda 3727 /[\mathrm{OIII}] \lambda 5007$ vs. $\mathrm{HeII} / \mathrm{H} \beta$ (C). Como se discutió en la Sección 2.4.1, las variaciones de intensidad en [OII] $\lambda 3727 /[\mathrm{OIII}] \lambda 5007$ son un indicador de variaciones en las condiciones de ionización del gas bajo la hipótesis de fotoionización central. Teniendo en cuenta que el comportamiento de este cociente puede seguirse hasta una distancia de $\pm 4.5 "$ ( $\pm 4 \mathrm{kpc}$, aproximadamente), entonces se puede concluir que a lo largo de esa zona (en cada nebulosa, individualmente) no se producen cambios en las condiciones de ionización.

Los comportamientos tanto teórico como observado en los cocientes [OII] $\lambda 3727 /[\mathrm{OIII}] \lambda 5007$ y $[\mathrm{NeIII}] \lambda 3869 /[\mathrm{OII}] \lambda 3727$ merecen especial atención, por lo que se discuten en los apartados siguientes.

\section{El rol de la fotoionización central.}

En lo que respecta al oxígeno, y en particular al aumento en la emisión del [OII] $\lambda 3727$, cabe la pregunta sobre qué papel desempeña el campo de radiación central proveniente del núcleo activo. Concretamente, podría suceder que el gas haya sido fotoionizado por el AGN. O incluso también podría suceder que, luego del paso de la onda de choque, el estado del gas sea tal que ese campo ionizante encuentre condiciones más favorables para cambiar su estado de ionización (Best, Röttgering \& Longair 2000; Solórzano-Iñarrea, Tadhunter \& Axon 2001). Sin embargo existen indicios para considerar que los efectos de la fotoionización deben ser secundarios, y se detallan a continuación:

- si el MIE estuviera fotoionizado, el comportamiento de [OII] $\lambda 3727 /[\mathrm{OIII}] \lambda 5007$ en función de la distancia debería mostrar cómo el campo de fotones se ve afectado por la dilución geométrica a la que está sometido (ver Penston et al. 1990, y sus referencias). Para estos casos, existen dos tipos de indicadores de las variaciones espectrales que ocurren en la región: uno en el óptico y otro en la banda de rayos-X. En el óptico, la relación entre [OII] $\lambda 3727 /[\mathrm{OIII}] \lambda 5007$ y el parámetro de ionización $U$ (Eq. 2.2) permite concluir, como se señalaba en el párrafo anterior, que no hay cambios en las condiciones de ionización del gas en función de la distancia a la fuente central (Heckman et al. 1982; Reynaldi \& Feinstein 2013b), al menos a lo largo de una extensión radial de 4.5" a cada lado del núcleo, distancia que equivale al $50 \%$ de la región donde se concentra la emisión nebular. En rayos-X, el cociente de dureza (HR, por su sigla en inglés, hardness ratio) se define como la razón entre los flujos en rayos-X duros y rayos-X blandos, y también se utiliza para buscar variaciones espectrales en objetos que presentan emisión extendida. Este parámetro fue calculado por Hardcastle et al. (2012), quienes concluyeron que no hay evidencia clara de que HR varíe en función de la posición, por lo cual tampoco se pueden inferir variaciones espectrales notables en esta banda del espectro. Si el MIE hubiera sido fotoionizado por la fuente central, tanto $U$ como HR deberían variar significativamente, mostrando cómo disminuye la cantidad de fotones ionizantes conforme la distancia al centro aumenta. Esto no se observa ni en el óptico, ni en rayos-X. Aún más, el máximo de emisión del espectro óptico se produce a una distancia de 2-3" del núcleo (Sección 5.6), y esto se observa en todas las líneas del espectro, incluso en las de mayor excitación, como HeII o [NeIII] $\lambda 3869$.

- La cinemática de la región (Fig. 5.10) muestra que las componentes más perturbadas del campo de velocidad se encuentran aproximadamente en la misma posición donde ocurre el pico de intensidad del espectro.

- El análisis del espectro de emisión extendida en rayos-X indica que el gas fue ionizado colisionalmente (Hardcastle et al. 2012). Y en este sentido cabe señalar que es posible que la emisión en la banda soft (que domina la emisión en rayos-X, en el caso de 3C 305) y en el óptico tengan un origen común (Bianchi et al. 2006; Massaro et al. 2009). 


\section{La densidad ambiental}

En los diagramas $\mathbf{A}, \mathbf{C}$ y $\mathbf{D}$ se puede apreciar que cuando el cociente de oxígenos o el cociente [NeIII] $\lambda 3869 /[\mathrm{OII}] \lambda 3727$ se combinan con $[\mathrm{OIII}] \lambda 5007 / \mathrm{H} \beta$ o con HeII $/ \mathrm{H} \beta$, los modelos son fuertemente sensibles a la densidad ambiental (densidad pre-shock). Si estos dos últimos cocientes se combinan juntos (diagrama B) la información se pierde. Cuando $[\mathrm{OII}] \lambda 3727 /[\mathrm{OIII}] \lambda 5007$ se combina con $[\mathrm{NeIII}] \lambda 3869 /[\mathrm{OII}] \lambda 3727$ también se produce una degeneración completa en densidad. Sin embargo, esa degeneración se puede resolver construyendo un diagrama $3 \mathrm{D}$, donde el tercer eje puede ser tanto [OIII] $\lambda 5007 / \mathrm{H} \beta$ como HeII $/ \mathrm{H} \beta$. Cualquiera de estos dos cocientes son particularmente útiles en este aspecto.

Por las razones que se explicarán a continuación, se estudió el comportamiento de los modelos para diferentes configuraciones de densidad pre-shock y de abundancias del gas en este tipo de diagramas 3D. El resultado más importante de ese análisis radica en que cuando el tercer eje se construye con el cociente $\mathrm{HeII} / \mathrm{H} \beta$ se obtiene una resolución simultánea para la degeneración que ocurre tanto en densidad como en abundancias. Esta solución, a su vez, tiene una dependencia con la velocidad de propagación de la onda, por lo que la solución definitiva se alcanza para velocidades en el rango $v_{s}<700 \mathrm{~km} \mathrm{~s}^{-1}$.

El motivo por el cual se analizaron otras configuraciones de modelos (diferentes de aquellos de la Fig. 6.13) reside en que según los resultados de Hardcastle et al. (2012) y de Heckman et al. (1982) es posible que exista equilibrio de presión entre el gas óptico y el gas caliente, responsable de la emisión en rayos-X. Bajo esta hipótesis, la temperatura en el gas ionizado $\left(T \gtrsim 10^{4} \mathrm{~K}\right)$ limita la densidad al rango $n_{e} \lesssim 180 \mathrm{~cm}^{-3}$; es una estimación cruda, ya que no se realiza ningún tipo de consideración sobre el volumen emisor, ni en rayos- $\mathrm{X}$ ni en el óptico. Sin embargo, la temperatura y densidad estimadas por Hardcastle et al. (2012, desde donde se deriva la relación con la temperatura y densidad del gas óptico) se obtuvieron bajo condiciones de abundancia sub-solar. Por este motivo fue necesario cambiar los modelos de IOC, para adaptarlos a las condiciones físicas que se desprenden de la hipótesis de equilibrio de presiones.

En la Figura 6.14 se comparan las siguientes configuraciones:

I. Abundancia solar, $n_{e}=10^{2} \mathrm{~cm}^{-3}$ (esta combinación es la misma que se utilizó en los diagramas de la Fig. 6.13, por lo cual se grafica del mismo modo: líneas punteadas, color negro).

II. Abundancia solar, $n_{e}=1 \mathrm{~cm}^{-3}$ : líneas de punto-punto-trazo corto, color verde.

III. Abundancia de la Nube Mayor de Magallanes (LMC, tal como se define en A08), $n_{e}=$ $1 \mathrm{~cm}^{-3}$ : líneas de punto-trazo corto, color magenta.

Se utilizaron los modelos con densidad de $1 \mathrm{~cm}^{-3}$; este es el conjunto de menor densidad posible dentro de la librería MAPPINGS III que permite realizar las comparaciones deseadas. En la Fig. 6.14 se utiliza el diagrama formado por $[\mathrm{OII}] \lambda 3727 /[\mathrm{OIII}] \lambda 5007$ vs $\mathrm{HeII} / \mathrm{H} \beta$ porque resulta ser la proyección más ilustrativa del diagrama $3 \mathrm{D}$ formado por $[\mathrm{OII}] \lambda 3727 /[\mathrm{OIII}] \lambda 5007$ vs [NeIII] $\lambda 3869 /[\mathrm{O}$ II] $\lambda 3727$ vs HeII/H $\beta$ que se mencionaba anteriormente. Por simplicidad sólo se ilustran dos casos: el comportamiento de los modelos (y la consecuente respuesta de las observaciones) ante variaciones en la densidad, manteniendo fija la abundancia solar (panel izquierdo), y ante variaciones en la abundancia, manteniendo fija la densidad en el valor mínimo extremo (panel derecho). Para evaluar las variaciones en densidad se tomaron los dos valores extremos disponibles en la librería, en el rango que determina la condición de equilibrio de presión $\left(n_{e}=1-100 \mathrm{~cm}^{-3}\right)$. En este caso la abundancia se mantiene fija al valor solar. Para evaluar las variaciones en la abundancia se comparan el valor solar (estándar) con los valores correspondientes a la Nube Mayor de Magallanes (LMC, por su nombre en inglés Large Magellanic Cloud), por tratarse del conjunto que mejor se adecua a las abundancias derivadas por Hardcastle et al. (2012). Los parámetros magnéticos y el rango de velocidades 
Figura 6.14. 3C 305. Comparación de modelos de IOC variando densidades y abundancias.
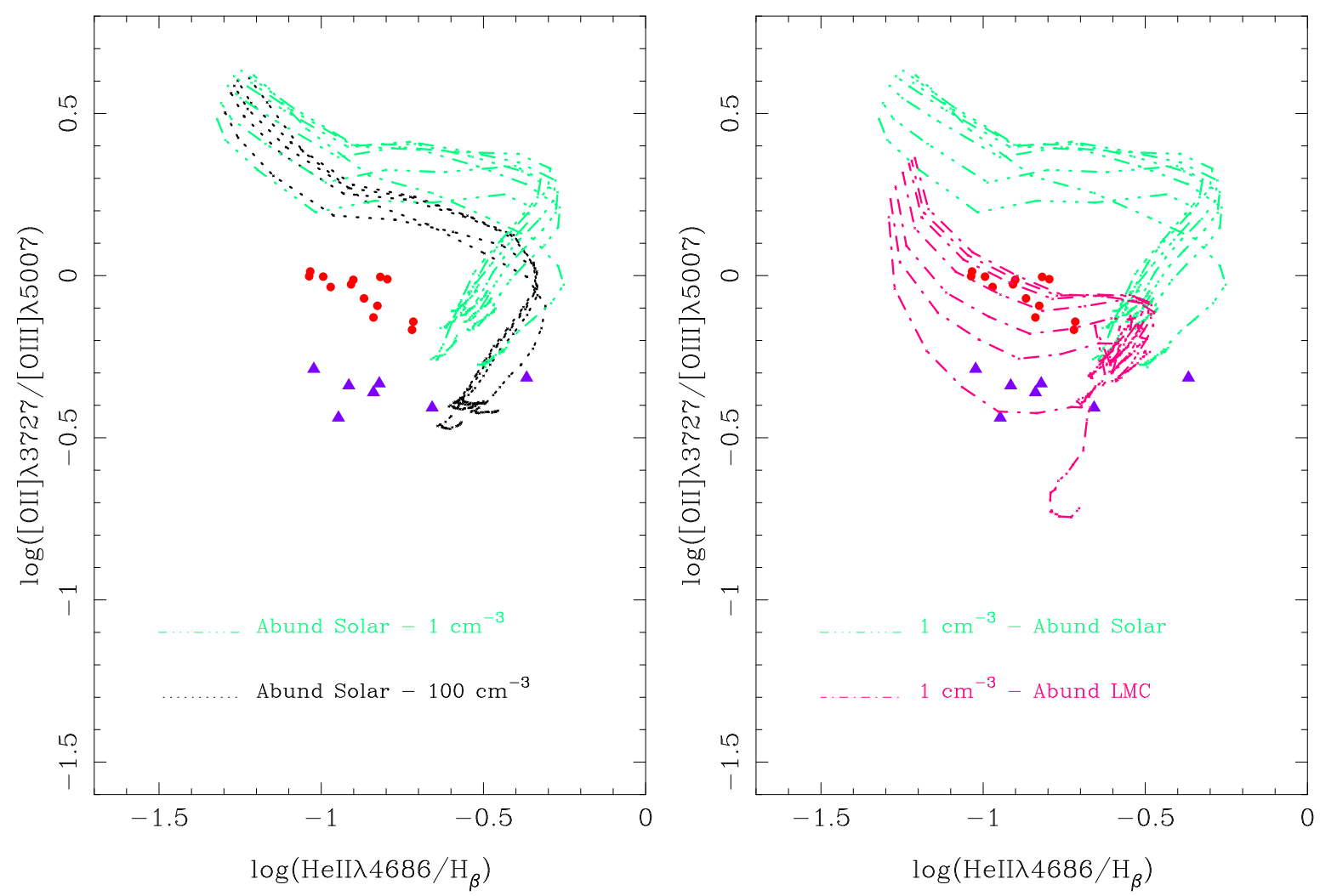

Izquierda: comparación entre modelos de igual abundancia (solar) para dos valores de densidad: $n_{e}=$ $1 \mathrm{~cm}^{-3}$ (líneas de punto-punto-trazo corto, color verde) y $n_{e}=10^{2} \mathrm{~cm}^{-3}$ (línea punteada, color negro, como en la Fig. 6.13). Derecha: comparación entre modelos de igual densidad $\left(n_{e}=1 \mathrm{~cm}^{-3}\right)$ para dos valores de abundancia: solar (como en el panel izquierdo), y de la Nube Mayor de Magallanes (LMC, líneas de punto-trazo corto, color magenta). Las observaciones de 3C 305 se mantienen como en la Fig. 6.13. 
son los mismos que los de la Fig. 6.13.

Del panel izquierdo de la Fig. 6.14 se desprende que las observaciones no pueden reproducirse si sólo se considera un medio más diluido, manteniendo la abundancia solar. El mejor ajuste se obtiene cuando la disminución de la densidad ambiental se acompaña con la reducción de las abundancias metálicas (panel derecho). Por lo tanto, este resultado permite comprobar que efectivamente las nebulosas ópticas están en equilibrio de presiones con el gas caliente, que domina la emisión en rayos-X blandos, tal como propusieran Hardcastle et al. (2012).

Se obtiene, entonces, que la densidad típica del gas ionizado es de $n_{e} \sim 1 \mathrm{~cm}^{-3}$. Bajo la hipótesis del equilibrio de presión, la temperatura alcanza valores altos, en torno a $T \sim 10^{6} \mathrm{~K}$. Cuando se analizan las condiciones del gas dentro de la estructura de una onda de choque, se encuentra que la temperatura típica de las zonas radiativa de alta temperatura, y de la zona de enfriamiento fuera del equilibrio (discutidas en la Sección 2.4.3, e indicadas como Regiones 2 y 3 , respectivamente) ronda, justamente, $T \sim 10^{6} \mathrm{~K}$. Más aún, es en estas zonas donde los modelos predicen la emisión en los rangos UV y rayos-X blandos.

\subsubsection{Resumen}

Las condiciones de ionización en la EELR se estudiaron en dos etapas. Se analizaron los resultados de los modelos de IOC, condicionando la densidad ambiental de acuerdo a la información proveniente del mismo material de la EELR. Se encontró que los modelos que mejor se aproximan a las observaciones son aquellos en los cuales las ondas de choque se propagan en un medio de baja densidad, y con velocidades en el rango $300<v_{s}<500 \mathrm{~km} \mathrm{~s}^{-1}$. Como las líneas de baja ionización del espectro son especialmente intensas, se deduce que existe una contribución importante a la emisión total proveniente de la zona de recombinación. Sin embargo, a la hora de poder reproducir las intensidades observadas esta contribución no es suficiente, siendo absolutamente necesario contemplar también la emisión de la zona precursora.

Luego, como segunda etapa, se investigó el comportamiento de los modelos ante variaciones en la densidad y abundancia del MIE, para contrastar estos resultados con aquellos obtenidos por Hardcastle et al. (2012) en la banda de rayos-X. Las variaciones propuestas en los modelos se sustentan en los parámetros que estos autores derivaron para la fase del MIE responsable de la emisión en rayos-X blandos, que a su vez, sugieren que podría existir equilibrio de presiones entre las dos fases del medio involucradas (rayos-X y óptico). Como resultado de estos cambios se encontró que el mejor ajuste para las observaciones de la EELR en el óptico se obtiene con los modelos de IOC de más baja densidad y abundancia. Esto es, $n_{e} \sim 1 \mathrm{~cm}^{-3}$ y abundancias equivalentes a las de la Nube Mayor de Magallanes, valor comparable al derivado del análisis de la emisión en rayos-X (0.1-0.2 del valor solar).

La relación entre densidad y temperatura que se desprende de la condición de equilibrio de presiones, establece que la temperatura en el gas óptico ronda $T \sim 10^{6} \mathrm{~K}$. Los modelos de IOC predicen que la temperatura en la zona de recombinación, detrás del frente de choque, son tan altas como indica en este caso el resultado de las condiciones de equilibrio. Como, según las hipótesis de estos modelos, la mayor contribución a la emisión en líneas de baja ionización se produce en esa zona, se obtiene absoluta consistencia entre ambos resultados.

El aumento en la emisión global, que se manifiesta claramente en el espectro GMOS (ver Fig 4.8 y Sección 5.6) se explica mediante la interacción entre los radio-jets y el medio. Durante esta interacción se inyectan enormes cantidades de energía mecánica en el sistema gaseoso, desencadenando así ondas de choque muy rápidas y muy potentes. La capacidad ionizante está directamente relacionada con la velocidad de propagación: se obtiene un campo ionizante más duro cuanto mayor sea la velocidad la onda (ver Fig 2.6). Los fotones de ese 
campo local generan la emisión del precursor radiativo (la contribución es muy importante), que debe sumarse a la emisión proveniente de la zona de recombinación. Las características de esta zona son muy diferentes respecto de las del precursor, dado que, en la región de recombinación, el gas se está enfriando. Y en ese sentido debe resaltarse que la presencia de flujos (outflows) de material neutro (Morganti et al. 2005) tanto como la intensidad de las líneas de baja excitación son importantes indicadores de la efectividad con la que se produce tal enfriamiento.

La interacción entre los jets y el MIE no sólo provoca la aceleración del material sino que desencadena la emisión del gas. Los modelos de IOC son capaces de reproducir la intensidad relativa del conjunto de líneas de emisión, con el agregado de que existe un rango de validez para esas predicciones dado por las velocidades de propagación de la onda. Ese rango de validez es perfectamente compatible con los resultados derivados del campo de velocidad del gas.

\section{5. $3 \mathrm{C} 321$.}

Este objeto presenta características diferentes según se lo analice en la escala de la emisión óptica, o en la escala de la emisión extendida en radio. Como antecedentes sobre su estudio, existen dos trabajos dedicados a cada una de estas regiones. Robinson et al. (2000) estudiaron la emisión óptica en todas las nebulosas espacialmente resueltas que comprenden la región con emisión de líneas, y llegaron a la conclusión de que el estado de la región responde al mecanismo de fotoionización multifase con poca o nula contribución de procesos de choque. Evans et al. (2008), por su parte, analizaron la emisión en radiofrecuencias, tanto en la escala de los lóbulos como en la región interna, donde las características del jet (en dirección NO) son completamente diferentes. Sus conclusiones indican que, en esta escala, el jet interactúa con la galaxia compañera localizada hacia el NO, lo cual induce el cambio observado en su dirección de propagación.

En el presente trabajo se realiza un estudio comparativo completo entre los modelos de IOC y FMF. La evaluación de estos mecanismos responde a dos factores: por un lado, la posible influencia de la IOC no se ha estudiado con anterioridad, y por el otro, los resultados de Evans et al. (2008) sugieren que la interacción propuesta podría influir sobre el estado del gas en las cercanías de la región de interacción. Si bien Robinson et al. (2000) estudiaron la FMF, el estado de la región sólo se analizó bajo las condiciones del modelo (aquí denominado) $\mathrm{T}$.

En 3C 321 las nebulosas en emisión se pueden resolver espacialmente con claridad. En la Figura 6.15 se indica cada una de ellas con la nomenclatura que se empleará en adelante. El panel izquierdo corresponde a la imagen nebular pura de WFPC2 y el panel derecho, a la línea de emisión [OIII] $\lambda 5007$ del espectro GMOS. Las regiones se identifican como (según la convención adoptada en la Sección 5.7, las distancias se expresan respecto a la galaxia dominante, o núcleo sur):

- A (magenta): es la nebulosa más alejada del sistema, ubicada a una distancia media de 7.9" en dirección NO.

- B (celeste): es la nebulosa (espacialmente resuelta) más cercana a la galaxia compañera, se encuentra a una distancia media de 5.4" hacia el NO.

- $\mathrm{C}_{N}$ (verde): corresponde a la galaxia compañera (o núcleo norte), en el espectro también se puede identificar la existencia de una componente nebular no resuelta, extendida en dirección NO (coordenadas negativas en el espectro 2D). En la imagen nebular pura se observa que la emisión se elonga en esta dirección. La distancia media a la galaxia dominante es de 3.4". - $\mathrm{C}_{S}$ (amarillo): galaxia dominante (núcleo sur, en la terminología de la Sección 5.7). 
Figura 6.15. 3C 321. Identificación de las regiones en emisión.

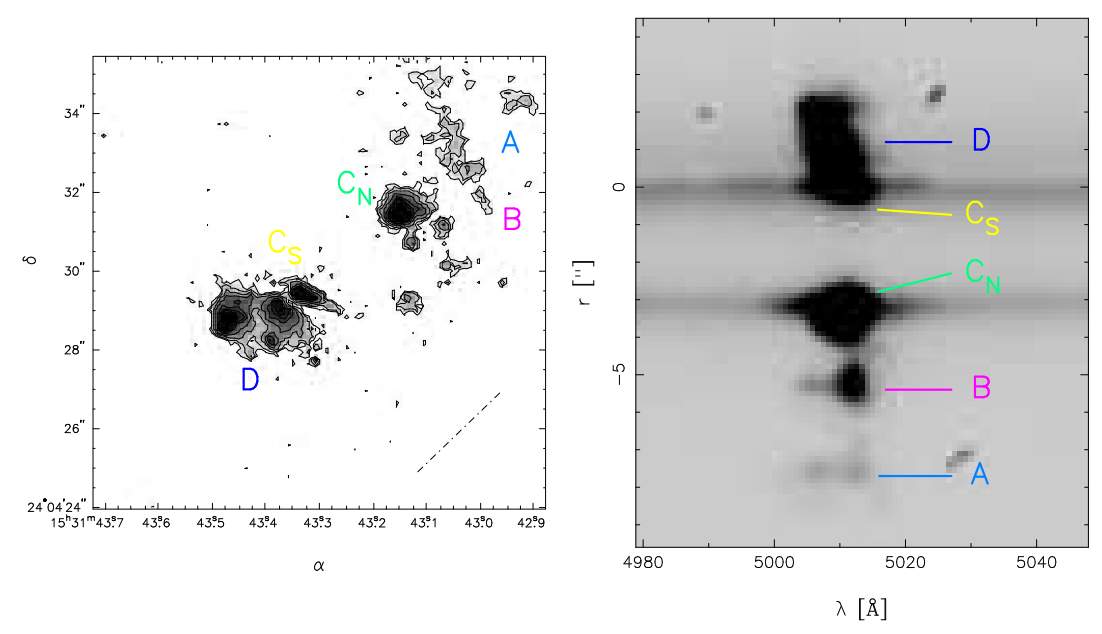

Correspondencia entre las regiones en emisión detectadas por WFPC2/HST (imagen nebular pura, panel izquierdo) y la estructura del [OIII] $\lambda 5007$ en el espectro GMOS/Gemini (panel derecho). Las regiones identificadas como $\mathrm{C}_{S}$ y $\mathrm{C}_{N}$ corresponden a los núcleos sur y norte, respectivamente. En el panel izquierdo se indica la dirección del jet, que coincide aproximadamente con la orientación de la ranura del espectro. Se realzó el contraste en el panel derecho para resaltar la presencia de la estructura A, de bajo brillo superficial.

- D (azul): es la única región nebular ubicada en dirección SE, su distancia media al núcleo sur es de $1.8 \%$

\subsubsection{Mecanismo de ionización}

El espectro presenta características bien diferenciadas entre las nebulosas del NO y la del SE. Concretamente, la zona puramente nebular de mayor excitación corresponde a la región D. Las líneas de mayor excitación del espectro, $[\mathrm{NeV}] \lambda 3424$ y HeII se concentran en las regiones nucleares $\mathrm{C}_{N}$ y $\mathrm{C}_{S}$, siendo la región $\mathrm{D}$ la única zona no nuclear donde también se pueden detectar ambas, incluso con intensidad comparable. En la región D se produce el máximo absoluto de emisión, a la distancia de 0.7", resultado que concuerda con los de Robinson et al. (2000). La emisión en esta región muestra un corte pronunciado a 2.3" (aproximadamente $4 \mathrm{kpc}$ ) del núcleo sur, distancia hasta la cual coexisten líneas de baja y alta excitación.

Hacia el NO, en la región B se detectan prácticamente las mismas líneas de emisión que en la nebulosa SE con la excepción del $[\mathrm{NeV}] \lambda 3424^{20}$. En cambio, sí existe emisión del HeII aunque con menor intensidad que en aquella región. El máximo de emisión en esta zona se produce a 5.2". La región A tiene muy bajo brillo superficial, y lamentablemente sólo se puede detectar la emisión de las líneas más intensas: [OII] $\lambda 3727, \mathrm{H} \beta$ y [OIII] $\lambda \lambda 4959,5007$. El máximo de emisión se produce a 7.6". Aproximadamente en el mismo $\operatorname{lugar}^{21}$ (7.3") se produce un aumento en la emisión del jet, junto con el cambio en su dirección de propagación (Evans et al. 2008).

En la Figura 6.16 se presenta un conjunto de diagramas de diagnóstico, donde se utilizan

\footnotetext{
${ }^{20}$ Tampoco se detecta el complejo de líneas identificados bajo el nombre de [NeIII] $\lambda 3968$; ver Tabla 5.6.

${ }^{21} \mathrm{El}$ PA con que se tomó el espectro utilizado por Robinson et al. (2000) es de $130^{\circ}$, mientras que el espectro GMOS se tomó con $\mathrm{PA}=127^{\circ}$; las diferencias quedan absorbidas por el ancho de la ranura en el espectro GMOS (0.75").
} 
todas las líneas más intensas del espectro, para evaluar los mecanismos de ionización propuestos. Dado que las regiones presentan características espectrales diferentes, los diagramas se construyeron diferenciando claramente cada una de las cinco regiones. Se emplea la convención de colores descripta antes y, para una mayor claridad en la información, también se utilizan símbolos diferentes en cada caso: las regiones ubicadas al NO se grafican con cuadrados, las regiones nucleares con triángulos, y la región SE con círculos. Dentro de las regiones nucleares $\mathrm{C}_{N}$ y $\mathrm{C}_{S}$, los símbolos de mayor tamaño muestran la intensidad que adquieren las líneas en cuestión en la posición del centro galáctico; esta posición se determinó, como en todos los casos, donde se aprecia la mayor emisión del continuo. Todos los diagramas incluyen los modelos de IOC (líneas punteadas, en negro; las velocidades se indican con líneas continuas, en magenta oscuro) cuya densidad ambiental preshock es de $n_{e}=10^{2} \mathrm{~cm}^{-3}$ (de acuerdo con las estimaciones de Robinson et al. 2000, 2002) y abundancia solar, y los cuatro modelos de FMF. Los diagramas se eligieron de modo tal de evitar la repetición en el análisis de la información presentada por Robinson et al. (2000, algunos diagramas se repiten porque son necesarios en el marco de la evaluación de IOC). En ese trabajo se evaluaron únicamente modelos de fotoionización y, dentro de la FMF, sólo el modelo T; también el modelo de fotoionización simple fue ampliamente discutido, motivo por el cual no se aborda aquí.

En términos generales las diferencias que se observan en los espectros de las distintas regiones no se manifiestan en los cocientes (y por ende, en los diagramas), con la excepción obvia de aquellas diferencias inherentes a la ausencia de alguna de las líneas en cuestión. El hecho de que los cocientes se mantengan aproximadamente constantes a lo largo de todo el complejo nebular también había sido notado por Robinson et al. (2000). En el Apéndice E se graficaron los diagramas de la Fig. 6.16 con los datos de estos autores, para mostrar no sólo la equivalencia entre los resultados, sino también la de las diferentes metodologías empleadas (en el citado trabajo y en esta Tesis) para obtenerlos.

El diagrama I es el único que reúne las cinco regiones. Es el único diagrama significativo que puede construirse con las líneas presentes en la región A; a pesar de que la muestra de esta región es pequeña, se distingue claramente apartada de todas las otras regiones. Los valores promedio de los cocientes involucrados en esta zona son $\langle\log ([\mathrm{OII}] /[\mathrm{OIII}])\rangle=-0.24$ y $\langle\log ([\mathrm{OIII}] / \mathrm{H} \beta)\rangle=0.9$. Si el comportamiento de la región A se analiza bajo la FMF, se observa una tendencia en favor de los modelos $\mathrm{T}$ y $\mathrm{H}$. El ajuste se produce en la zona para la cual $A_{M / I} \simeq 1$, lo que estaría indicando que tanto el sistema gaseoso MB como el IB subtienden aproximadamente el mismo ángulo desde el objeto central. En virtud de la disposición espacial del material, tal como se observa en la Fig. 6.15, esta hipótesis es poco probable, particularmente por la presencia, distribución y tamaño (proyectados) de la nebulosa $\mathrm{B}^{22}$. Analizada bajo los modelos de IOC, la intensidad de estas líneas en la región A puede reproducirse con shocks de velocidades altas, en el rango $400<v_{s}<500 \mathrm{~km} \mathrm{~s}^{-1}$. El campo de velocidades del gas (ver Fig. 5.12) indica que a 8" en dirección NO, distancia media a la que se encuentra la región A, se observan movimientos (relativamente estables) cuya amplitud de velocidades coincide con ese rango. El comportamiento de las regiones restantes $\left(\mathrm{B}, \mathrm{C}_{N}, \mathrm{C}_{S}\right.$ y $\left.\mathrm{D}\right)$ se caracteriza por valores menores en el cociente $[\mathrm{OII}] /[\mathrm{OIII}]$ y mayores en $[\mathrm{OIII}] / \mathrm{H} \beta$, con lo cual su posición en el diagrama las ubica en la zona de mayor excitación, en el marco de la FMF; en esta zona los cuatro modelos disponibles predicen valores muy similares, sin embargo se observa una leve tendencia hacia los modelos M y L. A su vez, los cocientes se ubican dentro de los valores esperados bajo IOC extremadamente violentos, con velocidades en el rango $500 \lesssim v_{s} \lesssim 1000 \mathrm{~km} \mathrm{~s}^{-1}$; el campo de velocidades evidencia movimientos de velocidad extrema (consistentes con el límite superior en este rango)

\footnotetext{
${ }^{22}$ En rigor, debería aclararse cuál de los dos núcleos se considera como la referencia desde la cual se miden los ángulos, sin embargo, por las características de las nebulosas, la conclusión no se ve afectada por tal elección.
} 
en la región $\mathrm{C}_{S}$, y de amplitud algo menor en las regiones $\mathrm{B}$ y $\mathrm{C}_{N}\left(\lesssim 600 \mathrm{~km} \mathrm{~s}^{-1}\right)$.

En el diagrama II se evalúan los dos ejes de excitación: HeII/H $\beta$ versus [OIII] $\lambda 5007 / \mathrm{H} \beta$. Se observa una notable uniformidad en el comportamiento de estos cocientes, particularmente en $\mathrm{HeII} / \mathrm{H} \beta$, en las cuatro regiones donde es posible encontrar emisión de $\mathrm{He}$ : $\mathrm{B}, \mathrm{C}_{N}, \mathrm{C}_{S} \mathrm{y}$ $\mathrm{D}$; uniformidad que se caracteriza por superar las predicciones de ambos modelos. A partir de este diagrama ya no es posible identificar una tendencia hacia ningún modelo de FMF particular en ninguna de estas regiones.

Los diagramas III y IV utilizan combinaciones con el [Nev] $\lambda 3424$; esta línea sólo está presente en tres regiones $\mathrm{C}_{N}, \mathrm{C}_{S}$ y $\mathrm{D}$. Se produce un ajuste notable en favor de la FMF, en el extremo de mayor excitación. Por el hecho de involucrar al [Nev], este resultado es esperable en términos teóricos, como se discutió en Secciones anteriores. Sin embargo también es importante porque refuerza la tendencia de todos los diagramas a mostrar que el ajuste se produce siempre en el extremo de mayor excitación, aún cuando se utilizan líneas de excitación baja ([OII] $\lambda 3727, \mathrm{H} \beta)$. Se puede identificar una subregión $\mathrm{C}_{N}$, asociada a un grupo levemente apartado y caracterizado por $\langle\log ([\mathrm{OII}] /[\mathrm{Nev}])\rangle \sim 0.5 \mathrm{y}\langle\log ([\mathrm{NeV}] /[\mathrm{NeII}])\rangle \sim-0.2$; esta subregión corresponde a la zona más interna de $\mathrm{C}_{N}$, que a su vez es el lugar donde se observa la mayor amplitud de velocidad de la región. De todos modos, los modelos de IOC no son capaces de reproducir ni esta submuestra ni el resto de la región $\mathrm{C}_{N}$, ni tampoco la región $\mathrm{C}_{S}$ donde se observa claramente la presencia de outflows con altísima amplitud de velocidades, aún si se considerara el límite superior de velocidades del shock.

En el diagrama $\mathbf{V}$ se mantiene la tendencia señalada en cuanto a la FMF. Pero también se advierte que cuando se emplean líneas de excitación media, como [NeIII] $\lambda 3869$ (o incluso las controvertidas líneas del [OIII], cuyos diagramas no se muestran) se "recupera" el ajuste en favor de IOC dentro del rango de velocidades que marca el campo de velocidad del gas, como también sugiere el diagrama $\mathbf{I}$.

A raíz de esta aparente ambigüedad se evaluaron dos tipos de diagramas tridimensionales, uno con el cociente [NeIII] $\lambda 3869 /[\mathrm{OII}] \lambda 3727$ y otro con el cociente [OII] $\lambda 3727 /[\mathrm{NeV}] \lambda 3424$, de manera tal de combinar estados de ionización bajo, medio y alto. Los diagramas (en la Fig. 6.16 se muestran las proyecciones 2D) fueron construidos como:

- [OIII] $\lambda 5007 / \mathrm{H} \beta$ vs. HeII/H $\beta$ vs. [NeIII] $\lambda 3869 /[\mathrm{OII}] \lambda 3727$, y luego se reemplazó [OIII]/H $\beta$ en abscisas por $[\mathrm{OII}] \lambda 3727 /[\mathrm{OIII}] \lambda 5007$.

- [OIII $] \lambda 5007 / \mathrm{H} \beta$ vs. HeII/H $\beta$ vs. [OII] $] \lambda 3727 /[\mathrm{Nev}] \lambda 3424$; aquí también se realizó el mismo cambio de abscisas.

El cambio entre $[\mathrm{OIII}] \lambda 5007 / \mathrm{H} \beta$ y $[\mathrm{OII}] \lambda 3727 /[\mathrm{O}$ III $] \lambda 5007$ se implementó para estudiar posibles cambios en los comportamientos de los modelos y las observaciones con líneas de excitación baja.

De este análisis resultan cuatro diagramas 3D que simultáneamente resuelven las degeneraciones (multi-valuaciones) observadas en los diagramas bidimensionales y la ambigüedad sobre el mecanismo de ionización. El diagrama VI ([OII] $\lambda 3727 /[\mathrm{OIII}] \lambda 5007$ vs. HeII/H $\beta$ ) completa el conjunto de proyecciones más significativas de tales diagramas.

En cualquiera de los casos se observa que las cuatro regiones $\mathrm{B}, \mathrm{C}_{N}, \mathrm{C}_{S}$ y D responden de manera indudable al mecanismo de FMF. Los cambios en abscisas no producen ningún tipo de modificación. Incluso se obtiene el mismo resultado para los diagramas 3D del primer grupo, esto es, aquellos que utilizan los cocientes [NeII] $] \lambda 3869 /[\mathrm{OII}] \lambda 3727$ о [OII] $\lambda 3727 /[\mathrm{OIII}] \lambda 5007$, que son los que indican una tendencia en favor de la IOC según el análisis 2D (ver diagramas I y V de la Fig. 6.16). 
Figura 6.16. 3C 321. Evaluación de los mecanismos de ionización.
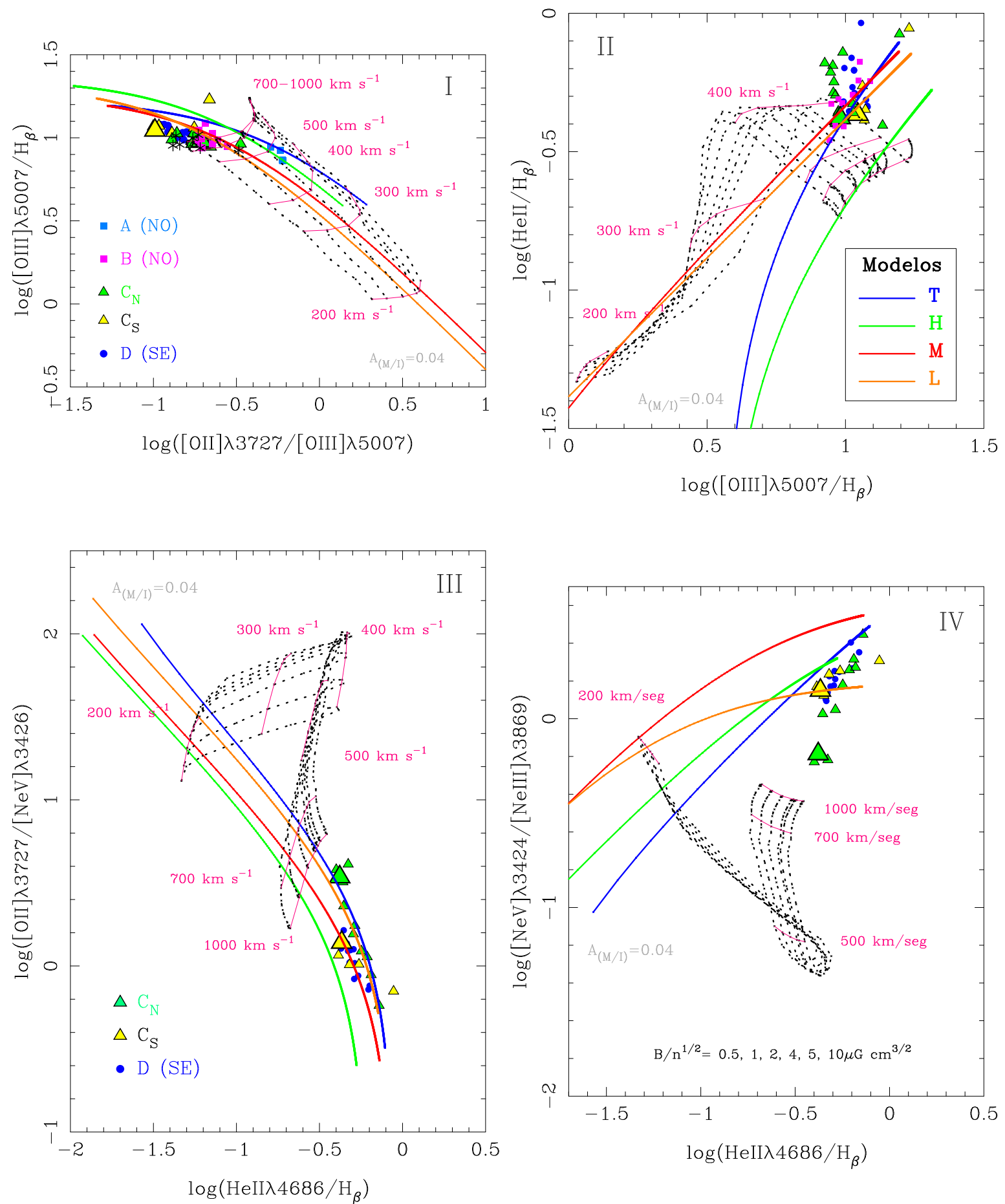
Fig. 6.16: continuación
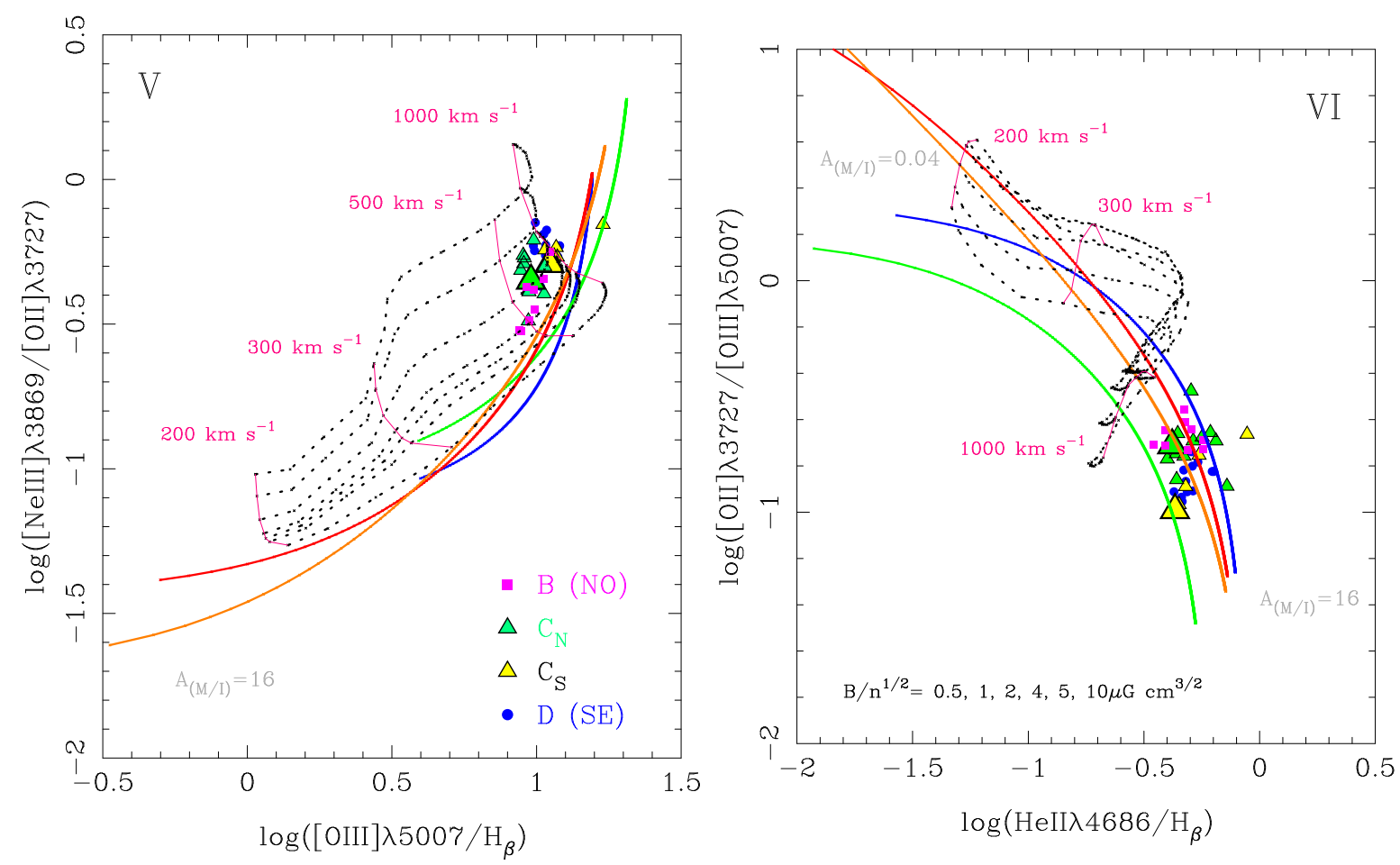

Con respecto a este comportamiento, el análisis 3D muestra que tal ajuste es ficticio. Los diagramas 2D donde se aprecia que las observaciones se pueden reproducir con los modelos de IOC (I y V) están formados por líneas de excitación media ([OIII] y [NeIII]) y baja ([OII] y $\mathrm{H} \beta$ ). Sin embargo, cuando se utiliza un tercer eje con una de las líneas de mayor excitación (HeII) se comprueba que se trata de un efecto de proyección. Esto ocurre por la curvatura que adquieren todos los modelos involucrados (tanto IOC como FMF) en el espacio determinado por cualesquiera de las combinaciones estudiadas; y el mismo efecto permite comprobar que las observaciones no están localizadas en el rango de valores que predice la IOC.

La influencia de las líneas de mayor excitación se puede apreciar en las proyecciones dadas por los diagramas II y VI donde interviene una única línea de excitación alta (HeII) y la tendencia del ajuste cambia drásticamente. El efecto más notorio se observa en las proyecciones plasmadas en los diagramas III y IV, donde interviene dos de estas líneas.

Además del ajuste que resulta de los diagramas 3D, cuya eficacia radica en la curvatura que adquieren los modelos cuando se consideran líneas de excitación alta, cabe destacar que en las regiones (que aquí se denominaron) $\mathrm{C}_{S}$ y $\mathrm{D}$ se detectó emisión proveniente de las líneas coronales [Fevir] $\lambda 6086$ y $[\mathrm{Fex}] \lambda 6374$ (Robinson et al. 2000). Como se ha señalado en otras oportunidades, los modelos H, M y L de FMF fueron desarrollados con el propósito de reproducir líneas coronales (y éstas en particular; Binette et al. 1997), y también se ha mencionado que tanto [FeviI] como [Nev] se forman en condiciones similares (Stasińska 1984). Luego, la presencia de las líneas del hierro en el espectro nebular se convierte en pieza clave en favor del ajuste observado en las regiones $\mathrm{C}_{S}$ y D, y de forma extensiva, en la validación del ajuste en la región $\mathrm{C}_{N}$. Dicho de otro modo; podría esperarse un buen ajuste de la FMF las regiones $\mathrm{C}_{S}$ y $\mathrm{D}$ por el hecho de conocer la existencia de la emisión de [FeviI] $\lambda 6086$ y [Fex] $\lambda 6374$, de conocer la relación entre estas líneas y los modelos, y de saber que, si [FeviI] y $[\mathrm{Nev}]$ se forman en condiciones similares, entonces los modelos también "deben" ajustar 
con $[\mathrm{Nev}]$. Ahora bien, cuando se omite el [Nev] y se incorpora el [NeIII] $\lambda 3869$ se pierde esa conexión por la cual el ajuste podría resultar sospechoso (porque no hay relación entre [FeviI] y [NeIII], y porque [Nev] y [NeIII] definitivamente no se forman en las mismas condiciones; Stasińska 1984), y sin embargo los modelos de FMF siguen siendo capaces de reproducir las observaciones sin ningún tipo de ambigüedad. Por lo tanto el ajuste se sustenta tanto desde punto de vista teórico (por las razones expuestas) como desde punto de vista observacional: porque la región $\mathrm{C}_{N}$ muestra un comportamiento indistinguible del de $\mathrm{C}_{S}$ o $\mathrm{D}$, pero allí no hay indicios de que exista emisión ni de [Fevir] ni de [Fex] ni de [Nev].

Como la ambigüedad sólo se puede resolver cuando el análisis contempla líneas de excitación alta, por el momento no se pueden obtener resultados determinantes sobre el estado de la región A.

\subsubsection{Resumen}

Se estudió el estado de excitación e ionización en las cinco concentraciones gaseosas de 3C 321 donde se observa emisión de líneas. Dos de esas nebulosas corresponden a las regiones nucleares $\mathrm{C}_{S} \mathrm{y} \mathrm{C}_{N}$. La región $\mathrm{C}_{N}$ no es estrictamente circumnuclear, sino que muestra indicios de contener una región nebular en dirección $\mathrm{NO}$ que no puede resolverse espacialmente con el espectro GMOS.

Hacia el SE sólo se observa la región D, cuyo estado de excitación/ionización es alto; todas las líneas de esta región están presentes hasta una distancia correspondiente al $73 \%$ de la extensión del [OIII] $\lambda 5007$, a partir de donde la intensidad cae súbitamente en todos los casos. Las líneas de mayor excitación del espectro, HeII y [Nev] $\lambda 3424$, muestran exactamente el mismo comportamiento que las demás. El hecho de que toda la emisión esté igualmente extendida (es decir, que la emisión de todas las especies presentes y en prácticamente todos los estados de ionización observados se detecte hasta la misma distancia) es curioso desde el punto de vista de la relación entre el parámetro de ionización y la estructura de ionización; esto es, que líneas de excitación alta y baja no pueden producirse bajo los mismos valores de $U$. Para que esto suceda, debe existir algún tipo de relación entre la distancia nebulosa-fuente central y la densidad de la nebulosa cuyo estudio excede el presente análisis.

Hacia el NO se observan dos nebulosas: la región B es la más cercana al núcleo norte y la región A es la más alejada y más tenue del sistema. En esta última sólo es posible detectar la emisión proveniente de las líneas más intensas del espectro [OIII] $\lambda \lambda 4959,5007$, [OII] $\lambda 3727$ y $\mathrm{H} \beta$. El estado de excitación en la región $\mathrm{B}$ es menor que en la región $\mathrm{D}$; en $\mathrm{B}$ no se detecta emisión del $[\mathrm{NeV}] \mathrm{y}$, en términos generales, la intensidad del conjunto de líneas presentes representa alrededor del $25 \%$ de la intensidad observada en D.

La cinemática del complejo nebular indica la existencia de movimientos de alta velocidad, pero estables. Las amplitudes de velocidad medida alcanzan 500-600 $\mathrm{km} \mathrm{s}^{-1}$. La única excepción se encuentra en la región nuclear $\mathrm{C}_{S}$ donde claramente se puede identificar la presencia de outflows, cuyas velocidades respecto de la velocidad sistémica de la galaxia son alrededor de $\pm 1000 \mathrm{~km} \mathrm{~s}^{-1}$; se trata de movimientos estrictamente confinados a la zona más interna de la región $\mathrm{C}_{S}$.

La principal diferencia entre las cinco regiones queda establecida por la intensidad de las líneas. Sin embargo, los cocientes de líneas presentan un comportamiento llamativamente uniforme cuando se comparan las regiones entre sí. Tal uniformidad no puede inferirse de ninguna manera a partir de los espectros individuales de cada región. Este aspecto también fue señalado por Robinson et al. (2000). La única potencial excepción podría encontrarse en la región A.

Los mecanismos de IOC y FMF se evaluaron a través de diferentes diagramas, es decir, diferentes combinaciones entre los cocientes. En principio se observa que cuando se utilizan 
líneas de excitación alta (HeII y [Nev]) los modelos de FMF pueden reproducir las observaciones (diagramas III y IV), pero que cuando se utilizan líneas de excitación media ([OIII] y $[\mathrm{NeIII}]$ ), resulta una tendencia en favor del mecanismo de IOC (diagramas I y V). Para resolver la indeterminación se estudiaron los comportamientos de los modelos (IOC y FMF) y las observaciones (región por región) en diagramas 3D. Los diagramas se construyeron con los cocientes donde la ambigüedad es más evidente, y con [OIII $] \lambda 5007 / \mathrm{H} \beta$ y HeII/H $\beta$, y luego [OII] $\lambda 3727 /[\mathrm{OIII}] \lambda 5007$ y HeII/H $\beta$ como ejes de excitación; de esta manera el análisis contempla líneas de todos los estados de excitación observados en forma simultánea (en un mismo diagrama). Desde el punto de vista teórico, los diagramas tridimensionales resuelven las multi-valuaciones de los diagramas $2 \mathrm{D}$ (en los modelos de IOC) y permiten identificar que las curvas de los modelos de IOC y FMF no siempre están superpuestas, sino que ocupan regiones diferentes del espacio determinado por los ejes en cuestión. Desde el punto de vista observacional, se comprueba la uniformidad de los cocientes de líneas entre regiones (en otras palabras, las muestras de cada región se mantienen siempre juntas). El resultado del análisis de estos diagramas indica sin ningún tipo de ambigüedad que las observaciones se reproducen con el mecanismo de FMF, por lo tanto, el ajuste que se infiere en el diagrama $\mathbf{V}$ (e incluso en el diagrama I para las regiones $\mathrm{B}, \mathrm{C}_{N}, \mathrm{C}_{S}$ y D) es ficticio. Sin embargo, no es posible identificar cuál de los cuatro modelos de FMF ajusta mejor a las observaciones, esto se debe a que el ajuste global se produce en la zona de valores altos del parámetro $A_{M / I}$, donde las diferencias entre los cuatro modelos ( T, H, M y L) son mínimas.

Como se mencionó antes, la única posible excepción al comportamiento generalizado podría encontrarse en la región A. A la distancia característica de esta región se produce la deflexión y el ensanchamiento del jet interno (jet característico de una fuente FRI), que luego continúa su camino (ya con la apariencia típica de una fuente FRII) hacia el hot spot del NO (Evans et al. 2008). El campo de velocidades muestra signos de perturbación en torno a esta zona (también fueron reportados por Robinson et al. 2000), con movimientos cuya amplitud alcanza alrededor de $500 \mathrm{~km} \mathrm{~s}^{-1}$. Debido a la escasa disponibilidad de líneas de emisión en la región A, la factibilidad de los mecanismos de ionización se puede evaluar sólo a través del diagrama I. Según él, los cocientes de la región pueden reproducirse mediante IOC con velocidades compatibles con el resultado cinemático, que a su vez, marcaría una estrecha relación con el comportamiento del jet, tal como se observa en ondas de radio. Lamentablemente, los datos de esta región son insuficientes para explorar esta hipótesis en profundidad.

A diferencia de lo que ocurre con otros objetos estudiados en esta Tesis, en 3C 321 no se observan correspondencias entre los resultados del análisis cinemático (el campo de velocidades obtenido a partir de la descomposición Gaussiana del perfil del [OIII] $\lambda 5007$ ) con los resultados del análisis del estado de ionización. El ejemplo más llamativo de este comportamiento se observa en la región circumnuclear $\mathrm{C}_{S}$. Debe señalarse, sin embargo, que también 3C 321 es el primer objeto de la muestra donde se observan movimientos de alta velocidad extendidos (en el sentido de que se detectan con continuidad sobre rangos de distancia grandes) y estables (las amplitudes de velocidades se mantienen relativamente constantes sobre esos rangos de distancia), mientras que en todos los otros casos, los movimientos de alta velocidad responden a fenómenos locales que pueden asociarse a perturbaciones espacialmente acotadas (la región $\mathrm{C}_{S}$ es una excepción en este sentido).

\section{6. $3 \mathrm{C} 381$.}

La mayor parte del contenido de esta Sección fue publicado en Reynaldi \& Feinstein (2013a). 
En la Sección 5.8 se analizaron las características del campo de velocidades en 3C 381 (Fig. 5.14). Se encontró que existe un claro movimiento ordenado, una curva de rotación, que incluso es apreciable desde la propia forma de las líneas de emisión en el espectro 2-D (Fig. 4.10). Sin embargo, los perfiles de emisión presentan múltiples componentes, muchas de las cuales indican la existencia de movimientos violentos apartados de la curva de rotación. Los procesos asociados a estos movimientos, es decir, los procesos que los desencadenan, pueden estar relacionados con el comportamiento de las estructuras observadas en radiofrecuencias, particularmente en lo que concierne al estado del gas una vez que es atravesado por ellas. En los casos más evidentes, existe superposición espacial y coincidencias morfológicas entre el gas óptico y el radio-plasma. Pero a partir del trabajo pionero de Solórzano-Iñarrea, Tadhunter \& Axon (2001) se pudo comprobar que los efectos de la interacción pueden encontrarse, incluso, cuando las estructuras en radio se encuentren localizadas a grandes distancias de la EELR.

3C 381 es uno de esos ejemplos donde las escalas de la emisión son completamente diferentes: la extensión de la EELR ${ }^{23}$ es de 12", mientras que la de la emisión sincrotrón es de 74". Sin embargo, a través de la cinemática, la EELR muestra indicios de que han existido o todavía existen procesos violentos dentro del sistema gaseoso. El estudio de los mecanismos de excitación e ionización del material de la EELR no puede dejar de lado su estado cinemático.

\subsubsection{Mecanismo de ionización}

El modelo de fotoionización simple se puede evaluar directamente a través del parámetro de ionización $U$. Mediante la relación entre $U$ y el cociente de líneas [OIII] $\lambda 5007 /[\mathrm{OII}] \lambda 3727$ (ver Ec. 2.2) se puede estimar la cantidad de fotones ionizantes que recibe la nebulosa a una cierta distancia $r$ del centro. Para ello es necesario conocer la densidad. Robinson et al. (2002) realizaron un análisis espectroscópico de la región con el mismo ángulo de posición que el empleado en el espectro GMOS $\left(\mathrm{PA}=155^{\circ}\right)$ y obtuvieron que la densidad del gas a la distancia de $1.4 \mathrm{kpc}$ del núcleo es de $n_{e}=370 \mathrm{~cm}^{-1}$.

Dado que el espectro long-slit permite conocer cómo se comportan las líneas de emisión conforme la distancia al núcleo aumenta, también es posible hacer el seguimiento espacial en el cociente [OІІі] $\lambda 5007 /[\mathrm{OII}] \lambda 3727$, y por ende, en $U$. En la Figura 6.17 se muestra este comportamiento. A la distancia de $1.4 \mathrm{kpc}$ se obtiene $U=9.35 \times 10^{-2}$. Luego, conociendo la densidad allí, se puede estimar la cantidad de fotones ionizantes emitidos por el núcleo activo $(Q)$ mediante la Ec. 2.1. Se puede suponer que $Q$ es constante, aún si la densidad sufriera variaciones en función de la distancia al centro. De este modo se obtiene que $Q=$ $2.4 \times 10^{56}$ fotones $\mathrm{s}^{-1}$. Los valores de $U$ y $Q$ deben considerarse cotas mínimas, dado que ambos están afectados por la posible inclinación del objeto respecto de la visual (Reynaldi \& Feinstein 2013a).

Este valor de $Q$ es comparable al que obtuvieron Robinson et al. $(2000)^{24}$ para 3C 273 , el quasar RL más potente a bajo redshift $\left(Q_{3 C} 273=3.8 \times 10^{56}\right.$ fotones s$\left.^{-1} ; z=0.1583\right)$. Por otra parte, en un estudio realizado en rayos-X, Hardcastle et al. (2009) mostraron que la luminosidad nuclear asociada al proceso de acreción ${ }^{25}$ (corregida por absorción) es un buen indicador de la potencia del AGN. La luminosidad nuclear de 3C 381 es aproximadamente un orden de magnitud menor que la correspondiente a los quasars (ver la fig. 13 de Hardcastle

\footnotetext{
${ }^{23}$ según el [OIII] $\lambda 5007, \mathrm{PA}=155^{\circ}$. Ver Sección 5.8 .

${ }^{24} \mathrm{El}$ valor usado aquí difiere del publicado por los autores en un factor $4 \pi$; la modificación se realizó para unificar las unidades empleadas.

${ }^{25}$ Para reproducir la emisión nuclear de muchos objetos de su muestra, Hardcastle et al. (2009) emplearon dos componentes. Las dos son leyes de potencia, pero una sufre una importante absorción por parte del material absorbente circunnuclear si éste bloquea la visión directa del núcleo. Esta es la componente asociada al proceso de acreción.
} 
Figura 6.17. 3C 381. Parámetro de ionización

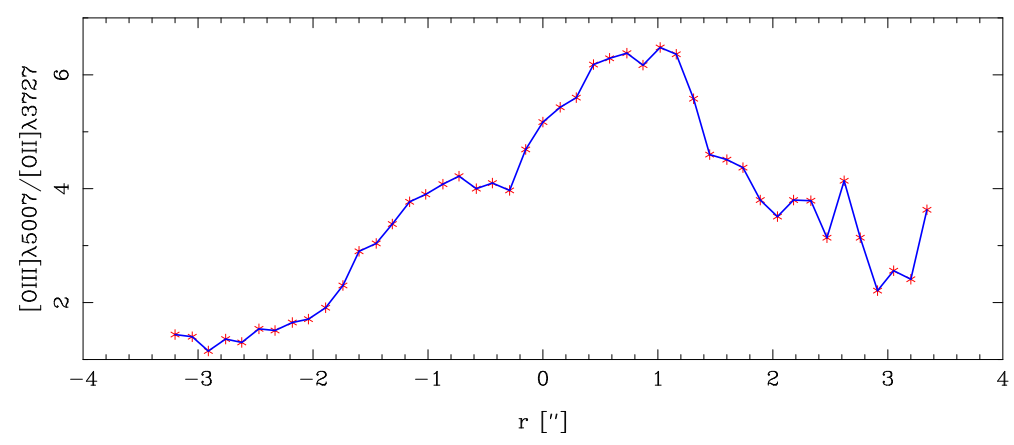

Variación espacial de $U$ expresada según el comportamiento del cociente [OIII] $\lambda 5007 /[\mathrm{OII}] \lambda 3727$ (Penston et al. 1990). Según la convención adoptada en la Sección 5.8, las distancias negativas corresponden a la región SE y las positivas, a la NO. No hay evidencia de dilución geométrica en el comportamiento de $U$; por el contrario se observa un aumento local alrededor de $\sim 1$ " hacia el SE. Todas las líneas del espectro aumentan su emisión en esta zona.

et al. 2009). Aún más, la luminosidad nuclear en [OIII] $\lambda 5007$ también. Por lo tanto es muy probable que el valor de $Q$ obtenido para 3C 381 sea una medición sobreestimada del poder ionizante de esta radiogalaxia.

En cuanto a la evolución espacial de $U$, en virtud de la Ec. 2.1 se espera que este parámetro se comporte como $U \propto n_{e}^{-1} r^{-2}$. Es decir, que sea sensible a la dilución geométrica sufrida por el campo ionizante central y a los cambios en la densidad. La Fig. 6.17 se puede interpretar como el comportamiento de $U$ si la densidad fuera constante (Penston et al. 1990), y allí no hay indicios de dilución geométrica $\left(r^{-2}\right)$ en un rango de distancias considerablemente grande. Por el contrario, el parámetro de ionización muestra un claro aumento en dirección SE, aproximadamente a 1" del centro de la galaxia. En este punto cabe mencionar que todas las líneas del espectro en 3C 381 aumentan su intensidad en esta zona (Sección 5.8), por lo tanto el incremento en el cociente [OIII] $\lambda 5007 /[\mathrm{OII}] \lambda 3727$ es una consecuencia de este comportamiento general. Para que se produzca un aumento semejante en la emisión, la densidad debería caer con la distancia a una velocidad mayor que $r^{-2}$ en escala de kiloparsecs; sin embargo no existen argumentos para sostener esta hipótesis (Reynaldi \& Feinstein 2013a). El comportamiento del cociente de oxígenos podría apartarse significativamente de las predicciones dadas por el modelo de fotoionización central si en el MIE/MIG existiera otra fuente no nuclear de fotones ionizantes. Un ejemplo de este tipo de campo local es el que puede producir una onda de choque radiativa de alta velocidad.

Antes de abordar este mecanismo, es posible analizar algunas características del espectro bajo el modelo de fotoionización multifase (Sección 2.4.2). En particular, el papel que desempeña la línea de emisión HeII. Como se explicó oportunamente, el modelo se basa en las propiedades ópticas de dos sistemas de nubes, siendo las MB las más cercanas al núcleo activo y las que reciben el campo de radiación tal como fue generado. La principal contribución a las líneas de mayor excitación del espectro proviene del sistema MB. La extensión de este sistema queda establecida según la distancia hasta la cual es posible encontrar fotones capaces de ionizar el ion $\mathrm{He}^{+}$(BWS96), los cuales, a su vez, se manifiestan por la presencia de líneas de recombinación del HeII (Osterbrock 1989). Por su parte, la variación de intensidad del HeII está intrínsecamente relacionada con el parámetro $A_{M / I}$, que define la evolución en las condiciones de ionización.

En el espectro de 3C 381, la línea HeII $\lambda 4686$ se extiende a lo largo de 2.5", aproximadamente $8 \mathrm{kpc}$, tanto al SE como al NO. Y en cuanto a su intensidad, a diferencia de lo que 
ocurre, por ejemplo con el [OIII] $\lambda 5007$, no se produce una variación notable: en el extremo de cada EELR la intensidad del HeII cae al $\sim 10 \%$ de su máximo valor, que se produce en los alrededores del núcleo, mientras que la intensidad del [OIII] $\lambda 5007$ (la estructura más importante del espectro) cae a menos de $5 \%$ de su máximo a lo largo de la misma extensión.

Estas dos características representan sendos problemas para el modelo multifase. Por un lado, no puede hablarse de modelo multifase en los \pm 2.5 " internos, dado que en esta zona la presencia de nubes IB es despreciable (BWS96). Luego, correspondería aplicar nuevamente las condiciones del modelo de fotoionización simple, ya discutido en párrafos anteriores. Por otro lado, dado que las condiciones de ionización varían conforme lo hace el cociente HeII/H $\beta$ (parametrizado por $A_{M / I}$ ) conviene analizar uno de los diagramas de diagnóstico más importante del modelo. La Figura 6.18 presenta el diagrama formado por el cociente de oxígenos y HeII/H $\beta$ como eje de excitación; los cuatro modelos multifase se indican con sus cuatro colores diferentes, la cruz (en negro) indica la posición para la cual se obtiene $A_{M / I}=1$ en cada modelo. Como se indica en el trabajo original de BWS96 (fig. 7), las dos secuencias de ionización $\left(U_{\mathrm{y}} A_{M / I}\right)$ son aproximadamente perpendiculares en este diagrama, hecho que lo convierte en una herramienta de particular utilidad. La banda (en amarillo) que atraviesa el diagrama corresponde a la localización aproximada ${ }^{26}$ de la secuencia de ionización dada por $U$. Las observaciones de 3C 381 se representan con distintos símbolos, triángulos (violeta) para la región SE y puntos (rojo) para la NO. Las intensidades obtenidas en la región central se muestran sólo como referencia para localizar el centro de la galaxia en el diagrama; se simboliza con un cuadrado (en naranja). Las observaciones están conectadas, en cada caso, para poder seguir la evolución espacial desde el centro hacia los extremos de la EELR. En ambas regiones la evolución del estado de ionización no responde a cambios en $A_{M / I}$, sino en $U$ (Reynaldi \& Feinstein 2013a). En el diagrama puede apreciarse un aparente ajuste del modelo M a la región SE. Sin embargo, tal ajuste no puede considerarse como válido dado que según las características del propio modelo, se superaría el valor de densidad crítica del [OII $] \lambda 3727\left(n^{\text {crit }}=4.5 \times 10^{3} \mathrm{~cm}^{-3}\right)$. Dado que esta línea es, justamente, una de las líneas que intervienen en el diagrama, tal ajuste carece de sentido ${ }^{27}$.

Una explicación posible para el aumento local del parámetro de ionización $U$, en virtud de que este incremento se produce por el aumento en la emisión tanto del [OIII] $\lambda 5007$ como del $[\mathrm{OII}] \lambda 3727$, se puede encontrar en términos del modelo de ionización por ondas de choque (IOC). Bajo esta hipótesis, puede ocurrir que exista un campo ionizante local dentro de la EELR, si la velocidad de la onda es suficientemente alta, o bien que el mecanismo de fotoionización, gobernado por el AGN, se vea favorecido por los procesos que tienen lugar dentro de la nebulosa como consecuencia del paso de la onda (Solórzano-Iñarrea \& Tadhunter 2003). Un proceso de estas características debería poder identificarse también a través de la cinemática de la región.

El modelo de IOC apropiado para cotejar con las observaciones de 3C 381 es el conjunto caracterizado por abundancia solar y densidad ambiental de $n_{e}=10^{2} \mathrm{~cm}^{-3}$. La elección responde a que este valor de densidad es, dentro de la librería MAPPINGS-III, el más cercano al que determinaron Robinson et al. (2002) (utilizado anteriormente en la discusión sobre la

\footnotetext{
${ }^{26}$ La secuencia de ionización de $U$ que utilizan BWS96 se derivó según los parámetros de las nubes IB del modelo T. Las secuencias de $U$ construidas según los parámetros de los modelos H, M y L no están disponibles en la literatura. La banda que define las posibles localizaciones de las secuencias de $U$ en la Fig. 6.18 es estimativa y sólo pretende reflejar, por consistencia con los resultados obtenidos para el modelo T, que la secuencia de $U$ debe ser aproximadamente vertical y que debe ubicarse en esa zona del diagrama.

${ }^{27}$ Este aspecto constituye un punto débil en común para la evaluación de los modelos H, M y L. Aquí se los evalúa por completitud, pero debe resaltarse que, por la forma en que fueron definidos, siempre es posible que se supere el valor de densidad crítica de una línea tan importante en todos los objetos de la muestra (ver Tabla 2.1).
} 
Figura 6.18. 3C 381. Modelos de fotoionización

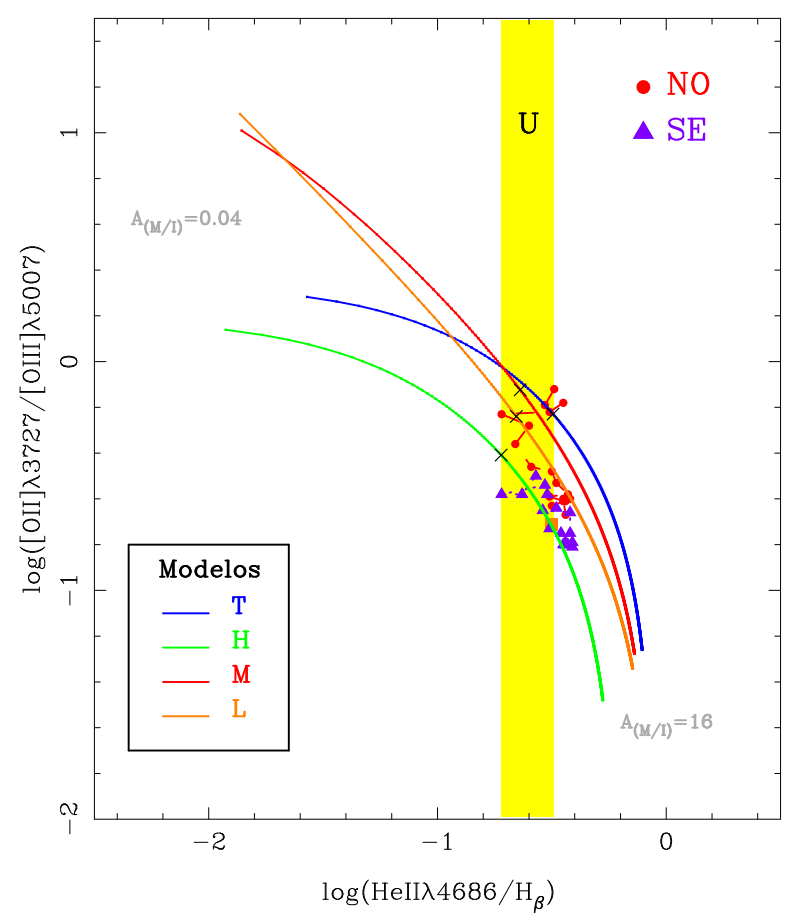

Fotoionización multifase: modelos T, H, M y L, la cruz en cada curva indica la posición para la cual $A_{M / I}=1$. Los valores máximo y mínimo de este parámetro se indican en los extremos de las curvas. Fotoionización central: la banda amarilla indica las posibles localizaciones de las secuencias del parámetro de ionización $U$. Las regiones nebulares de 3C 381 se indican por separado para evaluar el comportamiento desde el centro de la galaxia (se grafica con un cuadrado) hacia los extremos de la EELR; la región SE con triángulos (violeta) y la NO con puntos (rojo). La evolución del estado de ionización no responde a cambios en $A_{M / I}$, sino en $U$ (Reynaldi \& Feinstein 2013a). 
fotoionización central). En la Figura 6.19 se utiliza este modelo, graficado con líneas punteadas (color negro, una curva por cada parámetro magnético) junto con las mediciones de 3C 381 (se utiliza la misma convención de símbolos que para la Fig. 6.18). Las líneas continuas (color verde) indican la velocidad de propagación de la onda. Estas curvas representan los modelos de shocks autoionizantes (la emisión proviene del shock y de la zona precursora).

En el diagrama A se muestra un segundo conjunto de curvas (líneas de trazos cortos, color naranja) que corresponden a los modelos de choques "puros" o no-autoionizantes, es decir, aquellos que no incluyen la contribución del precursor fotoionizado por el shock. La línea continua en color azul marca la máxima velocidad de la onda $\left(400 \mathrm{~km} \mathrm{~s}^{-1}\right)$ adoptada para graficar el comportamiento del modelo. Sin embargo debe interpretarse sólo cualitativamente porque se trata de una cota superior extremadamente holgada: como se señaló en la Sección 2.4.3, los efectos del precursor dejan de ser despreciables a partir de velocidades cercanas a $200 \mathrm{~km} \mathrm{~s}^{-1}$. Aquí se muestran con el único propósito de enfatizar que las intensidades observadas no pueden ser explicadas si sólo se contempla la contribución del shock "puro". La evaluación de este conjunto de modelos queda descartada en adelante.

En los siguientes diagramas $(\mathbf{B}, \mathbf{C}, \mathbf{D}, \mathbf{E}$ y $\mathbf{F})$ los cocientes $[\mathrm{OIII}] \lambda 5007 / \mathrm{H} \beta$ y HeII $/ \mathrm{H} \beta$ se utilizan indistintamente como eje de excitación. Como característica general, el modelo predice valores más bajos que los observados en ambos cocientes. Aún así, se obtiene un ajuste consistente cualquiera sea la combinación de líneas adoptadas, incluso cuando ambos ejes de excitación se combinan en el mismo diagrama (B). Las observaciones pueden reproducirse cuando el medio es atravesado por las ondas de choque más veloces $\left(500<v_{s}<1000 \mathrm{~km} \mathrm{~s}^{-1}\right)$.

Los diagramas $\mathbf{C}$ y D ilustran el comportamiento del cociente [OII] $\lambda 3727 /[\mathrm{Nev}] \lambda 3424$ en función de los cocientes de excitación anteriores. La línea $[\mathrm{NeV}] \lambda 3424$, la línea de mayor excitación observada está presente a lo largo de una distancia de $5.5 \mathrm{kpc}$ desde el AGN. Se necesitan fotones con energías muy altas (alrededor de $100 \mathrm{eV}$ ) para producir esta línea de emisión, por lo cual es extremadamente difícil para cualquier modelo de fotoionización poder explicar este tipo de emisión a distancias tan grandes del núcleo (Stasińska 1984; Komossa \& Schulz 1997). Por el contrario, la interacción ente los jets y el MIE/MIG sí es capaz de generar un campo local de fotones suficientemente energéticos. En ambos diagramas se puede ver que los modelos pueden reproducir la intensidad del cociente [OII] $\lambda 3727 /[\mathrm{Nev}] \lambda 3424$ en el mismo rango de velocidades mencionado anteriormente.

En los últimos dos diagramas ( $\mathbf{E}$ y $\mathbf{F}$ ) de la Fig. 6.19 se evalúa el comportamiento de otro cociente de oxígenos, $[\mathrm{OIII}] \lambda 4363 /[\mathrm{OIII}] \lambda 5007$, conocido ampliamente en la literatura por su relación con la temperatura del gas (ver Sección 2.3.2). En el marco del estudio de mecanismos de ionización, ya sea fotoionización o IOC, el comportamiento de este cociente siempre ha sido problemático. Mientras que los modelos de fotoionización predicen temperaturas demasiado bajas comparadas con las mediciones obtenidas para distinta clase de objetos (Seyfert 2 o LINERs), las temperaturas obtenidas con los modelos de IOC arrojan mejores resultados. Sin embargo las predicciones sobre el valor del cociente [OIII] $\lambda 4363 /[\mathrm{OIII}] \lambda 5007$ siguen estando por debajo de los valores medidos tanto para la muestra de DS95, donde se presentan los modelos, como para 3C 381. Este hecho podría deberse a la metalicidad. Si los objetos estudiados (todos aquellos donde se haya manifestado el problema de la temperatura) tuvieran metalicidad sub-solar, entonces la temperatura de la región de enfriamiento, así como en el precursor sería mayor comparada con el caso de metalicidad solar. También se obtendría una tasa de enfriamiento menor. Ambos aspectos conducirían a que los iones $\mathrm{O}^{++}$presentes en el medio se recombinen a temperaturas mayores que las previstas, con lo cual la transición que origina la línea $[\mathrm{OIII}] \lambda 4363$ se vería más favorecida que la que origina el [OIII] $\lambda 5007$ (ver Fig. 2.3). En conclusión, los valores medidos de los cocientes [OIII] $\lambda 4363 /[\mathrm{OIII}] \lambda 5007$ serían sistemáticamente mayores, explicando así las diferencias con el modelo usado (DS95). No 
Figura 6.19. $3 \mathrm{C}$ 381. Modelo de IOC: $n_{e}=10^{2} \mathrm{~cm}^{-3}$; abundancia solar.
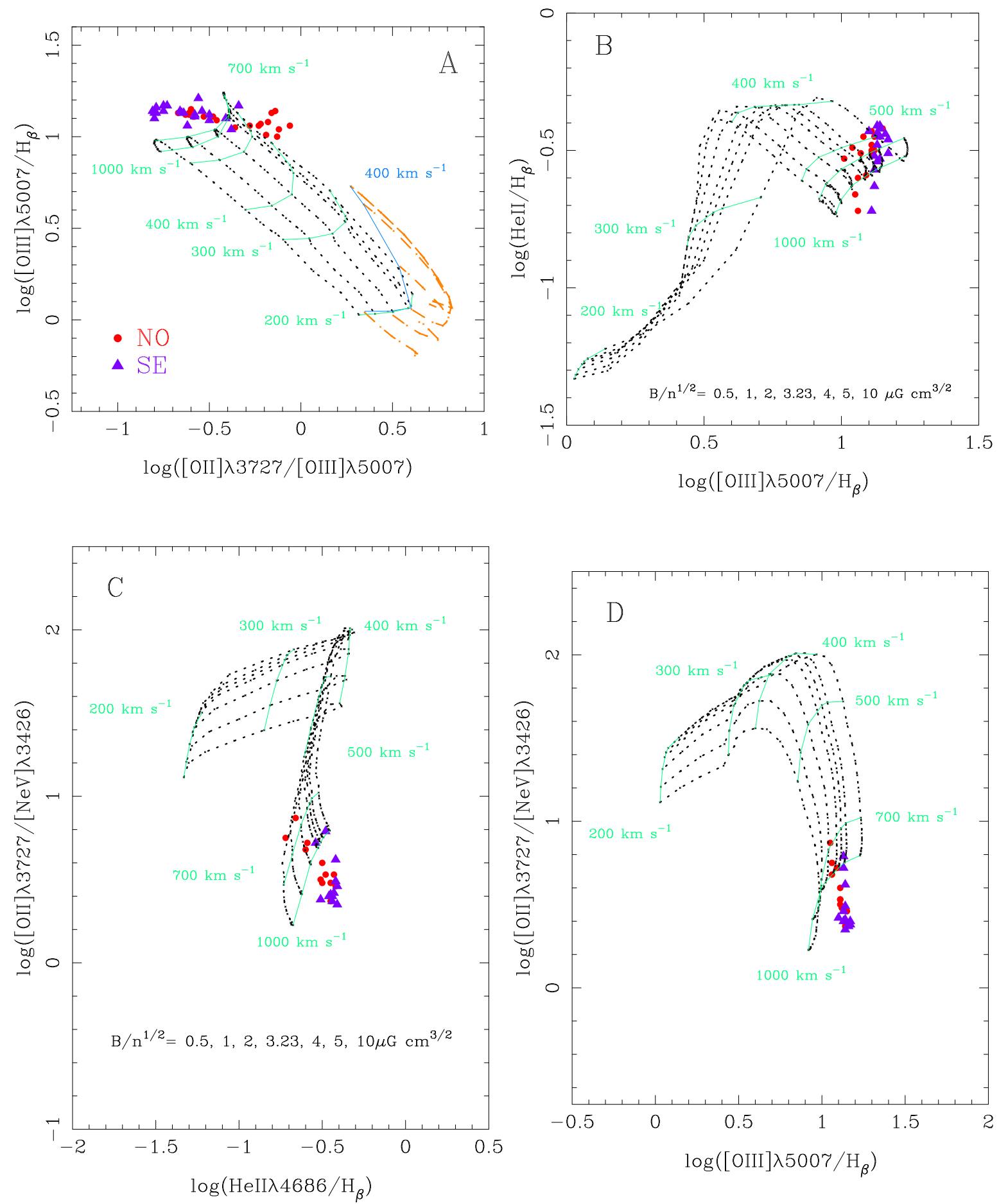
Fig. 6.19: continuación
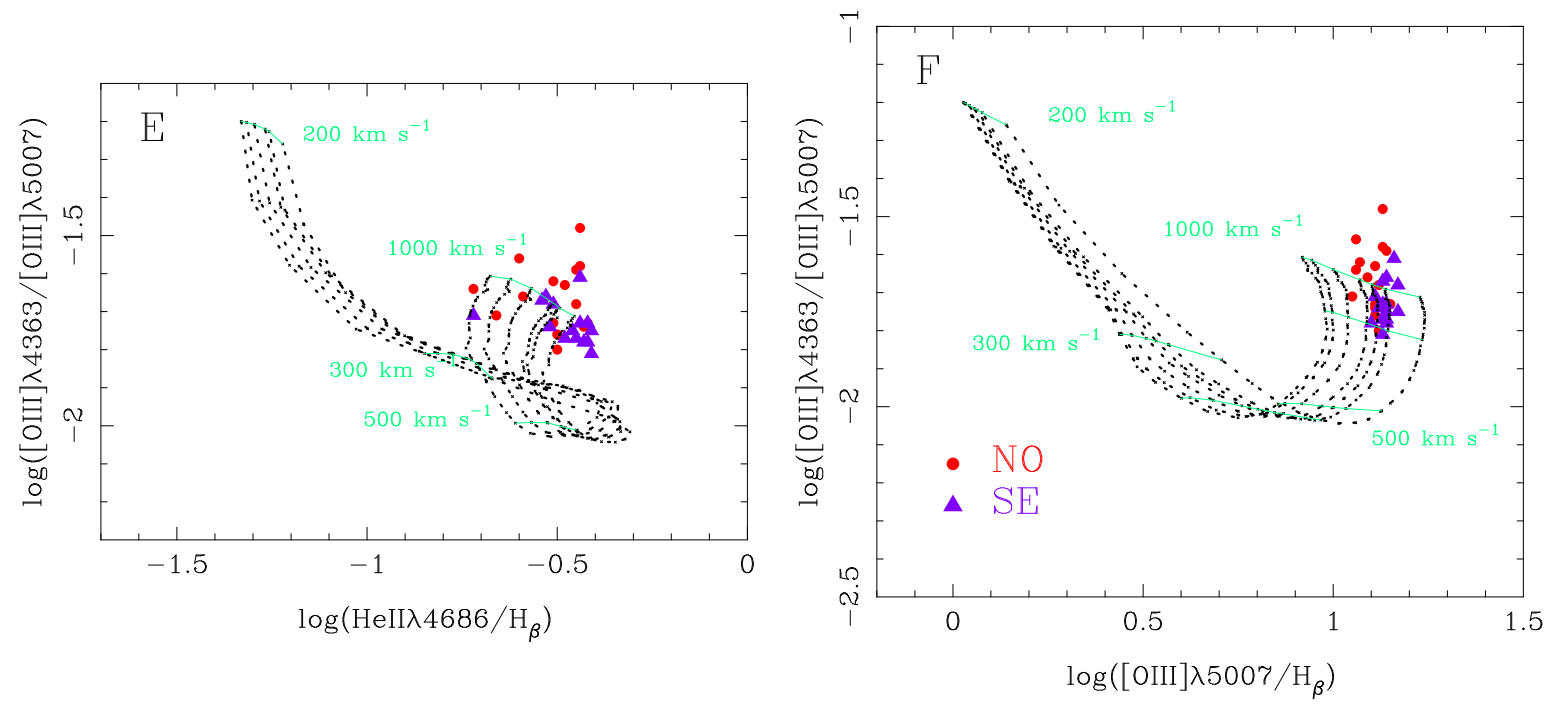

Modelos de ionización por ondas de choque autoionizantes en un medio con abundancia solar: las curvas de líneas punteadas (negro) corresponden al modelo cuya densidad ambiental es de $n_{e}=$ $10^{2} \mathrm{~cm}^{-3}$. Cada curva se corresponde con un valor dado del parámetro magnético. Las líneas continuas (verde) indican la velocidad de propagación de la onda de choque. En el diagrama A se muestra el comportamiento del modelo no-autoionizante (línea de trazos, color naranja). Las EELR se representan como en la Fig. 6.18.

hay información sobre la metalicidad de 3C 381 en la literatura, y aunque las conclusiones basadas en estos diagramas deban ser tomadas con precaución, cabe destacar que no existen diferencias significaticas (exceptuando que se observa mayor dispersión) con las que puedan derivarse de los diagnósticos anteriores $(\mathbf{A}, \mathbf{B}, \mathbf{C}$ y $\mathbf{D})$.

\subsubsection{Resumen}

El modelo de fotoionización central simple no puede explicar el comportamiento del cociente entre $[\mathrm{OII}] \lambda 3727$ y $[\mathrm{OIII}] \lambda 5007$, a la vez que sobreestima la magnitud del campo de radiación ionizante emitido por el núcleo activo. Los modelos multifase, por su parte, no pueden reproducir el comportamiento del cociente HeII/H $\beta$ aún cuando (particularmente el modelo T) fue desarrollado con ese propósito. La distancia hasta la cual es posible encontrar la emisión del HeI indica que, a lo largo de esa extensión, valen las hipótesis del modelo simple, de manera que no es posible reconciliar los resultados conjuntos de la fotoionización en general. Aún cuando el mecanismo necesariamente está presente, es muy probable que no domine el estado de ionización de la región.

Tanto las líneas de baja excitación como las de alta excitación se pueden reproducir con los modelos de IOC, aunque la intensidad observada en [OIII] $\lambda 5007$ y HeII es ligeramente mayor que la que éstos predicen. Por otra parte, la distancia hasta la cual es posible encontrar la línea de alta excitación $[\mathrm{NeV}] \lambda 3424$ requiere de la existencia/disponibilidad de una cantidad significativa de fotones altamente energéticos a tales distancias. Este campo puede ser creado localmente por ondas de choque radiativas. En este mismo sentido es posible explicar el comportamiento del parámetro de ionización $U$. La intensidad de todos los cocientes estudiados son compatibles con los modelos de IOC en el rango de velocidades dado por $500<v_{s}<1000 \mathrm{~km} \mathrm{~s}^{-1}$, sin excepciones. El análisis del campo de velocidades (Sección 5.8 y 
Fig. 5.14) indica que las componentes de alta velocidad, cuya presencia se evidencia en el perfil de emisión del $[\mathrm{OIII}] \lambda 5007$, se mueven con velocidades en este mismo rango. Este aspecto merece especial atención, dado que se trata de dos resultados completamente independientes que señalan al modelo de shocks como actor principal en la región.

Ciertamente, la evidencia más impactante de interacción entre los radio-jets y el MIE/MIG se observa en los extremos de los lóbulos: en los hot spots, cuando el medio circundante frena bruscamente las ondas de choque originadas por el jet. Estas regiones se caracterizan por su brillo superficial intenso (en radio) y porque la presión del gas (en los casos donde ha sido posible medirla) es mayor que en los alrededores. También el gas óptico muestra los efectos de ser atravesado por estas ondas de choque. Un ejemplo importante donde se encontraron signos de interacción jet-nube y lóbulo-nube (entendiendo por "nube" a las nebulosas ópticas) es el caso de 3C 299 (Feinstein et al. 1999) donde la EELR y el lóbulo se encuentran en la misma región. Sin embargo, el trabajo de Solórzano-Iñarrea et al. (2001) fue determinante para mostrar que, a pesar de las grandes distancias que en muchos casos separan los lóbulos de las EELR, el gas puede manifestar signos de procesos violentes inducidos y/o desencadenados por el paso del jet. El tipo de procesos que se observan en 3C 381.

Pero no sólo en los extremos de los lóbulos se generan ondas de choque, sino también en las regiones cercanas al AGN (cercanas, comparadas con la escala de los lóbulos), donde los jets son supersónicos $\left(\right.$ Leahy $\left.^{28}\right)$. Cuando eso sucede, se generan zonas de alta presión dentro de las nebulosas ópticas. Tal exceso de presión se reportó en el ya citado trabajo de Robinson et al. (2002). Allí se mostró que el material de la EELR sufre un exceso de presión con respecto al halo de rayos-X. También se señaló que esto podría ser el resultado de la existencia de ondas de choque inducidas por el jet, pero que al momento no existía ninguna evidencia cinemática en favor ese escenario. El campo de velocidades de la Fig. 5.14 constituye tal evidencia.

\footnotetext{
${ }^{28}$ www.jb.man.ac.uk/atlas/dragns.html
} 


\section{Capítulo 7}

\section{Conclusiones}

\subsection{Sobre la muestra definitiva de objetos analizados.}

En esta Tesis se analizaron las condiciones de excitación e ionización del medio interestelar/intergaláctico (MIE/MIG) localizado en las afueras de un reducido grupo de radiogalaxias; por su localización y por sus características espectrales la zona recibe el nombre de Región Extendida con Emisión de Líneas (EELR). Baum et al. (1988) mostraron que, sobre una muestra de 37 radiogalaxias, aproximadamente el $85 \%$ tiene regiones nebulares extendidas, cuyo tamaño medio es de $10 \mathrm{kpc}$. Estos sistemas gaseosos detectados en el óptico, con escalas de kpc a decenas de kpc, que se encuentran asociados a radiogalaxias (Sección 1.2.3) y quásars RL (Sección 1.2.2) constituyen la componente de galaxias elípticas más fácil de estudiar porque a través de sus mapas de emisión es posible derivar algunos parámetros geométricos importantes (BWS96, Robinson et al. 2000). Y, por otra parte, la cinemática y los cocientes entre las líneas de su espectro de emisión sirven como prueba única de las propiedades físicas e historia reciente de la galaxia anfitriona, de las propiedades del continuo ionizante nuclear y de la física del radio plasma eyectado (Baum et al. 1992).

Los objetos se eligieron de acuerdo al tamaño de sus EELR, según las imágenes obtenidas con el Telescopio Espacial Hubble durante los programas de observación especialmente destinados a observar las contrapartes ópticas y la emisión nebular de las radiofuentes del Catálogo 3C (y/o sus revisiones, ver Capítulo 3). De este modo, la muestra está compuesta por las radiogalaxias más potentes con EELR de mayor tamaño. Dado que el trabajo de investigación es de carácter espectroscópico, este criterio fue estrictamente necesario para asegurar que los espectros que se fueran a obtener con el Telescopio Gemini tuvieran la mayor información espacial posible de la región.

Se utilizó el instrumento GMOS, y se obtuvieron espectros de ranura larga (long-slit) de diez (10) radiofuentes: 3C 381, 3C 305, 3C 268.2, 3C 268.3, 3C 303.1, 3C 321, 3C 285, 3C 284, 3C 184.1 y 3C 196.1. Todos los espectros se tomaron de manera tal que el rango espectral cubierto fue $3200 \AA-5300 \AA$, aproximadamente. En este rango se espera encontrar la emisión de importantes líneas que se utilizan como herramientas de diagóstico sobre el estado del plasma.

El objetivo de la investigación fue analizar el nivel de competencia entre los dos mecanismos de ionización que pueden tener influencia sobre el estado de las EELR (Viegas \& de Gouveia dal Pino 1992; BWS96; Tadhunter 2002): el efecto fotoionizante del campo de radiación proveniente del núcleo activo, y la ionización por ondas de choque radiativas.

El efecto fotoionizante del núcleo activo no se evalúa por la capacidad de éste para ionizar la EELR sino a través de las propiedades físicas del medio. Concretamente, según el modo en que el MIE/MIG absorbe el campo central y luego reprocesa la radiación absorbida 
bajo ciertas consideraciones geométricas, que a su vez (por las condiciones del modelo utilizado) encierran características intrínsecas del gas (Viegas \& Prieto 1992; BWS96) ${ }^{1}$. Las peculiaridades en la morfología de las regiones, particularmente la disposición espacial, que casi siempre está caracterizada por una (única) dirección preferencial, se explicarían naturalmente por la anisotropía del campo de radiación central (ver Capítulo 2, Robinson et al. 2000).

En cambio, para que la evaluación del mecanismo de ionización por ondas de choque desencadenadas por la interacción de los jets con el MIE/MIG sea consistente con su planteo, se requiere que los jets y las nebulosas se encuentren aproximadamente en la misma dirección. Siguiendo el criterio adoptado por de Vries et al. (1999), se consideró que estas estructuras están alineadas cuando la relación entre sus ángulos de posición es $\Delta \mathrm{PA} \lesssim 15^{\circ}$. De los diez objetos seleccionados por la extensión de sus EELR en las imágenes del HST, cinco (5) satisfacen este nuevo criterio: 3C 268.3, 3C 305, 3C 321, 3C 303.1 y 3C 285. Sin embargo, la muestra definitiva de objetos analizados se completa con 3C 381 y 3C 268.2 ya que, aunque no satisfacen el criterio de alineación (ver Tabla 3.5), presentan características particulares que ameritan el análisis.

En 3C 381 no hay alineación entre los jets y las EELR, pero en la zona más interna de los lóbulos (más cercana a la fuente puntual) se observa que éstos son rotacionalmente simétricos, distorsionados y desalineados respecto del jet del mismo modo que el material de la EELR (Reynaldi \& Feinstein 2013a). Entonces, aunque no hay alineamiento entre el jet y la EELR, sí se puede decir que el alineamiento se da entre la EELR y la zona lobular interna. La incorporación de 3C 381 en la muestra responde a que existen antecedentes en la literatura donde se ha comprobado que no sólo la interacción jet-nube, sino también la interacción lóbulo-nube puede desencadenar shocks ionizantes. Feinstein et al. (1999) encontraron ambos tipos de interacción en la expectacular radiofuente 3C 299, cuya disposición del gas óptico acompaña asombrosamente las estructuras de radio. Incluso Solórzano-Iñarrea et al. (2001) mostraron que el gas de la EELR puede haber experimentado procesos de choque desencadenados por el paso del radio-jet aún cuando, habiendo alineamiento, la distancia que separa los lóbulos de las nebulosas de la EELR es muy grande.

En 3C 268.2, la EELR y el radio-eje presentan una distribución espacial bien definida por la dirección preferencial de elongación de cada una, aunque difieren significativamente una de otra. Es decir, no existe ninguna clase de alineamiento entre ambas estructuras. La incorporación de esta fuente en la muestra definitiva se debe a las peculiaridades derivadas de su campo de velocidades en la dirección de la EELR, que pueden interpretarse como la manifestación de eyecciones de material (outflows). Características del mismo tipo también fueron encontradas en la radiofuente cercana (AGN tipo Seyfert 2, Sección 1.2.1) NGC 5929, y, en ese caso, se comprobó que se trata de outflows en dirección perpendicular al radio-eje (Riffel et al. 2014). 3C 268.2 se incorporó a la muestra con el objetivo de analizar si estos outflows son capaces de desencadenar, también, ondas de choque ionizantes. No hay ningún indicio de la existencia de gas ionizado en la dirección del radio-eje.

\footnotetext{
${ }^{1}$ La "capacidad" del núcleo para generar un campo de radiación que pueda ionizar el gas a las distancias típicas de la EELR fue un tema ampliamente discutido en los comienzos de los estudios de estos sistemas gaseosos porque rápidamente se reconoció el problema del "déficit de fotones" (Robinson 1989). Es decir: de las luminosidades observadas en las EELR se podía deducir la cantidad de fotones ionizantes necesarios para obtener esos valores; pero teniendo en cuenta las distancias a las que se encuentran las EELR, la dilución geométrica que experimenta el campo emitido por el objeto central indicaba que la cantidad de fotones que efectivamente llegaban a la EELR era menor. El problema se resuelve si se considera que el núcleo activo emite un campo anisótropo, tal como se propone en el Modelo de Unificación de AGNs.
} 


\subsection{Sobre los mecanismos de ionización estudiados.}

La naturaleza y la fuente de excitación de las EELR se transformaron en interrogantes tan pronto como las EELR fueron detectadas porque permitían estudiar, antes que nada, sistemas gaseosos asociados a galaxias elípticas y la influencia de un núcleo activo sobre ellos. El hecho de que los espectros de las EELR/ENLR compartieran prácticamente todas las características de la NLR, más cercana al objeto central y fotoionizada por éste (Penston et al. 1990; Peterson 1997, y sus referencias) iniciaron el camino hacia la explicación más natural: las EELR también debían estar ionizadas por algún mecanismo asociado a la actividad nuclear. Por las características espectroscópicas compartidas y las diferentes distancias involucradas se encontró que las NLR y EELR podían definir una secuencia ${ }^{2}$ dada por un único parámetro, y que ese parámetro $(U)$ mediría el grado de excitación del gas (Robinson et al. 1987). Por otra parte, como también se observaban EELR con distintos grados de excitación se propusieron explicaciones centradas en las propiedades del núcleo y en las propiedades del propio sistema gaseoso: las EELR de menor excitación o bien recibían un campo de radiación menos potente, o bien su densidad era mayor que la de las EELR de mayor excitación. Las dos explicaciones resultaban válidas, pero la tendencia de que las EELR de mayor excitación fueran también aquellas que manifestaran mayor brillo superficial sugería que, efectivamente, recibían mayor flujo ionizante, cualquiera fuera el comportamiento de la densidad ${ }^{3}$ (Robinson et al. 1987). Así, el estudio de las EELR bajo la suposición de que el núcleo activo es su fuente de excitación, permitía utilizar su espectro de emisión para derivar o inferir propiedades de la propia fuente emisora (Robinson et al. 2000).

Por su parte, también se observada cierto vínculo con la radiofuente. No sólo porque las EELR se encontraban en las afueras de una importante cantidad de radiogalaxias y quásars RL (Baum et al. 1988), sino: porque el efecto de alineamiento resultaba particularmente curioso (Sección 2.2), porque pronto se encontró que la luminosidad en radio (en $178 \mathrm{MHz}$ ) y la luminosidad del sistema ionizado (en [OIII]) mostraban una marcada correlación (Rawlings \& Saunders 1991; Tadhunter et al. 1998; Hardcastle et al. 2009), o porque las características de los espectos de emisión permitían proponer el análisis de fuentes de excitación distintas del núcleo activo (es decir, mecanismos que producen características prácticamente idénticas sobre el espectro emergente de la nebulosa excitada). Por ejemplo, para que las líneas de emisión $\operatorname{HeII}(\lambda 4686)$ o $[\mathrm{Nev}] \lambda 3424$ estén presentes en el espectro de la EELR con la intensidad observada, se necesita que el gas haya sido fotoionizado por un continuo UV duro o que haya sido colisionalmente ionizado por shocks (Penston et al. 1990, y sus referencias). Sin embargo, cuando las galaxias se clasifican como de alta o baja excitación basándose en la presencia, ausencia o intensidad de las líneas de emisión del espectro óptico se da por aceptado que el origen de esa radiación es el continuo nuclear. De este modo, si una galaxia (radiogalaxia) se clasifica como de baja excitación, entonces se concluye que su núcleo activo no es lo suficientemente potente. Este razonamiento puede estar equivocado, porque en muchos casos es necesario considerar el rol que pudieran desempeñar los jets en su interacción con el medio (Evans et al. 2008). Mientras que la ausencia de líneas de emisión de excitación alta intensas podría ser un indicador de que la galaxia no alberga un núcleo activo radiativamente eficiente, la presencia de tales líneas no necesariamente implica lo contrario (que el núcleo sea radiativamente eficiente; Hardcastle et al. 2009).

Se trata de un problema sumamente complejo, no sólo porque la interacción entre los

\footnotetext{
${ }^{2}$ La secuencia de excitación se observaba mediante diagramas de diagnóstico formados por cocientes entre líneas de emisión comunes a los dos espectros.

${ }^{3} \mathrm{El}$ aumento de la densidad no puede ser arbitrario. Los espectros de la EELR son muy intensos en [Оіг] $\lambda 3727$, por ejemplo, cuya densidad crítica $\left(4.5 \times 10^{4} \mathrm{~cm}^{-3}\right)$ limita fuertemente la hipótesis de un crecimiento desmesurado de la densidad ambiental.
} 
radio-jets con el medio puede contribuir al espectro resultante (Viegas \& de Gouveia dal Pino 1992), sino también porque las características propias del medio también influyen en la forma en que éste reprocesa la radiación que sobre él incide (Viegas \& Prieto 1992; BWS96). Más aún cuando se tiene en cuenta que la interacción de la radiofuente con el gas, cuyo resultado más directo se observa en la excitación/ionización colisional del material, también puede generar un campo de radiación local que lo fotoioniza (Viegas \& de Gouveia dal Pino 1992; DS95; DS96; A08). Luego, existe una importante dificultad en la identificación de la fuente que origina el campo de radiación que ioniza el gas. Dicho de otro modo, el efecto fotoionizante no es privativo del campo central.

Una de las características que comparten muchas de las EELR conocidas es la cinemática. Los campos de velocidades suelen mostrar patrones colectivos a los que se superponen movimientos apartados de esos patrones. Aunque en muchos casos el movimiento del gas es predominantemente gravitacional (movimientos colectivos, curva de rotación), hay muchos ejemplos donde el gas muestra claros signos de perturbación (apartamientos de la curva) provocados por la inyección de energía mecánica que experimenta durante la interacción con los radio-jets. En esos casos, las EELR se encuentran generalmente en las cercanías del jet (interacción jet-nube) o de los lóbulos (interacción lóbulo-nube). Muchas veces también se observan signos de la interacción en el propio jet, como cambios en la dirección de propagación, ensanchamiento (de-colimación), o reducción del porcentaje de polarización (Viegas \& de Gouveia dal Pino 1992). En los modelos de ionización por ondas de choque, el estado de ionización de la región debería estar relacionado con su cinemática (Clark et al. 1998); en cambio, si la ionización está dominada por el campo de radiación del AGN, el nivel de ionización y la cinemática del gas podrían ser completamente independientes (Labiano et al. 2005). Estos resultados sugieren que el impacto que la actividad nuclear en radiogalaxias (englobando allí toda la actividad conocida, desde la potencia de su campo de radiación hasta la misma generación de los jets) tiene sobre su medio ambiente puede ser tanto dramático como diverso (van Breugel \& Dey 1993), pero también resaltan la importancia del mecanismo de IOC por su potencialidad para poder explicar simultáneamente, en principio, el estado cinemático y el estado de ionización en la región.

\subsection{Sobre los resultados de la investigación.}

Los cocientes entre las líneas de emisión del espectro de un sistema gaseoso tienen la capacidad de poder reflejar el mecanismo por el cual el gas fue ionizado (Baldwin et al. 1981; Baum et al. 1992; BWS96; DS95; A08). Los diagramas de diagóstico que con ellos se construyeron, junto con su evolución espacial, se transformaron en las herramientas principales del análisis llevado a cabo en este trabajo. Con los diagramas de diagnóstico se evaluaron los mecanismos de fotoionización multifase (FMF) desarrollados por BWS96 y Binette et al. (1997), y los mecanismos de ionización por ondas de choque (IOC) radiativas, y no-radiativas en algunos casos, pertenecientes a la librería MAPPINGS III de A08 y Groves \& Allen (2010). Los comportamientos espaciales de algunos cocientes de líneas se utilizaron para analizar la evolución de las condiciones físicas del gas a lo largo de la extensión de la EELR en cuestión (en la dirección de la ranura, que prácticamente siempre coincide con la única dirección preferencial de elongación de la EELR).

La distinción entre uno y otro modelo no puede realizarse únicamente mediante los diagramas porque en todos los diagramas construidos con las líneas de los espectros GMOS las predicciones de ambos se superponen para ciertos rangos de valores de cada cociente empleado. Y en la mayoría de los objetos, esos rangos de superposición coinciden con la zona donde se ubican las observaciones. Sólo en un objeto de la muestra (3C 285) fue posible "ampliar" el 
espectro de emisión (bajo ciertas consideraciones) con la información proveniente de la zona del espectro dominada por $\mathrm{H} \alpha$ (disponible en la literatura). De esta manera, se incorporó otro conjunto de líneas muy sensibles a los modelos y muy importantes para el análisis. En los seis casos restantes, la herramienta complementaria principal provino de los comportamientos espaciales de algunas líneas de emisión, especialmente sensibles a alguno de los escenarios en particular, de la mano del comportamiento del parámetro de ionización.

El cociente de líneas más importante es [OIII] $25007 /[$ OII] $\lambda 3727$, por su capacidad de reflejar el comportamiento del parámetro de ionización $U$ (Ec. 2.2). El parámetro de ionización $U$ es una magnitud "construida" sobre la idea de una fuente emisora central y un sistema gaseoso de determinada densidad, ubicado a una cierta distancia de ésta (Ec. 2.1). Si bien su aplicación o utilización en el marco de la fotoionización central es directa, también desempeña un papel importante en la evaluación de procesos de choque (DS95; DS96). Las condiciones MHD y las drásticas variaciones que sufre la densidad en estos casos repercuten directamente en el comportamiento de $U$ (ver Apéndice B).

En el marco del mecanismo de fotoionización, la formación de las líneas de emisión depende tanto del campo de ionización actuante como de la distancia entre la fuente emisora de ese campo y la nube de gas. Es decir, depende de $U$; luego, a través suyo es posible determinar la viabilidad de la formación de esas líneas bajo el escenario planteado. En el marco del mecanismo de ionización por ondas de choque radiativas, el crecimiento o decrecimiento de la intensidad de ciertas líneas, de la mano del comportamiento espacial de $U$, sirven para aceptar o descartar la posibilidad de que esas líneas de emisión se hayan formado a merced de las condiciones físicas del sistema una vez que es alterado por el shock (región de recombinación), o bien antes de que ocurra el proceso violento (precursor radiativo). Tanto el cociente de oxígenos $([\mathrm{OIII}] /[\mathrm{OII}] \equiv U)$ como la intensidad de las líneas más importantes del espectro se analizaron espacialmente para determinar si los dos conjuntos de modelos propuestos son capaces de predecir las tendencias observadas en esos comportamientos a las distancias observadas.

Como las conclusiones del análisis de cada objeto se presentaron al final de la Sección dedicada a cada uno de ellos en el Capítulo anterior, no se repetirán aquí. En su lugar, se resaltarán las herramientas que resultaron determinantes para arribar a esos resultados finales. Una de ellas es el comportamiento/evolución espacial de las líneas de mayor y menor excitación, como $[\mathrm{Nev}] \lambda 3424$ y HeII, y [OII] $\lambda 3727$. La otra es el estado cinemático de las nebulosas.

El mecanismo de FMF es fortísimamente dependiente del HeII $(\lambda 4686)$ al punto tal que define una secuencia de ionización basada en (y diseñada para reproducir la intensidad de) esta línea de emisión (respecto de $\mathrm{H} \beta$ ). También está intrínsecamente relacionado "transitivamente" con el $[\mathrm{NeV}] \lambda 3424$ por la relación que existe entre esta línea y la línea coronal [FeviI] $\lambda 6086$ (en lo que respecta a sus condiciones de formación; Stasińska 1984; BWS96), y entre la línea del hierro y las hipótesis del modelo (Binette et al. 1997). Luego, para aceptar la validez de la FMF como mecanismo de ionización dominante fue necesario comprobar que, además del ajuste posicional en los diagramas de diagnóstico, también se cumplían tanto las predicciones del modelo que competen a estas líneas en particular, como las condiciones dadas a priori, como por ejemplo, su compatibilidad con $U$ (o equivalentemente, con el sistema nebular ópticamente delgado, o MB). Estos análisis resultaron determinantes, dado que el mecanismo de IOC también propone una explicación natural al comportamiento de las líneas de excitación alta. Si las líneas se forman como resultado de procesos locales de choque, entonces la relación con $U$, tal como se propone en los modelos de fotoionización, se pierde (principalmente debido a las distancias a las cuales se producen los procesos de 
choque); pero su existencia e intensidad a tales distancias se explica por la formación y el efecto del campo ionizante local. Por ejemplo, un aumento de intensidad en el [Nev] $\lambda 3424$, acompañado de la disminución de $U$ en función de la distancia (creciente) a la fuente central es completamente incompatible con las predicciones (las líneas de excitación alta no se pueden formar donde $U$ disminuye) e hipótesis (el sistema nebular MB es el más cercano a la fuente emisora; [Nev] $\lambda 3424$ se forma predominantemente en el sistema MB) de la FMF, pero perfectamente aceptable en condiciones de ionización por ondas de choque radiativas (precursor radiativo; fotoionización en la zona de recombinación).

El comportamiento de las líneas de baja ionización, entre las cuales [OII] $\lambda 3727$ es la más importante en los espectos GMOS, está relacionado con $U$, según la fotoionización en general y el mecanismo de FMF en particular, en el límite de menor excitación (o equivalentemente, con el sistema nebular ópticamente grueso, o IB). Como la formación de esta línea no puede ocurrir, predominantemente, en un sistema gaseoso dominado por las condiciones físicas favorables a la formación de líneas como [Nev] 33424 o HeII, su evolución espacial también debe ser notoriamente diferente. Este fue otro de los aspectos claves que se utilizaron para aceptar o rechazar el ajuste de los modelos de FMF porque, como sucede en el caso de las líneas de excitación alta, las predicciones de la IOC son significativamente diferentes. En este escenario, se puede obtener un aumento simultáneo en la emisión de [Nev] $\lambda 3424$ y [OII] $\lambda 3727$ proveniente de la zona de recombinación del shock, porque por un lado, la emisión de líneas de excitación baja es importante (el gas está en pleno proceso de enfriamiento), y porque por el otro, existe un campo ionizante local (los fotones serán más energéticos cuanto mayor sea la velocidad de propagación del shock) cuyo efecto también se observa sobre el gas chocado.

En todos los casos, los resultados de los diagramas favorables al mecanismo de IOC fueron contrastados (también) con el campo de velocidades de cada objeto analizado en busca de consistencia. El ajuste se consideró válido siempre que el campo de velocidades acompañara las predicciones del modelo en cuanto al rango de velocidades para el cual éste es capaz de predecir las intensidades observadas en las líneas del espectro. El dominio de la fotoionización central puede, en cambio, estar completamente desacoplado del estado cinemático.

Como conclusión general, se comprueba que el efecto de alineamiento no es condición suficiente para asegurar la existencia de interacción entre los radio-jets y el MIE/MIG. De acuerdo a la muestra estudiada, no hay una relación evidente entre la disposición del gas óptico y el radio plasma que indique que tales procesos ocurren, y que, de ocurrir, tienen influencia directa sobre el estado de excitación e ionización del gas. Incluso esta conclusión es válida para objetos cuyos campos de velocidades en la dirección del jet muestran claros indicios de perturbaciones, apartamientos bruscos de la curva de velocidad, como la región nuclear $\left(\mathrm{C}_{S}\right)$ de $3 \mathrm{C} 321$.

Respecto de los campos de velocidades en sí, se observaron dos tipos de movimientos de velocidad alta. Comportamientos claramente asociados a perturbaciones locales, espacialmente acotados y visiblemente apartados de la (generalmente existente) curva de rotación. Y movimientos estables y extendidos por grandes distancias, que por su forma pueden asociarse directamente con curvas de velocidad, pero cuyas velocidades de estabilización son demasiado altas $\left(v>350 \mathrm{~km} \mathrm{~s}^{-1}\right)$ para ser compatibles con los movimientos esperados dentro del potencial galáctico (Tadhunter et al. 1989). Según Holt et al. (2008) este tipo de movimientos pueden asociarse al MIE/MIG estacionario del halo galáctico.

Los análisis espectroscópicos del mecanismo de IOC, completamente independientes del análisis cinemático, indican que cuando éste domina el estado de ionización de una dada región, en esa región se observan movimientos del primer grupo (3C 381; 3C 305; 3C 268.3; 3C 303.1; y la zona interna de 3C 268.2). En cambio, no se observaron correspondencias entre 
los movimientos del segundo grupo y los procesos de choques ionizantes (3C 321 y 3C 268.2). En un único caso (3C 285) todos los movimientos que se manifiestan en el campo de velocidades presentan velocidad baja, por lo cual no se puede hablar de procesos turbulentos que provoquen movimientos fuera del potencial gravitatorio; y en este caso el mecanismo de IOC falla.

Como comentario final, pero no por eso menos importante, debe resaltarse la importancia del análisis multifrecuencia. Ninguna de las conclusiones a las que se arribaron en el transcurso de este trabajo son independientes de la información provista por otros análisis en otras bandas del espectro electromagnético. Este estudio partió de la base de una posible conexión entre las EELR y las radiofuentes a las cuales pertenecen, en virtud de disposiciones espaciales particulares, y de la potencialidad de la radiofuente en tanto inyector de energía mecánica en el sistema gaseoso. Sin embargo, en el desarrollo del trabajo se encontraron fortísimas conexiones de tipo espectroscópico con resultados conocidos en otras frecuencias. La emisión proveniente del IR cercano y de rayos-X puede contener las claves para determinar el dominio de un mecanismo sobre el otro. El IR, porque allí se encuentran las líneas del hierro indicadoras de procesos de choque (como [FeII] $\lambda 1.64 \mu \mathrm{m}$ ). La emisión en rayos-X blandos, por las hipótesis que señalan que podría tener el mismo origen que la emisión óptica; pero también porque, cuando la calidad de las observaciones de la fuente lo permite, los resultados de los ajustes espectrales pueden proveer información que en el óptico es más difícil de obtener.

\subsubsection{Sobre los resultados secundarios de la investigación.}

La descomposición Gaussiana de los perfiles de emisión permitió advertir que en tres (3) de las diez (10) galaxias observadas, existen diferencias con los corrimientos al rojo ( $z$, redshift) encontrados en la literatura. Estas tres fuentes son 3C 268.2, 3C 303.1 y 3C 196.1; sus redshift conocidos fueron determinados por Spinrad et al. (1985, 3C 268.2), Holt et al. (2008, 3C 303.1) y Smith \& Spinrad (1980, 3C 196.1); sólo en el caso de 3C 303.1 se conoce el error en la determinación de $z$. Estos valores son los que se encuentran en la base de datos NED:

$$
\begin{aligned}
& z(3 \mathrm{C} 268.2)=0.362 \\
& z(3 \mathrm{C} 303.1)=0.2704 \pm 6 \times 10^{-5} \\
& z(3 \mathrm{C} 196.1)=0.198
\end{aligned}
$$

La inspección de los centroides medidos $\left(\Lambda_{c}\right)$ de todas las líneas del espectro, pero particularmente de aquellas cuyos perfiles de emisión pudieron reproducirse con una única componente, mostró que los desplazamientos de $\Lambda_{c}$ respecto del valor de la longitud de onda en reposo $\left(\lambda_{0}\right)$ de cada línea en cuestión, no son compatibles con los redshift anteriores. En el caso de líneas con perfiles múltiples, como el [OIII] $\lambda \lambda 4959,5007$ o [OII] $\lambda 3727$, también se observa que ninguna de las componentes tiene su centroide $\Lambda_{c}$ desplazado de $\lambda_{0}$ de acuerdo a $z$.

Se siguió el procedimiento propuesto por Holt et al. (2008), y se determinaron los corrimientos al rojo $z^{\prime}$ de las tres galaxias, de acuerdo con las mediciones de los espectros GMOS/Gemini. El procedimiento se dividió en dos etapas; en la primera, los cálculos de $z^{\prime}$ se realizaron sólo con las líneas que pudieron reproducirse con una única componente Gaussiana; en la segunda etapa se incorporó la información de las líneas con perfiles múltiples. En este caso, se incorporó sólo la componente cuyo desplazamiento del centroide fuera compatible con el valor de $z^{\prime}$ obtenido en la primera etapa. Finalmente, se determinaron los siguientes 
nuevos valores de corrimiento al rojo, junto con su error:

$$
\begin{aligned}
& z^{\prime}(3 \mathrm{C} 268.2)=0.36280 \pm 3 \times 10^{-5} \\
& z^{\prime}(3 \mathrm{C} 303.1)=0.26862 \pm 3 \times 10^{-5} \\
& z^{\prime}(3 \mathrm{C} 196.1)=0.19753 \pm 2 \times 10^{-5}
\end{aligned}
$$

Los campos de velocidades de las Figs. 5.25 .8 y 5.18 se obtuvieron según estos valores. 


\title{
Apéndice A
}

\section{Mecanismos de formación de líneas de emisión.}

\author{
[Adaptación de Stasińska (2009)]
}

Un sistema gaseoso de baja densidad sometido a un campo de radiación produce líneas de emisión cuando un átomo o ion regresa a sus estados de energía más bajos. Este proceso, también conocido como decaimiento, se caracteriza por la emisión de fotones cuya frecuencia (energía) está determinada por las diferencias de energía entre los niveles actuantes. Por esta razón la emisión característica es discreta (es decir, líneas) y no continua.

Los tres procesos principales por los cuales un átomo o ion puede alcanzar un estado excitado (necesario para que luego se produzca el decaimiento y se emita un fotón) son:

1. Recombinación

2. Excitación colisional

3. Excitación radiativa, también llamada fotoexcitación

\section{A.1. Recombinación}

Cuando un ion se recombina luego de haber sido ionizado, generalmente lo hace en un estado excitado. Luego se producen desexcitaciones en cascada que llevan al átomo o ion a su estado fundamental. En este proceso se emiten fotones, y las líneas que originan en el espectro del objeto en cuestión se llaman líneas de recombinación. En los espectros que se analizan en esta Tesis, se observan tres líneas de recombinación del hidrógeno neutro en la serie de Balmer (transiciones hacia el nivel $n=2)$ : $\mathrm{H} \beta(\lambda 4861), \mathrm{H} \gamma(\lambda 4340)$ y $\mathrm{H} \delta(\lambda 4104)$, y una línea de recombinación el helio ionizado: HeII $(\lambda 4686)$. Aunque estas líneas reciben sus nombres del átomo o ion recombinado (HI, HeII), sus intensidades están determinadas por la abundancia de las especies que se recombinan, es decir, la intensidad del HeII depende de la abundancia del ion $\mathrm{He}^{++}$(helio dos veces ionizado), que es quien captura el electrón que desencadena la transición cuya longitud de onda es $\lambda 4686 \AA$.

\section{A.2. Excitación colisional}

Este proceso ocurre cuando los electrones libres dentro de la nebulosa chocan con los átomos o iones presentes; como durante el choque se produce transferencia energía, los iones quedan en un estado excitado. 
Las temperaturas típicas dentro de una nebulosa cuyo espectro óptico sea rico en líneas de emisión, pueden situarse en el rango $8 \times 10^{3}<T_{e}<1.2 \times 10^{4} \mathrm{~K}$. Esto implica que la energía cinética media de los electrones es de aproximadamente algunos eV (electrón-Volt). Los elementos pesados como nitrógeno, oxígeno o neón, tienen desdoblamientos de estructura fina en su nivel fundamental cuyas energías de excitación son compatibles con estos valores. Por lo tanto los electrones del medio pueden funcionar como proyectiles para excitar los niveles más bajos de iones metálicos. Por este mecanismo se pueblan los estados superiores de las transiciones que originan las líneas [OII] $\lambda 3727$, [OIII] $\lambda 5007$ o [NeIII] $\lambda 3869$, por ejemplo.

En general, no se observan líneas del hidrógeno excitadas colisionalmente porque se necesitaría una población de electrones más energéticos: la energía mínima que tendrían que tener para poblar el primer estado excitado del hidrógeno es de $10.2 \mathrm{eV}$, aproximadamente un orden de magnitud mayor que la necesaria para excitar metales. Cuando la temperatura del medio aumenta, y los electrones ganan energía, también es posible obtener líneas de excitación colisional en el UV.

Una vez que un dado ion se encuentra en un estado colisionalmente excitado, su decaimiento se puede dar por tres tipos de transiciones que lugar a tres tipos de líneas de emisión (en otras palabras, las líneas de excitación colisional se dividen en tres grupos):

- Prohibidas

Las líneas prohibidas se forman a partir de transiciones electrónicas prohibidas, esto es, transiciones donde se viola alguna de las reglas de selección que la Mecánica Cuántica establece. Se trata de transiciones dipolares magnéticas o cuadrupolares eléctricas, que se originan en niveles de energía metaestables, y cuyas probabilidades de ocurrencia son del orden de $10^{-2} \mathrm{~s}^{-1}$. Esta probabilidad es tan baja que las transiciones sólo pueden ocurrir cuando la densidad del medio es lo suficientemente baja como para que la desexcitación colisional sea aún menos probable.

- Semi-prohibidas

Las líneas semi-prohibidas, también llamadas líneas de intercombinación, se forman por transiciones dipolares eléctricas pero no se cumple la regla de selección que indica que la transición debe ocurrir entre niveles cuyo valor del número cuántico $S$ (asociado al momento angular intrínseco total, o spin total, bajo el acoplamiento $L S$ ) sea diferente. Es decir, en estas transiciones $\Delta S=0$. La probabilidad de que ocurra este tipo de transiciones es del orden de $10^{2} \mathrm{~s}^{-1}$.

\section{- Permitidas}

Las líneas permitidas corresponden a transiciones dipolares eléctricas que cumplen con todas las reglas de selección. Son las transiciones más probables, $10^{8} \mathrm{~s}^{-1}$, lo que equivale a decir que el tiempo de vida medio del electrón en el estado excitado es muy corto. Por esta razón, estas líneas no están condicionadas por la densidad del medio del modo en que sí lo están los otros conjuntos. Dentro de las líneas permitidas se encuentran las líneas resonantes, que son las que corresponden a las transiciones de mayor longitud de onda (menor energía) donde el decaimiento se produce al nivel fundamental; un ejemplo de línea resonante es H Ly $\alpha$ (transición $n=2 \rightarrow n=1$ en el átomo de hidrógeno).

\section{A.2.1. Ionización colisional}

Existen situaciones particulares donde factores externos al MIG pueden inyectar energía mecánica al sistema. Este proceso se traduce inmediatamente en un aumento de temperatura, que, en el caso de los electrones libres, puede alcanzar valores extremadamente altos (del orden de $\gtrsim 10^{6} \mathrm{~K}$ ). Todas las partículas del sistema experimentan el aumento de energía, 
pero éste más notable para las partículas más livianas. Bajo estas condiciones la energía de los electrones es suficientemente alta como para ionizar algunas especies (es decir, la energía es mayor que la del umbral de ionización de algunos átomos o iones) y por lo tanto es posible obtener iones del tipo $\mathrm{O}^{+3}$ o $\mathrm{He}^{++}$mediante este mecanismo.

Dependiendo de la condiciones del medio, los estados (metaestables) desde donde se producen las líneas prohibidas también pueden poblarse por las cascadas que tienen lugar cuando estos iones se recombinan en niveles superiores ${ }^{1}$ (Porter \& Ferland 2007).

\section{A.3. Excitación radiativa}

En este proceso, el átomo o ion llega al estado excitado por la absorción de un fotón cuya energía coincide con la diferencia de energía entre los dos niveles involucrados. Cuando se produce el decaimiento se emite un fotón con esta misma energía, pero su dirección de propagación no necesariamente coincide con la del fotón absorbido. Las transiciones que originan estas líneas son dipolares eléctricas, por lo cual también se trata de líneas permitidas.

Dentro de este grupo están las líneas fluorescentes. Se producen cuando el fotón es absorbido por un electrón de las capas internas, y durante el proceso de desexcitación se producen decaimientos en cascada. Los fotones absorbidos provienen del campo de radiación externo o del campo difuso que se genera dentro de la misma nebulosa, compuesto por otros fotones emitidos durante la recombinación del gas. Un ejemplo de este último caso es el complejo conocido como líneas de Bowen: OIII $\lambda \lambda 3133,3444$ y OIII $\lambda 304$, cuya excitación se produce cuando el ion $\mathrm{O}^{++}$absorbe un fotón Ly $\alpha$ del HeII (la nomenclatura de la línea es HeII Ly $\alpha$, y corresponde a la transición $n=2 \rightarrow n=1$ en el helio ionizado. Como el $\mathrm{He}^{+}$es un ion hidrogenoide se utizan denominaciones análogas a las líneas del hidrógeno).

\footnotetext{
${ }^{1}$ Este proceso también es importante en plasmas en recombinación (Sección A.1); en esos casos se observa particularmente en el espectro de rayos-X blandos.
} 



\section{Apéndice B}

\section{Algunas consideraciones sobre Magnetohidrodinámica.}

En esta parte del trabajo no se busca hacer un desarrollo completo ni detallado sobre las ondas magnetohidrodinámicas u ondas de choque magéticas, sino resaltar algunos aspectos importantes de sus comportamientos que resultan de utilidad para comprender, particularmente, los modelos utilizados.

\section{B.1. Sobre la aproximación MHD y el congelamiento del plas- ma}

La rama de la física conocida como magnetohidrodinámica (MHD) estudia el comportamiento de un sistema combinado, formado por campos electromagéticos y fluidos conductores. Los campos actúan sobre todas las partículas cargadas del plasma, iones y electrones, produciendo efectos dinámicos. El movimiento en masa del fluido produce, a su vez, cambios en los campos electromagnéticos, generando así un sistema acoplado y complejo de materia y campos (Jackson 1975).

En la MHD ideal se considera que

1. el plasma puede describirse por su movimiento colectivo;

2. el plasma es eléctricamente neutro, o casi neutro, de manera que la densidad de carga eléctrica es muy pequeña;

3. las variaciones temporales de las magnitudes características del sistema son mucho menores que el producto entre la velocidad de la luz en el vacío $(c)$ y las variaciones espaciales de esas magnitudes $(\partial / \partial t \ll c \cdot \partial / \partial x$, siendo $t$ y $x$ las coordenadas temporal y espacial, respectivamente); y

4. la Ley de Ohm tiene la forma $J^{\prime}=\sigma E^{\prime}$, donde $J^{\prime}$ y $E^{\prime}$ son la densidad de corriente y el campo eléctrico en el sistema de referencia en que el elemento de plasma está en reposo, y $\sigma$ es la conductividad.

Del punto 3. se desprende un resultado muy importante, que constituye una de las aproximaciones más relevantes de la MHD. Ella, y la Ley de Faraday $\left(\vec{\nabla} \times \vec{E}=-\frac{\partial \vec{B}}{\partial t}\right)$ implican que

$$
|\vec{\nabla} \times \vec{E}|=\left|\frac{\partial \vec{B}}{\partial t}\right| \ll \frac{B}{L} c
$$


donde $L$ representa la longitud característica de variación de las magnitudes medias. Luego

$$
\frac{E}{L} \ll \frac{B}{L} c \Rightarrow E \ll B c
$$

Por lo tanto, en la Ley de Ampère-Maxwell se tiene

$$
\vec{\nabla} \times \vec{B}=\mu \vec{J}+\mu \varepsilon \frac{\partial \vec{E}}{\partial t} \simeq \mu \vec{J}+\frac{1}{c^{2}} \frac{\partial \vec{E}}{\partial t} \simeq \mu \vec{J}
$$

Es decir, las variaciones temporales del campo eléctrico son tan pequeñas que permiten despreciar la corriente de desplazamiento. En la última ecuación se ha supuesto que los valores de permitividad $\varepsilon$ y permeabilidad $\mu$ del medio pueden aproximarse por sus respectivos valores en el vacío.

El punto 4. establece la conexión entre densidad de corriente y campo eléctrico en un sistema de referencia solidario al elemento de plasma. Si éste se mueve con velocidad $v$ respecto del sistema de referencia donde la densidad de corriente y el campo son $J$ y $E$ (como en las expresiones anteriores), de las ecuaciones de transformación resulta que:

$$
\begin{gathered}
\vec{J}^{\prime}=\vec{J}+\hat{\rho} \vec{v} \simeq \vec{J} \\
\vec{E}^{\prime}=\vec{E}+\vec{v} \times \vec{B}
\end{gathered}
$$

con lo cual se obtiene

$$
\vec{J}=\sigma(\vec{E}+\vec{v} \times \vec{B})
$$

que representa a la Ley de $\mathrm{Ohm}$ en este sistema de referencia. Esto permite reemplazar al campo eléctrico $E$ en la Ley de Faraday, resultando

$$
\frac{\partial \vec{B}}{\partial t}=-\vec{\nabla} \times \vec{E}=-\vec{\nabla} \times\left[\frac{\vec{J}}{\sigma}-\vec{v} \times \vec{B}\right]
$$

De este resultado, junto con el anterior $(\vec{\nabla} \times \vec{B}=\mu \vec{J})$ se obtiene la ecuación fundamental de la MHD, conocida como Ecuación de Inducción

$$
\frac{\partial \vec{B}}{\partial t}=\vec{\nabla}(\vec{v} \times \vec{B})+\frac{1}{\mu \varepsilon} \nabla^{2} \vec{B}
$$

Los dos términos de esta ecuación reciben el nombre de conductivo y difusivo, respectivamente; el comportamiento temporal de $B$ dependerá de cuál de estos términos domine en una dada configuración física. En el límite de conductividad perfecta $(\sigma \rightarrow \infty)$ domina el término conductivo; luego, la ecuación se reduce a:

$$
\frac{\partial \vec{B}}{\partial t} \simeq \vec{\nabla}(\vec{v} \times \vec{B})
$$

o, equivalentemente, se puede pensar que la Ley de Ohm toma la forma

$$
\vec{E}+\vec{v} \times \vec{B}=0
$$

Cuando esto sucede se dice que el campo magnético está congelado en el plasma porque sus líneas se comportan como si se movieran con el plasma (Teorema de Alfvèn del flujo congelado; Jackson 1975; Priest 1984). 


\section{B.2. Sobre la compresión del gas en ondas de choque mag- néticas y la definición del parámetro magnético}

Cuando existe un campo magnético en el sistema hidrodinámico, la ecuación de movimiento se modifica. La presión del gas tiene que reemplazarse por la presión total: la presión térmica del gas y la presión magética. El enfriamiento radiativo y la compresión que tienen lugar detrás del shock, junto con el congelamiento del flujo hacen que el término magnético domine en la presión total si la compresión es suficientemente alta. Aún cuando el valor característico de la presión total sigue siendo $\rho_{g} v_{g}^{2}$ (ram pressure, o presión dinámica), como cuando no hay un campo magético presente, el dominio del término magnético tiene dos efectos importantes.

Por un lado, el estado final del gas comprimido consiste en una lámina delgada con el campo magnético paralelo al plano de la lámina (el plano de choque). Ese campo puede afectar la estabilidad gravitatoria del gas chocado (inestabilidades de Raleigh-Taylor y KelvinHelmholtz).

Por otro lado, se modifica la dinámica del gas postshock. Mientras éste se enfría y comprime, el dominio de la presión magética hace que esa compresión alcance un valor de saturación. El valor de la densidad de saturación generalmente es mucho menor que el valor que alcanza la compresión en ondas de choque radiativas en ausencia de campo magnético $(B)$. Como consecuencia, si existiera un cierto campo de radiación incidente, el efecto de este campo sobre el gas sería mayor en el caso magneto-dominante que en el caso donde $B=0$. Esto se debe a que como la compresión es menor, el cociente entre fotones (del supuesto campo externo) y partículas (del gas) es mayor, es decir, el campo de radiación es sería eficiente (Shapiro et al. 1992).

Para evaluar la compresión en este caso, considérese una onda de choque estacionaria, unidimensional, con simetría plana, propagándose a velocidad constante a través de un medio homogéneo cuyo campo magnético sea paralelo al plano de choque $\left(B=B_{\|}\right)$. Estas son las condiciones propuestas en los modelos de Dopita \& Sutherland $(1995,1996)$ y Allen et al. (2008), desarrollados en el Capítulo 2. La ventaja de utilizar una onda de choque transversal radica en que se busca que el campo magnético no provoque ningún efecto dinámicamente importante en el gas sin perturbar, simplemente porque no se observa (Shapiro et al. 1992). Aún si existiera una componente de $B$ perpendicular al frente de choque (es decir, si se tuviera un choque oblicuo), la hipótesis de congelamiento del campo con el plasma indica que esa componente permanecerá constante en su paso a través del shock ${ }^{1}$, mientras que la otra (la paralela al frente de choque) variará en proporción a la densidad (McKee \& Hollenbach 1980).

Durante el proceso de choque, justo detrás del frente se forma una capa de gas fuertemente comprimido. En el límite cuando la presión total está dominada por la presión magnética, el campo magnético alcanza su valor de saturación $\left(B_{\text {sat }}\right)$. Utilizando la misma nomenclatura que en el Capítulo 2, esto puede expresarse como:

$$
\rho_{0} v_{s}^{2} \approx p_{M} \Rightarrow \rho_{0} v_{s}^{2}=\frac{B_{s a t}^{2}}{8 \pi}
$$

La máxima compresión del gas en estas circunstancias puede derivarse de las condiciones

\footnotetext{
${ }^{1}$ En el desarrollo de ondas de choque magnéticas oblicuas (Priest 1984) se puede comprobar que para que este resultado sea cierto es necesario que la relación entre las componentes del campo $B$ paralela $\left(B_{\|} \mathrm{y}\right.$ perpendicular $\left(B_{\perp}\right)$ al plano de choque y la componente de la velocidad del shock perpendicular al plano de choque $\left(v_{s}^{\perp}\right)$ en el gas preshock sea

$$
\frac{B_{\|}}{B_{\perp}} \ll \frac{c}{v_{s}^{\perp}}
$$
}


de salto de Rankine-Hugoniot (ver Sección 2.4.3):

$$
\frac{B_{s a t}}{B_{0}}=\frac{\rho_{s a t}}{\rho_{0}}
$$

Luego, como $B_{\text {sat }}=\sqrt{8 \pi \rho_{0}} v_{s}$, resulta

$$
\frac{\rho_{s a t}}{\rho_{0}}=\frac{\sqrt{8 \pi \rho_{0}} v_{s}}{B_{0}}
$$

que también puede expresarse como (por simplicidad se quitan los subíndices)

$$
\frac{\rho_{\text {sat }}}{\rho}=\frac{\sqrt{8 \pi \mu m_{H} n} v_{s}}{B / n^{1 / 2}}
$$

donde $\rho=\mu m_{H} n$, siendo $\mu$ el peso molecular medio, $m_{H}$ la masa del átomo de hidrógeno, $\mathrm{y}$ $n$ la densidad numérica en el gas preshock.

Es a partir de la Ecuación B.1 que Dopita \& Sutherland $(1995,1996)$ incorporan la definición de parámetro magnético para la expresión $B / n^{1 / 2}$, como una manera de absorber las incertezas en los valores del campo y la densidad del gas. 


\section{Apéndice $\mathrm{C}$}

\section{Proceso de reducción de datos Gemini/GMOS en modo long-slit.}

A continuación se describe el proceso de reducción, completo y ordenado, de los espectros long-slit tomados con el Telescopio Gemini Norte. Se utilizó el paquete GEMINI.GMos (versiones 1.12beta, 1.11.1, 1.11 y 1.10) dentro de IRAF (version 2.14.1).

Muchas de las tareas involucradas en el procesamiento se ejecutaron en modo interactivo (fl_inter+, en la línea de comando), para controlar, en particular, el comportamiento de los errores en los ajustes polinomiales. Cabe destacar, en este sentido, la importancia de realizar de forma interactiva la corrección por overscan al momento de generar el archivo MasterBias.fits (ver a continuación). El efecto del overscan fue especialmente nocivo en los objetos más débiles de nuestra muestra, que casualmente son aquellos cuya emisión sufre mayor corrimiento al rojo (3C 268.2 y 3C 268.3; ver Tabla 3.1). Dado que la corrección de este efecto fue prácticamente nula cuando la tarea se ejecutó de forma automática, se resalta la importancia de su ejecución en modo interactivo.

En esta secuencia no se ha incluido la corrección por rayos cósmicos por los motivos expuestos en el Capítulo 4.

Por simplicidad se adopta la siguiente convención en cuanto a la nomenclatura de los archivos involucrados (todos se encuentran en el mismo directorio de trabajo):

- bias-lista.dat: es el listado (ASCII) de todos los archivos que contienen los bias tomados durante el mes en que se produjo la observación que se está procesando.

- MasterBias.fits: es el bias resultante de la combinación de todos los archivos .fits listados en el archivo ASCII bias-lista.dat

- flat.fits: es el archivo que contiene la imagen de campo plano (flat field). Cada una de nuestras observaciones se tomó con su propio flat field (uno solo) y su propia lámpara de comparación. En general, para observaciones donde se tengan más de una imagen de campo plano, se recomienda generar un archivo ASCII con el listado de tales archivos, tal como se hizo con los bias.

- MasterFlat.fits: es el flat resultante de la combinación de todos los flats disponibles. Aún cuando se disponga de sólo una imagen de campo plano (como ha sido nuestro caso) es necesario ejecutar la tarea que genera el archivo MasterFlat.fits.

- lampara.fits: es la lámpara de comparación (Cu-Ar) para realizar la calibración por longitud de onda. Cada espectro fue obtenido con su respectiva lámpara, ambos con la misma longitud de onda central.

- estandar.fits: es el archivo que contiene el espectro de la estrella estándar de flujo, centrado en la misma longitud de onda que el objeto de ciencia y su lámpara de comparación. 
- objeto.fits: es el archivo que contiene el espectro del objeto de ciencia. Las diferentes tareas que se aplican sucesivamente sobre este archivo van generando sus respectivos archivos de salida. Si bien cada una de esas tareas permite al usuario generar un nombre arbitrario para su salida, en lo que sigue no se ha utilizado esta opción. Por el contrario, se utiliza el nombre que cada tarea le asigna automáticamente a su archivo de salida, que consiste en el nombre del archivo original (en nuestro caso, objeto.fits) precedido de una letra. En cada etapa del procesamiento a continuación se indicará esta letra, cuando corresponda.

1. gmos.logfile="reduccion-gmos.log"

- Indica que toda la información, registro y posibles mensajes que surjan en el proceso de reducción serán copiados, en forma concatenada por todas las tareas, en el archivo ASCII reduccion-gmos.los. Muchos de estos mensajes también son impresos en pantalla.

2. gbias @bias-lista.dat MasterBias.fits fl_over $+\mathrm{fl} \_i n t e r+\mathrm{fl} \_$trim + nbiascontam $=4$

- Se genera el bias combinado.

- fl_over+ habilita la corrección por overscan.

- fl_inter+ habilita el modo interactivo.

- nbiascontam indica la cantidad de columnas del CCD que deben eliminarse antes de aplicar la corrección por overscan. Dado que nuestros datos se obtuvieron con los detectores EEV, corresponde usar nbiascontam $=4$.

- El archivo salida es MasterBias.fits.

3. gsflat flat.fits MasterFlat.fits fl_keep- fl_inter $+\mathrm{fl} \_a n s w e r+\mathrm{fl}$ over $+\mathrm{fl} \_$trim $+\mathrm{fl} \_b i a s+$ bias="MasterBias.fits" fl_fixpix + fl_detec+order $=12,10,7$

- Se genera la imagen de campo plano combinada. Aún cuando no haya más de una imagen para combinar es necesario que esa única imagen sea procesada con esta tarea, dado que durante esta parte del procesamiento se realizan llamados internos a muchas otras tareas, entre las cuales la más importante es gprepare que realizan modificaciones sobre lo/s flat fields individuales sin importar su cantidad.

- fl_keep- evita guardar todos los archivos intermedios que se van creando en el transcurso de la ejecución.

- fl_answer+ obliga a realizar (o revisar) todos los ajustes de forma interactiva.

- fl_trim + realiza un pequeño recorte sobre los datos, eliminando regiones espurias.

- fl_bias+ realiza la corrección por bias, y bias indica el nombre del archivo con el cual se realizará la corrección.

- fl_fixpix realiza una interpolación de la información de manera de eliminar los gaps existentes entre los CCDs al momento de armar el espectro completo, uniendo la información de los tres (3) CCD.

- fl_detec+ realiza la corrección para cada detector (CCD) de manera independiente. 
- order indica el grado del polinomio a utilizar en el ajuste de la respuesta de cada detector. Los tres números $(12,10,7)$ indican que la respuesta de cada CCD debe ajustarse con polinomios de distinto grado. El orden más alto corresponde al CCD 1, el más rojo, y el más bajo al CCD 3, el más azul ${ }^{1}$. Estos valores pueden cambiarse durante la ejecución, dado que con fl_inter+ se ha habilitado el modo interactivo.

- El archivo de salida es MasterFlat.fits.

4. gsreduce lampara.fits fl_over+ ovs_flinter+ fl_trim + fl_bias+ bias="MasterBias.fits" fl_flatfl_fixpix+fl_gmosaic+ fl_gsappwave+

- Realiza el procesamiento completo de la lámpara de comparación, en este caso.

- ovs_flinter+ habilita el modo interactivo para la corrección por overscan (fl_over+). Es equivalente al parámetro fl_inter+ de las tareas anteriores; cambia su nombre aquí para enfatizar que la única corrección que se permite realizar de forma interactiva es la del overscan.

- fl_flat- indica que no se realiza la corrección por campo plano: para el procesamiento de las lámparas no es necesario.

- fl_gmosaic+ indica que los datos de los tres CCD, que hasta el momento se conservan en tres extensiones diferentes del mismo archivo fits se combinan para que el archivo de salida contenga toda la información unificada.

- fl_gsappwave+ realiza una calibración preliminar en longitud de onda.

- Se agrega el prefijo gs al nombre del archivo de entrada para crear el archivo de salida: gslampara.fits

5. gswavelength gslampara.fits fl_inter-

- Realiza la calibración por longitud de onda sobre la lámpara de comparación.

- La tarea sobreescribe el archivo de entrada. De esta manera, queda listo para calibrar los espectros de ciencia, una vez que éstos hayan completado su procesamiento.

6. gsreduce objeto.fits fl_over+ fl_trim + fl_bias+ bias="MasterBias.fits" fl_flat + flatim="MasterFlat.fits" fl_gmosaic + fl_fixpix + fl_gsappwave+

- Realiza el procesamiento completo de los espectros de ciencia.

- fl_flat+ realiza la corección por campo plano, y flatim indica el nombre del archivo con el cual se realizará la corrección.

- Se agrega el prefijo gs al nombre del archivo de entrada para crear el archivo de salida: gsobjeto.fits

\section{7. gstransform gsobjeto.fits fl_wavtran+ wavtraname="gslampara"}

- Realiza la calibración del espectro, basándose en la lámpara ya reducida.

- fl_wavtran+ habilita la calibración.

\footnotetext{
${ }^{1}$ Notar que el sentido de la dispersión en los datos crudos es el opuesto al usual: la parte roja del espectro se encuentra a la izquierda. Esta orientación se corrige durante el procesamiento, y finalmente, los datos limpios tienen el espectro orientado de la forma convencional: la parte roja del espectro a la derecha.
} 
- wavtraname indica el nombre del archivo con el cual se debe realizar la calibración, sin su extensión (.fits).

- Se agrega el prefijo $\mathbf{t}$ al nombre del archivo de entrada para crear el archivo de salida: tgsobjeto.fits

8. gsskysub tgsobjeto.fits fl_answer-fl_inter- long_sample="850:1000,1310:1430"

- Realiza la corrección (resta) por la contribución del brillo del cielo, y de sus posibles líneas de emisión.

- fl_answer-fl_inter-deshabilita completamente el modo interactivo.

- long_sample indica las regiones (filas) del detector que se utilizarán como patrón para realizar la corrección. En este caso, se utilizaron dos rangos de filas, comprendidos en los intervalos (coordenada 'y'del detector) $[850,1000]$ y $[1310,1430]$.

- Se agrega el prefijo s al nombre del archivo de entrada para crear el archivo de salida: stgsobjeto.fits

9. Se repiten los pasos 6, 7. y 8. sobre el espectro de la estrella estándar de flujo (el archivo de entrada será el que contenga este espectro: estandar.fits), necesarios para realizar la última calibración (en flujo) sobre el espectro de ciencia. Al finalizar este paso, se obtiene un archivo stgsestandar.fits, corregido por overscan, bias, campo plano y calibrado en longitud de onda. al igual que el espectro de cuencia, con el archivo gslampara.fits.

10. gsextract stgsestandar.fits

- Se extrae un espectro unidimensional de la estrella estándar, necesario para la siguiente tarea.

- Se agrega el prefijo e al nombre del archivo de entrada para crear el archivo de salida: estgsobjeto.fits

11. gsstandard estgsestandar.fits

- Establece la calibración espectro-fotométrica.

- Esta tarea crea dos (2) archivos sens.fits y std, que serán necesarios para la calibración del espectro de ciencia.

12. gscalibrate stgsobjeto.fits fl_flux $+\mathrm{fl} \_f n u-f l \_s c a l e+$ fluxscale $=10 E+15$

- Realiza la calibración en flujo sobre el espectro de ciencia, para lo cual lee los archivos sens.fits y std, creados en el paso previo.

- fl_flux+ habilita la calibración.

- fl_fnu- hace que el espectro resultante tenga unidades de flujo por unidad de longitud de onda: $F_{\lambda}$ (si fl_fnu+ se obtiene $F_{\nu}$ ).

- fl_scale+ Multiplica el espectro calibrado resultante por un factor de escala arbitrario, dado por el valor asignado a fluxscale. 


\section{Apéndice D}

\section{Efecto de la extinción provocada por el material interestelar en los valores de los cocientes de líneas}

La radiación emitida por un dado objeto se atenúa en el camino que los fotones recorren desde el lugar de emisión hasta su detección. Esta atenuación se debe a la presencia de material interestelar (MIE) en todo el trayecto recorrido, que o bien absorbe o bien dispersa parte de esa radiación. Como lo que ocurre es la pérdida de una parte del campo de radiación emitido, el efecto de la presencia del MIE se denomina "extinción" de la radiación.

Para el caso de los objetos estudiados en esta Tesis, la extinción podría tener tres componentes: 1) extinción Galáctica, es decir, provocada por el MIE perteneciente a la Vía Láctea, distribuido a lo largo de la línea de la visual a cada objeto; 2) extinción intergaláctica; producida por el material intergaláctico (MIG) situado en la línea de la visual entre la Vía Láctea y cada galaxia estudiada; y 3 ) la extinción que se produciría en la propia galaxia de estudio.

La extinción Galáctica (1) puede estimarse en función del conocimiento que se tiene de la estructura de la Vía Láctea, y particularmente de su distribución de gas y polvo. Los objetos estudiados en este trabajo son radiofuentes 3CRR, es decir pertencen a la segunda revisión del Catálogo de Cambridge. Esto significa (ver Capítulo 3) que se sitúan en latitudes galácticas suficientemente altas como para que el efecto de la Vía Láctea en la extinción total sea despreciable.

La extinción provocada por el MIG (2), o extinción intergaláctica, es conocida por ser extremadamente baja, y por lo tanto su efecto también puede despreciarse.

La tercer componente de la extinción total, es decir, la que se produce en la propia galaxia es mucho más difícil de estimar porque requeriría conocer la distribución de gas y polvo; y una vez conocida esa estructura, determinar el efecto de la extinción en la dirección de las EELR. En muchas radiogalaxias se observan estructuras de polvo o nubes densas de MIE en las regiones cercanas al núcleo. Hacia las afueras de la galaxia, en cambio, estas estructuras no se observan. Por supuesto, esto no es suficiente para asegurar que no existan zonas donde la extinción sea importante.

En el caso particular donde el análisis de las regiones nebulares se realiza a través de cocientes de líneas de emisión, muchas veces se realiza una estimación de la extinción a través del decremento de Balmer. Lamentablemente este procedimiento no se puede realizar en el presente trabajo, ya que esto requeriría de la medición simultánea de los flujos recibidos en las dos líneas más importantes de la Serie de Balmer $\mathrm{H} \alpha$ y $\mathrm{H} \beta$; además sería necesario suponer que ambas líneas provienen exactamente de la misma región. Los espectros tomados para esta investigación cubren el rango $3300 \AA-5300 \AA$, por lo tanto no incluyen la emisión de 
Tabla D.1. Efecto de la extinción en los cocientes de líneas.

\begin{tabular}{c|c}
\hline \hline Cociente & $\operatorname{coef}_{(\mathrm{A} / \mathrm{B})}$ \\
\hline $\mathrm{HeII} / \mathrm{H} \beta$ & -0.0222 \\
\hline$[\mathrm{OIII}] \lambda 5007 / \mathrm{H} \beta$ & 0.017 \\
\hline$[\mathrm{OII}] \lambda 3727 /[\mathrm{OIII}] \lambda 5007$ & -0.1611 \\
\hline$[\mathrm{OII}] \lambda 3727 /[\mathrm{NeV}] \lambda 3426$ & 0.0272 \\
\hline$[\mathrm{NeIII}] \lambda 3869 /[\mathrm{OII}] \lambda 3727$ & 0.0138 \\
\hline$[\mathrm{OIII}] \lambda 4363 /[\mathrm{OIII}] \lambda 5007$ & -0.0839 \\
\hline \hline
\end{tabular}

Todos los cocientes se expresan en escala logarítmica para facilitar el análisis sobre los diagramas del Capítulo 6.

$\mathrm{H} \alpha$. Por otra parte, dadas las distancias involucradas en las nebulosas (e incluso los modelos utilizados para su análisis), tampoco sería posible asegurar que la emisión de ambas se produce exactamente en la misma región, y no, por ejemplo, en una mezcla de sistemas gaseosos con características diferentes. En otros casos, la estimación de la extinción se realiza mediante las líneas interestelares difusas del sodio $(\mathrm{Na})$ o calcio $(\mathrm{Ca})$. En todos los espectros obtenidos para este trabajo, la contribución del continuo a la emisión global en las zonas externas de las galaxias es extremadamente baja (ver Capítulo 5). Por tal motivo, estas líneas de absorción son, en absoluto, indistinguibles.

Sin embargo, tratando con cocientes de líneas, sí es posible calcular el efecto relativo de la extinción entre las dos líneas involucradas, bajo ciertas suposiciones sobre las características del MIE/MIG en la galaxia. El cálculo se basa en las relaciones planteadas por Cardelli, Clayton \& Mathis (1989). En cuanto a las características del medio en cada galaxia observada, se supone que en todos los casos las propiedades físicas del gas y polvo son similares a las del promedio del medio interestelar en la Vía Láctea. De este modo, utilizando las relaciones dadas por las ecuaciones 3a y 3b de Cardelli et al. (1989, válidas para su aplicación en el rango óptico-IR cercano: 3000-9000 ̊) aplicadas sobre cada cociente de interés, se obtiene una relación entre la intensidad observada en el cociente de líneas A y B, la intensidad intrínseca, el coeficiente de extinción característico para el par de líneas involucradas y la absorción en el filtro $\mathrm{V}$ de Johnson $\left(A_{V}\right)$ que actúa como factor de normalización. Como a lo largo de este trabajo se utilizan siempre escalas logarítmicas, la relación adopta la forma:

$$
\log \left(\frac{\text { Linea } \mathrm{A}}{\text { Linea B }}\right)_{o b s}=\log \left(\frac{\text { Linea } \mathrm{A}}{\text { Linea B }}\right)_{\text {int }}+\operatorname{coe} f_{(\mathrm{A} / \mathrm{B})} \cdot A_{V}
$$

En la Tabla D.1 se listan los valores del coeficiente de extinción coe $f_{(\mathrm{A} / \mathrm{B})}$ para cada uno de los cocientes de líneas utilizados en esta Tesis; se consideró que $A_{V}=1$. Puede observarse que el cociente que más sufre de extinción es el de [OHI $] \lambda 3727 /[\mathrm{OIII}] \lambda 5007$, debido a que es el que utiliza las líneas mán distantes. 


\section{Apéndice E}

\section{Validación del método de medición. Diagramas complementarios de $3 \mathrm{C} 321$.}

En el trabajo de Robinson et al. (2000) se realizaron dos correcciones sobre el espectro: resta del continuo y corrección por enrojecimiento. Como se describió en el Capítulo 5, la emisión del continuo en los espectros GMOS es completamente despreciable (ver, por ejemplo, el panel inferior de la Fig. 5.11, que corresponde a las zonas aledañas al núcleo sur, en la región $\mathrm{C}_{S}$ ) frente a la intensidad de las líneas. Sin embargo, el hecho de que exista un trabajo donde se realizan estas correcciones es valioso como método de comparación entre los resultados finales de las mediciones obtenidos por estos autores y en el presente trabajo, y constituye una herramienta de evaluación y validación determinante sobre el proceso de medición discutido en el Capítulo 4.

Los resultados de la evaluación se pueden apreciar a partir de la comparación directa entre los flujos medidos en las líneas de emisión (respecto de $\mathrm{H} \beta$ en todos los casos), en la Figura E.1, y también a través de los diagramas de diagnóstico, en la Figura E.2. En el primer caso (Fig. E.1) se graficaron todas las mediciones obtenidas para las líneas [Nev] $\lambda 3424$, [OII] $\lambda 3727$, [NeIII] $\lambda 3869$, HeII (4686) y [OIII] $\lambda 5007$ según la metodología descripta en la Sección 4.2. Estas mediciones se grafican con círculos junto con sus barras de error (color azul), en función de la distancia angular (se respeta la convención adoptada en la Sección 6.5). Las observaciones de Robinson et al. (2000) se graficaron en los dos grupos disponibles: el grupo representado por las barras de color rojo (en la Fig. E.1 se etiquetó con la leyenda no corregido) corresponde a las mediciones donde no se realizó la corrección por enrojecimiento, mientras que el grupo representado por las barras de color verde son aquellas mediciones corregidas por enrojecimiento (la leyenda indica corregido). Según se expresa en el citado artículo, ambos grupos están corregidos por la emisión del continuo (la resta). Para cada una de las regiones identificadas allí se obtuvo un único valor característico de la emisión en cada línea, junto con su error. En términos generales, esas regiones coinciden con las identificadas en el espectro GMOS (ver Fig.6.15; la región D fue resuelta en dos componentes por estos autores, pero en este caso, a los efectos de comparación se tomó el valor medio de sus mediciones).

En el segundo caso (Fig. E.2) la evaluación se realizó a través de los diagramas de diagnóstico, dado que es el método de análisis empleado en ambos trabajos. Se replicaron los diagramas de la Fig. 6.16 para incorporar las mediciones obtenidas por Robinson et al. (2000), que se grafican como asteriscos (en negro; son las mediciones representadas por las barras verdes en la Fig. E.1). Por las razones explicadas en el párrafo anterior, cada nebulosa queda representada por un único punto de referencia en el diagrama. En cuanto a las referencias 
Figura E.1. Validación del método de medición
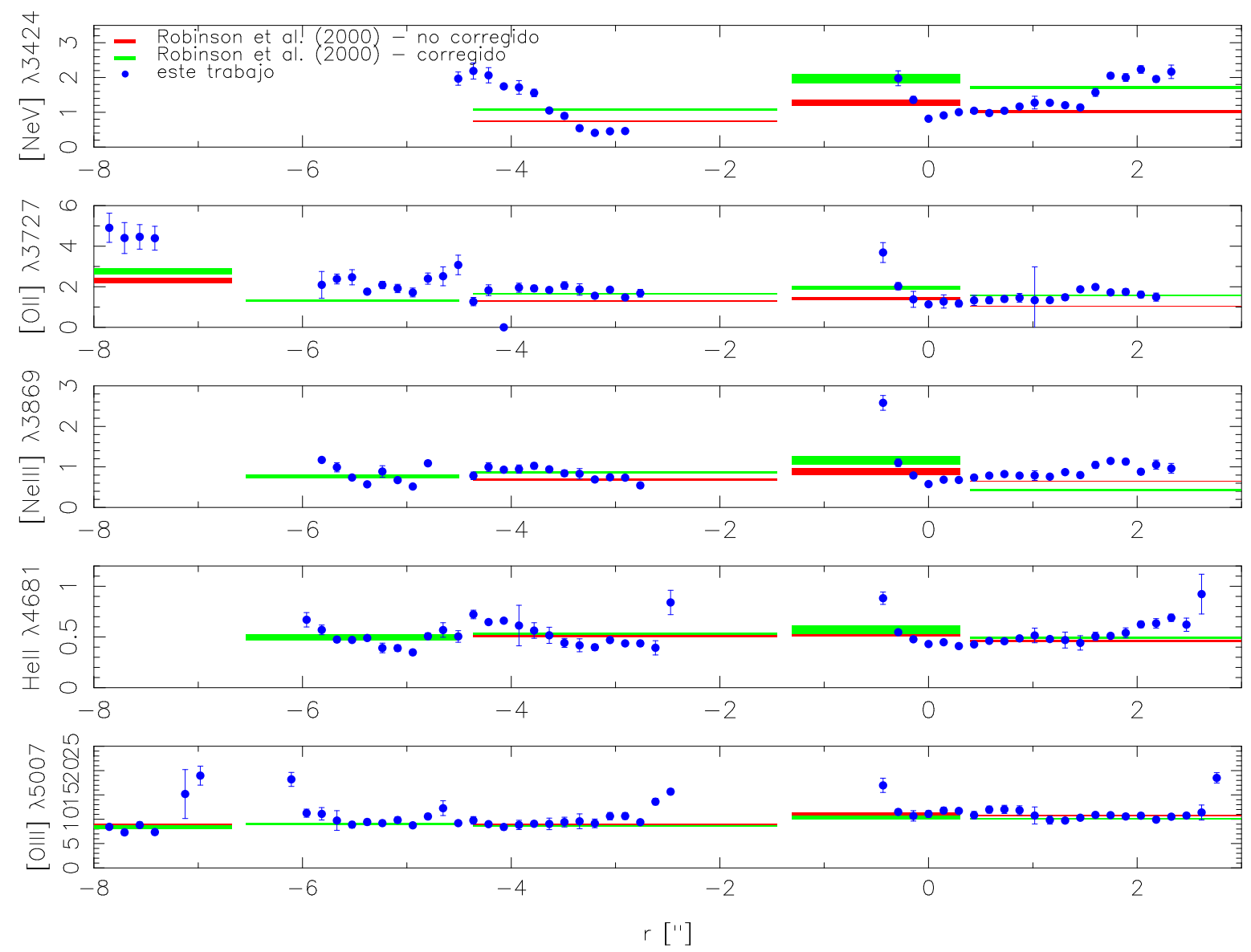

Flujo medido en cada línea de emisión respecto del de $\mathrm{H} \beta$ según este trabajo (círculos, color azul) y según la técnica empleada por Robinson et al. (2000); en este último caso se grafican las mediciones que incluyen la corrección por enrojecimiento (barras, color verde) y las que no la incluyen (barras, color rojo). 
restantes, se mantienen las establecidas en la Sección 6.5. Se modificó la escala de los gráficos en relación a la que se utilizó en la Fig. 6.16; el propósito de este cambio responde a que, en este caso, se busca evaluar el comportamiento relativo entre mediciones obtenidas con métodos diferentes y no el comportamiento de las observaciones respecto de los modelos empleados. Aún así, los diagramas conservan los modelos por completitud y como referencia.

Tanto en los gráficos de intensidad (cuya escala es lineal) como en los diagramas de diagnóstico (cuya escala es logarítmica) se observa que las mediciones son equivalentes. Las mayores dispersiones se observan en los gráficos de intensidad de las líneas más azules del espectro ([Nev] $\lambda 3424$ y [OII] $\lambda 3727)$; comportamiento que se manifiesta entre los dos conjuntos de medidas de Robinson et al., y entre éstos y nuestras mediciones. Sin embargo, y con la única excepción del $[\mathrm{OII}] \lambda 3727$ en la región A $(r \sim-8$ "), las mediciones de Robinson et al. se pueden interpretar como los valores medios de las nuestras en cada una de las nebulosas espacialmente resueltas.

A modo de conclusión debe señalarse que:

- el método de medición adoptado en esta Tesis, descripto en el Capítulo 4, remueve la emisión del continuo con efectividad equivalente a la que se obtiene con los métodos de remoción aplicables sobre espectros de mayor rango espectral (notar que el rango del espectro GMOS/Gemini es aproximadamente la mitad del rango del espectro ISIS/WHT, empleado por Robinson et al.).

- la corrección por enrojecimiento no afecta los resultados: esto puede deberse a la combinación de dos efectos: 1) que el enrojecimiento no es significativo, y 2) que el análisis se realiza con mediciones en escala logarítmica, con lo cual las diferencias, cuando existen, se reducen drásticamente.

- las conclusiones derivadas de la evaluación de los mecanismos de ionización son, también, equivalentes para los dos (tres) conjuntos de datos.

Figura E.2. 3C 321. Diagramas complementarios.
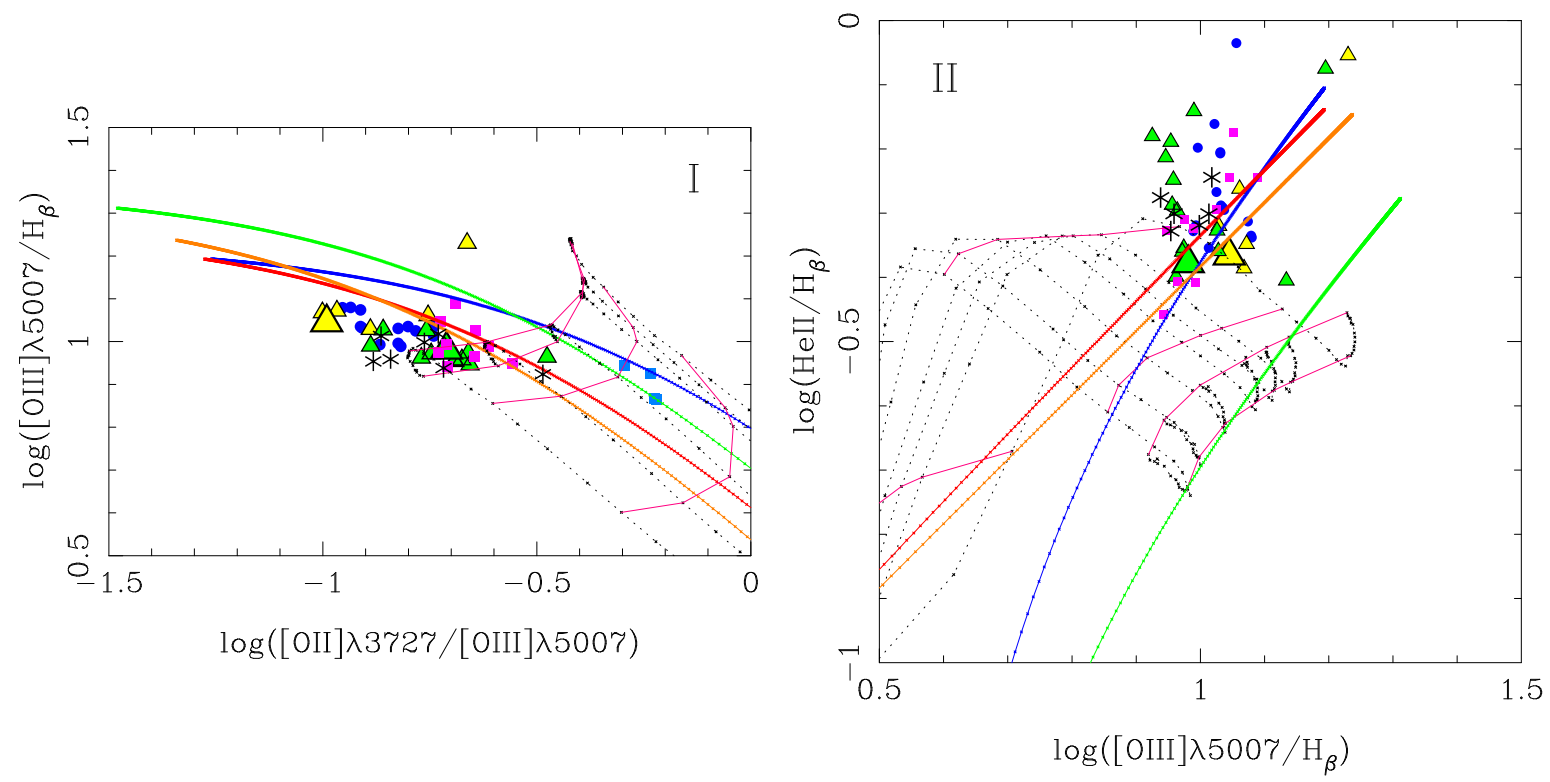
Fig. E.2: continuación
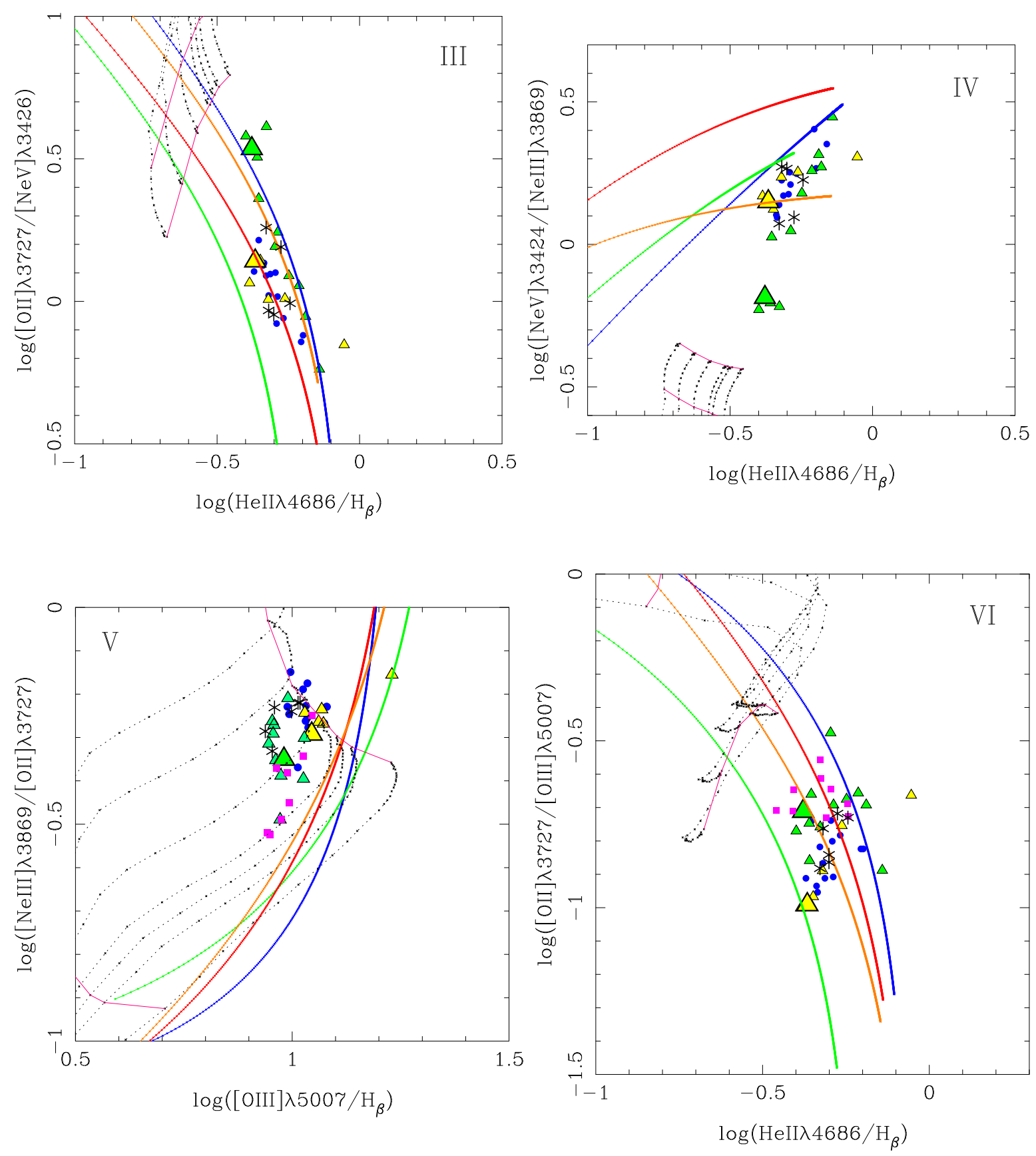

Diagramas de diagnóstico para el análisis de los mecanismos de ionización actuantes en las regiones nebulares de 3C 321. Se trata de los mismos diagramas de la Fig. 6.16, donde se incluyen las mediciones de Robinson et al. (2000), representadas por asteriscos (color negro), corregidas por enrojecimiento y por la emisión del continuo (barras verdes en la Fig. E.1). 


\section{Bibliografía}

Akujor C. E., Garrington S. T., 1995, A\&AS, 112, 235

Allen M. G., Dopita M. A., Tsvetanov Z. I., 1998, ApJ, 493, 571

Allen M. G., Groves B. A., Dopita M. A., Sutherland R. S., Kewley L. J., 2008, ApJS, 178, 20. (A08)

Allen M. G., Sparks W. B., Koekemoer A., Martel A. R., O’Dea C. P., Baum S. A., Chiaberge M., Macchetto F. D., Miley G. K., 2002, ApJS, 139, 411

Andruchow I., 2006, Tesis Doctoral, Facultad de Ciencias Astronómicas y Geofísicas. Universidad Nacional de La Plata

Antonucci R., 1993, ARA\&A, 31, 473

Antonucci R. R. J., Miller J. S., 1985, ApJ, 297, 621

Axon D. J., Capetti A., Fanti R., Morganti R., Robinson A., Spencer R., 2000, AJ, 120, 2284

Baker J. G., Menzel D. H., 1938, ApJ, 88, 52

Baldi R. D., Capetti A., 2008, A\&A, 489, 989

Baldwin J. A., Phillips M. M., Terlevich R., 1981, PASP, 93, 5

Balmaverde B., Capetti A., Grandi P., Torresi E., Chiaberge M., Rodriguez Zaurin J., Tremblay G. R., Axon D. J., Baum S. A., Giovannini G., Kharb P., Macchetto F. D., O'Dea C. P., Sparks W., 2012, A\&A, 545, A143

Baum S. A., Heckman T., 1989a, ApJ, 336, 681

Baum S. A., Heckman T., 1989b, ApJ, 336, 702

Baum S. A., Heckman T., van Breugel W., 1990, ApJS, 74, 389

Baum S. A., Heckman T. M., Bridle A., van Breugel W. J. M., Miley G. K., 1988, ApJS, 68, 643

Baum S. A., Heckman T. M., van Breugel W., 1992, ApJ, 389, 208

Bennett A. S., 1962a, MNRAS, 125, 75

Bennett A. S., 1962b, MmRAS, 68, 163

Best P., Longair M. S., Rottgering H. J. A., 1996, MNRAS, 280, L9

Best P., Röttgering H. J. A., Longair M. S., 2000, MNRAS, 311, 23 
Bianchi S., Guainazzi M., Chiaberge M., 2006, A\&A, 448, 499

Binette L., Matadamas R., Hägele G. F., Nicholls D. C., Magris C. G., Peña-Guerrero M. Á., Morisset C., Rodríguez-González A., 2012, A\&A, 547, A29

Binette L., Wilson A. S., Raga A., Storchi-Bergmann T., 1997, A\&A, 327, 909

Binette L., Wilson A. S., Storchi-Bergmann T., 1996, A\&A, 312, 365. (BWS96)

Biretta J. A., Martel A. R., McMaster M., Sparks W. B., Baum S. A., Macchetto F., McCarthy P. J., 2002, NewA Rev, 46, 181

Brown R. L., Mathews W. G., 1970, ApJ, 160, 939

Buttiglione S., Capetti A., Celotti A., Axon D. J., Chiaberge M., Macchetto F. D., Sparks W. B., 2009, A\&A, 495, 1033

Buttiglione S., Capetti A., Celotti A., Axon D. J., Chiaberge M., Macchetto F. D., Sparks W. B., 2010, A\&A, 509, A6

Cardelli J. A., Clayton G. C., Mathis J. S., 1989, ApJ, 345, 245

Chambers K. C., Miley G. K., van Breugel W., 1987, Nature, 329, 604

Clark N. E., Axon D. J., Tadhunter C., Robinson A., O’Brien P., 1998, ApJ, 494, 546

Cox D. P., 1972, ApJ, 178, 143

Croston J. H., Birkinshaw M., Hardcastle M. J., Worrall D. M., 2004, MNRAS, 353, 879

de Koff S., Baum S. A., Sparks W. B., Biretta J., Golombek D., Macchetto F., McCarthy P., Miley G. K., 1996, ApJS, 107, 621

de La Calle Pérez I., Longinotti A. L., Guainazzi M., Bianchi S., Dovčiak M., Cappi M., Matt G., Miniutti G., Petrucci P. O., Piconcelli E., Ponti G., Porquet D., Santos-Lleó M., 2010, $\mathrm{A} \& \mathrm{~A}, 524, \mathrm{~A} 50$

de Vries W. H., O’Dea C. P., Baum S. A., Barthel P. D., 1999, ApJ, 526, 27

de Vries W. H., O’Dea C. P., Baum S. A., Sparks W. B., Biretta J., de Koff S., Golombek D., Lehnert M. D., Macchetto F., McCarthy P., Miley G. K., 1997, ApJS, 110, 191

Di Matteo T., Springel V., Hernquist L., 2005, Nature, 433, 604

Donzelli C. J., Chiaberge M., Macchetto F. D., Madrid J. P., Capetti A., Marchesini D., 2007, ApJ, 667, 780

Dopita M. A., Sutherland R. S., 1995, ApJ, 455, 468. (DS95)

Dopita M. A., Sutherland R. S., 1996, ApJS, 102, 161. (DS96)

Edge D. O., Shakeshaft J. R., McAdam W. B., Baldwin J. E., Archer S., 1959, MmRAS, 68, 37

Evans D. A., Fong W.-F., Hardcastle M. J., Kraft R. P., Lee J. C., Worrall D. M., Birkinshaw M., Croston J. H., Muxlow T. W. B., 2008, ApJ, 675, 1057 
Evans D. A., Hardcastle M. J., Lee J. C., Kraft R. P., Worrall D. M., Birkinshaw M., Croston J. H., 2008, ApJ, 688, 844

Fanaroff B. L., Riley J. M., 1974, MNRAS, 167, 31P

Fath E. A., 1909, Lick Observatory Bulletin, 5, 71

Feinstein C., Macchetto F. D., Martel A. R., Sparks W. B., McCarthy P. J., 1999, ApJ, 526, 623

Ferland G. J., 2003, ARA\&A, 41, 517

Ferland G. J., Netzer H., 1983, ApJ, 264, 105

Ferland G. J., Osterbrock D. E., 1986, ApJ, 300, 658

Filippenko A. V., 1987, in Hewitt A., Burbidge G., Fang L. Z., eds, Observational Cosmology Vol. 124 of IAU Symposium, The 'gravitational lens'3C 321 : a remarkable impostor.. pp $751-754$

Fosbury R. A. E., 1989, in Meurs E. J. A., Fosbury R. A. E., eds, European Southern Observatory Conference and Workshop Vol. 32 of European Southern Observatory Conference and Workshop Proceedings, Extranuclear activity in galaxies. p. 169

Gopal-Krishna Wiita P. J., 2000, A\&A, 363, 507

Grandi S. A., Osterbrock D. E., 1978, ApJ, 220, 783

Greenhouse M. A., Woodward C. E., Thronson Jr. H. A., Rudy R. J., Rossano G. S., Erwin P., Puetter R. C., 1991, ApJ, 383, 164

Groves B. A., Allen M. G., 2010, NewA, 15, 614

Hardcastle M. J., Alexander P., Pooley G. G., Riley J. M., 1997, MNRAS, 288, 859

Hardcastle M. J., Evans D. A., Croston J. H., 2006, MNRAS, 370, 1893

Hardcastle M. J., Evans D. A., Croston J. H., 2009, MNRAS, 396, 1929

Hardcastle M. J., Massaro F., Harris D. E., Baum S. A., Bianchi S., Chiaberge M., Morganti R., O'Dea C. P., Siemiginowska A., 2012, MNRAS, 424, 1774

Hardcastle M. J., Worrall D. M., 1999, MNRAS, 309, 969

Harvanek M., Hardcastle M. J., 1998, ApJS, 119, 25

Harvanek M., Stocke J. T., 2002, AJ, 124, 1239

Heckman T. M., Miley G. K., Balick B., van Breugel W. J. M., Butcher H. R., 1982, ApJ, 262,529

Heckman T. M., Smith E. P., Baum S. A., van Breugel W. J. M., Miley G. K., Illingworth G. D., Bothun G. D., Balick B., 1986, ApJ, 311, 526

Hewitt A., Burbidge G., 1991, ApJS, 75, 297

Holt J., Tadhunter C., Morganti R., 2003, MNRAS, 342, 227 
Holt J., Tadhunter C., Morganti R., 2008, MNRAS, 387, 639

Holt J., Tadhunter C., Morganti R., 2009, MNRAS, 400, 589

Hopkins P. F., Hernquist L., Cox T. J., Di Matteo T., Martini P., Robertson B., Springel V., 2005, ApJ, 630, 705

Hubble E. P., 1926, ApJ, 64, 321

Hurt T., Antonucci R., Cohen R., Kinney A., Krolik J., 1999, ApJ, 514, 579

Jackson J., 1975, Classical electrodynamics. Wiley

Jackson N., Beswick R., Pedlar A., Cole G. H., Sparks W. B., Leahy J. P., Axon D. J., Holloway A. J., 2003, MNRAS, 338, 643

Jackson N., Sparks W. B., Miley G. K., Macchetto F., 1995, A\&A, 296, 339

Jansky K. G., 1933, Popular Astronomy, 41, 548

Kauffmann G., Heckman T. M., Tremonti C., Brinchmann J., Charlot S., White S. D. M., Ridgway S. E., Brinkmann J., Fukugita M., Hall P. B., Ivezić Ž., Richards G. T., Schneider D. P., 2003, MNRAS, 346, 1055

Kawara K., Taniguchi Y., Nishida M., 1988, ApJ, 328, L41

Keiter P. A., Drake R. P., Perry T. S., Robey H. F., Remington B. A., Iglesias C. A., Wallace R. J., Knauer J., 2002, Phys. Rev. Lett., 89, 16

Kewley L. J., Dopita M. A., Sutherland R. S., Heisler C. A., Trevena J., 2001, ApJ, 556, 121

Kewley L. J., Groves B., Kauffmann G., Heckman T., 2006, MNRAS, 372, 961

Komossa S., Schulz H., 1997, A\&A, 323, 31

Korista K., Ferland G., Baldwin J., 1997, ApJ, 487, 555

Labiano A., O'Dea C. P., Gelderman R., de Vries W. H., Axon D. J., Barthel P. D., Baum S. A., Capetti A., Fanti R., Koekemoer A. M., Morganti R., Tadhunter C., 2005, A\&A, 436, 493

Laing R. A., Peacock J. A., 1980, MNRAS, 190, 903

Laing R. A., Riley J. M., Longair M. S., 1983, MNRAS, 204, 151

Leahy J. P., Perley R. A., 1991, AJ, 102, 537

Leahy J. P., Williams A. G., 1984, MNRAS, 210, 929

Lena D., Robinson A., Seelig T., Schnorr-Muller A., Riffel R. A., Storchi-Bergmann T., Couto G., 2014, in American Astronomical Society Meeting Abstracts \#223 Vol. 223 of American Astronomical Society Meeting Abstracts, Gas Flows in the Inner Kiloparsec of NGC 1386. p. 251.07

Li J., Ostriker J., Sunyaev R., 2013, ApJ, 767, 105

Lüdke E., Garrington S. T., Spencer R. E., Akujor C. E., Muxlow T. W. B., Sanghera H. S., Fanti C., 1998, MNRAS, 299, 467 
Madrid J. P., Chiaberge M., Floyd D., Sparks W. B., Macchetto D., Miley G. K., Axon D., Capetti A., O’Dea C. P., Baum S., Perlman E., Quillen A., 2006, ApJS, 164, 307

Martel A. R., Baum S. A., Sparks W. B., Wyckoff E., Biretta J. A., Golombek D., Macchetto F. D., de Koff S., McCarthy P. J., Miley G. K., 1999, ApJS, 122, 81

Massaro F., Chiaberge M., Grandi P., Giovannini G., O’Dea C. P., Macchetto F. D., Baum S. A., Gilli R., Capetti A., Bonafede A., Liuzzo E., 2009, ApJ, 692, L123

Massaro F., Harris D. E., Tremblay G. R., Axon D., Baum S. A., Capetti A., Chiaberge M., Gilli R., Giovannini G., Grandi P., Macchetto F. D., O’Dea C. P., Risaliti G., Sparks W., 2010, ApJ, 714, 589

Massaro F., Harris D. E., Tremblay G. R., Liuzzo E., Bonafede A., Paggi A., 2013, ApJS, 206,7

Massaro F., Tremblay G. R., Harris D. E., Kharb P., Axon D., Balmaverde B., Baum S. A., Capetti A., Chiaberge M., Gilli R., Giovannini G., Grandi P., Macchetto F. D., O’Dea C. P., Risaliti G., Sparks W., Torresi E., 2012, ApJS, 203, 31

McCarthy P. J., Miley G. K., de Koff S., Baum S. A., Sparks W. B., Golombek D., Biretta J., Macchetto F., 1997, ApJS, 112, 415

McCarthy P. J., Spinrad H., van Breugel W., 1995, ApJS, 99, 27

McCarthy P. J., van Breugel W., Spinrad H., Djorgovski S., 1987, ApJ, 321, L29

McKee C. F., Hollenbach D. J., 1980, ARA\&A, 18, 219

Moorwood A. F. M., Oliva E., 1988, A\&A, 203, 278

Morganti R., Oosterloo T. A., Tadhunter C., van Moorsel G., Emonts B., 2005, A\&A, 439, 521

Morganti R., Robinson A., Fosbury R. A. E., di Serego Alighieri S., Tadhunter C., Malin D. F., 1991, MNRAS, 249, 91

Neff S. G., Roberts L., Hutchings J. B., 1995, ApJS, 99, 349

Netzer H., 2008, NewA Rev, 52, 257

O'Brien P. T., Reeves J. N., Turner M. J. L., Pounds K. A., Page M., Gliozzi M., Brinkmann W., Stephen J. B., Dadina M., 2001, A\&A, 365, L122

O'Dea C. P., de Vries W. H., Koekemoer A. M., Baum S. A., Morganti R., Fanti R., Capetti A., Tadhunter C., Barthel P. D., Axon D. J., Gelderman R., 2002, AJ, 123, 2333

Osterbrock D. E., 1989, Astrophysics of gaseous nebulae and active galactic nuclei. Research supported by the University of California, John Simon Guggenheim Memorial Foundation, University of Minnesota, et al. Mill Valley, CA, University Science Books

Penston M. V., Robinson A., Alloin D., Appenzeller I., Aretxaga I., Axon D. J., Baribaud T., Barthel P., Baum S. A., Boisson C., et al. 1990, A\&A, 236, 53

Peterson B. M., 1997, An Introduction to Active Galactic Nuclei. Cambridge, New York Cambridge University Press 
Peterson B. M., Wilkes J. B., 2001, Active Galaxies: Unified Model en Encyclopedia of Astronomy and Astrophysics [Murdin, P.M.]. Institute of Astronomy, Cambridge, UKC R C Press LLC

Porter R. L., Ferland G. J., 2007, ApJ, 664, 586

Priest E., 1984, Solar Magnetohydrodynamics. Geophysics and Astrophysics Monographs, Kluwer Academic Pub

Privon G. C., O'Dea C. P., Baum S. A., Axon D. J., Kharb P., Buchanan C. L., Sparks W., Chiaberge M., 2008, ApJS, 175, 423

Rawlings S., Saunders R., 1991, Nature, 349, 138

Reynaldi V., Feinstein C., 2013a, MNRAS, 430, 2221

Reynaldi V., Feinstein C., 2013b, MNRAS, 435, 1350

Riffel R. A., Storchi-Bergmann T., Riffel R., 2014, ApJ, 780, L24

Robinson A., 1989, in Meurs E. J. A., Fosbury R. A. E., eds, European Southern Observatory Conference and Workshop Vol. 32 of European Southern Observatory Conference and Workshop Proceedings, Ionization Mechanisms and Physical Conditions in Extra-Nuclear Emission Line Nebulae. p. 259

Robinson A., Binette L., Fosbury R. A. E., Tadhunter C., 1987, MNRAS, 227, 97

Robinson T. G., Tadhunter C., Axon D. J., Robinson A., 2000, MNRAS, 317, 922

Robinson T. G., Tadhunter C., Dyson J. E., 2002, MNRAS, 331, L13

Russell S. C., Dopita M. A., 1992, ApJ, 384, 508

Schnorr-Müller A., Storchi-Bergmann T., Nagar N. M., Ferrari F., 2014a, MNRAS, 438, 3322

Schnorr-Müller A., Storchi-Bergmann T., Nagar N. M., Robinson A., Lena D., Riffel R. A., Couto G. S., 2014b, MNRAS, 437, 1708

Seyfert C. K., 1943, ApJ, 97, 28

Shapiro P. R., Clocchiatti A., Kang H., 1992, ApJ, 389, 269

Shields G. A., 1999, PASP, 111, 661

Slipher V. M., 1917, Lowell Observatory Bulletin, 3, 59

Smith H. E., Spinrad H., 1980, PASP, 92, 553

Solórzano-Iñarrea C., Tadhunter C., 2003, MNRAS, 340, 705

Solórzano-Iñarrea C., Tadhunter C., Axon D. J., 2001, MNRAS, 323, 965

Spinrad H., Marr J., Aguilar L., Djorgovski S., 1985, PASP, 97, 932

Spitzer Jr. L., Greenstein J. L., 1951, ApJ, 114, 407

Stasińska G., 1984, A\&A, 135, 341 
Stasińska G., 2009, in Cepa J., ed., Canary Islands Winter School on Astrophysics, 18th, 2006, The Emission-Line Universe. Instituto de Astrofísica de Canarias: Canary Islands Winter School on Astrophysics, What can emission lines tell us?

Storchi-Bergmann T., 2014, in Sjouwerman L. O., Lang C. C., Ott J., eds, IAU Symposium Vol. 303 of IAU Symposium, Feeding and feedback in nearby AGN - comparison with the Milky Way center. pp 354-363

Strom R. G., Riley J. M., Spinrad H., van Breugel W. J. M., Djorgovski S., Liebert J., McCarthy P. J., 1990, A\&A, 227, 19

Tadhunter C., 2002, in Henney W. J., Steffen W., Binette L., Raga A., eds, Revista Mexicana de Astronomia y Astrofisica Conference Series Vol. 13 of Revista Mexicana de Astronomia y Astrofisica Conference Series, The Ionization of the Emission Line Gas in Nearby Powerful Radio Galaxies. p. 213

Tadhunter C., Fosbury R. A. E., Quinn P. J., 1989, MNRAS, 240, 225

Tadhunter C., Morganti R., Robinson A., Dickson R., Villar-Martin M., Fosbury R. A. E., 1998, MNRAS, 298, 1035

Tremblay G. R., Chiaberge M., Sparks W. B., Baum S. A., Allen M. G., Axon D. J., Capetti A., Floyd D. J. E., Macchetto F. D., Miley G. K., Noel-Storr J., O'Dea C. P., Perlman E. S., Quillen A. C., 2009, ApJS, 183, 278

Tyson J. A., Crane P., Saslaw W. C., 1977, A\&A, 59, L15

Urry C. M., Padovani P., 1995, PASP, 107, 803

van Breugel W. J. M., Dey A., 1993, ApJ, 414, 563

van Dokkum P. G., 2001, PASP, 113, 1420

Veilleux S., Osterbrock D. E., 1987, ApJS, 63, 295

Véron-Cetty M.-P., Véron P., 2006, A\&A, 455, 773

Viegas S. M., de Gouveia dal Pino E. M., 1992, ApJ, 384, 467

Viegas S. M., Prieto M. A., 1992, MNRAS, 258, 483

Wu Q., Cao X., Ho L. C., Wang D.-X., 2013, ApJ, 770, 31

Wyndham J. D., 1966, ApJ, 144, 459 